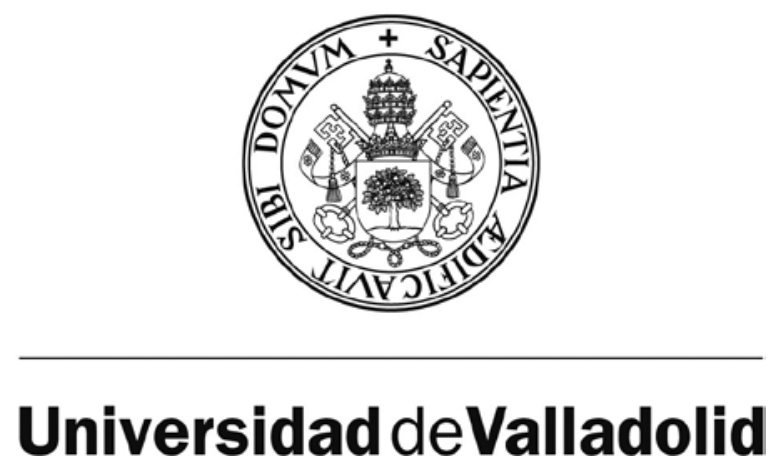

FACULTAD DE CIENCIAS ECONÓMICAS Y EMPRESARIALES

DEPARTAMENTO DE ORGANIZACIÓN DE EMPRESAS Y COMERCIALIZACIÓN E INVESTIGACIÓN DE MERCADOS

TESIS DOCTORAL:

\title{
CONSTRUYENDO RELACIONES DIÁDICAS Y EN RED EN ENTORNOS PROTEGIDOS. EL CASO DE LAS INCUBADORAS UNIVERSITARIAS
}

Presentada por María Redondo Carretero para optar al grado de doctora por la Universidad de Valladolid

Dirigida por:

Dra. Da Carmen Camarero Izquierdo 



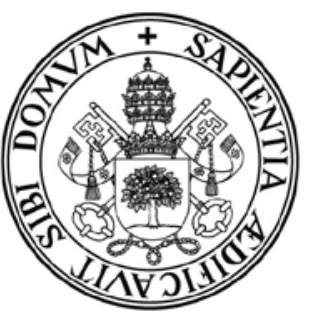

\section{Universidad deValladolid}

FACULTY OF ECONOMIC AND BUSINESS

DEPARTMENT OF BUSINESS AND MARKETING

PHD DISSERTATION:

\section{BUILDING DYADIC AND NETWORK RELATIONSHIPS IN PROTECTED ENVIRONMENTS. THE CASE OF UNIVERSITY BUSINESS INCUBATORS}

A dissertation submitted by María Redondo-Carretero to the University of Valladolid in partial fulfilment of the requirements for the $\mathrm{PhD}$ degree with international doctor mention

Supervised by:

Dr. Da Carmen Camarero-Izquierdo

Valladolid, 2016 

DOCTORAL DISSERTATION:

\title{
BUILDING DYADIC AND NETWORK RELATIONSHIPS IN PROTECTED ENVIRONMENTS. THE CASE OF UNIVERSITY BUSINESS INCUBATORS
}

\author{
PhD Candidate
}

María Redondo-Carretero

Supervisor:

Dr. Da Carmen Camarero-Izquierdo (University of Valladolid) 



\section{AGRADECIMIENTOS}

Durante el camino recorrido para desarrollar esta tesis doctoral, me he sentido muy agradecida y afortunada. La razón para ello se encuentra en las personas que me han acompañado, y en todo lo que me han aportado. A ellas les dedico las siguientes líneas, como muestra de mi agradecimiento.

Primeramente, a la Doctora Carmen Camarero, por guiarme de forma enriquecedora y estimulante. Por trasmitirme su pasión por la investigación, la importancia del rigor y de la variabilidad. Por hacerme ver la luz, por sus consejos y propuestas siempre tan valiosos. Por ser una excepcional mentora en el proceso de enseñanza-aprendizaje en el mundo de la investigación. Por el entusiasmo que tengo por continuar trabajando juntas. Por una relación basada en la confianza, el compromiso y el intercambio de conocimiento.

A los miembros del Departamento de Organización de Empresas y Comercialización e Investigación de Mercados de la Facultad de Ciencias Económicas y Empresariales, y de la Facultad de Comercio de la Universidad de Valladolid. Primero como profesores, y luego como compañeros. Por sus enseñanzas, apoyo y cariño. Por hacerme sentir parte del equipo. Una mención especial para Chanthaly S. Phabmixhay, por el día a día.

Al Doctor Peter van der Sijde, por permitirme realizar dos estancias de investigación tan fructíferas en la Vrije Universiteit de Ámsterdam. Por la acogida, el apoyo y las oportunidades que me ha brindado. Por su calidad profesional y humana. A su equipo, especialmente al incipiente Doctor Firmansyah David, compañero y amigo. Por nuestras conversaciones y debates sobre las lógicas. Por la colaboración que hemos iniciado, y por el cumplimiento de los proyectos planteados.

A los mánagers e incubados, tanto españoles como holandeses, que desinteresadamente han facilitado su tiempo e información. Y a Itziar, por su ayuda e implicación. Sin ellos, no se hubiera podido llevar a cabo la presente investigación.

A mi red de Ámsterdam: Laura, Asia, Marta, Adrià, Pablo y Mohamed. Por lo que hemos pasado juntos, y por lo que me habéis aportado. Por nuestros vínculos, más allá de la amistad.

A mis amigas de Quintanilla, las TDR. A mis amigas del colegio: Carmen, Lidia, Mónica, Vero, Beatriz, Raquel, y Alicia. A Ricardo, por estar siempre para escucharme. A dos personas que tienen mucha luz propia con la que brillar, Mariajo y Esther. A los magníficos: Rebeca, Sole, Lola, Gloria, y Miguel. A Siro, por estar siempre ahí, dispuesto a ayudarme. A Vane, por su bondad y generosidad, así como por formar parte de la familia, al igual que Rosi. A todos ellos, gracias por vuestro apoyo, gran amistad, y por creer en mí.

A mi familia. A mi prima Fátima, por ser tan especial. A mis abuelos, os tengo presentes.

A Fer, por su comprensión, paciencia, apoyo, y amor incondicional. Por estimular mi forma de pensar. Por estar en cada momento, y ser lo que necesito.

Y mi más profundo y sentido agradecimiento para mis padres, Javier y Ana. Ejemplo de vida, fuente de equilibrio, fuerza e inspiración. Por vuestra dedicación, entrega y enseñanzas. Todo lo bueno que hay en mí, os lo debo y os lo dedico a vosotros. 

A mis padres, 

Table of contents 



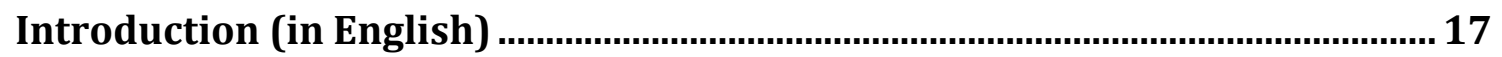

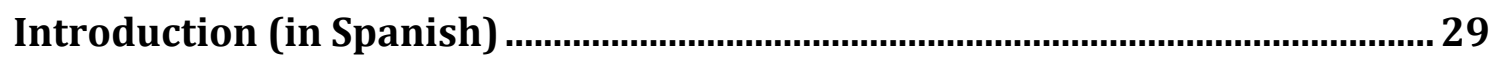

Chapter 1. Conceptual framework on entrepreneurship and incubation....... 37

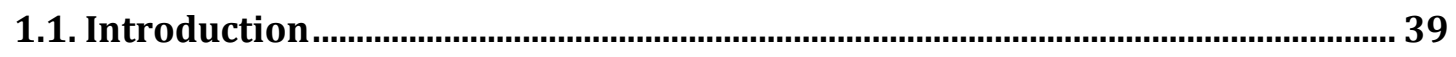

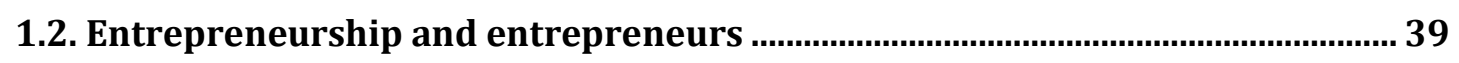

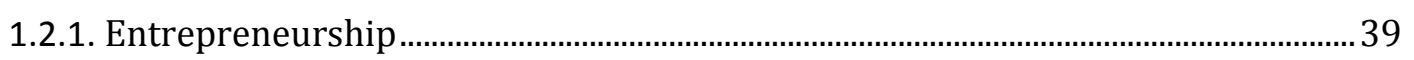

1.2.2. Academic entrepreneurs ............................................................................................... 43

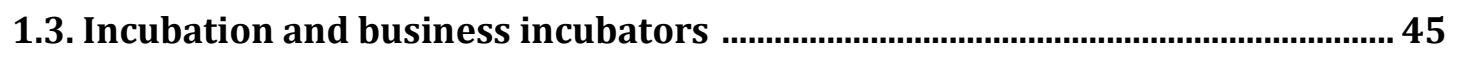

1.3.1. Historic context of incubation and incubators ..........................................................4 46

1.3.2. Evolution of incubators. Expanding the value proposition ..................................... 48

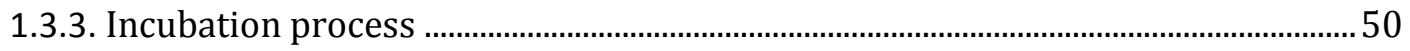

1.3.4. Stages of development of a new business through incubation: pre-incubation,

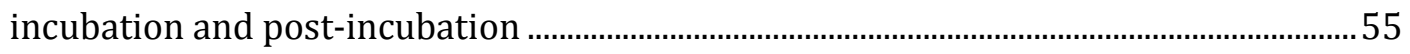

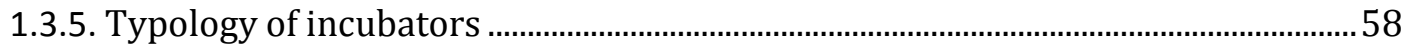

\subsection{Transfering technology, fostering the entrepreneurial spirit and}

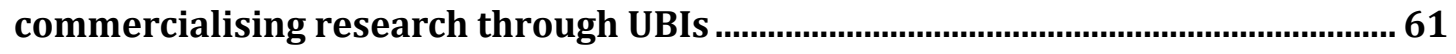

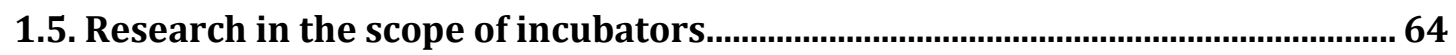

Chapter 2. Building long-term relationships between incubatees ...................69

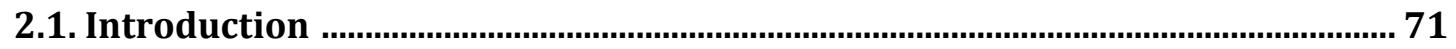

2.2. Conceptual framework on business to business relationships............................ 72

2.2.1. Relationship marketing ............................................................................................... 72

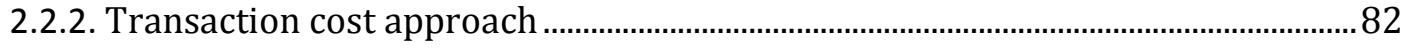

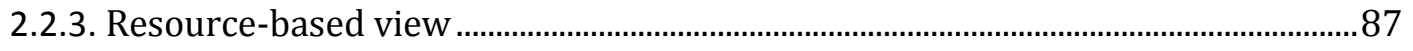

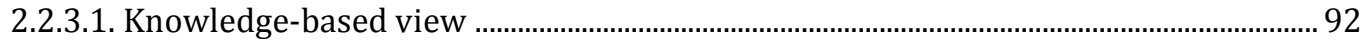

2.3. Conceptualisation and description of relationships between incubatees ....... 95

2.3.1. Quality of relationships through trust and relational commitment........................ 96

2.3.2. Content of relationships: the exchange of knowledge ............................................ 100

2.3.3. The interaction between trust, exchange of knowledge, and relational

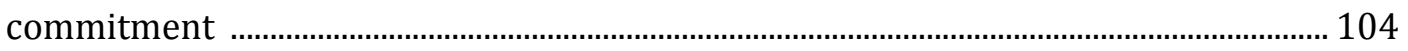

2.4. Antecedents of dyadic relationships between incubatees.................................107

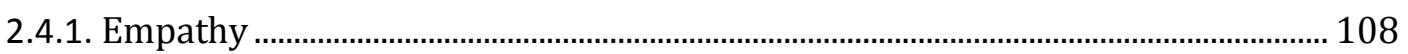

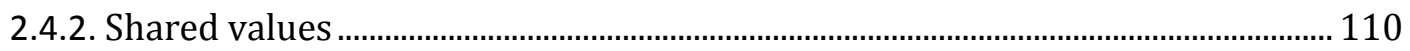

2.4.3. Complementary resources ………......................................................................... 113 
2.4.4. Supplementary resources

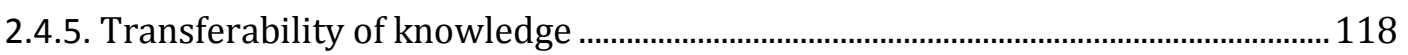

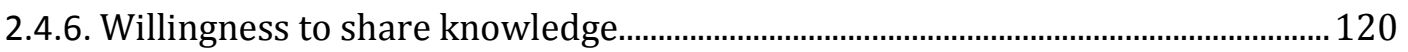

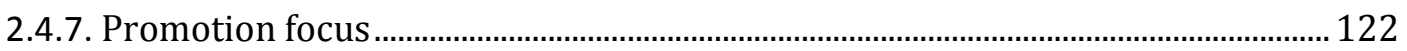

2.5. Outcomes of dyadic relationships between incubatees..................................125

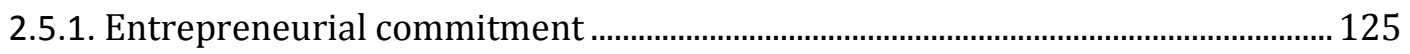

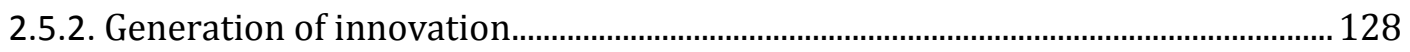

2.5.3. Business results................................................................................................. 131

2.6. Proposed model for the dyadic relationships between incubatees.................134

Chapter 3. The role of the manager in building relationships and social

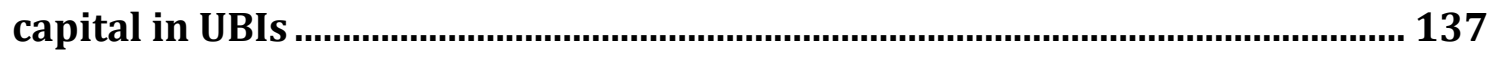

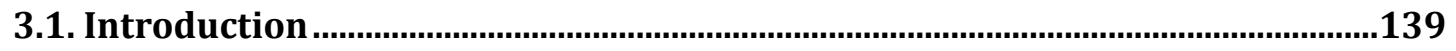

3.2. Conceptual framework for the role of the manager: institutional logics

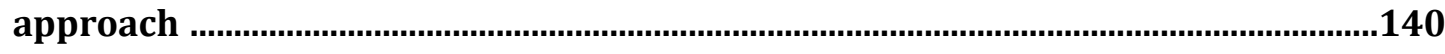

3.3. Relationship between the professional profile of the manager and the services offered by UBIs..........................................................................................141

3.3.1. Commercial logic: managers' business experience .................................................. 142

3.3.2. Academic logic: managers' scientific experience ....................................................... 144

3.3.3. Proposed model for the manager's role impacts on the prevision of services in

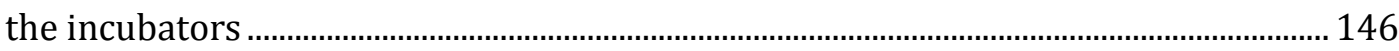

3.4. Conceptual framework for the networks of relationships: social capital

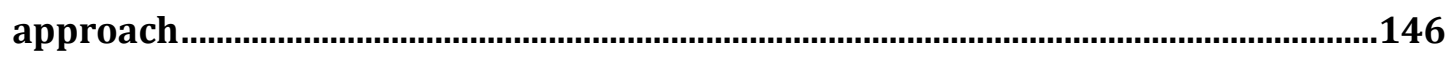

3.5. The role of the incubator manager in building social capital ...........................157

3.5.1. Social capital within incubators. Dimensions and interrelation ............................ 158

3.5.1.1. Incubatee' structural social capital ............................................................................... 159

3.5.1.2. Incubator' relational social capital ............................................................................... 161

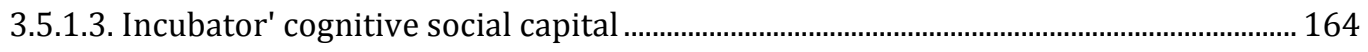

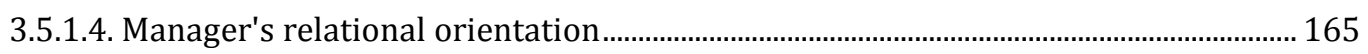

3.5.2. Proposed model for social capital and efficiency of incubatees businesses ..... 168

Chapter 4. Methodology and research design: data collection and analysis 169

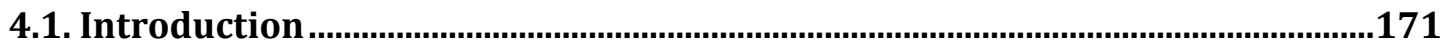

4.2. Study I. Relationships between entrepreneurs in BICs. An exploratory case study. 


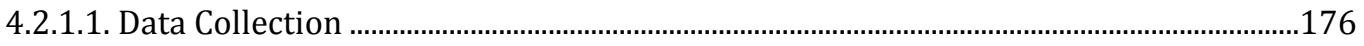

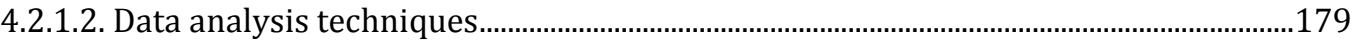

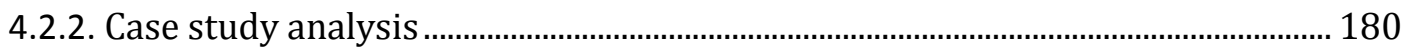

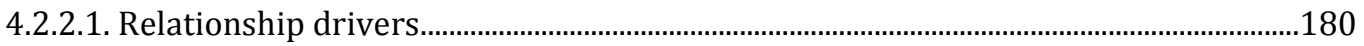

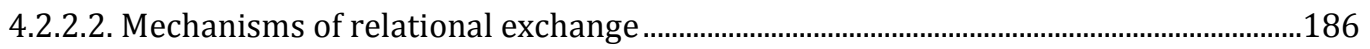

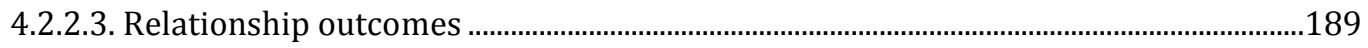

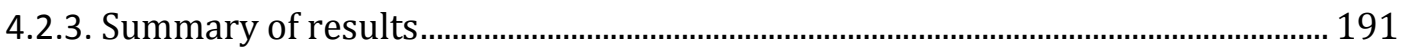

4.3. Data collection for quantitative studies................................................................193

4.3.1. Questionnaire to incubatees: design and description ........................................... 193

4.3.2. Questionnaire to managers: design and description ................................................ 205

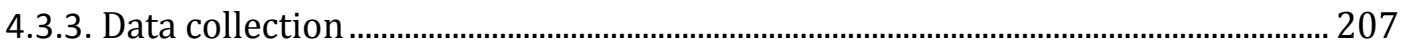

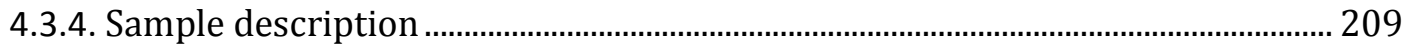

\subsection{Study II. Determinants and outcomes of dyadic relationships between}

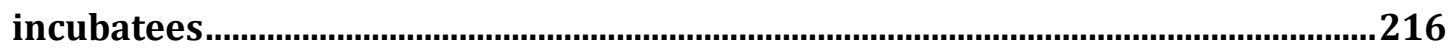

4.4.1. Descriptive statistics of the measurement variables............................................ 216

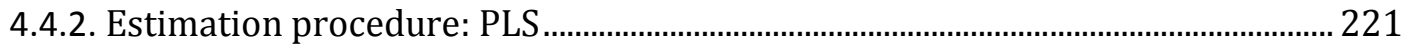

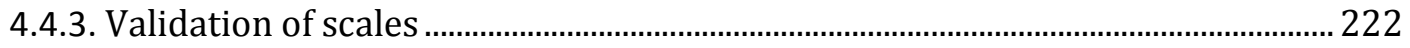

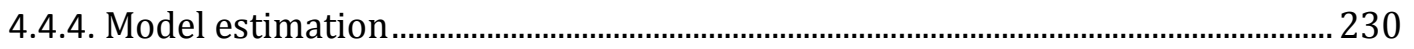

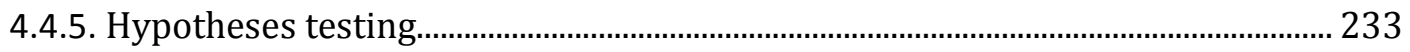

\subsection{Study III. The role of the manager in building relationships and social capital}

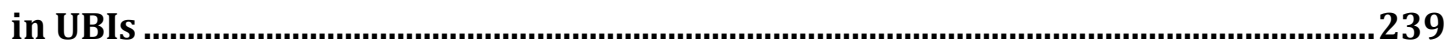

4.5.1. Study III.1. Relationship between the professional profile of the manager and

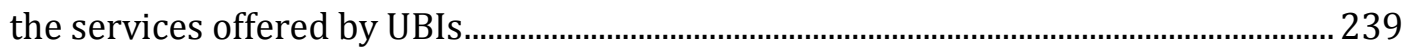

4.5.1.1. Descriptive statistics of the measurement variables ....................................................239

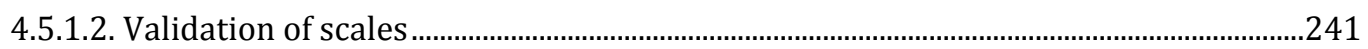

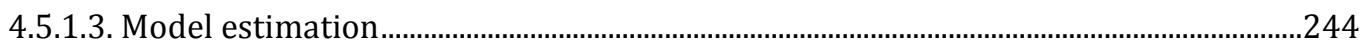

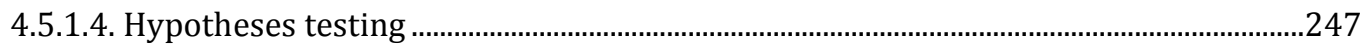

4.5.2. Study III.2. The role of the incubator manager in building incubatees' social

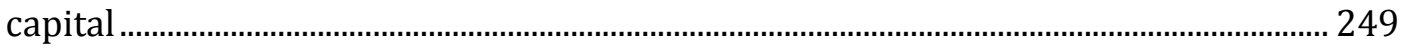

4.5.2.1. Descriptive statistics of the measurement variables .....................................................249

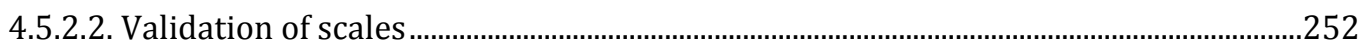

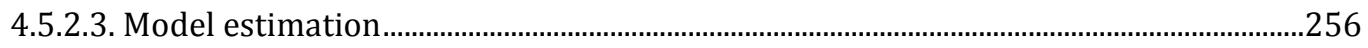

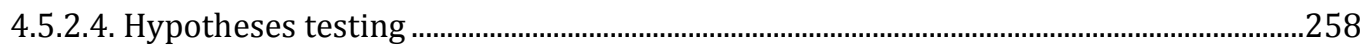

Chapter 5. Conclusions, limitations and further research ...................................263

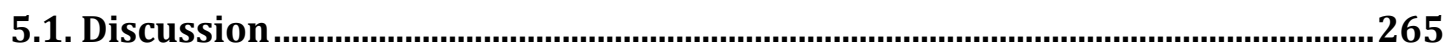


5.1.1. Dyadic relationships between incubatees.

5.1.2. The manager's role in generating relationships and social capital within UBIs 270

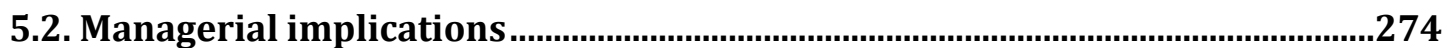

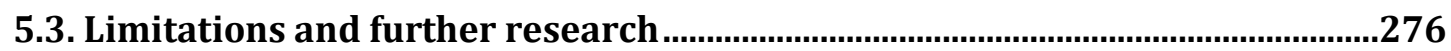

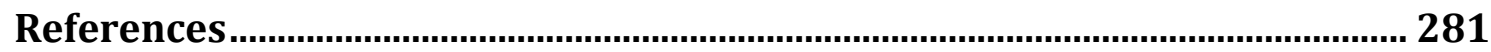

Appendix I: Questionnaire to incubatees (Spanish version) ……...................... 325

Appendix II: Questionnaire to incubatees (English version) .......................... 333

Appendix III: Questionnaire to managers (Spanish version) ........................... 341

Appendix IV: Quesitonnaire to managers (English version) ............................ 345 
Índice general 

Capítulo 1. Marco conceptual sobre emprendimiento e incubación 37

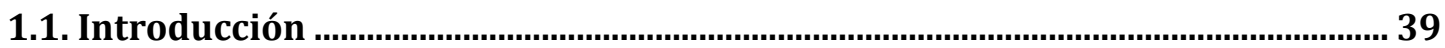

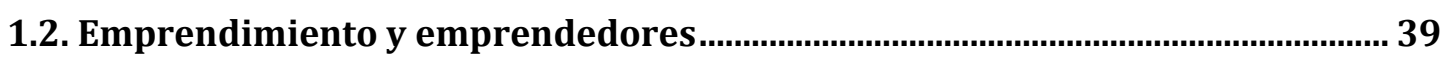

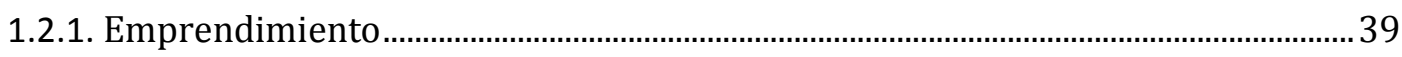

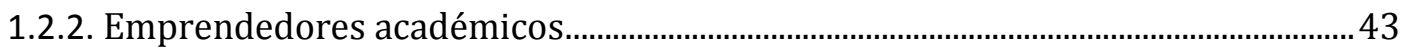

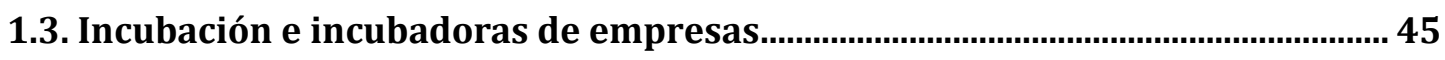

1.3.1. Contexto histórico de incubación e incubadoras ........................................................... 46

1.3.2. Evolución de las incubadoras. Extendiendo la proposición de valor....................... 48

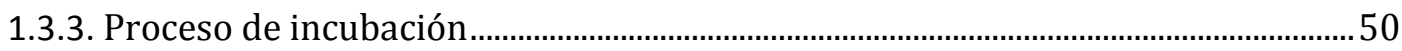

1.3.4. Etapas de desarrollo de un nuevo negocio a través de incubación: preincubación, incubación y post-incubación ..............................................................................55

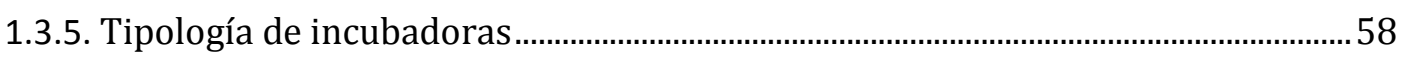

\subsection{Transferir tecnología, fomentar el espíritu emprendedor y}

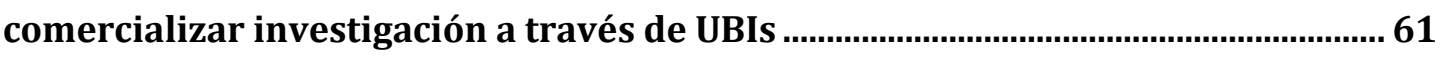

1.5. Investigación en el ámbito de las incubadoras .....................................................64

Capítulo 2. La creación de relaciones a largo plazo entre incubados ...............69

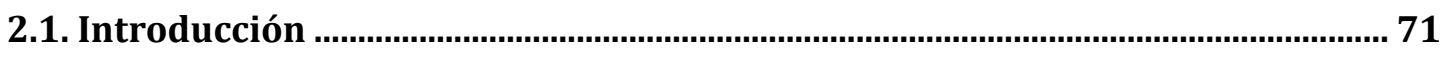

2.2. Marco teórico de las relaciones entre empresas ................................................. 72

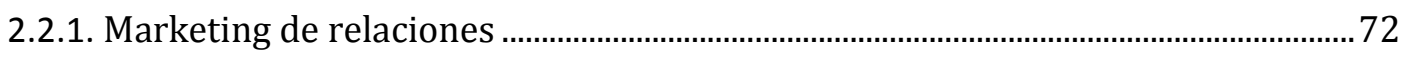

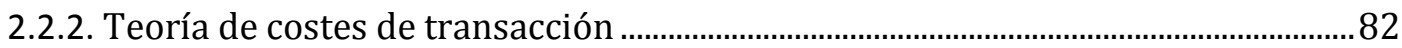

2.2.3. Enfoque basado en los recursos .................................................................................. 87

2.2.3.1. Enfoque basado en el conocimiento ................................................................................... 92

2.3. Conceptualización y caracterización de las relaciones entre incubados.......... 95

2.3.1. Calidad de las relaciones a través de la confianza y el compromiso

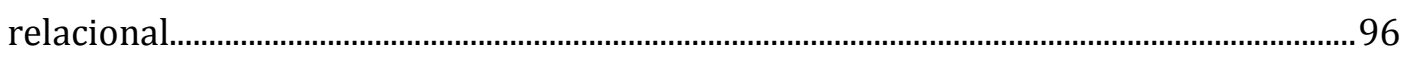

2.3.2. Contenido de las relaciones: el intercambio de conocimiento ............................... 100

2.3.3. La interacción entre confianza, intercambio de conocimiento y

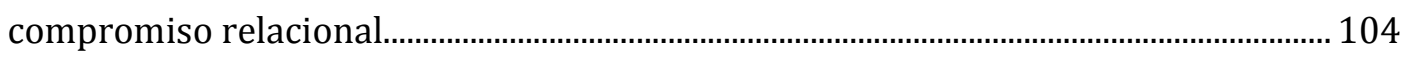

2.4. Determinantes de las relaciones diádicas entre incubados.............................107

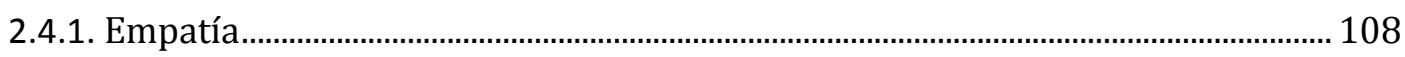

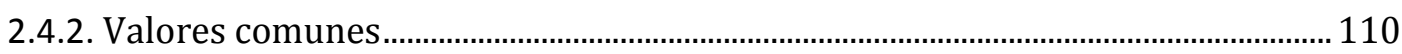


2.4.3. Complementariedad de recursos

2.4.4. Suplementariedad de recursos...................................................................................115

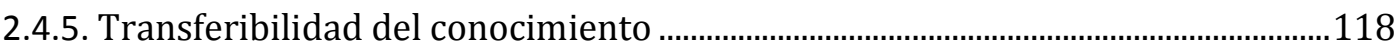

2.4.6. Predisposición a compartir conocimiento...................................................................120

2.4.7. Enfoque regulador basado en promoción ..................................................................122

2.5. Resultados de las relaciones diádicas entre incubados.....................................125

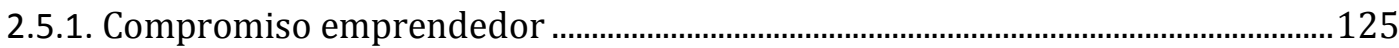

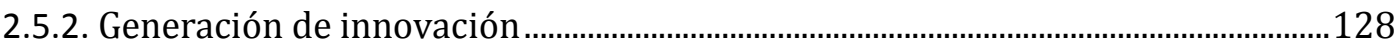

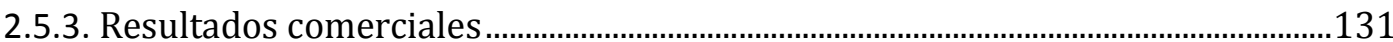

2.6. Propuesta de un modelo explicativo de relaciones diádicas entre

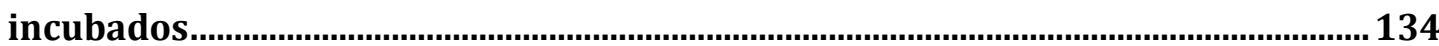

Capítulo 3. El rol del mánager en la generación de relaciones y capital

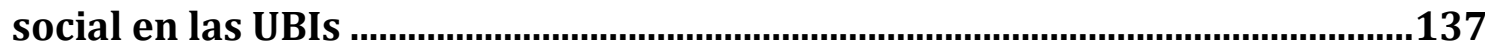

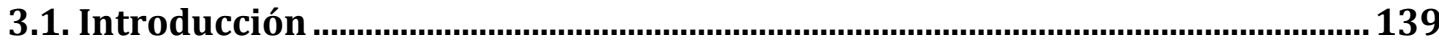

3.2. Marco teórico para el rol del mánager: el enfoque de las lógicas

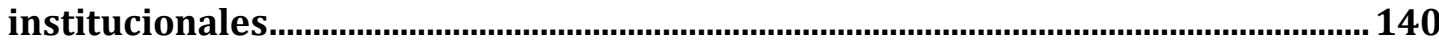

3.3. Relación entre el perfil profesional del mánager y la prestación de

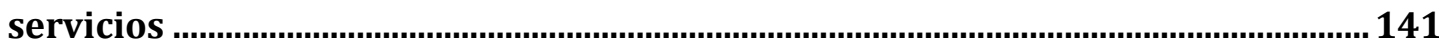

3.3.1. La lógica comercial: experiencia del mánager en el mundo de los negocios ....142

3.3.2. La lógica académica: experiencia científica del mánager.........................................144

3.3.3. Propuesta de un modelo explicativo del perfil del mánager y la prestación

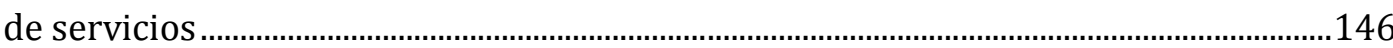

3.4. Marco teórico de las redes de relaciones: el enfoque del capital social ..........146

3.5. El papel del mánager en la creación de capital social .........................................157

3.5.1. El capital social dentro de las incubadoras. Dimensiones e interrelación ..........158

3.5.1.1. Capital social estructural del incubado............................................................................... 159

3.5.1.2. Capital social relacional de la incubadora …………........................................................... 161

3.5.1.3. Capital social cognitivo de la incubadora ……………………………………………... 164

3.5.1.4. Orientación relacional del mánager ................................................................................... 165

3.5.2. Propuesta de un modelo explicativo de capital social y eficiencia en los negocios de los incubados

Capítulo 4. Methodology and research design: data collection and analysis 


\subsection{Study I. Relationships between entrepreneurs in BICs. An exploratory}

case study.

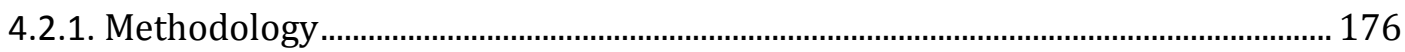

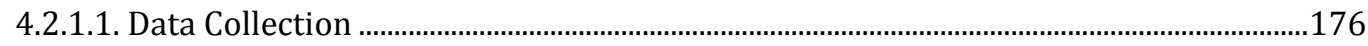

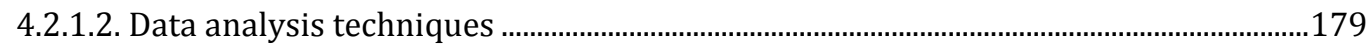

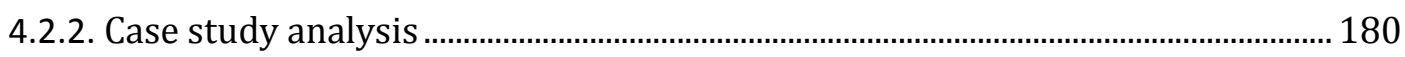

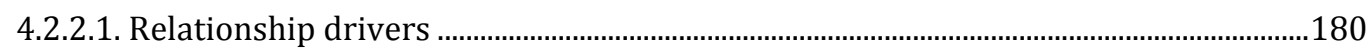

4.2.2.2. Mechanisms of relational exchange .................................................................................186

4.2.2.3. Relationship outcomes .......................................................................................................189

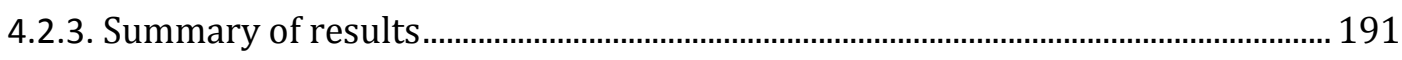

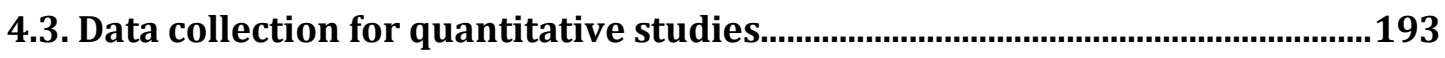

4.3.1. Questionnaire to incubatees: design and description............................................ 193

4.3.2. Questionnaire to managers: design and description.............................................. 205

4.3.3. Data collection .................................................................................................... 207

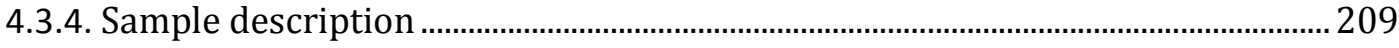

\subsection{Study II. Determinants and outcomes of dyadic relationships between}

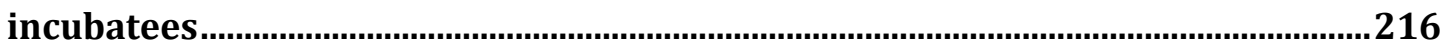

4.4.1. Descriptive statistics of the measurement variables............................................... 216

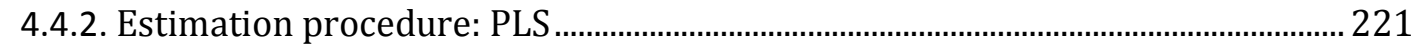

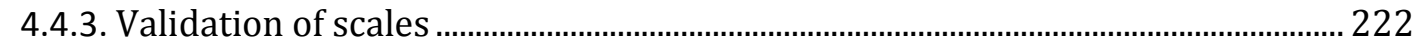

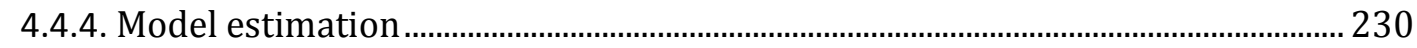

4.4.5. Hypotheses testing......................................................................................................... 233

\subsection{Study III. The role of the manager in building relationships and social}

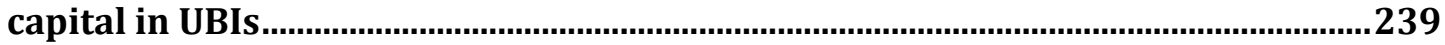

4.5.1. Study III.1. Relationship between the professional profile of the manager

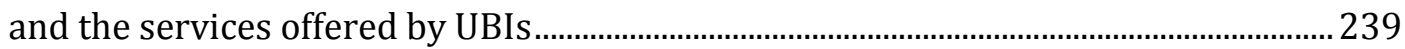

4.5.1.1. Descriptive statistics of the measurement variables …………………………………...239

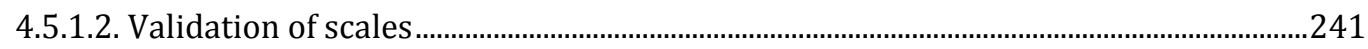

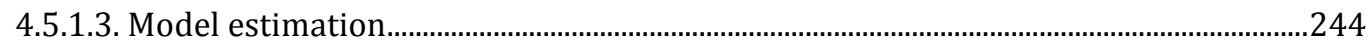

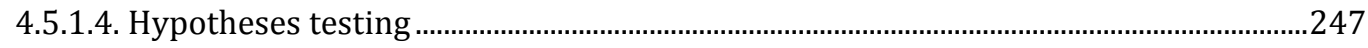

4.5.2. Study III.2. The role of the incubator manager in building incubatees'

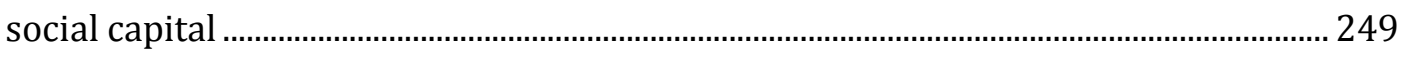

4.5.2.1. Descriptive statistics of the measurement variables ......................................................249

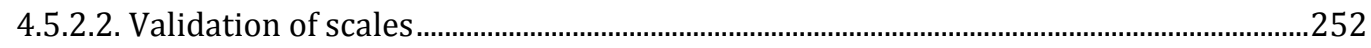

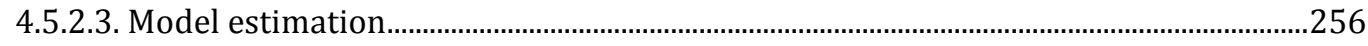

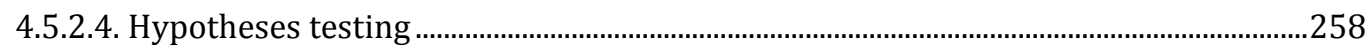


Capítulo 5. Conclusions, limitations and further research ..............................263

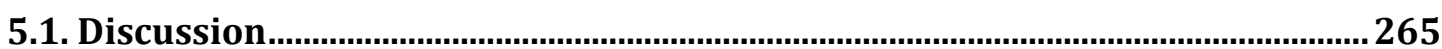

5.1.1. Dyadic relationships between incubatees ....................................................................2. 265

5.1.2. The manager's role in generating relationships and social capital within

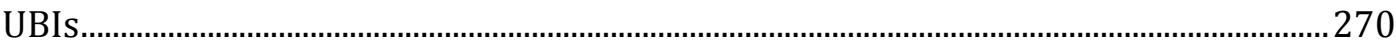

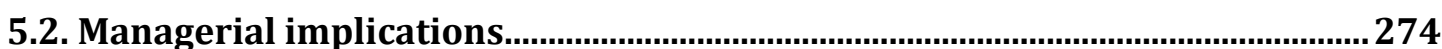

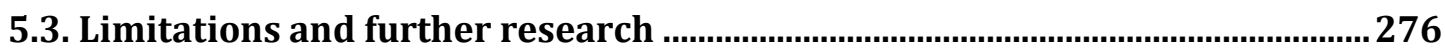

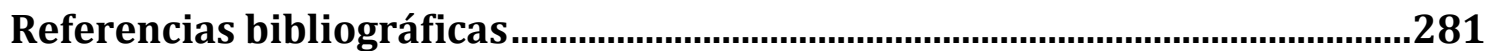

Anexo I: Cuestionario para incubados (versión en español) ..............................325

Anexo II: Cuestionario para incubados (versión en inglés) ..............................333

Anexo III: Cuestionario para mánagers (versión en español) ...........................341

Anexo IV: Cuestionario para mánagers (versión en inglés) ................................345 


\section{Introduction}



Incubation is a process undertaken with a view to meeting the needs of emerging entrepreneurs, developing their business ideas and transforming them into viable and sustainable activities. Three key actors are involved in this process: the incubator (the space), the incubatee (the reason underlying the whole process), and the manager (who organises the services offered during incubation).

The idea behind business incubators first emerged in universities in 1942 in the USA, where physical space was given to students enabling them to start up their businesses. The first incubator was opened in 1959, also in the USA. Later, in the 1980s, the concept spread around the world under a variety of names such as business incubators, business centres or innovation centres. Incubators arrived in Spain some time later. One example of this is reflected by the fact that the number of incubators grew from 45 in 2008 to 578 in 2015.

In contrast to the market, incubators may be seen as protected environments for entrepreneurs who are embarking on the early stages of their business career. Incubators are places where individuals share spaces, activities and time, which might help to encourage more frequent face-to-face interaction, and communication. In addition to actual spaces and activities, incubatees also share common goals, problems and similar situations at the same time, given that they form part of a specific community (entrepreneurs). However, merely being in such close proximity should not lead us to assume that relationships will spring up amongst entrepreneurs.

For those setting up a business, incubators provide a range of different services aimed at accompanying and supporting. These include offering facilities for business activities, training in various areas of business, business assistance, and access to networking, amongst others. Yet, the range of services available differs, with some depending to a large extent on the manager's profile. Based on the study "Los servicios que prestan los viveros de empresas en España. Rankings 2013 [Services provided by business incubators in Spain. 2013 Rankings]”, which has involved the participation of Spanish incubator managers, key aspects of incubation include mentoring, personalised training, maintaining constant relations between incubatees and managers, fostering links between firms in the incubator, as well as links between the latter and external agents, in addition to maintaining direct contact with firms after they leave and seek to make their way in the market. Although the term relationship appears time and again due to the 
synergies which may emerge thanks to the contacts forged within the incubator, as managers themselves point out, the reality tells a different story. $31.8 \%$ of managers admit to never organising any activities of a relational nature, and $10.5 \%$ do so only once a year. As far as contacts between managers and incubatees are concerned, 18.5\% do not get together with incubatees, and $21.0 \%$ do so only once a year. Thus, despite the manager's importance as an orchestrator and promoter of relationships in incubators, and of the relationships amongst incubatees, the reality reveals that most fail to play such a role or do so only on scant occasions.

Research literature has not been blind to the process of incubation nor to the key role which relationships play therein. It has been highlighted that access to and membership of networks is vital to the development of the firms located in incubators (McAdam and McAdam, 2008). Indeed, networking has even been viewed as the number one factor in successful incubation programmes (Hansen et al., 2000). Yet, research into the incubation process remains scarce; hence the need to gain further insights into what factors are able to generate success at a micro level, such as the relationship between the various parts involved in incubation (Ahmad and Ingle, 2011; Eriksson et al., 2014). The same is also true of managers and their impact and involvement in the incubation process. Studies exploring the role of the manager as a driving force behind relations both inside and outside the incubator remain few and far between (Hansen et al., 2000; Rice, 2002; Hannon and Chaplin, 2003; Tötterman and Sten, 2005; Scillitoe and Chakrabarti, 2010; Cooper et al., 2012; Vedel and Gabarret, 2014).

Both in the business as well as in the academic sphere, there is a need to examine the issue of the relations which emerge in incubators. This is the starting point for the present research, wherein we seek to gauge the extent to which incubators may prove to be spaces unto themselves in which to forge long-term relationships amongst incubatees as well as tools favouring access to and training in business networks.

Specifically, we distinguish between two types of relations in the area of incubators. Firstly, dyadic relationships, in other words links between two incubatees which are expected to go on, to survive beyond the process of incubation and to continue into the market. Secondly, networking; namely the series of contacts which may emerge at both a collective (incubator) as well as an individual (incubatee) scale. 
Exploring the links which may surface in incubators is the ultimate goal the present doctoral thesis pursues. Specifically, the aim is to gain an understanding of the determinants which favour the creation of dyadic relationships between incubatees, their effect on emerging businesses, and to what extent managers are able to foster the appearance and development of relationships in the incubator, and between incubatees and external agents, and how all of this may, in turn help improve the efficiency of an incubatee's business, all within a specific incubation domain, namely university incubators.

As pointed out previously, early incubators were to be found at universities, this by no means being a chance occurrence. Universities are charged with three missions: higher education, research, and innovation. In an effort to achieve the so-called "third mission", focused on innovation, universities have set up incubators, known as University Business Incubators (UBIs), since they encourage transfer of technology and scientific knowledge, foster entrepreneurship, and the marketing of cutting edge research (Zucker et al., 2002; Lockett and Wright, 2005; Nouira et al., 2005). In this regard, the European Commission (2003, 2004) has stressed the role played by universities as agents of transfer and dissemination of knowledge to society, with a view to furthering and shaping the construction of the "Europe of Knowledge 2020”.

The present doctoral thesis is structured in five chapters, which we briefly outline below.

Chapter 1 sets out the conceptual framework within which we structure, on the one hand, entrepreneurship and the figure of the entrepreneur and, on the other, the incubation process and incubators.

Chapter 2 focuses on the creation of long-terms relationships between incubatees. To this end, we first set out the theoretical foundations that provide the basis on which to explore such specific relationships, said foundations being the relationship marketing approach, the transaction cost approach, resource-based view, and knowledge-based view. In order to accomplish the goals which the research pursues vis-à-vis the features of long-term relationships between incubatees, an explanation is given of the conceptualisation and description of such relationships. This allows the hypotheses which respond to our aim of understanding the drivers and outcomes of dyadic relationships to be set out and posited. To conclude the second chapter, a summary is 
presented of the proposed model for the dyadic relationships between incubatees, this being Model 1 posited in the doctoral thesis.

Chapter 3 then addresses network relationships within the incubator as well as the role played by the manager in fostering such relationships and in providing the various services. To achieve this, the chapter starts out by offering the theoretical framework for the role of the manager, institutional logics approach, and continues with the hypotheses set out and a proposed model to gauge the extent to which the manager's profile impacts on the provision of services in the incubators, this being Model 2. Subsequently, it is explained the theoretical framework for the networks of relationships, social capital approach, and the same sequence of research is put forward to conjecture how the manager influences the creation of social capital in the incubator, and what interrelation exists between the various dimensions of social capital in this specific area, all of which is embodied in Model 3.

Chapter 4, which focuses on the methodology, data collection and analysis thereof, commences with a proposal to integrate the three models set out in chapters 2 and 3 , and with a summary of the hypotheses to be tested. Firstly, Study I is explained, consisting of a qualitative analysis that is exploratory in nature based on case studies of Spanish Business Innovation Centres (BICs), the goal of which was to delineate and clarify Model 1, and to evaluate the timeliness and relevance of the proposed hypotheses. In order to empirically test Models 1, 2 and 3, information was taken from a sample of Spanish and Dutch UBI incubatees and managers. This chapter provides an explanation of how the questionnaires were devised and drawn up as well as the various stages involved in the information gathering process. Models 1, 2 and 3 are then quantitatively tested in Studies II, III.1 and III.2.

The thesis concludes with chapter 5 , which details the findings to emerge from the empirical research carried out, and presents the conclusions at an academic level as well as the practical implications for incubator management. It also addresses the limitations inherent in the research conducted and posits some future lines of inquiry. 


\section{Introducción}



La incubación es un proceso que se activa con el fin de nutrir las necesidades de incipientes emprendedores, desarrollar sus ideas de negocio, y transformarlas en actividades viables y sostenibles. Se pueden diferenciar tres protagonistas clave en este proceso: la incubadora (el espacio), el incubado (razón de ser del proceso), y el mánager (quién articula los servicios ofrecidos en incubación).

Los antecedentes de las incubadoras de empresas surgieron en el entorno universitario, en el año 1942 en Estados Unidos, donde se facilitaba un espacio físico para que las empresas creadas por los alumnos comenzaran a desarrollar su actividad. En 1959, también en Estados Unidos, se estableció la primera incubadora. Posteriormente, en los años 80, el concepto se generalizó y extendió al resto del mundo, bajo una variedad de conceptos tales como viveros de empresas, centros de negocios o centros de innovación. En España, el desarrollo de las incubadoras ha sido tardío. Una muestra de ello lo encontramos en la evolución del número de incubadoras, pasando de 45 en el año 2008 a 578 en 2015.

Las incubadoras pueden entenderse como entornos protegidos, frente al mercado, para emprendedores que se encuentran en la etapa inicial de sus negocios. En ellas, los individuos comparten espacios, actividades y tiempo, lo cual puede estimular y favorecer la frecuencia de interacciones cara a cara, y la comunicación. Además de los espacios y las actividades, los incubados también tienen en común objetivos, problemas y situaciones similares, en el mismo momento de tiempo, al ser parte de una comunidad específica (emprendedores). Sin embargo, no podemos sobreentender que la mera cercanía va a desencadenar relaciones entre ellos.

Las incubadoras prestan diferentes servicios, con el objetivo de acompañar y apoyar a las personas que emprenden, tales como cesión de infraestructuras para el desarrollo de la actividad empresarial, formación en distintas áreas de negocio, asistencia empresarial, y acceso a networking, entre otros. No obstante, no se da una homogeneidad en los servicios ofrecidos, y algunos de ellos dependen, en gran medida, del perfil del mánager. De acuerdo con el estudio "Los servicios que prestan los viveros de empresas en España. Rankings 2013”, en la que han participado mánagers de incubadoras españolas, entre los aspectos clave en incubación se encuentran la realización de actividades de mentoring, formación a medida, mantener una relación constante entre los incubados y mánagers, fomentar relaciones entre las empresas incubadas, y de éstas 
con agentes externos, así como mantener un contacto directo con las empresas tras su salida de la incubadora e inmersión en el mercado. A pesar de que el término relación aflora en repetidas ocasiones debido a las sinergias que pueden derivarse por los contactos gestados en el seno de la incubadora, como así lo mencionan los propios mánagers, esto discrepa con la realidad. El 31,8\% de los mánagers reconoce que nunca realiza actividades de índole relacional, y el 10,5\% lo hace una vez al año. De otra parte, en cuanto a los contactos entre mánagers e incubados, un 18,5\% no se reúne con los incubados, y el 21,0\% lo hacen, únicamente, una vez al año. Así pues, a pesar de la relevancia del mánager como gestor y promotor de relaciones en las incubadoras, y de las propias relaciones entre incubados, la realidad nos muestra que la mayoría de ellos no desarrolla ese rol o lo hace de manera sucinta.

La literatura en investigación no es ajena al proceso de incubación, ni a la importancia de las relaciones en ese ámbito. A este respecto, se ha puesto de manifiesto que el acceso y la pertenencia a redes es un elemento crítico para el desarrollo de las empresas que están en incubadoras (McAdam y McAdam, 2008). Incluso, se ha considerado el networking como el factor más importante en los programas exitosos de incubación (Hansen et al., 2000). Sin embargo, la investigación en torno al proceso de incubación ha sido reducida, lo cual hace que sea necesario generar conocimiento con respecto a resultados exitosos a nivel micro, tales como las relaciones entre las partes implicadas en incubación (Ahmad e Ingle, 2011; Eriksson et al., 2014). Ocurre de igual forma con la figura del mánager y su incidencia e implicación en el proceso de incubación. Es reducido el número de investigaciones en las que se analiza el rol del mánager como impulsor de relaciones dentro y/o fuera de la incubadora (Hansen et al., 2000; Rice, 2002; Hannon y Chaplin, 2003; Tötterman y Sten, 2005; Scillitoe y Chakrabarti, 2010; Cooper et al., 2012; Vedel y Gabarret, 2014).

Tanto en el ámbito empresarial como en el académico, hay una necesidad de estudiar el fenómeno de las relaciones que nacen en las incubadoras. Ello constituye el punto de partida de la presente investigación, en la cual nos planteamos en qué medida las incubadoras pueden ser espacios propicios para crear relaciones a largo plazo entre incubados, así como herramientas que favorezcan el acceso y la formación de redes empresariales. 
Específicamente, diferenciamos dos tipos de relaciones en el ámbito de las incubadoras. En primer lugar, relaciones diádicas, esto es, vínculos entre dos incubados con expectativas de continuidad, que sobreviven al proceso de incubación y continúan en el mercado. Y, en segundo lugar, relaciones en red (networking), las cuales se refieren al conjunto de contactos que puede darse a nivel colectivo (incubadora), y a nivel individual (incubado).

Explorar las relaciones que emergen en el ámbito de las incubadoras es el objetivo final de la presente tesis doctoral. Más concretamente, se pretende conocer cuáles son los determinantes que favorecen la gestación de relaciones diádicas entre incubados, el efecto de las mismas sobre los negocios emergentes, y en qué medida el mánager puede favorecer la creación y el desarrollo de relaciones en la incubadora, y de los incubados con agentes externos, y cómo todo ello, a su vez, permite mejorar la eficiencia de los negocios incubados. Todo lo cual, en un contexto concreto de incubación: las incubadoras universitarias.

Los antecedentes de las incubadoras los encontramos en el entorno universitario, como enunciamos previamente, no siendo un hecho fortuito. Las universidades tienen tres misiones fundamentales: educación superior, investigación e innovación. En pro de conseguir la denominada “tercera misión”, focalizada en la innovación, las universidades han creado incubadoras, las llamadas University Business Incubators (UBIs), dado que favorecen la transferencia de tecnología y conocimiento científico, el fomento del espíritu emprendedor, y la comercialización de investigación de vanguardia (Zucker et al., 2002; Lockett y Wright, 2005; Nouira et al., 2005). A este respecto, la Comisión Europea (2003, 2004) ha enfatizado el papel de la universidad como agente de transferencia y difusión del conocimiento a la sociedad, para fortalecer y orientar la construcción de la “Europa del Conocimiento 2020”.

La presente tesis doctoral se estructura en cinco capítulos, los cuales procedemos a explicar de forma concisa a continuación.

En el capítulo 1 se presenta el marco conceptual en el que encuadrar, por una parte, el emprendimiento y la figura del emprendedor, y, por otra, el proceso de incubación y las incubadoras. 
El capítulo 2 se centra en la creación de relaciones a largo plazo entre incubados. Para ello, primeramente se explican los fundamentos teóricos en los que nos basamos para estudiar este tipo concreto de relaciones, que son los enfoques de marketing de relaciones, teoría de costes de transacción, enfoque basado en los recursos, y enfoque basado en el conocimiento. Para dar respuesta al objetivo de investigación sobre cuáles son las dimensiones de las relaciones a largo plazo entre incubados, explicamos la conceptualización y caracterización de este tipo de relaciones. Ello permite exponer y plantear las hipótesis que van a dar respuesta al objetivo de conocer los determinantes y resultados de las relaciones diádicas. Para concluir con este segundo capítulo, se presenta una síntesis del modelo propuesto para las relaciones diádicas entre incubados, siendo el Modelo 1 planteado en esta tesis doctoral.

A continuación, en el capítulo 3, se abordan las relaciones en red en la incubadora, así como el rol del mánager en el fomento de las mismas y en la prestación de diferentes servicios. Para tal pretensión, el capítulo se inicia con el marco teórico para el rol del mánager, enfoque de las lógicas institucionales, y continúa con el planteamiento de las hipótesis y la propuesta de un modelo para explicar en qué medida el perfil del mánager influye en la prestación de servicios en las incubadoras, configurando el Modelo 2. Posteriormente, se explica el marco teórico para las redes de relaciones, enfoque de capital social, y se sigue la misma secuencia de investigación que en el modelo anterior para plantear cómo el mánager afecta a la creación de capital social en la incubadora, y cuál es la interrelación entre las distintas dimensiones del capital social en este ámbito concreto, constituyendo, todo ello, el Modelo 3.

El capítulo 4, centrado en la metodología, recogida de datos y análisis de los mismos, comienza con una propuesta de integración de los tres modelos planteados en los capítulos 2 y 3, y con una síntesis de las hipótesis a testar. En primer lugar, se explica el Estudio I, que consiste en un análisis cualitativo de carácter exploratorio basado en estudio de casos en Business Innovation Centres (BICs) españoles, y cuyo objetivo fue definir y clarificar el Modelo 1, y valorar la pertinencia de las hipótesis propuestas. Para el contraste empírico de los Modelos 1, 2 y 3, se recogió información de una muestra de incubados y mánagers de UBIs españolas y holandesas. En este capítulo, se explica el proceso de diseño y elaboración de cuestionarios, así como las fases de la recogida de 
información. Seguidamente, se contrastan cuantitativamente los Modelos 1, 2 y 3 en los Estudios II, III.1 y III.2.

La tesis concluye con el capítulo 5, en el que se detallan los resultados de la investigación empírica desarrollada. En él se presentan las conclusiones extraídas, a nivel académico, y las implicaciones prácticas para la gestión de las incubadoras. Asimismo, se plantean limitaciones de la investigación realizada, y futuras líneas de trabajo. 



\section{Capítulo 1. Marco conceptual sobre emprendimiento e incubación}





\subsection{Introducción}

La presente tesis doctoral dota de carácter protagonista a las incubadoras universitarias, a los emprendedores ubicados en ellas y a los mánagers encargados de su gestión. En este contexto específico, para poder entender el nacimiento, desarrollo y funcionamiento de las incubadoras, así como el papel de los mánagers y de los incubados académicos, se requiere un marco conceptual en el que todos estos elementos tengan cabida. Sirva este primer capítulo para tal pretensión, a través del planteamiento de cuatro epígrafes cuyo contenido procedemos a explicar de manera sucinta a continuación.

Primeramente, se aborda el emprendimiento y la figura del emprendedor, en especial, aquellos individuos que, procediendo de la academia, tienen un comportamiento emprendedor. Tras enmarcar conceptualmente al emprendedor académico, en el segundo epígrafe se realiza una breve introducción y contextualización del fenómeno de la incubación. A continuación, explicaremos cuál ha sido la evolución seguida por las incubadoras, en qué consiste el proceso de incubación, sus etapas, y cuáles son los principales tipos de incubadoras de empresas. En este último punto es dónde se introduce el concepto de incubadoras de empresas universitarias para posteriormente, ya en el tercer epígrafe, describir el origen de este tipo de incubadoras, así como su justificación como vehículos para la transferencia de conocimiento. El capítulo concluye con una síntesis de la literatura sobre incubadoras e incubación.

\subsection{Emprendimiento y emprendedores}

En el presente epígrafe se procede a presentar los conceptos de emprendimiento y emprendedores en un ámbito concreto: académico o universitario.

\subsubsection{Emprendimiento}

Emprender se ha definido como un proceso, una forma de pensar y hacer, que transforma las innovaciones en oportunidades de mercado (Hitt y Reed, 2000).

La teoría sobre emprendimiento se ha configurado en torno al concepto de oportunidad emprendedora (Shane y Venkataraman, 2000). Se entiende por oportunidad emprendedora el hecho de detectar cuál es el momento oportuno para introducir nuevos 
productos, procesos o mercados (Lumpkin y Dess, 1996; Ireland et al., 2003), o para implementar innovaciones a nivel organizacional (Sharma y Chrisman, 1999), todos ellos enfocados a la creación de valor en sentido amplio (Casson, 1982; Shane y Venkataraman, 2000).

Por lo que se refiere al emprendimiento académico propiamente dicho, Etzkowitz (2004) lo define como la extensión de las actividades de enseñanza e investigación, así como la internacionalización de las capacidades de transferir tecnología, asumiendo un papel que tradicionalmente ha sido desempeñado por la industria. Según Etzkowitz (2004), esta capitalización del conocimiento es el corazón de la nueva misión de las universidades. Sin embargo, otros autores utilizan el concepto en un sentido más restrictivo para referirse a las actividades de transferencia de resultados de investigación (Gibson, 1988; Audretsch et al., 2006; Renault, 2006) o a la creación de spin-offs basadas en resultados de investigación (Doutriaux y Peterman, 1982; Vesper y Crosswhite, 1983; Doutriaux y Dew, 1992; Samsom y Gurdon, 1993; Franklin et al., 2001). También, algunos autores incluyen en el emprendimiento académico a las empresas de base tecnológica creadas por estudiantes o egresados de las universidades (Chrisman et al., 1995; Shane, 2004).

Según Clarysse et al. (2011a), en la literatura sobre emprendimiento académico se diferencian tres líneas de investigación.

(1) Labor de las Oficinas de Transferencia de Resultados de Investigación (OTRIs). Inicialmente, los esfuerzos se focalizaron en el papel crucial de las OTRIS en el fomento del comportamiento emprendedor (Colyvas et al., 2002; Clarysse et al., 2005), en cómo las OTRIs pueden crear un ambiente estructural que facilite la creación de spin-offs académicas (Clarysse et al., 2005; Wright et al., 2007) y/o mejore la cultura emprendedora dentro de los departamentos. Sin duda, esta línea de investigación ha sobreestimado el rol que las OTRIs han desempeñado en cuanto a la estimulación del comportamiento emprendedor se refiere, $\mathrm{y}$ ha subestimado el papel de las diferencias individuales entre los académicos (Clarysse et al., 2011a).

(2) Factores del entorno social. Las investigaciones posteriores se centraron en las variables del entorno social para tratar de explicar el comportamiento emprendedor, sin apenas abordar los atributos individuales. Esto se refleja en los estudios empíricos centrados en la importancia de lo local (departamental) y del contexto social a nivel 
universitario para explicar el comportamiento emprendedor en los individuos procedentes de la academia. A este respecto, Stuart y Ding (2006) y Bercovitz y Feldman (2008) han analizado el papel del estímulo a nivel organizacional de una forma indirecta, observando la importancia del entorno social para explicar el grado en el que los científicos en los campos de la biotecnología y de la medicina son propensos a participar en actividades empresariales. Bercovitz y Feldman (2008) encuentran que el hecho de estar rodeado de un entorno social emprendedor aumenta la probabilidad de que un científico se dedique a actividades empresariales. Sin embargo, es difícil saber si es el entorno social el que favorece las iniciativas emprendedoras del individuo o, por el contrario, los individuos que ya demuestran iniciativa emprendedora se sienten atraídos por los departamentos en los que su actividad es apoyada. En este sentido, como así lo admiten Bercovitz y Feldman (2008), su estudio no es concluyente acerca de si el entorno social tendrá el mismo efecto para académicos con bajos grados de capacidad emprendedora, o si sólo los científicos con un grado relativamente alto de capacidad emprendedora tenderán a unirse a tales departamentos. En un contexto diferente, Kraatz y Moore (2002) sugieren que es una combinación de los dos procesos.

(3) Diferencias específicas de carácter individual. Por último, encontramos los estudios que se centran en el papel de las diferencias individuales en el emprendimiento académico (Mosey y Wright, 2007; Clarysse et al., 2011a). A este respecto, primero es necesario considerar la capacidad emprendedora, la cual ha sido definida por Clarysse et al. (2011a, p.1086) como "la habilidad que los individuos tienen de detectar, reconocer y absorber oportunidades”. Este concepto se ha consolidado en la literatura sobre emprendimiento como una característica individual necesaria para convertirse en emprendedor (Shane y Venkataraman, 2000; Nicolaou et al., 2008). Nicolaou et al. (2009) han demostrado que aproximadamente el 60\% de la variación en la capacidad emprendedora se halla en las diferencias genéticas entre las personas, no estando relacionado con el entorno en el que los individuos han crecido o con el entorno en el que operan en la actualidad. Por lo tanto, se puede inferir que los académicos que tienen un alto grado de capacidad emprendedora, participarán más activamente en las iniciativas emprendedoras en el ámbito universitario (Clarysse et al., 2011a). El entorno social de la universidad y la profesionalización de la OTRI amplifican el impacto de la capacidad emprendedora, pero no tienen, o sólo marginalmente, efectos directos sobre la misma. 
Schumpeter sostenía, ya en el año 1934, que la creación de nuevas empresas depende de la existencia de individuos que posean ciertos rasgos de personalidad que, combinados con sus propias circunstancias personales, desemboquen en la creación de nuevas empresas. Desde el enfoque de los rasgos de personalidad del emprendedor, se han desarrollado variadas investigaciones. Sin embargo, los resultados al respecto no son concluyentes (Gartner, 1988; Robinson et al., 1991; Gustafsson, 2006). Las diferencias de rasgos de personalidad sólo permiten explicar una parte del comportamiento emprendedor (Gartner, 1988; Dyer, 1994; Veciana, 2007), por lo que no se puede hablar de una personalidad emprendedora (Gustafsson, 2006). Concretamente, desde el enfoque social o demográfico, el perfil del emprendedor se ha descrito a través de factores tales como antecedentes familiares, edad, nivel de formación, experiencia laboral, y/o redes sociales, entre otros (Cooper y Gimeno-Gascón, 1990; Robinson et al., 1991; Veciana, 1999; Colette et al., 2003). Aunque se han podido establecer relaciones entre la decisión de emprender y determinadas características sociodemográficas de los individuos, no ha sido posible identificar un perfil propio del emprendedor (Low y McMillan, 1988; Robinson et al., 1991; Reynolds, 1997).

Tras el amplio desarrollo de la literatura sobre emprendimiento, se ha constatado que las diferencias individuales son un factor crítico que explica quién llega a ser emprendedor (Shane y Venkataraman, 2000). Nicolaou et al. (2008) muestran que las diferencias individuales son importantes, independientemente de cómo se mida la iniciativa emprendedora (creación de empresas o participación en la puesta en marcha de un negocio). Hay dos factores principales que parecen explicar las diferencias entre los individuos: las diferencias genéticas, comentadas previamente, y la experiencia (Shane, 2010) para identificar, reconocer y absorber oportunidades (Nicolaou et al., 2009). Los hallazgos de Shane (2010) ponen de manifiesto que la probabilidad de empezar con un nuevo negocio se incrementa significativamente si el individuo ha estado involucrado en la fundación de uno previo, sin tener en cuenta los resultados de dicho negocio. Sin embargo, los estudios sobre emprendimiento académico apenas hacen referencia a los atributos individuales (Mosey y Wright, 2007; Clarysse et al., 2011a).

Mosey y Wright (2007) analizan cómo las diferencias en el capital humano de los emprendedores académicos influyen en su capacidad para desarrollar el capital social 
necesario para hacer frente a las barreras a las que se enfrentan para establecer un negocio. Concretamente, estudian el desarrollo del capital social en tres tipos de emprendedores académicos, con diferentes niveles de experiencia emprendedora: nacientes, individuos que están iniciando su propio negocio (Ucbasaran et al., 2003); novatos, quienes han creado una empresa por primera vez; y emprendedores habituales, los cuales emprenden múltiples iniciativas empresariales (Westhead y Wright, 1998). Observan que los emprendedores con experiencia emprendedora previa tienen unas amplias redes sociales y son más eficaces en el desarrollo de vínculos en las redes. Por el contrario, los emprendedores con menos experiencia probablemente encuentren agujeros estructurales entre sus redes de investigación científica y las redes de la industria. Concluyen que, independientemente de la disciplina académica, la experiencia en los negocios parece esencial para aprender a construir relaciones con directivos y con potenciales inversores de capital.

\subsubsection{Emprendedores académicos}

Aunque ya se han comentado los rasgos esenciales que según la literatura definen al emprendedor, hay que añadir ciertos rasgos específicos a la figura del emprendedor universitario.

Cuando se crea una empresa en el seno de la universidad, los fundadores suelen ser los investigadores y/o estudiantes que han desarrollado ese proyecto (Birley, 2002). Pero hay que considerar que el investigador universitario tiene una cultura académica y suele tener una clara preferencia por la investigación básica (Ndonzuau et al., 2002), de cuyo éxito en esta actividad depende la mayor parte de su reconocimiento profesional. Tanto es así, que el investigador, cuyo lema suele ser "publicar o perecer”, se orienta hacia la realización de publicaciones científicas de calidad en pro del reconocimiento de otros investigadores de su campo, a través de citas o referencias bibliográficas (Stephan, 1996). Es más, el profesor e investigador universitario suele escoger la carrera académica motivado por su vocación profesional por la ciencia y el desinterés económico, los cuales constituyen obstáculos para el desarrollo de comportamientos emprendedores, tales como la creación de una spin-off (Etzkowitz, 1998; Stuart y Ding, 2006). Los investigadores académicos pueden ser emprendedores en la identificación de nuevas áreas de investigación y fuentes de recursos, pero pueden tener dificultades en la identificación de oportunidades con aplicaciones comerciales (Lockett et al., 2003). 
Los estudios que se han realizado sobre el emprendedor académico se han centrado en intentar establecer los factores que influyen en la probabilidad de que un investigador decida crear una spin-off (Jones-Evans, 1998; Shane y Khurana, 2003; Shane, 2004; Audretsch et al., 2006; Landry et al., 2006; Renault, 2006; Stuart y Ding, 2006). En la consecución de este objetivo, se ha puesto énfasis en aspectos como el momento profesional, el rango académico, la experiencia en investigación, la calidad y la producción científicas, y la experiencia previa en actividades emprendedoras en la academia.

Primeramente, en cuanto al momento profesional, los investigadores suelen crear una empresa al final de su carrera (Feldman et al., 2001; Shane, 2004; Franzoni y Lissoni, 2006) como un medio para apropiarse del valor de su propiedad intelectual y acceder a mecanismos de financiación adicionales que les permita el desarrollo de futuras investigaciones (Feldman et al., 2001).

Sobre el rango académico, Shane (2004) manifiesta que los investigadores que han alcanzado un alto rango académico tienen una mayor probabilidad que otros investigadores de crear una empresa. Sin embargo, los estudios sobre esta cuestión son contradictorios: Doutriaux y Peterman (1982) encontraron que el 46\% de los entrevistados en su estudio tenían el mayor rango en la universidad, mientras que Landry et al. (2006) desarrollaron un estudio en el que concluyeron que el rango del investigador no influye positivamente sobre la probabilidad de crear una empresa.

La experiencia en investigación o producción científica también influye positivamente (Landry et al., 2006). Los académicos que tienen un mayor número de publicaciones son los que presentan una mayor probabilidad de crear una empresa (Stuart y Ding, 2006). En esta misma idea, un aspecto analizado en la literatura con detenimiento es la calidad de la investigación, entendida como relevancia nacional e internacional e impacto de las publicaciones. Los científicos de mayor calidad presentan una mayor probabilidad de crear una spin-off (Di Gregorio y Shane, 2003), así como aquellos que gozan de prestigio (Stuart y Ding, 2006).

Por último, destacamos la experiencia previa en actividades emprendedoras en la academia por parte de los investigadores. Siguiendo a Jones-Evans (1998), se consideran actividades emprendedoras dentro de la academia la explotación de patentes, la consultoría, la obtención de proyectos científicos a gran escala, y la participación 
previa en la creación de spin-offs, entre otras. Esta experiencia les permite adquirir habilidades y capacidades necesarias para obtener y gestionar los recursos requeridos para llevar a la práctica una idea de negocio (Gartner, 1988).

\subsection{Incubación e incubadoras de empresas}

Encontramos las raíces etimológicas de la palabra incubación remontándonos a la Grecia clásica, donde a la práctica de yacer en un templo sobre la piel de un animal recientemente sacrificado para tener un sueño visionario se la llamaba incubatio. Una de las razones más comunes para practicar incubatio era la de obtener una visión sobre cómo superar una enfermedad; por ello, la incubatio tuvo lugar frecuentemente en el templo de Aesculapius, el Dios griego de la medicina (Aernoudt, 2004).

La incubación está presente tanto en la ciencia natural como en la ciencia empresarial, como un fenómeno que se describe a partir de términos tales como seguridad, protección, aceleración y nutrición, entre otros (Hannon, 2004).

En la ciencia empresarial la incubación es el proceso a través del cual se favorece la creación y desarrollo de proyectos empresariales. Estos proyectos suelen llevarse a cabo en espacios físicos concretos, las incubadoras. Existen diferentes denominaciones para referirse a las incubadoras: viveros, semilleros, centros de empresas innovadoras, centros de iniciativas empresariales, centros de promoción empresarial, centros de apoyo al desarrollo empresarial, entre otras. No obstante, a pesar de la amplia terminología y de las numerosas y amplias investigaciones en torno a las incubadoras de empresas, tanto a nivel teórico como empírico, aún no se ha encontrado una definición consensuada (Bruneel et al., 2012).

Hackett y Dilts (2004a, p.57), en su revisión sistemática de la investigación sobre incubadoras de empresas, definen "una incubadora de empresas es una infraestructura de oficinas compartidas que busca suministrar a sus incubados (portfolio - o clientes - o empresas arrendatarias) a través de un sistema de intervención estratégico de valor añadido (la incubación de empresas) de supervisión y asistencia empresarial. Este sistema controla y vincula recursos con el objetivo de facilitar el desarrollo exitoso del nuevo negocio de los incubados, mientras que al mismo tiempo contiene el coste de su potencial fracaso”. Asimismo, Hackett y Dilts (2004b) llaman la atención sobre la necesidad de diferenciar el contenido semántico de los términos incubadora e 
incubación, en ocasiones utilizados erróneamente como sinónimos. Mientras que la incubadora se refiere únicamente al espacio físico, la incubación es el proceso a través del cual se favorece el desarrollo de los incubados.

\subsubsection{Contexto histórico de incubación e incubadoras}

Los antecedentes de las incubadoras de empresas se produjeron en el entorno universitario en Estados Unidos. En el año 1942, se creó la Students Agencies Inc. en Ithaca (Nueva York) para ofrecer un espacio físico adecuado donde las empresas creadas por los alumnos comenzaran a desarrollar su actividad. En 1946, Kart Compton, el presidente del Massachussets Institute of Technology (MIT) y un grupo de alumnos crearon la American Research Development para dar apoyo a las empresas surgidas en el seno del MIT, utilizando edificios y recursos de esta institución (Andrew, 2005).

Está aceptado, de manera generalizada, que la primera incubadora se estableció en 1959, en the Batavia Industrial Center, Nueva York (Lewis, 2001). En ese mismo año, una familia neoyorquina, Charles Mancuso \& Son, que contaba con una amplia cartera de negocios en la parte occidental del estado de Nueva York, adquirieron un edificio (McKee, 1992) con una estructura de $850.000 \mathrm{~m}^{2}$ que había sido ocupado, previamente, por la empresa fabricante de cosechadoras Massey Ferguson. Joseph Mancuso, el miembro de la familia asignado al proyecto, ante la imposibilidad de poder alquilar toda la propiedad a un único arrendatario, optó por alquilar particiones subdivididas del edificio a distintos inquilinos (Barrow, 2001), algunos de los cuales solicitó asesoramiento y/o asistencia para la obtención de capital (Adkins, 2001). Uno de sus primeros inquilinos fue una empresa que se dedicaba a la incubación de pollos. Cuando a Joseph Mancuso le preguntaban qué estaba haciendo con su edificio, bromeaba diciendo que estaba incubando pollos; de ahí que se tomara el término de incubadora y que a su negocio se le conociera como incubadora de empresas (Barrow, 2001).

En las décadas de 1960 y 1970, los programas de incubación se caracterizaron por avanzar con una escasa concreción, así como por ser, principalmente, iniciativas desarrolladas por organismos públicos como respuesta a la revitalización económica de zonas específicas. Más concretamente, en los años 60, el interés en incubadoras e incubación surgió por el desarrollo de la University City Science Center (UCSC) de Philadelphia, en un esfuerzo de colaboración para racionalizar los outputs del proceso 
de comercialización de la investigación básica (Adkins, 2001). En la década de los 70, los conceptos de incubadora e incubación fueron canalizados a través de los desarrollos del National Science Foundation's Innovation Centers Program, en un esfuerzo por fomentar e institucionalizar las mejores prácticas en los procesos de evaluación y comercialización de innovaciones de carácter tecnológico (Scheirer, 1985; BowmanUpton et al. 1989).

Posteriormente, en las décadas de 1980 y 1990, la tasa de difusión de incubación aumentó de manera significativa cuando se aprobó la Bayh-Dole Act (1980) y el Federal Transfer Act (1985) en Estados Unidos. Esta legislación otorgó el derecho de propiedad y comercialización de las innovaciones provenientes de investigaciones con fondos públicos a las universidades. Esto permitió, además de un mayor reconocimiento por parte del sistema legal del país de la importancia de la innovación y de la protección de los derechos de propiedad intelectual, una disminución de la incertidumbre asociada con la comercialización de los frutos de la investigación básica. Es más, a partir de ese momento, la innovación comercializada desde las universidades se incrementó de manera muy notoria (Mowery et al., 2001; Nelson, 2001).

En este entorno se generaron guías, informes no académicos y artículos con un enfoque geográfico y normativo centrado en la incubación de negocios. En el año 1980 solo existían 12 incubadoras en Estados Unidos, llegando a alcanzar la cifra de 63 en 1984 (Allen, 1985). En este proceso de creciente interés, se crea la National Business Incubation Association (NBIA) en el año 1985. La NBIA es “... la organización líder en el mundo promoviendo la incubación de empresas y el emprendimiento. Cada año, ofrece a miles de profesionales información, educación, promoción y una red de recursos para llevar la excelencia al proceso de asistencia a las empresas en su etapa inicial”"1.

Los estudios sobre incubación a nivel académico se iniciaron para dar un marco teórico y conceptual al estudio y al potencial de las empresas incubadas en aras de fomentar el desarrollo económico. Concretamente, las primeras investigaciones se plantearon para dar respuesta a las siguientes preguntas: “¿qué es una incubadora?” y “¿qué se necesita para desarrollar una incubadora efectiva?”. El primer intento académico para abordar las cuestiones planteadas se encuentra en Business Incubator Profiles: A National

\footnotetext{
${ }^{1}$ http://www.nbia.org/about_nbia/
} 
Survey (Temali y Campbell, 1984), que recoge y trata información sobre el funcionamiento de 55 incubadoras en Estados Unidos. Su alcance es amplio puesto que considera la incubadora, el gestor de la misma, los incubados y los servicios prestados por la incubadora, como varias unidades de análisis. Aunque no se contrastan hipótesis, ni pretende construir o aportar teoría, ofrece interesantes y amplios datos de carácter descriptivo, que han permitido crear una base sobre la que, posteriormente, se ha desarrollado investigación sobre incubadoras (Hackett y Dilts, 2004a).

\subsubsection{Evolución de las incubadoras. Extendiendo la proposición de} valor

Como se ha explicado con anterioridad, las primeras incubadoras se establecieron en Estados Unidos (Adkins, 2002). Posteriormente, en los años 80, el concepto se generalizó y se extendió al resto del mundo bajo una variedad de formas tales como centros de negocios o centros de innovación (European Commision, 2002). Esta primera generación de incubadoras de empresas ofrecía espacios para oficinas y recursos compartidos (Lalkaka y Bishop, 1996; Barrow, 2011). La infraestructura, es decir, los espacios alquilados en condiciones favorables (Bergek y Norrman, 2008), es la función básica común a todos los tipos de incubadoras, y el núcleo de su propuesta de valor (Allen y McCluskey, 1990). La provisión de espacio es crítico para la incubación de negocios y ha sido identificado por determinados incubados como la característica más beneficiosa de las incubadoras (Chan y Lau, 2005).

Los recursos compartidos como recepción, servicios administrativos, salas de reuniones, salas de conferencias o aparcamientos (European Comission, 2002; McAdam y McAdam, 2008), suelen ser mucho menos costosos en las incubadoras que las instalaciones y los servicios individuales (Markman et al., 2005). Asimismo, recursos más especializados, como laboratorios y equipos/material de investigación, también pueden considerarse como parte de la proposición de infraestructura (Grimaldi y Grandi, 2005).

Los inquilinos, mediante el acceso a las oficinas y a los recursos compartidos en las incubadoras, se benefician de economías de escala (Bruneel et al., 2012), concretándose así la proposición de valor de las incubadoras de primera generación. 
A lo largo de la década de los 80, y debido a la aceleración del desempleo en sectores como el automovilístico y el de la industria pesada, tanto en Europa como en Estados Unidos, ambos gobiernos estuvieron confrontados (Reich, 1991). Frente a esta situación, se desarrollaron nuevas estrategias para revitalizar la economía, poniendo especial énfasis en la innovación y la tecnología con la finalidad de favorecer el crecimiento económico. En este escenario es donde las incubadoras de empresas tomaron protagonismo como herramientas para fomentar la creación de empresas intensivas en tecnología (Lewis, 2001). El acceso a oficinas y a recursos compartidos, servicios que ofrecían las incubadoras de primera generación, no se ajustaba a las necesidades concretas de este tipo de empresas puesto que necesitaban servicios específicos adicionales. Debido a ello, se incluyeron en las incubadoras servicios basados en conocimiento, dando como resultado una segunda generación de incubadoras representara mucho más que una simple disposición de espacios físicos para empresas de nueva creación (Smilor y Gill, 1986). Entre los nuevos servicios destacan el coaching y la formación. El coaching se refiere a iniciativas de apoyo oneto-one destinadas a acelerar el proceso de aprendizaje de los inquilinos y el proceso de desarrollo de habilidades, a través de coachs o mentores asignados, pudiendo estar sujetos al pago de una cuota (Barrow, 2001; Knopp, 2007). En cuanto a la formación, también constituye un servicio importante que, habitualmente, las incubadoras prestan a sus inquilinos (Mian, 1996; Hansen et al., 2000), especialmente las incubadoras universitarias, como herramienta para preparar a los emprendedores y sus equipos en aspectos prácticos (Barrow, 2001).

Por último, encontramos la tercera generación de incubadoras de empresas, la cual surgió durante la década de los 90, centrando su aportación en proporcionar acceso a recursos y servicios a través de redes externas (Lalkaka y Bishop, 1996; Comisión Europea, 2002).

Distintas investigaciones han demostrado que las empresas de nueva creación tienen poca legitimidad organizacional, lo cual limita sus oportunidades para la adquisición de recursos y la reducción de su probabilidad de supervivencia (Freeman et al., 1983; Hannan y Freeman, 1984). Sin embargo, el networking con otras empresas suministra una mayor legitimidad en el mercado (Aldrich y Fiol, 1994), y la escasez de recursos inherente a las nuevas empresas puede verse superada a través de las redes, que 
permiten acelerar su crecimiento (Zhao y Aram, 1995). Pero las limitaciones de las empresas noveles no terminan ahí, sino que no suelen tener acceso a las redes establecidas para la contratación de asesoramiento especializado en aspectos con una alta especialización, tales como desarrollo tecnológico (Schwartz y Hornych, 2010) o consultoría estratégica (Lee y Osteryoung, 2004).

Las redes institucionalizadas, establecidas y gestionadas por las incubadoras garantizan que las redes de los inquilinos no dependan sólo de sus contactos o redes personales (Bøllingtoft y Ulhøi, 2005). Es más, se puede considerar a las incubadoras de empresas como nodos de redes para las relaciones con agentes externos, tales como consultores empresariales, abogados (Lender, 2003), clientes potenciales y proveedores, favoreciendo un acceso preferencial a los mismos (Hansen et al., 2000; Scillitoe y Chakrabarti, 2010), y permitiendo el establecimiento de vínculos con otros empresarios (Leung et al., 2006). Ese desarrollo de relaciones con agentes externos se traduce en el acceso a conocimientos y recursos que favorecen el crecimiento empresarial (Peters et al., 2004).

Pero las incubadoras no sólo permiten el acceso a redes, también proporcionan un mecanismo formal para la incorporación en redes empresariales, ayudando así a las empresas a desarrollar su propio conjunto de relaciones, de forma más rápida, y aumentando su probabilidad de supervivencia (Lender, 2003).

A la vista de estas aportaciones, no sorprende que el acceso a redes sea un elemento crítico para el desarrollo de las empresas que están en las incubadoras (McAdam y McAdam, 2008) y que el networking sea considerado el factor más importante en los programas exitosos de las incubadoras (Hansen et al., 2000).

\subsubsection{Proceso de incubación}

Al revisar la literatura sobre el proceso de incubación, se detecta que son escasos los esfuerzos de investigación dedicados a las variables asociadas con el proceso de incubación en sí, a pesar de que organismos como el NBIA han insistido, en numerosas ocasiones, en que el proceso de incubación es mucho más importante que la instalación de la incubadora (Adkins, 2001). Hackett y Dilts (2004a) también lo manifiestan así, puntualizando que, más allá de la definición implícita del proceso de incubación realizada por Campbell et al. (1985), y la especificación de configuraciones generales 
de incubadoras, los esfuerzos que se han hecho por analizar las variables asociadas a incubación son reducidos.

Siguiendo a Costa-David et al. (2002) nos encontramos con que el proceso de incubación es un conjunto de inputs preparados para conseguir unos outputs requeridos. Los inputs consisten, fundamentalmente, en las aportaciones hechas por los stakeholders, los recursos de gestión y los proyectos de los emprendedores. Durante el proceso de incubación, esos inputs se congregan a través de la provisión de espacio y de los distintos servicios que generan valor añadido a las empresas. Por otra parte, los outputs resultantes se concretan en que las empresas se gradúen con éxito, produciendo impactos positivos de creación de riqueza. La representación gráfica desagregada de este proceso se puede ver en la Figura 1.1 (Costa-David et al., 2002). 


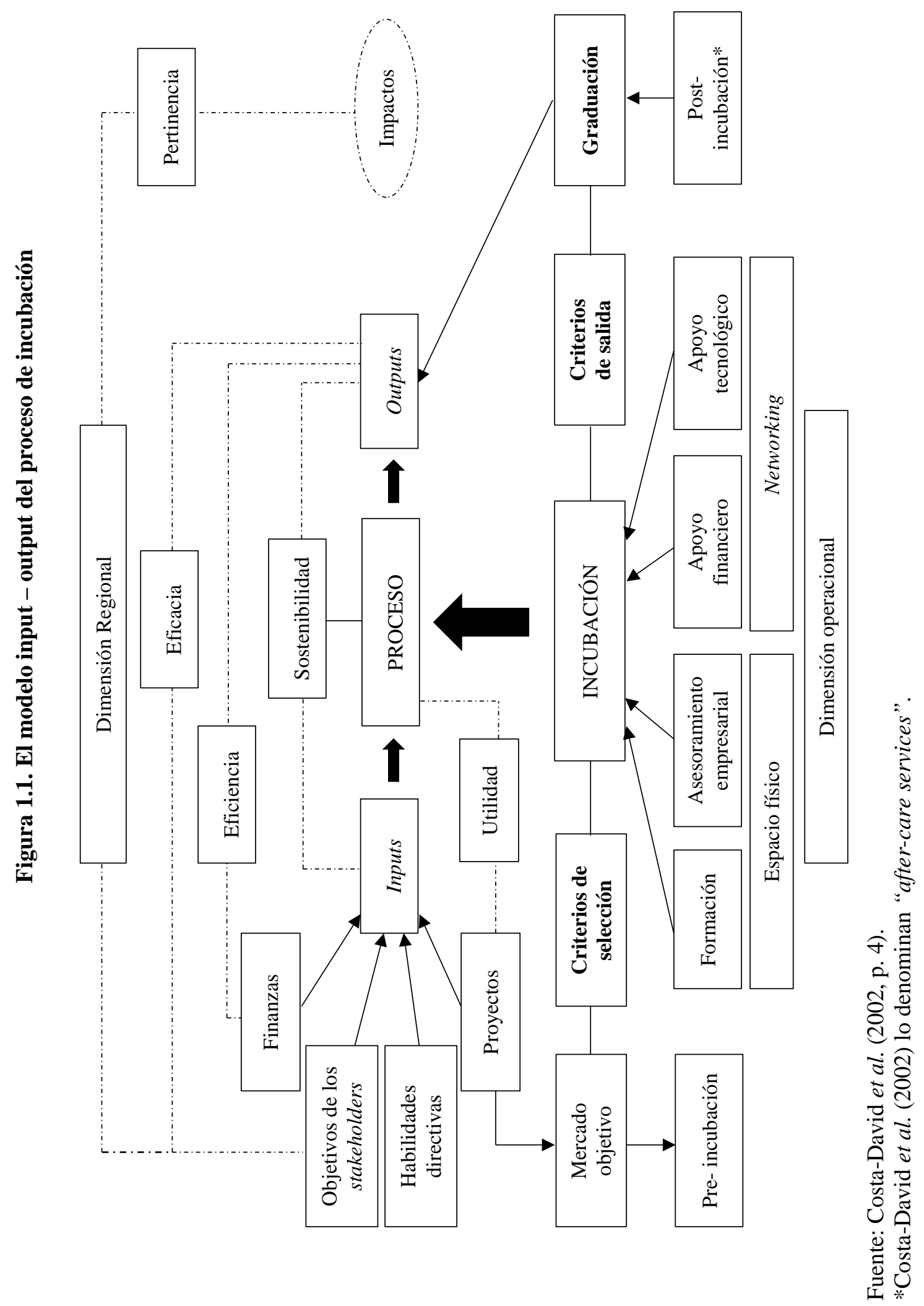


De los trabajos realizados por Costa-David et al. (2002) y Hackett y Dilts (2004a), entre otros, se deriva que los elementos fundamentales del proceso de incubación son los actores partícipes en el mismo, los criterios de selección, así como los criterios de salida y la graduación.

Actores involucrados. Los principales actores partícipes en el proceso de incubación son tres: incubado, mánager y coach.

El incubado es el protagonista y la razón de ser del proceso de incubación. Recibe asesoramiento empresarial y diferentes recursos con el objetivo de facilitar un desarrollo exitoso del negocio que ha establecido (Hackett y Dilts, 2004a).

El mánager (o el equipo de dirección en su defecto) es quien suele orquestar los servicios ofrecidos en incubación, a los propios incubados y a su red de contactos (NBIA, 2009). Aunque la NBIA (2009) ha enfatizado el rol del mánager, la literatura previa sobre incubadoras ha considerado distintos niveles de análisis, prestando escasa atención a la figura del mánager (Phan et al., 2005).

El coach es la persona que desarrolla iniciativas de apoyo one-to-one dirigidas a acelerar los procesos de aprendizaje y desarrollo de las habilidades y competencias de los incubados (Barrow, 2001; Knopp, 2007). El apoyo que presta cubre, habitualmente, necesidades científicas y de negocios (Clarysse y Bruneel, 2007). El coaching es uno de los servicios destacados que suministran algunas incubadoras a sus inquilinos (ej. Mian, 1996; Hansen et al., 2000; Bruneel et al., 2012).

Criterios de selección. Uno de los retos al que se enfrentan las incubadoras es atraer un número suficiente de solicitantes pero, a su vez, atraer a los solicitantes adecuados (Aaboen, 2009). Bajo la concepción de solicitantes correctos subyacen los criterios de selección. La selección se refiere a las decisiones sobre a qué empresa se acepta para su entrada en incubación y a cuál se rechaza (Bergek y Norrman, 2008). Como mencionan Hackett y Dilts (2004a), la mayor parte de las investigaciones que se han realizado sobre modelos de incubadoras está relacionada con la cuestión de la selección de incubados.

Merrifield (1987), a través de un enfoque de análisis restrictivo, plantea un estudio articulado en torno a tres cuestiones. La primera de ellas plantea: “¿es éste un buen negocio en el que involucrarse?”. Para responder a esta cuestión define seis factores 
críticos que determinan el atractivo de un negocio: potencial de ganancias en ventas, limitaciones sociales y políticas, potencial de crecimiento, análisis competitivo, distribución de riesgos y restructuración de la industria. Si el negocio es atractivo en base a los criterios citados, se plantea la segunda pregunta: “¿es éste un negocio en el que nuestra organización tiene la competencia para competir?”. Otros seis factores definen si el negocio cumple lo requerido para ser comercialmente exitoso. Si la respuesta es afirmativa, se plantea la tercera y última cuestión: “¿cuál es el mejor método para la entrada y/o crecimiento?”. Merrifield (1987) plantea que puede realizarse con capacidades internas, a través de una joint-venture, una adquisición o ambas. Este planteamiento presenta una serie de limitaciones, tales como su énfasis en la capacidad de fabricación de las empresas excluyendo la posibilidad de outsourcing. A su vez, adolece de un exceso de confianza, puesto que presupone el éxito de los incubados hasta tal punto que no es realista (Hackett y Dilts, 2004a).

Kuratko y LaFollete (1987) ponen de manifiesto uno de los sesgos intrínsecos a la investigación de incubación-incubadoras al postular que la variabilidad en el proceso de evaluación y selección de candidatos puede conducir a fallos en la incubadora y/o en los incubados a través de la selección de empresas que no merecen la incubación por ser demasiado débiles o demasiado fuertes. A este respecto, Culp (1996) menciona la necesidad de seleccionar a los que son esencialmente “débiles-pero-que-prometen”.

Lumpkin e Ireland (1988) categorizaron las incubadoras en base a los criterios de selección que empleaban. Estos autores proporcionan una visión útil de la variabilidad en la configuración de criterios de selección (fortaleza financiera y factores relacionados con el mercado, entre otros). Sin embargo, no llegan a concluir cuáles son mejores o cuáles son peores, y tampoco establecen vínculos entre los criterios de selección y los resultados de incubación.

Por su parte, Bearse (1998) esboza una comparación entre la selección de las empresas para incubación y la selección de los estudiantes para el ingreso en la Universidad de Harvard. Plantea la duda de si los estudiantes de Harvard - los cuales serían el equivalente a los incubados - tienen éxito debido a la influencia y a las actuaciones que la Universidad de Harvard - equivalente a la incubadora - desarrolla para y con ellos, o se debe a que Harvard selecciona sólo a aquellos estudiantes que tienen y tendrán éxito, con independencia de las actuaciones que la universidad desarrolle. 
En ausencia de respuestas precisas, ante la diversidad de investigaciones realizadas sobre el proceso de selección de candidatos para la incubación, y ante la falta de consenso, Autio y Kloftsen (1998) citan la importancia de que haya un ajuste adecuado entre las necesidades de los incubados y los servicios proporcionados por parte de las incubadoras.

Criterios de salida y graduación. Las políticas de salida se refieren a las decisiones acerca de bajo qué circunstancias los incubados deben salir de la incubadora (Bergek y Norrman, 2008). Al revisar la literatura nos encontramos que las políticas de salida, junto con los criterios de selección, están consideradas entre las funciones gerenciales más importantes en las incubadoras (Lumpkin e Ireland, 1988; Lee y Osteryoung, 2004; Aerts et al., 2007).

Las incubadoras son instalaciones que tienen políticas de salida bien definidas (Martin, 1997), en las que suelen especificar que las empresas deben "graduarse” (Lalkaka, 2003), por lo que la relación entre la graduación y las políticas de salida es directa (Bergek y Norrman, 2008). Más concretamente, y siguiendo a Hackett y Dilts (2004a), se entiende por "graduación” al momento en el cual el incubado puede sostener su estructura empresarial fuera de la incubadora. Sería, pues, la medida más simple del éxito de un incubado.

No hay discusión acerca de que las incubadoras tienen un plazo de tiempo predeterminado para el periodo de incubación (Martin, 1997). Sin embargo, este periodo varía, pudiendo depender de la disponibilidad de inquilinos potenciales (Sternberg, 2004; Schwartz y Hornych, 2008). Según la Comisión Europea (2002), la mayoría de las incubadoras tienen reglas formales de salida que requieren que los incubados tengan que abandonar la incubadora en un periodo comprendido entre los $3 \mathrm{y}$ los 5 años.

\subsubsection{Etapas de desarrollo de un nuevo negocio a través de incubación: pre-incubación, incubación y post-incubación}

La incubación es un proceso que se activa para nutrir las necesidades de los futuros emprendedores, para desarrollar sus ideas de negocio y transformarlas en actividades viables y sostenibles (European Comission, 2010). En dicho proceso puede haber hasta 
tres etapas secuenciales de incubación que se complementan: pre-incubación, incubación - propiamente dicha - y post-incubación.

(a) Pre-incubación.

Los antecedentes de las incubadoras de empresas se produjeron en el entorno universitario (Andrew, 2005), por ello, no es de extrañar que la pre-incubación en Europa naciera en ese mismo entorno. Así, la primera pre-incubadora se estableció en el año 1997 por parte de la Universidad de Bielefeld, Alemania (USINE, 2002).

Su origen radica en que, tras la introducción de procesos de incubación por parte de las universidades, se detectaron deficiencias, lo cual llevó a plantear la necesidad de una “pre-phase facility” para cubrir el gap entre las universidades y las incubadoras, y que sirviera como solución para potenciales emprendedores. En un mayor nivel de concreción, se ha considerado que las pre-incubadoras fueron diseñadas con el propósito de promover spin-offs y start-ups, especialmente desde dentro de las instituciones de educación superior, abordando los obstáculos percibidos por parte de los académicos a la hora de emprender, tales como un conocimiento económico insuficiente, el desconocimiento del potencial de los mercados de los productos y/o servicios desarrollados, y la falta de capital (USINE, 2002).

Entre las definiciones propuestas destaca la aportada por Dickson (2005) en la que pone de manifiesto que en pre-incubación se testan ideas, antes de progresar en incubación: “...entorno de riesgo reducido dónde las ideas empresariales pueden ser probadas para su viabilidad de mercado antes de avanzar hacia la incubadora de empresas” (Dickson, 2005, p. 533). Así pues, las pre-incubadoras son un mecanismo que permite filtrar las ideas de negocio no viables (USINE, 2002; Hackett y Dilts, 2004a). Para ello, los participantes reciben apoyo en el desarrollo de su idea y plan de negocios (Dickson, 2005), no en negocios que ya estén registrados (USINE, 2002).

La Comisión Europea (2010, p.5), por su parte, no solo define la etapa de preincubación, sino que también hace referencia a las actividades que suelen desarrollarse en la misma: "Pre-incubación se refiere a las actividades generales necesarias para apoyar al potencial emprendedor en el desarrollo de su idea de negocio, modelo de negocio y plan de negocio, para aumentar las posibilidades de llegar a la creación de una start-up efectiva. Por lo general implica una primera evaluación de la idea, 
capacitaciones, y asistencia directa one-to-one necesarios para poner al cliente en las condiciones de redactar un plan de negocios integral.”

El tiempo de pre-incubación es limitado, y suele considerarse un "período de prueba", de duración variable, pudiendo prolongarse entre dos meses a varios años, dependiendo de la cultura y el funcionamiento de la pre-incubadora (Dickson, 2005).

Como mencionan Voisey et al. (2013), las pre-incubadoras son una innovación relativamente reciente. Consecuentemente, la literatura disponible al respecto es reducida, en contraposición con las investigaciones desarrolladas a nivel teórico y empírico sobre la etapa de incubación (Dickson, 2005).

(b) Incubación.

Tras la pre-incubación, la siguiente etapa es la de incubación. La Comisión Europea (2010, p.6) la define haciendo referencia a los servicios que tienen por objetivo prestar el apoyo necesario a los emprendedores: "La incubación se refiere al apoyo dado al emprendedor desde la puesta en marcha hasta la fase de expansión. Normalmente es un proceso a medio plazo, que habitualmente dura los tres primeros años de actividad de la empresa de reciente creación, siendo los años en los que puede afirmarse con seguridad que la nueva empresa tendrá éxito o tendrá una buena oportunidad de convertirse en una empresa plenamente madura. Las medidas activadas generalmente son acceso a financiación, coaching directo y servicios de mentoring, así como servicios de alojamiento y formación específica. Por lo tanto la incubación física, aunque es un servicio muy importante, es un subconjunto del proceso general de incubación.”

(c) Post-incubación.

Por último, se encuentra la etapa de post-incubación, la cual es definida por la Comisión Europea (2010, p.6) como sigue: "Post-incubación, se refiere a las actividades que se llevan a cabo cuando la empresa ha alcanzado la fase de madurez, y por lo tanto está lista para caminar por sí misma. Es el momento en que, si se ha incubado físicamente, la empresa abandona la incubadora. Varios servicios todavía podrían ser necesarios por la PYME por ejemplo para incrementar sus ventas o mejorar sus procesos productivos, como los servicios de internacionalización o de introducción de innovación a través de actividades de exploración y detección.” 
En la Figura 1.2 se observan las tres etapas descritas, con los servicios que suelen prestarse a los incubados en cada una de ellas.

Figura 1.2. Etapas de incubación

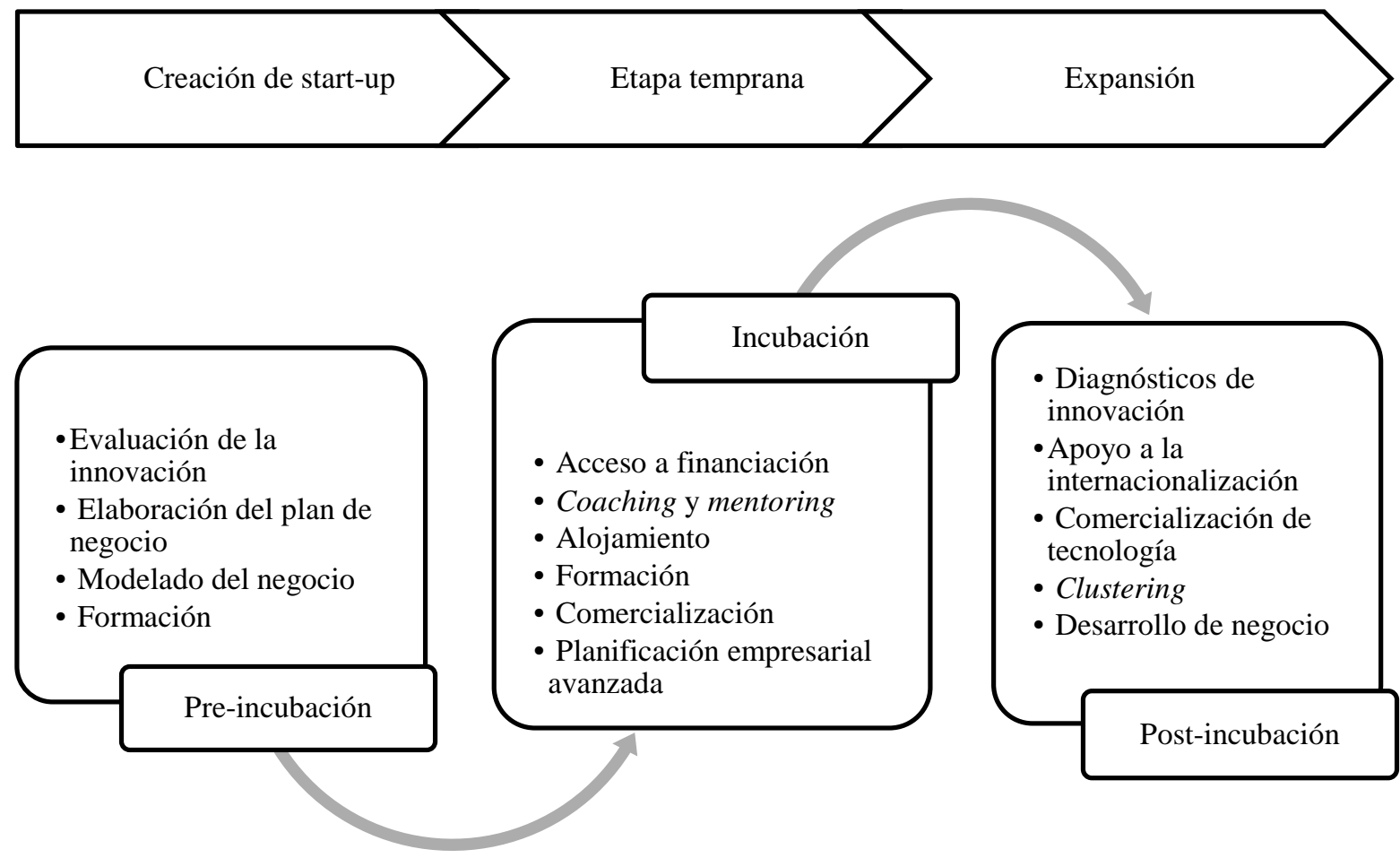

Fuente: Comisión Europea (2010, p. 6).

\subsubsection{Tipología de incubadoras}

Desde la creación de la primera incubadora, y en los momentos iniciales de desarrollo, la mayoría de las incubadoras se han establecido vinculadas a organismos públicos, con la finalidad de fomentar el empleo, revitalizar económicamente una zona concreta, así como transferir y comercializar innovaciones generadas en el seno de las universidades (Campbell y Allen, 1987). Para ello, las incubadoras han ofreciendo una serie de servicios que abarcan desde la puesta a disposición de un espacio físico, infraestructuras y facilidades, a servicios más elaborados, como la asistencia en planes de negocios. Las principales fuentes de recursos para estas incubadoras públicas se encuentran en las tasas que cobran a los incubados por los servicios que prestan, y en la financiación pública, procedente de planes de carácter local, nacional e, incluso, internacional (Cooper, 1985; Merrifield, 1987; Mian, 1996; Autio y Klofsten, 1998).

En Europa, concretamente, las primeras y más populares incubadoras públicas fueron los Business Innovation Centres (BICs). Su origen se remonta al año 1984, cuando se 
crearon los primeros por iniciativa de la Comisión Europea. Su actividad consiste en ofrecer un conjunto de servicios básicos a las empresas incubadas, incluyendo la dotación de un espacio, infraestructura y visibilidad, entre otros (Comisión Europea, 1984).

Las University Business Incubators (UBIs) representan otro tipo de incubadoras públicas. Las UBIs son similares a los BICs, pero ponen un mayor énfasis en la transferencia de conocimientos científicos y tecnológicos de las universidades a las empresas (Grimaldi y Grandi, 2001). Su nacimiento obedece a que los gobiernos ven la ciencia, cada vez más, como un vehículo para dinamizar las economías nacionales y regionales, y se da una tendencia creciente en las universidades a facilitar recursos, tiempo, talento y esfuerzos para el desarrollo económico (Roberts, 1991; Stankiewicz, 1994; Mian, 1994, 1996). Aunque el principal objetivo de las universidades es la educación, también realizan contribuciones sustanciales a las economías locales a través de la investigación que desarrollan, de las empresas spin-off y de la transferencia de tecnología (Rogers, 1986; Mansfield, 1990; Schutte, 1999; Chiesa y Piccaluga, 2000). Este tipo de incubadora suele ser creada por aquellas universidades que desean desempeñar un rol empresarial en la generación y difusión del conocimiento científico y tecnológico (Radosevich, 1995; Jones-Evans y Klofsten, 1998).

El interés por las UBIs radica en el importante potencial del concepto, puesto que ofrece la posibilidad de vincular tecnología, capital y conocimientos en aras de hacer fructificar el talento empresarial y, no sólo eso, sino que también favorece el aceleramiento de la comercialización de la tecnología a través del fomento de la creación de nuevas empresas basadas en el conocimiento (Heydebreck et al., 2000; Grimaldi y Grandi, 2001). Los servicios facilitados por las UBIs a sus arrendatarios se estructuran en dos categorías. En primer lugar, los típicos servicios ofrecidos por las incubadoras, que son los servicios de oficina, asistencia empresarial y el acceso a capital, entre otros. En segundo término, los servicios relacionados con la propia universidad, que incluyen mentores académicos, acceso a estudiantes como fuente de mano de obra, imagen de la universidad, programas de transferencia de tecnología y formación (Mian, 1996).

Tras un período de desarrollo de mecanismos públicos de incubación, se cuestionó su eficacia como herramientas de desarrollo económico (Autio y Klofsten, 1998; Sherman, 
1999), lo cual, junto con los cambios que se han ido produciendo en el mercado, ha suscitado un mayor interés en las incubadoras privadas con ánimo de lucro. El principal objetivo de estas incubadoras privadas es acelerar el crecimiento de nuevas empresas a cambio de una participación en las mismas, en contraprestación por los servicios prestados (Chinsonmboon, 2000; Hansen et al., 2000).

Entre los cambios producidos en el mercado destaca la revolución producida por las tecnologías de la información y la comunicación. Esta transformación se ha traducido en un incremento en la velocidad del mercado, en el acceso al capital y a sinergias, claves básicas para el éxito de las empresas relacionadas con internet (Chinsonmboon, 2000). Todo ello también ha repercutido en el crecimiento de las incubadoras privadas. Según Grimaldi y Grandi (2005), las incubadoras privadas pueden ser clasificadas en dos categorías, Corporate Private Incubators (CPIs) e Independent Private Incubators (IPIs). Las CPIs son incubadoras creadas por grandes empresas con el objetivo de apoyar nuevas iniciativas de negocios independientes surgidas en su seno (von Zedtwitz, 2003). Por su parte, las IPIs son incubadoras promovidas por individuos, grupos de individuos o empresas con la pretensión de ayudar a los empresarios a crear y hacer crecer sus negocios (von Zedtwitz, 2003).

Las tipologías de incubadoras, que han ido surgiendo y se han ido desarrollando, han sido intentos por satisfacer las necesidades de las nuevas empresas emergentes. El creciente interés en los servicios más intangibles y de alto valor (redes, sinergias, y/o experiencias de aprendizaje, entre otros) ha llevado a la aparición de un nuevo modelo de incubadora, la networked incubator. Este tipo de incubadora incorpora y promueve mecanismos que fomentan asociaciones entre las empresas incubadas y otros agentes externos, facilitando la transferencia de conocimientos y experiencias entre las pequeñas empresas de nueva creación, y sentando así las bases para una relación fructífera (Hansen et al., 2000).

Por último, conviene mencionar las incubadoras virtuales o incubadoras sin muros, que sirven a sus clientes como una instalación o recurso virtual dentro de internet y suministran sus servicios a través de una metodología de e-learning (Hackett y Dilts, 2004a; Folinas et al., 2006). Su aparición ha sido problemática debido a que se pone en duda si pueden considerarse auténticas incubadoras (Bearse, 1998). Siguiendo a Hackett y Dilts (2004a), si se las define como incubadoras, se estará considerando incubadora, 
de manera implícita, a cualquier entidad que preste servicios de apoyo a las empresas, lo cual aumentaría la población y la heterogeneidad de incubadoras, limitando la capacidad para generalizar los resultados de investigación. Teniendo en cuenta que el ambiente dentro de la incubadora (incluyendo los efectos generados por la agregación y la interacción entre los distintos emprendedores que están ubicados en la misma incubadora) es un aspecto fundamental dentro del fenómeno incubadora-incubación, con fines académicos, se pueden definir las incubadoras virtuales como programas de intervención, en lugar de programas de incubación de empresas propiamente dichos.

\subsection{Transferir tecnología, fomentar el espíritu emprendedor y comercializar investigación a través de UBls}

Las universidades son consideradas, cada vez más, como parte del ecosistema de la innovación y como actores importantes en la creación y adecuación del conocimiento para ser comercializado a través de diferentes formas. De manera gradual, las universidades se han tenido que adaptar a este "nuevo" papel (Etzkowitz, 2002; Wissema, 2009) en la comercialización de resultados de investigación (ej. Etzkowitz, 1998) y en el fomento de actividades emprendedoras (Lockett et al., 2005).

Para comercializar la innovación universitaria existen, básicamente, dos opciones: por un lado, vender licencias, y, por otro, generar empresas de base tecnológica o spin-offs (Herrero y Ángel, 2008). En una primera etapa, para proceder a la comercialización, la empresa paga, habitualmente, un honorario fijo a la universidad para desarrollar una investigación concreta. En caso de éxito, y si la empresa quiere seguir adelante, abona royalties, si se licencia; o concede acciones, si se crea una spin-off.

Siguiendo a Callan (2001), el término spin-off se refiere a empresas nuevas, pequeñas y de alta tecnología cuyo capital intelectual tiene su origen en una universidad o en una institución de investigación pública, aunque también pueden provenir de otras organizaciones diferentes tales como laboratorios de I+D y empresas privadas (Pérez y Sánchez, 2003). Según donde se encuentre el origen de ese capital intelectual, se establecerá el tipo de spin-off. Por ejemplo, Lindholm (1997) las clasifica en university spin-off y en corporate spin-off. Centrándonos en la spin-off universitaria, Pirnay et al. (2003) la definen como un tipo particular de spin-off que es creada con el propósito de explotar comercialmente el conocimiento, la tecnología, o los resultados de 
investigación desarrollados dentro de una universidad. Asimismo, establecen una serie de criterios para que se pueda catalogar una spin-off como universitaria: (1) el fundador o fundadores de la empresa deben provenir de la universidad, (2) la actividad de la empresa debe basarse en ideas técnicas generadas en el entorno universitario, y (3) la transferencia de la universidad a la empresa debe ser directa. Se ha manifestado que las spin-offs académicas son empresas con sus propias particularidades, puesto que son empresas de alta tecnología y nacen en un contexto en el que tradicionalmente ha existido una aversión por utilizar la ciencia con ánimo de lucro (Birley, 2002; Etzkowitz, 2004; Vohora et al., 2004).

Históricamente, la transferencia al mercado de una innovación procedente del entorno universitario ha estado dominada por las licencias (Siegel et al., 2003); sin embargo, no está claro qué forma de transferencia debe predominar. Para que un proyecto pueda ser comercializado tienen que desarrollarse de manera exitosa tres procesos (Siegel et al., 2003): (1) que haya investigadores que lo realicen y que lo presenten OTRI; (2) que ésta lo considere apto y busque empresas que puedan estar interesadas en el mismo y (3) que, finalmente, encuentren empresa o empresas interesadas (Jensen y Thursby, 2001; Jensen et al., 2003). Considerando estas premisas, Chukumba y Jensen (2005) analizan la cuestión relativa a la prevalencia de una forma de transferencia sobre otra, concluyendo que se licenciará cuando la OTRI busque y encuentre empresas que estén dispuestas a ello, mientras que aquellos proyectos que la OTRI no haya seleccionado, por no ser factibles sus licencias, tienen probabilidades de ser desarrollados por su creadores como spin-offs.

Por otra parte, para justificar la existencia de las spin-offs, Shane y Stuart (2002) y Lockett et al. (2003) plantean esta alternativa en el caso de los proyectos que se protegen con patentes ineficientes, siendo así cuando los beneficios del proyecto son inobservables para la OTRI y no susceptibles de figurar en un contrato dada la dificultad de demostrar su cumplimiento. En estos casos los royalties no se corresponderían con los beneficios reales originados por la invención, y los investigadores tendrían menos incentivos para desarrollar la innovación en cuestión. No ocurre así en el caso de que la comercialización se realice con una spin-off. Una spin-off sería más idónea puesto que, a través de este mecanismo, el inventor puede hacer el 
esfuerzo de encontrar inversores, lo cual se traduce en un ahorro de costes para la OTRI al no tener que comercializar a través de licencias (Chukumba y Jensen, 2005).

Retomando el papel de las OTRIs, se han desarrollado distintas investigaciones sobre qué factores las llevan al fomento de la creación de spin-offs (Di Gregorio y Shane, 2003; Lockett at al., 2003; Hindle y Yencken, 2004; De Coster y Butler, 2005). De los resultados de estas investigaciones se extrae que aquellas universidades que han obtenido un mayor éxito en comercializar la innovación a través de licencias, han puesto en marcha estrategias pro-activas más concretas para favorecer la creación de spin-offs. Otros factores que también influyen positivamente son la participación de la propia universidad en la estructura de capital, y la presencia de investigadores en la universidad con exitosas carreras a nivel académico. Una vez que la empresa ya está creada, se ha constatado que la relación de la misma con la universidad se reduce con el tiempo (Lockett et al., 2003; Pérez y Sánchez, 2003), y que el papel del investigador académico en la empresa es variado, pudiendo ocupar desde puestos de gerencia a cargos consultivos (Lockett et al., 2003; Murray, 2004).

Las universidades, persiguiendo su "tercera" misión a través de la transferencia de tecnología, fomento del espíritu emprendedor, y la comercialización de investigación de vanguardia (Zucker et al., 2002; Lockett y Wright, 2005; Nouira et al., 2005), han creado UBIs como herramientas del mundo académico, pero con un énfasis en el mundo y en la lógica de los negocios (van der Sijde et al., 2014). A su vez, muchas universidades han establecido incubadoras para fomentar la creación de empresas basadas en tecnología con participación de la propia universidad (Link y Scott, 2003).

La proximidad de las incubadoras a la universidad, junto con el acceso al conocimiento, las instalaciones y la mano de obra puede ser útil para los emprendedores de distintas maneras (Löfsten y Lindelöf, 2001, 2003; Dettwiler et al., 2006).

En cuanto a los recursos humanos, los vínculos entre la universidad y los emprendedores que están en incubación se concretan en la posibilidad de contratar mano de obra especializada (McAdam y Marlow, 2008), gracias a la disponibilidad de estudiantes y graduados recientes con habilidades y competencias en distintas disciplinas o áreas de conocimiento específicas (Quintas et al., 1992; Barrow, 2001). Asimismo, la cooperación con el personal de la universidad puede proporcionar acceso a los últimos avances en distintas áreas de conocimiento, lo que se traduce en la 
oportunidad de desarrollar productos más innovadores (Felsenstein, 1994; Lockett y Wright, 2005; Nouira et al., 2005). La proximidad entre una universidad y sus unidades de incubación facilita el desarrollo de elevados contactos y la interacción personal entre los investigadores académicos y los emprendedores (McAdam y Marlow, 2008).

Dado el acceso de las universidades a la investigación más actual, las incubadoras universitarias se encuentran en una posición única para permitir la transferencia de tecnología entre la investigación puntera y las organizaciones económicas (Hansen et al., 2000; Bøllingtoft y Ulhøi, 2005). Pero el vínculo con la universidad no sólo permite el acceso a conocimientos, sino que también puede permitir una reducción de los costes de desarrollo (Markman et al., 2005), y proporcionar al cliente una garantía de que los productos o servicios se basan en los conocimientos disponibles más recientes (Zucker et al., 2002). Es decir, puede dotar de una mayor credibilidad a las empresas incubadas al beneficiarse del apoyo y el expertise universitario, pudiendo proyectar así una imagen positiva a una red más amplia de clientes y otros agentes del mercado (McAdam y Marlow, 2008). Esa credibilidad es un beneficio clave considerando que las empresas que comienzan su actividad son de tamaño pequeño, tienen un carácter novel como empresa (Smilor y Gill, 1986), y necesitan desarrollar relaciones con los clientes. La incubadora ubica a la empresa en una red profesional, que proporciona credibilidad a esas empresas surgidas en el ámbito académico, pudiendo proyectar así una imagen positiva a una red más amplia de clientes, proveedores y otros agentes del mercado (McAdam y Marlow, 2008).

\subsection{Investigación en el ámbito de las incubadoras}

En lo que respecta a la literatura sobre incubadoras, los autores identifican cuatro niveles de análisis diferentes: (1) las incubadoras en sí mismas; (2) las empresas incubadas; (3) los emprendedores; y (4) los equipos de emprendedores participantes en las empresas (Phan et al., 2005).

La revisión más profunda y sistemática en cuánto a incubación se refiere ha sido realizada por Hackett y Dilts (2004a). Para proceder a ello, revisaron los estudios existentes sobre incubadoras de empresas en el periodo comprendido entre 1984 - 2000, estableciendo las siguientes cinco líneas de investigación en este ámbito: 
(1) Estudios de desarrollo de la incubadora, caracterizados por los esfuerzos para definir el concepto de incubadora-incubación, para crear categorías taxonómicas, y proporcionar directrices de políticas.

(2) Estudios de configuración de la incubadora, centrados en el estudio de la infraestructura de la incubadora y sus operaciones.

(3) Estudios de desarrollo del incubado, para comprender cómo se desarrollan los incubados dentro de la incubadora.

(4) Estudios del impacto incubadora-incubación, los cuales proponen medidas de éxito para la incubadora y el incubado, impacto económico de la comunidad, así como variables asociadas con el éxito del incubado tales como la formación, servicios de apoyo o las relaciones entre mánager-incubado.

(5) Estudios que teorizan sobre incubadoras-incubación. Estos estudios encuentran apoyo en diferentes teorías como la teoría de costes de transacción, la teoría de contingencia estructural, la teoría de redes, entre otras, para analizar la reducción de costes en incubadoras o el conocimiento institucionalizado.

Estas corrientes de investigación y sus principales características se resumen en la Tabla 1.1. 


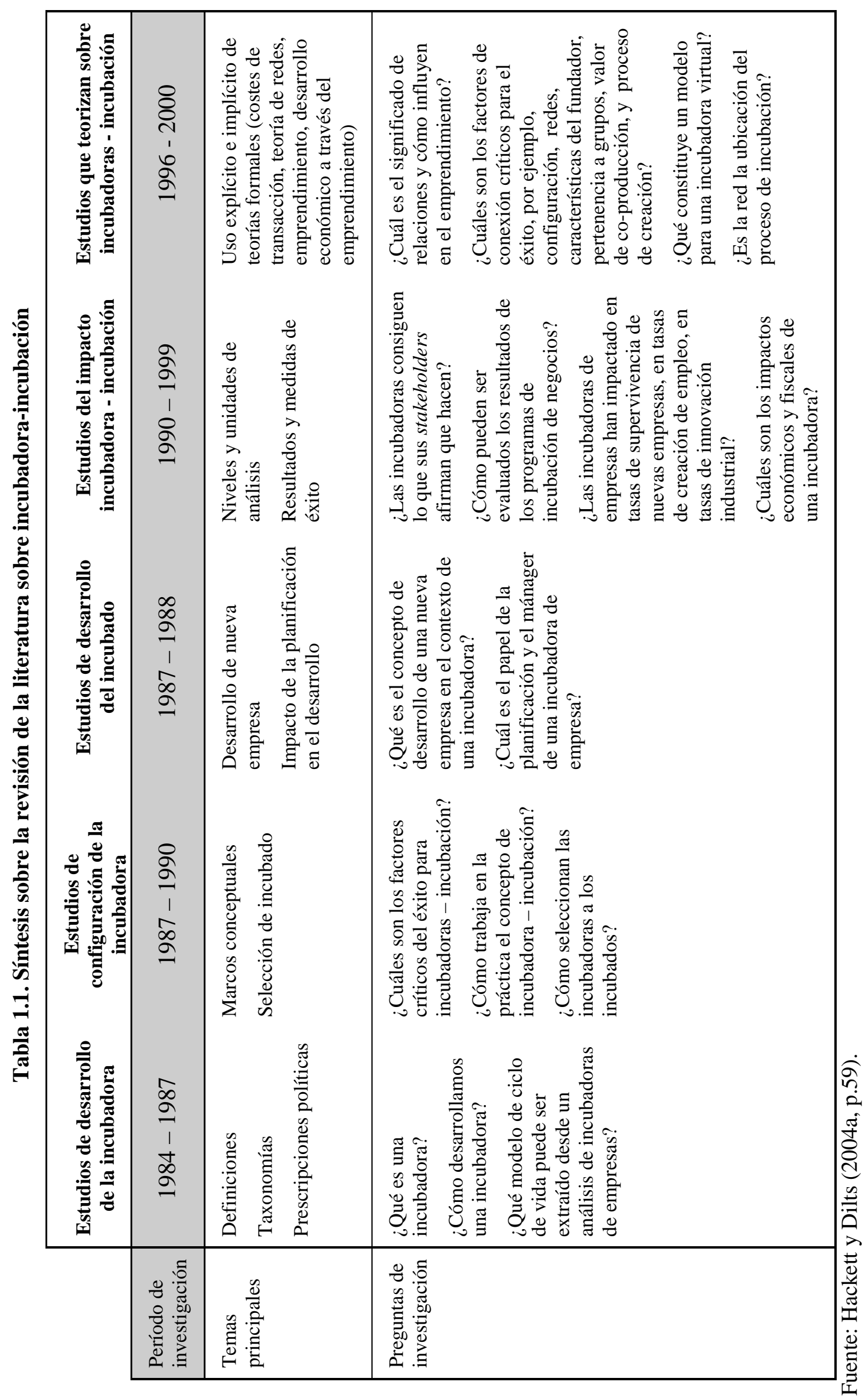


A modo de conclusión de este primer capítulo, destacamos las siguientes ideas:

- Las incubadoras han evolucionado desde meros espacios físicos donde los emprendedores podían dar los primeros pasos en sus negocios, a organizaciones que tienen como finalidad contribuir al proceso emprendedor ofreciendo diversos servicios y oportunidades a los incubados.

- Las incubadoras universitarias constituyen un tipo de incubadoras que nacen con unos objetivos específicos: transferir el conocimiento científico y tecnológico desde la universidad a las empresas, fomentar el espíritu emprendedor de los universitarios (alumnos y académicos) y promover el desarrollo de las economías locales y regionales.

- Los emprendedores académicos carecen de una lógica de negocios, lo cual puede resultar un obstáculo para identificar oportunidades de negocio y comerciales. Sin embargo, su experiencia investigadora puede suponer un activo a la hora de emprender, por el alto grado de conocimiento específico que poseen.

- La incubación es un proceso en el cual se testan, se ejecutan y se maduran los proyectos empresariales de los emprendedores. Dicho proceso de incubación implica también la transformación de los incubados en empresarios. Al final del proceso habrán madurado tanto el proyecto como el propio incubado. 



\section{Capítulo 2. La creación de relaciones a largo plazo entre incubados}





\subsection{Introducción}

Durante el proceso de incubación, como ya se ha puesto de manifiesto en el capítulo 1, no sólo se incuba la spin-off, sino que también se incuba el emprendedor en sí. A esta maduración de la empresa y el emprendedor contribuyen las relaciones diádicas entre incubados. Enmarcar teóricamente la propuesta enunciada, así como plantear las hipótesis correspondientes constituyen la razón de ser del presente capítulo. Para ello, en un primer epígrafe procedemos a exponer los fundamentos teóricos de las relaciones diádicas entre empresas a través de cuatro enfoques, que son: (1) marketing de relaciones; (2) teoría de costes de transacción; (3) enfoque basado en los recursos; y (4) enfoque basado en el conocimiento. Asimismo, plantearemos y esbozaremos diferentes cuestiones, entre las que se encuentran las que formulamos a continuación:

- ¿Cuáles son las características de las relaciones diádicas entre incubados? ¿En qué se basan la confianza y el compromiso en el caso de los incubados que no han mantenido relaciones empresariales previas?

- ¿ ¿Cuáles son los recursos que poseen los académicos que deciden emprender a través de UBIs? Y, ¿en qué medida facilitan los citados recursos el establecimiento de relaciones con otros incubados?

- ¿Qué comportamientos de los emprendedores facilitan el intercambio de conocimiento?

- ¿Qué resultados se derivan de las relaciones entre emprendedores que han germinado en UBIs?

Las preguntas anteriores se pueden sintetizar en los siguientes objetivos de investigación:

- (1) Concretar cuáles son las dimensiones de las relaciones a largo plazo entre incubados.

- (2) Conocer los determinantes y resultados de las relaciones diádicas entre incubados.

Con la pretensión de dar respuesta al primer objetivo, analizamos en el segundo epígrafe la conceptualización y caracterización de las relaciones entre negocios que se encuentran en incubación, en la esfera de la investigación desarrollada. Las relaciones se han caracterizado en términos de calidad, a través de las variables confianza y 
compromiso; y de contenido, vía intercambio de conocimiento. Asimismo, en el tercer y cuarto epígrafe, se enuncian los determinantes y los resultados de las relaciones que nacen entre incubados académicos, en pro de la consecución del segundo objetivo mencionado. El capítulo concluye con una síntesis del modelo explicativo propuesto para las relaciones diádicas entre incubados.

\subsection{Marco teórico de las relaciones entre empresas}

Para abarcar el objeto de estudio de la presente tesis doctoral, y debido a que diferentes corrientes de pensamiento o planteamientos teóricos subyacen tras las relaciones entre empresas, hemos adoptado un marco teórico multidisciplinar, en el que se incluyen, además del enfoque de marketing de relaciones, la teoría de costes de transacción, y los enfoques basados en recursos y conocimiento.

Para cada uno de los enfoques, que procedemos a explicar en los siguientes subepígrafes, hemos seguido un tratamiento análogo. Primeramente, especificamos cuál ha sido su evolución, con la finalidad de conocer los planteamientos en los que se sustentan. Para ello, plasmamos las aportaciones más relevantes realizadas por diferentes autores a cada uno de los enfoques. A continuación, explicamos la vinculación que cada enfoque teórico tiene con el marketing y, específicamente, con las relaciones entre empresas. Asimismo, presentamos de forma sintética las aplicaciones de cada uno al ámbito del emprendimiento y de las incubadoras. Para concluir, y en pro de vincular y justificar la adecuación del marco teórico elegido, planteamos una serie de cuestiones de investigación en el ámbito de las relaciones entre incubados que pueden encontrar respuesta a través de cada uno de los enfoques.

\subsubsection{Marketing de relaciones}

El término marketing relacional apareció por primera vez en la literatura en el año 1983. Berry fue quién lo mencionó para referirse a un nuevo enfoque de marketing. Concretamente, el autor presentó un paper titulado, simple y llanamente, "relationship marketing” en la American Marketing Association's Services Marketing Conference. Una de sus principales aportaciones radicaba en que la disciplina de marketing no sólo debe referirse a la adquisición de clientes, sino también a su mantenimiento, como lo reconocería con posterioridad el propio autor. 
En esta primera aproximación, el eje central se hallaba en la relación con el cliente. También se consideraba la relación con los empleados de la empresa, pero de forma limitada y sólo como un medio para apoyar el establecimiento de relaciones fuertes con los clientes. Berry (1983, p.27) lo expresaba de la siguiente forma: “En la medida en la que las empresas de servicios pueden utilizar el marketing para atraer, mantener, y motivar personal de calidad, mejoran su capacidad para ofrecer un servicio de calidad. Ofrecer servicios que cumplan consistentemente los requisitos de calidad de los mercados objetivo es claramente un factor importante en la construcción de relaciones fuertes con los clientes en muchas industrias”. Por tanto, Berry (1983) no consideró ni sugirió, en ningún caso, la importancia de otras posibles relaciones con distintos stakeholders con los que las empresas interactúan.

En la década de los 80 los trabajos que se publicaron sobre marketing relacional fueron reducidos. En uno de ellos, Jackson (1985) define el marketing de relaciones a través del contraste con el marketing transaccional. Las relaciones tienen una naturaleza más a largo plazo y constan de acciones asociadas con el intercambio y la adaptación entre las partes, mientras que las interacciones tienen una naturaleza a corto plazo (Johanson y Mattsson, 1987). De su investigación se puede extraer la conclusión de que construir relaciones a largo plazo a través del marketing de relaciones no siempre puede ser recomendable. En determinadas ocasiones es preferible la aplicación del marketing transaccional y una visión a corto plazo.

Sin embargo, en la primera mitad de los años 90 emergió el interés por el marketing relacional, inicialmente a un ritmo lento, para ir incrementando su velocidad de forma vertiginosa (Berry, 2002). Ese interés se vio impulsado por algunas cuestiones como la maduración de la literatura sobre marketing de servicios, un incremento en el reconocimiento de los beneficios del marketing relacional, y los avances en las tecnologías de la información y la comunicación (Berry, 1995).

Autores como Heide, Morgan y Hunt han realizado las aportaciones más relevantes a la disciplina. Heide (1994) identificó tres formas de gobierno para las relaciones en el canal de distribución: de mercado, unilateral y bilateral. El gobierno de mercado no se diferencia significativamente del concepto referido a transacción discreta de Macneil $(1980)^{2}$. Dentro de los mecanismos de "no mercado”, el gobierno unilateral se basa en

\footnotetext{
${ }^{2}$ Bajo el término transacción discreta Macneil (1980) se refiere a un intercambio único en un contexto legal.
} 
la autoridad que ejerce una de las partes de la relación, así como en su capacidad para desarrollar reglas, dar instrucciones e imponer decisiones, mientras que el gobierno bilateral se basa en el desarrollo conjunto de políticas dirigidas a la consecución de objetivos comunes.

Por su parte, Hunt y Morgan (1994) promulgaron que la construcción de relaciones permite la creación de una valiosa oferta de mercado, con el objetivo de preparar mejor a la empresa para una era de “network competition”. Asimismo, Morgan y Hunt (1994, p.22) definen el marketing relacional de una forma concisa: "marketing relacional se refiere a todas las actividades de marketing dirigidas a establecer, desarrollar, y mantener intercambios relacionales exitosos”. Además, amplían el alcance del marketing relacional para incluir no sólo las relaciones con los clientes, sino todas las formas de intercambio relacional: intercambios con proveedores, competidores, organizaciones sin ánimo de lucro, gobiernos, unidades de negocio, departamentos funcionales y empleados. De hecho, en muchas de las definiciones de marketing relacional se puede encontrar un destacado énfasis en la necesidad de desarrollar relaciones a largo plazo con los distintos agentes (ej. Ballantyne, 1994; Grönroos, 2000).

El marketing de relaciones no sólo se ha quedado en el ámbito académico, sino que la orientación a la relación ha llevado a las empresas a abandonar el enfoque basado en la transacción para buscar un enfoque, posiblemente más rentable, basado en la retención de clientes (Bowen y Shoemaker, 1998; Jayachandran et al., 2005; Küster y Vila, 2007; Kodish y Pettegrew, 2008), y en las relaciones con otros agentes (ej. Ballantyne, 1994; Morgan y Hunt, 1994; Grönroos, 2000; Möller y Törrönen, 2003; Dyer y Hatch, 2006).

En la actualidad, el concepto de marketing relacional sigue siendo complejo, ya que procede de una gran variedad de teorías y líneas de investigación que le han proporcionado contribuciones válidas hasta alcanzar su estado actual de desarrollo (Jung et al., 2013).

La investigación en el ámbito del marketing relacional se puede clasificar en dos grupos: (1) investigación business-to-consumer (B2C), en la que se analizan relaciones entre las empresas y sus clientes; e (2) investigación business-to-business (B2B), que engloba relaciones con otras empresas (Egan, 2011). A su vez, dentro del B2B se pueden diferenciar dos subgrupos: 
1) Estudios centrados en las relaciones con empresas a nivel vertical, dentro de la cadena de suministro. Se incluyen las relaciones comprador-vendedor (ej. Möller y Törrönen, 2003; Hsieh et al., 2008) y las relaciones fabricantedistribuidor (ej. Siguaw et al., 1998; Elg, 2002; Dyer y Hatch, 2006).

2) Aquellos referidos a relaciones a nivel horizontal, con otras empresas. Puesto que la investigación que nos ocupa se centra en este tipo de relaciones, posteriormente se tratan con detalle.

Bajo los enfoques de marketing relacional y de redes de negocios (business networks), Möller (2013) elabora un mapa metateórico que permite comprender las diferentes líneas y enfoques de investigación dentro del marketing de relaciones y de redes aplicados al ámbito empresarial, en un continuo que va desde las relaciones menos complejas a los contextos relacionales más complejos. A continuación se explica cada una de ellas, siguiendo dicho continuo.

(1) Marketing de relaciones enfocado a CRM (Customer Relationship Marketing).

La investigación enfocada al CRM persigue objetivos normativos y de gestión. En concreto, tiene dos objetivos primordiales. Por un lado, mejorar la eficiencia del marketing, mediante una óptima focalización de las actividades propias de marketing en el público objetivo adecuado, especialmente las relativas a comunicación (Rust et al., 2004). Y, por otro, lograr un alto nivel de retención de clientes (Rust et al., 2004). En este caso, la clave se encuentra en optimizar el valor del lifetime de los clientes a través de las relaciones y la gestión de la cartera de clientes por parte de la empresa (Malthouse y Blattberg, 2005). Para la consecución de los objetivos citados se utilizan herramientas como bases de datos de clientes y técnicas de minería de datos.

La investigación en CRM sigue un enfoque pragmático (sin claras asunciones ni teorías), y se basa en el principio microeconómico de utilidad marginal (Möller, 2006). El objetivo es saber cómo mantener de forma eficiente consumidores leales y rentables. Para dicho fin no profundiza en aspectos comportamentales y psicológicos de las relaciones con los clientes, ni en el contexto en el que se producen esas relaciones.

(2) Marketing de relaciones de enfoque comportamental.

Este enfoque es clave en el marketing relacional. Persigue la comprensión del intercambio relacional, y cubre cualquier tipo de relación comprador - vendedor. Más concretamente, sus objetivos básicos son identificar los antecedentes que conforman las 
relaciones proveedor - cliente, y explicar cómo las características de la relación influyen en los resultados de la misma.

A diferencia de la perspectiva de CRM, este enfoque se sustenta en marcos teóricos para proponer modelos de relaciones y su evaluación. Esta orientación se ha visto influida por la teoría de intercambio social (Emerson, 1976; Cropanzano y Mitchell, 2005). Asimismo, ha recibido influencias de la teoría de costes de transacción y del enfoque de contratos relaciones de Macneil, aunque en menor medida. Conceptos claves de la teoría de intercambio social, como la reciprocidad del actor, la confianza, los valores compartidos y el compromiso, han jugado un papel central en el estudio de las relaciones entre comprador-vendedor.

El enfoque comportamental se centra en el estudio de relaciones diádicas, explicando el contenido y los resultados en términos específicos de la relación, pero no considera la influencia del contexto sobre las partes implicadas o sobre la propia relación.

La investigación académica en marketing relacional de enfoque comportamental sigue, por lo general, la línea antecedentes-características de la relación-resultados, influenciada principalmente por el estudio de Morgan y Hunt (1994), y la metodología de ecuaciones estructurales.

(3) Relaciones entre los miembros del canal.

En las investigaciones centradas en los canales y sus miembros se pueden diferenciar dos niveles: sistema y relacional. A nivel de sistema, el objetivo es explicar cómo evoluciona la estructura del canal y cuál es su influencia en las relaciones diádicas. A nivel relacional, el objetivo es comprender las relaciones entre sus miembros e identificar estructuras de gobierno eficientes para las distintas relaciones.

Las estructuras y las relaciones en el canal son estudiadas desde una perspectiva económica y comportamental. La perspectiva económica está influida por la teoría de costes de transacción. Sus conceptos básicos incluyen la especificidad de los activos, la incertidumbre y la frecuencia de la transacción. La perspectiva comportamental se basa en la teoría del intercambio social y en la sociología de las organizaciones, y emplea conceptos de economía política (como dependencia), así como aspectos sociales (expectativas, cooperación, confianza, compromiso y comunicación) para analizar las relaciones. 
El canal y la relación diádica entre sus miembros son las unidades de análisis recomendadas. Ambas están interrelacionadas, ya que las relaciones complejas no pueden ser entendidas fuera de su contexto (Heide, 1994; Rindfleisch y Heide, 1997; Wathne y Heide, 2004).

Según Möller (2013), a pesar de la investigación empírica desarrollada dentro de este enfoque, aún es necesario profundizar en la evolución y en las relaciones en los canales. Para ello, se pueden aplicar estudios longitudinales.

(4) Mercados como redes y relaciones red-actor.

Bajo la denominación mercados como redes se proporciona un marco teórico, a nivel macro, para las relaciones entre actores y la gestión de la empresa en el contexto de redes. La comprensión de las redes a este nivel y su dinámica son clave para la gestión de relaciones diádicas. A nivel teórico se ha abordado la emergencia y estructura de redes, desde la sociología económica (Powell et al., 1996; Powell et al., 2005), y la formación de redes a través de alianzas estratégicas, desde un enfoque organizacional (Rosenkopf y Schilling, 2007; Rosenkopf y Padula, 2008).

Por otra parte, las investigaciones sobre actores en redes, a nivel micro, se centran en qué tipo de lazos y recursos, sociales y organizativos, conectan a los actores en las redes, y a través de qué tipo de procesos las relaciones evolucionan y las partes tratan de obtener beneficios relacionales (Håkansson y Ford, 2002). Las influencias que ha recibido esta corriente provienen de distintas disciplinas, entre las que se encuentran las teorías de dependencia de recursos (Pfeffer y Salancik, 1978), intercambio social y costes de transacción.

En este enfoque tienen cabida todo tipo de relaciones de actores (empresas, gobiernos, actores individuales y actores colectivos). La vinculación entre los actores se basa fundamentalmente en la dependencia de recursos, y se caracteriza por el intercambio y la co-creación de recursos. Las relaciones son vistas como vehículos para acceder y controlar recursos, así como para crear nuevos (Håkansson y Ford, 2002; Möller y Svahn, 2006).

La visión de los estudios de redes hace hincapié en el contexto y en el tiempo, puesto que los hechos acaecidos en las redes y las relaciones entre actores no pueden ser entendidos sin conocimiento sobre el contexto y sobre la evolución de la relación 
diádica particular inmersa en la red (Alajoutsijärvi et al., 1999). La metodología que suele aplicarse es el análisis cualitativo de casos.

(5) Redes focales y redes estratégicas.

Además del nivel macro y micro, previamente descritos, una última línea de investigación se dirige a un nivel meso en el ámbito de redes, en el que se encuentran las investigaciones sobre redes focales y redes estratégicas.

En cuanto a las redes focales, su estudio se basa en la idea de que si bien las redes no tienen fronteras, la capacidad cognitiva de los actores y los recursos limitados con los que cuentan limitan su capacidad para utilizar las redes. Esto hace que los actores traten, principalmente, con aquellos que forman su red focal (Alajoutsijärvi et al., 1999).

Los objetivos del enfoque de red focal se concretan en entender cómo estas redes evolucionan y cómo las empresas obtienen ventajas en ese marco. Un aspecto esencial son los roles y las posiciones que un actor puede tener en una red. Este proceso está influido por la capacidad de aprendizaje del actor, así como por su experiencia acumulada en la red. A su vez, esta experiencia está basada en la posición del actor, y el número y variedad de relaciones que tiene (Möller, 2010).

Por otra parte, las redes estratégicas o redes de valor hacen referencia a redes movilizadas y planificadas intencionadamente (Möller et al., 2005; Raab y Kenis, 2009). Académicos procedentes del ámbito de la dirección estratégica sugieren que las redes estratégicas creadas con un mayor grado de intencionalidad contienen un conjunto específico de organizaciones con tareas distribuidas y roles acordados (ej. Jarillo, 1993; Parolini, 1999; Möller y Rajala, 2007). Sin embargo, no hay un consenso a este respecto. Es más, esta visión está en contradicción con la referida a las redes como entidades emergentes y “no gestionables” (Håkansson y Ford, 2002; Ford, 2011).

Tanto las redes focales como las estratégicas comparten un background común, procedente de los estudios sobre redes a nivel macro y micro, los cuales se han explicado previamente. Pero incluyen el enfoque cognitivo y de aprendizaje organizacional en aras de comprender la creación de sentido por parte de los actores de las redes, así como la creación de nuevos recursos y prácticas a través del aprendizaje en red.

Para ilustrar los cinco enfoques propuestos por Möller (2013) se presenta la Figura 2.1. 


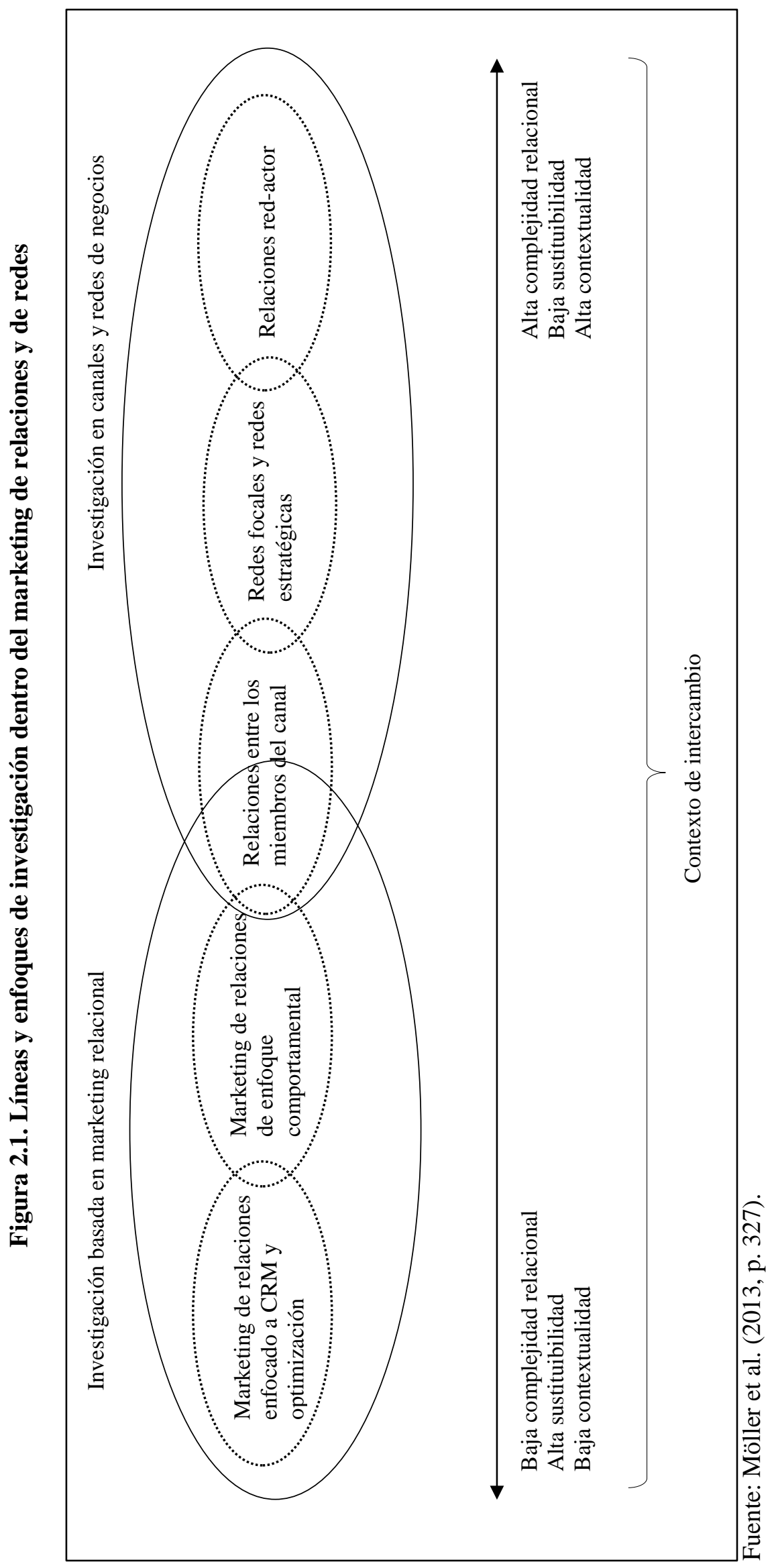




\section{Marketing relacional y emprendimiento}

Entre las diferentes aplicaciones del marketing de relaciones, y desde un enfoque comportamental y económico, nos interesamos por el marketing de relaciones entre empresas y, en especial, la aplicación del enfoque de marketing relacional al ámbito del emprendimiento.

Marketing y emprendimiento son dos disciplinas que están relacionadas, como bien indican las palabras de Day et al., (1998, p.828): "Marketing y emprendimiento son ideas relacionadas, los buenos emprendedores practican marketing, y alguno de los mejores comportamientos de marketing son emprendedores - pero no son lo mismo”.

Distintos estudios han tratado de integrar teorías de marketing y emprendimiento (Hultman y Hills, 2011; Miles et al., 2011), principalmente bajo la corriente denominada entrepreneurial marketing (Morrish et al., 2010; Jones y Rowley, 2011) o Small and Medium Sized Enterprises (SME) marketing (Gilmore, 2011; Harrigan et al., 2012). Asimismo, otros autores han tratado de aplicar conceptos de marketing para explicar los procesos de emprendimiento (Fillis, 2004; Bengtsson et al., 2007; O’Cass y Sok, 2013). Concretamente, y como Hansen y Eggers (2010) recogen, hay cuatro perspectivas de investigación en las que se pueden encuadrar los estudios realizados en torno al eje marketing-emprendimiento, y se presentan en la Tabla 2.1.

Tabla 2.1. Perspectivas de investigación marketing-emprendimiento

\begin{tabular}{ll}
\hline \multicolumn{1}{c}{ Perspectiva } & \multicolumn{1}{c}{ Descripción } \\
\hline 1. Marketing y emprendimiento & Similitudes entre ambas disciplinas \\
\hline 2. Emprendimiento en marketing & $\begin{array}{l}\text { Temas de emprendimiento enmarcados en el ámbito } \\
\text { del marketing o vistos a través de un enfoque teórico } \\
\text { de marketing }\end{array}$ \\
\hline 3. Marketing en emprendimiento & $\begin{array}{l}\text { Temas de marketing enmarcados en el campo del } \\
\text { emprendimiento o vistos a través del enfoque teórico } \\
\text { de emprendimiento }\end{array}$ \\
\hline 4. Conceptos que nacen de la conexión \\
entre marketing y emprendimiento
\end{tabular} \begin{tabular}{l}
$\begin{array}{l}\text { Conceptos que no son comunes entre ambas } \\
\text { disciplinas, pero que evolucionan de la combinación } \\
\text { de emprendimiento y marketing }\end{array}$ \\
\hline
\end{tabular}

Fuente: Hansen y Eggers (2010, p.44).

Sin embargo, a pesar de los esfuerzos realizados a nivel teórico y conceptual, la integración entre ambas disciplinas no ha sido elevada, no ocurriendo así a nivel práctico. Webb et al. (2011, p.537) lo enuncian así: “A pesar de su estrecha integración en la práctica, marketing y emprendimiento como dominios de la investigación académica han progresado en gran medida dentro de sus respectivas fronteras con el mínimo cruce disciplinario”. 
Lam y Harker (2014), en su estudio sobre las interrelaciones entre el marketing y el emprendimiento en las distintas etapas del ciclo de vida de un negocio, trabajan con una idea clave sobre el marketing relacional. Esa idea es que las relaciones interpersonales y las redes personales tienen un papel crucial en el éxito en los negocios. Tomando en consideración esta premisa, junto con que los emprendedores tienen prioridades diferentes y emplean distintas estrategias de marketing, destacan el empleo y la notable importancia del marketing relacional en las fases de pre-start-up, early-start-up, growth y maturity.

En la aplicación del marketing de relaciones al ámbito del emprendimiento no se puede pasar por alto, ni a nivel teórico ni a nivel práctico, el hecho de que las relaciones en el ámbito de los negocios son de muchos tipos (Wilkinson y Young, 1994), y se requiere una comprensión de los procesos de generación de valor (Wilson y Jantrania, 1994; Ravald y Grönroos, 1996; Grönroos, 1997; Anderson y Narus, 1999; Payne y Holt, 1999; Donaldson y O’Toole, 2007). Los beneficios potenciales de la colaboración entre empresas (o entre emprendedores) se encuentran en la generación de valor por el acceso y el aprovechamiento de los recursos complementarios, incluyendo información, mercados y tecnología (Grant y Baden-Fuller, 2004; Goerzen y Beamish, 2005). Además, las empresas que mantienen una relación comparten los riesgos y la incertidumbre inherentes al desarrollo de productos y mercados (Doz y Hamel, 1998).

Sin embargo, a lo largo de los últimos años, desde un punto de vista predominante de relaciones entre empresas a nivel individual, se ha producido un movimiento significativo hacia interacciones entre empresas en red que persiguen relaciones a largo plazo (Möller et al., 2005; Dilk et al., 2008; Teng y Das, 2008; Pateli, 2009). En esta misma línea, también hay estudios que proponen la transición de relaciones diádicas entre empresas a alianzas y redes estratégicas (Ritter et al., 2002; Ploetner y Ehret, 2006; Dodourova, 2009; Butler, 2010; Rahman y Korn, 2010). Esta nueva perspectiva asume que los actores están involucrados dentro de redes de relaciones interconectadas que les brindan oportunidades, pero también restricciones en el desarrollo de sus acciones (Ellis y Mayer, 2001; Teng y Das, 2008; Das y Kumar, 2010).

En el contexto de las relaciones en el ámbito del emprendimiento, cabe mencionar que las nuevas empresas tienden a utilizar redes. Siguiendo a Hite y Hesterly (2001), cuando las empresas nacen, sus redes están basadas en conexiones sociales de los 
emprendedores. Posteriormente, cuando pasan a la etapa de crecimiento, esas redes cambian hacia lazos basados en costes y beneficios económicos. Así pues, las redes evolucionan para adaptarse a las necesidades cambiantes de recursos en las distintas etapas del ciclo de vida de la empresa. A su vez, la empresa aumenta su capacidad para gestionar activamente su red, dado que acumula experiencia y capacidades.

En diferentes estudios se destaca la importancia de las redes y del networking para la actividad del marketing (ej. Gilmore et al., 2006); viendo a las redes como familia, amigos y otros contactos sociales (Lam y Harker, 2014). Sin embargo, el marketing en el proceso de emprendimiento va más allá del networking (Carson y Gilmore, 2000).

En definitiva, y para concluir, cabe decir que si bien el marketing relacional ha sido considerado en numerosas industrias y nuevos contextos (Khojastehpour y Johns, 2014), aún quedan otros escenarios de aplicación, entre los que se encuentran las relaciones en el ámbito de las incubadoras. En concreto, y para el análisis de las relaciones diádicas que se establecen entre incubados, el marketing de relaciones nos permitirá responder a diferentes interrogantes:

- ¿ ¿Qué factores comportamentales de los emprendedores facilitan el intercambio de conocimiento?

- ¿QQué variables relacionales definen y caracterizan la relación entre incubados?

- ¿En qué se basan la confianza y el compromiso en el caso de incubados que no han mantenido relaciones empresariales previas?

A fin de dar respuesta a estas preguntas, en la presente tesis doctoral nos apoyamos en el marketing de relaciones para fijar el binomio confianza - compromiso como elemento que define la calidad de las relaciones entre emprendedores. Asimismo, nos basaremos en las aportaciones del marketing de relaciones de enfoque comportamental para proponer los valores comunes y la afinidad entre los individuos como determinantes de las relaciones.

\subsubsection{Teoría de costes de transacción}

La teoría de costes de transacción es un enfoque que se incluye en la nueva economía institucional, la cual ha tendido a sustituir al modelo económico neoclásico (Rindfleisch y Heide, 1997). 
Esta teoría se fundamenta en las proposiciones realizadas por Coase (1937), en las que plantea que las empresas y los mercados son estructuras de gobierno alternativas que difieren en sus costes de transacción. Williamson (1975) impulsó, posteriormente, este enfoque económico cuya unidad fundamental de análisis es la transacción. Con este término se hace referencia a la fase contractual que precede al intercambio y que suele dar lugar a transferencias entre las partes implicadas. Más concretamente, se puede decir que transacción es la transferencia del derecho a utilizar determinados bienes y servicios de unos agentes a otros.

Según ha sido formulada por Williamson (1975), la teoría de los costes de transacción se basa en el supuesto de que los seres humanos cuentan con racionalidad limitada y, en determinadas ocasiones, muestran un comportamiento oportunista.

La economía de los costes de transacción toma como punto de partida la hipótesis de que los contratos económicos surgen para minimizar los costes de transacción entre los factores productivos. Los agentes económicos, dotados de racionalidad limitada, crean estructuras de gobierno (empresas, mercado y formas híbridas) para superar las dificultades de coordinación debidas a la incertidumbre que rodea la transacción y al comportamiento oportunista que puedan mostrar los agentes.

Los costes de transacción pueden descomponerse en cuatro tipos: costes de búsqueda, de contratación, de supervisión (monitoring), y de ejecución (enforcement) (Williamson, 1985; North, 1990; Hennart, 1993). El primero de ellos, costes de búsqueda, incluye todos aquellos derivados de recoger la información para identificar y evaluar los socios potenciales. Los de contratación, por su parte, se refieren a los costes asociados con la negociación y redacción del acuerdo. Los costes de supervisión están vinculados con el seguimiento del acuerdo, y persiguen el propósito de asegurar que cada parte cumple con el acuerdo de obligaciones predeterminado. Y, por último, los costes de ejecución son aquellos en los que se incurre a posteriori de la negociación, para sancionar a la otra parte por su incumplimiento con el acuerdo establecido.

Estos costes de transacción vienen determinados por tres factores (Williamson, 1985): especificidad de los activos, frecuencia del intercambio, e incertidumbre o complejidad del entorno. 
La especificidad de los activos. Es una dimensión determinante que se refiere al grado en el que el valor de un activo depende de la continuidad de la transacción. Hace referencia al grado de sustituibilidad de un activo concreto y al poder que tiene una de las partes en la transacción. A su vez, también se refiere a si el activo puede dedicarse a un solo uso concreto o a varios. Cuánto mayores sean los usos que se puedan dar a un activo, menor será su especificidad. La especificidad de los activos se puede referir tanto a activos físicos como humanos. El carácter específico de un activo puede venir determinado por la localización geográfica del mismo o por los conocimientos concretos de una persona, entre otros.

La frecuencia del intercambio. Hace referencia al número de veces que se repite una transacción. Las transacciones pueden ser únicas, ocasionales o recurrentes (Williamson, 1979). Los costes de una estructura de gobierno especializada se recuperan más fácilmente cuando la frecuencia de las transacciones sea alta y recurrente (Williamson, 1985).

La incertidumbre o complejidad del entorno. Esta dimensión surge por la falta de información, derivada de la racionalidad limitada a la que se enfrentan las partes vinculadas en relaciones de intercambio.

Las aportaciones realizadas por Williamson (1975) permiten la comparación institucional de los mecanismos de asignación de recursos, y caracterizan la transacción a través de los factores que inciden en los costes de transacción, y en la elección de la estructura (empresas, mercado y formas híbridas) a través de la cual resulte más eficiente realizar una transacción. Las estructuras de gobierno de las transacciones serán más complejas cuánto mayores sean la especificidad de los activos, la incertidumbre y la frecuencia de la transacción.

Entre las distintas aplicaciones y contribuciones de la teoría de costes de transacción, en la presente investigación nos centramos en las vinculadas con el marketing, con las relaciones entre empresas y, más concretamente, las producidas en el ámbito del emprendimiento.

\section{Teoría de costes de transacción, marketing y relaciones entre empresas}

Con la aparición de la teoría de costes de transacción se revitalizó la importancia de la teoría institucional en marketing (Rindfleisch y Heide, 1997). Esto desembocó en 
diferentes contribuciones en el campo de la estrategia de marketing (ej. Carson et al., 1999; Ghosh y John, 1999; John y Reve, 2010). Tanto es así que John y Reve (2010) afirman que la teoría de costes de transacción ha llegado a ocupar un lugar importante en la corriente de investigación de la estrategia de marketing.

Las contribuciones entre ambas disciplinas son mutuas. Williamson y Ghani (2012, p. 74) lo reflejan a través de la siguiente proposición: “... la relación entre economía de costes de transacción y marketing ha sido y debería ser una calle de doble sentido”.

Por una parte, la principal aportación de la teoría de costes de transacción a los investigadores en marketing ha sido: “... proporcionar un marco constructivo para analizar el intercambio contractual, con implicaciones comprobables que han demostrado robustez empírica a través de una amplia gama de aplicaciones” (Williamson y Ghani, 2012, p. 76). Por otra parte, el marketing ha ampliado el alcance de la teoría de costes de transacción, planteando retos y oportunidades de investigación para resolver (Williamson y Ghani, 2012).

Como conclusión acerca de la relación entre estos dos enfoques, Williamson y Ghani (2012) sostienen que el uso actual de la teoría de costes de transacción en la disciplina de marketing se centra, principalmente, en las estructuras de gobierno ("the play of the game”) y no en el entorno institucional ("the rules of the game”), aunque el entorno también es importante.

Dentro de esta aplicación al marketing, la teoría de costes de transacción se ha convertido en uno de los paradigmas dominantes en el análisis de las relaciones entre empresas, incluyendo aspectos claves tales como la selección de socios y la contratación (Anderson y Dekker, 2010).

La selección de un socio es crítico para la gestión efectiva de las relaciones entre empresas (Blumberg, 2001; Dekker, 2004, 2008). La selección cuidadosa de un socio puede disminuir la probabilidad de un comportamiento oportunista y la falta de cumplimiento de los compromisos por parte del mismo (Hitt et al., 2000). Los riesgos de cambio, originados a partir del contexto de transacción, contribuyen de manera significativa a explicar la elección de empresas de confianza para transacciones en la cadena de suministro (Dekker et al., 2013). 
En cuanto a los contratos que rigen las relaciones entre empresas, éstos suelen ser vistos como contratos relacionales caracterizados por una larga duración y por la interdependencia entre las partes (Luo, 2002). La teoría de costes de transacción postula que la principal función de los contratos es lidiar contra el comportamiento oportunista de la otra parte (Williamson, 1985). Pero esa es no es la única función de los contratos, ya que favorecen la creación de compromiso en las transacciones entre las empresas, así como el apoyo y la coordinación entre las partes (ej. Gulati y Singh, 1998; Woolthuis et al., 2005; Lumineau y Malhotra, 2011).

\section{Teoría de costes de transacción y emprendimiento}

La teoría de costes de transacción se ha utilizado, principalmente, en la investigación sobre empresas establecidas (Michael, 2007). Pero también se ha empleado en el ámbito del emprendimiento, en un contexto caracterizado por transacciones noveles (ej. Michael, 2007; Brettel et al., 2011). A continuación, procedemos a exponer la aplicación de la teoría de costes de transacción al concepto de oportunidad emprendedora y al denonimado transaction cost entrepreneurship.

La teoría sobre emprendimiento se ha configurado en torno a la oportunidad emprendedora (Shane y Venkataraman, 2000), como hemos mencionado en el primer capítulo, y ello ha motivado que la teoría de costes de transacción se haya aplicado a este concepto (ej. Plummer et al., 2007; Cai et al., 2012). Más concretamente, y siguiendo a Plummer et al. (2007), ante una oportunidad emprendedora el individuo se enfrenta a decisiones sobre diferentes modos de explotarla, lo cual se ve afectado por la estructura de gobierno. A su vez, esa estructura está condicionada por la naturaleza de la oportunidad emprendedora y por el ambiente en el que surge. Al seleccionar la estructura de gobierno, el emprendedor lo hace con una "previsión consciente”, la cual se basa en lo que el biólogo evolutivo Richard Dawkins define como la capacidad humana única para simular el futuro en la imaginación (Williamson, 2000).

En este sentido, la estructura de gobierno se selecciona para limitar, por ejemplo, el comportamiento oportunista de los individuos, tanto en el momento presente como en el futuro (Williamson, 2000). Esto hace que el emprendedor tome las decisiones sobre qué activos "hacer” o “comprar” en el proceso de consecución de la oportunidad emprendedora. Estas elecciones son factores críticos para el éxito de una nueva empresa (Mosakowski, 1991). También Michael (2007) parte de las premisas de la teoría de 
costes de transacción, y las extiende y adapta a las transacciones emprendedoras para desarrollar lo que él mismo denomina como transaction cost entrepreneurship, esto es, un análisis de costes de transacción a los que se enfrenta un emprendedor cuando inicia su relación con los clientes.

Para el contexto que nos ocupa, las relaciones entre incubados, la teoría de costes de transacción nos sirve de base para dar respuesta a los siguientes interrogantes:

- ¿ ¿Son las UBIs entornos que reducen el oportunismo percibido por parte de los emprendedores? ¿A través de qué mecanismos?

- ¿Las relaciones entre individuos en una UBI suponen menores costes de transacción frente a los que afrontaría un incubado en el supuesto de tener que iniciar una relación con empresas externas a la UBI?

En este sentido, planteamos que en las incubadoras pueden surgir relaciones (o formas de gobierno) caracterizadas por la confianza como mecanismo que mitiga la percepción de oportunismo y facilita el intercambio de conocimiento. Además, valoramos que las incubadoras constituyen un entorno privilegiado para la iniciación de relaciones entre emprendedores noveles, donde se eliminan muchos costes de transacción que surgirían de la búsqueda de información y evaluación de otros emprendedores o agentes en el mercado.

\subsubsection{Enfoque basado en los recursos}

El enfoque basado en los recursos proporciona un marco apropiado para tratar de explicar y predecir las bases en las que se sustentan las ventajas competitivas y los rendimientos de las empresas (Slotegraaf et al., 2003; Vorhies y Morgan, 2005; Barney et al., 2011). De acuerdo con esta teoría, las empresas son compilaciones de recursos y capacidades únicos, valiosos, raros, inimitables y no sustituibles, los cuales pueden proporcionar ventajas competitivas sostenibles (Barney, 1991). Por tanto, las empresas poseen y necesitan recursos heterogéneos y capacidades para desarrollarlos, con la finalidad de poder generar ventajas competitivas y explorar nuevos mercados (Barney 1991, 2002).

Las empresas poseen diferentes conjuntos de recursos (asunción de heterogeneidad de los recursos), incluso aquellas que operan dentro de la misma industria (Peteraf y Barney, 2003). Además, esta heterogeneidad lleva a que algunas empresas sean más 
hábiles en el cumplimiento de determinadas actividades porque poseen recursos específicos y únicos (Peteraf y Barney, 2003). Las diferencias producidas pueden persistir debido a la dificultad de distribuir recursos entre las empresas (asunción de inmovilidad de los recursos), lo cual favorece que los beneficios derivados de la heterogeneidad de los recursos persistan a lo largo del tiempo (Barney y Hesterly, 2012).

En palabras de Barney y Arikan (2001, p.138) "los recursos son activos tangibles e intangibles que las empresas utilizan para concebir y poner en práctica sus estrategias”. Más concretamente, bajo esta denominación de recursos se incluyen, entre otros, activos físicos, capital humano, y conocimiento que las empresas tienen en propiedad o tienen bajo su control (Amit y Schoemaker, 1993; Capron y Hulland, 1999). Sin embargo, no todos los recursos presentan las mismas características ni los mismos efectos para las empresas. Los recursos valiosos son los que permiten implementar y desarrollar estrategias que faciliten la reducción de costes y/o el incremento de ingresos, resultados que no podrían haberse conseguido sin estas estrategias (Barney y Arikan, 2001).

Por otra parte, el término capacidad se refiere a la competencia de la empresa para explotar y combinar recursos a través de rutinas organizacionales, con la finalidad de lograr determinados objetivos de la propia empresa (Amit y Schoemaker, 1993). La gestión y el aprovechamiento de las capacidades y los recursos también puede originar heterogeneidad en los mismos (Sirmon et al., 2007). Así pues, una gestión distinta de los recursos puede producir diferentes resultados, aun disponiendo de recursos y condiciones ambientales similares (Zott, 2003).

Si una empresa posee recursos valiosos que sólo tienen otro número reducido de empresas (recursos raros), y si a estas empresas les resulta demasiado costoso o difícil de imitar esos recursos (recursos imperfectamente imitables), entonces la empresa que controla esos recursos probablemente puede generar ventajas competitivas sostenibles (Barney y Hesterly, 2012). Una empresa tiene una ventaja competitiva sostenible “cuando está creando más valor económico que la empresa marginal (punto de equilibrio) en su industria y cuando otras empresas no son capaces de duplicar los beneficios de esta estrategia” (Barney y Clark, 2007).

Es necesario considerar que la mera posesión de recursos no garantiza una ventaja competitiva ni un rendimiento superior (Sirmon et al., 2008). Para crear valor con los 
recursos de los que disponen las empresas tienen que usarlos (Newbert 2007; Penrose, 2009). Específicamente, se crea valor, en términos de recursos, cuando son manipulados, evaluados y utilizados apropiadamente dentro del contexto en el que se enmarca la empresa (Sirmon et al., 2007).

Si un recurso puede ser identificado e imitado, la ventaja competitiva desaparecerá para la empresa, al igual que si es copiado (Kortelainen et al., 2010). Evitar esto es un reto cada vez más complicado, dado que el número de empresas imitadoras se incrementa a un ritmo elevado, llegando incluso a conseguir mejores resultados que las empresas a las que han copiado (Teece, 1986; Ihrig et al., 2010).

\section{Enfoque basado en los recursos, marketing y relaciones entre empresas}

Las aplicaciones e interacciones entre el enfoque basado en los recursos y la disciplina del marketing han crecido exponencialmente. Según Kozlenkova et al. (2014), en la década de los 90, sólo 19 papers en marketing hacían referencia expresa al enfoque basado en los recursos; mientras que en el período 2000-2010, la cifra ascendía a 104. Esta tendencia es un indicador de la creciente importancia de la vinculación entre ambas teorías.

Kozlenkova et al. (2014) realizan una exhaustiva revisión de los citados estudios y, en consecuencia, extraen tres perspectivas en las que enmarcan las interrelaciones entre ambos enfoques. A continuación se describen brevemente cada una de ellas.

(1) Enfoque basado en recursos aplicado a contextos de marketing. Los autores ponen de manifiesto que la principal razón para aplicar el enfoque basado en recursos radica en ofrecer un marco teórico que pueda explicar cómo las actividades de marketing, en diferentes contextos, conducen a recursos que puedan mejorar el rendimiento de las organizaciones.

(2) Recursos basados en el mercado. Se refieren a un subconjunto de recursos con los que cuentan las empresas y que se relacionan con actividades de marketing, tales como la construcción de relaciones, la marca, o el conocimiento. La investigación en marketing se centra, cada vez en mayor medida, en este tipo de recursos intangibles y complementarios, los cuales pueden generar ventajas competitivas sostenibles y rendimientos superiores a los recursos tangibles. A 
este respecto, el enfoque basado en recursos se utiliza como marco conceptual debido a que favorece la robustez teórica de las investigaciones.

(3) Extensión del enfoque basado en recursos a intercambios en marketing. Teniendo en cuenta que el enfoque basado en recursos se desarrolló en la disciplina de la gestión, y que inicialmente sus aplicaciones en marketing fueron en el ámbito de la estrategia, no sorprende que un elevado número de investigaciones tomaran como unidad de análisis a la empresa. Sin embargo, Kozlenkova et al. (2014) ponen de relieve que diversos investigadores en marketing (Jap, 1999; Samaha et al., 2011; Palmatier et al., 2013) están aplicando el enfoque de recursos a las relaciones diádicas para explicar, por una parte, cómo los recursos afectan al intercambio como factores contingentes y, por otra parte, el efecto de los recursos en términos de rendimiento del intercambio.

El interés de aplicar el enfoque de recursos a los intercambios y a las relaciones entre empresas es indiscutible. En palabras de Håkansson y Snehota (1989, p.187): “ningún negocio es una isla”. Esta proposición sirve de marco para las relaciones entre empresas en las que median recursos de distinta índole. Concretamente, dentro del enfoque basado en recursos, las relaciones y las redes entre empresas son recursos valiosos en la medida en que permiten no sólo el acceso a recursos, sino también su creación y modificación (Gulati, 1999).

En la cooperación entre empresas, y más si nos referimos a un contenido basado en recursos intangibles como el conocimiento, los recursos necesitan ser compartidos y transferidos. Las empresas implicadas pueden proteger su co-desarrollo y los recursos compartidos de imitaciones externas apoyándose en mecanismos de aislamiento, tales como derechos de propiedad y ambigüedad causal (Dyer y Singh, 1998). Pero es más efectiva la estrategia de competitividad sostenida, que consiste en asegurar el flujo constante de recursos recién creados a lo largo del tiempo (Dierickx y Cool, 1989).

\section{El emprendimiento y las UBIs en el marco del enfoque basado en los recursos}

Las oportunidades emprendedoras existen, principalmente, porque diferentes agentes tienen distintas ideas sobre el valor relativo de los recursos, ideas que otros no tienen, y actúan sobre esas oportunidades no explotadas (Schumpeter, 1934; Kirzner, 1979; Casson, 1982; Shane y Venkataraman, 2000). Ante esta situación, el enfoque basado en 
recursos se presenta como un marco destacado para la búsqueda y evaluación de las necesidades de recursos en las empresas, así como de posibles oportunidades de negocio (Barney, 2002; Penrose, 2009). Asimismo, explica cómo el emprendimiento requiere la capacidad de adquirir los recursos necesarios para aprovechar la oportunidad emprendedora, así como la capacidad organizativa para transformar inputs homogéneos en outputs heterogéneos (Alvarez y Busenitz, 2001). Así pues, la heterogeneidad de los recursos es una premisa básica del enfoque de recursos y también del emprendimiento (Kirzner, 1997).

Otro aspecto relevante en el ámbito del emprendimiento es la orientación emprendedora. Este concepto hace referencia a los procesos, las intenciones y las actividades de los actores claves en el proceso dinámico de creación de una nueva empresa (Lumpkin y Dess, 1996). Grande et al. (2011) consideran que la orientación emprendedora puede ser un recurso importante que debe ser tenido en cuenta ya que explica, de manera significativa, las variaciones entre los rendimientos longitudinales de las empresas a través, por ejemplo, del uso alternativo de los recursos de los que disponen.

Aplicando el enfoque basado en recursos a las UBIs, encontramos que éstas logran ventajas competitivas sostenibles cuando sus inquilinos, empresas incubadas, sobreviven y crecen (Lendner, 2007). En este ámbito, el enfoque basado en recursos puede ser aplicado para explicar cómo los recursos y capacidades de las UBIs activan start-ups, a la propia universidad, incluso a la incubadora en sí misma, para obtener ventajas competitivas y un rendimiento superior, y explicar la influencia de los recursos en el éxito de las UBIs (Somsuk y Laosirihongthong, 2014).

En el contexto del estudio de las relaciones diádicas entre incubados, el enfoque de recursos nos lleva a plantearnos las siguientes cuestiones:

- ¿ ¿Qué recursos son valiosos para los emprendedores académicos?

- ¿Qué tipo de recursos son necesarios para la construcción de relaciones entre incubados?

- ¿En qué medida las relaciones diádicas y en red dentro de las UBIs pueden entenderse como un recurso en tanto que conducen a la creación de ventajas competitivas? 
Para dar respuesta a las dos primeras preguntas, nos centraremos en las características de los recursos en términos de complementariedad, suplementariedad y transferibilidad. Por lo que se refiere a la tercera pregunta, en el epígrafe 2.5. describiremos los resultados de las relaciones diádicas entre incubados.

\subsubsection{Enfoque basado en el conocimiento}

El conocimiento es una actividad creativa de construcción de la realidad (Von Krogh et al., 1994), que se cimienta y crea significado a través de interacciones sociales basadas en rutinas de trabajo (Weick y Roberts, 1993; Cook y Brown, 1999), y en características específicas del entorno social y cultural (Blackler, 1995; Galunic y Rodan, 1998).

Diferentes investigadores han tratado de crear una teoría de empresa basada en una perspectiva de conocimiento. Uno de los primeros intentos fue realizado por Dierickx y Cool (1989). Ambos autores conceptualizaron el conocimiento de las empresas en términos de flujos y stocks. Los flujos se refieren a arroyos de conocimiento que fluyen dentro y a través de las organizaciones, y que contribuyen a la acumulación de conocimiento. Los stocks, por su parte, son activos de conocimiento acumulados. Los denominados flujos y stocks superiores de conocimiento son vistos como recursos de una ventaja competitiva y un rendimiento superiores.

Posteriormente, en el año 1992, Kogut y Zander también hacen hincapié en la importancia estratégica del conocimiento como fuente de ventaja, y establecen las bases para una teoría de empresa. Ellos parten de que el conocimiento está en manos de los individuos (know-what y know-how), los cuales forman parte de las organizaciones, como trabajadores. Las empresas crean y transfieren conocimiento dentro de las organizaciones mejor que los mercados. Es más, las empresas existen porque proveen una comunidad social de acciones estructuradas por principios organizacionales que permiten la creación de nuevos conocimientos. Considerando lo anterior, el conocimiento colectivo de la empresa evoluciona en una trayectoria dependiente, a través de la replicación y recombinación de conocimiento existente. En lo que podría constituir la base para una teoría de estrategia, los autores también argumentan que la capacidad de replicar el conocimiento determina la tasa de crecimiento de la empresa, pero que tal réplica también facilita la imitación por parte de los competidores. Por lo tanto, las empresas son capaces de crecer y de disuadir la imitación competitiva 
únicamente recombinando continuamente sus conocimientos y aplicándolos a nuevas oportunidades de mercado. Es decir, en un entorno competitivo, un rendimiento superior sólo puede mantenerse a través de la innovación continua.

El trabajo de Kogut y Zander (1992) fue completado por Nonaka y Takeuchi (1995), quienes proporcionaron un marco para la comprensión de la integración del conocimiento individual y organizacional. Sostienen que el conocimiento organizacional debe entenderse como todos aquellos procesos que amplifican el conocimiento creado por individuos y lo cristalizan como una parte de la red de conocimiento de la organización. Estos procesos constituyen una espiral de conocimiento, la cual es altamente iterativa y se produce, principalmente, a través de redes informales de relaciones en la organización. Esta espiral implica interacciones continuas entre el conocimiento tácito y explícito ${ }^{3}$, a nivel individual y de la organización. El modelo propuesto por Nonaka y Takeuchi (1995) identifica algunas condiciones favorables para el proceso de creación de conocimiento, entre las que se encuentran la existencia de redundancia, la variedad y un caos creativo.

Grant (1996) articula, en mayor medida, los fundamentos teóricos para el enfoque basado en el conocimiento. Las actividades de producción en las empresas requieren, generalmente, la combinación de una amplia gama de conocimiento especializado que reside en los individuos. A este respecto, la esencia de las organizaciones es su capacidad, a través de estructuras jerárquicas, para integrar conocimiento especializado de los individuos, y aplicarlo a nuevos productos y servicios. Los mecanismos que permiten tal integración son la dirección, las rutinas, y la coordinación por parte de la organización. Sobre la base de esta comprensión de las organizaciones, Grant (1996) propone la teoría basada en el conocimiento. Argumenta que la fuente de ventaja competitiva en entornos dinámicos no es el conocimiento propiedad de la organización, ya que el valor de ese conocimiento se erosiona rápidamente debido a la obsolescencia y la imitación. Más bien, la ventaja competitiva sostenible está determinada por el conocimiento no patentado, o que no tiene en propiedad, en la forma de conocimiento individual tácito. El conocimiento tácito puede constituir la base de ventaja competitiva

\footnotetext{
${ }^{3}$ El conocimiento tácito es el "conocimiento escondido" que los individuos poseen, pero que no pueden explicar fácilmente (Byosiere et al., 2010). Por su parte, el conocimiento explícito es el conocimiento sencillo de codificar (Byosiere et al., 2010). En los subepígrafes 2.3.2 y 2.4.5. se amplían ambas dimensiones del conocimiento.
} 
debido a que es único y relativamente inmóvil a la vez. Sin embargo, y dado que el conocimiento está en posesión de los individuos y no de la organización, un elemento crítico de ventaja competitiva sostenible es la capacidad de integrar el conocimiento tácito y especializado de los individuos. Grant (1996) identifica tres características del proceso de integración de conocimientos, que incrementan su valor estratégico. La primera es la eficiencia de la integración, la cual es una función del conocimiento común, la frecuencia y la variabilidad de las tareas, y una estructura que reduce la comunicación. La segunda se refiere al ámbito de esa integración, con un alcance más amplio se facilita la creación y el mantenimiento de la ventaja competitiva. La tercera es la flexibilidad de la integración para incluir nuevo conocimiento, y la reconfiguración de conocimiento existente. Además, Grant, al igual que otros autores (Kogut y Zander, 1996; Kogut, 2000), señala que el conocimiento también se puede integrar externamente a través de redes relacionales que están dentro de los límites de la organización. Estas redes proporcionan mecanismos eficientes para el acceso y la integración de nuevo conocimiento, especialmente en entornos dónde la velocidad y el alcance de la integración son de suma importancia para el mantenimiento de la ventaja competitiva. De manera generalizada, el enfoque de "conocimiento como recurso" se ha convertido en la perspectiva dominante, pudiéndolo considerar una consecuencia del enfoque basado en recursos (Eisenhardt y Santos, 2002). Sin embargo, encontramos discrepancias al respecto. Por ejemplo, Spender (1996) sostiene que una teoría dinámica de la empresa basada en el conocimiento debe ser conceptualmente diferente de un enfoque basado en recursos. La razón para ello se encuentra en que el conocimiento no es un producto observable y transferible. Las organizaciones aprenden y tienen conocimiento en la medida en que sus miembros son seres maleables cuyo sentido de sí mismos se ve influido por la evolución de la identidad de la organización, lo cual también es argumentado por Kogut y Zander (1996). Así pues, la empresa es vista de forma evolutiva, como un sistema cuasi-autónomo de producción y aplicación de conocimiento, con emergentes y auto-organizadas propiedades que se derivan de la interacción de sus elementos, semi-autónomos entre sí, y del ambiente externo (Spender, 1996).

Remitiéndonos a la investigación que nos ocupa, el enfoque basado en el conocimiento sienta las bases para comprender que las relaciones entre incubados académicos permiten el acceso y la creación de conocimiento útil para las partes de la díada 
implicadas, constituyendo este recurso una posible fuente de ventaja competitiva sostenible. En concreto, en tanto que el objeto de estudio de esta tesis son empresas basadas en conocimiento, este enfoque nos conduce a algunas de las cuestiones que se plantean en este trabajo, en línea con Grant (1996):

- ¿Qué ámbitos de conocimientos o recursos se integran en las relaciones entre incubados?

- ¿ ¿Cuáles son los mecanismos para la integración eficiente de conocimiento?

De nuevo, estas preguntas encuentran respuesta bajo el enfoque de los recursos. La complementariedad, suplementariedad y transferibilidad del conocimiento se plantean como requisitos para el intercambio elocuente del conocimiento. Además, se propone un intercambio de conocimiento bidireccional, de modo que ambas partes ven enriquecido el core business de su negocio (el conocimiento) y, por ende, sus resultados.

\subsection{Conceptualización y caracterización de las relaciones entre incubados}

El intercambio relacional es un concepto clave en las relaciones entre empresas, como lo hemos expuesto al tratar el enfoque de marketing relacional. El intercambio es una alternativa al mercado o a las formas de gobierno contractual, sobre la base de mecanismos que no se materializan en contratos. Tales mecanismos se concretan en la confianza, el compromiso, la comunicación, la cooperación, y las expectativas de continuidad (Heide y John, 1990; Morgan y Hunt, 1994; Hunt et al., 2006). Tomando esto en consideración, en el presente epígrafe consideramos la conceptualización de las relaciones, tanto en términos de calidad como de contenido.

- Para la calidad de las relaciones, y partiendo de las contribuciones realizadas por Morgan y Hunt (1994), planteamos que la confianza y el compromiso son variables adecuadas para caracterizar las relaciones entre incubados, si bien el binomio confianza - compromiso no ha sido analizado en el ámbito de las incubadoras.

- En cuanto al contenido de las relaciones, nuestra propuesta se concreta en el intercambio de conocimiento, debido a que las empresas incubadas en UBIs se 
basan y son intensivas en ese recurso, siendo fuente potencial de ventaja competitiva.

\subsubsection{Calidad de las relaciones a través de la confianza y el compromiso relacional}

La calidad de la relación se refiere al grado en el que esa interacción está marcada por el desarrollo de confianza y expectativas de reciprocidad (Larson, 1992; Ring y van de Ven, 1994; Dyer y Singh, 1998). A continuación, procedemos a explicar el papel de la confianza y del compromiso en el ámbito de las relaciones en incubadoras, y la vinculación entre las dos variables.

\section{Confianza}

En el marketing relacional el concepto de confianza es un elemento central (ej. Morgan y Hunt, 1994; Fontenot y Wilson, 1997; Ndubisi y Wah, 2005), dado que abarca los valores ideológicos de este enfoque, y refuerza sus preceptos (Mitussis et al., 2006).

La confianza entre empresas ha sido definida de diferentes y numerosas formas en la literatura. Siguiendo a Anderson y Narus (1990), la confianza puede definirse como la creencia de una empresa en que otra desarrollará las actuaciones que den lugar a resultados positivos para la primera, así como en que no realizará acciones inesperadas que pudieran resultar negativas. Esto se refiere a que la empresa con la que se mantiene una relación no mostrará un comportamiento oportunista y cumplirá con sus obligaciones (Dyer y Chu, 2003; Leonidou et al., 2006). Por su parte, Sako (1992) define la confianza como un estado de la mente referido a las expectativas que tiene una empresa de que la conducta de otra empresa es predecible y mutuamente aceptable. Esto quiere decir que ambas partes cumplirán los compromisos asumidos. Para Chattananon y Trimetsoontorn (2009), la confianza es la creencia o convicción sobre las intenciones de la otra parte dentro de una relación.

En la construcción y el desarrollo de relaciones a largo plazo, la confianza juega un papel crítico (Anderson y Weitz, 1989). Esta variable genera ventajas competitivas, ya que mejora las rutinas para compartir información (Zaheer et al., 1998; Robson et al., 2008), facilita el alcance de acuerdos y la creación de expectativas positivas sobre futuras contribuciones a la relación (Tomkins, 2001), reforzando la relación entre las empresas (Johanson y Mattson, 1987). 
La literatura ha analizado también las diferentes dimensiones de la confianza (Ganesan, 1994; Doney y Cannon, 1997; Ganesan y Hess, 1997; Singh y Sirdeshmukh, 2000). Tanto a nivel interpersonal como a nivel organizacional, se han considerado como principales dimensiones de la confianza la credibilidad y la benevolencia. La credibilidad se refiere a la buena intención y a la capacidad del otro socio o empresa para mantener las promesas y los acuerdos. Esta credibilidad está vinculada a características como las competencias específicas, la fiabilidad para la entrega de productos y servicios o la forma de trabajo observados en la otra empresa. La benevolencia se basa en las cualidades, intenciones y características que se atribuyen al otro socio o empresa, y que demuestran una implicación genuina y honesta en la relación, y que va más allá de la mera motivación lucrativa.

En las relaciones en el ámbito de las incubadoras, la confianza ha sido analizada en dos niveles de relaciones, las cuales procedemos a exponer a continuación.

(1) Relación mánager - incubados. La confianza ha sido identificada como un mecanismo que permite construir una buena relación entre el mánager, o el equipo de dirección en su defecto, y los incubados (Scillitoe y Chakrabarti, 2005, 2009, 2010; Tötterman y Sten, 2005; Vedel y Gabarret, 2014). A su vez, esa confianza favorece el desarrollo y el crecimiento de los negocios incubados a través de la optimización de los servicios de incubación de los que se benefician (Scillitoe y Chakrabarti, 2010).

(2) Relaciones entre incubados. La confianza es una variable determinante en intercambios entre incubados y en la formación de relaciones (McAdam y Marlow, 2008), siendo más efectiva que mecanismos formales como los contratos (Bøllingtoft y Ulhøi, 2005; Vedel y Gabarret, 2014). Es más, la falta de confianza es un obstáculo, junto con la ausencia de conocimiento de otros incubados, que impide compartir información y conocimiento en UBIs, dado que los incubados no siempre se sienten seguros de que la información compartida con otros inquilinos sea tratada de forma confidencial (Cooper et al., 2012). Esto les lleva a temer que los intercambios de información y conocimiento entre ellos puedan ser perjudiciales. Frente a esta situación, los valores en los que se basa una incubadora y el rol ejercido por el mánager son claves para limar las trabas mencionadas. Concretamente, los valores de la incubadora pueden facilitar y promover la construcción de confianza entre los incubados (Bøllingtoft y Ulhøi, 2005). El mánager, por su parte, puede crear un buen ambiente de trabajo y 
confianza (Tamásy, 2002), y debe establecer las bases para que entre los incubados se den relaciones basadas en la confianza (Schwartz y Hornych, 2010).

\section{Compromiso relacional}

El compromiso es una variable ampliamente estudiada en marketing (ej. Morgan y Hunt, 1994; Geyskens et al., 1996; Siguaw et al., 1998; Jap y Ganesan, 2000), siendo un eje central en la disciplina, a medida que se ha alejado de la visión transaccional del intercambio y ha adoptado una visión relacional (Gundlach et al., 1995). Helfert et al. (2002) utilizan cuatro características para describir el compromiso en la relación, que son la lealtad, la buena disposición para realizar sacrificios a corto plazo, la inversión en la relación, y la orientación a largo plazo.

Más concretamente, y en lo que se refiere a las relaciones entre empresas, Morgan y Hunt (1994) definen el compromiso en la relación como el deseo duradero de una empresa por continuar una relación con otra, acompañada de su buena disposición para la realización de esfuerzos con la finalidad de mantenerla. A través del compromiso mutuo, aquellas empresas que, por ejemplo, trabajan de manera conjunta para satisfacer mejor las necesidades del cliente, pueden aumentar su rentabilidad (Jap y Ganesan, 2000). Así pues, el compromiso es uno de los elementos que define el desarrollo y la consolidación de una relación, junto con la comunicación, la cooperación y las expectativas de continuidad (Heide y John, 1990; Morgan y Hunt, 1994; Hunt et al., 2006). Es más, el compromiso es una variable fundamental en las relaciones exitosas entre empresas (ej. Dwyer et al., 1987; Mohr y Spekman, 1994; Morgan y Hunt, 1994; Jap, 1999).

Aunque el compromiso no ha sido una variable analizada expresamente para el contexto de las relaciones entre incubados, sí que es, sin lugar a dudas, uno de los conceptos más estudiados en el ámbito de las relaciones entre empresas. Para afianzar una relación se deben hacer promesas y llegar a acuerdos, pero también son necesarios sacrificios y perseverancia para que se hagan efectivos (Murphy et al., 2007). El cumplimiento de las promesas hechas es trascendente en las relaciones entre las empresas y en las relaciones con los diferentes agentes con los que interactúan, como un medio para alcanzar otros objetivos: satisfacción de clientes, fidelización, u obtención de una rentabilidad a largo plazo (Grönroos, 1994). A medida que la relación evoluciona, el cumplimiento de los acuerdos previstos no sólo crea una percepción favorable del desempeño de una 
empresa, sino que también consolida y da forma a las expectativas de la otra parte a lo largo del tiempo (Narayandas y Rangan, 2004).

\section{La relación confianza-compromiso entre incubados}

De acuerdo con la teoría confianza - compromiso (Morgan y Hunt, 1994), la confianza es el principal antecedente del compromiso. Confianza y compromiso son necesarios para producir resultados que promuevan eficiencia, productividad, y efectividad. Ambos elementos son los más prominentes a nivel relacional (Achrol, 1991; Morgan y Hunt, 1994).

Podría decirse que la relación confianza-compromiso constituye ya un axioma del marketing de relaciones y, por tanto, no requiere de un planteamiento hipotético en esta tesis. No obstante, al revisar la literatura en el ámbito relacional en incubadoras, hemos detectado que si bien la confianza en otro incubado, o entre los miembros de la red en la que está inmersa la citada incubadora, ha sido tratada por determinados autores (Bøllingtoft y Ulhøi, 2005; McAdam y Marlow, 2008; Scillitoe y Chakrabarti, 2010; Vedel y Gabarret, 2014), no se ha considerado al compromiso y, por ende, el binomio confianza - compromiso no ha sido objeto de estudio en ninguna investigación. Ello nos ha llevado a plantearnos el interrogante de si el tándem confianza - compromiso también puede sentar las bases para definir las relaciones entre emprendedores académicos en incubadoras.

Autores como McAdam y Marlow (2008) y Cooper et al. (2012) coinciden en destacar la ausencia de una imagen completa acerca de cómo funcionan las interacciones y relaciones dentro de las incubadoras. Durante las primeras etapas de un nuevo negocio, el emprendedor utiliza, en gran medida, redes personales y sociales de carácter informal basadas en experiencias compartidas, confianza mutua y respeto (Shaw, 1998; Chell y Baines, 2000; Sherer, 2003). Los emprendedores que están en UBIs, provienen del mundo académico y se encuentran en el mismo momento incipiente a nivel profesional: empezando a construir un negocio basado en conocimiento. Esto puede llevar a que los individuos, a través de contactos en la incubadora, puedan compartir inquietudes y experiencias entre ellos. Según Stiglitz (2000), la confianza se puede adquirir mediante interacciones frecuentes durante un período de tiempo a través de las acciones humanas. Sin embargo, los problemas pueden surgir en saber en quién confiar y en qué medida se puede confiar (Krishna, 2000). Ese temor puede aminorarse entre los incubados debido 
a los aspectos que tienen en común, así como en la frecuencia de los contactos mantenidos, y en el hecho de que conocen quién está detrás de cada negocio, y de que saben dónde encontrarlos. Una vez que la confianza se haya creado entre dos incubados, esto influirá positivamente en la creación y mantenimiento de un compromiso entre ambos, que se irá afianzando con el paso del tiempo.

En definitiva, y como axioma general, mantenemos que la confianza entre incubados favorece el compromiso en las relaciones profesionales que pueden nacer entre ellos.

\subsubsection{Contenido de las relaciones: el intercambio de conocimiento}

Intercambiar conocimiento $^{4}$ es el proceso por el cual el conocimiento que posee un individuo se convierte o se expresa para que pueda ser entendido, absorbido y utilizado por otros individuos (Ipe, 2003). Este proceso implica una relación, al menos, entre dos partes: una que posee el conocimiento y otra que lo adquiere (Hendriks, 1999). El intercambio no sólo es unidireccional, sino que también se puede producir una transferencia mutua de conocimiento (Szulanski, 1996, 2000). Con un mayor nivel de concreción, en el presente trabajo, al hablar de intercambio de conocimiento nos referimos a cuando los actores organizacionales reciben el conocimiento de sus pares de manera recíproca y son influenciados por él (van Wijk et al., 2008).

\section{Dimensiones del intercambio de conocimiento}

Las empresas están expuestas e inmersas en diferentes relaciones con otras empresas a través de las cuales pueden acceder y adquirir nuevo conocimiento (Lyles y Salk, 1996; Tsai, 2001). En este proceso de intercambio, y siguiendo a van den Hooff y de Leeuw van Weenen (2004), se pueden identificar dos dimensiones: donación de conocimiento (knowledge donating) y recogida de conocimiento (knowledge collecting). La donación de conocimiento es definida como "comunicar a los demás el capital intelectual personal”, y la recogida de conocimiento como "consultar a los compañeros con el fin de llegar a compartir su capital intelectual” (van den Hooff y de Leeuw van Weenen, 2004, p. 14). Así pues, la donación de conocimiento supone compartir el capital intelectual que posee un individuo con otros, mientras que la recogida de conocimiento le permite a uno mismo aprovecharse del capital intelectual de otros.

\footnotetext{
${ }^{4} \mathrm{Al}$ intercambio de conocimiento también se la denomina knowledge sharing o transferencia de conocimiento (van Wijk et al., 2008).
} 
En la presente tesis doctoral se proponen dos dimensiones que aluden al intercambio de conocimiento, una referida al contenido (transferencia de conocimiento) y otra al proceso (comunicación).

Transferencia de conocimiento. Atendiendo al contenido del conocimiento a nivel de empresa, se pueden transferir dos tipos: (1) external "business" knowledge conocimiento de productos, mercados, y tecnología - y, (2) “organizing” knowledge conocimiento de estructuras y sistemas (Eriksson et al., 1997).

El conocimiento que resulta de las relaciones entre empresas puede constituir una fuente de ventajas competitivas (Powell et al., 1996) y oportunidades de negocio únicas (Uzzi, 1997). Hay que considerar que las ventajas competitivas se derivan de los recursos a nivel de empresa, así como de capacidades difíciles de imitar, y que son específicas de relaciones diádicas y de red (Dyer y Singh, 1998; Lane y Lubatkin, 1998). A través de la construcción de los activos específicos de la relación, compartiendo rutinas de conocimiento y mecanismos eficaces para ello, no sólo se puede adquirir conocimiento, sino también explotarlo (Yli-Renko et al., 2001).

El papel que las relaciones entre organizaciones desempeñan en el intercambio de conocimiento puede variar y depende de distintas variables que caracterizan a la relación, tales como similitud social, valores compartidos (Song et al., 2003; Dhanaraj et al., 2004) y confianza (Tsai y Ghoshal, 1998; Levin y Cross, 2004; Szulanski et al., 2004).

Comunicación. Puesto que el intercambio de conocimiento implica convertirlo o expresarlo para que pueda ser absorbido por otros, un elemento fundamental es la comunicación. La comunicación es definida como un intercambio de información pertinente y oportuna (Sin et al., 2002). Siguiendo a Duncan y Moriarty (1998, p.2) encontramos que: "la comunicación es la actividad humana que vincula a la gente y crea relaciones. (...) Sirve como forma de desarrollar, organizar, y diseminar conocimiento”. Por ello, no es de extrañar que "la comunicación es una actividad indispensable en el funcionamiento de todos los procesos (...)” Ahmed y Rafiq (2003, p. 1183). La comunicación conecta a las personas y facilita conexiones sociales (Blazevic y Lievens, 2004). A su vez, ayuda a la comprensión de las intenciones y habilidades de cada parte (Kucukkancabas et al., 2009). 
La calidad de la comunicación fomenta la formación de vínculos sociales necesarios para el intercambio de conocimiento (Lin, 2007), el cual se ve favorecido por la existencia y riqueza de canales de transmisión (Gupta y Govindarajan, 2000). Además, para que la comunicación sea efectiva, el objeto de la transmisión tiene que ser percibido como de alta calidad, es decir, completo, preciso, y adecuado (Johlke y Duhan, 2001).

Otro aspecto relevante de la comunicación es su frecuencia. Una comunicación frecuente y el establecimiento de adecuados enlaces de comunicación y visitas en persona entre las partes implicadas son importantes en un contexto de relación (Leonidou et al., 2011). La frecuencia en la comunicación es definida como el número de veces que la información es intercambiada entre distintas personas en el ámbito empresarial a lo largo de un periodo de tiempo (van de Ven y Ferry, 1980; Fisher et al., 1997).

De acuerdo con el enfoque de marketing relacional, la comunicación es una variable clave para la construcción y el mantenimiento de relaciones estables (Anderson y Weitz, 1989; Paden y McAlister, 1996; Duncan y Moriarty, 1998). Una buena comunicación requiere contacto, tiempo y esfuerzo, y puede que las partes no encuentren tiempo o motivación para invertir en ello. Más concretamente, se requiere una integración de todos los mensajes de comunicación para apoyar la creación, el mantenimiento y la mejora de las relaciones (Morgan y Hunt, 1994; Grönroos, 1994, 2004).

La frecuencia de la comunicación y de contactos también es señalada por la teoría de costes de transacción como un factor clave desde el punto de vista relacional (Williamson, 1985). La frecuencia de los contactos y la cercanía caracterizan la fuerza de una relación (Hansen, 1999; Levin y Cross, 2004). Las relaciones fuertes y estrechas se caracterizan por la cercanía y el contacto frecuente, y conducen a una mayor frecuencia de intercambios de conocimiento entre empresas (Uzzi, 1997; Hansen, 1999), facilitando la recepción de conocimiento útil (Levin y Cross, 2004) y creando condiciones específicas para que el intercambio se realice con éxito (Hansen, 1999). Una alta frecuencia en las interacciones favorece un intercambio de conocimiento efectivo (Nonaka, 1994; Szulanski, 1996; Blumenberg et al., 2009), reduce la incertidumbre (Weick, 1993), lleva a un mejor entendimiento entre las partes 
(Dougherty, 1992; Massey y Dawes, 2007), y favorece la confianza mutua (Johnson y Lederer, 2005).

\section{EI intercambio de conocimiento en el ámbito del emprendimiento y de las UBIs}

El intercambio de conocimiento es un factor determinante en las distintas fases del proceso emprendedor, desde la puesta en marcha de la empresa (Gartner, 1988), la creación en sí del negocio y sus primeros años de vida (Reuber y Fischer, 1999), hasta la gestión de la empresa en su fase de madurez (Dess et al., 2003; García-Morales et al., 2006).

La acumulación de conocimiento a través del aprendizaje constituye una fuerza conductora en el desarrollo y crecimiento de empresas noveles (Spender y Grant, 1996; Penrose, 2009) porque el intercambio de conocimiento abre nuevas oportunidades productivas (Penrose, 2009). Además, en el contexto emprendedor, la finalidad del aprendizaje no se refiere únicamente a la capacitación para responder a los cambios del entorno y sobrevivir, sino también a la capacitación para crear y proyectar en el futuro la experiencia y el conocimiento que se posee actualmente (Gibb, 1997). Esta forma de aprendizaje, llamada generativa (Senge, 2006), supone la aplicación proactiva del conocimiento adquirido mediante experiencias previas a futuras acciones.

En lo que se refiere a las UBIs y su vinculación con el conocimiento es clara: son incubadoras creadas por las universidades que quieren difundir el conocimiento científico y tecnológico (Radosevich, 1995; Jones-Evans y Klofsten, 1998). Para ello, fomentan la creación de nuevas empresas basadas en el conocimiento (Heydebreck et al., 2000; Grimaldi y Grandi, 2001). Una característica clave del conocimiento utilizado por las spin-offs universitarias es que, en la mayoría de los casos, se encuentra en una fase embrionaria - prueba de concepto o prototipo inicial - del desarrollo de una tecnología, con independencia de si su intención es aplicarlo en la industria en una etapa inicial o madura (Clarysse et al., 2011b). Es más, una razón clave para crear empresas en el ámbito académico es incubar la tecnología para su desarrollo y comercialización (Jensen y Thursby, 2001; Feldman et al., 2002; Katila y Shane, 2005; Lowe y Ziedonis, 2006). 


\subsubsection{La interacción entre confianza, intercambio de conocimiento y}

compromiso relacional

Como hemos indicado anteriormente, en esta tesis damos por supuesta la relación confianza-compromiso relacional, suficientemente testada y confirmada por la literatura. Esta relación la completamos introduciendo el intercambio de conocimiento como el contenido o actividad necesarios en las relaciones entre emprendedores para que la confianza se transforme en compromiso. Como a continuación procedemos a exponer, la confianza es un elemento clave en el proceso de intercambio de conocimiento entre empresas, y el intercambio de conocimiento, a su vez, es la señal de que la relación funciona y que anima a los incubados a compromisos a largo plazo.

\section{Confianza e intercambio de conocimiento}

Las relaciones entre empresas son una de las vías que permiten la obtención de conocimiento externo. Más concretamente, la medida en la que una empresa adquiere ese conocimiento depende de distintos aspectos: (1) la disposición de ese tipo de conocimiento por la otra empresa, (2) la habilidad de la empresa para reconocer y evaluar el valor de los conocimientos, (3) la intensidad y repetición de la interacción, y (4) la predisposición de la otra empresa a compartir información (Cohen y Levinthal, 1990; Dyer y Singh, 1998).

El proceso de intercambio se ve influido por factores que lo pueden dificultar o facilitar. Cuando el conocimiento es tácito, no codificado, y alto en ambigüedad causal, las empresas se encuentran con barreras que inhiben el intercambio de conocimiento (Nonaka, 1991; Kogut y Zander, 1992; Szulanski et al., 2004). Éstas pueden ser salvadas por variables como la comunicación (Nadler et al., 2003), la existencia y la riqueza de canales de transmisión (Gupta y Govindarajan, 2000), o la confianza (Tsai y Ghoshal, 1998; Levin y Cross, 2004), dado que todas ellas favorecen que se pueda producir un intercambio. Específicamente, la confianza favorece que las partes estén más dispuestas a dar y recibir conocimiento útil, reduciendo los costes de intercambio de conocimiento (Tsai y Ghoshal, 1998; Levin y Cross, 2004), así como promoviendo el aprendizaje y el desarrollo de las relaciones (Larson, 1992). Es más, el análisis de la acción conjunta de las características del conocimiento y de las características de las relaciones pone de manifiesto que para intercambios de conocimiento difíciles (con conocimiento complejo y ambiguo), se necesita una relación basada en la confianza y 
fuerte para que la transferencia se realice con éxito (Hansen, 1999; Dhanaraj et al., 2004; Levin y Cross, 2004).

Considerando todo lo anterior, se plantea la siguiente hipótesis:

H1: La confianza de un incubado hacia otro influye positivamente en el intercambio de conocimiento.

\section{Intercambio de conocimiento y compromiso relacional}

Las spin-offs universitarias están formadas por emprendedores académicos que proceden de un contexto basado en el conocimiento, por ello es previsible que cuando estén en cualquiera de las fases de incubación, el conocimiento siga siendo el marco en el que se encuadre y desarrolle su actividad. Sin embargo, poseer conocimiento es necesario, pero no suficiente, para que el proyecto emprendedor fructifique. El conocimiento individual de un emprendedor puede ser insuficiente si no se asocia con el de otras empresas o emprendedores. De hecho, el intercambio de conocimiento y recursos son necesarios para crear una empresa, y ello requiere hacer conexiones con nuevos actores (Carter et al., 1996). Las UBIs pueden ser un entorno favorecedor para que los emprendedores se expongan y decidan sumergirse en relaciones con otros incubados con los que puedan intercambiar conocimiento.

Una UBI es un entorno en el que se puede estimular y favorecer la frecuencia de interacciones cara a cara, la comunicación, y el posterior intercambio de conocimiento entre los incubados. La cercanía es una de las claves para ello. Sin embargo, no es el único factor que puede influir. La utilización de espacios comunes y la participación en las distintas actividades organizadas en la propia incubadora, pueden dar lugar a contactos. Cuanto mayor sea la frecuencia de esos contactos, mayor será la probabilidad de interactuar y comunicarse. A su vez, en un entorno en el que predomina el conocimiento, parece probable que el contenido de las comunicaciones se base precisamente en intercambios de conocimiento.

El conocimiento adquirido y compartido a través de relaciones contribuye a un mayor compromiso que se puede manifestar en la inversión para el desarrollo de nuevos productos en sectores intensivos en conocimiento, tales como sectores de alta tecnología. Esto se debe a que el desarrollo de este tipo de productos requiere la integración y la combinación de inputs de conocimiento especializados procedentes de 
diferentes áreas de tecnología (Cohen y Levinthal, 1990; Brown y Eisenhardt, 1998). Asimismo, ese conocimiento compartido mejora la capacidad de concebir y desarrollar una diferenciación significativa del producto (Zahra et al., 2000).

En definitiva, el intercambio de conocimiento entre incubados influirá en el compromiso adquirido, dado que es un indicador de la buena voluntad de las partes y de sus capacidades, y una señal de las posibilidades que puede brindar una relación para que se consoliden los respectivos negocios. Además, cuando dos empresas comparten conocimiento, se reduce la probabilidad de comportamientos oportunistas y se hace posible que las empresas coordinen sus actividades (Cannon y Homburg, 2001).

Con todo lo anterior, se propone la siguiente hipótesis:

H2: El intercambio de conocimiento entre los incubados influye positivamente en el compromiso en la relación.

Las hipótesis H1 y $\mathrm{H} 2$ vienen a establecer un efecto mediador del intercambio de conocimiento en la relación confianza-compromiso. La confianza en las capacidades y competencias de otros incubados, así como en su honestidad y benevolencia, constituyen un requisito para que los incubados se involucren en actividades de intercambio y transferencia de conocimiento. En la medida en que estos intercambios se suceden con éxito surge el deseo expreso de continuar e invertir en el mantenimiento a largo plazo de la relación. En definitiva, las relaciones se consolidan mediante un compromiso relacional.

En la Figura 2.2. se representa la interacción entre las tres dimensiones propuestas para caracterizar las relaciones entre incubados.

Figura 2.2. Interacción entre las dimensiones propuestas para las relaciones entre incubados

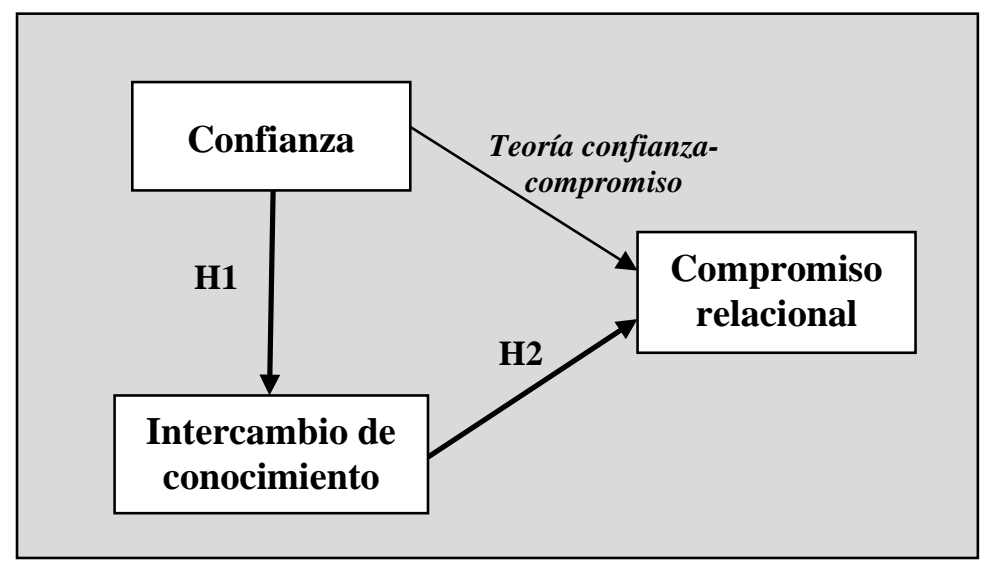




\subsection{Determinantes de las relaciones diádicas entre incubados}

En virtud de los enfoques teóricos y corrientes de investigación revisados, en la presente tesis doctoral hemos considerado tres grupos de variables que determinan la confianza, el compromiso y el intercambio de conocimiento en las relaciones diádicas entre incubados: (1) afinidad y entendimiento mutuo, (2) recursos, y (3) características del incubado.

(1) Determinantes basados en el enfoque relacional: afinidad y entendimiento mutuo. La comunicación y el entendimiento entre los individuos se ve favorecido cuando comparten o comprenden una situación que están viviendo y los valores que rigen su comportamiento. Esta actitud se resume en dos variables: la empatía y los valores compartidos. Desde el marketing de relaciones, la empatía se ha considerado una variable clave en las relaciones entre empresas (ej. Sin et al., 2005; Chattananon y Trimetsoontorn, 2009), al igual que los valores compartidos, que han sido identificados como determinantes para el inicio de relaciones (Morgan y Hunt, 1994).

(2) Determinantes basados en el enfoque de recursos: características de los recursos de los incubados. De acuerdo con el enfoque basado en recursos, y según ha sido formulado por Barney (1991), los recursos (únicos, valiosos, raros, inimitables y no sustituibles) son fundamentales para el desarrollo de cualquier tipo de actividad empresarial. En las etapas iniciales de los negocios las dificultades para acceder a los mismos son mayores que en cualquier otro momento, y es cuando más tiempo emplean los emprendedores en ello (Greve y Salaff, 2003). A través de las relaciones, los individuos pueden acceder a recursos, crearlos y modificarlos (Gulati, 1999). En la presente tesis, la complementariedad y la suplementariedad de recursos se plantean como variables determinantes en el inicio de relaciones entre incubados. Asimismo, y especialmente si nos centramos en recursos intangibles como el conocimiento, la transferibilidad de los recursos es fundamental para el intercambio. Sin embargo, las empresas pueden proteger su conocimiento a través de distintos mecanismos que dificultan su transferencia (Dyer y Singh, 1998). Considerando estas ideas y que las relaciones entre los inquilinos de una UBI se basan en el intercambio de conocimiento, la transferibilidad del mismo aparece como una variable explícita a considerar en el estudio del inicio de relaciones diádicas. 
(3) Determinantes basados en la investigación sobre emprendimiento: características

del incubado. Las investigaciones iniciales sobre emprendedores se limitaron a los atributos propios de este colectivo para determinar qué factores individuales eran característicos o específicos, y permitían explicar cuestiones tales como el éxito de los negocios. Este enfoque, centrado en las características individuales, fue criticado por sobrepersonalizar los factores determinantes de aspectos concretos empresariales (Low y MacMillan, 1988), y por no dar respuesta a la pregunta de por qué cuando los emprendedores se enfrentan a la misma información, algunos ven oportunidades mientras que otros no lo hacen (Venkataraman, 1997). Lo anterior lleva a la necesidad de profundizar y analizar la influencia de factores individuales. Concretamente, se analizará el posible efecto que tengan el enfoque basado en promoción y la predisposición a compartir conocimiento por parte de los incubados como determinantes de las relaciones con otros incubados.

En los siguientes subepígrafes se analiza y argumenta el efecto de cada una de las variables propuestas.

\subsubsection{Empatía}

La empatía consiste en la capacidad de un individuo para comprender cómo se siente otra persona en una situación determinada, tanto a nivel cognitivo como emocional (Granzin y Olsen, 1991).

En el ámbito de las relaciones, y siguiendo a Sin et al. (2002), la empatía se da cuando las partes de una relación de negocios pueden ver la situación desde la perspectiva de la otra parte, entendiendo sus deseos y objetivos. Desde el marketing relacional, distintos estudios han permitido identificar la empatía como una de las variables clave para el éxito en las relaciones (ej. Sin et al., 2005; Chattananon y Trimetsoontorn, 2009; Day et al., 2013). Asimismo, la empatía ha aparecido tanto en estudios de relaciones entre empresas (ej. Sin et al., 2005; Chattananon y Trimetsoontorn, 2009), como en estudios centrados en las relaciones entre empresas y consumidores (ej. Rashid, 2003; Bojei y Alwie, 2010). A la vista de los resultados de estas investigaciones, se observa que la empatía es clave para hacer negocios (Tripp, 2013) y que está correlacionada positivamente con el rendimiento empresarial (Sin et al., 2005; Olotu et al., 2010). 
Por otra parte, y desde la perspectiva del emprendimiento, la empatía también ha sido considerada, tanto a nivel teórico como empírico, en el área del emprendimiento social. Wallace (1999) define el emprendimiento social como la búsqueda de iniciativas para explorar y reconocer oportunidades viables y sostenibles, con la finalidad de solventar problemas sociales a través de un proceso de evaluación de la viabilidad en términos del efecto catalizador en la transformación positiva de la sociedad (Dees, 1998). Específicamente, la empatía es una de las razones que puede llevar a los emprendedores sociales a actuar; así lo sugieren evidencias empíricas a través de relaciones significativas y positivas entre la empatía y un comportamiento prosocial (Eisenberg y Miller, 1987).

En el caso de los investigadores, alumnos y egresados, la empatía puede nacer de una cultura académica y de unos objetivos y dificultades compartidos. Cuando se plantean emprender, se están enfrentando a un reto nuevo, en el que tendrán que ir adaptando su forma de pensar y actuar. Son conscientes de que provienen del ámbito académico y de que tienen que entrar a competir en el mundo de los negocios. Los emprendedores académicos, que sean empáticos y estén en una incubadora, van a ser capaces de entender perfectamente la situación en la que se encuentran el resto de sus compañeros incubados, debido a dos causas:

1) Tienen una procedencia común: entorno académico. Así pues, comparten una cultura, una filosofía y pautas de trabajo.

2) Se enfrentan a las mismas dificultades inherentes a la etapa concreta de incubación en la que se encuentran, y en el mismo momento de tiempo.

Los individuos con una tendencia natural a la empatía, como rasgo personal, y que estén en una incubadora universitaria tenderán a mostrar una propensión mayor a iniciar relaciones con otros incubados, debido a la comprensión de la situación en la que estos últimos se encuentran. Además, y en cuanto al desarrollo de las relaciones se refiere, hay una consecuencia más de la empatía: la facilidad del individuo de encontrar iniciativas que le permitan emprender. Esta búsqueda no tiene por qué ser compartida por todos los miembros del entorno académico, pero sí será más fácil para los individuos empáticos que están en incubación. 
Más concretamente, y en lo que se refiere a la calidad de la relación entre empresas, la empatía fomenta la comprensión y la tolerancia (Wang, 2007). Asimismo, la empatía se relaciona positivamente con la calidad de la comunicación (Mentzer et al., 2001; Devaraj et al., 2002). Es más, los individuos comparten espacios, actividades y tiempo dentro de la incubadora, lo cual favorece que la empatía acelere los contactos y la confianza entre ellos. Por lo tanto, la empatía que sienta un incubado hacia otro podrá afectar de manera positiva a la calidad de la relación entre ellos, tanto en términos de confianza como en términos de compromiso e intención de reforzar la relación en el largo plazo.

H3: La empatía de un incubado hacia otro influye positivamente en la confianza en la otra parte (H3a), así como en el compromiso en la relación (H3b).

\subsubsection{Valores comunes}

Los valores de un individuo han sido definidos como las creencias, las preferencias, los objetivos y los criterios de selección de los objetivos, que se desarrollan y transmiten a través de la cultura, de la sociedad y la personalidad, dando lugar a un comportamiento específico (Dose, 1997).

Los emprendedores, al ser parte de una comunidad específica, comparten objetivos, problemas y situaciones similares (Bøllingtoft y Ulhøi, 2005; Abduh et al., 2007); mostrando una especial predisposición a establecer relaciones con agentes de su entorno (Weitz y Jap, 1995).

Puesto que en nuestra investigación nos centramos en las relaciones generadas y mantenidas por parte de los emprendedores académicos bajo el amparo de las incubadoras, los valores que determinan la creación de relaciones entre los emprendedores, así como la calidad de las mismas, pueden ser de tres tipos: (1) valores correspondientes a las creencias y a la cultura académica que comparten; (2) valores específicos a la etapa de incubación en la que se encuentran; (3) valores desarrollados y trasmitidos en la incubadora.

(1) Creencias y cultura académica. Cuando se crea una empresa en el entorno académico, los emprendedores suelen ser investigadores y/o estudiantes que han desarrollado un proyecto en el seno de la universidad en cuestión (Birley, 2002). El investigador universitario, inicialmente, no es un emprendedor “al 
uso” puesto que tiene una cultura académica y una clara preferencia por la investigación básica (Ndonzuau et al., 2002). Es posible que tenga dificultades para identificar oportunidades con aplicaciones comerciales (Lockett et al., 2003). Estos emprendedores procedentes de la academia pueden compartir una misma filosofía de trabajo, puesto que piensan y actúan basándose en los estudios cursados pero, sobre todo, en su experiencia profesional en el mundo de la ciencia. Pueden compartir, por tanto, valores propios e inherentes al mundo académico, a diferencia de los emprendedores que proceden del mundo de los negocios, y cuya trayectoria y carrera profesional no están vinculadas con el mundo de la ciencia.

(2) Valores específicos a cada etapa de incubación. En pre-incubación, los académicos son emprendedores potenciales, ya que aún no han creado una empresa; pero sí tienen una idea de negocio en la que están trabajando y con la que se pueden plantear la opción de crear una empresa. Por lo tanto, los preincubados se enfrentan a objetivos similares: testar la viabilidad de su idea de negocio y tomar una decisión frente a la disyuntiva de crear o no una empresa.

Por otra parte, los que están en incubación, ya han tomado la decisión de emprender, a través de la creación de una spin-off. En este caso, los individuos que se encuentran en esta etapa, tienen el objetivo de aprovechar los recursos que les prestan en pro de garantizar la supervivencia en la etapa inicial de su negocio.

Por último, aquellos que han abandonado la incubadora, pero que están en postincubación, comparten el objetivo de favorecer la expansión de su negocio.

(3) Valores desarrollados y trasmitidos en la incubadora. Hackett y Dilts (2004b) distinguen dos conceptos importantes: incubadora e incubación. El espacio físico (la incubadora) incluye la amplia red de apoyo y actores que facilitan el proceso (de incubación). Aunque en el proceso de incubación hay tres etapas secuenciales con unos objetivos claramente establecidos, sin embargo, no hay un consenso sobre los objetivos de las incubadoras.

Las incubadoras son organizaciones con su propia identidad, con un conjunto de rutinas y un núcleo estratégico, con un centro administrativo, una misión, y que interactúan con el ambiente externo como una entidad unificada. En muchos 
sentidos, la incubadora es, en sí misma, una empresa y se organiza como tal (Phan et al., 2005), con su propio ciclo de vida y sus propios objetivos ${ }^{5}$.

Si bien es cierto que uno de los objetivos comunes de las UBIs es favorecer el aceleramiento de la comercialización del conocimiento a través del fomento de la creación de nuevas empresas (Heydebreck et al., 2000; Grimaldi y Grandi, 2001), también pueden tener objetivos propios relacionados, por ejemplo, con las necesidades y prioridades específicas de la universidad a la que están vinculadas. A su vez, la forma de desarrollar y trasmitir los objetivos y valores propios que posea, también pueden diferir de unas a otras.

Los valores comunes ya han sido considerados como requisitos para el inicio de una relación. Morgan y Hunt (1994) llaman la atención sobre la importancia de la percepción de valores comunes para iniciar o consolidar una relación. El compromiso en la relación aumenta si el "emprendedor x" percibe y cree que el "emprendedor y" tiene valores similares a los suyos. Igualmente, la confianza entre las partes también se ve favorecida por la similitud entre ellos (Doney y Cannon, 1997).

En el ámbito de las relaciones entre empresas se ha constatado que estas últimas se comprometen en relaciones cuando identifican otras empresas con las que son compatibles (Weitz y Jap, 1995; Morgan y Hunt, 1999). Esta compatibilidad se refiere al nivel de congruencia de la cultura y capacidades organizativas entre empresas, y a la compatibilidad entre objetivos (Sarkar et al., 2001), lo cual afecta a cualquier acción desarrollada de manera conjunta y al beneficio obtenido (Naudé y Buttle, 2000). Asimismo, la interacción entre las empresas es mayor cuando se parecen entre sí, cuando comparten el mismo campo de negocios, mercados o tienen clientes similares (McAdam y McAdam, 2006; Schwartz y Hornych, 2008).

Por todo ello, cabe esperar que cuando un emprendedor percibe valores comunes con otro emprendedor, como resultado de valores adquiridos en la universidad y en la incubadora, y los innatos que se corresponden con cada etapa concreta de incubación,

${ }^{5}$ La fase de start-up de la incubadora comienza con su establecimiento y concluye una vez que ha alcanzado la plena ocupación. La etapa de desarrollo viene indicada por un aumento en la frecuencia de interacciones entre el mánager de la incubadora y los inquilinos, así como por un mayor apoyo por parte de la comunidad local para la incubadora. La fase de madurez refleja el punto en el que la incubadora tiene más demanda de espacio de la que puede asumir, y se ha convertido en un centro de referencia para los emprendedores de esa zona geográfica (Allen, 1988). 
aumentará su confianza en la otra parte y estará dispuesto a comprometerse seriamente en una relación, esto es, a compartir ideas, conocimiento e innovación en el futuro.

H4: La percepción de valores comunes de un incubado hacia otro influye positivamente en la confianza en la otra parte (H4a), así como en el compromiso en la relación (H4b).

\subsubsection{Complementariedad de recursos}

Los recursos complementarios son aquellas capacidades, conocimientos y recursos diferentes con los que cuenta una empresa A y que permiten completar el rendimiento de otra empresa B (Jap, 1999). Esos recursos pueden ser de distinta índole y derivarse de las diferentes experiencias y backgrounds de los individuos.

Los individuos actúan sobre las oportunidades de mercado cuando perciben que son deseables y viables (Krueger, 1993). Sin embargo, la forma en la que pueden actuar varía. Pueden tomar la decisión de crear su propia empresa, vender la idea a otra persona (Shane y Venkataraman, 2000), o colaborar con otras organizaciones que posean recursos complementarios (Hitt et al., 2000; Sarkar et al., 2001).

En la literatura sobre emprendimiento académico se han considerado tres líneas de investigación en relación al papel de los recursos complementarios.

(1) Recursos complementarios como factor que favorece las tasas de actividad emprendedora en las universidades. Distintas investigaciones han demostrado que las universidades que ponen a disposición de sus científicos recursos complementarios para fomentar un comportamiento emprendedor - a nivel de estructuras (oficinas de transferencia de tecnología, redes sociales e infraestructuras), política (concesión de licencias, apropiación de rentas generadas, excedencias) y cultura (actitudes académicas hacia la comercialización, modelos de empresarios) - son más propensas a tener altas tasas de emprendimiento (Hsu y Bernstein, 1997; Shane, 2004; Lockett y Wright, 2005; Stuart y Ding, 2006; Bercovitz y Feldman, 2008; Kenney y Patton, 2011).

(2) Activos complementarios como barreras para la creación de spin-offs universitarias. Se ha constatado que las spin-offs universitarias son menos probables en aquellas industrias en las que se requieren activos complementarios importantes, especialmente en las áreas de fabricación y 
marketing (Shane, 2001, 2004; Katila y Shane, 2005). Por contra, en industrias como la biotecnológica y del software es dónde son más frecuentes. Las razones para ello se encuentran en que estas industrias representan contextos dónde las innovaciones pueden darse de forma aislada, no requiriendo una integración significativa con otras tecnologías y activos complementarios (Shane, 2004).

(3) Las capacidades complementarias en los científicos, es decir aquellas que no son propias o inherentes al mundo de la ciencia, son críticas para el éxito de las empresas que crean. Entre esas capacidades destacan, en mayor medida, las siguientes: acceso a redes sociales (Stuart y Ding, 2006), colaboraciones con la industria y experiencia previa, acceso a financiación (Shane y Stuart, 2002), y capacidad para contratar personal que tenga conocimiento de mercado y operativo (Vohora et al., 2004).

Teniendo en cuenta que los incubados están empezando con sus negocios, las necesidades latentes inherentes a ese momento son variadas y numerosas: desde formar parte de una red de negocios hasta tener acceso a financiación. Así pues, parece probable que los recursos complementarios sean una causa que propicia el inicio de relaciones, y el óptimo funcionamiento de las mismas. Más concretamente, si consideramos el caso de aquellos incubados que poseen recursos complementarios, y donde cada parte puede aportar su know-how para, por ejemplo, prestar un servicio de manera conjunta, la dependencia entre ambas partes aumentará, al igual que el compromiso, la confianza y el intercambio de conocimiento.

La literatura en marketing ha identificado a los recursos complementarios como clave para el inicio y la consolidación de relaciones entre empresas. En un mayor nivel de concreción, y siguiendo a Morgan y Hunt (1999), las empresas se comprometen en relaciones cuando identifican otras con las que son compatibles y que disponen de recursos complementarios que, combinados con sus propios recursos, proporcionan ventajas competitivas basadas en la relación, que llevan al afianzamiento de la misma. Por su parte, Sarkar et al. (2001) señalan que las empresas, congregando recursos y capacidades complementarios, pueden iniciar y desarrollar de forma competitiva proyectos que no podrían haber llevado a cabo de manera individual. Es necesario considerar que el acceso a recursos complementarios a través de mecanismos de mercado no siempre es factible, ni tampoco su desarrollo interno (Chung et al., 2000; 
Sarkar et al., 2001). Por lo tanto, las relaciones entre empresas con recursos complementarios puede ser la única vía para ellas de acometer determinados proyectos.

Así pues, por lo citado con anterioridad, cabe esperar que cuando un incubado percibe que los recursos de otros incubados son complementarios a los suyos estará más predispuesto a confiar en sus capacidades y a comprometerse a largo plazo en una relación. Asimismo, la complementariedad es fuente de intercambio de conocimiento.

H5: La percepción de recursos complementarios de un incubado hacia otro influye positivamente en la confianza en la otra parte (H5a), en el compromiso en la relación (H5b), y en el intercambio de conocimiento (H5c).

\subsubsection{Suplementariedad de recursos}

Para el desarrollo de la actividad de una empresa y para aprovechar las oportunidades de mercado se requieren recursos. Como se ha mencionado en el apartado anterior, la colaboración entre competidores con frecuencia se forma con el objetivo de construir sinergias creadas a través de recursos diferentes o complementarios (Garrette et al., 2009). Sin embargo, la búsqueda de los recursos de los que no disponen las empresas siempre es arriesgada y consume, a su vez, muchos recursos. Una alternativa considerable a este respecto, y de la que se pueden derivar beneficios, es colaborar con otras empresas que no ofrezcan recursos complementarios, sino que permitan combinar recursos suplementarios de distinta índole (Ritala et al., 2014).

En el ámbito de las relaciones entre empresas, los recursos suplementarios son aquellos superpuestos, comunes a ambas partes, pero que pueden ser útiles para una colaboración. Es más, la integración de recursos suplementarios es un intento de crear más valor que el que se podría obtener si se utilizaran dichos recursos por separado (Das y Teng, 2000). Para ejemplificar la suplementariedad de recursos, podemos considerar dos empresas diferentes, formadas por equipos de biólogos, que centran su actividad en el desarrollo de productos biotecnológicos basados en citometría de flujo ${ }^{6}$. El

${ }^{6}$ El Centro Nacional de Biotecnología define a la citometría de flujo como sigue: "es una técnica que permite obtener información sobre poblaciones celulares a partir de un estudio individualizado de un gran número de células (...). La suspensión de células en solución isotónica se hace pasar a través de un pequeño orificio de modo que cuando salen lo hacen una a una (en fila india) formando parte de una corriente continua o flujo cilíndrico. Sobre esta corriente de células se hace incidir un haz de luz láser, cuya dispersión y reflexión son analizados en duración, intensidad y espectro.” 
conocimiento en el que ambas se basan para el desarrollo de su actividad es común, por lo tanto se da suplementariedad entre el principal recurso del que ambas disponen. Pese a ello, la superposición de sus recursos puede permitir acelerar la innovación o añadir nuevas líneas de productos a su cartera ${ }^{7}$. La suplementariedad también puede darse en otros recursos, como las habilidades de las que disponen los emprendedores. Por ejemplo, habilidades sociales para iniciar contactos y generar relaciones en el ámbito de los negocios.

Las empresas competidoras, por su naturaleza, tienen un alto grado de recursos similares entre ellas (ej. Chen, 1996). Sin embargo, aquellas que realizan esfuerzos en compartir recursos suplementarios pueden ver incrementada su eficiencia, obtener beneficios y compartir costes (Dussauge et al., 2000). A su vez, explotar recursos y capacidades suplementarios por empresas que están en el mismo eslabón de la cadena de valor está relacionado con modelos de negocio eficientes (Ritala et al., 2014). Pero el mero hecho de que las empresas compartan este tipo de recursos no es suficiente. Se debe trabajar de forma sinérgica para que se suplementen entre sí (Wittmann et al., 2009).

Con respecto a la investigación que nos ocupa, planteamos que las UBIs pueden generar un clima que favorezca la creación y el mantenimiento de relaciones, especialmente en cuanto a la suplementariedad de recursos se refiere. A priori, cuando un incubado percibe que otro tiene recursos similares a los suyos, pensará que es su competencia, porque puede satisfacer necesidades similares a los mismos clientes potenciales y/o reales. Sin embargo, el hecho de que el contacto con ese "competidor" sea en el ambiente de una UBI, y no en el mercado, puede cambiar su percepción por diferentes razones, que explicamos a continuación.

(1) Hay que considerar que los individuos que están en UBIs proceden del contexto académico, dónde se suele trabajar en equipo con compañeros del mismo departamento, se tiene un interés acentuado por la ciencia y aversión a utilizarla como fuente de enriquecimiento personal (Birley, 2002; Etzkowitz, 2004; Vohora et al., 2004). Estas características no suelen coincidir con las

(http://www.cnb.csic.es/ fotonica/Photonic_en/Review/citometria_de_flujo.htm)

${ }^{7}$ Las nuevas líneas de productos se pueden basar en diferentes aplicaciones para esta técnica de análisis celular, tales como hematología, inmunología y microbiología, entre otras. 
presentadas por los emprendedores que se encuentran en el mercado, fuera del ámbito universitario. En ellos prima el interés económico y no tienen por qué mostrar una alta predisposición a colaborar con empresas, especialmente con aquellas que apenas conocen y con las que comparten recursos similares.

(2) Los incubados pueden participar en distintas actividades desarrolladas en las UBIs, desde recibir sesiones o talleres formativos hasta compartir servicios de asesoramiento del mismo coach en reuniones grupales. Para participar activamente en ellas y aprovecharlas de manera óptima, los incubados que compartan recursos similares (por ejemplo, que estén trabajando en el mismo sector de actividad) tendrán sinergias mayores frente a aquellos con los que no tengan recursos o capacidades que sean un punto de encuentro entre las partes.

Los activos suplementarios y el conocimiento común tienen, sin embargo, un hándicap. Diversos autores sostienen que los equipos más heterogéneos tienen una mayor oportunidad de aprovechar la experiencia de cada individuo y aplicar un amplio rango de información al proceso creativo (Cohen y Levinthal, 1990; Dahlin et al., 2005). Cuando en los equipos se combinan diferentes tipos de conocimientos y experiencias, al tener distintas perspectivas, es probable que permita una búsqueda más amplia para obtener soluciones con respecto a lo que se está trabajando (Wiersema y Bantel, 1992; Rivkin y Siggelkow, 2003). Por el contrario, cuando los miembros del equipo poseen conocimientos similares, corren el riesgo de agotamiento tecnológico y una menor probabilidad de avances significativos (Fleming, 2001). Más concretamente, y en lo que se refiere al entorno universitario, cuando los miembros del equipo tienen backgrounds similares y están en el mismo departamento, su desempeño como equipo puede verse atenuado por una tendencia a buscar soluciones usando un marco específico de la disciplina (Henderson, 1995).

Sin embargo, la existencia de conocimiento similar disminuye los costes asociados al proceso de transferencia de conocimiento (Reagans y McEvily, 2003). Cuando dos emprendedores mantienen una relación y poseen conocimientos similares o afines, hablan el mismo lenguaje. Los contactos entre ellos serán más efectivos en cuestión de tiempo, porque alcanzar un óptimo entendimiento les requerirá un menor esfuerzo que en el caso de que se trabaje en distintas disciplinas. Por lo tanto, la comunicación será más fluida entre ambos. Asimismo, e independientemente del tipo de conocimientos del 
que dispongan, si tienen habilidades o competencias que se suplementen, tales como habilidades sociales, el entendimiento entre ellos será más fluido dado que tienen un punto de encuentro. El entendimiento y la buena comunicación entre los incubados, hará que las probabilidades de que sigan colaborando juntos en la generación y explotación de nuevo conocimiento, sean elevadas. Esto se debe a que al trabajar con conocimiento similares, ambas partes pueden vislumbrar con una mayor claridad futuras líneas en las que colaborar, incrementando su compromiso, y el esfuerzo requerido será menor para su explotación. La suplementariedad de recursos tendrá, pues, un efecto directo y positivo en la confianza y en el compromiso entre los miembros de una alianza (Huang et al., 2013).

En conclusión, cuando dos emprendedores perciben recursos suplementarios entre ellos, la comunicación será fluida, favoreciendo el funcionamiento de la relación así como las expectativas de continuidad. También se verán reforzados la confianza y el compromiso generado entre las partes, y se enriquecerán los conocimientos que comparten.

H6: La percepción de recursos suplementarios de un incubado hacia otro influye positivamente en la confianza en la otra parte (H6a), en el compromiso en la relación (H6b), y en el intercambio de conocimiento (H6c).

\subsubsection{Transferibilidad del conocimiento}

El conocimiento puede definirse como una mezcla fluida de experiencias, valores, información contextual, específica y experta que proporciona un marco para evaluar e incorporar nuevas experiencias e información (Davenport y Prusak, 1998). Asimismo, el conocimiento es una creencia que los individuos justifican como verdadera en base a sus observaciones del mundo (Nonaka y Takeuchi, 1995).

A la vista de estas dos definiciones, podemos extraer algunas de las dimensiones básicas del conocimiento.

En primer lugar el conocimiento se puede caracterizar en función del grado de especificidad. El conocimiento específico es aquel que se deriva de situaciones particulares de espacio y tiempo (Hayek, 1945). Su transferencia e intercambio es más difícil que en el caso del conocimiento general (Jensen y Meckling, 1992).

En segundo lugar, y en función de su procedencia, puede ser interno o externo. El conocimiento interno es aquel que ya posee el individuo o la empresa, y se deriva de 
experiencias y del contexto en el que se está inmerso. Por el contrario, el conocimiento externo es aquel que se encuentra fuera del individuo o la empresa y no ha sido adquirido.

Otra de las dimensiones clave del conocimiento, y a la que más atención se le ha prestado, es su codificación, pudiendo ser tácito o explícito. El conocimiento tácito o procesal (Anderson, 2013) es el que reside en los procesos de las empresas y en los individuos. A menudo se describe como el "conocimiento escondido" que los individuos poseen, pero que no pueden explicar fácilmente (Byosiere et al., 2010). Polanyi (1966, p. 4) se refiere así al conocimiento tácito: “... podemos saber más de lo que podemos decir”. Por el contrario, el conocimiento explícito o declarativo (Harvey y Anderson, 1996) es el conocimiento sencillo de codificar y contenido en manuales, por lo que puede ser fácilmente articulado, adquirido y transferido (Byosiere et al., 2010). El tipo de conocimiento afecta a su adquisición y explotación (Lane y Lubatkin, 1998), siendo el conocimiento tácito, alto en el nivel de ambigüedad causal, más difícil de intercambiar (ej. Nonaka, 1991; Zander y Kogut, 1995; Szulanski et al., 2004).

Como acabamos de ver, las características del conocimiento afectan al proceso de intercambio del mismo (Gorovaia y Windsperger, 2010). Cuando el conocimiento sea de fácil interpretación y absorción (Hamel et al., 1989), y cuanto menor sea su ambigüedad, su resistencia a una comunicación clara, su arraigo en el contexto, así como su idiosincrasia (Hedlund y Zander, 1993), más fácil será el intercambio de conocimiento entre las partes. Las características del conocimiento también afectan a la generación de ventajas competitivas. En este caso, cuanto mayor sea el nivel de concreción, la diversidad, complejidad y el carácter táctico del conocimiento, mayor es su potencial de generar ventajas competitivas (Kogut y Zander, 1992; Grant, 1996).

Otros dos factores determinantes que van a afectar al intercambio de conocimiento son quién lo posee y quién lo recibe. En la investigación que nos ocupa, el depositario y el receptor son académicos. Su conocimiento interno es científico, está vinculado a una disciplina concreta, y está dotado de una naturaleza innovadora, lo cual le lleva a tener un carácter tácito. Así pues, y sopesando unilateralmente la transferibilidad del conocimiento de un emprendedor académico podríamos indicar que, a priori, es poco transferible y no favorece el intercambio. Sin embargo, desde otra perspectiva argumental, un inquilino de una UBI sí puede percibir que su conocimiento es 
fácilmente transferible, puesto que lo domina y sabe cómo trasmitirlo, y que el conocimiento que poseen sus compañeros de incubación también lo es. Ello puede deberse a su pertenencia a la comunidad científica, lo cual hace que la comunicación y el entendimiento entre ellos sea fluido. No ocurrirá así en la relación con otro tipo de emprendedores. Por ejemplo, la percepción de transferibilidad por parte de un emprendedor procedente del mundo científico con respecto a otro que realice su actividad en un sector que requiera una cualificación no científica será baja, y ello dificultará el proceso de intercambio de conocimiento así como la utilidad del mismo.

Así pues, en la medida en que los inquilinos de las UBIs perciban que su conocimiento es fácil de transferir, bien por la naturaleza del mismo, bien por la comunicación y el entendimiento con otros incubados, mayor será la probabilidad de mantener una relación basada en intercambio de conocimiento.

H7: La transferibilidad del conocimiento influye positivamente en el intercambio de conocimiento entre los incubados.

\subsubsection{Predisposición a compartir conocimiento}

La predisposición ha sido considerada como uno de los principales factores determinantes de la transferencia de conocimiento exitosa (Gupta y Govindarajan, 2000; Inkpen, 2000; Lahti y Beyerlein, 2000; Minbaeva, 2007; Liu, 2009).

Distintas investigaciones han puesto de manifiesto que la predisposición del individuo a compartir conocimiento se ve afectada por diferentes factores. Algunos de esos factores son sistemas de incentivos, motivaciones extrínsecas e intrínsecas, grado de protección del que posee el conocimiento, relación entre costes y beneficios, clima organizacional, y disfrute en ayudar a los demás (ej., Simonin, 1999; Purvis et al., 2001; Bock y Kim, 2002; Bock et al., 2005).

Los sistemas de incentivos o recompensas son de los factores a los que más atención se les ha prestado. Su influencia es positiva en la predisposición de un remitente (sender) para diseminar conocimiento (Gupta y Govindarajan, 2000; O’Neill y Adya, 2007; Choi et al., 2008). Sin embargo en el largo plazo las recompensas tienen un impacto negativo en el intercambio de conocimiento, puesto que destruyen el equilibrio entre el uso y la contribución del conocimiento (Zhang et al., 2010). 
Por otra parte, la predisposición aumenta cuando el conocimiento está codificado, y disminuye cuando la amenaza competitiva de un receptor (receiver) es alta (Cowan et al., 2001).

La motivación también influye positivamente en el proceso de compartir conocimiento (Gupta y Govindarajan, 2000). Foss et al., (2009) definen tres tipos de motivación a este respecto:

(1) Intrínseca. Se da cuando la actividad de compartir conocimiento se percibe interesante y estimulante en sí misma.

(2) Introyectada. Los individuos se preocupan por mantener y mejorar los sentimientos de valor en sus grupos sociales (Ryan y Deci, 2000; Koestner y Losier, 2002).

(3) Externa. Se asocia con la consecución de logros positivos o con prevenir resultados negativos.

El grado de protección o proteccionismo es un atributo propio del que posee el conocimiento. Durante el proceso de intercambio de conocimiento, el aprendizaje tiene lugar cuando se procesa el conocimiento y se amplía la gama de comportamientos potenciales (Huber, 1991). La capacidad de las empresas de trasmitir no sólo reside en su propia capacidad de absorción interna, sino también en la voluntad plena de cooperar de la parte que posee el conocimiento (Pisano, 1988), lo cual equivale a un nivel mínimo de proteccionismo. Como Simonin (1999) sostiene, el nivel de proteccionismo de un socio tiene que estar en su nivel más bajo para que el intercambio de conocimiento pueda producirse, ya que el proteccionismo del remitente impacta negativamente en el intercambio de conocimiento (Simonin, 2004).

Por lo tanto, la predisposición a compartir conocimiento se puede ver afectada por las características del individuo y por el ambiente en el que está involucrado.

Compartir conocimiento es, con frecuencia, antinatural porque las personas piensan que su conocimiento es valioso e importante (Davenport y Prusak, 1998). Además, hay un riesgo asociado a compartir conocimiento - y especialmente en las spin-offs universitarias focalizadas en nuevas aplicaciones y desarrollos basados en el conocimiento - y es la ineficacia de las patentes en la protección de la innovación (Grosse, 1996). Por el contrario, los individuos tienen una mayor disposición a 
compartir conocimiento si creen que en el ambiente en el que lo hacen se aprecia, y si están convencidos de que será útil (Hall, 2001). En todo caso, la predisposición a compartir conocimiento es un rasgo implícito a cada individuo y no es aplicable a todos los emprendedores. A pesar de que las incubadoras son ambientes “protegidos” para los emprendedores y sus incipientes negocios, pueden darse situaciones de temor a compartir conocimiento, de oportunismo en el manejo de la información, o de inseguridad a la hora de crear y desarrollar relaciones en un entorno al que se están adaptando con un nuevo rol, en nuestro caso de académicos a emprendedores.

Inmersos en el citado contexto, los emprendedores académicos que se encuentren en incubación y que puedan estar predispuestos a compartir conocimiento, potenciarán los contactos y una mayor y más fluida comunicación con otros incubados para poder realizar con éxito un intercambio de conocimiento. Por lo tanto, la predisposición a compartir conocimiento influirá positivamente sobre el contenido de la relación, viéndose potenciado en las incubadoras universitarias.

H8: La predisposición a compartir conocimiento por parte de los incubados afecta positivamente al intercambio de conocimiento.

\subsubsection{Enfoque regulador basado en promoción}

La teoría enfocada en la regulación (Higgins, 1998) explica cómo los individuos tratan de desarrollar tareas y conseguir objetivos, basándose en tendencias motivacionales y estratégicas. Promulga que todo comportamiento dirigido hacia una meta es regulado por un sistema o enfoque. Ese enfoque puede estar basado en la promoción o en la prevención. La diferencia entre ambos enfoques radica en la naturaleza de los objetivos que los individuos tratan de alcanzar y en la forma o el modo de intentar conseguirlos.

Enfoque basado en la promoción. Cuando las metas representan aspiraciones, crecimiento y logro, los individuos buscan y persiguen oportunidades que les permitan la consecución de las mismas. Los objetivos representan un estado ideal que los motiva a canalizar sus ansias, persiguiendo opciones y oportunidades consideradas como aciertos que los aproximen a la meta (Crowe y Higgins, 1997).

Enfoque basado en la prevención. Por otra parte, cuando las metas representan deberes, obligaciones o responsabilidades para los individuos, éstos se inclinan estratégicamente a buscar su progreso siendo prudentes y precavidos. Debido a ello, se basan en la 
seguridad y protección, con el fin de evitar errores y desaciertos, ya que representan posibilidades de alejarse de la meta (Crowe y Higgins, 1997).

Brockner et al. (2004), especifican cuál es el enfoque, o combinación de enfoques, más adecuado en las distintas etapas del proceso de emprender:

(1) Creación o generación de una idea potencialmente exitosa. La invención requiere estar abierto al cambio, considerar nuevas posibilidades y generar alternativas varias. Pero la creatividad requiere, además, descubrir posibilidades que están ocultas, así como nuevos usos (Brockner et al., 2004). Se ha constatado que los individuos con un enfoque basado en la promoción generan más alternativas e ideas creativas que los individuos centrados en la prevención (Crowe y Higgins, 1997; Liberman et al., 1999; Friedman y Förster, 2001).

(2) Cribado de la idea. Filtrar una idea implica la evaluación de la viabilidad del potencial negocio, por lo que es importante ser preciso y minucioso, y no impulsivo. En este proceso debe prevalecer la calidad frente a la cantidad. Las personas enfocadas en la promoción están ansiosas por conseguir éxitos, y este afán estratégico las motiva hacia la velocidad y la cantidad de outputs. Por el contrario, las personas enfocadas en la prevención están atentas para no cometer errores, y esta vigilancia estratégica les inclina hacia la regularidad y la calidad (Förster et al., 2001, 2003).

(3) Adquisición de recursos. Para conseguir recursos financieros se requiere capacidad de persuasión para presentar el negocio, en términos ideales y de aspiraciones, a los posibles inversores y que opten por este proyecto frente a terceros, esto es, un enfoque de promoción. Además, la presentación debe ser precisa y sofisticada, lo cual requiere de un enfoque de prevención. Por lo tanto, la obtención de apoyo financiero y de otras fuentes de recursos requerirá de la actuación conjunta de ambos focos, si bien no hay resultados empíricos al respecto (Brockner et al., 2004).

(4) Proceso de implantación: probando el modelo de negocio. Este proceso requiere la construcción de una organización, la cual tiene pocos beneficios tangibles que ofrecer por el estado incipiente en el que se encuentra. El emprendedor tendrá que utilizar sus habilidades visionarias, basadas en ideas y aspiraciones, para lo que se nutre de un comportamiento centrado en la promoción. Además hay que 
asegurarse de que todas las tareas a realizar para el correcto funcionamiento del negocio se hagan de la mejor manera posible, lo cual está relacionado con no cometer errores, un enfoque de prevención (Brockner et al., 2004). Es más, cuando surgen las dificultades derivadas del uso y la aplicación de ideas creativas, los individuos enfocados en la prevención son más perseverantes que los individuos centrados en la promoción (Shah y Higgins, 1997).

La mayoría de los individuos académicos que deciden emprender son novatos en este ámbito, puesto que no tienen experiencia previa emprendedora ni conocimientos específicos al respecto. Por lo tanto, emprender es un proceso desconocido para ellos, tanto para los egresados, como para los profesores e investigadores, ya que emprender dista de sus actividades docentes e investigadoras. Ante esta nueva y diferente situación para ellos, la incubación se presenta como un medio para tratar de dirigirse de forma acertada hacia los resultados que están buscando. Al estar en una incubadora, los emprendedores académicos tienen la posibilidad de establecer relaciones con otros emprendedores. Pero no todos los individuos presentan las mismas actitudes. Independientemente de las actividades que se realicen y del entorno en el que se encuentren, la actitud que mantienen los individuos frente a la creación y el mantenimiento de relaciones con otros incubados difiere de unos a otros. En concreto, un factor determinante es el enfoque de cada individuo: la promoción o la prevención.

Los emprendedores académicos que se enfoquen hacia la prevención asumirán nuevos retos de manera prudente, controlando y vigilando las acciones que realicen, para evitar errores o desviarse del camino previsto hacia el logro de sus objetivos. Así pues, serán más reacios a intercambiar conocimiento con otros emprendedores con los que mantengan una relación, frente al riesgo de imitación de sus ideas, derivado de su instinto de protección y seguridad.

Por el contrario, los emprendedores académicos que se orienten hacia la promoción serán aquellos más creativos, que estén más abiertos al cambio, a resolver sus necesidades inherentes al proceso emprendedor en el que se encuentren, y que presenten una mayor disposición proactiva. La disposición proactiva se relaciona con un conjunto de predisposiciones personales, entre las cuales se incluyen iniciativa, autoeficacia y responsabilidad, y con un conjunto de factores contextuales, tales como cultura y normas organizacionales, y apoyo de la dirección/gestión, entre otros (Crant, 2000). Se 
han identificado comportamientos resultantes de disposiciones proactivas, como la innovación, la búsqueda de retroalimentación y la socialización (Crant, 2000).

Los incubados con un enfoque basado en promoción mostrarán una mayor tendencia a iniciar relaciones con otros emprendedores en la incubadora, como medio para obtener información que se adapte a la situación que se están enfrentando. Esto les permitirá generar alternativas que incrementen sus posibilidades para alcanzar los objetivos que persiguen de manera exitosa. Más concretamente, cuando un incubado con enfoque de promoción mantiene una relación con otro, mostrará una alta predisposición a intercambiar conocimiento como alternativa para obtener el valioso recurso sobre el que se sustenta su start-up, el conocimiento, a través del cual podrá obtener una mayor innovación y unos mejores resultados en su incipiente negocio.

H9: El enfoque basado en la promoción de un incubado influye positivamente en la predisposición a compartir conocimiento (H9a), así como en el intercambio de conocimiento con otro incubado (H9b).

\subsection{Resultados de las relaciones diádicas entre incubados}

Tras analizar los determinantes de las relaciones entre incubados, procedemos a explicar tres resultados derivados de las mismas: compromiso emprendedor de los incubados, la generación de innovación y resultados comerciales para los negocios emergentes.

\subsubsection{Compromiso emprendedor}

El compromiso emprendedor ha sido definido por Fayolle et al. (2011, p.161) como: “el momento en el cual el individuo comienza a dedicar la mayor parte de su tiempo, energía, y recursos financieros, intelectuales, relacionales y emocionales a su proyecto.” Estos mismos autores proponen dos condiciones que debieran darse para que un individuo tenga compromiso emprendedor: (1) la percepción de que apostar por la aventura empresarial es preferible a la situación actual (desempleo, empleo que se tenga o estudios que se estén cursando) o a cualquier otro cambio potencial a nivel profesional; y (2) la necesidad de superar la resistencia al cambio que puede derivarse de la incertidumbre, de los hábitos y formas de pensar y actuar adquiridos, y del coste de oportunidad, entre otros. 
El compromiso emprendedor nace y se desarrolla en determinados individuos, y sus ventajas se extienden a los negocios en los que participan activamente. El mantenimiento de este compromiso por parte de un individuo lleva a que desarrolle una competencia adicional y aumente sus capacidades, lo cual le puede proporcionar nuevas perspectivas y potencial para detectar oportunidades de negocio (Erikson, 2002). El compromiso determina el curso de los acontecimientos de una empresa (Vohora et al., 2004). Es más, según Istvan (1991), el compromiso emprendedor es una fuerza que impulsa a los negocios hacia el éxito.

Es evidente la necesidad de que un académico tenga compromiso emprendedor para que la empresa que ha creado y en la que está inmerso pueda ir hacia adelante. Determinados académicos son obstinados y no quieren renunciar al control de su empresa para cederlo a otro (Vohora et al., 2004), comportamiento que demuestra un compromiso emprendedor elevado. Pero esa no es la práctica dominante entre los emprendedores académicos, los cuales se enfrentan a una serie de limitaciones que pueden afectar a su compromiso emprendedor (Vohora et al., 2004):

(1) Las convicciones aceptadas por sus pares, y los sistemas de incentivos y promoción establecidos en el mundo académico distan del mundo de los negocios. Así pues, los académicos pueden renunciar a comprometerse y seguir con un negocio por no ir en contra de las premisas establecidas.

(2) Incapacidad para aceptar riesgos y para tolerar la incertidumbre. Los científicos trabajan con cierto grado de incertidumbre en sus investigaciones, tanto en los desarrollos como en la obtención de resultados. Sin embargo, lo hacen en un ambiente de estabilidad que les brinda el entorno universitario. No ocurre de igual forma en el ámbito de los negocios. Dado que no están acostumbrados a asumir riesgos en un ambiente cargado de incertidumbre (por ejemplo, a nivel de invertir sus propios recursos y no tener la certeza de si podrá recuperar esos recursos), esto puede suponer un freno al compromiso con su propio negocio.

(3) Falta de experiencia emprendedora previa. La mayor parte de los académicos adolece de una escasa o nula experiencia emprendedora, e incluso de experiencia en el ámbito de los negocios, aunque en menor medida. Ello puede desembocar en una falta de fe en sus propias capacidades para poder gestionar y desarrollar una empresa. 
En este escenario, las UBIs pueden ser herramientas que favorezcan el compromiso emprendedor en los académicos por diversas razones que explicamos a continuación. Primeramente, todos los incubados proceden del mundo universitario, pero han creado su empresa. Luego, pueden tener convicciones y actitudes no única y exclusivamente inherentes al mundo de la academia, también cierto grado de inquietud emprendedora.

En segundo lugar, los incubados pueden acceder a distintos servicios de formación y asesoramiento a través de los cuales obtendrán conocimientos profesionales para aplicar en sus negocios. Además, en las UBIs los inquilinos disfrutan de un ambiente de negocios "protegido" frente al exterior, pudiendo desarrollar sus capacidades emprendedoras, “learning by doing”, mediante los servicios de los que se beneficien. Esto puede ayudarles a paliar parcialmente la incertidumbre y los posibles riesgos a los que tendrían que enfrentarse. Sin embargo, aquellos que se dejen llevar por la complejidad o incertidumbre del entorno o por las implicaciones de gestionar un negocio, pueden desalentarse y verán reducido su compromiso emprendedor, o incluso desaparecerá, y no proseguirán con sus negocios.

El tercer factor que favorece el compromiso emprendedor son las relaciones que mantengan con otros incubados, aspecto que analizamos en esta tesis.

Si en las relaciones se ha forjado un nivel de compromiso entre las partes, esto podría desencadenar un mayor nivel de exigencia y ambición a nivel empresarial para ambas partes porque están involucrados en una relación de negocios de calidad.

Asimismo, en las relaciones con otros incubados, los emprendedores van a compartir sus inquietudes sobre el momento en el que se encuentran, sus experiencias profesionales, así como sus conocimientos. El intercambio de conocimiento les permitiría disponer de más recursos con los que suplir su falta de experiencia en el mundo empresarial, y podría reforzar sus capacidades para poder seguir con su negocio. Las personas con fuertes creencias sobre sus capacidades pueden ser más perseverantes en sus esfuerzos (Boyd y Vozikis, 1994). Además, cuanto mayor sea el nivel de competencia empresarial, en mayor medida se fortalece el compromiso emprendedor (Erikson, 2002).

Por lo tanto, las relaciones entre incubados que se basen en un intercambio fluido de conocimiento y que se caractericen por un compromiso entre las partes, podrían tener 
un efecto de refuerzo positivo sobre el nivel de compromiso del individuo con su negocio. Además, que los académicos estén en una UBI supone su inserción en una red de negocios (aunque todos estén en su fase de iniciación), y el desarrollo de sus habilidades sociales. Estas interacciones sociales también ayudan a fortalecer el compromiso emprendedor (Erikson, 2002).

En definitiva, todo lo anterior lleva a plantear las siguientes hipótesis:

H10a: El compromiso en la relación con otros incubados influye positivamente en el compromiso emprendedor de los incubados.

H10b: El intercambio de conocimiento entre los incubados influye positivamente en el compromiso emprendedor de los incubados.

\subsubsection{Generación de innovación}

La palabra innovación proviene del latín innovatio, acción y efecto de innovar; e innovar del término latino innovare, cambiar o alterar las cosas incorporándoles algo nuevo (Medina y Espinoza, 1994).

La innovación se puede concretar a través de distintas formas. Desde la innovación tecnológica, entendida como los esfuerzos de investigación e ingeniería dirigido al desarrollo de nuevos productos y procesos; la innovación de mercado/producto, que se refiere a los esfuerzos de investigación de mercado, el diseño de productos y la innovación en publicidad y promoción; hasta la innovación en administración, entendida como novedad en sistemas de gestión, técnicas de control y estructura organizacional (Dess y Lumpkin, 2005).

De acuerdo con los enfoques basados en recursos y en el conocimiento, tener acceso a conocimiento externo es uno de los requisitos clave para la generación de innovación (Ghoshal y Bartlett, 1988; Eisenhardt y Schoonhoven, 1996; Grant, 1996; Nonaka et al., 2006; Simonin y Özsomer, 2009). Más concretamente, el conocimiento basado en la ciencia fomenta el desarrollo de industrias y la obtención de resultados innovadores en las empresas (Narin et al., 1997; Zucker et al., 2002). Para que una empresa pueda ser competitiva debido a su desarrollo innovador, requiere que sus miembros compartan una cultura orientada hacia la innovación (Deshpandé et al., 1993). 
La generación de innovación requiere un proceso social de intercambio de conocimientos y recursos, así como el aprendizaje de competencias adquiridas a través de las interacciones entre las partes implicadas (Fabrizio, 2005). A su vez, implica una recombinación de conocimientos existentes, por lo que el acceso a un conjunto diverso de fuentes de conocimiento es crucial para que la innovación se realice con éxito (Henderson y Clark, 1990; Fleming y Sorenson, 2004).

La innovación no subyace en todos los emprendedores (Michael, 2007), pero en el caso que nos ocupa sí, ya que son científicos. Es más, éstos desempeñan un papel clave en los procesos de innovación (Zucker et al., 2002). Cuanta mayor sea la experiencia científica de los emprendedores que están involucrados en spin-offs académicas, mayor será el nivel de innovación de la misma y, consecuentemente, se incrementará su valor (Corolleur et al., 2004).

Sin embargo, es complejo que las empresas puedan disponer de todos los recursos y capacidades necesarias para innovar y competir con éxito en los campos científicos y tecnológicos que emergen continuamente. Frente a esta situación, las empresas se involucran con frecuencia en acuerdos de colaboración (Rothaermel y Deeds, 2004). La exploración de nuevas tecnologías a través de colaboraciones con socios que dispongan de conocimientos científicos refuerzan los resultados de innovación de una empresa (Jiang et al., 2011). A través de las colaboraciones se pueden adquirir distintos tipos de conocimiento, y esto puede influir en la dirección que tome la innovación de las empresas participantes (Inkpen, 2002; Rosenkopf y Almeida, 2003; Bercovitz y Feldman, 2007; Hohberger, 2014). Además, la reciprocidad en el intercambio de conocimiento y el compromiso mutuo son beneficiosos para la innovación (Park et al., 2014), dado que disminuyen la percepción de comportamientos oportunistas e incrementan la confianza entre las partes (Young-Ybarra y Wiersema, 1999; Rodríguez y Wilson, 2002).

Las empresas decididas a cooperar, en términos de innovación, pueden optar por alianzas de $\mathrm{I}+\mathrm{D}$ con otras empresas y/o por colaboraciones científicas individuales externas. Por medio de cualquiera de las dos vías de colaboración las empresas favorecen el intercambio de conocimiento y la innovación (Hohberger et al., 2015). Distintas investigaciones han puesto de relieve el papel de las alianzas como vía para que las empresas puedan acceder a conocimientos externos, relacionando directa y 
positivamente estas alianzas con resultados de innovación (Hagedoorn y Duysters, 2002; Rosenkopf y Almeida, 2003; Rothaermel y Deeds, 2004; Srivastava y Gnyawali, 2011). Asimismo, los estudios sobre colaboraciones con científicos denotan que son mecanismos que facilitan el flujo de conocimiento y la innovación (Singh, 2005; Fabrizio, 2009; Paruchuri, 2010; Almeida et al., 2011; Carnabuci y Operti, 2013).

Las relaciones entre emprendedores en las UBIs favorecen la generación de innovación por varios motivos: (1) las empresas incubadas tienen conocimiento y capacidad de innovación; (2) el compromiso en la relación crea un ambiente de seguridad y certidumbre para la innovación; y (3) el intercambio de conocimiento en las UBIs puede otorgar a los negocios que están en incubación una ventaja competitiva para innovar a la salida. A continuación se explica cada una de estas causas con un mayor grado de detalle.

1) La razón de ser de las spin-offs universitarias es explotar comercialmente el conocimiento, la tecnología o los resultados de investigación generados en el seno de las universidades (Pirnay et al., 2003). Esto quiere decir que todas las empresas incubadas se basan en el conocimiento y tienen capacidad de innovación. Para poder generar una innovación a través de una colaboración se necesita que se produzca un intercambio de conocimiento y el acceso a distintos recursos. En el caso de los incubados ese proceso se producirá en el mismo espacio dónde realizan su actividad: en la UBI. Aunque hay colaboraciones que se dan entre socios a nivel internacional basadas en intercambios de conocimiento con resultados positivos de innovación (Phene et al., 2006; Lahiri, 2010), el acceso e intercambio de conocimientos complejos se optimiza a nivel local, debido a la proximidad física y cultural (Zaheer y George, 2004).

2) Los emprendedores que están en incubación cuentan con apoyo desde la puesta en marcha del negocio hasta la fase de expansión (Comisión Europea, 2010). Además, y como ya se ha argumentado, pueden crear relaciones con otros emprendedores, con los que pueden compartir valores, sentir empatía y comprender el momento por el que están pasando, lo cual puede desencadenar un compromiso mutuo. Todo ello favorece la creación de un ambiente con cierto grado de seguridad y certidumbre, debido a que los académicos pueden sentirse acompañados y respaldados en sus respectivas aventuras empresariales. 
Teniendo en cuenta que las alianzas y las colaboraciones internas tienden a ser herramientas de cooperación útiles en entornos innovadores bastante estables (Hohberger et al., 2015), las UBIs podrían concebirse como este tipo de entornos que favorecen la colaboración entre los incubados y que pueden tener como resultado la generación de innovación.

3) Mientras estén en la UBI, los emprendedores que mantengan relaciones con otros incubados, basadas en intercambio de conocimiento científico y compromiso mutuo, podrán desarrollar una ventaja competitiva para ser generadores de innovación a la salida del proceso de incubación. Cuando los académicos se "gradúan” es el momento en el que deben sostener sus negocios fuera de la incubadora (Hackett y Dilts, 2004a). Esto se traduce en salir del ambiente protegido en el que iniciaron su aventura emprendedora y entrar a competir directamente en el mercado "real”. Es ahí donde las relaciones que se gestan en las UBIs pueden dar fruto en términos de capacidad de innovación.

A la vista de todo lo expuesto se propone:

H11a: El compromiso en la relación con otros incubados influye positivamente en la generación de innovación en los negocios de los incubados.

H11b: El intercambio de conocimiento entre los incubados influye positivamente en la generación de innovación en los negocios de los incubados.

\subsubsection{Resultados comerciales}

Los resultados económico-financieros y el desempeño de una empresa en términos de ventas y oportunidades de mercado pueden verse afectados positivamente por el intercambio de conocimiento (Davenport y Prusak, 1998; Liebowitz y Chen, 2001; Choi y Lee, 2003; Hsu, 2008), la innovación (Wang y Wang, 2012) y el compromiso (Siguaw et al., 1998; Jap y Ganesan, 2000). Para poder optar a estos beneficios, crear un mayor valor y obtener mejores resultados de los que obtendrían al actuar de manera individual, las empresas pueden participar en relaciones.

\section{Intercambio de conocimiento y resultados comerciales}

El acceso a conocimiento externo es beneficioso para las empresas cuando enriquecen su stock de conocimiento y lo explotan con recursos especializados (Mowery et al., 1996; Powell et al., 1996; Steensma y Corley, 2000). A su vez, les puede permitir 
mejorar sus niveles de rendimiento innovador en términos de variedad de productos y de reducción del tiempo de comercialización (Schoonhoven et al., 1990; Eisenhardt y Schoonhoven et al., 1996), así como incrementar su capacidad de resolución de problemas (Ahuja y Lampert, 2001; Vanhaverbeke et al., 2006). Una de las vías que permite el acceso a conocimiento externo es la transferencia de conocimiento interno a través de relaciones. Esto permitirá optar a los beneficios del acceso a conocimiento externo y a los derivados del intercambio en sí.

Intercambiar conocimiento también acelera el tiempo de desarrollo de nuevos productos, y favorece la capacidad de innovación y los resultados de la empresa incluyendo el crecimiento de las ventas o ingresos derivados de nuevos productos o servicios generados como consecuencia de ese intercambio (Hansen, 2002; Cummings, 2004; Hansen et al., 2005; Collins y Smith, 2006; Lin, 2007; Mesmer-Magnus y DeChurch, 2009).

Determinados tipos de alianzas, como logísticas y de servicios administrativos, tienen un efecto directo sobre los resultados económicos debido al ahorro de costes que se produce como consecuencia de las sinergias generadas entre las partes (CamisónZornoza et al., 2010). En otros casos, a través de la extensión y combinación de activos, las empresas que cooperan pueden crear conocimiento que, a su vez, puede conducir a ventajas competitivas sostenibles que permitan obtener mayores ingresos (Powell et al, 1996; Simonin, 1997; Dyer y Singh, 1998; George et al., 2001; Ireland et al., 2002). En su mayoría los resultados están asociados con innovación de productos (Deeds y Hill, 1996; Un et al., 2010) y resultados de carácter económico tales como mejoras en las ventas, beneficios y rentabilidad (De Man y Duysters, 2005). Por ende:

H12a: El intercambio de conocimiento entre los incubados influye positivamente en los resultados comerciales de los negocios de los incubados.

\section{Compromiso relacional y resultados comerciales}

Un mecanismo relacional que influye positivamente en el rendimiento de diferentes tipos de alianzas es el compromiso (Gulati, 1995; Uzzi, 1996; Dyer y Singh, 1998; Kale et al., 2000; Sarkar et al., 2001; McEvily y Marcus, 2005). Hay evidencias empíricas de esos efectos positivos en diferentes sectores, por ejemplo en la industria farmacéutica (Rothaermel y Deeds, 2004; Danzon et al., 2007; Arora et al., 2009; van de Vrande et 
al., 2011), donde uno de cada tres nuevos productos lanzados al mercado han sido desarrollados a través de alianzas basadas en el compromiso entre las partes (Collins y Hitt, 2006). Concretamente, las empresas implicadas asumen menos riesgos y también se produce una disminución en las tasas de fracaso (Fernald et al., 2015). De hecho, muchas alianzas fracasan en la consecución de los resultados que persiguen (Laroia y Krishnan, 2005) por la falta de compromiso entre las partes.

En lo que respecta a la colaboración y el compromiso entre emprendedores académicos, hay literatura que destaca los beneficios de las relaciones universidad-empresa. Las empresas que colaboran con universidades tienen unas cuotas de ventas de nuevos productos mayores que aquellas comprometidas en otros tipos de colaboraciones (Arvanitis et al., 2008). Entre los factores de éxito en los proyectos de cooperación universidad-empresa destaca el nivel de compromiso de los académicos involucrados, ya que tiene un impacto positivo en los resultados (Mora-Valentin et al., 2004; Agrawal, 2006; von Raesfeld et al., 2012). Por consiguiente, se propone que:

H12b: El compromiso en la relación con otros incubados influye positivamente en los resultados comerciales de los negocios de los incubados.

\section{Innovación y resultados comerciales}

La literatura ha recogido en numerosas ocasiones los efectos positivos que la innovación tiene sobre los resultados empresariales (ej. Darroch, 2005; Clifton et al., 2010; Liao et al., 2010; Vaccaro et al., 2010 ; Wang y Wang, 2012).

Como ya se ha insistido, en las UBIs la unidad de incubación son empresas noveles que se basan en el conocimiento para crear y desarrollar productos/servicios innovadores. Ese carácter innovador es intrínseco a cada empresa incubada y precede al momento de su fundación. Es más, se podría decir que la semilla de estos negocios es la innovación, ya que su comercialización o aplicación fuera del laboratorio o del ámbito académico es lo que lleva a su establecimiento. Al tratar las relaciones entre inquilinos en UBIs, nos estamos refiriendo a relaciones entre científicos. El arraigo en relaciones entre los individuos crea oportunidades económicas que difícilmente pueden ser replicadas a través de otros mecanismos como mercados, contratos o procesos de integración vertical (Uzzi, 1997). 
Como se planteó en apartados anteriores, las UBIs pueden ser entornos favorables para fraguar relaciones basadas en intercambios de conocimiento y compromiso entre las partes que, a su vez, pueden tener como resultado la generación de innovación. La colaboración entre incubados llevará aparejado un incremento en la velocidad de la innovación en comparación con el tiempo que se hubiera empleado si la innovación la hubiese realizado la empresa por separado. A su vez, la innovación se traduce en una respuesta más rápida y ágil frente a los cambios del entorno, así como en la posibilidad de explotar una incipiente oportunidad de mercado. Si esto ocurriese, las empresas podrían tener una ventaja competitiva, que al explotarla podría traducirse en un incremento en las ventas totales, por las ventas generadas por esa innovación concreta, y también podrían incrementarse los beneficios, derivado del reparto de tiempo, costes y recursos empleados para su desarrollo colaborativo. Por lo tanto, se propone la siguiente hipótesis:

H12c: La generación de innovación en las relaciones entre incubados influye positivamente en los resultados comerciales de los negocios de los incubados.

\subsection{Propuesta de un modelo explicativo de relaciones diádicas entre incubados}

Para concluir este capítulo, sintetizamos en las Figuras 2.3. y 2.4. las hipótesis propuestas, H1 a H12, que configuran lo que denominamos el Modelo 1. Sus objetivos son tratar de explicar cuáles son los determinantes que llevan al desarrollo de relaciones entre incubados, cómo se caracterizan, así como cuáles son los resultados de esas relaciones en los negocios y en los propios incubados. El modelo propuesto se recoge de forma sintética en la Figura 2.3., y de forma extensa en la Figura 2.4. 


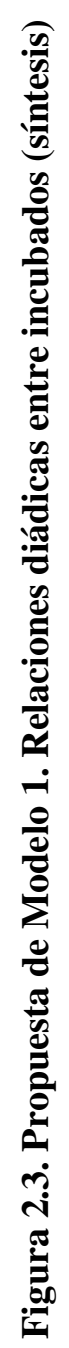

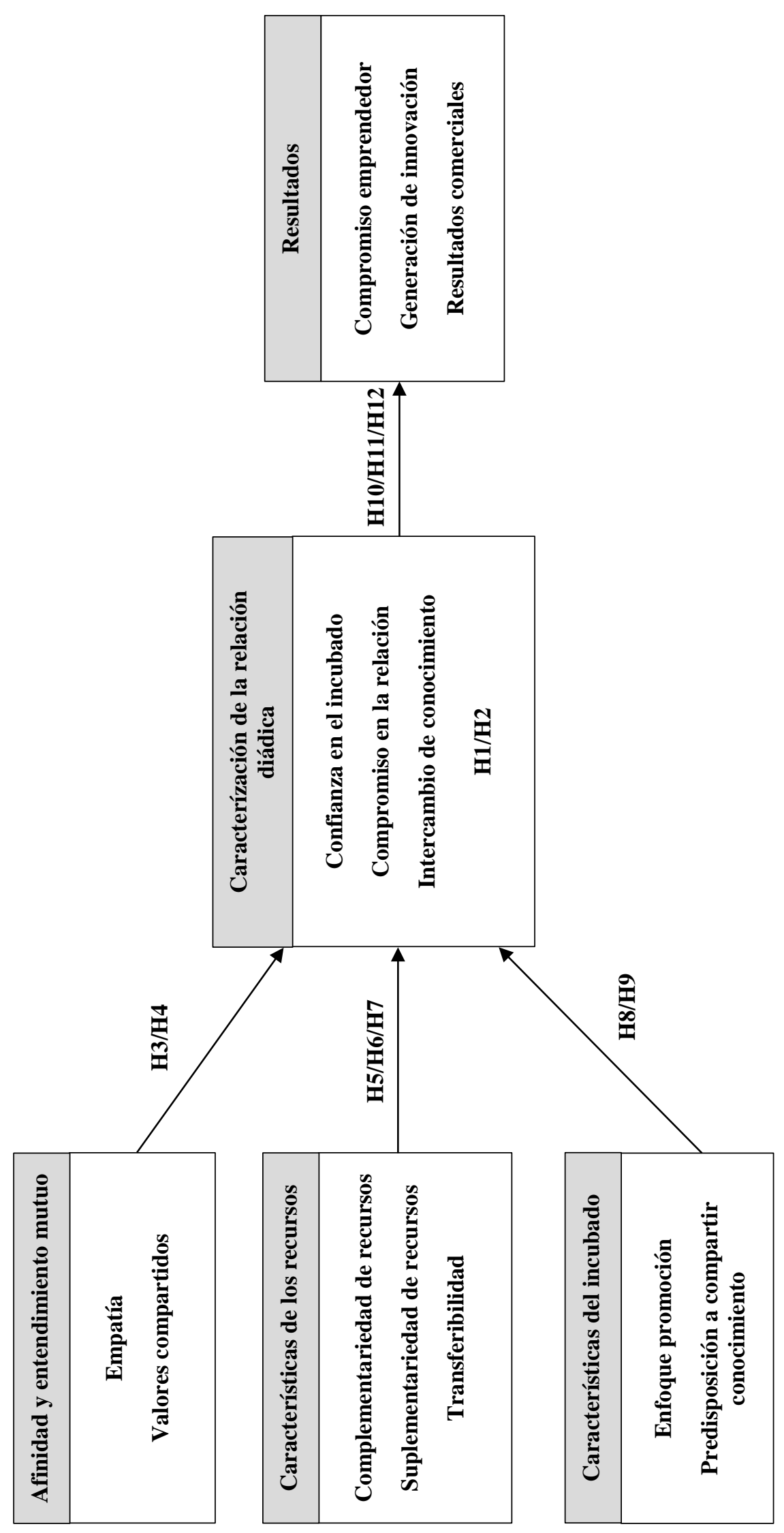




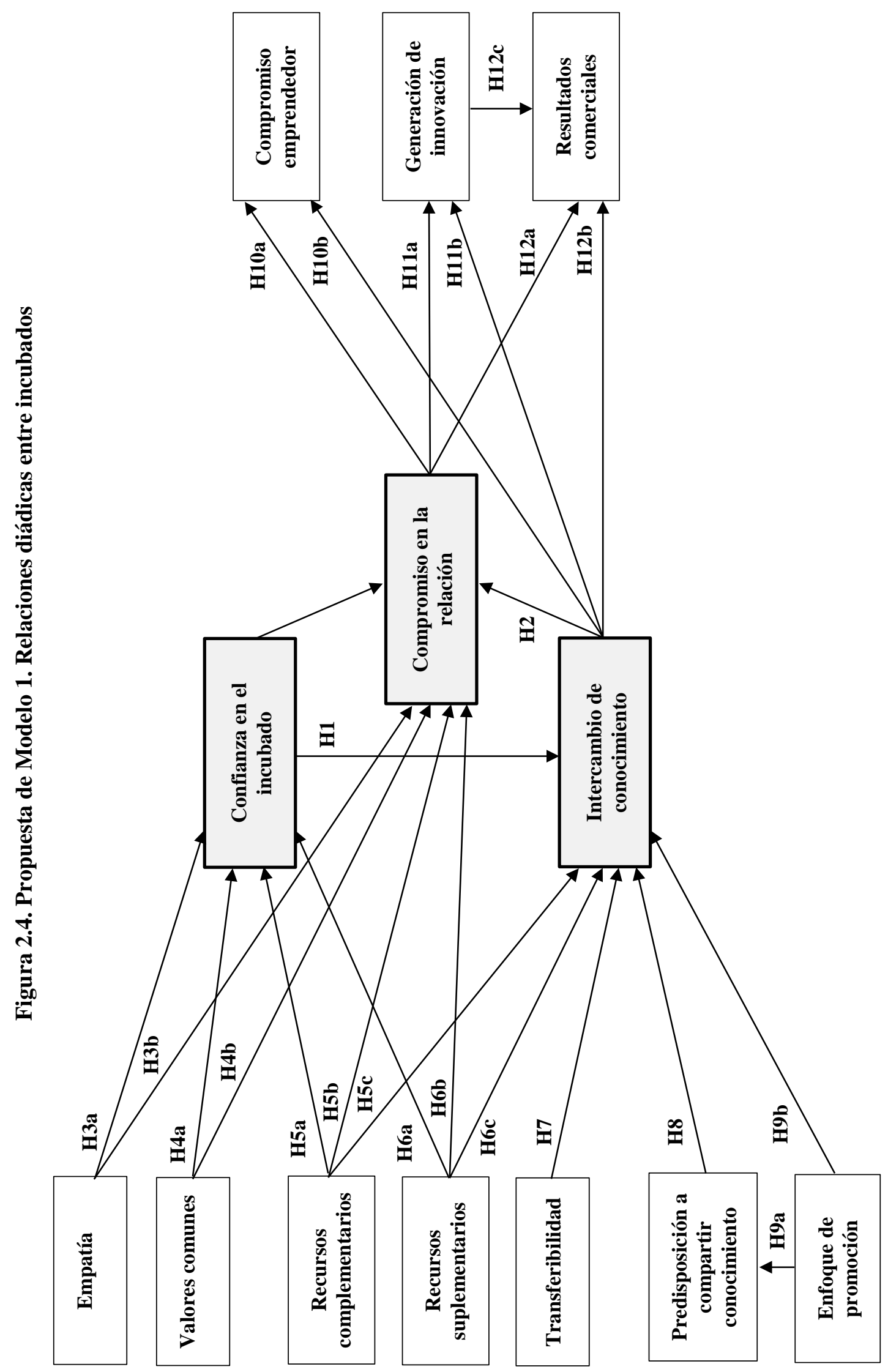




\section{Capítulo 3. El rol del mánager en la generación de relaciones y capital social en las UBIs}





\subsection{Introducción}

En el capítulo 2 planteamos y esbozamos diferentes cuestiones relativas a las relaciones diádicas entre incubados. Continuando en el ámbito concreto de las UBIs, en el presente capítulo introducimos la figura del mánager. El mánager (o el equipo de dirección en su defecto) es el encargado de organizar los servicios que se ofrecen a los incubados (NBIA, 2009). Su competencia para configurar los elementos del proceso de incubación y dar forma al contexto relacional en el que operan los incubados le convierten en un factor clave (Fry, 1987; Autio y Klofsten, 1998; Sherman, 1999; Lalkaka, 2002; Rice, 2002; Hackett y Dilts, 2004a; Hannon, 2005). Sin embargo, la literatura apenas ha prestado atención a la figura del mánager de las incubadoras (Theodorakopoulos et al., 2014). Los trabajos se centran en tratar de explicar cómo el ámbito o el alcance de una incubadora puede estar influido y determinado por el organismo o la autoridad que lo desarrolla (Vanderstraeten y Matthyssens, 2012), por las competencias profesionales de los mánagers (von Zedtwitz, 2003), y/o por el papel del mánager en la selección de incubados (Anderson y Al-Mubaraki, 2012; Wulung et al., 2014).

A lo largo de los últimos años, distintos autores han prestado atención a los llamados networked incubators (Hansen et al., 2000; Bøllingtoft y Ulhøi, 2005; Tötterman y Sten, 2005; McAdam y Marlow, 2007). En los estudios que han desarrollado se muestran cuáles son los mecanismos que los mánagers pueden emplear para crear y desarrollar relaciones entre los emprendedores dentro de las incubadoras, y también entre incubados y agentes externos. Sin embargo, son escasos los estudios empíricos y las aportaciones realizadas a este respecto.

En este contexto, se enmarcan dos de los objetivos de la presente tesis doctoral. El primero de ellos es analizar el papel de los mánagers de las UBIs como impulsores del tipo de servicios que se brinda a los emprendedores. Para abordar este objetivo se valora el papel del mánager desde el enfoque de la lógica institucional. El segundo objetivo se refiere al mánager como determinante clave del acceso a redes de relaciones y de la formación de un capital social dentro de la propia incubadora que pueda favorecer el desarrollo de los negocios incipientes e influir, en términos de eficiencia, en las empresas de los incubados. En este último caso, se ha seguido el enfoque del capital social. 
En este tercer capítulo, con afán de analizar cada uno de los dos objetivos enunciados, explicaremos los enfoques de la lógica institucional y de capital social, plantearemos hipótesis, y se propondrán dos modelos explicativos, uno por cada objetivo. Las hipótesis formuladas, tanto en este capítulo como en el anterior, se pretenden testar en la parte empírica de la presente tesis doctoral, recogida en el capítulo 4.

\subsection{Marco teórico para el rol del mánager: el enfoque de las lógicas institucionales}

Thornton y Ocasio (1999, p. 804) definen la lógica institucional como "lo construido socialmente, patrones históricos de prácticas materiales, supuestos, valores, creencias, y normas por las que las personas producen y reproducen su subsistencia material, organizan el tiempo y el espacio, y proporcionan un sentido a su realidad social”. Este concepto de lógica institucional se basa en la idea de que las instituciones determinan los valores a través de los cuales los individuos y las organizaciones proporcionan sentido a sus actividades, organizan su tiempo y desarrollan sus experiencias. Los intereses, identidades, valores y asunciones de los individuos y las organizaciones están integrados dentro de las lógicas institucionales que prevalecen.

La literatura sobre las lógicas institucionales ha analizado los efectos de las lógicas, dado que cambian con el tiempo (Thornton y Ocasio, 1999; Thornton, 2002), la interacción entre diferentes lógicas (Battilana et al., 2009), o la complejidad de organizaciones híbridas con lógicas institucionales competidoras (Battilana y Dorado, 2010; Pache y Santos, 2013).

La universidad y la empresa son dos ejemplos de mundos regidos por lógicas institucionales diferentes: la lógica académica y la lógica comercial, respectivamente (Merton, 1973; Perkmann y Salter, 2012). Las lógicas institucionales influyen en el comportamiento individual y organizacional, lo cual implica que la universidad y la empresa representan dos mundos con diferentes valores, formas de trabajo y objetivos. Bajo la lógica académica, los principales valores que prevalecen son la vocación por la ciencia y el desinterés económico. Estos valores pueden ser un obstáculo en el estímulo o en el desarrollo de comportamientos que llevan implícitos la transferencia de tecnología o la creación de spin-offs (Etzkowitz, 1998; Stuart y Ding, 2006). Por el contrario, en la lógica comercial, o en el mundo de los negocios, la obtención de 
beneficios rige las actuaciones de las empresas. Para conseguir este objetivo, las empresas tienen que afrontar las condiciones cambiantes del mercado (Cyert y Goodman, 1997; Dealtry et al., 2005), frente a los académicos, que trabajan en un entorno más previsible, aunque la ciencia pueda ser impredecible (van der Sijde et al., 2014).

Un concepto interesante, introducido por DiMaggio (1988), es la noción de emprendedor institucional. El autor los define como aquellos actores que inician cambios que contribuyen a crear una nueva institución o a transformar una existente. En las UBIs, este rol podría ser desarrollado por los mánagers, que son los responsables de trasmitir la lógica de los negocios a los incubados académicos. Sin embargo, la eficiencia en el desarrollo de esta tarea dependerá de la lógica dominante. Según el enfoque de las lógicas institucionales, el comportamiento de los individuos en las organizaciones responderá a su grado de adhesión a la lógica prevaleciente. Pache y Santos (2013) señalan que la respuesta de los individuos a una lógica estará determinado por el grado de adhesión a la misma, pudiendo ser: novato, familiar e identificado. Un individuo es novato en relación a una lógica cuando tiene nada o poco conocimiento o información disponible al respecto. Un mayor nivel de disponibilidad, accesibilidad y activación de una lógica se da cuando un individuo está familiarizado. Esto supone que tiene conocimientos disponibles sobre la lógica en cuestión, que pone a disposición de otros individuos a través de interacciones sociales. Por último, un individuo que se identifica con una lógica es aquel para el que está disponible y altamente accesible. En este caso, la lógica marca qué hace el individuo y la forma en la que se relaciona con cualquier agente.

\subsection{Relación entre el perfil profesional del mánager y la prestación de servicios}

La realidad de las incubadoras nos muestra que, incluso aunque tengan objetivos similares, su funcionamiento no es homogéneo. Los servicios facilitados por las UBIs a sus inquilinos se estructuran en dos categorías. La primera de ellas se refiere a los típicos servicios ofrecidos por las incubadoras, los servicios de oficina, asistencia empresarial y el acceso a capital, entre otros. La segunda se centra en la universidad en sí y en los servicios relacionados que incluyen mentores académicos, acceso a estudiantes, imagen de la universidad, programas de transferencia de tecnología y 
formación (Mian, 1996). Considerando estas posibilidades, en la presente investigación, consideramos tres tipos de servicios que básicamente describen cómo funcionan las incubadoras:

(1) Asesoramiento personal a través de un coach que puede responder a cada uno de los requisitos de conocimiento específicos que demanden los emprendedores.

(2) Asesoramiento empresarial relativo a diferentes funciones de gestión tales como marketing, recursos humanos, finanzas, etc.

(3) Acceso a actividades de networking que favorezcan el desarrollo de habilidades sociales y la introducción de los incubados en redes profesionales.

No todas las incubadoras ofrecen estos servicios de forma sistemática y generalizada, sino que hay servicios que dependen, en gran medida, del perfil del mánager. Mientras en unas incubadoras la formación y el asesoramiento es general para todos los incubados y se centra en el ámbito empresarial, en otras se ofrece un asesoramiento más individualizado, mediante coaching, y se fomentan las relaciones entre los incubados y de éstos con otros agentes, de modo que consoliden un capital social interno y externo.

En los siguientes subepígrafes planteamos en qué medida los servicios ofrecidos por las UBIs se determinan por las lógicas institucionales de los mánagers. Más concretamente, explicamos la relación entre las lógicas institucionales, los valores predominantes y los servicios ofrecidos en las incubadoras.

\subsubsection{La lógica comercial: experiencia del mánager en el mundo de los}

\section{negocios}

Un mánager con perfil profesional, bien porque haya creado su propio negocio o porque haya trabajado fuera del ámbito universitario, tendrá al menos un nivel familiar con la lógica comercial. Esto indica que el mánager ha estado inmerso en el mundo de los negocios. Su orientación es hacia el mercado. Sabe que la forma de trabajar y de obtener éxito es diferente en los negocios que en la universidad. Debido a su experiencia profesional, el mánager conoce el funcionamiento y los beneficios que se pueden obtener en los negocios. Así pues, en lo que se refiere a su actitud hacia esta lógica, y en su condición de "garante” de los incubados, estará dispuesto a “construir” un puente entre los dos mundos (van der Sijde et al., 2014) con la finalidad de que los emprendedores académicos puedan optimizar su proceso de incubación. 
El mánager con perfil profesional es consciente de que los incubados provienen del ámbito académico, y que su condición de principiantes en los negocios no les evitará tener que entrar a competir en el mercado con otras empresas, ni enfrentarse al resto de dificultades inherentes a ese ámbito. Más concretamente, y desde la visión de mercado del mánager, los emprendedores académicos se encontrarían con las siguientes barreras (Redondo Carretero et al., 2014): piensan que la investigación es suficiente para establecer un negocio; se centran en trabajar en su producto; desarrollan sus productos sin considerar al mercado y a los clientes; no cuentan con una orientación hacia las ventas; y no tienen un comportamiento proactivo para hablar con otros individuos sobre negocios. Por otra parte, y también desde la óptica del mánager profesional, entre los beneficios que pueden derivarse de la incubación para los emprendedores académicos se encuentran los siguientes (Redondo Carretero et al., 2014): obtener conocimientos e información sobre aspectos referidos a modelos de negocios y captación de financiación; aprender a priorizar las distintas actividades de negocios que deben realizar; y hacer contactos que les permitan construir su propia red, especialmente con personas del mundo de los negocios.

Siendo el mánager consciente de las limitaciones de los incubados y de los beneficios que puede reportar una UBI, parece probable que favorezca e impulse, fundamentalmente, servicios de asesoramiento empresarial, asesoramiento personal y networking. Primero, para superar limitaciones como la falta de visión de mercado, y para obtener conocimientos sobre modelos de negocios y otros aspectos, serían adecuados y necesarios los servicios de asesoramiento de negocios. Segundo, teniendo en cuenta que los incubados están lanzando sus empresas, las necesidades latentes e inherentes a ese momento serán variadas y numerosas. Así pues, para poder responder a ellas y a otros aspectos como la priorización de las actividades a desarrollar, el asesoramiento personal, ad hoc, a través de un coach, puede ser clave. Y, en tercer y último lugar, las actividades de networking. En los negocios las cuestiones en cuanto a procedimiento (tales como cuáles son las estrategias para implementar un producto) se pueden aprender, y en un plazo de tiempo menor que el necesario para formar un red de contactos. Dado que los contactos son clave para las empresas, y que los emprendedores académicos no suelen tener un comportamiento proactivo para relacionarse con agentes del mundo de los negocios, el mánager profesional impulsará actividades que 
favorezcan los contactos, tanto a nivel interno (con otros incubados) como a nivel externo (profesionales fuera del mundo de la universidad). Por tanto:

H13: La experiencia en los negocios de los mánagers influye positivamente en el asesoramiento personal (H13a), pero también en el asesoramiento empresarial (H13b), y en el acceso de los incubados a networking (H13c).

\subsubsection{La lógica académica: experiencia científica del mánager}

Un científico, inicialmente, no tiene orientación emprendedora, puesto que tiene una cultura académica y una clara preferencia por la investigación básica (Ndonzuau et al., 2002). Incluso es posible que tenga dificultades para identificar oportunidades con aplicaciones comerciales (Lockett et al., 2003).

Un mánager con perfil científico, y que no tenga experiencia profesional fuera del ámbito académico, será novato en cuanto a la lógica de los negocios y familiar o identificado con la lógica académica ${ }^{8}$. Sin embargo, si considera su rol de mánager de una UBI, tendrá en cuenta dos apreciaciones: (1) las incubadoras son centros de apoyo al desarrollo empresarial y (2) los inquilinos o incubados tienen, en su mayor parte, un perfil estrictamente académico y falta de experiencia en el mundo de los negocios (al igual que el propio mánager). Por lo tanto, y ante esta situación, se planteará la siguiente cuestión: ¿qué servicios, de los que puede prestar una incubadora, pueden favorecer la preparación de los inquilinos para los negocios? Aquellos que les permitan obtener respuestas específicas y concretas a sus carencias (a través de asesoramiento personal), conocimientos empresariales a nivel procedimental (asesoramiento empresarial) y el acceso a redes de negocios (networking).

Parece adecuado suponer, por tanto, que el mánager con perfil académico entenderá que los incubados demandan y necesitan asesoramiento específico personal y empresarial

\footnotetext{
${ }^{8}$ Siguiendo el modelo ABC de van der Sijde et al. (2014), un académico, y por ende aquel que vaya a encargarse de dirigir una incubadora, puede presentar una de las tres posibles actitudes básicas para hacer frente a la lógica y al mundo de los negocios: (1) Reconocimiento (Acknowledgement). Los académicos saben que el mundo comercial tiene reglas de funcionamiento diferentes. Frente a ello, se decantan porque no haya una interferencia excesiva con la lógica académica. (2) Beneficios (Benefits). Conocen los beneficios que pueden derivarse del mundo de los negocios. Están dispuestos a tender un puente entre las dos lógicas, especialmente si los beneficios redundan en el mundo académico. (3) Cumplimiento (Compliance). Los académicos sólo cooperan con el mundo de la empresa cuando tienen la obligación de hacerlo. No muestran una disposición positiva a conocer o entender la lógica comercial.
} 
que se adecúe a sus necesidades concretas, que serán distintas y variadas debido a la falta de experiencia empresarial de los incubados. Asimismo, esas necesidades dependerán del perfil de cada individuo, así como de la fase en la que se encuentre su negocio. Por último, y en cuanto al acceso a redes se refiere, los incubados ya están inmersos en sus propias redes dentro del mundo académico, y tienen desarrolladas habilidades sociales. Esas redes pueden ser las de su departamento, equipos de investigación con los que trabajen, investigadores o profesores de otras universidades con los que tengan contactos. Sin embargo, el mánager será consciente de que las redes empresariales son diferentes a las científicas, y deberá promover el acceso y la inmersión de los incubados en redes de negocios, para que puedan tener acceso a recursos específicos que no están presentes en el mundo científico.

Esta propuesta se traduce en las siguientes hipótesis:

H14: La experiencia científica de los mánagers influye positivamente en el asesoramiento personal (H14a), pero también en el asesoramiento empresarial (H14b), y en el acceso de los incubados a networking (H14c).

Pese al hecho de que un mánager académico tenga interés en fomentar los servicios de asesoramiento personal, asesoramiento empresarial y actividades de networking, su falta de experiencia como emprendedor puede restarle eficiencia en la promoción de estos servicios. El nivel de inexperto en el ámbito empresarial supone que el mánager no ha estado expuesto, ni ha interactuado con frecuencia, con individuos del mundo de la empresa. Piensa y actúa basándose en su formación y, sobre todo, en su experiencia en el mundo científico. En el mundo científico, los individuos tienen el conocimiento y el saber hacer para obtener resultados de investigación. Sin embargo, no son conscientes de que los resultados de investigación no son similares a los resultados de mercado (Redondo Carretero et al., 2014). Por lo tanto, su idea acerca de cómo funciona el mercado se deriva de los estudios, proyectos e investigaciones que haya desarrollado. Todos ellos enmarcados en un nivel teórico, aunque se basen en datos u hechos procedentes del ámbito empresarial. En definitiva, esta falta de experiencia puede ir en detrimento de una oferta adecuada de servicios al emprendedor en comparación con la oferta que puede impulsar un mánager de perfil emprendedor. Por todo ello, proponemos:

H15: La experiencia científica de los mánagers tiene menor influencia en el asesoramiento personal (H15a), en el asesoramiento empresarial (H15b,) y en el 
acceso de los incubados a networking (H15c) que la experiencia emprendedora de los mánagers.

\subsubsection{Propuesta de un modelo explicativo del perfil del mánager y la} prestación de servicios

El segundo modelo propuesto en la presente tesis doctoral, Modelo 2, se ha configurado a través de las hipótesis H13, H14 y H15. Su objetivo es analizar en qué medida la experiencia científica y en el mundo de los negocios del mánager puede influir en los distintos servicios prestados en la incubadora, en los cuales pueden participar los emprendedores. La representación sintética del modelo se presenta a continuación, en la Figura 3.1.

Figura 3.1. Propuesta de Modelo 2. Perfil del mánager y servicios prestados

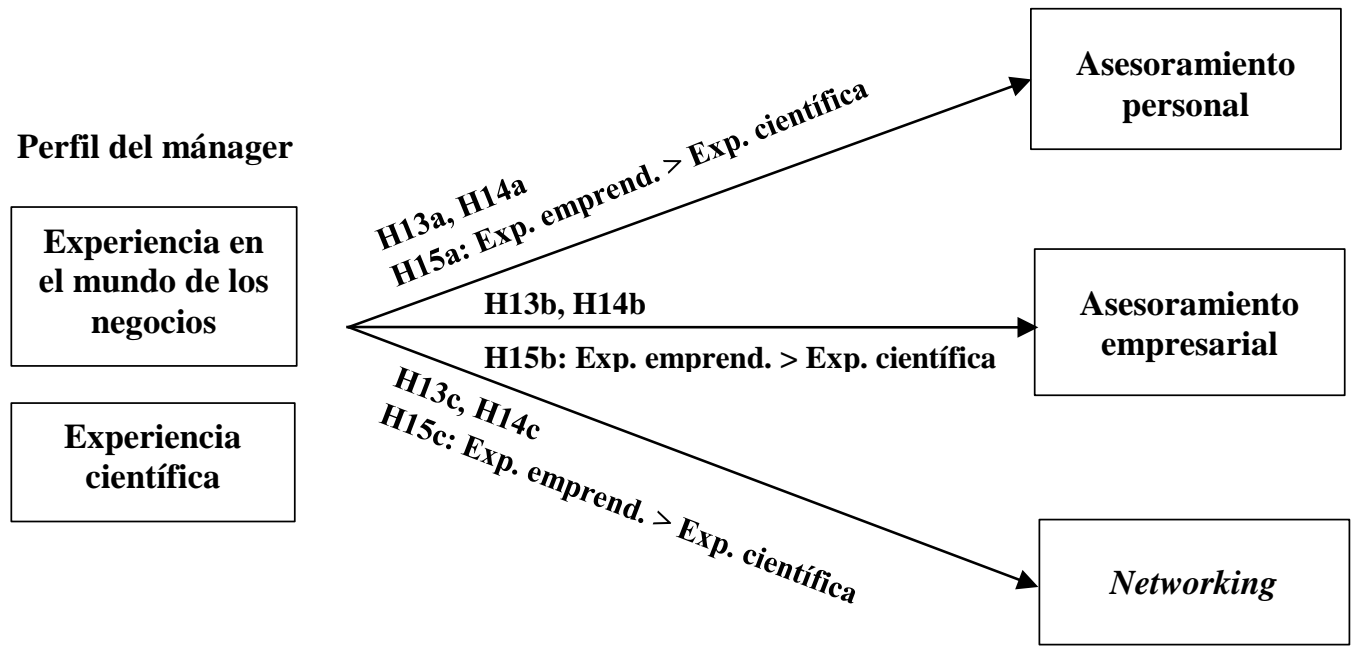

\subsection{Marco teórico de las redes de relaciones: el enfoque del capital social}

\section{El concepto de capital social}

El enfoque teórico del capital social incorpora aportaciones de diferentes ramas de las ciencias sociales (Adler y Kwon, 2002). Esto da lugar a una diversidad de propuestas acerca de su definición (Burt, 2000; Adler y Kwon, 2002; Vargas Forero, 2002), las dimensiones que lo componen y la forma de medirlas (Woolcock, 1998; Narayan y Cassidy, 2001; Chetty y Agndal, 2007). En todo caso, en las definiciones de capital social se alude, de forma explícita o implícita, a las redes de relaciones, a los recursos que contienen esas redes o a ambos (Payne et al., 2011). Ello permite que a través del 
capital social se capture el impacto de las relaciones humanas en la actividad económica (Barnes, 2001; Bathelt y Glückler, 2003; Boggs y Rantisi, 2003; Hauser et al., 2007).

La primera aparición del concepto de capital social se remonta a 1916, cuando Lyda Judson Hanifan, un inspector de escuelas de Virginia del Oeste, puso de relieve que las relaciones sociales favorecen la eficiencia de actuaciones específicas en el medio rural. Más concretamente, a través de esa argumentación explicó la obtención de resultados superiores de determinadas comunidades de alumnos (Putnam, 2000). Posteriormente, algunos autores mencionaron, pero sin impacto académico, el término capital social ${ }^{9}$, hasta la definición aportada por Bourdieu en 1985. Sin embargo, antes de llegar a ese punto, y dado que el capital social se refiere a las redes de relaciones, es necesario enmarcar y explicar el estudio de las redes sociales. Para ello, debemos remontarnos al trabajo de Mark Granovetter. En 1973 desarrolla un artículo titulado "la fuerza de los lazos débiles”, el cual revisará y ampliará en el año 1983 con la publicación de "la fuerza de los lazos débiles: una teoría de redes revisitada”. Este autor plantea la hipótesis de que un tipo concreto de vínculos entre las personas, lazos débiles, tiene especial importancia (Granovetter, 1973). Los lazos débiles son aquellos que se tipifican como distantes, siendo el resultado de interacciones infrecuentes, pero que, a la vez, son propensos a ser fuentes de recursos noveles, tales como información (Granovetter, 1973). Tomando observaciones de una investigación sobre búsquedas laborales constata que los lazos débiles que un individuo acumula a lo largo de su carrera profesional predicen su desarrollo profesional en mayor medida que sus lazos fuertes, entendiendo como tales los vínculos que mantiene con familia y/o amigos (Granovetter, 1974).

Retomando la mención a Bourdieu (1985), encontramos que define el capital social como el conjunto de recursos actuales o potenciales relacionados con la posesión de una red duradera de relaciones en cierta medida institucionalizada. Bourdieu (1985) se refiere a los recursos a los que acceden los individuos debido a sus relaciones con otros, al igual que Coleman $(1988)^{10}$. Sin embargo, el ámbito de aplicación del concepto se amplía con la aportación realizada por Putnam (1995, p.67), quién por capital social

\footnotetext{
${ }^{9}$ Jacobs (1961) atribuye las bajas tasas de criminalidad y la pulcritud de determinados barrios antiguos de las ciudades a la densa red de relaciones sociales que se forman dentro de ellos; y Loury, en 1977, emplea el término capital social para explicar cómo el conjunto de redes de relaciones sociales que utilizan los jóvenes con la finalidad de desarrollar su capital humano (Trigilia, 2003).

${ }^{10}$ Coleman (1988) define el capital social como los aspectos de la estructura social que facilitan determinadas acciones comunes de los actores que están dentro de la misma.
} 
entiende "las características de la organización social, tales como las redes, las normas y la confianza social que facilitan la coordinación y la cooperación para un beneficio mutuo".

Siguiendo a Adler y Kwon (2002) hay dos formas diferentes de crear valor a través del capital social: Coleman y las redes cerradas, frente a Burt y las redes dispersas y los agujeros estructurales. Ambas propuestas, que explicamos a continuación, constituyen las bases sobre las que se asienta el enfoque teórico del capital social.

Coleman (1988) sostiene que una red con una estructura cerrada, en términos de lazos existentes entre los actores, facilita la aparición de normas efectivas que, a su vez, mantienen la confianza entre los miembros. Esas normas fortalecen el capital social dentro de la estructura de la red, disminuyendo comportamientos oportunistas. Por el contrario, en una estructura de red más abierta, el incumplimiento de las normas puede no ser detectado y, por tanto, quedar impune. Esto llevaría a una menor confianza dentro de la estructura de la red. En consecuencia, una estructura de red abierta es más débil en relación al capital social, mientras que una red cerrada, con una estructura cohesionada y única, basada en normas y confianza entre sus miembros, favorece el capital social. No obstante, una red cerrada es más rígida y menos innovadora que una red abierta.

En contraste con Coleman (1988), quién ensalza la estructura y el funcionamiento de las redes cerradas, Burt (1992) argumenta que una red dispersa, con pocos lazos redundantes, a menudo proporciona mayores beneficios en cuanto a capital social se refiere. Esto se debe a la noción de agujeros estructurales del propio Burt (1992). Para explicarlo, se basa en los peligros de las normas consistentes fomentadas en las redes cohesionadas, y con ello plantea un argumento similar a los planteados por Granovetter (1983), quién sostiene que las redes cohesionadas y densas no proporcionan el ambiente más favorable para conexiones sociales activas. Esta función se realiza a través de lazos débiles, es decir, conexiones temporales o intermitentes a través de las cuales se canalizan inesperados flujos de información. Enlazándolo con ello, Burt (1992) afirma que la diversidad de información y las oportunidades de brokerage derivadas de la falta de lazos redundantes que existen dentro de una red dispersa son la fuente de valor. La existencia de agujeros estructurales dentro de una red permite a un agente actuar como bróker de información mediante la combinación de información de diferentes actores dentro de una red. Es decir, el individuo que ocupa un agujero estructural en una red 
controla los flujos de información y de recursos entre los miembros de la mencionada red (Burt, 1992). A su vez, los agujeros estructurales sirven de nexo entre individuos que, de otro modo, no estarían conectados.

La razón por la qué Coleman y Burt sugieren condiciones opuestas, redes cerradas frente a redes dispersas, y un uso diferente del capital social, radica en la diferencia entre sus respectivos enfoques, interno y externo, y en la diferencia en los objetivos asumidos (Adler y Kwon, 2002). A modo de resumen, podemos plantear que siguiendo a Coleman, una red cohesionada y cerrada proporciona beneficios a nivel de capital social dentro de la comunidad o grupo, mientras que en una red dispersa, los agujeros estructurales (Burt, 1992) suministran al actor focal los recursos efectivos que permiten acciones competitivas. Estos dos aspectos, los cuales se refieren a diferentes tipos de conexiones de red, se concretan y toman denominaciones específicas en el marco del capital social: bridging y bonding (Putnam, 2000).

Granovetter (1973, p. 1364) introduce el concepto de bridge como “una línea en una red que provee el único camino entre dos puntos”. Posteriormente, en 1983, utiliza el término bridging para referirse a cómo los vínculos débiles pueden crear puentes entre el contexto social de un actor y el de otro, lo que contribuye a ampliar su marco de referencia. El término de Granovetter (1983) es desarrollado por Putnam (2000), quién define el capital social bridging como lazos débiles, vínculos más relajados entre los actores, contactos con otros grupos de personas con diferentes backgrounds, pero que pueden permitir el acceso a nuevos recursos. El bridging implica heterogeneidad y diversidad de la red (Lee, 2009).

De otra parte, el capital social bonding representa relaciones estrechas, lazos fuertes entre individuos que se conocen bien, dentro de grupos homogéneos, los cuales permiten el intercambio de recursos entre los mismos, y a menudo excluyen la interacción fuera del grupo. La cohesión o la existencia de lazos fuertes es un rasgo característico de aquellas redes en las que se desalientan los comportamientos oportunistas y que favorecen el intercambio de información entre sus miembros (Granovetter, 1973; Coleman, 1990; Levin y Cross, 2004).

La combinación de patrones diferentes de capital social bonding y bridging tiene efectos positivos. Las relaciones densas y agrupadas fomentan la confianza y la colaboración estrecha, mientras que los lazos distantes actúan como puentes para que fluya información nueva y no redundante (He y Fallah, 2009). Así pues, las organizaciones 
necesitan una mezcla de ambos lazos, fuertes y débiles, ya que los lazos fuertes implican intercambios más profundos, mientras que los lazos débiles proporcionan más amplitud y diversidad de conocimientos y recursos (Parmigiani y Rivera-Santos, 2011).

\section{Niveles de análisis y dimensiones del capital social}

En cuanto a los niveles de análisis del capital social, se puede diferenciar entre individual y colectivo (Payne et al., 2011). El nivel individual se refiere al capital social de un individuo, y alude a las redes que él mismo ha creado en su propio beneficio. El nivel colectivo, por su parte, hace referencia a un recurso público, basado en comunidades y redes sociales de las que se benefician todos los miembros del grupo, comunidad o colectivo en cuestión. Ambos tipos de capital social, individual y colectivo, tienen sus propios antecedentes y resultados, pero pueden interrelacionarse entre sí (Portes, 1998; Woolcock, 1998).

En un mayor grado de detalle, y siguiendo a Payne et al. (2011), el capital social colectivo se puede diferenciar entre capital social interno y externo. El capital social interno es el que se establece entre los miembros de un grupo, centrándose en las características internas de los miembros involucrados (Adler y Kwon, 2002). Mientras que el capital social externo se refiere a los vínculos que una organización mantiene con agentes externos (Adler y Kwon, 2002; Yli-Renko et al., 2002). El capital social interno guarda un paralelismo con el capital social bonding, al igual que el capital social externo hace lo propio con el bridging (Adler y Kwon, 2002; Chetty y Agndal, 2007).

Puesto que el capital social es el resultado de las redes de relaciones del individuo, Nahapiet y Ghoshal $(1998)^{11}$ plantean tres dimensiones que aluden a las características de esas redes: estructural, relacional y cognitiva.

(1) La dimensión estructural abarca la interacción social que se produce en una red, centrándose en las propiedades del sistema social y de la red de relaciones como un todo (Nahapiet y Ghoshal, 1998). Más concretamente, se refiere al modelo de conexiones entre los actores de una red, representando a quién se alcanza y cómo (Burt, 1992). El

\footnotetext{
${ }^{11}$ Nahapiet y Ghoshal (1998) plantean que el capital social es la suma de los recursos actuales y potenciales a los que puede acceder el individuo a través de sus redes de relaciones. Así pues, el capital social representa los recursos relacionales alcanzables por los actores a través de nexos sociales (Coleman, 1990; Bourdieu y Wacquant, 1992; Putnam, 1995; Adler y Kwon, 2002), pudiendo ser de distinta índole: conocimiento, experiencia, habilidades, y otras capacidades como innovación y colaboración (Yli-Renko et al., 2001; Hatzakis et al., 2005; Liao y Welsch, 2005).
} 
capital social, bajo esta dimensión, se puede analizar a través de la configuración de la red, que determina las uniones entre sus miembros, en términos de densidad, conectividad y jerarquía (Nahapiet y Ghoshal, 1998). Burt (2000), por su parte, se centra en las siguientes variables para configurar una red: densidad, jerarquía, y tamaño. En la investigación que nos ocupa, vamos a centrarnos en la propuesta de Burt (2000). La densidad se asocia con la flexibilidad y la facilidad en el nivel de contacto o de accesibilidad entre los miembros de una red (Ibarra, 1992; Nahapiet y Ghoshal, 1998). La jerarquía hace referencia a redes verticales, en las que se vinculan agentes desiguales en relaciones asimétricas de dependencia (Putnam, 2000). Y, por último, el tamaño se refiere al número de miembros que forman parte de una red (Burt, 2000).

(2) El capital social en su dimensión relacional alude al grado en el cual dentro de una red existen relaciones fluidas entre los participantes. En concreto, Nahapiet y Ghoshal (1998) caracterizan el capital social relacional a partir del grado de confianza, normas comunes, obligaciones e identificación como grupo. Putnam (1993) indica la necesidad de que las organizaciones, internamente, inculquen a sus miembros hábitos de cooperación y solidaridad. Esos hábitos se pueden verter posteriormente en la participación de sus miembros en otras organizaciones, y pueden generar confianza (Eklinder-Frick et al., 2012). Altos niveles de confianza lleva a que los individuos estén más dispuestos a participar en el intercambio social y en interacciones cooperativas, tales como pedir ayuda, tener conversaciones espontáneas y reuniones no planificadas, así como intercambio de información, conocimiento y recursos (Lee et al., 2005).

(3) Por último, el capital social cognitivo se refiere a la capacidad de los individuos para interactuar a través de lenguajes comunes, códigos, formas narrativas, y entendimiento entre los miembros de una comunidad, así como a través de objetivos compartidos y una cultura común (Nahapiet y Ghoshal, 1998).

Las redes de relaciones en las que puede estar inmerso un individuo son de distinta índole. Stone y Hughes (2002) sugieren que el capital social presente en cada una de ellas no tiene por qué ser similar y, por ello, proponen diferenciar tres tipos de redes y analizarlas por separado. El primer tipo son las denominadas relaciones informales, de las cuales forman parte familiares, amigos, conocidos y compañeros de trabajo. El segundo son las relaciones generalizadas, que hacen referencia a las que se tienen con colectivos como asociaciones, agrupaciones o comunidades en general. Y el tercer tipo se refiere a relaciones institucionales, que son aquellas mantenidas con miembros de 
organismos públicos y medios de comunicación, entre otros. En la investigación que nos ocupa nos centraremos específicamente en las redes de negocios o de ámbito empresarial en la que las empresas puedan relacionarse directamente con otras empresas, a nivel horizontal.

\section{Capital social, marketing de relaciones y relaciones entre empresas}

Las evidencias son cada vez mayores acerca del efecto que tiene el capital social en el acceso a los recursos y capacidades de otros agentes, así como en el establecimiento y mantenimiento de relaciones de negocios (Partanen et al., 2008). El capital social y el marketing de relaciones se convierten, por tanto, en enfoques complementarios dado que se centran en las relaciones como mecanismo para acceder a recursos y poder intercambiarlos, así como para mejorar capacidades de los individuos implicados. Es más, hay algunos autores, como Lawson et al. (2007), que vinculan conceptos de ambas teorías. En concreto, se da un paralelismo entre los conceptos de capital social relacional y orientación relacional de las relaciones diádicas.

Sin embargo, mientras que el marketing de relaciones también se enfoca al estudio del establecimiento, desarrollo, y mantenimiento de relaciones diádicas (Morgan y Hunt, 1994), y se ha aplicado de manera extensa al ámbito empresarial, el enfoque de capital social resalta la importancia de las redes de relaciones y el acceso a los recursos que contienen (ej. Gilmore et al., 2006).

En relación a las bondades del capital social en el ámbito empresarial, se puede decir que es un recurso estratégico para las empresas y una fuente de acceso a conocimiento, experiencia, habilidades y otras capacidades como la innovación (Hatzakis et al., 2005). Pero no sólo eso, sino que a través de las relaciones con las empresas que están dentro de una red se pueden favorecer intercambios entre ellas, por ejemplo basados en conocimiento (Nahapiet y Ghoshal, 1998). Para ello, las partes implicadas tienen que mostrar predisposición y capacidad para identificar, intercambiar y asimilar conocimiento (Yli-Renko et al., 2001). Las empresas son capaces de incrementar la profundidad, amplitud y eficiencia del intercambio de conocimiento mediante una estrecha interacción social (Lane y Lubatkin, 1998). Así pues, y considerando que las empresas son depositarias de conocimiento y competencias (Kogut y Zander, 1996; Spender, 1996), el capital social permite a una empresa involucrada en una relación aprovechar el conocimiento de su compañero de intercambio. 


\section{El emprendimiento y las incubadoras bajo el enfoque del capital social}

Las investigaciones sobre emprendimiento y capital social se han ido incrementando a lo largo de los años, poniendo de manifiesto una relación entre ambas disciplinas (Hoang y Antoncic, 2003; Slotte-Kock y Coviello, 2010). La razón para ello la encontramos en que las ideas procedentes del capital social han sido aplicadas con éxito al ámbito del emprendimiento (Smeltzer et al., 1991; Lin y Steven, 2010; Comeche y Loras, 2010). Así pues, un número significativo de estudios en ese campo se ha centrado en las relaciones en redes, su estructura y mecanismos de gobernanza (Hoang y Antoncic, 2003). Es más, algunos autores han identificado al capital social como un tema clave en la literatura sobre emprendimiento (Fornoni et al., 2011).

Los emprendedores necesitan recursos de distinta índole. Además, tienen que enfrentarse a dificultades y trabas inherentes al carácter novel de su negocio y a su nueva condición profesional para acceder a ellos. Con frecuencia complementan sus recursos mediante el acceso a sus contactos (Aldrich y Zimmer, 1986; Aldrich et al., 1991; Cooper et al., 1995; Hansen, 1995). Los contactos que conducen a resultados exitosos son su capital social y constituyen un componente clave de las redes empresariales (Burt, 1992). Por tanto, y a tenor de lo expuesto, los nuevos emprendedores pueden desarrollar capital social como una estrategia que ayude a adquirir recursos clave para el desarrollo de sus negocios, tales como conocimiento (Yli-Renko et al., 2001). Las evidencias empíricas señalan que los emprendedores utilizan su capital social para acceder a recursos no de manera puntual, sino en cada una de las fases de proceso de establecimiento de sus negocios (Greve y Salaff, 2003). A este respecto, se pueden diferenciar tres fases claves (Wilken, 1979):

(1) Fase de motivación. El individuo discute su idea inicial y desarrolla el concepto de su negocio con sus contactos más próximos.

(2) Fase de planificación. El potencial emprendedor prepara la creación de su negocio. Para ello necesita conocimientos y recursos. La obtención de los mismos conlleva muchas actividades de distinta naturaleza (Zhao y Aram, 1995; Carter et al., 1996). Esta fase, dotada de incertidumbre, es la que más tiempo requiere para buscar y establecer relaciones (Hansen, 1995).

(3) Fase de establecimiento. El emprendedor establece la empresa. Dirige las actividades diarias y la resolución de problemas que van surgiendo. Debe hacer 
frente a numerosos contactos con diferentes agentes, y es precisamente en esta fase cuando desarrolla y potencia su capital social.

A lo largo de este proceso, la construcción de relaciones varía en función del número de contactos y del tiempo dedicado a la creación y al mantenimiento de las mismas, dependiendo de la fase en la que se encuentre el emprendedor (Greve y Salaff, 2003).

Centrándonos en el ámbito de la investigación que nos ocupa, las incubadoras de empresas, apreciamos que los trabajos que han tratado el capital social que se desarrolla en el ámbito de las incubadoras son de muy diversa índole. Como se observa en la Tabla 2.2., en la que se describen las investigaciones más relevantes que analizan el capital social en las incubadoras, abundan los estudios de casos, donde los datos se han recogido en un número reducido de incubadoras (Lyons, 2002; Bøllingtoft y Ulhøi, 2005; Tötterman y Sten, 2005; Ahmad, 2014), centrados en empresas tecnológicas (Scillitoe y Chakrabarti, 2005; Studdard, 2006; Hughes et al., 2007; Scillitoe y Chakrabarti, 2010; Hughes et al., 2011), y en países nórdicos y Estados Unidos (Lyons, 2002; Bøllingtoft y Ulhøi, 2005; Scillitoe y Chakrabarti, 2005; Tötterman y Sten, 2005; Studdard, 2006; Scillitoe y Chakrabarti, 2010). Solamente uno de ellos, el realizado por Tötterman y Sten (2005), considera el capital social de las incubadoras en sus tres dimensiones, pero ninguno diferencia entre el capital social del incubado y de la incubadora. 


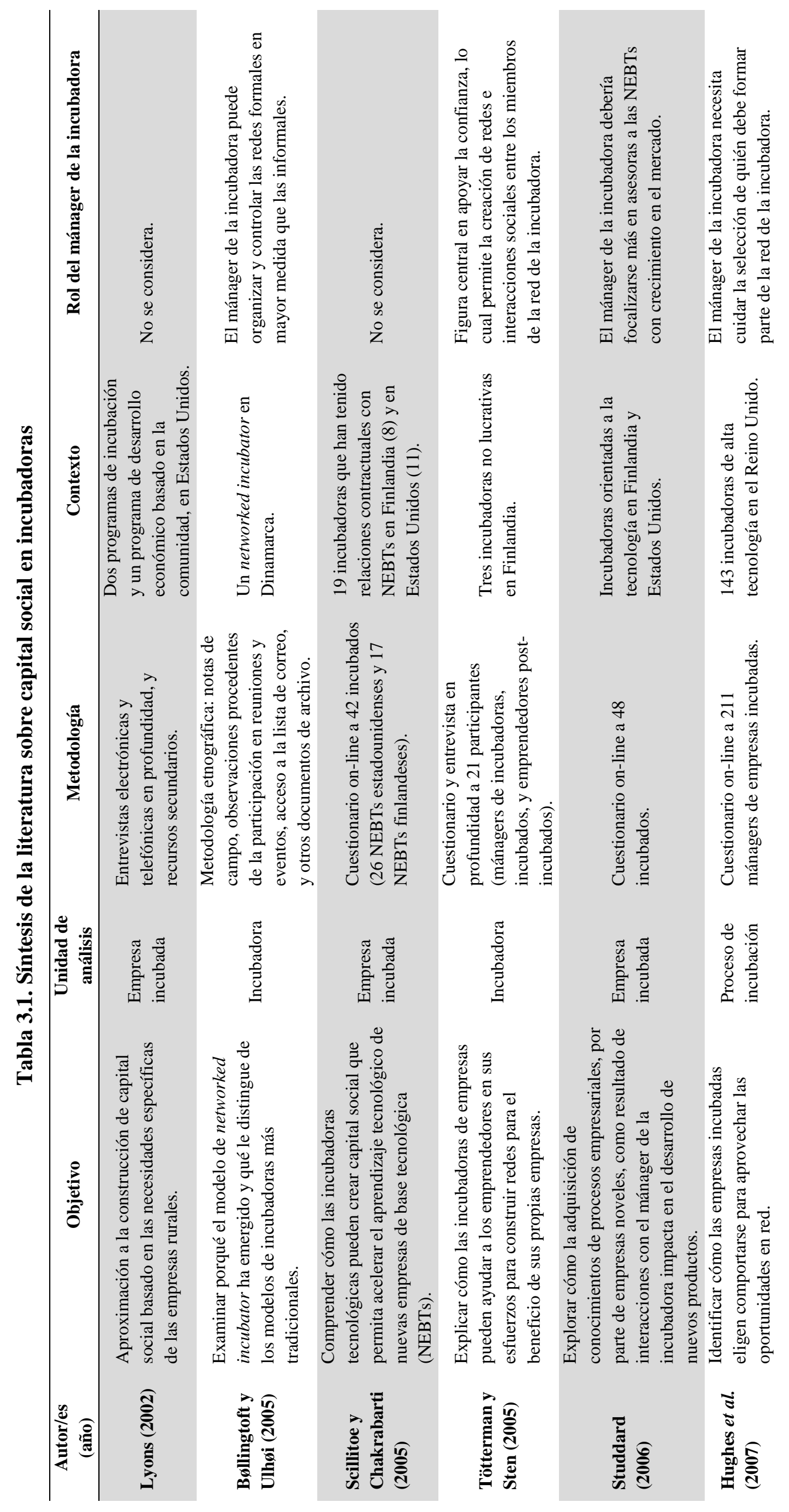




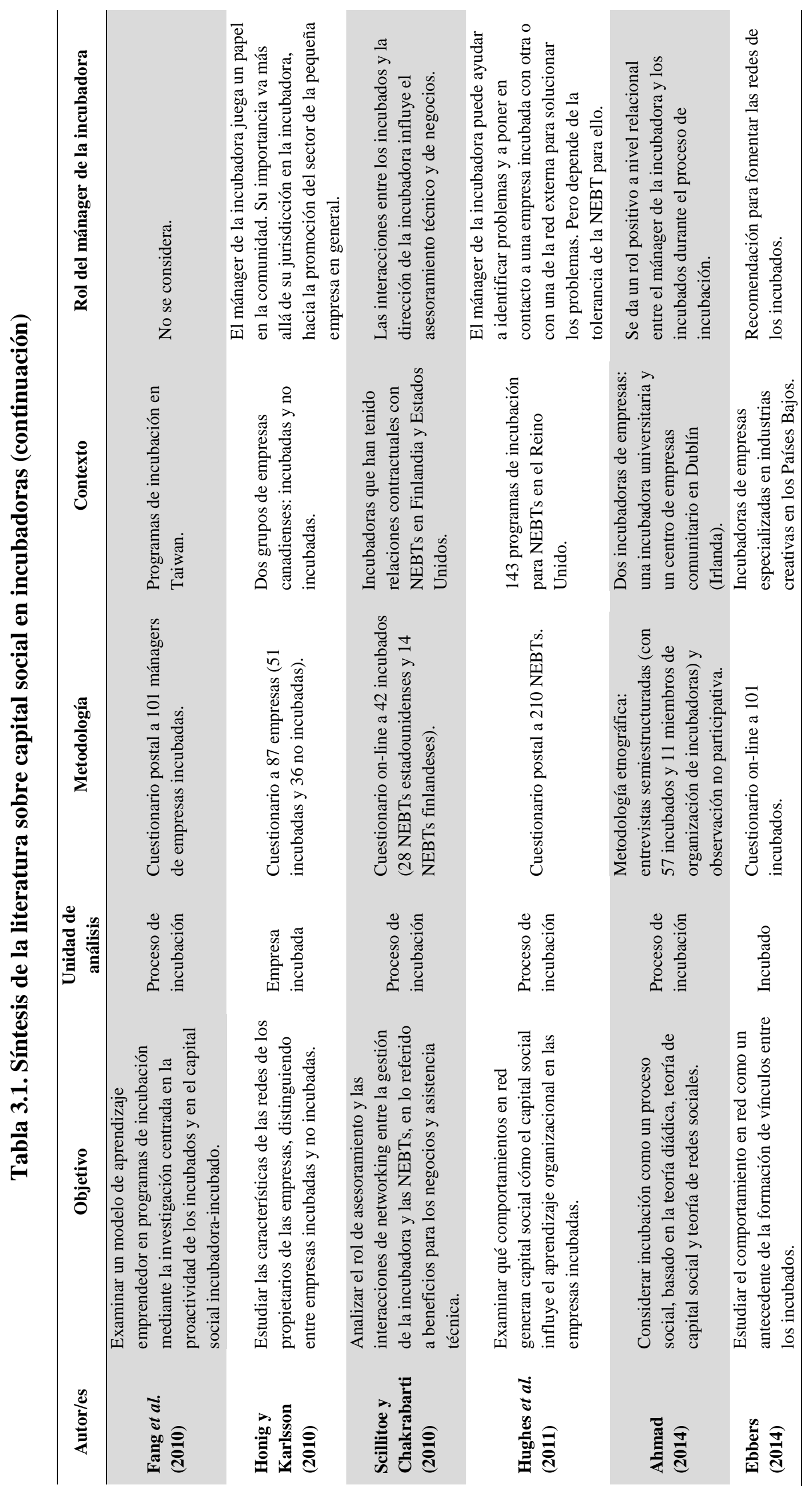


A la vista de lo expuesto con anterioridad, e inmersos en la tesis doctoral, el marco teórico de capital social nos permitirá responder diferentes cuestiones, entre las que se encuentran:

- ¿Cómo se pueden fomentar los contactos internos y externos de los emprendedores que están en incubadoras?

- ¿Cuál es la labor del mánager en la construcción del capital social de la incubadora y del incubado?

- ¿Cuál es la influencia del capital social interno de la incubadora en la formación del capital social propio del incubado y en el desarrollo de su negocio?

Adoptando el enfoque del capital social, en esta tesis explicaremos el papel de las incubadoras como espacios para el desarrollo de capital social interno (a nivel cognitivo y relacional) y analizaremos en qué medida el capital social interno de la incubadora favorece el desarrollo del capital social individual del incubado (a nivel estructural) y el desarrollo de su negocio.

\subsection{El papel del mánager en la creación de capital social}

Los mánagers pueden añadir valor al proceso de fomento y generación de relaciones en las incubadoras. Es más, la relación entre el mánager y los inquilinos es una de las variables que afecta directamente al éxito de los incubados (Fry, 1987; Udell, 1990; Autio y Kloftsen, 1998; Sherman, 1999; Rice, 2002). A pesar de ello, hay un número limitado de estudios en los que se analiza el rol del mánager como impulsor de relaciones dentro y/o fuera de la incubadora (Hansen et al., 2000; Rice, 2002; Hannon y Chaplin, 2003; Tötterman y Sten, 2005; Scillitoe y Chakrabarti, 2010; Cooper et al., 2012; Vedel y Gabarret, 2014).

Los estudios sobre incubadoras y capital social se han centrado en el funcionamiento de las relaciones dentro de las incubadoras (Lyons, 2002; Hughes et al., 2007), la comparación del capital social de incubados y no incubados (Honig y Karlsson, 2010) o el rol del mánager como asesor (Studdard, 2006; Scillitoe y Chakrabarti, 2010; Ahmad, 2014) y apoyo en la formación de vínculos entre los incubados y agentes externos (Bøllingtoft y Ulhøi, 2005; Tötterman y Sten, 2005). Ebbers (2014) también resalta la importancia de que el mánager fomente redes entre los incubados. Sin embargo, pese a 
que la literatura ha enfatizado la idea de que las incubadoras contribuyen al desarrollo de capital social, no existen trabajos que analicen empíricamente las relaciones causaefecto entre la labor del mánager como elemento central para el desarrollo de capital social ni la influencia del capital social colectivo en el capital social individual y en el éxito de los negocios incubados.

Aunque los contactos entre los mánagers y los inquilinos suelen ser infrecuentes (Honig y Karlsson, 2010), el interés por la faceta relacional del mánager y el reducido número de investigaciones desarrolladas nos lleva a explicar a continuación cómo y en qué medida la orientación relacional del mánager puede favorecer la creación y el desarrollo de diferentes dimensiones del capital social en la incubadora en pro de vínculos entre los incubados, y de éstos con agentes externos, y cómo todo ello, a su vez, permite mejorar la eficiencia de los negocios incubados.

\subsubsection{El capital social dentro de las incubadoras. Dimensiones e} interrelación

El capital social puede analizarse a nivel individual, cuando se refiere a un recurso privado de un individuo y que alude a las redes que él mismo ha creado en su propio beneficio, o a nivel colectivo, cuando se refiere a un recurso público, basado en comunidades y redes sociales de las que se benefician todos los miembros (Payne et al., 2011). En las UBIs los individuos tienen la posibilidad de desarrollar tanto su capital social individual, como la posibilidad de ser miembros de un grupo o un colectivo (incubados), y acceder así al capital social colectivo.

El capital social colectivo de una incubadora se deriva de vínculos internos entre los incubados, vínculos que se pueden caracterizar por las tres dimensiones previamente definidas (estructural, relacional y cognitivo). Si bien en el caso de las incubadoras universitarias, a nivel estructural, no existen diferencias relevantes entre ellas, ni en densidad (el número de incubados suele ser semejante en todas las incubadoras) ni en conectividad (puesto que comparten espacios, en todas las incubadoras todos los incubados tienen posibilidad de contactar entre sí).

Por otro lado, el capital social individual del incubado incluye tanto las relaciones que mantiene dentro de la incubadora como el acceso a redes y contactos en el exterior. De acuerdo con Lyons (2000), las redes internas y externas son fundamentales para los 
emprendedores que están en incubadoras, dado que les ayudan a tener acceso a redes de negocios. Para medir el capital social del incubado nos centramos en la estructura de su red de relaciones. Como ya se apuntó anteriormente, la estructura de una red ha sido asociada con dos tipos de conexiones: bonding y bridging (Granovetter, 1973; Putnam, 2000; Lee, 2009). Bajo el término bonding social capital se recogen relaciones estrechas, lazos fuertes entre individuos que se conocen bien, los cuales permiten el intercambio de recursos entre los mismos. Por su parte, bridging social capital hace referencia a lazos débiles, a contactos con otros grupos de personas con diferentes backgrounds, pero que pueden permitir el acceso a nuevos recursos.

A continuación procedemos a explicar las interrelaciones que pueden establecerse entre las distintas dimensiones de capital social en las incubadoras, y su influencia en la eficiencia de los negocios de los incubados.

\subsubsection{Capital social estructural del incubado}

El capital social estructural indica la configuración y estructura de las relaciones que se dan en una red. De acuerdo con la literatura de capital social (Granovetter, 1973; Burt, 1992), esta estructura se caracteriza por el capital social bonding, o cohesión entre sus miembros, y por el capital social bridging, o acceso y contacto con otras redes o grupos. En el caso de los incubados, las relaciones que establecen dentro de la incubadora les permitirán crear una red de relaciones que, siguiendo este planteamiento, caracterizaremos por el número de contactos estrechos con otros incubados (capital social bonding del incubado), y por el acceso que consiga a redes externas (capital social bridging del incubado).

El capital social bonding hace referencia a los lazos estrechos y a la cohesión que caracterizan a una red de relaciones, y al nivel de confianza mutua que facilita el intercambio y la acción colectiva (Putnam, 1995). De acuerdo con Coleman (1988), los miembros de una red cohesionada confían unos en otros, lo que disminuye la incertidumbre de los intercambios y permite la cooperación. El capital social bridging alude a los lazos débiles o "menos estrechos” que los individuos establecen con otros grupos y que les pueden brindar acceso a nuevas ideas, oportunidades o información (Putnam, 1995). Podríamos decir que es el capital social "puente" hacia nuevo conocimiento. 
La incubadora es un entorno que favorece el desarrollo de relaciones entre los incubados (Bøllingtoft y Ulhøi, 2005) y, por tanto, la adquisición de capital social bonding. Este capital social bonding del incubado, esto es, el grado en el cual él mantiene relaciones estrechas con otros miembros de la incubadora, es un recurso intangible cuyo valor radica en que permite el acceso de los incubados a diferentes recursos valiosos para su negocio difíciles de obtener por otra vía. En el caso de los incubados universitarios es evidente su necesidad de diversos recursos, como se ha mencionado con anterioridad, así como las dificultades y trabas para acceder a ellos derivado de su falta de expertirse en el mundo empresarial. Gracias a los contactos y relaciones que mantienen los incubados entre ellos, se produce un intercambio de información que permite mejorar sus habilidades empresariales y acceder a recursos.

El capital social bonding del incubado también permite el desarrollo de relaciones externas. La relación con otros incubados puede ser el "puente” para conectar con otras redes o grupos externos, es decir, acceder a capital social bridging. Otros emprendedores con una posición de brokerage (Burt, 2000) pueden actuar como agujeros estructurales (Burt, 1992) que conectan a un incubado con otros grupos. Entre los contactos y relaciones dentro de la incubadora, el emprendedor puede encontrar agujeros estructurales que le vinculen con otras redes y otros contactos, de los que pueden derivarse ventajas competitivas para sus incipientes negocios (Baron y Markman, 2000). Concretamente, esas interacciones podrán extenderse a potenciales clientes y socios que estén fuera de la incubadora (Bøllingtoft y Ulhøi, 2005). Por tanto, y considerando todo lo anterior, se enuncia la siguiente hipótesis:

H16: El capital social bonding del incubado influye positivamente en su capital social bridging.

En el contexto del emprendimiento, los emprendedores tendrán más posibilidades de éxito cuando tienen conexiones de negocios con otros emprendedores e instituciones diversas, tales como consultores y centros de información (Smilor y Gill, 1986). Las redes de relaciones de una empresa, y por extensión de un incubado, pueden abarcar relaciones con organizaciones, grupos de empresa, así como a otras personas que ayudan en el proceso de establecimiento de la empresa (Hansen, 1995).

En relación al caso de investigación que nos ocupa, los emprendedores académicos pueden tener acceso a redes externas empresariales a través de las UBIs en las que están 
ubicados, bien por los propios acuerdos de la UBI, los contactos del mánager o bien a través del contacto con otros incubados. Cuando el negocio es incipiente, y derivado de las dificultades a las que se enfrentan, puede que sea el único medio que los emprendedores tengan para acceder a esas redes, compuestas por profesionales de distinta índole, de las que pueden obtener beneficios para sus negocios. En definitiva, el acceso a capital social bridging permite a los emprendedores ser más eficientes y acceder a oportunidades de negocio privilegiadas (Batjargal, 2003; Baregheh et al., 2009; Toivonen y Tuominen, 2009; Abreu et al., 2010; Rubalcaba et al., 2010). Por ende:

H17: El capital social bonding del incubado - H17a - y el capital social bridging $\mathrm{H17b}$ - influyen positivamente en la eficiencia de su negocio.

\subsubsection{Capital social relacional de la incubadora}

Como ya se indicó en el epígrafe 3.4., el capital social relacional alude al grado en el cual dentro de una red existen relaciones fluidas entre los participantes. En concreto, Nahapiet y Ghoshal (1998) caracterizan el capital social relacional a partir del grado de confianza, normas comunes, obligaciones e identificación como grupo. En el contexto de los incubados, las relaciones que se pueden dar entre ellos no suelen implicar obligaciones (ni tácitas ni explicitas), pero sí puede surgir confianza entre ellos y generarse un sentimiento de identidad y normas de reciprocidad. Por tanto, nos centraremos con estas tres dimensiones (confianza, identificación y reciprocidad) como principales características del capital social relacional de una incubadora.

(1) La primera dimensión, la confianza, se refiere a la creencia de los individuos de una organización (una incubadora) en la buena fe y capacitación de la propia organización y de los miembros integrantes de la misma (incubados) (Nahapiet y Ghoshal, 1998; Leana y van Buren, 1999).

(2) La identificación, por su parte, es el proceso mediante el cual las personas se ven a sí mismas como uno, en relación a otra persona o a un grupo de personas determinado (Nahapiet y Ghoshal, 1998).

(3) Por último, la reciprocidad se refiere a las obligaciones mutuas que fomentan normas que facilitan la cooperación (Nahapiet y Ghoshal, 1998). Según Putnam (2000) existen dos tipos de reciprocidades. La reciprocidad es específica cuando uno hace algo 
por otro, si el otro le corresponde con otra acción. Por otra parte, el autor señala la reciprocidad generalizada, la cual se refiere a yo hago esto por ti, sin esperar de ti nada concreto, al menos por el momento.

\section{Interacción entre las dimensiones del capital social relacional}

Un elemento fundamental del capital social relacional es la confianza entre los miembros del grupo. En las incubadoras, la proximidad favorece la posibilidad de interactuar en el día a día, los contactos frecuentes (Lyons, 2000) y la generación de confianza entre los incubados (McAdam y Marlow, 2008). Esta confianza posee una relevancia considerable en un contexto en el que los emprendedores temen que las ideas y secretos sobre sus negocios puedan ser robados, tanto por otros incubados (McAdam y Marlow, 2007; Vanderstraeten y Matthyssens, 2012) como por expertos y/o consultores externos (Chan y Lau, 2005). De este modo, el hecho de que los incubados forjen relaciones dentro de la incubadora basadas en la confianza, fomenta la reciprocidad entre los incubados. En un entorno donde prima la confianza, los incubados estarán dispuestos a brindarse ayuda mutuamente porque el riesgo de oportunismo es menor. Por ello:

H18a: El capital social relacional en su dimensión confianza dentro de la incubadora influye positivamente en el capital social relacional en su dimensión reciprocidad.

La identificación como grupo es un sentimiento que puede nacer entre los inquilinos de la incubadora como consecuencia de la situación común que comparten. Hay que tener presente que los incubados de las UBIs, por norma general, no han trabajado fuera del entorno académico o, en caso de haberlo hecho, no durante un periodo de tiempo prolongado. Esto lleva a que se encuentren con diversas trabas en el desarrollo del ejercicio de su actividad empresarial, dado que no conocen cómo funciona el mercado en realidad. Puede que, incluso, algunos emprendedores académicos tengan cierta hostilidad o adversidad hacia ese escenario diferente y cargado de incertidumbre. Sin embargo, necesitan introducirse y competir en el mismo, dado que su futura trayectoria profesional depende de que lo hagan con éxito. Todo ello les lleva a identificarse como colectivo que comparte una misma idiosincrasia. Este sentimiento de grupo y de 
colectividad facilitará que los miembros estén dispuestos a ayudarse mutuamente y a que surja, dentro de la incubadora, una norma tácita de reciprocidad. Por tanto:

H18b: El capital social relacional en su dimensión identidad dentro de la incubadora influye positivamente en el capital social relacional en su dimensión reciprocidad.

\section{Influencia del capital social relacional dentro de la incubadora en el capital social estructural del incubado y en la eficiencia del negocio}

Los recursos y las oportunidades que ofrece una incubadora a sus inquilinos pueden ser tangibles o intangibles (Bøllingtoft y Ulhøi, 2005). Uno de esos intangibles son las relaciones entre los incubados. Centrándonos en el estudio que estamos desarrollando, el recurso más importante ofrecido por las incubadoras es la oportunidad de desarrollar relaciones de confianza, identidad y reciprocidad entre los inquilinos.

El hecho de que los incubados mantengan relaciones basadas en confianza, identidad y reciprocidad entre ellos hace que tengan su propio capital social bonding. Esto se traduce en que a nivel individual cada incubado tiene relaciones estrechas con otros emprendedores de la incubadora. Asimismo, lo anterior les habilita para el networking y para que puedan acceder a otras redes externas. Más concretamente, la confianza y la reciprocidad facilitan que estén dispuestos a poner su propia red de relaciones a disposición de otros incubados, de modo que estos últimos tengan así la posibilidad de crear su propio capital social bridging. Además, cuando dentro de la incubadora se dan relaciones de igual a igual entre los incubados y surge entre ellos un sentimiento de pertenencia e identificación como grupo (inquilinos de la misma UBI), es más fácil que adquieran seguridad en sí mismos y en su reciente condición de emprendedores, y que desarrollen habilidades sociales. Esta seguridad y habilidades les facilitarán desarrollar vínculos con otros agentes externos e iniciar relaciones comerciales en el mercado. En definitiva, crear su propio capital social bridging. Asimismo, y como ocurre con la confianza, la reciprocidad y la identificación como grupo facilita que los incubados pongan sus recursos relacionales a disposición del resto y se fomenten las relaciones externas.

Por otro lado, la confianza entre las partes favorece el intercambio de conocimiento (Tsai y Ghoshal, 1998; Levin y Cross, 2004). Los incubados intercambiarán conocimiento con aquellos miembros de la incubadora con los que tengan confianza, 
con lo beneficioso que supone para las partes implicadas y sus negocios. En esta misma línea, el desarrollo de capital relacional basado en la identidad y reciprocidad entre los incubados convierte a la UBI en un entorno amigable, agradable para el ejercicio de la actividad profesional, que puede llevar a que los emprendedores sean más eficientes en la gestión e implementación de actividades concretas de sus respectivos negocios.

Así pues, se proponen las hipótesis que a continuación se enuncian:

H19: El capital social relacional dentro de la incubadora -en sus dimensiones confianza (H19a), identidad (H19b) y reciprocidad (H19c)- influye positivamente en el capital social bonding.

H20: El capital social relacional dentro de la incubadora -en sus dimensiones confianza (H20a), identidad (H20b) y reciprocidad (H20c)- influye positivamente en el capital social bridging.

H21: El capital social relacional dentro de la incubadora -en sus dimensiones confianza (H21a), identidad (H21b) y reciprocidad (H21c)- influye positivamente en la eficiencia del negocio del incubado.

\subsubsection{Capital social cognitivo de la incubadora}

El capital social cognitivo se refiere a que los individuos que forman parte de una red compartan el mismo lenguaje, así como objetivos y una cultura común (Nahapiet y Ghoshal, 1998). Esto facilita los contactos y la comunicación entre los implicados, dificultándolo en el caso contrario. Así, cuando los individuos no comparten el mismo vocabulario o lenguaje se dificulta el entendimiento entre las partes (Reagans y McEvily, 2003).

Las UBIs son entornos favorables a la formación de capital social cognitivo. Las razones para ello, las cuales enunciamos a continuación, se hallan en características específicas de los inquilinos que se alojan en las citadas UBIs.

(1) Tienen una procedencia común: la universidad. Aunque su vinculación con la misma difiere de unos a otros, desde egresados a profesores e investigadores.

(2) Poseen una falta de experiencia generalizada en el mundo empresarial.

(3) Comparten un objetivo similar: poner en marcha un negocio en el mismo momento de tiempo. 
Sin embargo, también es probable que haya diferencias entre ellos porque el grupo de incubados tiene un carácter "híbrido", debido a que puede conjugar perfiles académicos dispares (distintas áreas de conocimiento, diferente trayectoria investigadora y/o diferencias en la experiencia de gestión, entre otros aspectos).

En la medida en que dentro de la incubadora se favorece un sentimiento de pertenencia e identidad entre los inquilinos, se estará formando un capital social cognitivo que favorece que fluya un buen entendimiento y comunicación entre los incubados. Esto, unido a contactos frecuentes en el ambiente protegido en incubación frente al exterior, puede fomentar un clima de confianza. Por consiguiente, se propone la siguiente hipótesis:

H22: El capital social cognitivo dentro de la incubadora influye positivamente en el capital social relacional en sus dimensiones confianza (H22a), identidad (H22b), y reciprocidad (H22c).

\subsubsection{Orientación relacional del mánager}

En una incubadora es fundamental la labor del mánager como impulsor de relaciones y redes, tanto de las relaciones individuales que crean los incubados, como de la consolidación de un capital social colectivo del que se benefician todos los incubados. Sin embargo, el comportamiento de los mánagers es dispar a este respecto. Podemos caracterizar a los mánagers en función de su orientación relacional, entendiendo como tal la predisposición y tendencia a fomentar contactos entre los incubados, así como contactos con agentes fuera de la incubadora. Algunos tienen una baja orientación relacional y tienden a desempeñar un papel más pasivo, como gatekeepers, mientras otros manifiestan una mayor orientación relacional, lo cual les lleva a desempeñar un papel activo como intermediarios, facilitando contactos entre incubados y otros agentes como asesores, mentores, académicos e inversores (Lewis et al., 2011; UKBI, 2012).

En las UBIs todos los inquilinos tienen vinculación con la universidad y sus empresas son intensivas en conocimiento. Asimismo, comparten inquietudes y pretensiones inherentes a su condición de emprendedores noveles. Los mánagers tienen constancia de esta procedencia y anhelos comunes, que pueden configurar las bases sobre las que se cimiente el capital social cognitivo en las UBIs. Sin embargo, cada individuo, y por ende, cada negocio tiene sus propios objetivos. Esto no es incompatible con objetivos 
colectivos. Por ello, si no hay personas o mecanismos que velen por el interés conjunto del grupo de incubados, que promuevan una cultura y unos objetivos comunes, no se podrá crear el citado capital social cognitivo. El mánager debiera proyectarse como una bisagra, como el eje vertebrador de la incubadora que fomente objetivos comunes y relevantes a nivel empresarial para los inquilinos, lo cual repercutirá en el éxito de la incubadora en su conjunto y de los incubados, en particular. Derivado de lo anterior, se propone la siguiente hipótesis:

H23: La orientación relacional del mánager influye positivamente en el capital social cognitivo.

Las incubadoras y sus redes internas son especialmente útiles para construir capital social relacional. El capital social relacional puede surgir por el simple hecho de compartir el mismo espacio físico. Más concretamente, Tötterman y Sten (2005) señalan que los incubados ven como los contactos entre ellos se ven favorecidos por compartir necesidades similares y espacio físico. Algunos autores entienden que la acción del mánager no es una condición necesaria para que se creen relaciones, porque existe una tendencia natural de los incubados a colaborar entre sí (Bøllingtoft, 2012).

No obstante, junto a este rasgo inherente a una incubadora, la orientación relacional del mánager también puede estimular la reciprocidad y la puesta en común de recursos, lo cual elimina barreras de acceso y disponibilidad (Lyons, 2000, 2002). Para que puedan fluir y se puedan optimizar las relaciones en las incubadoras, los mánagers resaltan la importancia de que los incubados tengan una predisposición a implicarse en las distintas actividades que organizan y a actuar de manera recíproca (Vanderstraeten y Matthyssens, 2012). Asimismo, los mánagers son agentes que articulan y fomentan redes e interacciones sociales, basadas en confianza, entre los miembros de la incubadora (Tötterman y Sten, 2005). Así pues, la orientación relacional del mánager puede favorecer relaciones cordiales entre los incubados, la generación de un clima de confianza, así como la reciprocidad y el sentimiento de comunidad entre ellos. Por lo tanto, se plantean las siguientes hipótesis: 
H24: La orientación relacional del mánager influye positivamente en el capital social relacional en sus dimensiones confianza (H24a), identidad (H24b) y reciprocidad (H24c).

Los mánagers pueden estimular la frecuencia de los contactos y la cooperación entre los incubados a través de la oferta de actividades interactivas tales como talleres, conferencias y eventos de networking para los incubados (Chan y Lau, 2005) y del esfuerzo por crear un buen ambiente de trabajo y confianza (Tamásy, 2002). Este último aspecto es fundamental dado que los incubados temen que sus ideas y secretos de negocio puedan ser robados por otros individuos que estén en la incubadora (McAdam y Marlow, 2007; Vanderstraeten y Matthyssens, 2012). Como ya hemos indicado, todo ello favorece el capital social relacional dentro de la incubadora, pero también la posibilidad de que cada incubado, a nivel particular, cree lazos estrechos y duraderos con otros incubados.

De lo anterior se desprende la siguiente hipótesis:

H25: La orientación relacional del mánager influye positivamente en el desarrollo de capital social bonding del incubado.

En la presente tesis doctoral, los individuos objeto de estudio provienen del ámbito universitario y están orientados a la ciencia. Pero han comenzado una aventura empresarial que les llevará a estar inmersos en el mundo de los negocios. Así pues, necesitan orientarse al mercado, así como acceder y formar parte de redes empresariales, y no sólo mantener sus redes en el mundo académico (Redondo Carretero et al., 2014). Así pues, los emprendedores universitarios necesitan introducirse en redes empresariales externas y, de nuevo, el mánager puede actuar de enlace entre los incubados y aquellas redes externas útiles y necesarias para sus negocios. De esta forma, el mánager se convierte así en un agujero estructural (Burt, 1992) que pone en contacto a los incubados con otros agentes externos. A través del mánager o el equipo de dirección de la incubadora, los incubados pueden iniciar contactos con consultores, entidades financieras o profesionales de diferentes industrias (Bøllingtoft y Ulhøi, 2005; Buche y Scillitoe, 2007). Además, dado que los mánagers pueden tener experiencia, incluyendo experiencia previa en el ámbito de las incubadoras o a nivel profesional (Hannon, 2005), pueden traer consigo una variedad de contactos 
del mundo de los negocios y ponerlos a disposición de los incubados (Vanderstraeten y Matthyssens, 2012). Por lo tanto:

H26: La orientación relacional del mánager influye positivamente en el desarrollo de capital social bridging del incubado.

\subsubsection{Propuesta de un modelo explicativo de capital social y eficiencia}

\section{en los negocios de los incubados}

Por último, las hipótesis H16 a H26 configuran el tercer modelo, Modelo 3, propuesto en la presente tesis doctoral. Este modelo se ha planteado para analizar el efecto que la orientación relacional del mánager puede tener sobre la creación y el fomento de las diferentes dimensiones de capital social dentro de la incubadora, la interrelación entre ellas, así como sobre la eficiencia de los negocios incubados. Para mayor nivel de detalle, se puede consultar la Figura 3.2., en la que se recoge el modelo planteado y las hipótesis propuestas.

Figura 3.2. Propuesta de Modelo 3. Capital social y eficiencia en incubadoras

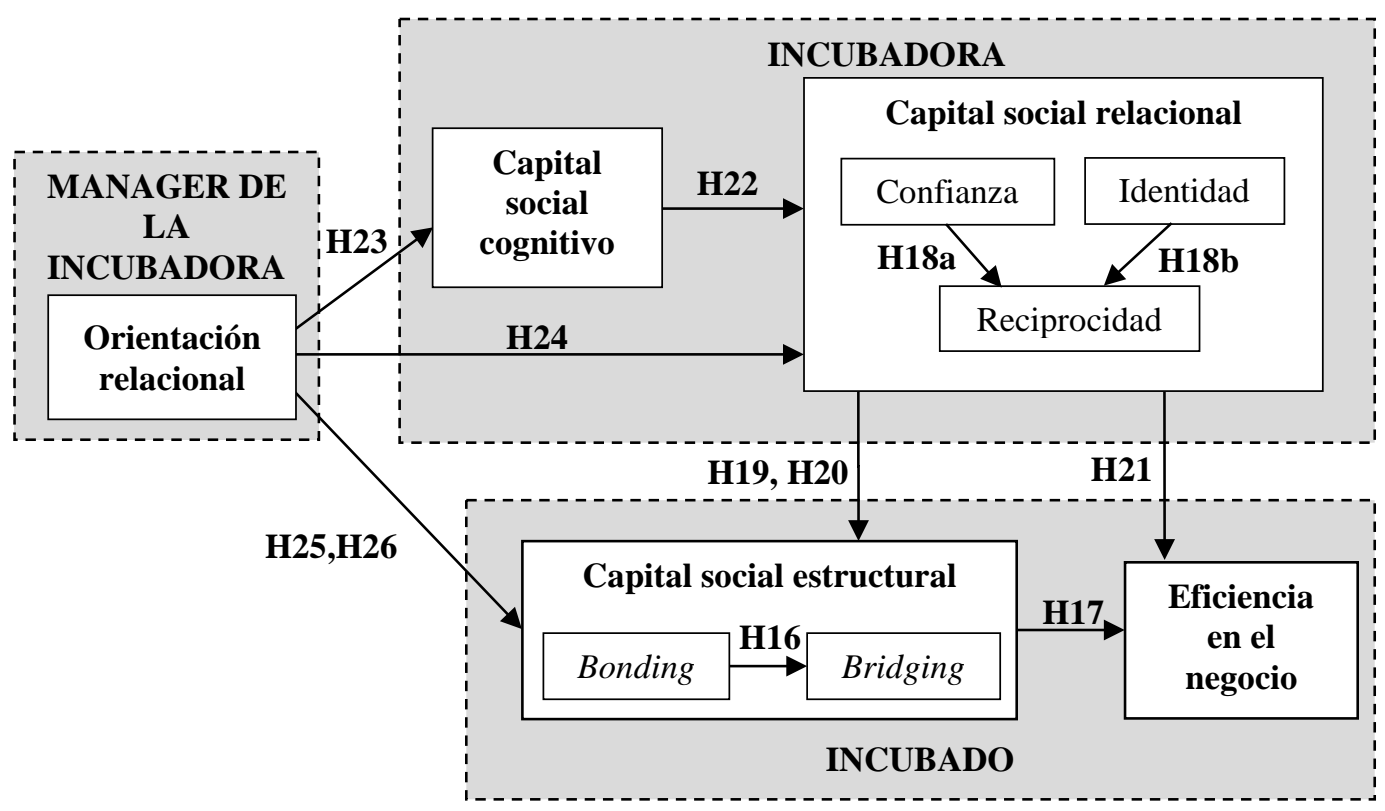




\section{Capítulo 4. Methodology and research design: data collection and analysis}





\subsection{Introduction}

The synthesis of the proposed global model in this doctoral dissertation is shown in Figure 4.1 and the set of proposed hypotheses, structured by research objectives, is shown in Table 4.1.

Figure 4.1. Proposed global model. Dyadic and network relationship in incubators

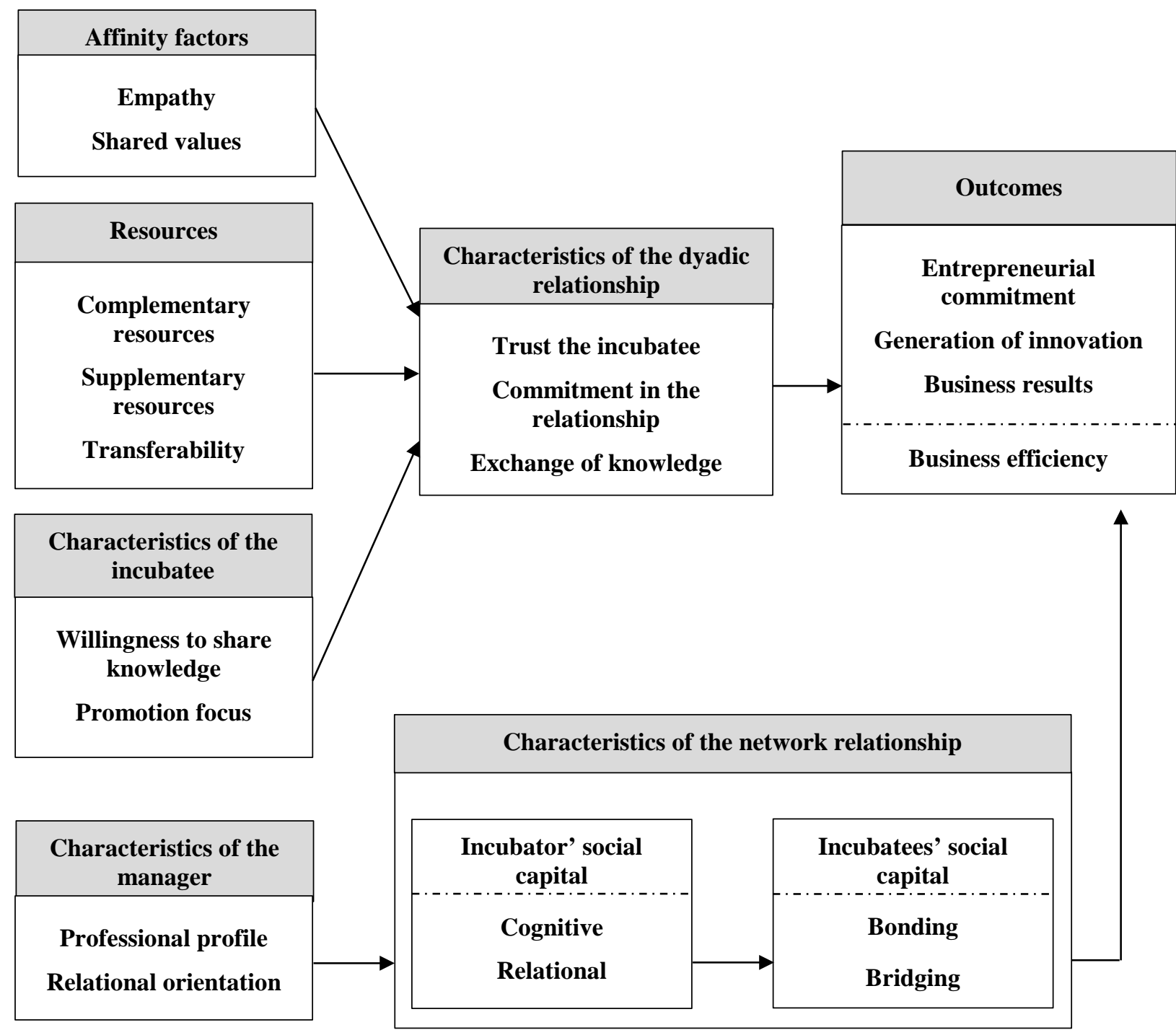


Table 4.1. Set of proposed hypotheses

\begin{tabular}{|c|c|c|c|}
\hline \multicolumn{2}{|c|}{ Research objectives } & \multicolumn{2}{|c|}{ Hypotheses } \\
\hline \multirow{2}{*}{ 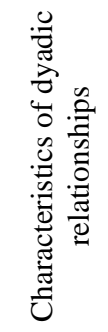 } & $\underset{\Xi}{\stackrel{\Xi}{\Xi}}$ & H1: & Trust between incubatees has a positive influence on exchange of knowledge \\
\hline & $\begin{array}{l}\overrightarrow{0} \\
\stackrel{0}{0} \\
ن\end{array}$ & H2: & $\begin{array}{l}\text { Exchange of knowledge between incubatees has a positive influence on the } \\
\text { commitment in the relationship }\end{array}$ \\
\hline \multirow{10}{*}{ 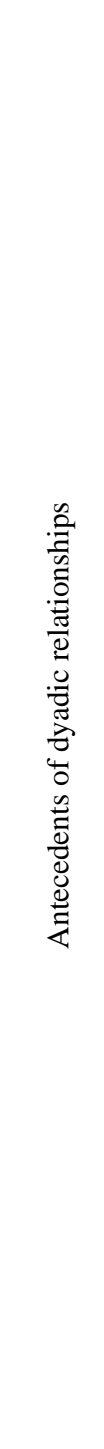 } & \multirow{2}{*}{ 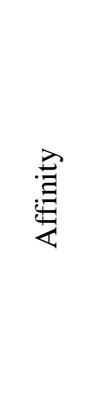 } & HЗа: & $\begin{array}{l}\text { Incubatee empathy towards other incubatees has a positive influence on } \\
\text { confidence in the other party } \\
\text { Incubatee empathy towards other incubatees has a positive influence on } \\
\text { commitment in the relationship }\end{array}$ \\
\hline & & H4b: & $\begin{array}{l}\text { Incubatee perception of shared values with other incubatees has a positive } \\
\text { influence on confidence in the other party } \\
\text { Incubatee perception of shared values with other incubatees has a positive } \\
\text { influence on commitment in the relationship }\end{array}$ \\
\hline & \multirow{5}{*}{ 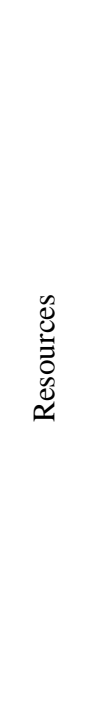 } & H5b: & $\begin{array}{l}\text { Incubatee perception of complementary resources with other incubatees has a } \\
\text { positive influence on confidence in the other party } \\
\text { Incubatee perception of complementary resources with other incubatees has a } \\
\text { positive influence on commitment in the relationship } \\
\text { Incubatee perception of complementary resources with other incubatees has a } \\
\text { positive influence on exchange of knowledge }\end{array}$ \\
\hline & & H6a: & $\begin{array}{l}\text { Incubatee perception of supplementary resources with other incubatees has a } \\
\text { positive influence on confidence in the other party }\end{array}$ \\
\hline & & H6b: & $\begin{array}{l}\text { Incubatee perception of supplementary resources with other incubatees has a } \\
\text { positive influence on commitment in the relationship }\end{array}$ \\
\hline & & H6c: & $\begin{array}{l}\text { Incubatee perception of supplementary resources with other incubatees has a } \\
\text { positive influence on exchange of knowledge }\end{array}$ \\
\hline & & H7: & $\begin{array}{l}\text { Transferability of knowledge has a positive influence on exchange of knowledge } \\
\text { between incubatees }\end{array}$ \\
\hline & \multirow{3}{*}{ 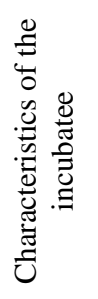 } & H8: & $\begin{array}{l}\text { Incubatee willingness to share knowledge has a positive influence on exchange of } \\
\text { knowledge with other incubatees }\end{array}$ \\
\hline & & H9a: & $\begin{array}{l}\text { Incubatee promotion focus has a positive influence on willingness to share } \\
\text { knowledge }\end{array}$ \\
\hline & & H9b: & $\begin{array}{l}\text { Incubatee promotion focus has a positive influence on exchange of knowledge } \\
\text { with other incubatees }\end{array}$ \\
\hline
\end{tabular}


Table 4.1. Set of proposed hypotheses (II)

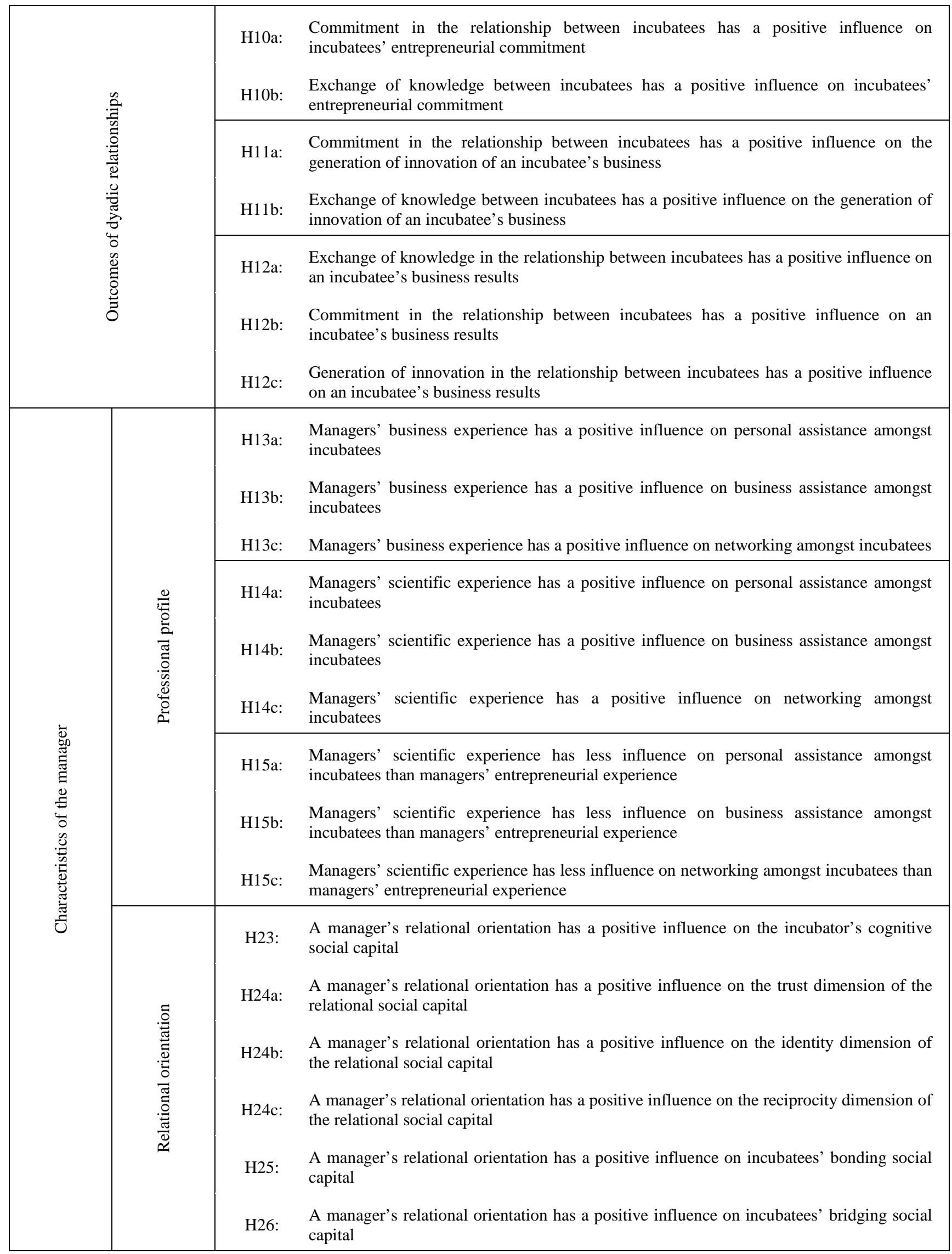


Table 4.1. Set of proposed hypotheses (III)

\begin{tabular}{|c|c|c|c|}
\hline \multirow{9}{*}{ 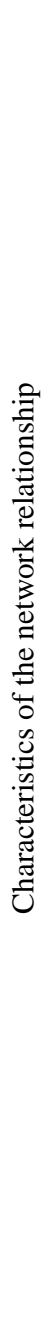 } & 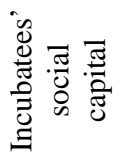 & H16: & $\begin{array}{l}\text { Incubatees' bonding social capital has a positive influence on bridging social } \\
\text { capital }\end{array}$ \\
\hline & \multirow{8}{*}{ 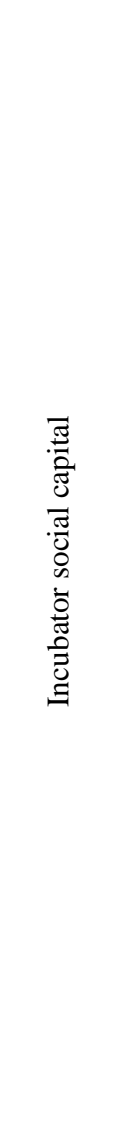 } & H18a: & $\begin{array}{l}\text { The trust dimension of the incubator's relational social capital has a positive } \\
\text { influence on the reciprocity dimension } \\
\text { The identity dimension of the incubator's relational social capital has a positive } \\
\text { influence on the reciprocity dimension }\end{array}$ \\
\hline & & H19c: & $\begin{array}{l}\text { The trust dimension of the incubator's relational social capital has a positive } \\
\text { influence on bonding social capital } \\
\text { The identity dimension of the incubator's relational social capital has a positive } \\
\text { influence on bonding social capital } \\
\text { The reciprocity dimension of the incubator's relational social capital has a positive } \\
\text { influence on bonding social capital }\end{array}$ \\
\hline & & H20a: & $\begin{array}{l}\text { The trust dimension of the incubator's relational social capital has a positive } \\
\text { influence on bridging social capital }\end{array}$ \\
\hline & & H20b: & $\begin{array}{l}\text { The identity dimension of the incubator's relational social capital has a positive } \\
\text { influence on bridging social capital }\end{array}$ \\
\hline & & H20c: & $\begin{array}{l}\text { The reciprocity dimension of the incubator's relational social capital has a positive } \\
\text { influence on bridging social capital }\end{array}$ \\
\hline & & H22a: & $\begin{array}{l}\text { The incubator's cognitive social capital has a positive influence on the trust } \\
\text { dimension of the relational social capital }\end{array}$ \\
\hline & & H22b: & $\begin{array}{l}\text { The incubator's cognitive social capital has a positive influence on the identity } \\
\text { dimension of the relational social capital }\end{array}$ \\
\hline & & H22c: & $\begin{array}{l}\text { The incubator's cognitive social capital has a positive influence on the reciprocity } \\
\text { dimension of the relational social capital }\end{array}$ \\
\hline \multirow{5}{*}{ 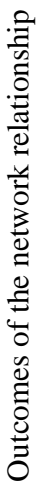 } & \multirow{5}{*}{ 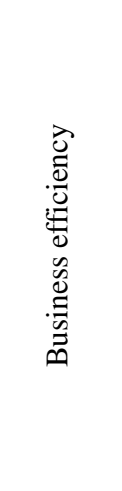 } & H17a: & Incubatees’ bonding social capital has a positive influence on business efficiency \\
\hline & & H17b: & Incubatees’ bridging social capital has a positive influence on business efficiency \\
\hline & & H21a: & $\begin{array}{l}\text { The trust dimension of the incubator's relational social capital has a positive } \\
\text { influence on incubatees' business efficiency }\end{array}$ \\
\hline & & H21b: & $\begin{array}{l}\text { The identity dimension of the incubator's relational social capital has a positive } \\
\text { influence on incubatees' business efficiency }\end{array}$ \\
\hline & & H21c: & $\begin{array}{l}\text { The reciprocity dimension of the incubator's relational social capital has a positive } \\
\text { influence on incubatees' business efficiency }\end{array}$ \\
\hline
\end{tabular}

Empirical testing of the hypotheses proposed was carried out using three different studies.

Study I aims to assess the relevance and consistency of the proposed variables and hypotheses ( $\mathrm{H} 1$ to $\mathrm{H} 6$ ), concerning antecedents and consequences of relations between incubatees, in order to draw initial conclusions. To this end, we conducted an 
exploratory qualitative analysis based on semi-structured interviews with entrepreneurs located in Spanish Business Innovation Centres (BICs).

Study II aims to explore the antecedents which favour relations between incubatees and the consequences of these relations through a quantitative comparison of hypotheses $\mathrm{H} 1$ to H12, which make up Model 1, dealt with in chapter 2. To achieve this, we follow the sequence of analysis set out below and which will be explained throughout this chapter, using PLS-SEM (Partial Least Squares-Structural Equation Modelling) as an estimation procedure. First, a description is provided of the variables measured in the study, and an explanation is given of the process used to validate the scales of the various constructs. The results to emerge from estimating the structural model are then presented as are the indirect and total effects. Finally, a robustness analysis is included and the results to come out of the hypotheses posited are evaluated.

Study III seeks to gauge the extent to which the manager influences the business and relational skills developed by incubatees, set out in Models 2 and 3, and explained in chapter 3. This study is divided into two parts. Study III.1 explores how the manager's professional profile may shape the type of services offered to incubator tenants. Specifically, a quantitative comparison is made of hypotheses H13, H14 and H15 (Model 2). Finally, Study III.2 aims to provide insights into the influence of an incubators' internal social capital in developing incubatees' individual social capital and the efficiency of their businesses as well as the role of the incubator manager in building incubator and incubatee social capital. In this study, we quantitatively test hypotheses H16 to H26 (Model 3). The estimation process followed is similar to Study II.

In order to estimate Models 1, 2 and 3, information was gathered from UBIs located in Spain and the Netherlands. Specifically, for Studies II and III.2, information collected through a questionnaire aimed at incubatees was used, whereas for Study III.1 information was provided by UBI managers. In order to identify possible differences between incubatees and managers in the two countries, a test was carried out to check for the possible existence of a different response pattern for the indicators used. This was done by conducting a homogeneity analysis of the samples employed (Spanish and Dutch incubatees) through a $t$ test for independent samples. 


\subsection{Study I. Relationships between entrepreneurs in BICs. An exploratory case study}

This section explains how Study I was developed in order to achieve the objective described above, and to evaluate the relevance of hypotheses H1 to H6. First, we describe the data collection process as well as the analysis technique used. We then explain the detailed case study analysis, and conclude with a summary of the main results.

\subsubsection{Methodology}

Case study based research is one of the most frequently used methodological tools in the area of qualitative research. Case studies allow for descriptions and provide for explanations or interpretations of the phenomenon being investigated, permitting the nature and function thereof to be explored and evaluations to be made (Merriam, 1988; Yin, 2009). Yin (2009), a seminal reference in the field of case studies, points out that one of the main biases linked to case studies is that their conclusions are not statistically generalizable. However, the purpose of such a research tool is to understand the interaction between the various parts involved in a system and to gain key insights into it, such that the analysis carried out may be applied generically (Hartley, 1994) even when based on a single case. More than establishing correlations or cause and effect relations (Gummesson, 2000), an understanding may therefore be gained of the processes, structure, and driving forces involved.

\subsubsection{Data Collection}

Literature on business incubators has considered four levels of analysis: incubators themselves, firms located in incubators, entrepreneurs, and entrepreneurial teams of entrepreneurs involved in these firms and at a systemic level (Phan et al., 2005). In the present study, the unit of analysis is the entrepreneur, and we analyze nine such cases. Prior to selection, we chose two Spanish BICs, which form part of the Chamber for Business Creation and Development (INCYDE) network of incubators ${ }^{12}$. This agency, in conjunction with Chambers of Commerce and Industry as well as local public agencies, and European Union ERDF funds, has set up in Spain the largest network of incubators in Europe, with a total of 96 currently operating. The incubators in the

\footnotetext{
${ }^{12}$ See www.incyde.org/viveros-empresas.aspx
} 
INCYDE network provide entrepreneurs with access to ideally priced office space under favourable terms and conditions when they embark on their business activity. Some incubators also boast specific buildings where certain industrial activities may be conducted in addition to the offices which are used more for services. Entrepreneurs can also benefit from services which offer guidance and training in business creation and management, internationalization, quality management, environmental issues, occupational health and safety, as well as legal advice offered through the corresponding provincial Chamber of Commerce and Industry. The services offered through the INCYDE network are available to newly created firms who put forward a financially viable project, who have undergone a self-employment or business creation training programme or who commit to doing so, and whose business address is registered in the province in which the incubator in question is located.

One final point worth highlighting is that the INCYDE network does not envisage any particular formal action plan to promote or foster relationships. Individual incubator managers may opt to undertake action in this matter at their own initiative. Therefore, any relationships which emerge between entrepreneurs are informal and brought about or actively sought by themselves.

From a perspective focused more on understanding rather than on verification, we opted to conduct the empirical work on the basis of an exploratory study of multiple cases, grounded on the experience of nine entrepreneurs, selection of whom was based on the following criteria: entrepreneurs had commenced their business activity in one of the incubators involved in the INCYDE network at least two years prior to the interview and had had at least one cooperation experience with another company in the same incubator with the idea of continuing (since the study seeks to investigate relationships, not transactions). Eisenhardt (1989) suggests that between four and ten cases is an appropriate number for a case study, contending that the larger the number of units studied the greater the reliability that can be achieved. Voss et al., (2002) hold that there is no optimal number, but rather that the cases chosen should embrace the range of possible situations. Therefore, we chose cases that represent different driving forces at the start of a relationship as well as different features related to maintaining the relationships. In order to access appropriate entrepreneurs, we contacted the managers of two incubators, in an effort to explain to them the goal of our research and to request their cooperation in the selection process. We were provided with a list of the contact 
details of the firms housed in the incubators at that time as well as of some who had just left. We telephoned all of them, and found that seven incubator tenants fulfilled all the criteria required to take part in the research, together with a further two entrepreneurs who had recently left.

These nine cases were representative of typical entrepreneurs and provided us with the opportunity to show both similarities and differences in business relationship experiences. The nine entrepreneurs taking part belonged to BICs in the INCYDE network, all of them having set up there between December 2006 and January 2008. All of the entrepreneurs shared a series of common traits, namely that they had completed a university education related to the business activity in which they were engaged, and described themselves as restless and determined to consolidate their position in the field in which they were involved. There were, however, differences with regard to the number of members (there are five single-person firms), in terms of gender (two women as opposed to seven men), and as regards age, which ranged from 28 to 52 years of age. As for the reasons why they had decided to become entrepreneurs, some described themselves as entrepreneurs whereas others referred to themselves as continuers, the loss of their job as salaried workers having triggered their decision to set up their own business. The entrepreneurs' business activities are summarized in Table 4.2.

Table 4.2. Sampling of interviewees.

\begin{tabular}{cll}
\hline Label & \multicolumn{1}{c}{ Business activity } & \multicolumn{1}{c}{$\begin{array}{c}\text { Date they set up in } \\
\text { the BIC }\end{array}$} \\
\hline E1 & Services related to boilers, heating and cooling equipment & December 2006 \\
E2 & Consulting services: projects in innovation and development & December 2006 \\
E3 & Developing customised software & February 2006 \\
E4 & Consulting services: market studies and marketing plans & April 2006 \\
E5 & Advertising agency focusing on the Internet & April 2008 \\
E6 & Human resources: training, management skills and selection process & January 2005 \\
E7 & Engineering projects and consulting & April 2008 \\
E8 & Programming and specializing in webpage design & June 2007 \\
E9 & Computer sales, repair and maintenance & January 2008 \\
\hline
\end{tabular}

In order to gather data, we conducted an interview with each of the nine entrepreneurs between February and March 2010. The interviews were held in their own offices, and each lasted 45-60 minutes. We used a semi-structured interview, following a script comprising the following themes: (1) first cooperation experience with another incubator tenant, (2) a description of the business relationships that had commenced in the incubator, were still going strong, and which the entrepreneurs intended to pursue in 
the future; and (3) a failed cooperation experience with an incubator tenant (if there had been one).

In February 2012, we again telephoned the nine entrepreneurs in order to ascertain the continuity or otherwise of the relationships about which they had initially been asked. In all instances, we were assured that relationships remained ongoing. We did this in order to expand the horizon of inquiry. If a relationship had broken down, the entrepreneur would have been asked about the causes, specifically, whether it had been related to the fact that the entrepreneurs were no longer in the incubator.

\subsubsection{Data analysis techniques}

We followed certain case study techniques in order to increase research reliability and validity (Riege, 2003; Yin, 2009). We first attempted to refine the case study protocol so as to ensure reliability. All the interviews were recorded and later transcribed verbatim to guarantee accuracy of the information. We also used the same study protocol for each case, again so as to ensure the empirical validity of the information. Second, in order to ensure construct validity, in addition to semi-structured interviews, we collected certain data about the entrepreneurs (features in contacts between them) from incubator managers. Data from these sources were triangulated to enhance information credibility. Third, to increase internal validity, the transcripts and notes were read by the researchers and data were organized and catalogued in a database around topics and central questions. Data was then carefully examined to see how it fitted or failed to fit the expected categories or variables that define the drivers and characteristics of relational exchange. Finally, external validity was ensured using several case studies (nine entrepreneurs) and comparing the evidence with the extant literature.

According to Langley and Royer (2006), in multiple case studies, it is essential to determine similarities or differences between the cases being studied. In our research, although all cases were initially treated similarly, only four of the nine entrepreneurs had had failed experiences with another incubator tenant, and so we only explored this question in these cases. Following these premises, below we describe the outcomes of the interviews. 


\subsubsection{Case study analysis}

Case study analysis was structured into three parts: relationship drivers, mechanisms of relational exchange, and relationship outcomes.

\subsubsection{Relationship drivers}

The starting point in the interviews was the reasons that led entrepreneurs located in the same incubator to cooperate with another. Through this, we sought to evaluate the relevance of the variables and the pertinence of hypotheses $\mathrm{H} 3$ to H6.

Empathy, not only as a result of being entrepreneurs but also due to having started out in the business incubator, was highlighted by five entrepreneurs. Sharing common values, complementarity, personal attention and a professional approach are the traits cited by various entrepreneurs to define the relationships with other companies that are, or in most cases were, incubator tenants. Other variables cited were specialization, sharing a common focus toward the client, flexibility in each task, a specific knowledge of the particular working philosophy.

The results of this part of the interviews are organized according to six key aspects: (1) empathy; (2) solidarity and common awareness; (3) shared values; (4) complementarity; (5) linking-persons; (6) proximity and time-saving.

Empathy. In several cases, the interviewees highlighted how much they were aware of being entrepreneurs and empathy as key factors in sparking the relation.

Entrepreneur 1 provides a wide range of services related to boilers as well as heating and cooling equipment, with two other partners. He describes themselves not as entrepreneurs in the strict sense of the word but as continuers. From the moment they entered the incubator, they had a clear idea that when the need for anything arose they would seek the help of another entrepreneur in the incubator rather than resort to an outside firm. One of the members put it in these terms:

We've worked with other people in the incubator (...). Rather than seeking the help of another firm that offers the same services as me, they asked me to do it. And I, since we were here, rather than asking another firm who could do the same job, because we know that we're all entrepreneurs and we're all just starting out, and we know each other and are all in the same boat, well, we have to help each other out. 
This meant that one of their earliest business needs, namely website and server maintenance as well as the supply of computer consumables, was met by an incubator tenant, giving rise to their first experience of cooperation.

Empathy, but more specifically the awareness that they were entrepreneurs at the same time and in the same place, was the main factor that led Entrepreneur 2 to seek an advisory service amongst the entrepreneurs located in the incubator when they moved in. However, there were two entrepreneurs offering the same service, and so the choice was made based on the following:

The first thing we did was to speak to the incubator manager who told us about the two contacts. We then spoke to both and finally decided on one. The main advantage we saw at the beginning, and indeed we still see, is that the people were in the same situation as us and had recently been through the same experience as us (...) It was a direct experience. That was also one of the reasons that led us to decide, apart from the fact that they offered us a good price. You could say that at first, in order to get yourself customers, you have to charge less.

Solidarity and common awareness. As soon as they needed computer services, Entrepreneur 7, who works in the area of engineering projects and consulting, did not hesitate and visited the office of an incubator tenant who specialized in computer matters. In their opinion, entrepreneurs are keen to cooperate and to work with others but find it hard to take the first step.

The first time I worked with an entrepreneur in the incubator was when they did my website for me and I went to the only company that offered that kind of service. After that, when we were in the incubator we used to go into each other's office and chat for a while. One thing is clear; people are keen to do things. The problem is that sometimes it's hard to break the ice.

Shared values. Entrepreneurs that set up in the Chamber of Commerce incubators have to do a business start-up course in which they are given basic knowledge on a range of business related matters. During this course, Entrepreneur 6, who specializes in human resources, met another incubator tenant and realised that they shared a similar working philosophy, as well as being in the same situation of starting up a business. This, 
together with the need to have a website, was what led to this first job as a clientsupplier. This was how the entrepreneur in question described it:

When I started out I didn't have a website or anything like it. There was a computer firm in the incubator and I spoke to the guy. I already knew him because we'd done the business start-up course together. I mentioned the fact that I wanted to set up a website and we discussed some options, and he showed me some work he'd done, and so on. I really liked the way he went about things. I think we really hit it off because our philosophy is very similar.

Complementarity. In instances in which entrepreneurs cooperate in order to offer their clients a specific product or service, complementarity of activities was one of the key drivers.

Entrepreneur 3's activity focuses exclusively on developing customised software. The first contact with another entrepreneur in the incubator was due to a hardware maintenance service they were asked to perform. Since Entrepreneur 3 did not provide such a service but knew of another entrepreneur in the incubator who did, Entrepreneur 3 acted as a go-between. Making such a contact possible was the first step towards establishing a link with the other entrepreneur, the two realising that they provided complementary services and could work together. Many clients needed software development and installation and not only hardware maintenance and networks systems installations, and vice-versa. The situation was summed up by Entrepreneur 3 thus:

We engaged in specific and spontaneous cooperation, which proved simple and quick, but that was the first cooperation I had. After that, we actually became friends and realised that we were two entrepreneurs who offered complementary services and that was how more long-term cooperation began.

Physical proximity proved to be the key factor to the first contact, although complementarity, empathy, and shared values were what led the initial contact to develop positively and favourably into a relationship between the two entrepreneurs, which remains until today.

Complementarity was also the reason which led Entrepreneur 5, an advertising agent focusing on the Internet, to engage in their first experience of cooperation with another entrepreneur in the incubator, specifically one focusing on payment through the Internet. In addition to coinciding in the same space and being in the same situation at a 
business level, their contact proved beneficial at a professional level because they spoke the same professional jargon.

... we could converse using the same jargon. We understood each other, which is important.

Linking-persons. Another prominent feature is having a mutual contact who acts as a link and a kind of security or guarantor in the relationship. For instance, Entrepreneur 4, who provides consulting services to their clients, needed a technological supplier to undertake a project in innovation and development. This was the reason for their search, which proved to be very short since the entrepreneur they successfully cooperated with was located in the office next door. The key to starting this joint cooperation was through a mutual contact who was able to vouch for the professionalism of both parts.

The initial contact was strange because the entrepreneur was located next door to us and we got to know about them through another firm we had both worked for and who had been satisfied with the work we'd done. We did the project and we were so pleased with the supplier that we've worked with them on other projects.

Proximity and saving time. Some entrepreneurs stressed proximity as a vital factor in the initial contact as well as the time variable. Entrepreneur 8, specializing in webpage design and programming, received a visit from an entrepreneur who was an incubator tenant and who had two clear ideas: setting up a website for her firm and the possibility of cooperating by passing on clients in exchange for a commission. The entrepreneur seeking these services did not spend much of her time in the incubator because she had a number of business trips, but knew that when she was there she wanted to make the most of the time she saved by being in the same place as others. At that moment, there was only one entrepreneur offering the kind of services she was looking for.

The entrepreneur I had my first experience with in that sense was with a person who was just starting up. She saw my office and came in to ask me something. She first suggested that I should set up her website for her and then, as she had a list of clients, she proposed bringing me clients in exchange for commission. This was what this entrepreneur needed when she came in and I was the only IT entrepreneur in the incubator at that time. As she had experience in the field, you could say she had a very clear of what she wanted her company to be like 
and she didn't want to waste much time setting it up or on any of the other basic issues you have to deal with when starting out. She wanted to do it as quickly as possible.

When IT problems arise they have to be dealt with sharply in order to be able to carry on working. This was how Entrepreneur 9 had their first contact as a supplier for another incubator tenant, specifically with the one right next door, after the latter's email server was down. The immediate solution to the problem heralded the first satisfactory contact between the two entrepreneurs. In this particular case, the time factor, in the sense of solving a problem quickly, was the key.

The first experience of cooperation I had was with one of our neighbours, who was right next door. I remember he knocked on the door and looked a bit flustered. He had a basic knowledge of IT but only enough to work in his particular area. He told me that he had a problem with his e-mail and that it didn't work. I went into his office, fixed it for him and he was really grateful. After that initial experience, we must have had between seven and ten entrepreneurs from the incubator coming in to ask us about things.

In most cases, these examples of initial cooperation experiences between entrepreneurs in the incubator proved successful. Specifically, seven of the experiences have led to long-term relationships which still exist today. Despite being successful, Entrepreneur 5's experience did not continue because the client closed down the business. In Table 4.3, we show the first cooperation experience for each entrepreneur. 
Table 4.3. First experience of cooperation with an incubator tenant

\begin{tabular}{|c|c|c|c|c|c|}
\hline Label & Date & Type of relation & $\begin{array}{c}\begin{array}{c}\text { Collaboration } \\
\text { goal }\end{array} \\
\end{array}$ & Reasons for collaborating & Development \\
\hline E1 & December 2006 & $\begin{array}{l}\text { Client-supplier } \\
\text { relation }\end{array}$ & $\begin{array}{l}\text { Server } \\
\text { maintenance and } \\
\text { computer } \\
\text { consumables }\end{array}$ & $\begin{array}{l}\text { Use of common areas, } \\
\text { affability, awareness of } \\
\text { being entrepreneurs, } \\
\text { empathy, future reciprocity } \\
\text { and greater attention to detail } \\
\text { when working }\end{array}$ & $\begin{array}{l}\text { Long-term } \\
\text { relation }\end{array}$ \\
\hline E2 & January 2007 & $\begin{array}{l}\text { Client-supplier } \\
\text { relation }\end{array}$ & $\begin{array}{l}\text { Accounting and } \\
\text { tax consultancy }\end{array}$ & $\begin{array}{l}\text { Physical proximity, empathy, } \\
\text { awareness of being } \\
\text { entrepreneurs, direct } \\
\text { experience in the process of } \\
\text { creating a firm and } \\
\text { competitive prices }\end{array}$ & $\begin{array}{l}\text { Long-term } \\
\text { relation }\end{array}$ \\
\hline E3 & May 2006 & $\begin{array}{l}\text { Cooperation } \\
\text { relation with } \\
\text { client }\end{array}$ & $\begin{array}{l}\text { Hardware } \\
\text { maintenance } \\
\text { service }\end{array}$ & $\begin{array}{l}\text { Physical proximity, empathy, } \\
\text { complementarity, similar } \\
\text { socio-demographic traits, } \\
\text { open personality, mutual } \\
\text { contact and future reciprocity }\end{array}$ & $\begin{array}{l}\text { Long-term } \\
\text { relation }\end{array}$ \\
\hline E4 & September 2006 & $\begin{array}{l}\text { Cooperation } \\
\text { relation with } \\
\text { client }\end{array}$ & $\begin{array}{l}\text { Developing } \\
\text { customised } \\
\text { software }\end{array}$ & $\begin{array}{l}\text { Physical proximity, empathy, } \\
\text { mutual contact and future } \\
\text { reciprocity }\end{array}$ & $\begin{array}{l}\text { Long-term } \\
\text { relation }\end{array}$ \\
\hline E5 & May 2008 & $\begin{array}{l}\text { Cooperation } \\
\text { relation with } \\
\text { client }\end{array}$ & $\begin{array}{l}\text { On-line } \\
\text { marketing: } \\
\text { positioning on } \\
\text { the Internet }\end{array}$ & $\begin{array}{l}\text { Physical proximity, empathy, } \\
\text { use of common areas, same } \\
\text { professional jargon and } \\
\text { specialization }\end{array}$ & $\begin{array}{l}\text { One of the firm } \\
\text { closed down }\end{array}$ \\
\hline E6 & February 2005 & $\begin{array}{l}\text { Client-supplier } \\
\text { relation }\end{array}$ & $\begin{array}{l}\text { Setting up a } \\
\text { website }\end{array}$ & $\begin{array}{l}\text { Physical proximity, empathy, } \\
\text { professional service and } \\
\text { greater attention to detail } \\
\text { when working }\end{array}$ & $\begin{array}{l}\text { Long-term } \\
\text { relation }\end{array}$ \\
\hline E7 & April 2008 & $\begin{array}{l}\text { Client-supplier } \\
\text { relation }\end{array}$ & $\begin{array}{l}\text { Setting up a } \\
\text { website }\end{array}$ & $\begin{array}{l}\text { Physical proximity, empathy } \\
\text { and willingness to } \\
\text { collaborate }\end{array}$ & $\begin{array}{l}\text { Long-term } \\
\text { relation }\end{array}$ \\
\hline E8 & July 2007 & $\begin{array}{l}\text { Supplier-client } \\
\text { relation }\end{array}$ & $\begin{array}{l}\text { Setting up a } \\
\text { website }\end{array}$ & $\begin{array}{l}\text { Physical proximity, time- } \\
\text { saving, empathy and greater } \\
\text { attention to detail when } \\
\text { working }\end{array}$ & $\begin{array}{l}\text { Long-term } \\
\text { relation }\end{array}$ \\
\hline E9 & July 2008 & $\begin{array}{l}\text { Supplier-client } \\
\text { relation }\end{array}$ & $\begin{array}{l}\text { Solving a } \\
\text { computer } \\
\text { problem }\end{array}$ & $\begin{array}{l}\text { Physical proximity, } \\
\text { "urgency" to solve a problem } \\
\text { and mutual contact }\end{array}$ & $\begin{array}{l}\text { Specific } \\
\text { transaction }\end{array}$ \\
\hline
\end{tabular}

From the above, it may be concluded that three of the proposed variables (empathy H3, shared values - H4, and complementarity resources - H5) are highlighted by interviewees, although none of the incubatees mentioned supplementarity resources. This result is not surprising since all the interviewees mentioned relationships with other entrepreneurs with different business activities as well as different experiences and professional skills.

On the other hand, two aspects not included in the model were mentioned as determinants of the relationships: contact persons, and proximity. 


\subsubsection{Mechanisms of relational exchange}

The second aspect discussed in the interviews was the characteristics that determine the success and the endurance of the relationships. All the entrepreneurs concurred when pointing to continuity, followed by trustworthiness, frequency in contacts and friendship, which were mentioned by seven of the nine entrepreneurs. Other aspects were the consolidation of the relationship, and involvement, the latter stemming from having been working together since the outset of their business activity.

Trustworthiness. Trust was considered a basic element for relationship success. In fact, different ways of working and mistrust were cited as the reasons for failure.

Entrepreneur 3 provided a service for a client, who needed a further service which was not offered by the first entrepreneur. In order to help the client out and increase their client's satisfaction, entrepreneur three contacted an incubator tenant who specialized in providing such a service, an incubator tenant that entrepreneur three did not know previously and about whom they had no references. The second entrepreneur completed the work, but entrepreneur three was not satisfied because the two did not share the same work philosophy or way of dealing with the client. This led to dissatisfaction on the part of entrepreneur three, who decided not to work with the second one again, and led them to change their ideas about recommending others if they did not have any prior knowledge of how they worked.

I knew that in the incubator there were two or three entrepreneurs that provided a particular service I needed for my client. I chose one of them just as I could have chosen another, as I hadn't had any previous references or contact with any of them. The entrepreneurs in question made a favourable impression on me although I didn't like the way they worked. We get on well personally, but the way they went about their work just did not fit in with my idea of things. I wasn't happy with how the final product turned out, the impression they made on the client, and I wasn't happy with the way they dealt with the client. It simply wasn't the way I like to go about my work; and that was the bad experience.

Entrepreneur 4 suggested an original business idea to another incubator tenant whereby each of them would be responsible for the specific aspects of their proposal and would, if the proposal were approved, subsequently take charge of the part they specialized in. The proposal was not drawn up jointly, each entrepreneur doing it individually as they 
were unable to agree over certain technical issues in the project. The entrepreneur ultimately chosen to carry out the project was not entrepreneur four, but the other one, who did not compensate or involve entrepreneur four in any way despite the latter having provided them with the idea. This failed experience led to entrepreneur four displaying mistrust towards engaging in projects if they had not previously worked with the entrepreneur or firm.

This failed experience arose as a result of another entrepreneur that we did not initially consider to be a competitor, but who eventually proved to be so as they gradually saw that our business might prove profitable. That leads you to mistrust others, and I still have misgivings about other firms when it comes to large scale projects. This was affected by the character of the other entrepreneur. There was no mutual feeling either at a personal or a business level. This led us to break off relationships with that particular entrepreneur, although we do cooperate with many others. That particular experience did not signal the end of our cooperation.

Trust was also related to the partner's capabilities and honesty. In fact, what stood out behind the failure of relationships in these cases was the lack of agreement or failure to establish prior conditions.

Entrepreneur 5 was hired by another incubator tenant to provide an ad-hoc service for a client, although the service the client required was not very clearly defined. This led to a timeframe for the delivery of a series of items which proved unworkable. This sparked discontent in the client, who decided to break off all contact with entrepreneur five, who in turn saw the unsuccessful episode as a learning experience, realising that even if both parts know each other, the terms and conditions of any agreement have to be set out very clearly.

It was an entrepreneur who commissioned a job, also I think because they didn't really know what it was about. When we thought out the project, a delivery timeframe was set out which we apparently failed to meet, leading the first entrepreneur to break off the relationship, and that was that. I think there were other reasons behind it which made them take that decision, although I don't know what they were. 
Entrepreneur 6 was asked to do a specific task by another incubator tenant they were friends with. The work involved conducting a selection process. After the whole procedure had been completed, entrepreneur six billed their client for the service, and the latter did not want to pay as they knew each other and had seen it as a personal favour. Entrepreneur 6 was annoyed, as they had provided a professional service from which they make their living and had not seen it as a personal favour.

I had the chance to cooperate in a selection process with one of the people I'd done the business start-up course with, and who had a renewable energies firm. But this person thought that I wasn't going to bill him because we knew each other, and that I was just going to do it. But it wasn't like that. This is my job and this is how I make my living. I thought it was quite cheeky of him to think that just because we got on well with each other and were both entrepreneurs and have to help each other that well you know... But that's not the way things work.

These failed experiences with incubator tenants are shown in Table 4.4.

Table 4.4. Failed experiences with incubator tenants.

\begin{tabular}{|c|c|c|c|}
\hline Label & $\begin{array}{c}\text { Reasons for starting the } \\
\text { collaboration }\end{array}$ & Key factors & Result \\
\hline E3 & $\begin{array}{l}\text { Physical proximity and } \\
\text { friendly attitude of the } \\
\text { entrepreneurs }\end{array}$ & $\begin{array}{l}\text { Cooperation relation with a } \\
\text { client. They made a bad } \\
\text { impression on the client. }\end{array}$ & Less trust \\
\hline E4 & $\begin{array}{l}\text { Physical proximity and } \\
\text { proposal for collaboration }\end{array}$ & $\begin{array}{l}\text { Initial proposal for a joint } \\
\text { project between two firms. } \\
\text { Finally, the firm became a } \\
\text { competitor. }\end{array}$ & Less trust \\
\hline E5 & Physical proximity & $\begin{array}{l}\text { Delivery timeframe was set } \\
\text { out which the firm failed to } \\
\text { meet. }\end{array}$ & $\begin{array}{l}\text { Experiential } \\
\text { learning }\end{array}$ \\
\hline E6 & $\begin{array}{l}\text { Physical proximity and } \\
\text { empathy }\end{array}$ & $\begin{array}{l}\text { An incubator tenant saw a } \\
\text { professional service as a } \\
\text { personal favour }\end{array}$ & $\begin{array}{l}\text { Trust may not be } \\
\text { reciprocated }\end{array}$ \\
\hline
\end{tabular}

Cooperation and exchange of knowledge. None of the entrepreneurs have gone so far as to materialize such cooperation in formal agreements, mergers or the creation of joint firms, not even with the entrepreneurs with whom they had their initial cooperation experience in the incubator and which continues to today, although the following comments were made.

Entrepreneur 4 (has been collaborating with another entrepreneur since September 2006):

... we have come to see them as a technological partner. 
Entrepreneur 6 (has been collaborating with another incubator tenant since January 2005):

... he has always lived up to expectations. I consult him on all matters related to his field, which is the IT sector, even on matters familiar to me.

Entrepreneur 8 (has been collaborating with another entrepreneur since July 2007):

If he can do something for me, he doesn't hesitate, and he suggests various projects in which to cooperate.

Commitment and expectations of continuity. All the entrepreneurs involved in the research currently maintain the relationships they commenced with other entrepreneurs located in the incubator.

Entrepreneur 2 had their initial cooperation experience when they first entered the incubator. Specifically, it was with an entrepreneur who was a consultant and left the incubator a few months later, but with whom they are still working.

The consultant left a few months later because he had been one of the first to set up in the incubator and he had then opened an office elsewhere. We are still working with him and we get on really well.

Entrepreneur 1 made specific reference to the fact that relationships with other entrepreneurs are not restricted to when they are in the incubator but continue when they leave, as they remember the entrepreneurs that were there.

When entrepreneurs leave, they do remember us. In fact, not just one but quite a few. I think that what most drives them in this sense is being aware of how difficult it is, how hard it is to attract clients, sell your products, etc. In the end, if you can help the guys next door... we've all helped one another out.

\subsubsection{Relationship outcomes}

Finally, incubatees were asked about the outcomes and advantages to emerge from the relationships (Table 4.5). 
Table 4.5. Characterizations of relationships born in the incubator.

\begin{tabular}{|c|c|c|}
\hline Label & Features used to Describe the Relations & Advantages \\
\hline E1 & $\begin{array}{l}\text { Trust, physical proximity, personalized treatment, } \\
\text { continuity and involvement }\end{array}$ & $\begin{array}{l}\text { Introduction into networks and } \\
\text { professional service }\end{array}$ \\
\hline E2 & $\begin{array}{l}\text { Trust, frequency, empathy, personal relation, } \\
\text { specialization, personalized treatment and } \\
\text { continuity }\end{array}$ & $\begin{array}{l}\text { Tremendous availability and } \\
\text { involvement in joint projects }\end{array}$ \\
\hline E3 & $\begin{array}{l}\text { Trust, frequency, similar working philosophy and } \\
\text { continuity }\end{array}$ & $\begin{array}{l}\text { Entrepreneurs share the common values } \\
\text { which tend to characterize business } \\
\text { people }\end{array}$ \\
\hline E4 & $\begin{array}{l}\text { Empathy, personal relation, continuity, similar } \\
\text { working philosophy and client approach }\end{array}$ & $\begin{array}{l}\text { Availability, competitive prices and } \\
\text { professional services }\end{array}$ \\
\hline E5 & $\begin{array}{l}\text { Frequency, "business friends", continuity, } \\
\text { empathy, relation with peers, capability and } \\
\text { consolidation }\end{array}$ & $\begin{array}{l}\text { Introduction in networks, experience and } \\
\text { assurance }\end{array}$ \\
\hline E6 & $\begin{array}{l}\text { Trust, flexibility, continuity, frequency, capability, } \\
\text { empathy and friendship }\end{array}$ & $\begin{array}{l}\text { Adaptability, professional services and } \\
\text { introduction into networks }\end{array}$ \\
\hline E7 & $\begin{array}{l}\text { Frequency, trust, friendship, continuity and } \\
\text { empathy }\end{array}$ & Introduction into networks \\
\hline E8 & $\begin{array}{l}\text { Frequency, continuity, trust, friendship and similar } \\
\text { working philosophy }\end{array}$ & Tremendous availability \\
\hline E9 & Trust, frequency, friendship and continuity & Convenience \\
\hline
\end{tabular}

Introduction in networks and assurance. Firstly, entrepreneurs cited matters related to having shared the same physical area, such as the assurance that comes from working with entrepreneurs they have known close at hand, and the large number of contacts that can be made in a short space of time. Entrepreneur 5 explained:

... being in an incubator is like taking a crash course in entrepreneurship, which, on the one hand, makes you less afraid. If you have not been in an incubator, then you might engage in relationships with other firms differently; if you go to a bigger firm you feel a bit intimidated because you don't know how to approach them (...). But when you've dealt with a large number of firms, big companies are just like any other.

In the words of entrepreneur 5, we can figure out that those entrepreneurs who are in incubation can strengthen their entrepreneurial commitment because of the trust and the confidence they gain due to relations in the incubator.

Flexibility, availability and convenience. Secondly, factors which were cited to a greater extent relate to actual entrepreneurship. Specifically, these factors are relationships with peers, since business incubator tenants are people who share similar sociodemographic traits, competitive prices, tremendous flexibility and availability, greater attention to detail when working, and the convenience factor when engaging in joint projects. Entrepreneur 5: 
When you leave, you might have relationships with other companies, but it's not the same. In the incubator, you reveal information about your firm that you would never disclose out there in the market. That's because peer relationships occur since we are small business people, and most of us are aged between 30 and 40. This allows friendly business relationships to spring up, but not friendship. Outside the incubator, if you are going to meet an entrepreneur who employs 40 workers, you can share a coffee but you don't talk to each other as equals.

The incubator is a protected environment for business that allows exchange of knowledge that can foster generation of innovation, contrary to the market, where the development of innovation may delay for a considerable period of time.

New projects. Finally, aspects stemming from the experience of working or cooperating were mentioned. These include creating networks, involvement in joint projects and, in specific cases, totally frank cooperation. These were the comments of Entrepreneurs 4 and 2:

Collaboration is established for three years. As things developed so normally, there was no need to sign contracts because there is enough trust for you to be able even to introduce your clients to other entrepreneurs.

During our time in the incubator, we have always felt that sharing similar experiences, working together, and being so close, gave us the chance to set up joint projects and even create our own joint brand name "incubator firms" with aim of attracting more clients.

The opportunity to be involved in new projects allows entrepreneurs commit more with their businesses and open doors to new pathways in income generation.

\subsubsection{Summary of results}

This study shows three key aspects in the dyadic relationships between incubatees: (1) the main factors that influence the creation of this type of relationship; (2) the mechanisms that encourage its development; and (3) the most immediate results in the field of incubators. Figure 4.2 illustrates the relevant variables at each stage of the relationship. 
With regard to the drivers that foster the beginning and the creation of relationships, as proposed in hypotheses $\mathrm{H} 3, \mathrm{H} 4$ and $\mathrm{H} 5$, empathy, shared values and complementarity were mentioned. It can thus be concluded that hypotheses H3 to H5 are relevant, although there is no empirical support for hypothesis H6 (the effect of supplementarity resources).

Among the mechanisms that characterize the survival and continuity of relationships are trust, commitment, and exchange of knowledge, thus confirming the dimensions of relationships in the proposed model. Worth highlighting is the key role played by trust/mistrust as a vital factor in either sustaining the relationship (supporting hypothesis H1) or causing it break down. In this study, we also detect, in line with hypothesis H2, the link between exchange of knowledge and commitment. Successful knowledge exchanges were associated with expectations of continuity.

Other complementary aspects of the relationships are special treatment, flexibility, and involvement.

Finally, as regards relationship outcomes, inclusion in networks and open collaboration were mentioned. However, business efficiency and generation of innovation, proposed variables in the model, were not specified by the interviewees.

Figure 4.2. Relevant variables at each stage of the relationship.

\begin{tabular}{|l|l|}
$\begin{array}{l}\text { Relationship drivers } \\
\text { - Success factors } \\
\text { - Empathy } \\
\text { - Solidarity and common } \\
\text { awareness } \\
\text { - Shared values } \\
\text { - Pomplementarity } \\
\text { saving } \\
\text { - Failure factors and time- } \\
\text { - Different work style } \\
\text { - Mistrust }\end{array}$
\end{tabular}

Further conclusions of this research, in line with the other studies, are explained in Chapter 5. 


\subsection{Data collection for quantitative studies}

After Study I, which is qualitative, Studies II, III.1 and III.2 were carried out. These are quantitative and aim to further, extend as well as confirm the results to emerge from the first study and to analyse empirically the other hypotheses proposed in the thesis. Information for three studies was collected through questionnaires aimed at UBI managers and incubatees in Spain and the Netherlands. Specifically, two questionnaires were drawn up: one for incubatees and the other for incubator managers. It was decided to use the format of a compulsory answer on-line questionnaire for all the questions posed, which ensured that no data were missing.

Since the information is common to all three surveys, this section explains the process used when devising the questionnaires, measuring the variables and gathering data. In addition, the study sample is described, and further details are then given concerning each study carried out and the results obtained.

\subsubsection{Questionnaire to incubatees: design and description}

In order to ensure the questionnaire fulfilled its purpose as a measurement tool that did not distort reality, two sources were used: bibliographical review and specific information from the field of UBIs.

First, a review was conducted of the academic literature, focusing primarily on empirical works within the framework of relationship marketing, incubators and entrepreneurship, as set out in previous chapters.

Secondly, information from the field of UBIs was used, this proving to be key when drawing up the final questionnaire. This information was obtained by reviewing external documentation although it was mainly gathered through conversations with incubator managers and tenants in Spain and the Netherlands. This enabled items to be adapted to the specific area of research and even for ad hoc indicators to be designed.

After drawing up an initial version of the questionnaire, two pre-tests were carried out in order to check the validity of its content, in other words determining to what extent a questionnaire measures what it sets out to measure (Fink, 1995; Creswell, 2003). The 
first pre-test was developed personally and in situ with six incubatees from the ACE Venture $\mathrm{Lab}^{13}$, located in Amsterdam, in November $2013^{14}$.

This proved to be particularly important as it led to the wording of several items being changed so as to make them clearer and easier to understand, and it ensured they were not open to subsequent misinterpretation by respondents when answering the questionnaire. After making the necessary changes, in December the same year the second pre-test was carried out with three members of a research group from Vrije University Amsterdam. ${ }^{15}$ Thanks to this group, it could be seen that the scales reflected the content and scope of the constructs included in the proposed models. The possibility of asking about one relationship that had been successful and another that had failed, or about all of the relationships that respondents had had with other incubatees, was also discussed. However, both possibilities were ruled out: the first because cooperation between entrepreneurs might prove to be neutral, and need not necessarily be either positive or negative. In the case of the second option, it was felt that the answers would not be so specific when asking a general question concerning all the relationships taken as a whole. Bearing in mind that the goal of the research focused on describing the relationships to develop in the incubators, without biasing or restricting in any way towards a specific type of cooperation, it was decided, as had initially been posited, that individuals should consider one particular interaction, contact or professional relation they had had with another entrepreneur whilst in the incubator so as to be able to respond to the questions put to them. This can be seen in the final version of the questionnaire, both in Spanish and in English, and which may be found in Annexes 1 and 2, respectively. The indication was as follows:

${ }^{13}$ The Amsterdam Center for Entrepreneurship (ACE) Venture Lab is an incubator set up by the University of Amsterdam, the Vrije University Amsterdam, and the Amsterdam University of Applied Sciences. Its main goal is to support researchers, $\mathrm{PhDs}$, students, graduates, and science based start-ups to facilitate the growth and commercialization of feasible business ideas.

${ }^{14}$ At the same time as the pre-test was being conducted, qualitative research was also being carried out in the same incubator (see Redondo et al., 2014). This allowed us "...to understand the context or setting of the participants through visiting this context and gathering information personally" (Creswell, 2003, p. 9).

${ }^{15}$ Members of the group: Professor Dr. Peter van der Sijde, and the researchers Firmansyah David and Hans Frederik. Their research interests are entrepreneurship, university-business cooperation, technology transfer and university programs in IT and interaction with the professional field. 
“Consider ONE professional relationship, interaction or contact that you have or have had with ANOTHER ENTREPRENEUR IN THE INCUBATION PROCESS and answer the following questions"

Before moving on to the explanation concerning the design of the questionnaire, one clarification should be made. The proposed model was posited for relationships between individuals both at the pre-incubation as well as incubation stage. In order to adjust the questionnaire to each stage, the wording of certain questions and items was adapted. One example is that in the pre-incubation stage reference is made to the idea of business, and in the incubation stage to the actual business itself, since this has already been created, which is not the case in the previous stage. When gathering the information, 101 incubatee responses were obtained, of which 92 correspond to individuals at the incubation stage and only nine to those at pre-incubation.

With regard to measuring the variables included in the questionnaire, all of these are set out below, grouped as follows: (1) affinity and mutual understanding; (2) characteristics of resources; (3) characteristics of the incubatee; (4) description of the dyadic relationship; (5) results of the dyadic relationship; (6) manager's relational orientation; (7) social capital; (8) efficiency of the incubatee's business; and (9) control variables.

\section{(1) Affinity and mutual understanding}

Affinity and mutual understanding are specified in two variables: empathy and shared values.

An incubatee's empathy towards another incubatee was measured through a single item, the one displaying the greatest content validity and consistency in the present study, taken from Hogan's original scale (1969), and which has been widely used and verified in a number of empirical works.

In order to identify a scale for measuring the shared values on the part of the other party involved in the dyad, the works of a number of authors were reviewed. It was decided to use a three-item reflective scale based on Sarkar et al. (2001), due to its concurrence with the goals of research regarding the variable in question, and given its validity.

Table 4.6 shows the corresponding measurement items for the two variables. 
Table 4.6. Measurement of affinity and mutual understanding: items and references

\begin{tabular}{|c|c|}
\hline Variables and items & References \\
\hline \multicolumn{2}{|c|}{ Empathy (5-point Likert scale, anchored by “strongly disagree” and “strongly agree”) } \\
\hline $\begin{array}{l}\text { Evaluate the following statements: } \\
\text { I have little difficulty in "putting myself into other people's shoes" }\end{array}$ & Hogan (1969) \\
\hline \multicolumn{2}{|c|}{ Shared values (5-point Likert scale, anchored by “strongly disagree” and “strongly agree”) } \\
\hline $\begin{array}{l}\text { This entrepreneur: } \\
\text { His/her values and conduct norms are congruent with mine } \\
\text { His/her philosophy/approach to business is compatible with mine } \\
\text { His/her goals and objectives are compatible with mine }\end{array}$ & $\begin{array}{l}\text { Sarkar, Echambadi } \\
\text { Cavusgil, and } \\
\text { Aulakh (2001) }\end{array}$ \\
\hline
\end{tabular}

\section{(2) Characteristics of resources}

Measuring the supplementarity and complementarity of incubatees' resources was carried out using the scales proposed by Sarkar et al. (2001) and Lambe et al. (2002). In both cases, and as emerged from the first pre-test, it was necessary to modify the wording of the items in order to improve the understanding thereof and so as to ensure they would not be misinterpreted. The greatest changes were made to supplementarity of resources. Given the absence of a reliable and valid scale that could be used, a scale similar to the one employed for the complementarity of resources was drawn up. Four indicators for complementarity and three for supplementarity were used, all of which are reflective. Both variables were measured from the viewpoint of the respondent with regard to a specific incubatee they had been involved with.

In order to measure transferability of knowledge, two reflective items taken from the empirical work carried out by Simonin (1999) were included, said model being one which has also been widely validated. Each item's content is similar, as can be seen in Table 4.7, although there is a difference vis-à-vis the standpoint from which they are measured: in the first person and with regard to the other part of the dyad. 
Table 4.7. Measurement of variables of characteristics of resources: items and references

\begin{tabular}{|c|c|}
\hline Variables and items & References \\
\hline \multicolumn{2}{|c|}{ Resource complementary (5-point Likert scale, anchored by “strongly disagree” and “strongly agree”) } \\
\hline \multicolumn{2}{|l|}{ This entrepreneur: } \\
\hline Has different resources to mine that are very precious to me & $\begin{array}{c}\text { Sarkar, Echambadi, } \\
\text { Cavusgil, and } \\
\text { Aulakh (2001) }\end{array}$ \\
\hline $\begin{array}{l}\text { His/her resources are necessary to achieve my goals } \\
\text { Has different and complementary resources to mine } \\
\text { His/her resources, combined with mine, enable me to achieve more satisfactory results }\end{array}$ & $\begin{array}{l}\text { Lambe, Spekman, } \\
\text { and Hunt (2002) }\end{array}$ \\
\hline \multicolumn{2}{|c|}{ Resource supplementary (5-point Likert scale, anchored by “strongly disagree” and “strongly agree”) } \\
\hline This entrepreneur: & $\begin{array}{l}\text { From Sarkar, } \\
\text { Echambadi, }\end{array}$ \\
\hline Has similar resources to mine, but nevertheless they are very precious to me & $\begin{array}{l}\text { Cavusgil, and } \\
\text { Aulakh (2001) } \\
\end{array}$ \\
\hline $\begin{array}{l}\text { Has resources that are similar but supplementary to mine } \\
\text { His/her resources are similar to mine, but when combined, allow me to achieve more } \\
\text { satisfactory results }\end{array}$ & $\begin{array}{l}\text { From Lambe, } \\
\text { Spekman, and } \\
\text { Hunt (2002) }\end{array}$ \\
\hline \multicolumn{2}{|l|}{ Transferability. (5-point Likert scale, anchored by “strongly disagree” and “strongly agree”) } \\
\hline $\begin{array}{l}\text { Regarding my knowledge or training applied to the business I have started: } \\
\text { The knowledge (technical-scientific) held by me is easily transferable } \\
\text { Evaluate the following statements about this entrepreneur: } \\
\text { The knowledge (technical-scientific) held by him/her is easily transferable }\end{array}$ & Simonin (1999) \\
\hline
\end{tabular}

\section{(3) Incubatee characteristics}

Measurement of incubatees' individual traits was based on a review of the literature. The traits in question are: willingness to share knowledge and promotion focus.

As regards the willingness to share knowledge variable, three reflective indicators proposed by van den Hooff and de Leeuw van Weenen (2004) were included. Two of these measure willingness to acquire knowledge and the other the willingness to share it.

Determining whether the individual displays a promotion focus was measured through three items of a reflective nature. The first is one proposed by Higgins et al. (2001) to measure whether individuals seek and pursue opportunities that will enable them to accomplish their goals, reflected in achievements and growth. To complete the scale and to adapt it to the area of entrepreneurship, two further items proposed by Florin et al., (2007) were used. Said authors explain the attitudinal dimensions of the urge to engage in entrepreneurship, which they define as: "an individual`s perception of the desirability and feasibility to proactively pursue opportunities and creatively respond to challenges, tasks, needs, and obstacles in innovative ways" (Florin et al., 2007, p. 26). These dimensions include proactivity, a feature of promotion focus individuals. 
The three personal variables were formulated in the first person, without reference to the other entrepreneur with whom individuals were cooperating, since these are subjects' own and specific attributes which might shape the relationship they are involved in. Table 4.8 shows the variables in question as well as the items and scales used to measure them, together with the sources from which they were taken.

Table 4.8. Measurement of individual characteristics: items and references

\begin{tabular}{|c|c|}
\hline Variables and items & References \\
\hline \multicolumn{2}{|c|}{ Willingness to share knowledge (5-point Likert scale, anchored by “strongly disagree” and "strongly agree”) } \\
\hline $\begin{array}{l}\text { Evaluate the following statements: } \\
\text { When I learn something new, I tell my colleagues } \\
\text { I share the information I have with my colleagues when they ask me to } \\
\text { I share my skills with my colleagues when they ask me to } \\
\end{array}$ & $\begin{array}{l}\text { van den Hooff and } \\
\text { de Leeuw van } \\
\text { Weenen (2004) }\end{array}$ \\
\hline \multicolumn{2}{|c|}{ Promotion focus (5-point Likert scale, anchored by “never or seldom” and “very often”) } \\
\hline $\begin{array}{l}\text { The following questions concern specific events in your life: } \\
\text { I feel like I have made progress toward being successful in my life }\end{array}$ & $\begin{array}{l}\text { Higgins, Friedman, } \\
\text { Harlow, Idson, and } \\
\text { Ayduk (2001) }\end{array}$ \\
\hline \multicolumn{2}{|l|}{ (5-point Likert scale, anchored by “strongly disagree” and "strongly agree”) } \\
\hline $\begin{array}{l}\text { Evaluate the following statements: }(*) \\
\text { I am always looking for better ways to do things } \\
\text { No matter what the odds are, if I believe in something I will make it happen }\end{array}$ & $\begin{array}{l}\text { Florin, Karri, and } \\
\text { Rossiter (2007) }\end{array}$ \\
\hline
\end{tabular}

\section{(4) Characterization of the dyadic relationship}

The quality of the relationship between incubatees was reflected through variables which have been widely studied in relationship marketing: commitment and trust.

Mutual commitment in the relationship was measured through a reflective scale comprising six indicators, adapted from the scale proposed by Wilson and Vlosky (1997) and also used by Moberg and Speh (2003). As these were closely aligned to the objectives pursued, three items were formulated in the first person and the other three with regard to the other person involved in the collaboration.

As regards trust, and in an effort to ensure measurement was comprehensive and covered the dimensions of honesty and kindness, scales taken from the empirical works of Ganesan (1994), Sarkar et al. (2001), and McKnight et al. (2002) were used. Specifically, a seven-item reflective scale was devised to measure incubatee trust towards those with whom they were cooperating.

Cooperation content was also reflected in terms of exchange of knowledge. In order to measure various dimensions of this variable, a total of fifteen items were used, which make up two reflective scales: one nine-indicator scale to measure knowledge transfer 
and another six-indicator scale to measure communication. The knowledge transfer scale was constructed based on the items proposed by Yli-Renko et al. (2001) and by Simonin (1999).

Communication in the relationship was measured using the reflective scale proposed by Mohr and Spekman (1994). Also included were two indicators reflecting the frequency of contacts, proposed by Nicholson et al. (2001).

The scales of trust, commitment, and exchange of knowledge are shown in Table 4.9. 
Table 4.9. Measurement of characterization of the dyadic relationship: items and references

\begin{tabular}{|c|c|}
\hline Variables and items & References \\
\hline \multicolumn{2}{|c|}{ Commitment (5-point Likert scale, anchored by “strongly disagree” and “strongly agree”) } \\
\hline $\begin{array}{l}\text { Evaluate the following statements: } \\
\text { I intend to strengthen our relationship over time } \\
\text { I intend to continue our relationship for a long time } \\
\text { I am committed to sharing ideas and knowledge with him/her } \\
\text { This entrepreneur: } \\
\text { He/she is willing to strengthen our relationship over time } \\
\text { He/she is willing to continue our relationship for a long time } \\
\text { He/she is committed to sharing ideas and knowledge with me }\end{array}$ & $\begin{array}{l}\text { Wilson and Vlosky } \\
\text { (1997); Moberg } \\
\text { and Speh (2003) }\end{array}$ \\
\hline \multicolumn{2}{|c|}{ Trust (5-point Likert scale, anchored by “strongly disagree” and “strongly agree”) } \\
\hline \multicolumn{2}{|l|}{ This entrepreneur: } \\
\hline He/she is honest and truthful & $\begin{array}{l}\text { Sarkar, Echambadi, } \\
\text { Cavusgil, and } \\
\text { Aulakh (2001) } \\
\end{array}$ \\
\hline $\begin{array}{l}\text { The information he/she exchanges with me is reliable } \\
\text { He/she honestly communicates any problem that may affect me } \\
\text { He/she is willing to provide assistance and support when circum }\end{array}$ & Ganesan (1994) \\
\hline $\begin{array}{l}\text { I believe that he/she acts in my best interest } \\
\text { In general, he/she is a person who honours his/her commitments } \\
\text { He/she is competent and effective }\end{array}$ & $\begin{array}{l}\text { McKnight, } \\
\text { Choudhury, and } \\
\text { Kacmar (2002) }\end{array}$ \\
\hline
\end{tabular}

\section{Exchange of knowledge}

Knowledge transfer (5-point Likert scale, anchored by “strongly disagree” and "strongly agree”)

Through this entrepreneur:

I learn from his/her knowledge

I learn from his/her experience

I assimilate the knowledge that he/she gives me and it helps develop my start-up

Through me, the other entrepreneur:

Simonin (1999)

Learns from my knowledge

Learns from my experience

Assimilates the knowledge that I give him/her and it helps develop his/her start-up

Through this entrepreneur:

I acquire technical knowledge and a tremendous amount of know-how

Yli-Renko,

Through me, the other entrepreneur:

Autio,and Sapienza

Has access to market knowledge

(2001)

Acquires technical knowledge and a tremendous amount of know-how

Communication (5-point Likert scale, anchored by "strongly disagree” and "strongly agree”)

In our relationship:

We seek mutual advice and recommendations

We share all types of information

Mohr and

We provide any information that may be useful to the other party

Each party informs the other about events that may affect them

In our relationship:

We work together frequently

Nicholson,

We frequently have contact

Compeau, and

Sethi (2001)

\section{(5) Outcomes of the dyadic relationship}

The model proposes three outcomes that might emerge from relationships between incubatees: entrepreneurial commitment, generation of innovation and business results. 
Entrepreneurial commitment was measured through a four-item reflective scale defined by Erikson (2002). Its content refers to the level of commitment, demands and the individual's business goals.

Generation of innovation was reflected through a five-indicator reflective scale, three reflecting what the relationship has provided up to that point and two dealing with future expectations in terms of what innovation might emerge from the cooperation. After reviewing the literature and failing to find any scale which exactly reflected what we were aiming to measure, one was designed ad hoc.

Finally, the business results outcome was included. This was reflected through three reflective indicators from the work of Gassenheimer and Ramsey (1994) in the area of relations. Specifically, the items deal with sales, profits and new market opportunities.

The measurement of the three variables of the results proposed is shown in Table 4.10.

Table 4.10. Measurement of the dyadic relationship: items and references

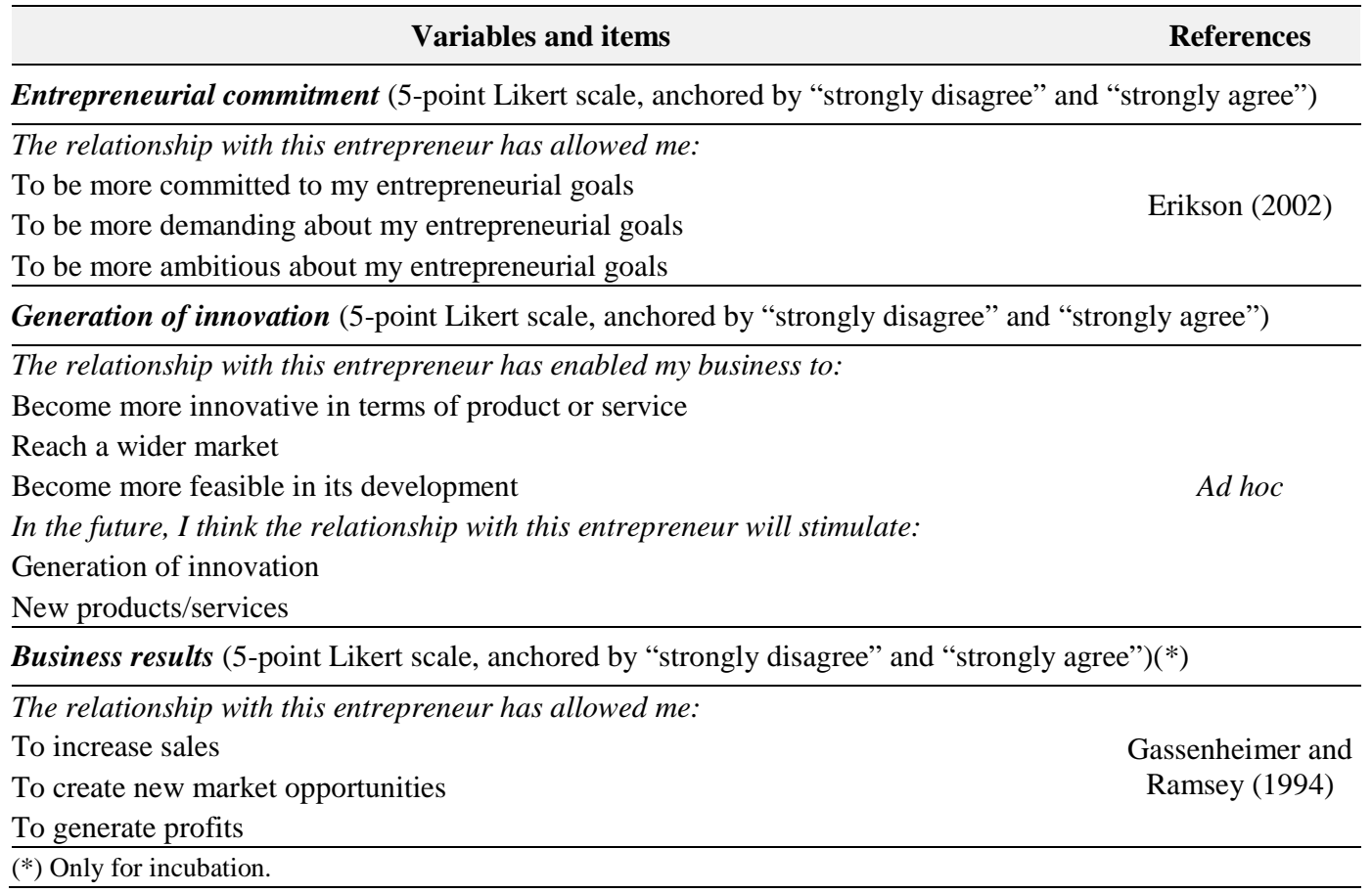

\section{(6) Manager's relational orientation}

Another of the variables included in the incubatees' questionnaire dealt with the manager's relational orientation. To measure this, the manager's involvement vis-à-vis fostering contacts and relations amongst incubatees and with agents from outside the incubator was considered. Due to its specific nature and the lack of any empirical 
studies addressing this issue, a reflective scale containing four indicators defined ad hoc was constructed (Table 4.11) for the present research.

Table 4.11. Measurement of manager's relational orientation: items and reference

\begin{tabular}{lc}
\hline \multicolumn{1}{c}{ Variable and items } & Reference \\
\hline $\begin{array}{l}\text { Manager's relational orientation (5-point Likert scale, anchored by "strongly disagree” and "strongly } \\
\text { agree") }\end{array}$ & \\
\hline $\begin{array}{l}\text { Think of the incubator manager and assess your level of agreement or disagreement } \\
\text { with each of the following statements: }\end{array}$ & Ad hoc \\
I think he/she encourages contacts between entrepreneurs & \\
He/she tries to establish links between entrepreneurs who can thus collaborate & \\
He/she facilitates networking between all entrepreneurs & \\
He/she facilitates contacts outside the incubator
\end{tabular}

\section{(7) Social capital}

Measuring the creation of social capital in UBIs included a total of fifteen items dealing with its various dimensions.

First, to measure incubatees' structural social capital, and following social capital literature (Granovetter, 1973; Burt, 1992), the concepts of bridging social capital and bonding were taken. Specifically, in order to measure bridging social capital an ad hoc scale was devised comprising two formative items. As regards bonding social capital, a question was introduced to give an indication of the number of incubatees with whom frequent contacts were maintained.

The incubator's relational social capital was measured through the three dimensions of: trust, identity and reciprocity (Nahapiet and Ghoshal, 1998). For the dimension of trust, the four-indicator reflective scale proposed by Chiu et al. (2006) was used. The scale used by said authors for identification with the community was also used to measure relational social capital in its identification dimension through two reflective items. Finally, to measure reciprocity, the two-item reflective scale proposed by Wasko and Faraj (2005) was considered.

To measure the components of cognitive social capital, two reflective indicators from the shared language scale proposed by Chiu et al. (2006) were used, together with a further two reflective items from the shared interests scale of Kleijnen et al. (2009).

All the dimensions of social capital, as well as the items used and the references, are shown in Table 4.12. 
Table 4.12. Measurement of social capital: items and references

\begin{tabular}{|c|c|}
\hline Variables and items & References \\
\hline \multicolumn{2}{|c|}{$\begin{array}{l}\text { Structural social capital. Bridging social capital (5-point Likert scale, anchored by “strongly disagree" and } \\
\text { "strongly agree") }\end{array}$} \\
\hline \multicolumn{2}{|l|}{ Since I joined incubation, I have managed ... } \\
\hline To develop social skills for the business world & \\
\hline To increase my network of business contacts & Ad hoc \\
\hline \multicolumn{2}{|l|}{ Structural social capital. Bonding social capital } \\
\hline Indicate the number of incubatees with whom you are in frequent contact & Ad hoc \\
\hline \multicolumn{2}{|c|}{$\begin{array}{l}\text { Relational social capital. Dimension trust (5-point Likert scale, anchored by “strongly disagree” and } \\
\text { "strongly agree”) }\end{array}$} \\
\hline \multicolumn{2}{|l|}{ The entrepreneurs who are in incubation, in the same incubator as me ... } \\
\hline \multicolumn{2}{|l|}{ Would not take advantage of others even if the opportunity arose } \\
\hline Always keep their promises & Chiu, Meng, and \\
\hline Behave in a consistent and honest manner & Wang (2006) \\
\hline \multicolumn{2}{|l|}{ Are truthful when dealing with one another } \\
\hline \multicolumn{2}{|c|}{$\begin{array}{l}\text { Relational social capital. Dimension identity (5-point Likert scale, anchored by “strongly disagree” and } \\
\text { "strongly agree") }\end{array}$} \\
\hline \multicolumn{2}{|l|}{ Evaluate the following statements: } \\
\hline There is a sense of group belonging within us, the incubatees & Chiu, Meng, and \\
\hline I have the feeling of group togetherness or closeness & Wang (2006) \\
\hline \multicolumn{2}{|c|}{$\begin{array}{l}\text { Relational social capital. Dimension reciprocity (5-point Likert scale, anchored by “strongly disagree” and } \\
\text { "strongly agree") }\end{array}$} \\
\hline \multicolumn{2}{|l|}{ Evaluate the following statements: } \\
\hline When I ask for help, I feel that other incubatees will provide it & Wasko and Faraj \\
\hline Even if an incubatee I have helped cannot help me in the future, others will be able to & (2005) \\
\hline \multicolumn{2}{|c|}{ Cognitive social capital (5-point Likert scale, anchored by “strongly disagree” and "strongly agree”) } \\
\hline \multicolumn{2}{|l|}{ The entrepreneurs who are in incubation, in the same incubator as me ... } \\
\hline Use a similar language and jargon to me & Chiu, Meng, and \\
\hline Use an understandable communication pattern & Wang (2006) \\
\hline $\begin{array}{l}\text { Share similar interests to mine } \\
\text { Are people whose interests I can identify with }\end{array}$ & $\begin{array}{l}\text { Kleijnen, Lievens, de } \\
\text { Ruyter, and Wetzels } \\
\text { (2009) }\end{array}$ \\
\hline
\end{tabular}

\section{(8) Business efficiency}

A specific result to emerge from incubation was considered: namely business efficiency. As no empirical work has been carried out in which this construct has been measured for the specific area under study, three reflective indicators were devised ad hoc. These measured whether during the incubation process the entrepreneur had managed to become more efficient in a range of aspects (planning, management and implementation), as shown in Table 4.13.

Table 4.13. Measurement of incubation result: items and reference

\begin{tabular}{lc}
\hline \multicolumn{1}{c}{ Variable and items } & Reference \\
\hline Business efficiency. (5-point Likert scale, anchored by "strongly disagree” and "strongly agree”) & \\
\hline Since I joined incubation, I have managed & Ad hoc \\
To be more efficient in planning and strategy for my business & \\
To be more efficient in managing my business & \\
To be more efficient in implementing specific activities for my business
\end{tabular}




\section{(9) Control variables}

In order to conclude the measurement of the variables through the questionnaire for incubatees, mention should be made of the nine control variables included, which were kept constant so as to offset their effects on the dependent variable posited. These variables are the following: entrepreneurial experience, experience as an employee in a company, academic/scientific experience, partners, time in incubation, existence of a coach, country and proactivity of the university.

Entrepreneurial experience. In the case of our particular study, academic incubatees (for example, teaching staff and researchers) do not tend to have any prior entrepreneurial experience. Although this is the usual case, it is by no means an axiom. As a result, a control variable was introduced to determine whether the individual had had any prior business experience (dichotomous scale $0=$ No, $1=$ Yes).

Experience as an employee in a company. Professional experience outside the academic and entrepreneurial field might impact on how individuals relate. Professional experience was thus also measured using a dichotomous variable through the question: "have you ever been a salaried worker outside the academic field?” ( $0=$ No, $1=$ Yes).

Academic/scientific experience. Possible UBI tenants are teaching staff, researchers, students and former students, all of whom have in one form or another been linked to the academic world, albeit in a different way. Students have benefitted from the university through the education and training they have received, although not all of them have scientific or academic experience. As a result, they were specifically asked whether they had any professional experience at a university or research centre (dichotomous scale $0=$ No, $1=$ Yes).

Partners. Academics tend to work in teams, yet not everyone who decides to engage in entrepreneurship and to enter a UBI has partners with whom to undertake their project. As a result, the following question was asked: “do you have partners?” (dichotomous scale $0=$ No, $1=$ Yes).

Time in incubation. The time individuals might spend in an incubator varies depending on a range of variables. What is more, each UBI can decide whether it establishes a maximum period its tenants can stay. In order to determine the exact value of this control variable, the number of months in incubation was measured. 
Existence of a coach. UBIs offering incubatees the services of a coach is optional. A dichotomous question was therefore included to determine whether individuals in the sample had been afforded this service ( $0=$ No, $1=$ Sí).

Country. At the start of the questionnaire, after being asked the name of the incubator, the following question dealt with the country in which it was located. Spain took the value 0 and the Netherlands the value 1 .

Proactivity of the university. Finally, aspects related to the university or research centre should be mentioned since the entrepreneur comes from said institutions and the UBI is linked and influenced by it. As a result, and in order to measure the proactive nature of the university with regard to entrepreneurship, a three-item reflective scale was included, shown in Table 4.14, and taken from the work of Morales (2008).

Table 4.14. Measurement of proactivity of the university: items and reference

\begin{tabular}{lc}
\hline \multicolumn{1}{c}{ Variable and items } & Reference \\
\hline Proactivity of the university (5-point Likert scale, anchored by “strongly disagree” and "strongly agree”) \\
\hline Rate the following aspects of your university/research centre of origin: \\
There is a tradition of creating spin-offs \\
There are specific regulations for creating spin-offs at my university/research centre & Morales (2008) \\
There is a positive attitude within my university/research centre towards entrepreneurship & \\
\hline
\end{tabular}

\subsubsection{Questionnaire to managers: design and description}

The drafting and design of the questionnaire given to managers was similar to that used for the incubatees' questionnaire. The sources used were bibliographical review and UBI information.

Amongst other sources, the review of UBI literature was based on the work of Radosevich (1995), Mian (1996), Jones-Evans and Klofsten (1998), Heydebreck et al. (2000), Grimaldi and Grandi (2001), dealt with in Chapter 1. In addition to contacting both Spanish and Dutch managers, documents from various agencies and bodies that foster entrepreneurial initiatives were consulted as were European UBIs that are examples of good practice ${ }^{16}$.

After drafting a version of the questionnaire which could have been final, a pre-test was conducted with the manager of the UBI at the Centre for the Transfer of Applied

\footnotetext{
${ }^{16}$ These include the IDEAS Institute at Valencia Polytechnic University, UNINOVA at the University of Santiago de Compostela, and The Netherlands Institute for Knowledge Intensive Entrepreneurship (NIKOS).
} 
Technologies (CTTA $)^{17}$ in September 2014. The pre-test led to the wording of various items being changed so as to make them more precise and easier to understand and to ensure they reflected what they sought to measure. Likewise, an indicator dealing with the services provided was added, specifically "guidance and support in securing funding, presentation of R\&D\&i projects to national and European calls, etc.”

Managers can be in charge of different incubation programmes: pre-incubation, incubation, and post-incubation. Bearing this in mind, they were asked in the questionnaire about the services provided in each, as can be seen in the final version of the questionnaire in Spanish, in Annex 3, and in English in Annex 4.

An explanation is given below of the various concepts measured in the questionnaire, as well as the items used to accomplish this. Given the specific nature of the study and the lack of empirical works, all scales were created ad hoc.

The variables were grouped into: (1) profile of the manager; (2) services offered by incubators; and (3) control variables.

\section{(1) Profile of the manager}

The UBI managers' professional career varies enormously: some only have experience in the academic world, others only have experience in business, and there are managers who have been involved in both worlds; hence, the importance and timeliness of gaining an insight into the managers' professional profile.

Scientific experience was measured through a single item, years of experience in the world of science. Experience in business was reflected in two formative items that dealt with years of experience as an entrepreneur and in the business world. Both were measured in five-item interval scales, 1 indicating "no experience”; 2 "up to 3 years”; 3 "between 3 and 5 years"; 4 "between 5 and 10 years"; and 5 “over 10 years".

\section{(2) Services offered by incubators}

For each incubation programme, a list of services was detailed allowing managers to indicate whether these had been provided or not in the UBI they managed and if they were offered, to what extent they were fostered.

${ }^{17}$ The CTTA belongs to and is located in the University of Valladolid Science Park. The person in charge of the incubator is Lourdes Rodríguez Blanco. 
The first variable, personal assistance, was measured based on a single indicator dealing with the availability of coaching or mentoring. For business assistance, four formative indicators were considered, encompassing assistance in financial planning, strategic decisions, preparing a business plan, and training in entrepreneurship. Finally, networking through the incubator was measured through two formative items reflecting access to incubator networks (business, associations, freelance, etc.), and meetings and events amongst incubatees aimed at promoting contacts amongst them.

All of these items (Table 4.15) were measured in six-position scales, where 1 indicates the service was not available in the incubator and 6 indicates the service was promoted very strongly.

Table 4.15. Measurement of incubation services: variables and items

\begin{tabular}{ll}
\hline \multicolumn{1}{c}{ Variables } & \multicolumn{1}{c}{ Items } \\
\hline Personal assistance & Coaching or mentoring \\
\hline & Assistance in planning financing and in obtaining financing \\
& Assistance in strategic decisions (internationalization, commercialization, \\
Business assistance & $\begin{array}{l}\text { implementation of products and services, etc.) } \\
\text { Sparring and assistance in preparing a business plan }\end{array}$ \\
& Business and entrepreneurship training (workshops, sessions, etc.) \\
\hline \multirow{3}{*}{ Networking } & Access to networks outside the incubator (business, associations, freelance, etc.) \\
& Meetings and events between incubatees in order to foster contacts and relationships \\
& between them
\end{tabular}

\section{(3) Control variables}

Three control variables were considered. Years the incubator had been in operation and years as incubator manager were each measured with a single item, the number of years the incubator had been operating and the number of years the manager had been running it, respectively. Finally, the country variable was included.

\subsubsection{Data collection}

Data were collected between September 2014 and March 2015 from UBIs in Spain and the Netherlands. The decision to opt for these two countries was based on the interest they created and the possibility they afforded of obtaining information concerning UBIs.

Since there are no databases of the number of UBIs in Spain and the Netherlands, we consulted each university webpage or phoned to find out the number of incubators. In 
Spain, 52 universities have an incubator ${ }^{18}$. Some are involved in more than one incubation initiative in collaboration with other universities or with different types of agencies. One university even has two incubators. To sum up, in Spain there are 53 university incubators, and in the Netherlands there are $16^{19}$.

The data collection process commenced in Spain on 15 September 2014, and was conducted in two stages. During the first stage, all UBI managers were contacted by phone. The procedure followed was very much the same in each call: an explanation of the framework and goal of the study, and a two-fold request for their cooperation (asking them to fill in the questionnaires designed specifically for them as the person in charge of the various incubation programmes, and asking them to pass on the information and a questionnaire to their incubatees). If we received a positive reply, the link was immediately sent via e-mail indicating where the questionnaire for the manager together with the information and questionnaire for the incubatees could be found. The second stage commenced three weeks after the first had concluded. When no reply had been received from the manager and/or incubatees, managers were again contacted to remind them and to re-send them the information.

Whilst the first series of contacts was being completed with the managers of the Spanish incubators, collection of data from the Netherlands commenced. To do this, between 17 November and 9 December 2014, personal visits were made to two UBIs in the Netherlands (ACE Venture Lab in Amsterdam and TU/e Innovation Lab in Eindhoven). During these two visits, personal interviews were held with the managers. The latter filled in the questionnaires and contacted various incubatees, who were then provided with the information and questionnaires. Subsequently, the remaining managers and incubatees were telephoned and e-mailed to request their participation in the research. When a further three weeks had elapsed without receiving any reply from managers and/or incubatees, the information and questionnaires were sent once again.

\footnotetext{
${ }^{18}$ In Spain, there are 83 universities according to the information provided by the Spanish Government Ministry of Education, Culture and Sport through their website: www.universidad.es/universidades. At the time the present research was conducted, 31 universities had no incubator and were not directly involved in any incubation initiatives.

${ }^{19}$ In order to obtain this information, in addition to conducting an online search and consultation, we were fortunate to have the invaluable help of Professor Dr. Peter van der Sijde from VU University Amsterdam and Robert Al, founder of STARTUP/Eindhoven, the student incubator at Eindhoven University of Technology.
} 
Managers were asked to fill in one questionnaire for each incubation programme they ran (pre-incubation, incubation or post-incubation), since the management and services offered in each programme might differ. In certain instances, managers filled in up to three questionnaires.

After this process had concluded, 47 responses were obtained from managers, who provided information concerning a total of 93 incubation programmes and 101 incubatees.

Since we cannot know the exact number of tenants in the incubators (there are no databases of the number of UBIs and incubatees), we calculated an approximate sampling error. First, we calculated the approximate mean number of tenants in the UBIs in each country (from data provided by the managers), and then multiplied this figure by the number of UBIs in Spain, 53, and in the Netherlands, 16.

Population sizes, sample sizes, and sampling errors, for a confidence level of 95\%, are shown in Table 4.16 (managers) and Table 4.17 (incubatees).

Table 4.16. Population and sample sizes, and sampling errors of managers.

\begin{tabular}{lccc}
\hline Location of incubator & Population & Sample & $\begin{array}{c}\text { Sampling } \\
\text { error }\end{array}$ \\
\hline Spain & 53 & 39 & $8.14 \%$ \\
The Netherlands & 16 & 8 & $25.30 \%$ \\
\hline Total & 69 & 47 & $8.13 \%$ \\
\hline
\end{tabular}

Table 4.17. Population and sample sizes, and sampling errors of incubatees.

\begin{tabular}{lccc}
\hline \multicolumn{1}{c}{ Location of incubator } & Estimated population & Sample & Sampling error \\
\hline Spain & $1.855^{*}$ & 66 & $11.85 \%$ \\
The Netherlands & $544^{* *}$ & 35 & $16.04 \%$ \\
Total & 2.399 & 101 & $9.55 \%$ \\
\hline (*) Population of incubators in Spain (53) x Average number of incubatees in Spain (35) $^{* *}$ Population of incubators in the Netherlands (16) x Average number of incubatees in the Netherlands (34) \\
\hline
\end{tabular}

\subsubsection{Sample description}

The UBIs that form part of the sample account for $68.12 \%$ of the total population. Table 4.18 shows their features. Worth highlighting is the fact that $38.3 \%$ offer two (of the possible three) incubation programmes; $42.55 \%$ are supported by a university as well as by at least a further two other organisations; and 51.06\% have no means of selffinancing. 
Table 4.18. Description of the sample of incubators ( 47 incubators)

\begin{tabular}{|c|c|c|}
\hline & No. & $\%$ \\
\hline \multicolumn{3}{|l|}{ Location of incubator } \\
\hline Spain & 39 & 82.98 \\
\hline The Netherlands & 8 & 17.02 \\
\hline \multicolumn{3}{|l|}{ Years incubator has been in operation } \\
\hline Up to 2 years & 8 & 17.02 \\
\hline Between 3 and 5 years & 14 & 29.79 \\
\hline Between 6 and 8 years & 12 & 25.53 \\
\hline More than 8 years & 13 & 27.66 \\
\hline \multicolumn{3}{|l|}{ Incubation programmes/services } \\
\hline Pre-incubation & 6 & 12.77 \\
\hline Incubation & 9 & 19.15 \\
\hline Pre-incubation and incubation & 12 & 25.53 \\
\hline Incubation and post-incubation & 6 & 12.77 \\
\hline Pre-incubation, incubation and post-incubation & 14 & 29.79 \\
\hline \multicolumn{3}{|c|}{ Organizations that support and are involved with the incubator } \\
\hline University & 15 & 31.91 \\
\hline 2 organizations & 12 & 25.53 \\
\hline More than 2 organizations & 20 & 42.55 \\
\hline \multicolumn{3}{|l|}{ Self-financed incubator } \\
\hline $0 \%$ & 24 & 51.06 \\
\hline Between $1 \%$ and $25 \%$ & 3 & 6.38 \\
\hline Between $26 \%$ and $50 \%$ & 6 & 12.77 \\
\hline Between 51\% and 75\% & 2 & 4.26 \\
\hline Between $76 \%$ and $100 \%$ & 12 & 25.53 \\
\hline
\end{tabular}

As regards incubation programmes, displayed in Table 4.19, it is worth highlighting that pre-incubation has the shortest stay period (up to 6 months, or between 7 and 12 months), incubation the longest period (between 13 and 36 months), and that postincubation is noticeable for not having any maximum periods of stay in the programme (this happens in $65 \%$ of instances). As regards the cost of each programme for beneficiaries, pre-incubation stands out because it is free (81.25\%), and incubation and post-incubation because they depend on the various services in which incubatees are involved. Of the three, incubation displays the highest occupation rates and graduation ratio. 
Table 4.19. Description of the sample of incubation programs (93 incubation programs)

\begin{tabular}{|c|c|c|c|c|c|c|}
\hline & \multicolumn{2}{|c|}{ Pre-incubation } & \multicolumn{2}{|c|}{ Incubation } & \multicolumn{2}{|c|}{ Post-incubation } \\
\hline & No. & $\%$ & No. & $\%$ & No. & $\%$ \\
\hline \multicolumn{7}{|l|}{ Location of incubator } \\
\hline Spain & 26 & 81.25 & 33 & 80.49 & 17 & 85.00 \\
\hline The Netherlands & 6 & 18.75 & 8 & 19.51 & 3 & 15.00 \\
\hline \multicolumn{7}{|l|}{ Maximum incubation period } \\
\hline No maximum & 2 & 6.25 & 4 & 9.76 & 13 & 65.00 \\
\hline Up to 6 months & 15 & 46.88 & 3 & 7.32 & 2 & 10.00 \\
\hline Between 7 and 12 months & 15 & 46.88 & 6 & 14.63 & 0 & 0.00 \\
\hline Between 13 and 36 months & 0 & 0.00 & 20 & 48.78 & 5 & 25.00 \\
\hline More than 36 months & 0 & 0.00 & 8 & 19.51 & 0 & 0.00 \\
\hline \multicolumn{7}{|l|}{ Average incubation period (*) } \\
\hline Up to 6 months & 20 & 66.67 & 4 & 10.26 & 2 & 25.00 \\
\hline Between 07 and 12 months & 10 & 33.33 & 7 & 17.95 & 0 & 0.00 \\
\hline Between 13 and 36 months & 0 & 0.00 & 25 & 64.10 & 5 & 62.50 \\
\hline More than 36 months & 0 & 0.00 & 3 & 7.69 & 1 & 12.50 \\
\hline \multicolumn{7}{|c|}{$\begin{array}{l}\text { Space available (office, labs, etc.) in order to } \\
\text { work on business plan/to develop business } \\
\text { activities }\end{array}$} \\
\hline Yes & 28 & 87.50 & 40 & 97.56 & 20 & 100.00 \\
\hline No & 4 & 12.50 & 1 & 2.44 & 0 & 0.00 \\
\hline \multicolumn{7}{|l|}{ Cost per month } \\
\hline Free & 26 & 81.25 & 7 & 17.07 & 8 & 40.00 \\
\hline Variable & 1 & 3.13 & 23 & 56.10 & 10 & 50.00 \\
\hline$\underline{\text { Fixed }}$ & 5 & 15.63 & 11 & 26.83 & 2 & 10.00 \\
\hline \multicolumn{7}{|c|}{$\begin{array}{l}\text { Maximum occupancy (number of } \\
\text { projects/start-ups/firms) }\end{array}$} \\
\hline No maximum & 8 & 25.00 & 4 & 9.76 & 10 & 50.00 \\
\hline Up to 5 & 10 & 31.25 & 5 & 12.20 & 1 & 5.00 \\
\hline Between 6 and 10 & 7 & 21.88 & 10 & 24.39 & 1 & 5.00 \\
\hline Between 11 and 20 & 4 & 12.50 & 8 & 19.51 & 3 & 15.00 \\
\hline Between 21 and 50 & 2 & 6.25 & 11 & 26.83 & 4 & 20.00 \\
\hline More than 50 & 1 & 3.13 & 3 & 7.32 & 1 & 5.00 \\
\hline \multicolumn{7}{|c|}{$\begin{array}{l}\begin{array}{l}\text { Occupancy } \\
\text { ups/firms) }\end{array} \\
\text { (number of projects/start- }\end{array}$} \\
\hline No projects & 5 & 15.63 & 0 & 0.00 & 0 & 0.00 \\
\hline Up to 5 & 12 & 37.50 & 11 & 26.83 & 5 & 25.00 \\
\hline Between 6 and 10 & 9 & 28.13 & 11 & 26.83 & 5 & 25.00 \\
\hline Between 11 and 20 & 3 & 9.38 & 9 & 21.95 & 4 & 20.00 \\
\hline Between 21 and 50 & 2 & 6.25 & 9 & 21.95 & 5 & 25.00 \\
\hline More than 50 & 1 & 3.13 & 1 & 2.44 & 1 & 5.00 \\
\hline \multicolumn{7}{|c|}{ Occupancy (number of incubatees/partners) } \\
\hline No incubatees & 5 & 15.63 & 0 & 0.00 & 0 & 0.00 \\
\hline Up to 5 & 8 & 25.00 & 6 & 14.63 & 4 & 20.00 \\
\hline Between 6 and 10 & 5 & 15.63 & 5 & 12.20 & 2 & 10.00 \\
\hline Between 11 and 20 & 7 & 21.88 & 10 & 24.39 & 6 & 30.00 \\
\hline Between 21 and 50 & 6 & 18.75 & 17 & 41.46 & 5 & 25.00 \\
\hline More than 50 & 1 & 3.13 & 3 & 7.32 & 3 & 15.00 \\
\hline \multicolumn{7}{|c|}{ Rate of graduated projects/companies (**) } \\
\hline Up to $20 \%$ & 5 & 20.83 & 1 & 3.13 & - & - \\
\hline Between 21\% and 40\% & 6 & 25.00 & 4 & 12.50 & - & - \\
\hline Between $41 \%$ and $60 \%$ & 6 & 25.00 & 2 & 6.25 & - & - \\
\hline Between $61 \%$ and $80 \%$ & 4 & 16.67 & 12 & 37.50 & - & - \\
\hline More than $80 \%$ & 3 & 12.50 & 13 & 40.63 & - & - \\
\hline
\end{tabular}


In the case of the managers, $82.98 \%$ of responses came from Spanish managers and the remaining $17.02 \%$ from Dutch managers. Taking into account the characteristics of the sample, shown in Table 4.20, managers are mainly between the ages of 36 and 45, and hold a master's degree in the area of social sciences. They have experience as entrepreneurs in the academic world and in the business world. They have also combined their work as UBI managers with other professional activities over the last year. 
Table 4.20. Description of the sample of managers (47 managers)

\begin{tabular}{|c|c|c|}
\hline & No. & $\%$ \\
\hline \multicolumn{3}{|l|}{ Location of incubator } \\
\hline Spain & 39 & 82.98 \\
\hline The Netherlands & 8 & 17.02 \\
\hline \multicolumn{3}{|l|}{ Age of manager } \\
\hline Between 25 and 35 & 8 & 17.02 \\
\hline Between 36 and 45 & 24 & 51.06 \\
\hline Between 46 and 55 & 12 & 25.53 \\
\hline Between 56 and 65 & 3 & 6.38 \\
\hline \multicolumn{3}{|l|}{ Gender } \\
\hline Male & 24 & 51.06 \\
\hline Female & 23 & 48.94 \\
\hline \multicolumn{3}{|l|}{ Qualifications } \\
\hline $\mathrm{PhD}$ & 10 & 21.28 \\
\hline Master & 22 & 46.81 \\
\hline Bachelor & 15 & 31.91 \\
\hline \multicolumn{3}{|l|}{ Area of knowledge } \\
\hline Sciences & 11 & 23.40 \\
\hline Health sciences & 2 & 4.26 \\
\hline Social sciences & 27 & 57.45 \\
\hline Engineering \& architecture & 6 & 12.77 \\
\hline Arts \& humanities & 1 & 2.13 \\
\hline \multicolumn{3}{|c|}{ Experience in the science world } \\
\hline No experience & 18 & 38.30 \\
\hline Up to 3 years & 7 & 14.89 \\
\hline Between 4 and 5 years & 3 & 6.38 \\
\hline Between 6 and 10 years & 9 & 19.15 \\
\hline More than 10 years & 10 & 21.28 \\
\hline \multicolumn{3}{|c|}{ Experience in the business world } \\
\hline No experience & 14 & 29.79 \\
\hline Up to 3 years & 7 & 14.89 \\
\hline Between 4 and 5 years & 3 & 6.38 \\
\hline Between 6 and 10 years & 12 & 25.53 \\
\hline More than 10 years & 11 & 23.40 \\
\hline \multicolumn{3}{|l|}{ Entrepreneurial experience } \\
\hline No experience & 21 & 44.68 \\
\hline Up to 3 years & 6 & 12.77 \\
\hline Between 4 and 5 years & 6 & 12.77 \\
\hline Between 6 and 10 years & 6 & 12.77 \\
\hline More than 10 years & 8 & 17.02 \\
\hline \multicolumn{3}{|c|}{ Years as manager of the incubator } \\
\hline Up to 12 months & 16 & 34.04 \\
\hline Between 13 and 24 months & 6 & 12.77 \\
\hline Between 25 and 36 months & 8 & 17.02 \\
\hline Between 37 and 48 months & 4 & 8.51 \\
\hline More than 48 months & 13 & 27.66 \\
\hline \multicolumn{3}{|c|}{ Incubator manager as only job } \\
\hline Yes & 14 & 29.79 \\
\hline No & 33 & 70.21 \\
\hline
\end{tabular}

As regards the incubatees, Spaniards accounted for $65.34 \%$ compared to $34.66 \%$ Dutch. The incubatees who make up the sample are mainly male (71.29\%), aged between 25 and 35 (57.43\%), are graduates (51.49\%) from the field of engineering and architecture (49.50\%), with no prior entrepreneurial experience (77.22\%). The full description of the sample is shown in Table 4.21. 
Table 4.21. Description of the sample of incubatees (101 incubatees)

\begin{tabular}{|c|c|c|}
\hline & No. & $\%$ \\
\hline \multicolumn{3}{|l|}{ Location of incubator } \\
\hline Spain & 66 & 65.35 \\
\hline The Netherlands & 35 & 34.65 \\
\hline \multicolumn{3}{|l|}{ Age of incubatee } \\
\hline Less than 25 & 15 & 14.85 \\
\hline Between 25 and 35 & 58 & 57.43 \\
\hline Between 36 and 45 & 20 & 19.80 \\
\hline Between 46 and 55 & 7 & 6.93 \\
\hline Between 56 and 65 & 1 & 0.99 \\
\hline \multicolumn{3}{|l|}{ Gender } \\
\hline Male & 72 & 71.29 \\
\hline$\underline{\text { Female }}$ & 29 & 28.71 \\
\hline \multicolumn{3}{|l|}{ Highest qualification } \\
\hline $\mathrm{PhD}$ & 14 & 14.29 \\
\hline Master & 34 & 34.69 \\
\hline Bachelor & 50 & 51.02 \\
\hline \multicolumn{3}{|c|}{ Incubatees studying at present (type of studies) } \\
\hline $\mathrm{PhD}$ & 3 & 9.09 \\
\hline Master & 18 & 54.54 \\
\hline Bachelor & 12 & 36.36 \\
\hline \multicolumn{3}{|l|}{ Status } \\
\hline Professor & 5 & 4.95 \\
\hline Researcher & 16 & 15.84 \\
\hline Student & 28 & 27.72 \\
\hline Graduate & 52 & 51.49 \\
\hline \multicolumn{3}{|l|}{ Area of knowledge } \\
\hline Sciences & 23 & 22.77 \\
\hline Health sciences & 6 & 5.94 \\
\hline Social sciences & 18 & 17.82 \\
\hline Engineering \& architecture & 50 & 49.50 \\
\hline Arts \& humanities & 4 & 3.96 \\
\hline \multicolumn{3}{|c|}{ Experience as an employee in a company } \\
\hline No experience & 35 & 34.65 \\
\hline Up to 3 years & 29 & 28.71 \\
\hline Between 4 and 5 years & 7 & 6.93 \\
\hline Between 6 and 10 years & 15 & 14.85 \\
\hline More than 10 years & 15 & 14.85 \\
\hline \multicolumn{3}{|c|}{ Previous entrepreneurial experience } \\
\hline No experience & 78 & 77.22 \\
\hline Up to 3 years & 15 & 14.85 \\
\hline Between 4 and 5 years & 4 & 3.96 \\
\hline Between 6 and 10 years & 2 & 1.98 \\
\hline More than 10 years & 2 & 1.98 \\
\hline \multicolumn{3}{|c|}{$\begin{array}{l}\text { Academic/scientific experience at a university/research } \\
\text { centre }\end{array}$} \\
\hline No experience & 79 & 78.22 \\
\hline Up to 3 years & 14 & 13.86 \\
\hline Between 4 and 5 years & 1 & 0.99 \\
\hline Between 6 and 10 years & 2 & 1.98 \\
\hline More than 10 years & 5 & 4.95 \\
\hline \multicolumn{3}{|l|}{ Research group } \\
\hline Research Group Member & 12 & 11.88 \\
\hline Research Group Director & 8 & 7.92 \\
\hline No member/director & 81 & 80.20 \\
\hline
\end{tabular}

Number of months in incubation 


\begin{tabular}{|c|c|c|}
\hline Less than 6 months & 19 & 18.81 \\
\hline Between 6 and 12 months & 38 & 37.62 \\
\hline Between 13 and 24 months & 27 & 26.73 \\
\hline More than 24 months & 17 & 16.83 \\
\hline \multicolumn{3}{|l|}{ Coach assigned } \\
\hline Yes, only for me & 16 & 15.84 \\
\hline Yes, he/she is a group coach & 28 & 27.72 \\
\hline No & 57 & 56.44 \\
\hline \multicolumn{3}{|l|}{ Group coach (number of people in the group) } \\
\hline Between 2 and 4 & 7 & 25.00 \\
\hline Between 5 and 8 & 7 & 25.00 \\
\hline Between 9 and 12 & 6 & 21.43 \\
\hline More than 12 & 8 & 28.57 \\
\hline \multicolumn{3}{|l|}{ Participation in pre-incubation } \\
\hline Yes & 43 & 42.57 \\
\hline No & 58 & 57.43 \\
\hline \multicolumn{3}{|l|}{ Partners } \\
\hline No partners & 29 & 28.71 \\
\hline 1 partner & 24 & 23.76 \\
\hline 2 partners & 27 & 26.73 \\
\hline$\underline{3}$ or more partners & 21 & 20.79 \\
\hline \multicolumn{3}{|l|}{ Open to having partners } \\
\hline No partner/s & 14 & 13.86 \\
\hline Yes, only academic background & 2 & 1.98 \\
\hline Yes, only business background & 51 & 50.49 \\
\hline Yes, but background not important & 25 & 24.75 \\
\hline It could be a possibility, but only academic background & 1 & 0.99 \\
\hline It could be a possibility, but only business background & 4 & 3.96 \\
\hline It could be a possibility, but background not important & 4 & 3.96 \\
\hline
\end{tabular}




\subsection{Study II. Determinants and outcomes of dyadic relationships between incubatees}

Study II aims to quantitatively test hypotheses H1 to H12, which make up Model 1 proposed in chapter 2. More specifically, this study seeks to explore the determinants driving the creation of relations between incubatees, and to examine the effect such relations have on new entrepreneurs and their businesses.

An explanation of how this sequence of analysis was carried out is given below. First, the descriptive statistics of the variables included in the study are shown, together with an analysis of the homogeneity of the samples used (Spanish and Dutch incubatees). Subsequently, the process for validating the scales of the various constructs is explained, and the results of estimating the structural model are presented together with the indirect and total effects. Finally, the results of the hypotheses posited are evaluated.

\subsubsection{Descriptive statistics of the measurement variables}

Part of the information gathered through the questionnaire given to incubatees was used in the present research. Table 4.22 shows the descriptive statistics corresponding to the variables and measures used. The lowest mean (2.68) corresponds to one of the indicators used to measure supplementarity of resources. By contrast, the highest mean (4.43) is found in an indicator of the promotion focus variable. Standard deviations range between 0.634 , the lowest, and 1.304 , the highest.

Table 4.22. Descriptive statistics of the variables (Study II)

\begin{tabular}{|c|c|c|c|c|}
\hline & Mean & S.D. & Min. & Max. \\
\hline \multicolumn{5}{|l|}{ Empathy. Evaluate the following statements: } \\
\hline I have little difficulty in "putting myself into other people's shoes" & 3.23 & 1.256 & 1 & 5 \\
\hline \multicolumn{5}{|l|}{ Shared values. This entrepreneur: } \\
\hline His/her values and behavioural norms are congruent with mine & 3.76 & 0.802 & 2 & 5 \\
\hline His/her philosophy/approach to business is compatible with mine & 3.59 & 0.866 & 2 & 5 \\
\hline His/her goals and objectives are compatible with mine & 3.72 & 0.862 & 2 & 5 \\
\hline \multicolumn{5}{|l|}{ Complementary resources. This entrepreneur: } \\
\hline Has different resources to mine that are very precious to me & 3.50 & 1.119 & 1 & 5 \\
\hline His/her resources are necessary to achieve my goals & 3.11 & 1.240 & 1 & 5 \\
\hline Has different and complementary resources to mine & 3.66 & 1.023 & 1 & 5 \\
\hline $\begin{array}{l}\text { His/her resources, combined with mine, enable me to achieve more satisfactory } \\
\text { results }\end{array}$ & 3.89 & 1.048 & 1 & 5 \\
\hline \multicolumn{5}{|l|}{ Supplementary resources. This entrepreneur: } \\
\hline Has similar resources to mine, but nevertheless they are very precious to me & 2.68 & 1.166 & 1 & 5 \\
\hline Has similar resources to mine, but supplementary to mine & 2.92 & 1.181 & 1 & 5 \\
\hline $\begin{array}{l}\text { His/her resources are similar to mine, but when combined, allow me to achieve } \\
\text { more satisfactory results }\end{array}$ & 2.98 & 1.304 & 1 & 5 \\
\hline
\end{tabular}

Transferability. Regarding my knowledge or training applied to business that I have started: 
The knowledge (technical-scientific) held by me is easily transferable

Evaluate the following statements about this entrepreneur:

The knowledge (technical-scientific) held by him/her is easily transferable

Willingness to share knowledge. Evaluate the following statements:

When I learn something new, I tell my colleagues

I share the information I have with my colleagues when they ask me to

I share my skills with my colleagues when they ask me to

Promotion focus. The following questions regard specific events in your life (from

1. never or seldom to 5. very often):

I feel like I have made progress toward being successful in my life

Evaluate the following statements:

I am always looking for better ways to do things

No matter what the odds are, if I believe in something I will make it happen

Trust in the incubatee. This entrepreneur:

is honest and truthful

exchanges information with me that is reliable

honestly communicates any problem that may affect me

is willing to provide assistance and support when circumstances so require

in my opinion acts in my best interest

is, in general, a person who honours his/her commitments

is competent and effective

Commitment in the relationship. Evaluate the following statements:

I intend to strengthen our relationship over time

I intend to continue our relationship for a long time

I am committed to sharing ideas and knowledge with him/her

This entrepreneur:

is willing to strengthen our relationship over time

is willing to continue our relationship for a long time

is committed to sharing ideas and knowledge with me

3.05

$3.07 \quad 1.032 \quad 1$

1

$3.41 \quad 1.022$

$4.28 \quad 0.709$

$4.27 \quad 0.691$

1

2

2

5

\section{Exchange of knowledge.}

Communication-Frequency. In our relationship:

We ask for mutual advice and recommendations

We share all types of information

We provide any information that may be useful to the other party

$\begin{array}{llll}3.92 & 0.845 & 1 & 5\end{array}$

$\begin{array}{llll}4.12 & 0.810 & 2 & 5\end{array}$

Each party informs the other about events that may affect them

We frequently work together

We frequently have contact

\section{Knowledge transfer.}

Through this entrepreneur:

I get technical knowledge and a tremendous amount of know-how

I learn from his/her knowledge

I learn from his/her experience

I assimilate the knowledge that he/she gives me and it contributes to the development of my start-up

Through me, the other entrepreneur:

Has access to market knowledge

$\begin{array}{llll}4.30 & 0.701 & 2 & 5\end{array}$

$\begin{array}{llll}4.27 & 0.720 & 2 & 5\end{array}$

$\begin{array}{llll}4.06 & 0.746 & 2 & 5\end{array}$

$\begin{array}{llll}4.07 & 0.778 & 2 & 5\end{array}$

$\begin{array}{llll}3.90 & 0.922 & 1 & 5\end{array}$

$\begin{array}{llll}4.11 & 0.799 & 2 & 5\end{array}$

$\begin{array}{llll}4.13 & 0.730 & 2 & 5\end{array}$

$\begin{array}{llll}4.09 & 0.907 & 1 & 5\end{array}$

$\begin{array}{llll}4.08 & 0.913 & 1 & 5\end{array}$

$\begin{array}{llll}4.00 & 0.872 & 1 & 5\end{array}$

$\begin{array}{llll}3.98 & 0.894 & 2 & 5\end{array}$

$\begin{array}{llll}4.01 & 0.943 & 1 & 5\end{array}$

$\begin{array}{llll}3.90 & 0.922 & 2 & 5\end{array}$

Acquires technical knowledge and a tremendous amount of know-how

Learns from my knowledge

Learns from my experience

Assimilates the knowledge that I give him/her, and which contributes to the development of his/her start-up

Entrepreneurial commitment. The relationship with this entrepreneur has allowed me:

To be more committed to my entrepreneurial goals

To be more demanding about my entrepreneurial goals

To be more ambitious about my entrepreneurial goals

$\begin{array}{llll}3.91 & 0.918 & 1 & 5 \\ 3.66 & 0.972 & 1 & 5 \\ 3.93 & 0.951 & 1 & 5 \\ 3.97 & 0.921 & 1 & 5 \\ 3.31 & 1.027 & 1 & 5 \\ 3.81 & 0.891 & 1 & 5\end{array}$

Generation of innovation. The relationship with this entrepreneur has enabled my business:

To be more innovative in terms of product or service

To reach a wider market

To be more feasible in its development

In the future, I think the relationship with this entrepreneur will stimulate:

$\begin{array}{llll}3.39 & 1.104 & 1 & 5 \\ 3.61 & 0.959 & 1 & 5 \\ 3.43 & 1.043 & 1 & 5 \\ 3.57 & 0.973 & 1 & 5 \\ & & & \\ 3.11 & 1.207 & 1 & 5 \\ 3.62 & 1.028 & 1 & 5 \\ 3.67 & 0.850 & 1 & 5 \\ 3.39 & 0.948 & 1 & 5 \\ 3.51 & 1.006 & 1 & 5\end{array}$

\begin{tabular}{llll}
3.35 & 1.170 & 1 & 5 \\
3.38 & 1.148 & 1 & 5 \\
3.59 & 1.106 & 1 & 5 \\
\hline
\end{tabular}

$\begin{array}{llll}3.56 & 1.117 & 1 & 5 \\ 3.72 & 1.115 & 1 & 5 \\ 3.68 & 1.174 & 1 & 5\end{array}$




\begin{tabular}{llrrr} 
Generation of innovation & 3.81 & 1.046 & 1 & 5 \\
New products/services & 3.81 & 1.093 & 1 & 5 \\
\hline Business results. The relationship with this entrepreneur has allowed me: & & & & \\
To increase sales & 3.07 & 1.274 & 1 & 5 \\
To create new market opportunities & 3.48 & 1.162 & 1 & 5 \\
To generate profits & 3.14 & 1.263 & 1 & 5 \\
\hline
\end{tabular}

As the sample is made up of individuals in Spain and the Netherlands, in order to pinpoint possible differences amongst incubatees from one country and another, the possibility of a different response pattern for the indicators used was examined. This analysis was performed by using a $t$ test for independent samples. Table 4.23 shows the results of comparing the means for each indicator. As can be seen in the Table referred to, only 13 of the 60 items used evidence differences in the means for the two groups. Specifically, Spanish incubatees gave higher scores to indicators measuring empathy and experience as a salaried worker outside the academic world. For their part, the Dutch awarded higher scores to complementarity and supplementarity of resources, promotion focus, trust and exchange of knowledge. In the light of these results, it can be affirmed that the two samples display a high degree of homogeneity.

It is worth noting that the two individual incubatee characteristics, promotion focus and willingness to share knowledge, have high values in both samples.

Table 4.23. Means test (Study II)

\begin{tabular}{|c|c|c|c|c|c|}
\hline & Country & $\mathbf{N}$ & Mean & S.D. & $\mathbf{t}$ \\
\hline \multicolumn{6}{|l|}{ Empathy } \\
\hline \multirow{2}{*}{$\begin{array}{l}\text { I have little difficulty in "putting myself into other people's } \\
\text { shoes" }\end{array}$} & Spain & 66 & 3.39 & 1.311 & \multirow{2}{*}{$1.848^{+}$} \\
\hline & The Netherlands & 35 & 2.91 & 1.095 & \\
\hline \multicolumn{6}{|c|}{ Shared values } \\
\hline \multirow{2}{*}{ His/her values and behavioural norms are congruent with mine } & Spain & 66 & 3.73 & 0.869 & \multirow{2}{*}{-0.654} \\
\hline & The Netherlands & 35 & 3.83 & 0.664 & \\
\hline \multirow{2}{*}{$\begin{array}{l}\text { His/her philosophy/approach to business is compatible with } \\
\text { mine }\end{array}$} & Spain & 66 & 3.65 & 0.860 & \multirow{2}{*}{0.955} \\
\hline & The Netherlands & 35 & 3.47 & 0.879 & \\
\hline \multirow{2}{*}{ His/her goals and objectives are compatible with mine } & Spain & 66 & 3.76 & 0.842 & \multirow{2}{*}{0.556} \\
\hline & The Netherlands & 35 & 3.66 & 0.906 & \\
\hline \multicolumn{6}{|l|}{ Complementary resources } \\
\hline \multirow{2}{*}{ Has different resources to mine that are very precious to me } & Spain & 66 & 3.55 & 1.192 & \multirow{2}{*}{0.659} \\
\hline & The Netherlands & 35 & 3.40 & 0.976 & \\
\hline \multirow{2}{*}{ His/her resources are necessary to achieve my goals } & Spain & 66 & 3.02 & 1.271 & \multirow{2}{*}{-1.044} \\
\hline & The Netherlands & 35 & 3.29 & 1.178 & \\
\hline \multirow{2}{*}{ Has different and complementary resources to mine } & Spain & 66 & 3.73 & 1.089 & \multirow{2}{*}{0.861} \\
\hline & The Netherlands & 35 & 3.54 & 0.886 & \\
\hline \multirow{2}{*}{$\begin{array}{l}\text { His/her resources, combined with mine, enable me to achieve } \\
\text { more satisfactory results }\end{array}$} & Spain & 66 & 3.73 & 1.117 & \multirow{2}{*}{$-2.402 *$} \\
\hline & The Netherlands & 35 & 4.20 & 0.833 & \\
\hline \multicolumn{6}{|l|}{ Supplementary resources } \\
\hline \multirow{2}{*}{$\begin{array}{l}\text { Has similar resources to mine. Nevertheless, they are very } \\
\text { precious to me }\end{array}$} & Spain & 66 & 2.45 & 1.139 & \multirow{2}{*}{$-2.798 * *$} \\
\hline & The Netherlands & 35 & 3.11 & 1.105 & \\
\hline \multirow{2}{*}{$\begin{array}{l}\text { Has similar resources to mine. However, they are } \\
\text { supplementary to mine }\end{array}$} & Spain & 66 & 2.73 & 1.158 & \multirow{2}{*}{$-2.311^{*}$} \\
\hline & The Netherlands & 35 & 3.29 & 1.152 & \\
\hline
\end{tabular}




\begin{tabular}{|c|c|c|c|c|c|}
\hline \multirow{2}{*}{$\begin{array}{l}\text { His/her resources are similar to mine, but when combined, } \\
\text { allow me to achieve more satisfactory results }\end{array}$} & Spain & 66 & 2.73 & 1.259 & \multirow{2}{*}{$-2.765 * *$} \\
\hline & The Netherlands & 35 & 3.46 & 1.268 & \\
\hline \multicolumn{6}{|l|}{ Transferability } \\
\hline \multirow{2}{*}{$\begin{array}{l}\text { The knowledge (technical-scientific) held by me is easily } \\
\text { transferable }\end{array}$} & Spain & 66 & 2.97 & 1.176 & \multirow{2}{*}{-0.970} \\
\hline & The Netherlands & 35 & 3.20 & 1.052 & \\
\hline \multirow{2}{*}{$\begin{array}{l}\text { The knowledge (technical-scientific) held by him/her is easily } \\
\text { transferable }\end{array}$} & Spain & 66 & 2.97 & 1.081 & \multirow{2}{*}{-1.337} \\
\hline & The Netherlands & 35 & 3.26 & 0.919 & \\
\hline \multicolumn{6}{|l|}{ Willingness to share knowledge } \\
\hline \multirow{2}{*}{ When I learn something new, I tell my colleagues } & Spain & 66 & 3.39 & 1.080 & \multirow{2}{*}{-0.161} \\
\hline & The Netherlands & 35 & 3.43 & 0.917 & \\
\hline \multirow{2}{*}{$\begin{array}{l}\text { I share the information I have with my colleagues when they } \\
\text { ask me to }\end{array}$} & Spain & 66 & 4.30 & 0.764 & \multirow{2}{*}{0.501} \\
\hline & The Netherlands & 35 & 4.23 & 0.598 & \\
\hline \multirow{2}{*}{ I share my skills with my colleagues when they ask me to } & Spain & 66 & 4.29 & 0.739 & \multirow{2}{*}{0.409} \\
\hline & The Netherlands & 35 & 4.23 & 0.598 & \\
\hline \multicolumn{6}{|l|}{ Promotion focus } \\
\hline \multirow{2}{*}{$\begin{array}{l}\text { I feel I have made progress towards being successful in my } \\
\text { life }\end{array}$} & Spain & 66 & 3.82 & 0.875 & \multirow{2}{*}{$-1.692^{+}$} \\
\hline & The Netherlands & 35 & 4.11 & 0.758 & \\
\hline I am alwavs looking for hetter wavs to do things & Spain & 60 & 4.38 & 0.666 & -1066 \\
\hline 1 am always looking for better ways to do tnings & The Netherlands & 32 & 4.53 & 0.567 & \\
\hline No matter what the odds are, if I believe in something I will & Spain & 60 & 3.93 & 0.800 & \\
\hline make it happen & The Netherlands & 32 & 4.47 & 0.718 & $-3.166^{* * *}$ \\
\hline Commitment in the relationship & & & & & \\
\hline Lintend to strengthen our relationshin over time & Spain & 66 & 4.08 & 0.933 & -0.202 \\
\hline 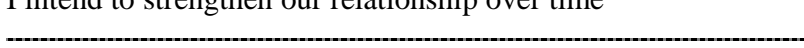 & The Netherlands & 35 & 4.11 & 0.867 & -0.202 \\
\hline I intend to continue our relationship for a long time & Spain & 66 & 4.03 & 0.944 & -0.738 \\
\hline 1 & The Netherlands & 35 & 4.17 & 0.857 & -0.150 \\
\hline I am committed to sharino ideas and knowledoe with him/her & Spain & 66 & 3.94 & 0.909 & 059 950 \\
\hline 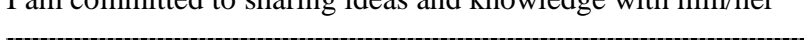 & The Netherlands & 35 & 4.11 & 0.796 & -0.909 \\
\hline $\mathrm{He} / \mathrm{she}$ is willing to strengthen our relationship over time & Spain & 66 & 3.89 & 0.947 & -1.336 \\
\hline & The Netherlands & 35 & 4.14 & 0.772 & -1.030 \\
\hline $\mathrm{He}$ /she is willing to continue our relationshin for a long time & Spain & 66 & 3.91 & 0.972 & -1484 \\
\hline 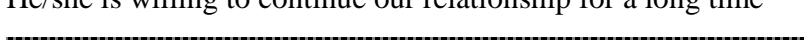 & The Netherlands & 35 & 4.20 & 0.868 & -1.404 \\
\hline & Spain & 66 & 3.80 & 0.980 & \\
\hline He/sne is committed to snaring ideas and knowleage with me & The Netherlands & 35 & 4.09 & 0.781 & -1.581 \\
\hline Trust in the incubatee & & & & & \\
\hline $\mathrm{He} /$ she is honest and truthful & Spain & 66 & 4.21 & 0.755 & \\
\hline He/sne is nonest and trutniul & The Netherlands & 35 & 4.46 & 0.561 & -1.688 \\
\hline The information he/she exchanges with me is reliable & Spain & 66 & 4.24 & 0.745 & -0.476 \\
\hline ine iniormation ne/sne excnanges witn me is relladie & The Netherlands & 35 & 4.31 & 0.676 & $-0.4 / 6$ \\
\hline $\mathrm{He} /$ she honestly communicates any problem that may affect & Spain & 66 & 4.08 & 0.751 & 0.301 \\
\hline & The Netherlands & 35 & 4.03 & 0.747 & 0.301 \\
\hline $\mathrm{He} / \mathrm{she}$ is willing to provide assistance and support when & Spain & 66 & 4.05 & 0.849 & -0.421 \\
\hline circumstances so require & The Netherlands & 35 & 4.11 & 0.631 & $-0.4 \angle 1$ \\
\hline I believe that he/she acts in my best interest & Spain & 66 & 3.80 & 0.964 & -1.475 \\
\hline 1 Deneve that me/sne acts in miny Dest interest & The Netherlands & 35 & 4.09 & 0.818 & $-1.4 / 5$ \\
\hline In general, he/she is a person who honours his/her & Spain & 66 & 4.00 & 0.823 & $-1.906^{+}$ \\
\hline commitments & The Netherlands & 35 & 4.31 & 0.718 & -1.900 \\
\hline $\mathrm{He} /$ she is competent and effective & Spain & 66 & 4.11 & 0.767 & -0.426 \\
\hline He/sne is competent and entective & The Netherlands & 35 & 4.17 & 0.664 & $-0.4<0$ \\
\hline Exchange of knowledge & & & & & \\
\hline Communication & & & & & \\
\hline We ask for mutual advice and recom & Spain & 66 & 3.82 & 0.975 & -1 \\
\hline 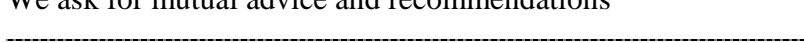 & The Netherlands & 35 & 4.09 & 0.781 & J1 \\
\hline We share all tvpes of information & Spain & 66 & 3.62 & 1.034 & -0.596 \\
\hline 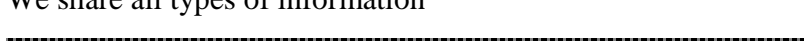 & The Netherlands & 35 & 3.74 & 0.852 & -0.030 \\
\hline We provide any information that may be useful to the other & Spain & 66 & 3.82 & 1.006 & -1.646 \\
\hline party & The Netherlands & 35 & 4.14 & 0.810 & -1.040 \\
\hline Each party informs the other about events that may affect & Spain & 66 & 3.91 & 0.988 & -0.916 \\
\hline them & The Netherlands & 35 & 4.09 & 0.781 & \\
\hline
\end{tabular}




\begin{tabular}{|c|c|c|c|c|c|}
\hline \multirow{2}{*}{ We work together frequently } & \multirow{2}{*}{$\begin{array}{c}\text { Spain } \\
\text { The Netherlands }\end{array}$} & \multirow{2}{*}{$\begin{array}{l}66 \\
35 \\
\end{array}$} & \multirow{2}{*}{$\begin{array}{l}3.29 \\
3.34 \\
\end{array}$} & \multirow{2}{*}{$\begin{array}{l}1.064 \\
0.968\end{array}$} & \multirow{2}{*}{-0.255} \\
\hline & & & & & \\
\hline \multirow{2}{*}{ We frequently have contact } & Spain & 66 & 3.76 & 0.978 & \multirow{2}{*}{-0.927} \\
\hline & The Netherlands & 35 & 3.91 & 0.702 & \\
\hline \multicolumn{6}{|l|}{$\begin{array}{l}\text { Knowledge transfer } \\
\text { Through this entrepreneur: }\end{array}$} \\
\hline \multirow{2}{*}{$\begin{array}{l}\text { I get technical knowledge and a tremendous amount of know- } \\
\text { how }\end{array}$} & Spain & 66 & 3.24 & 1.124 & \multirow{2}{*}{$-1.817^{+}$} \\
\hline & The Netherlands & 35 & 3.66 & 1.027 & \\
\hline \multirow{2}{*}{ I learn from his/her knowledge } & Spain & 66 & 3.59 & 1.037 & \multirow{2}{*}{-0.329} \\
\hline & The Netherlands & 35 & 3.66 & 0.802 & \\
\hline \multirow{2}{*}{ I learn from his/her experience } & Spain & 66 & 3.52 & 1.099 & \multirow{2}{*}{1.186} \\
\hline & The Netherlands & 35 & 3.26 & 0.919 & \\
\hline \multirow{2}{*}{$\begin{array}{l}\text { I assimilate the knowledge that he/she gives me and it } \\
\text { contributes to the development of my start-up }\end{array}$} & Spain & 66 & 3.53 & 1.056 & \multirow{2}{*}{-0.621} \\
\hline & The Netherlands & 35 & 3.66 & 0.802 & \\
\hline \multicolumn{6}{|l|}{ Through me, the other entrepreneur: } \\
\hline Acquires technical knowledge and a tremendous amount of & Spain & 66 & 3.48 & 1.070 & $-1888^{+}$ \\
\hline know-how & The Netherlands & 35 & 3.89 & 0.900 & -1.888 \\
\hline & Spain & 66 & 3.55 & 0.898 & $275 *$ \\
\hline Learns from my knowledge & The Netherlands & 35 & 3.91 & 0.702 & $-2.2 / 5^{*}$ \\
\hline & Spain & 66 & 3.39 & 0.959 & \\
\hline Learns from my experience & The Netherlands & 35 & 3.37 & 0.942 & 0.113 \\
\hline Assimilates the knowledge that I give him/her and contributes & Spain & 66 & 3.44 & 1.083 & \\
\hline to the development of his/her start-up & The Netherlands & 35 & 3.66 & 0.838 & -1.119 \\
\hline Entrepreneurial commitment & & & & & \\
\hline & Spain & 66 & 3.26 & 1.244 & \\
\hline To be more committed to my entrepreneurıal goals & The Netherlands & 35 & 3.51 & 1.011 & -1.050 \\
\hline & Spain & 66 & 3.29 & 1.237 & \\
\hline To be more demandıng about my entrepreneurial goals & The Netherlands & 35 & 3.54 & 0.950 & -1.063 \\
\hline & Spain & 66 & 3.50 & 1.193 & \\
\hline To be more ambitious about my entrepreneurial goals & The Netherlands & 35 & 3.77 & 0.910 & -1.276 \\
\hline Business results & & & & & \\
\hline & Spain & 60 & 3.18 & 1.347 & \\
\hline 10 increase sales & The Netherlands & 32 & 2.84 & 1.110 & 1.221 \\
\hline & Spain & 60 & 3.57 & 1.240 & \\
\hline 10 create new market opportunities & The Netherlands & 32 & 3.31 & 0.998 & 0.999 \\
\hline & Spain & 60 & 3.15 & 1.325 & \\
\hline lo generate proints & The Netherlands & 32 & 3.13 & 1.157 & 0.090 \\
\hline Generation of innovation & & & & & \\
\hline Is more innoyative in terms of product or service & Spain & 66 & 3.53 & 1.166 & -0419 \\
\hline Is more innovative in terms or proauct or service & The Netherlands & 35 & 3.63 & 1.031 & -0.419 \\
\hline & Spain & 66 & 3.79 & 1.170 & \\
\hline Can reach a wider market & The Netherlands & 35 & 3.60 & 1.006 & 0.805 \\
\hline Is more foacible in itc doyelonment & Spain & 66 & 3.70 & 1.265 & 0173 \\
\hline is more reasidie in ils deveropment & The Netherlands & 35 & 3.66 & 0.998 & $0.1 / 3$ \\
\hline & Spain & 66 & 3.79 & 1.117 & \\
\hline Generation of innovation & The Netherlands & 35 & 3.86 & 0.912 & -0.315 \\
\hline & Spain & 66 & 3.86 & 1.149 & \\
\hline New products/services & The Netherlands & 35 & 3.71 & 0.987 & 0.652 \\
\hline Prior entrepreneurial experience & & & & & \\
\hline & Spain & 66 & 0.20 & 0.401 & -0966 \\
\hline Prior entrepreneurrai experience & The Netherlands & 35 & 0.29 & 0.458 & -0.906 \\
\hline Experience as an employee in a company & & & & & \\
\hline & Spain & 66 & 0.74 & 0.441 & \\
\hline Experience as an employee in a company & The Netherlands & 35 & 0.49 & 0.507 & $2.531^{*}$ \\
\hline $\begin{array}{l}\text { Academic/scientific experience at a university/research } \\
\text { centre }\end{array}$ & & & & & \\
\hline demic/scientific experience at a univercity/recea & Spain & 66 & 0.24 & 0.432 & 0817 \\
\hline demic/scientunc experience at a university & The Netherlands & 35 & 0.17 & 0.382 & $0.81 /$ \\
\hline
\end{tabular}

$$
\left(^{+}\right) \mathrm{p}<0.10 ;\left({ }^{*}\right) \mathrm{p}<0.05 ;\left({ }^{* *}\right) \mathrm{p}<0.01
$$




\subsubsection{Estimation procedure: PLS}

The measurement model and the structural model were tested using PLS-SEM (Partial Least Squares-Structural Equation Modelling). This procedure was mainly chosen for four reasons:

(1) The model posited requires SEM analysis due to the nature of the relations proposed therein.

(2) PLS admits smaller samples than other SEM methods. Compared with covariance-based SEM, PLS-SEM has higher levels of statistical power with complex model structures or smaller simple sizes. Bearing in mind that the sample of incubatees is 101, use of this procedure would seem justified and appropriate $^{20}$.

(3) It enables reflective and formative scales to be combined. Although in Study II, we consider all the reflective constructs, in the other two studies reflective and formative scales are combined.

(4) It proves an appropriate method for explaining phenomena that are already known, as is the case with the research in question.

Although PLS-SEM is recommended for small sample sizes, the 10 times rule (Barclay, Higgins, and Thompson, 1995) offers a guideline for minimum sample size requirements. It indicates that the sample size should be equal to the larger of:

1. 10 times the largest number of formative indicators used to measure a single construct or

2. 10 times the largest number of structural paths directed at a particular construct in the structural model (Hair et al., 2014; p. 20).

Following the second criterion (the number of formative indicators is small), in Table 4.24, we observe that the samples in each model are higher than 10 times the largest number of structural paths directed at a construct. The samples are therefore adequate according to the 10 times rule.

\footnotetext{
${ }^{20}$ PLS-SEM is the technique used for the three quantitative studies carried out. For Studies II and III.2, the study sample is incubatees, with a size of 101. For Study III.1, the sample is the managers, comprising 47 individuals. However, in this latter group, the unit of analysis is each incubation programme. The total number of cases is 93 . The size of the two samples in the study is therefore small.
} 
Cohen (1992) also provides sample size recommendations in PLS-SEM to warrant a statistical power of $80 \%$. Table 4.24 shows the minimum sample size requirement necessary to detect minimum $\mathrm{R}^{2}$ values of $0.10,0.25,0.50$, and 0.75 . For instance, in Model 1, since the maximum number of independent variables in the structural model is 7 (for the variable "exchange of knowledge"), we would need 166 observations to achieve a statistical power of $80 \%$ to detect $\mathrm{R}^{2}$ values of at least 0.10 (with a $5 \%$ probability error). We observe that the sample sizes in the three models have statistical power to detect $\mathrm{R}^{2}$ values of at least 0.25 .

Table 4.24. Sample size requirements in PLS

\begin{tabular}{|c|c|c|c|c|c|c|c|}
\hline \multirow{3}{*}{ Models } & \multirow{3}{*}{$\begin{array}{l}\text { Sample } \\
\text { size }\end{array}$} & \multirow{3}{*}{$\begin{array}{l}\text { Maximum number of arrows } \\
\text { pointing at a construct }\end{array}$} & \multicolumn{5}{|c|}{ Sample size requirements } \\
\hline & & & \multirow{2}{*}{$\begin{array}{l}10 \text { times } \\
\text { rule }\end{array}$} & \multicolumn{4}{|c|}{ Cohen's rule. Minimum $R^{2}$ of } \\
\hline & & & & 0.10 & 0.25 & 0.50 & 0.75 \\
\hline $\begin{array}{c}\text { Model } \\
1\end{array}$ & 101 & $\begin{array}{c}7 \\
\text { (“exchange of knowledge” is } \\
\text { determined by } 6 \text { independent } \\
\text { variables and } 1 \text { control variable) }\end{array}$ & 70 & 166 & 80 & 51 & 41 \\
\hline $\begin{array}{c}\text { Model } \\
2\end{array}$ & 93 & $\begin{array}{c}\mathbf{4} \\
\text { (the endogenous variables are } \\
\text { determined by } 2 \text { independent } \\
\text { variables and } 2 \text { control variables) }\end{array}$ & 40 & 147 & 70 & 45 & 36 \\
\hline $\begin{array}{c}\text { Model } \\
3\end{array}$ & 101 & $\begin{array}{c}\mathbf{1 0} \\
\text { ("business efficiency” is } \\
\text { determined by } 5 \text { independent } \\
\text { variables and } 5 \text { control variables) }\end{array}$ & 100 & 189 & 91 & 59 & 48 \\
\hline
\end{tabular}

The SmartPLS 3 version 3.2.1 statistical program was used. (Ringle et al., 2015).

\subsubsection{Validation of scales}

Prior to analysing the data, the scales used must be evaluated. To do this, their convergent validity, reliability and discriminant validity are tested.

Convergent validity. In order to test the convergent validity of the reflective scales we performed several confirmatory factor analyses (CFA). Despite the small sample size, we used SEM estimation with AMOS software.

First, we performed a CFA for the independent latent variables: shared values, complementary resources, supplementary resources, transferability, willingness to share knowledge, and promotion focus. The results are shown in Table 4.25. Some lambda estimates or loading factors are low, the lowest being 0.407 . Nevertheless, we obtained higher values or loading factors in the estimation with PLS as will be shown 
later. As a result, we decided not to eliminate them. Moreover, the goodness of fit is adequate. Therefore, we accepted the convergent validity of the proposed scales.

Table 4.25. Results of CFA for the independent latent variables (Study II)

\begin{tabular}{|c|c|c|}
\hline Latent variables & Indicators & $\begin{array}{l}\text { Stand. } \\
\text { Estimate }\end{array}$ \\
\hline \multirow{3}{*}{ Shared values } & His/her values and behavioural norms are congruent with mine & 0.645 \\
\hline & $\begin{array}{l}\text { His/her philosophy/approach to business is compatible with } \\
\text { mine }\end{array}$ & 0.807 \\
\hline & His/her goals and objectives are compatible with mine & 0.827 \\
\hline \multirow{4}{*}{ Complementarity resources } & Has different resources to mine that are very precious to me & 0.644 \\
\hline & His/her resources are necessary to achieve my goals & 0.627 \\
\hline & Has different and complementary resources to mine & 0.799 \\
\hline & $\begin{array}{l}\text { His/her resources, combined with mine, enable me to achieve } \\
\text { more satisfactory results }\end{array}$ & 0.854 \\
\hline \multirow{3}{*}{ Supplementary resources } & $\begin{array}{l}\text { Has similar resources to mine which, nevertheless, are very } \\
\text { precious to me }\end{array}$ & 0.900 \\
\hline & $\begin{array}{l}\text { Has similar resources to mine. However, they are supplementary } \\
\text { to mine }\end{array}$ & 0.818 \\
\hline & $\begin{array}{l}\text { His/her resources are similar to mine, but when combined, allow } \\
\text { me to achieve more satisfactory results }\end{array}$ & 0.833 \\
\hline \multirow{2}{*}{ Transferability } & $\begin{array}{l}\text { The knowledge (technical-scientific) held by me is easily } \\
\text { transferable }\end{array}$ & 0.724 \\
\hline & $\begin{array}{l}\text { The knowledge (technical-scientific) held by him/her is easily } \\
\text { transferable }\end{array}$ & 0.762 \\
\hline \multirow{3}{*}{$\begin{array}{l}\text { Willingness to share } \\
\text { knowledge }\end{array}$} & When I learn something new, I tell my colleagues & 0.976 \\
\hline & $\begin{array}{l}\text { I share the information I have with my colleagues when they ask } \\
\text { me to }\end{array}$ & 0.488 \\
\hline & I share my skills with my colleagues when they ask me to & 0.407 \\
\hline \multirow{3}{*}{ Promotion focus } & $\begin{array}{l}\text { I feel like I have made progress toward being successful in my } \\
\text { life }\end{array}$ & 0.602 \\
\hline & I am always looking for better ways to do things & 0.589 \\
\hline & $\begin{array}{l}\text { No matter what the odds are, if I believe in something I will } \\
\text { make it happen }\end{array}$ & 0.741 \\
\hline Goodness of fit & $\begin{array}{c}\mathrm{X}^{2}(119)=196.932(\mathrm{p}=0.000) ; \mathrm{GFI}=0.839 ; \mathrm{NFI}=0.805 ; \\
\mathrm{CFI}=0.909 ; \mathrm{RMSEA}=0.081\end{array}$ & \\
\hline
\end{tabular}

Secondly, we performed a CFA for the variables trust and commitment. The results are shown in Table 4.26. All the lambda estimates are greater than 0.7 , and the goodness of fit is adequate. Thus, the results support the convergent validity of the scales. 
Table 4.26. Results of CFA for the variables Trust and Commitment (Study II)

\begin{tabular}{|c|c|c|}
\hline Latent variables & Indicators & $\begin{array}{c}\text { Stand. } \\
\text { Estimate }\end{array}$ \\
\hline \multirow{7}{*}{ Trust } & $\mathrm{He} / \mathrm{she}$ is honest and truthful & 0.731 \\
\hline & The information he/she exchanges with me is reliable & 0.762 \\
\hline & $\begin{array}{l}\text { He/she honestly communicates any problem that may affect } \\
\text { me }\end{array}$ & 0.843 \\
\hline & $\begin{array}{l}\text { He/she is willing to provide assistance and support when } \\
\text { circumstances so require }\end{array}$ & 0.787 \\
\hline & I believe that he/she acts in my best interest & 0.709 \\
\hline & $\begin{array}{l}\text { In general, he/she is a person who honours his/her } \\
\text { commitments }\end{array}$ & 0.859 \\
\hline & He/she is competent and effective & 0.737 \\
\hline \multirow{6}{*}{ Commitment } & I intend to strengthen our relationship over time & 0.964 \\
\hline & I intend to continue our relationship for a long time & 0.916 \\
\hline & I am committed to sharing ideas and knowledge with him/her & 0.830 \\
\hline & $\mathrm{He} /$ she is willing to strengthen our relationship over time & 0.813 \\
\hline & $\mathrm{He} /$ she is willing to continue our relationship for a long time & 0.857 \\
\hline & He/she is committed to sharing ideas and knowledge with me & $\mathrm{a}$ \\
\hline Goodness of fit & $\begin{array}{c}\mathrm{X}^{2}(50)=74.410(\mathrm{p}=0.014) ; \mathrm{GFI}=0.900 ; \mathrm{NFI}=0.934 ; \\
\mathrm{CFI}=0.977 ; \mathrm{RMSEA}=0.070\end{array}$ & \\
\hline
\end{tabular}

The indicator was eliminated because the measurement errors were excessively correlated with the measurement errors of other latent variables' indicators.

Third, in the case of the exchange of knowledge variable, as indicated, two dimensions were measured, communication and knowledge transfer. This is therefore a second order latent variable. In order to validate this scale, the second order model was estimated. The results are shown in Table 4.27. As can be seen, all the factor loadings are significant and the model adjustment is suitable, even though two of the measurement variables whose loading was too low had to be removed. Having estimated the model, the indicators of each dimension were reduced to a single indicator through factor analysis. Said indicators are those included as reflective measurements when estimating the model using PLS. 
Table 4.27. CFA results for the variable Exchange of knowledge (Study II)

\begin{tabular}{|c|c|c|}
\hline Latent variables & Indicators & $\begin{array}{l}\text { Stand. } \\
\text { Estimate }\end{array}$ \\
\hline \multirow{2}{*}{ Exchange of knowledge } & Communication & 0.956 \\
\hline & Knowledge transfer & 0.807 \\
\hline \multirow{6}{*}{ Communication } & We ask for mutual advice and recommendations & 0.838 \\
\hline & We share all types of information & 0.891 \\
\hline & $\begin{array}{l}\text { We provide any information that may be useful to the other } \\
\text { party }\end{array}$ & 0.788 \\
\hline & $\begin{array}{l}\text { Each party informs the other about events that may affect } \\
\text { them }\end{array}$ & 0.798 \\
\hline & We work together frequently & 0.643 \\
\hline & We frequently have contact & 0.805 \\
\hline \multirow{9}{*}{ Knowledge transfer } & $\begin{array}{l}\text { I acquire technical knowledge and a tremendous amount of } \\
\text { know-how }\end{array}$ & 0.834 \\
\hline & I learn from his/her knowledge & 0.903 \\
\hline & I learn from his/her experience & 0.595 \\
\hline & $\begin{array}{l}\text { I assimilate the knowledge that he/she gives me and it } \\
\text { contributes to the development of my start-up }\end{array}$ & 0.837 \\
\hline & Has access to market knowledge & $\mathrm{a}$ \\
\hline & $\begin{array}{l}\text { Acquires technical knowledge and a tremendous amount of } \\
\text { know-how }\end{array}$ & 0.695 \\
\hline & Learns from my knowledge & 0.799 \\
\hline & Learns from my experience & a \\
\hline & $\begin{array}{l}\text { Assimilates the knowledge that I give him/her and it } \\
\text { contributes to the development of his/her start-up }\end{array}$ & 0.843 \\
\hline Goodness of fit & \multicolumn{2}{|l|}{$\begin{array}{c}\mathrm{X}^{2}(59)=82.999(\mathrm{p}=0.021) ; \mathrm{GFI}=0.895 ; \mathrm{NFI}=0.925 ; \\
\mathrm{CFI}=0.977 ; \mathrm{RMSEA}=0.064\end{array}$} \\
\hline
\end{tabular}

The indicators were eliminated because the measurement errors were excessively correlated with the measurement errors of other latent variables' indicators.

Finally, we performed a CFA for the three variables of relationship outcomes: entrepreneurial commitment, generation of innovation, and business results. The results are shown in Table 4.28. Once again, the results (standardised coefficients and goodness of fit) ensure the convergent validity of the measurement scales.

Table 4.28. Results of CFA for the variables of relationship outcomes (Study II)

\begin{tabular}{|c|c|c|}
\hline Latent variables & Indicators & $\begin{array}{c}\text { Stand. } \\
\text { Estimate }\end{array}$ \\
\hline \multirow{3}{*}{ Entrepreneurial commitment } & To be more committed to my entrepreneurial goals & 0.938 \\
\hline & To be more demanding about my entrepreneurial goals & 0.894 \\
\hline & To be more ambitious about my entrepreneurial goals & 0.915 \\
\hline \multirow{5}{*}{ Generation of innovation } & Is more innovative in terms of product or service & 0.929 \\
\hline & Can reach a wider market & a \\
\hline & Is more feasible in its development & 0.903 \\
\hline & Generation of innovation & 0.845 \\
\hline & New products/services & 0.824 \\
\hline \multirow{3}{*}{ Business results } & To increase sales & 0.941 \\
\hline & To create new market opportunities & 0.880 \\
\hline & To generate profits & 0.967 \\
\hline Goodness of fit & $\begin{array}{c}\mathrm{X}^{2}(31)=53.556(\mathrm{p}=0.007) ; \mathrm{GFI}=0.914 ; \mathrm{NFI}=0 \\
\mathrm{RMSEA}=0.085\end{array}$ & $=0.979$; \\
\hline
\end{tabular}

The indicator was eliminated because the measurement errors were excessively correlated with the measurement errors of other latent variables' indicators. 
Reliability. Having tested the convergent validity of the scales, the overall model was estimated using PLS with a maximum number of 300 iterations. To calculate the significance of the factor loadings of the indicators in the measurement model, bootstrapping was applied to 1000 sub-samples.

Three indicators were used to measure the reliability of the scales: Cronbach's alpha $(\alpha)$, composite reliability (CR) and reliability of indicators. Cronbach's alpha measures a scale’s internal consistency (Malhotra, 1997), and should take values of over 0.6. Composite reliability measures the internal consistency of the construct indicators (Hair et al., 1999). Its values are acceptable when they are over 0.7 . Finally, the reliability of the indicators refers to each indicator's loading over the latent variable (Hair et al., 1999). An indicator is deemed reliable when it takes values above 0.6 .

Table 4.29 shows the measurement variable loadings and the reliability values of the latent variables. The Cronbach alpha values can be seen to be high, with most being around 0.8 and 0.9 , as is the case with composite reliability. Loadings are also significant and take values above 0.7 for all the indicators. Consequently, the reliability of all the measurement scales used is confirmed. It can also be seen that the factor loadings are above 0.7 for all the items, thus reaffirming the convergent validity of the measurement scales.

Table 4.29. Reliability of measurement scales and outer loadings (Study II)

\begin{tabular}{|c|c|c|}
\hline & Weights & Loadings \\
\hline \multicolumn{3}{|l|}{ Empathy } \\
\hline I have little difficulty in "putting myself into other people's shoes" & 1.000 & \\
\hline \multicolumn{3}{|l|}{ Shared values $(\alpha=.773 ; C R=.871 ; A V E=.693)$} \\
\hline His/her values and behavioural norms are congruent with mine & & $0.814 * * *$ \\
\hline His/her philosophy/approach to business is compatible with mine & & $0.816^{* * *}$ \\
\hline His/her goals and objectives are compatible with mine & & $0.866 * * *$ \\
\hline \multicolumn{3}{|l|}{ Complementary resources $(\alpha=.866 ; C R=.907 ; A V E=.709)$} \\
\hline Has different resources to mine that are very precious to me & & $0.844 * * *$ \\
\hline His/her resources are necessary to achieve my goals & & $0.846^{* * *}$ \\
\hline Has different and complementary resources to mine & & $0.839 * * *$ \\
\hline His/her resources, combined with mine, enable me to achieve more satisfactory results & & $0.840 * * *$ \\
\hline \multicolumn{3}{|l|}{ Supplementary resources $(\alpha=.887 ; C R=.929 ; A V E=.813)$} \\
\hline Has similar resources to mine, but nevertheless they are very precious to me & & $0.923 * * *$ \\
\hline Has similar resources to mine, but supplementary to mine & & $0.866 * * *$ \\
\hline $\begin{array}{l}\text { His/her resources are similar to mine, but when combined, allow me to achieve more } \\
\text { satisfactory results }\end{array}$ & & $0.916^{* * *}$ \\
\hline \multicolumn{3}{|l|}{ Transferability $(\alpha=.711 ; C R=.871 ; A V E=.771)$} \\
\hline The knowledge (technical-scientific) held by me is easily transferable & & $0.833^{* * *}$ \\
\hline The knowledge (technical-scientific) held by him/her is easily transferable & & $0.921 * * *$ \\
\hline \multicolumn{3}{|l|}{ Willingness to share knowledge $(\alpha=.793 ; C R=.875 ; A V E=.700)$} \\
\hline When I learn something new, I tell my colleagues & & $0.809 * * *$ \\
\hline I share the information I have with my colleagues when they ask me to & & $0.867 * * *$ \\
\hline I share my skills with my colleagues when they ask me to & & $0.832 * * *$ \\
\hline
\end{tabular}


Promotion focus $(\alpha=.660 ; C R=.831 ; A V E=.623)$

I feel like I have made progress toward being successful in my life

I am always looking for better ways to do things

No matter what the odds are, if I believe in something I will make it happen

Trust in the incubatee $(\alpha=.914 ; C R=.931 ; A V E=.660)$

$\mathrm{He} / \mathrm{she}$ is honest and truthful

The information he/she exchanges with me is reliable

$\mathrm{He} /$ she honestly communicates any problem that may affect me

$\mathrm{He} /$ she is willing to provide assistance and support when circumstances so require

$\mathrm{He} / \mathrm{she}$ is competent and effective

Commitment in the relationship $(\alpha=.946 ; C R=.959 ; A V E=.824)$

I intend to strengthen our relationship over time

I intend to continue our relationship for a long time

I am committed to sharing ideas and knowledge with him/her

$0.857 * * *$

$\mathrm{He} / \mathrm{she}$ is willing to strengthen our relationship over time

$0.886 * * *$

$\mathrm{He} /$ she is willing to continue our relationship for a long time

Exchange of knowledge $(\alpha=.814 ; C R=.915 ; A V E=.843)$

Communication

We ask for mutual advice and recommendations

We share all types of information

We provide any information that may be useful to the other party

Each party informs the other about events that may affect them

We work together frequently

We frequently have contact

Knowledge transfer

I acquire technical knowledge and a tremendous amount of know-how

I learn from his/her knowledge

I learn from his/her experience

I assimilate the knowledge that he/she gives me and it contributes to the development

of my start-up

Through me, the other entrepreneur:

Has access to market knowledge

Acquires technical knowledge and a tremendous amount of know-how

Learns from my knowledge

Learns from my experience

Assimilates the knowledge that I give him/her and contributes to the development of

his/her start-up

Entrepreneurial commitment ( $\alpha=.940 ; C R=.961 ; A V E=.892)$

To be more committed to my entrepreneurial goals

To be more demanding about my entrepreneurial goals

To be more ambitious about my entrepreneurial goals

Generation of innovation $(\alpha=.936 ; C R=.954 ; A V E=.839)$

Is more innovative in terms of product or service

$0.927 * * *$

Is more feasible in its development

In the future, I think the relationship with this entrepreneur will stimulate:

Generation of innovation

$0.923 * * *$

New products/services

$0.904 * * *$

Business results $(\alpha=.946 ; C R=.965 ; A V E=.903)$

To increase sales

$0.954 * * *$

To create new market opportunities

To generate profits

$0.963 * * *$ $(* * *) \mathrm{p}<0.001$

Discriminant validity. In order to evaluate discriminant validity, we first followed the criterion of Fornell-Larcker. The average variance extracted (AVE) of each construct should be greater than the square of its correlations with the remaining constructs in the model. This ensures that each latent variable's variance is explained more by its own 
indicators than by the indicators in the other variables (Fornell and Larcker, 1981). Table 4.30 shows the correlation matrix between latent constructs. The main diagonal includes the square root values of the AVE for each construct. Comparing each square root with the correlations in the corresponding row and column will indicate whether there is discriminant validity amongst the latent variables. This condition is met in all cases. Following Hair et al. (1999), a further indicator of discriminant validity is when the correlation between constructs is not too high, the extreme value being 0.9. As can be seen in Table 4.30, none of the correlations reaches that value. What is more, the highest correlation is 0.745 between exchange of knowledge and generation of innovation. Finally, Henseler et al. (2015) propose the heterotrait-monotrait (HTMT) ratio of correlations to evaluate discriminant validity. This ratio reflects the average of the correlations of indicators in constructs which measure different phenomena, compared to the average of the correlations of indicators within the same construct (Henseler et al., 2015). In order to evaluate discriminant validity through HTMT, correlations should not exceed 0.85 (Clark and Watson, 1995; Kline, 2011), although other authors suggest a higher threshold of 0.90 (Gold et al., 2001; Teo et al., 2008). The values corresponding to the ratio of HTMT correlations for each pair of constructs are included above the principal diagonal of the correlation matrix. As can be seen, only the ratio between exchange of knowledge and generation of innovation is at the critical limit, with a value of 0.851 . The remaining values virtually all take values which are well below.

Taking all of this into account, discriminant validity amongst all the various latent constructs considered in the research is shown to exist.

Common method variance bias. In order to examine whether common method variance (CMV) is a problem, we performed a Harman's one-factor test (Podsakoff et al., 2003). Since there was no single factor accounting for the majority of the covariance among the measures, we concluded that the possible impact of common method bias is not significant in this research. 


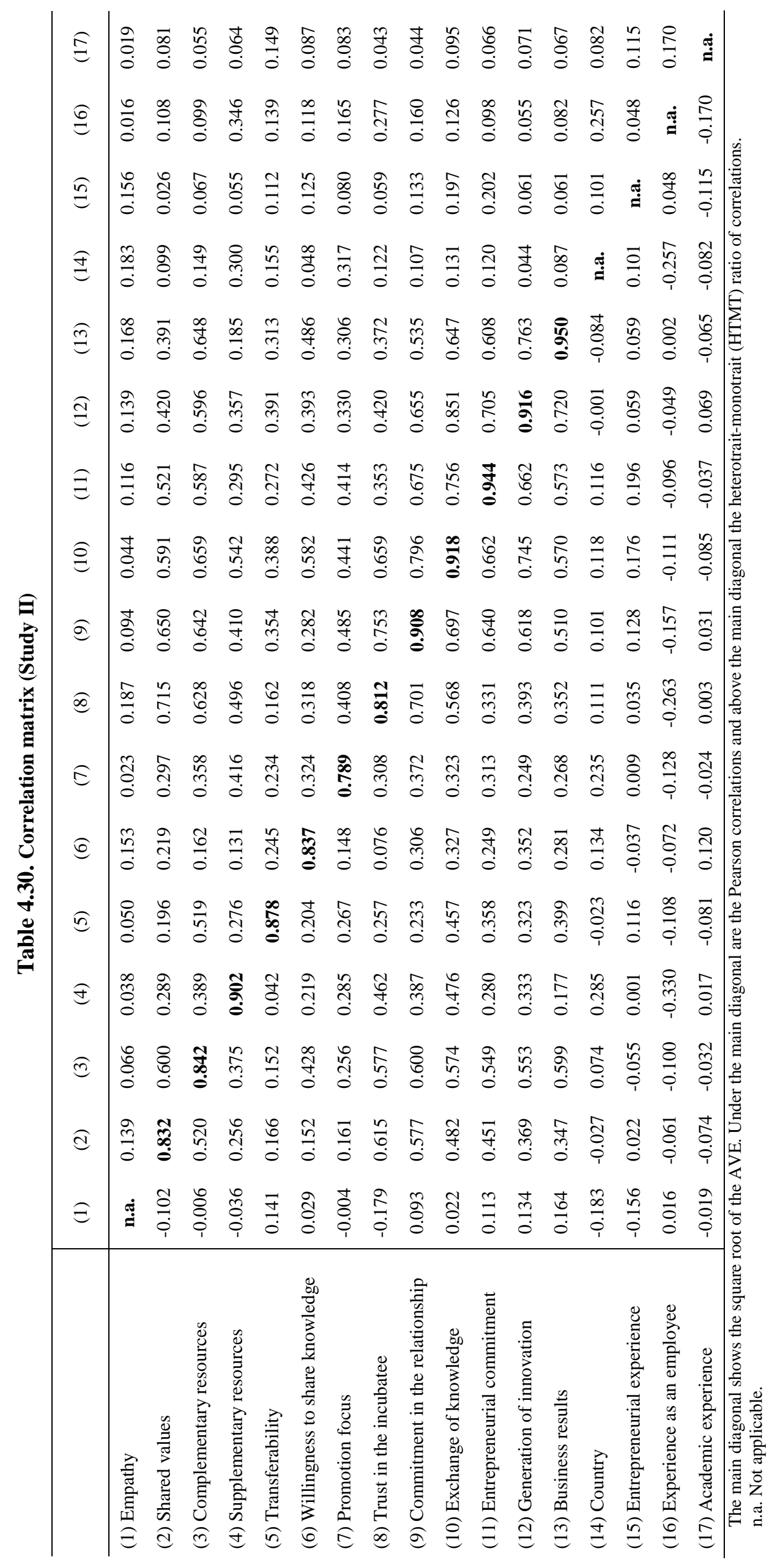




\subsubsection{Model estimation}

The results of estimating the overall structural Model 1 are shown in Table 4.31. In order to facilitate interpretation, significant relationships of proposed hypotheses are displayed in Figure 4.3.

Table 4.31. Model 1 estimation (Study II)

\begin{tabular}{|c|c|c|}
\hline \multicolumn{2}{|c|}{ Proposed hypotheses } & \multirow{2}{*}{$\begin{array}{l}\text { Estimate } \\
0.270^{*}\end{array}$} \\
\hline$H 1$ & Trust $\rightarrow$ Exchange of knowledge & \\
\hline & Trust $\rightarrow$ Commitment & $0.405 * * *$ \\
\hline H2 & Exchange of knowledge $\rightarrow$ Commitment & $0.355^{* * *}$ \\
\hline H3a & Empathy $\rightarrow$ Trust & $-0.127^{+}$ \\
\hline$H 3 b$ & Empathy $\rightarrow$ Commitment & $0.181 *$ \\
\hline $\mathrm{H} 4 \mathrm{a}$ & Shared values $\rightarrow$ Trust & $0.394 * * *$ \\
\hline$H 4 b$ & Shared values $\rightarrow$ Commitment & 0.133 \\
\hline H5a & Complementary resources $\rightarrow$ Trust & $0.276^{* *}$ \\
\hline $\mathrm{H} 5 \mathrm{~b}$ & Complementary resources $\rightarrow$ Commitment & 0.110 \\
\hline$H 5 c$ & Complementary resources $\rightarrow$ Exchange of knowledge & $0.209 *$ \\
\hline H6a & Supplementary resources $\rightarrow$ Trust & $0.251 * *$ \\
\hline$H 6 b$ & Supplementary resources $\rightarrow$ Commitment & -0.050 \\
\hline H6c & Supplementary resources $\rightarrow$ Exchange of knowledge & $0.213^{* *}$ \\
\hline$H 7$ & Transferability $\rightarrow$ Exchange of knowledge & $0.205^{* *}$ \\
\hline H8 & Willingness to share knowledge $\rightarrow$ Exchange of knowledge & $0.212^{*}$ \\
\hline H9a & Promotion focus $\rightarrow$ Willingness to share knowledge & $0.289 *$ \\
\hline$H 9 b$ & Promotion focus $\rightarrow$ Exchange of knowledge & 0.043 \\
\hline H10a & Commitment $\rightarrow$ Entrepreneurial commitment & $0.345^{* *}$ \\
\hline $\mathrm{H1Ob}$ & Exchange of knowledge $\rightarrow$ Entrepreneurial commitment & $0.405^{* *}$ \\
\hline$H 11 a$ & Commitment $\rightarrow$ Generation of innovation & $0.184^{+}$ \\
\hline$H 11 b$ & Exchange of knowledge $\rightarrow$ Generation of innovation & $0.652 * * *$ \\
\hline$H 12 a$ & Commitment $\rightarrow$ Business results & 0.119 \\
\hline$H 12 b$ & Exchange of knowledge $\rightarrow$ Business results & 0.004 \\
\hline$H 12 c$ & Generation of innovation $\rightarrow$ Business results & $0.651 * * *$ \\
\hline \multicolumn{3}{|c|}{ Control effects } \\
\hline & Country $^{\mathrm{a}} \rightarrow$ Empathy & $-0.183^{*}$ \\
\hline & Country $\rightarrow$ Shared values & -0.027 \\
\hline & Country $\rightarrow$ Complementary resources & 0.074 \\
\hline & Country $\rightarrow$ Supplementary resources & $0.285^{* *}$ \\
\hline & Country $\rightarrow$ Transferability & 0.134 \\
\hline & Country $\rightarrow$ Willingness to share knowledge & -0.091 \\
\hline & Country $\rightarrow$ Promotion focus & $0.235 *$ \\
\hline & Country $\rightarrow$ Trust & 0.006 \\
\hline & Country $\rightarrow$ Commitment & 0.059 \\
\hline & Country $\rightarrow$ Exchange of knowledge & -0.021 \\
\hline & Country $\rightarrow$ Entrepreneurial commitment & 0.027 \\
\hline & Country $\rightarrow$ Generation of innovation & -0.067 \\
\hline & Country $\rightarrow$ Business results & -0.104 \\
\hline & Entrepreneurial experience $\rightarrow$ Entrepreneurial commitment & 0.078 \\
\hline & Entrepreneurial experience $\rightarrow$ Generation of innovation & -0.062 \\
\hline & Entrepreneurial experience $\rightarrow$ Business results & 0.001 \\
\hline & Experience as an employee $\rightarrow$ Entrepreneurial commitment & 0.005 \\
\hline & Experience as an employee $\rightarrow$ Generation of innovation & 0.057 \\
\hline & Experience as an employee $\rightarrow$ Business results & 0.006 \\
\hline & Scientific experience $\rightarrow$ Entrepreneurial commitment & -0.001 \\
\hline & Scientific experience $\rightarrow$ Generation of innovation & 0.115 \\
\hline & Scientific experience $\rightarrow$ Business results & -0.120 \\
\hline
\end{tabular}

( $\left.{ }^{\mathrm{a}}\right)$ 0=Spain; 1=The Netherlands; $\left(^{+}\right) \mathrm{p}<0.10 ;\left(^{*}\right) \mathrm{p}<0.05 ;\left(^{* *}\right) \mathrm{p}<0.01 ;\left({ }^{* * *}\right) \mathrm{p}<0.001$ 


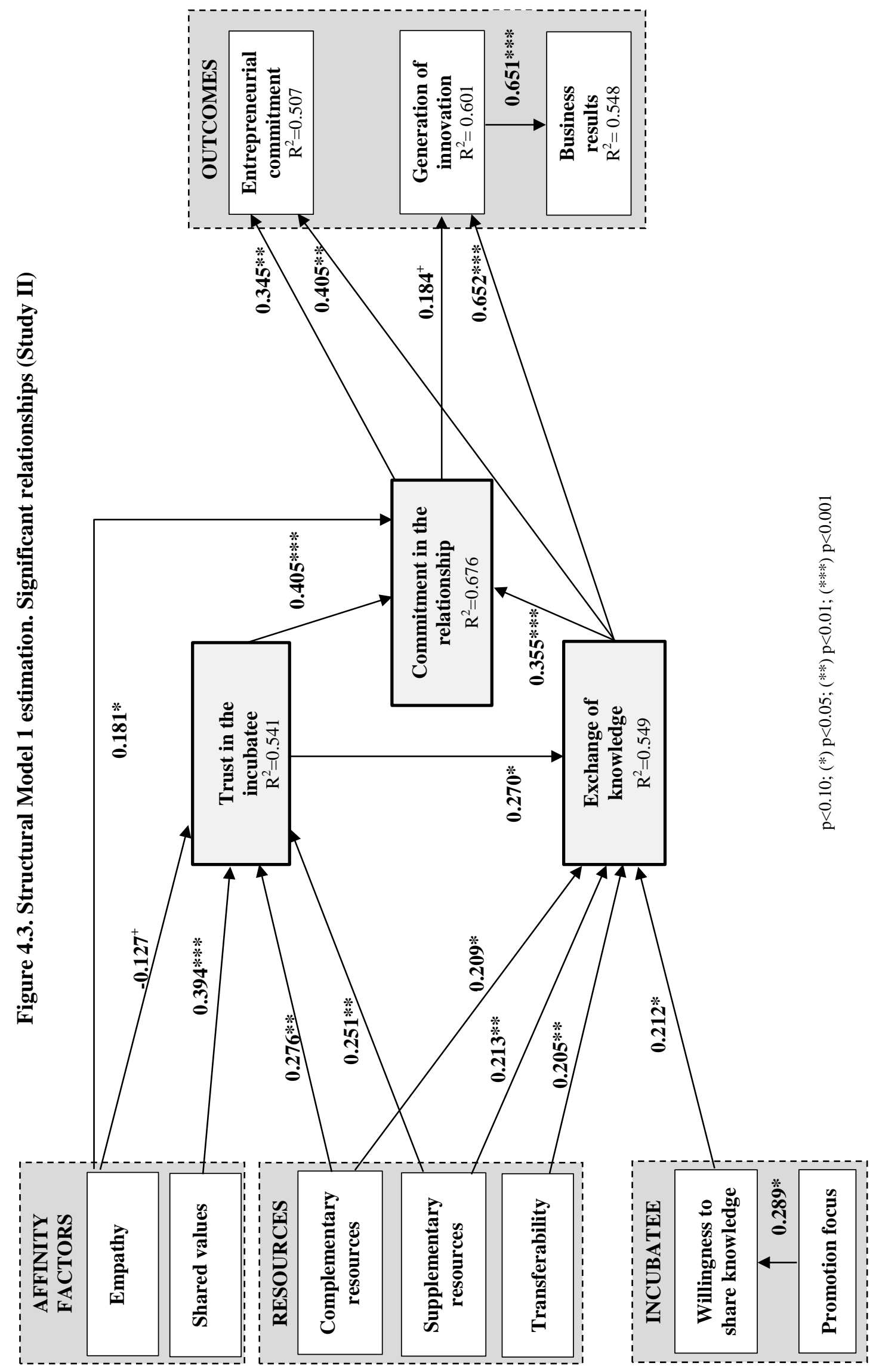


Robustness test. Additionally, we conducted a path analysis using the AMOS v20.0 statistical program to check the robustness of our results and to offer a global goodnessof-fit measure. We previously reduced each variable to a measurement index, specifically the latent variable scores provided by PLS in order to use similar measures. The results of the estimated model are shown in Table 4.32 and confirm an acceptable goodness of fit: $\chi^{2}(38)=75.346(p=0.000)$; RMR=0.072; RMSEA=0.099; GFI=0.902; $\mathrm{CFI}=0.938$; NFI=0.889. We observe that the AMOS estimation basically coincides with the PLS estimation.

Table 4.32. Path analysis estimation with AMOS (Study II)

\begin{tabular}{|c|c|c|c|}
\hline & & $\begin{array}{c}\text { Standardized } \\
\text { Estimate }\end{array}$ & S.E. \\
\hline \multirow[t]{2}{*}{$H 1$} & Trust $\rightarrow$ Exchange of knowledge & $0.274^{* *}$ & 0.088 \\
\hline & Trust $\rightarrow$ Commitment & $0.408 * * *$ & 0.087 \\
\hline$H 2$ & Exchange of knowledge $\rightarrow$ Commitment & $0.357 * * *$ & 0.078 \\
\hline HЗа & Empathy $\rightarrow$ Trust & -0.106 & 0.062 \\
\hline$H 3 b$ & Empathy $\rightarrow$ Commitment & $0.172 * *$ & 0.058 \\
\hline $\mathrm{H} 4 \mathrm{a}$ & Shared values $\rightarrow$ Trust & $0.386 * * *$ & 0.073 \\
\hline$H 4 b$ & Shared values $\rightarrow$ Commitment & 0.126 & 0.075 \\
\hline$H 5 a$ & Complementary resources $\rightarrow$ Trust & $0.319 * * *$ & 0.077 \\
\hline$H 5 b$ & Complementary resources $\rightarrow$ Commitment & 0.113 & 0.079 \\
\hline $\mathrm{H} 5 \mathrm{c}$ & Complementary resources $\rightarrow$ Exchange of knowledge & $0.213^{*}$ & 0.092 \\
\hline$H 6 a$ & Supplementary resources $\rightarrow$ Trust & $0.208 * *$ & 0.067 \\
\hline$H 6 b$ & Supplementary resources $\rightarrow$ Commitment & -0.039 & 0.067 \\
\hline H6c & Supplementary resources $\rightarrow$ Exchange of knowledge & $0.211^{* *}$ & 0.077 \\
\hline$H 7$ & Transferability $\rightarrow$ Exchange of knowledge & $0.205 * *$ & 0.075 \\
\hline H8 & Willingness to share knowledge $\rightarrow$ Exchange of knowledge & $0.217 * *$ & 0.070 \\
\hline$H 9 a$ & Promotion focus $\rightarrow$ Willingness to share knowledge & $0.267 * *$ & 0.096 \\
\hline$H 9 b$ & Promotion focus $\rightarrow$ Exchange of knowledge & 0.040 & 0.074 \\
\hline H1Oa & Commitment $\rightarrow$ Entrepreneurial commitment & $0.476^{* * *}$ & 0.095 \\
\hline$H 10 b$ & Exchange of knowledge $\rightarrow$ Entrepreneurial commitment & $0.381^{* * *}$ & 0.090 \\
\hline H11a & Commitment $\rightarrow$ Generation of innovation & $0.192 *$ & 0.089 \\
\hline$H 11 b$ & Exchange of knowledge $\rightarrow$ Generation of innovation & $0.609 * * *$ & 0.089 \\
\hline$H 12 a$ & Commitment $\rightarrow$ Business results & 0.082 & 0.093 \\
\hline$H 12 b$ & Exchange of knowledge $\rightarrow$ Business results & 0.076 & 0.111 \\
\hline$H 12 c$ & Generation of innovation $\rightarrow$ Business results & $0.607 * * *$ & 0.103 \\
\hline
\end{tabular}

The AMOS modification indices propose additional paths in order to improve the goodness of fit: a direct effect from business results to entrepreneurial commitment and a direct effect from complementary resources to business results. We added these paths, and the goodness of fit improved significantly: $\chi 2(36)=54.586(\mathrm{p}=0.024)$; RMR $=0.064$; RMSEA=0.072; GFI=0.928; CFI=0.969; NFI=0.920. The results are shown in Table 4.33. 
Table 4.33. Path analysis estimation with additional paths (Study II)

\begin{tabular}{|c|c|c|c|}
\hline & & $\begin{array}{c}\text { Standardized } \\
\text { Estimate }\end{array}$ & S.E. \\
\hline \multirow[t]{2}{*}{$H 1$} & Trust $\rightarrow$ Exchange of knowledge & $0.273 * *$ & 0.087 \\
\hline & Trust $\rightarrow$ Commitment & $0.408 * * *$ & 0.087 \\
\hline H2 & Exchange of knowledge $\rightarrow$ Commitment & $0.358 * * *$ & 0.078 \\
\hline H3a & Empathy $\rightarrow$ Trust & -0.115 & 0.063 \\
\hline$H 3 b$ & Empathy $\rightarrow$ Commitment & $0.172 * *$ & 0.058 \\
\hline$H 4 a$ & Shared values $\rightarrow$ Trust & $0.398 * * *$ & 0.074 \\
\hline$H 4 b$ & Shared values $\rightarrow$ Commitment & 0.126 & 0.075 \\
\hline H5a & Complementary resources $\rightarrow$ Trust & $0.287 * * *$ & 0.077 \\
\hline$H 5 b$ & Complementary resources $\rightarrow$ Commitment & 0.113 & 0.078 \\
\hline \multirow[t]{2}{*}{$H 5 c$} & Complementary resources $\rightarrow$ Exchange of knowledge & $0.214^{*}$ & 0.090 \\
\hline & Complementary resources $\rightarrow$ Business results & $0.326 * * *$ & 0.082 \\
\hline H6a & Supplementary resources $\rightarrow$ Trust & $0.229 * * *$ & 0.068 \\
\hline$H 6 b$ & Supplementary resources $\rightarrow$ Commitment & -0.039 & 0.068 \\
\hline H6c & Supplementary resources $\rightarrow$ Exchange of knowledge & $0.211 * *$ & 0.078 \\
\hline$H 7$ & Transferability $\rightarrow$ Exchange of knowledge & $0.205^{* *}$ & 0.075 \\
\hline H8 & Willingness to share knowledge $\rightarrow$ Exchange of knowledge & $0.217 * *$ & 0.070 \\
\hline H9a & Promotion focus $\rightarrow$ Willingness to share knowledge & $0.267 * *$ & 0.096 \\
\hline$H 9 b$ & Promotion focus $\rightarrow$ Exchange of knowledge & 0.040 & 0.074 \\
\hline H1Oa & Commitment $\rightarrow$ Entrepreneurial commitment & $0.420 * * *$ & 0.093 \\
\hline$H 10 b$ & Exchange of knowledge $\rightarrow$ Entrepreneurial commitment & $0.283^{* *}$ & 0.093 \\
\hline H11a & Commitment $\rightarrow$ Generation of innovation & $0.191 *$ & 0.089 \\
\hline$H 11 b$ & Exchange of knowledge $\rightarrow$ Generation of innovation & $0.609 * * *$ & 0.089 \\
\hline H12a & Commitment $\rightarrow$ Business results & -0.030 & 0.094 \\
\hline$H 12 b$ & Exchange of knowledge $\rightarrow$ Business results & 0.020 & 0.107 \\
\hline \multirow[t]{2}{*}{$H 12 c$} & Generation of innovation $\rightarrow$ Business results & $0.549 * * *$ & 0.096 \\
\hline & Business results $\rightarrow$ Entrepreneurial commitment & $0.226 * *$ & 0.084 \\
\hline
\end{tabular}

$(*) \mathrm{p}<0.05 ;\left({ }^{* *}\right) \mathrm{p}<0.01 ;(* * *) \mathrm{p}<0.001$. The new relationships introduced in the model are bold typed.

\subsubsection{Hypotheses testing}

Set out below are the results of testing the hypotheses formulated for this study.

\section{Effect of the control variables.}

The four control variables included in the model are country, entrepreneurial experience, experience as an employee and scientific experience.

The country in which the UBI is located was included so as to rule out its effect from the overall model. The location is linked to three variables that are determinant of the relations between incubatees. Specifically, lower levels of empathy and higher levels of promotion focus and supplementarity of resources in relations were in evidence in the Netherlands. These results might be due to cultural aspects such as greater encouragement of individualism, proactive initiative, dynamism and a clear business vision. 
UBI tenant experience in the business world, either through prior entrepreneurial experience or experience as a salaried worker in enterprise, has no significant impact on the results to emerge from the relations studied in the present research.

Finally, scientific experience affects generation of innovation, albeit with a significance below 95\%. This result is hardly surprising bearing in mind that scientific experience assumes that individuals have had access to, and possibly even created and applied, knowledge and innovation.

\section{Analysis of direct effects}

Trust between the parties in the dyad has a positive impact on exchange of knowledge and on commitment to the relation. Hypothesis $\mathrm{H} 1$ can thus be accepted, and the link between trust and commitment is once again borne out.

Hypothesis H2 conjectured a direct and significant relationship between exchange of knowledge and commitment amongst incubatees, and the results to emerge would appear to provide empirical support for this belief.

Empathy, perceived as a general trait of an individual, positively encourages commitment in the relation. As a result, hypothesis H3b is confirmed. By contrast, no support is in evidence to back up H3a, which hypothesised a positive relation between empathy and trust. What is more, results show a negative and significant relation between the two variables at a $90 \%$ significance level. Something which already emerged from the qualitative analysis carried out in Study I might provide us with a possible explanation for such an unexpected outcome. As became apparent from said study, empathy towards other incubatees sparked a certain generosity in the relationship, which on some occasions led to opportunistic behaviour by one of the partners and, as a result, subsequent mistrust.

Hypothesis H4a is supported, such that we are able to state that the perception of shared values between incubatees positively impacts on the trust between them. Contrastingly, no empirical support was obtained for the hypothesis which also conjectured a positive relation between shared values and commitment (H4b).

As regards complementarity of resources as a determinant variable in the relations generated in UBIs, its positive effect can be accepted on trust and exchange of knowledge (hypothesis H5a and H5c, respectively). However, no empirical support was found for hypothesis H5b, which conjectured that complementarity of resources might 
also affect commitment between the two parties. The same is true for the other variable related to resources included in the model: supplementarity. Its direct and positive link on trust (H6a) and exchange of knowledge (H6c) is supported, although the results to emerge suggest that hypothesis H6b, which posits a positive link with commitment, should be rejected.

Transferability of knowledge encourages exchange of said resource, which was conjectured in hypothesis H7, such that this may be accepted.

The individual trait willingness to share knowledge proves determinant for the exchange of knowledge. The greater an individual's willingness to share knowledge, the more said knowledge will flow and the greater will be the exchange thereof. This may be inferred from the results obtained and leads us to accept hypothesis H8.

Hypothesis H9a, stating that the promotion focus is an antecedent which stimulates willingness to share knowledge, is confirmed. By contrast, hypothesis H9b refers to a direct and positive relation between incubatees' promotion focus and exchange of knowledge. In this case, the hypothesis has failed to obtain empirical support.

Entrepreneurial commitment is one result to emerge from the relations between incubatees. A relation based on commitment and in which exchange of knowledge flows will encourage academics to increase their level of commitment and confirm their decision to become entrepreneurs. Both aspects were formulated in hypotheses H10a and H10b, which are supported.

Hypotheses H11a and H11b posit that commitment and exchange of knowledge between incubatees results in generation of innovation. Both hypotheses are supported empirically.

Finally, the results obtained bear out the support for hypothesis H12c, which establishes a relation between generation of innovation and business performance. Contrastingly, results suggest that $\mathrm{H} 12 \mathrm{a}$ and $\mathrm{H} 12 \mathrm{~b}$, which conjectured that exchange of knowledge and commitment impact on performance, should be rejected.

A summary of all the results of the hypotheses is shown in Table 4.34. 
Table 4.34. Results of hypothesis testing (Study II)

\begin{tabular}{|c|c|c|c|}
\hline \multicolumn{2}{|c|}{ Proposed hypotheses } & \multicolumn{2}{|c|}{ Conclusion } \\
\hline$H 1$ & Trust $\rightarrow$ Exchange of knowledge & Supported & $\checkmark$ \\
\hline & Trust $\rightarrow$ Commitment & Supported & $\checkmark$ \\
\hline H2 & Exchange of knowledge $\rightarrow$ Commitment & Supported & $\checkmark$ \\
\hline HЗа & Empathy $\rightarrow$ Trust & Not supported & $x$ \\
\hline$H 3 b$ & Empathy $\rightarrow$ Commitment & Supported & $\checkmark$ \\
\hline$H 4 a$ & Shared values $\rightarrow$ Trust & Supported & $\checkmark$ \\
\hline$H 4 b$ & Shared values $\rightarrow$ Commitment & Not supported & $x$ \\
\hline$H 5 a$ & Complementary resources $\rightarrow$ Trust & Supported & $\checkmark$ \\
\hline$H 5 b$ & Complementary resources $\rightarrow$ Commitment & Not supported & $x$ \\
\hline$H 5 c$ & Complementary resources $\rightarrow$ Exchange of knowledge & Supported & $\checkmark$ \\
\hline$H 6 a$ & Supplementary resources $\rightarrow$ Trust & Supported & $\checkmark$ \\
\hline$H 6 b$ & Supplementary resources $\rightarrow$ Commitment & Not supported & $\boldsymbol{x}$ \\
\hline$H 6 c$ & Supplementary resources $\rightarrow$ Exchange of knowledge & Supported & $\checkmark$ \\
\hline H7 & Transferability $\rightarrow$ Exchange of knowledge & Supported & $\checkmark$ \\
\hline H8 & Willingness to share knowledge $\rightarrow$ Exchange of knowledge & Supported & $\checkmark$ \\
\hline H9a & Promotion focus $\rightarrow$ Willingness to share knowledge & Supported & $\checkmark$ \\
\hline$H 9 b$ & Promotion focus $\rightarrow$ Exchange of knowledge & Not supported & $x$ \\
\hline H1Oa & Commitment $\rightarrow$ Entrepreneurial commitment & Supported & $\checkmark$ \\
\hline$H 10 b$ & Exchange of knowledge $\rightarrow$ Entrepreneurial commitment & Supported & $\checkmark$ \\
\hline H11a & Commitment $\rightarrow$ Generation of innovation & Supported & $\checkmark$ \\
\hline$H 11 b$ & Exchange of knowledge $\rightarrow$ Generation of innovation & Supported & $\checkmark$ \\
\hline$H 12 a$ & Commitment $\rightarrow$ Business results & Not supported & $x$ \\
\hline$H 12 b$ & Exchange of knowledge $\rightarrow$ Business results & Not supported & $x$ \\
\hline$H 12 c$ & Generation of innovation $\rightarrow$ Business results & Supported & $\checkmark$ \\
\hline
\end{tabular}

\section{Analysis of indirect and total effects}

Rejecting the direct effects of shared values (H4b), complementarity of resources (H5b) and supplementarity of resources (H6b) on commitment leads us to speculate as to the possibility of indirect effects through trust and exchange of knowledge. Moreover, by rejecting the direct effect of commitment (H12a) and the exchange of knowledge (H12b) on performance, we wonder whether such effects might be indirect.

Table 4.35 reflects the indirect and total effects for all the variables included in the model. 
Table 4.35. Indirect and total effects (Study II)

\begin{tabular}{|c|c|c|}
\hline & Indirect effect & Total effect \\
\hline \multicolumn{3}{|l|}{ Determinants of dyadic relationship } \\
\hline Empathy $\rightarrow$ Trust & - & $-0.127^{+}$ \\
\hline Shared values $\rightarrow$ Trust & - & $0.394 * * *$ \\
\hline Complementary resources $\rightarrow$ Trust & & $0.276^{* *}$ \\
\hline Supplementary resources $\rightarrow$ Trust & - & $0.251^{* *}$ \\
\hline Empathy $\rightarrow$ Commitment & -0.063 & $0.117^{+}$ \\
\hline Shared values $\rightarrow$ Commitment & $0.197 * * *$ & $0.331 * * *$ \\
\hline Complementary resources $\rightarrow$ Commitment & $0.212^{* *}$ & $0.323 * *$ \\
\hline Supplementary resources $\rightarrow$ Commitment & $0.202 * * *$ & $0.146 *$ \\
\hline Transferability $\rightarrow$ Commitment & $0.073^{* *}$ & $0.073 * *$ \\
\hline Willingness to share knowledge $\rightarrow$ Commitment & $0.075^{+}$ & $0.075^{+}$ \\
\hline Promotion focus $\rightarrow$ Commitment & 0.037 & 0.037 \\
\hline Empathy $\rightarrow$ Exchange of knowledge & -0.034 & -0.034 \\
\hline Shared values $\rightarrow$ Exchange of knowledge & $0.106^{+}$ & $0.106^{+}$ \\
\hline Complementary resources $\rightarrow$ Exchange of knowledge & 0.074 & $0.283^{* *}$ \\
\hline Supplementary resources $\rightarrow$ Exchange of knowledge & 0.068 & $0.281 * * *$ \\
\hline Transferability $\rightarrow$ Exchange of knowledge & - & $0.205^{* *}$ \\
\hline Willingness to share knowledge $\rightarrow$ Exchange of knowledge & - & $0.212 *$ \\
\hline Promotion focus $\rightarrow$ Exchange of knowledge & 0.061 & 0.105 \\
\hline Promotion focus $\rightarrow$ Willingness to share knowledge & - & $0.289 *$ \\
\hline \multicolumn{3}{|l|}{ Characterization of the dyadic relationship } \\
\hline Trust $\rightarrow$ Commitment & 0.096 & $0.501 * * *$ \\
\hline Trust $\rightarrow$ Exchange of knowledge & - & $0.270 *$ \\
\hline Exchange of knowledge $\rightarrow$ Commitment & - & $0.355^{* * *}$ \\
\hline \multicolumn{3}{|l|}{ Outcomes of the dyadic relationship } \\
\hline Empathy $\rightarrow$ Entrepreneurial commitment & 0.027 & 0.027 \\
\hline Shared values $\rightarrow$ Entrepreneurial commitment & $0.157^{*}$ & $0.157 *$ \\
\hline Complementary resources $\rightarrow$ Entrepreneurial commitment & $0.226^{* *}$ & $0.226^{* *}$ \\
\hline Supplementary resources $\rightarrow$ Entrepreneurial commitment & $0.164 * *$ & $0.164 * *$ \\
\hline Transferability $\rightarrow$ Entrepreneurial commitment & $0.108^{*}$ & $0.108^{*}$ \\
\hline Willingness to share knowledge $\rightarrow$ Entrepreneurial commitment & $0.112 *$ & $0.112 *$ \\
\hline Promotion focus $\rightarrow$ Entrepreneurial commitment & 0.055 & 0.055 \\
\hline Trust $\rightarrow$ Entrepreneurial commitment & $0.282 * *$ & $0.282 * *$ \\
\hline Commitment $\rightarrow$ Entrepreneurial commitment & - & $0.345^{* *}$ \\
\hline Exchange of knowledge $\rightarrow$ Entrepreneurial commitment & 0.123 & $0.528 * * *$ \\
\hline Empathy $\rightarrow$ Generation of innovation & -0.001 & -0.001 \\
\hline Shared values $\rightarrow$ Generation of innovation & $0.130 *$ & $0.130 *$ \\
\hline Complementary resources $\rightarrow$ Generation of innovation & $0.244 * *$ & $0.244 * *$ \\
\hline Supplementary resources $\rightarrow$ Generation of innovation & $0.210 * * *$ & $0.210 * * *$ \\
\hline Transferability $\rightarrow$ Generation of innovation & $0.147 * *$ & $0.147 * *$ \\
\hline Willingness to share knowledge $\rightarrow$ Generation of innovation & $0.152 *$ & $0.152 *$ \\
\hline Promotion focus $\rightarrow$ Generation of innovation & 0.075 & 0.075 \\
\hline Trust $\rightarrow$ Generation of innovation & $0.268^{* *}$ & $0.268 * *$ \\
\hline Commitment $\rightarrow$ Generation of innovation & - & $0.184^{+}$ \\
\hline Exchange of knowledge $\rightarrow$ Generation of innovation & 0.065 & $0.717 * * *$ \\
\hline Empathy $\rightarrow$ Business results & 0.013 & 0.013 \\
\hline Shared values $\rightarrow$ Business results & $0.125^{*}$ & $0.125 *$ \\
\hline Complementary resources $\rightarrow$ Business results & $0.199 * *$ & $0.199 * *$ \\
\hline Supplementary resources $\rightarrow$ Business results & $0.155^{* * *}$ & $0.155^{* * *}$ \\
\hline Transferability $\rightarrow$ Business results & $0.105^{*}$ & $0.105^{*}$ \\
\hline Willingness to share knowledge $\rightarrow$ Business results & $0.109 *$ & $0.109 *$ \\
\hline Promotion focus $\rightarrow$ Business results & 0.054 & 0.054 \\
\hline Trust $\rightarrow$ Business results & $0.235^{* *}$ & $0.235^{* *}$ \\
\hline Commitment $\rightarrow$ Business results & $0.119^{+}$ & $0.239^{+}$ \\
\hline Exchange of knowledge $\rightarrow$ Business results & $0.509 * * *$ & $0.514 * * *$ \\
\hline Generation of innovation $\rightarrow$ Business results & - & $0.651^{* * *}$ \\
\hline
\end{tabular}

$\left({ }^{\mathrm{a}}\right)$ 0=Spain; 1=The Netherlands $\left({ }^{+}\right) \mathrm{p}<0.10 ;\left({ }^{*}\right) \mathrm{p}<0.05 ;\left({ }^{* *}\right) \mathrm{p}<0.01 ;\left({ }^{* * *}\right) \mathrm{p}<0.001$ 
As regards the determinants of the dyadic relationships, specifically vis-à-vis commitment, results show that the indirect effects of shared values, complementarity, supplementarity and transferability of resources on commitment are significant. When incubatees share values, as a result of finding themselves at the same starting point in their business, they tend to commit long-term, through increased trust. In turn, complementarity and/or supplementarity in the resources they possess can boost their commitment to maintain a long-term relationship through increased trust and exchange of knowledge. In other words, trust and exchange of knowledge act as mediators between complementarity and supplementarity of resources and relational commitment between incubatees. Likewise, transferability of knowledge and the willingness to share it, which is fostered in those who display a promotion focus, also boost commitment in the relationships they maintain, through exchange of knowledge.

With regard to the results of relationships, it is worth highlighting the significant indirect effects of the antecedents of the relationship on results, through the following: shared values amongst incubatees, the characteristics of the resources (complementarity, supplementarity and transferability), and willingness to share knowledge, foster the three proposed results: boosting incubatees' entrepreneurial commitment, generating innovation in their business and, as a result, obtaining business performance. As regards business performance, generating innovation is the variable which acts as a mediator between features of the relationship (trust, exchange of knowledge and commitment) and performance. Dyadic relationships between university incubatees lead to better performance in that they generate innovations in the area of emerging businesses. 


\subsection{Study III. The role of the manager in building relationships and social capital in UBIs}

After an empirical analysis of the dyadic relationships between incubatees, the figure of the manager is introduced and highlighted in Study III of the present doctoral thesis. Specifically, this study is split into two parts, posited so as to test Models 2 and 3, and in order to evaluate hypotheses H13 to H26, all of this being set out in Chapter 3.

The first, Study III.1, focuses on relating the manager's professional profile and the services that can be provided in a UBI. Study III.2 then explores the role played by the manager in creating and fostering social capital in the incubator.

\subsubsection{Study III.1. Relationship between the professional profile of the manager and the services offered by UBIs}

Study III.1 seeks to gauge to what extent the manager's professional profile might shape the kind of services provided to UBI tenants (H13, H14 and H15), reflected in Model 2, presented in Chapter 3. In an effort to achieve the proposed objective, an explanation is given of the sequence of analysis carried out, which is similar to that followed in Study II: measuring the variables used in the study, validating the measurement scales used, estimating the structural model, and evaluating the hypotheses.

\subsubsection{Descriptive statistics of the measurement variables}

Data for this Study, III.1, were collected through questionnaires sent to managers. As explained before, managers may be in charge of several incubation programmes: preincubation, incubation, and post-incubation. Consequently, they were requested to answer questions dealing with each of the programmes they ran in their incubator in order to evaluate the services offered. Thus, the incubation programme is the unit of analysis in our research. Specifically, 93 valid questionnaires were obtained, 32 preincubation, 41 incubation, and 20 post-incubation.

As regards the variables and the indicators used to measure the various concepts, we started with the manager's experience. Scientific experience and business experience take mean values of around 2 (“up to 3 years”) and 3 (“between 3 and 5 years”). 
As for the services provided in each incubation programme ${ }^{21}$, mean values range from 4.81 (for advising on strategic decisions) to 5.08 (access to incubator networks). Not all incubators offer the three programmes and, within each programme, do not provide the same services, although it could be said that they do give a significant boost to each of the services they offer.

The UBIs in the sample have been working for an average of 7.29 years, with the dispersion being 6.09. The time the manager has been head of the incubator is around 3 years, and the dispersion is not high, as it stands at 1.65.

See Table 4.36 for further details.

Table 4.36. Descriptive statistics of the variables (Study III.1)

\begin{tabular}{|c|c|c|c|c|}
\hline & Mean & S.D. & Min. & Max. \\
\hline \multicolumn{5}{|l|}{ Business experience of the manager } \\
\hline Years of entrepreneurial experience & 2.56 & 1.59 & 1 & 5 \\
\hline Years of experience in the business world & 3.13 & 1.59 & 1 & 5 \\
\hline \multicolumn{5}{|l|}{ Scientific experience of the manager } \\
\hline Years of experience in the scientific world & 2.76 & 1.60 & 1 & 5 \\
\hline \multicolumn{5}{|l|}{$\begin{array}{l}\text { Personal assistance. Indicate to what extent you } \\
\text { offer/support the following services... }\end{array}$} \\
\hline \multicolumn{5}{|l|}{$\begin{array}{l}\text { Business assistance. Indicate to what extent you } \\
\text { offer/support the following services... }\end{array}$} \\
\hline $\begin{array}{l}\text { Assistance in planning financing and in obtaining financing } \\
\text { Assistance in strategic decisions (internationalization. }\end{array}$ & 4.92 & 1.12 & 1 & 6 \\
\hline $\begin{array}{l}\text { commercialization, implementation of products and } \\
\text { services, etc.) }\end{array}$ & 4.81 & 1.10 & 1 & 6 \\
\hline Sparring and assistance in preparing a business plan & 4.99 & 1.17 & 1 & 6 \\
\hline $\begin{array}{l}\text { Business and entrepreneurship training (workshops, } \\
\text { sessions, etc.) }\end{array}$ & 4.82 & 1.27 & 1 & 6 \\
\hline \multicolumn{5}{|l|}{$\begin{array}{l}\text { Networking. Indicate to what extent you offer/support the } \\
\text { following services... }\end{array}$} \\
\hline $\begin{array}{l}\text { Access to networks outside the incubator (business, } \\
\text { associations, freelance, etc.) }\end{array}$ & 5.08 & 1.11 & 1 & 6 \\
\hline $\begin{array}{l}\text { Meetings and events between incubatees in order to foster } \\
\text { contacts and relationships between them }\end{array}$ & 4.83 & 1.43 & 1 & 6 \\
\hline \multicolumn{5}{|l|}{ Age of the incubator } \\
\hline Years of the incubator & 7.29 & 6.09 & 0 & 31 \\
\hline \multicolumn{5}{|l|}{ Age of the manager in the incubator } \\
\hline Years as manager of the incubator & 2.96 & 1.65 & 0 & 18 \\
\hline
\end{tabular}

In order to ascertain whether there are any differences in the sizes of the variables between countries, a means $t$ test for independent samples was carried out. As can be seen in Table 4.37, differences were only apparent in two indicators: years of experience as an entrepreneur and years of experience in the world of science. Dutch

\footnotetext{
${ }^{21}$ As regards the services offered in the incubation programmes, all were measured on sixposition Likert scales, with 1 being the absence of the service and 6 reflecting that significant support was lent to the service.
} 
managers have greater experience in both areas, most noticeably with regard to their experience as entrepreneurs (the mean for Dutch managers being 3.65 years compared to 2.32 for Spanish managers). With the exception of these two variables, and in light of the findings to emerge, the samples of managers can be assumed to be fairly homogenous.

Table 4.37. Means test (Study III.1)

\begin{tabular}{|c|c|c|c|c|c|}
\hline & Country & $\mathbf{N}$ & Mean & S.D. & $\mathbf{t}$ \\
\hline \multicolumn{6}{|l|}{ Business experience of the manager } \\
\hline \multirow{2}{*}{ Years of entrepreneurial experience } & Spain & 76 & 2.32 & 1.525 & \multirow{2}{*}{$-3.280 * *$} \\
\hline & The Netherlands & 17 & 3.65 & 1.455 & \\
\hline \multirow{2}{*}{ Years of experience in the business world } & Spain & 76 & 3.07 & 1.603 & \multirow{2}{*}{-0.810} \\
\hline & The Netherlands & 17 & 3.41 & 1.543 & \\
\hline \multicolumn{6}{|l|}{ Scientific experience of the manager } \\
\hline \multirow{2}{*}{ Years of experience in the scientific world } & Spain & 76 & 2.63 & 1.632 & \multirow{2}{*}{$-1.895^{+}$} \\
\hline & The Netherlands & 17 & 3.35 & 1.367 & \\
\hline \multicolumn{6}{|c|}{$\begin{array}{l}\text { Personal assistance. Indicate to what extent you } \\
\text { offer/support the following services... }\end{array}$} \\
\hline \multirow{2}{*}{ Coaching or mentoring } & Spain & 76 & 4.24 & 1.680 & \multirow{2}{*}{-1.324} \\
\hline & The Netherlands & 17 & 4.82 & 1.510 & \\
\hline \multicolumn{6}{|c|}{$\begin{array}{l}\text { Business assistance. Indicate to what extent you } \\
\text { offer/support the following services... }\end{array}$} \\
\hline \multirow{2}{*}{$\begin{array}{l}\text { Assistance in planning financing and in obtaining } \\
\text { financing }\end{array}$} & Spain & 76 & 5.01 & 1.071 & \multirow{2}{*}{1.616} \\
\hline & The Netherlands & 17 & 4.53 & 1.305 & \\
\hline \multirow{2}{*}{$\begin{array}{l}\text { Assistance in strategic decisions (internationalization, } \\
\text { commercialization, implementation of products and } \\
\text { services, etc.) }\end{array}$} & Spain & 76 & 4.78 & 1.135 & \multirow{2}{*}{-0.753} \\
\hline & The Netherlands & 17 & 5.00 & 0.968 & \\
\hline \multirow{2}{*}{ Sparring and assistance in preparing a business plan } & Spain & 76 & 4.95 & 1.188 & \multirow{2}{*}{-0.725} \\
\hline & The Netherlands & 17 & 5.18 & 1.131 & \\
\hline \multirow{2}{*}{$\begin{array}{l}\text { Business and entrepreneurship training (workshops, } \\
\text { sessions, etc.) }\end{array}$} & Spain & 76 & 4.87 & 1.309 & \multirow{2}{*}{0.751} \\
\hline & The Netherlands & 17 & 4.62 & 1.111 & \\
\hline \multicolumn{6}{|l|}{$\begin{array}{l}\text { Networking. Indicate to what extent you offer/support } \\
\text { the following services... }\end{array}$} \\
\hline \multirow{2}{*}{$\begin{array}{l}\text { Access to networks outside the incubator (business, } \\
\text { associations, freelance, etc.) }\end{array}$} & Spain & 76 & 5.07 & 1.181 & \multirow{2}{*}{-0.172} \\
\hline & The Netherlands & 17 & 5.12 & 0.781 & \\
\hline \multirow{2}{*}{$\begin{array}{l}\text { Meetings and events between incubatees in order to } \\
\text { foster contacts and relationships between them }\end{array}$} & Spain & 76 & 4.82 & 1.521 & \multirow{2}{*}{-0.172} \\
\hline & The Netherlands & 17 & 4.88 & 0.993 & \\
\hline \multicolumn{6}{|l|}{ Age of the incubator } \\
\hline \multirow{2}{*}{ Years of the incubator } & Spain & 76 & 7.18 & 5.288 & \multirow{2}{*}{-0.353} \\
\hline & The Netherlands & 17 & 7.76 & 9.073 & \\
\hline \multicolumn{6}{|l|}{ Age of the manager in the incubator } \\
\hline \multirow{2}{*}{ Years as manager of the incubator } & Spain & 76 & 3.30 & 3.152 & \\
\hline & The Netherlands & 17 & 2.74 & 2.721 & $0.6 \%$ \\
\hline
\end{tabular}

$\left(^{+}\right) \mathrm{p}<0.10 ;\left({ }^{* *}\right) \mathrm{p}<0.01$

\subsubsection{Validation of scales}

The parameters of the measurement model indicators were estimated using PLS with a maximum of 300 iterations. In order to calculate the significance of the loadings and factor weight of the items, a bootstrapping procedure was applied to 1000 sub-samples.

Of the five constructs included in the model, three are formative compared to two which are reflective (business experience and networking). Prior to validating the scales, one 
aspect should be clarified: although the scale measuring the network was formative in nature, a high correlation between the two items (0.647) was found when the model was estimated, and consequently a problem of multicollinearity arose. To solve this problem, for the purposes of the current research this scale was treated as reflective.

First, the formative scales were validated. According to Diamantopoulos and Winklhofer (2001), a formative measure is essentially a multiple regression where the construct is the dependent variable and the indicators are the predictors. In these cases, the correlation between indicators causes problems of multicollinearity and instability of the coefficients. Moreover, PLS may pose problems when multicollinearity is in evidence. Checks thus need to be carried out to determine whether it is present and in order to avoid problems in the results of the analysis (Henseler et al., 2009). Table 4.38 shows the variance inflation factor (VIF) values, which are seen to be well below the critical level of 5 . In light of these values, multicollinearity is not a problem in the formative scales used.

In addition, Table 4.38 shows that the weights of the items of the formative variables do not display high values. As Hair et al. (2014) point out, this does not indicate poor quality in the measurement model. In addition to the relative contribution, these authors feel that it is also necessary to take into consideration the absolute contribution each formative indicator makes to its construct, in other words the information an indicator provides when bearing in mind other indicators. The absolute contribution is given by the outer loading. When an indicator does not display a significant weight but its outer loading is above 0.5 , as happens in the case in hand, the indicator might be deemed important at an absolute level, although not at a relative level.

As regards the reflective scales, their reliability as well as convergent and discriminant validity were evaluated. To measure their reliability, three indicators were used: Cronbach's alpha $(\alpha)$, composite reliability (CR) and reliability of the indicators (Table 4.38). Cronbach's alpha takes values above 0.6 (0.775 and 0.786), composite reliability above 0.7 (0.896 and 0.903) and the loadings for each indicator take values which are significantly above 0.6 . Reliability and convergent validity of the scales is thus ensured. 
Table 4.38. Reliability of measurement scales and outer weights and loadings (Study III.1)

\begin{tabular}{|c|c|c|c|}
\hline & Weights & Loadings & VIF \\
\hline \multicolumn{4}{|l|}{$\begin{array}{l}\text { Business experience of the manager }(\alpha=.775 ; \\
C R=.896 ; A V E=.811)\end{array}$} \\
\hline Years of entrepreneurial experience & & $0.939 * * *$ & \\
\hline Years of experience in the business world & & $0.861^{* * *}$ & \\
\hline \multicolumn{4}{|l|}{ Scientific experience of the manager } \\
\hline Years of experience in the scientific world & 1.000 & & 1.000 \\
\hline \multicolumn{4}{|l|}{ Personal assistance } \\
\hline Coaching or mentoring & 1.000 & & 1.000 \\
\hline \multicolumn{4}{|l|}{ Business assistance } \\
\hline $\begin{array}{l}\text { Assistance in planning financing and in obtaining } \\
\text { financing }\end{array}$ & 0.391 & $0.729 * * *$ & 1.262 \\
\hline $\begin{array}{l}\text { Assistance in strategic decisions (internationalization, } \\
\text { commercialization, implementation of products and } \\
\text { services, etc.) }\end{array}$ & 0.130 & $0.716^{* * *}$ & 1.779 \\
\hline Sparring and assistance in preparing a business plan & $0.418^{+}$ & $0.779 * * *$ & 1.577 \\
\hline $\begin{array}{l}\text { Business and entrepreneurship training (workshops, } \\
\text { sessions, etc.) }\end{array}$ & $0.389^{+}$ & $0.762 * * *$ & 1.406 \\
\hline \multicolumn{4}{|l|}{ Networking $(\alpha=.786 ; C R=.903 ; A V E=.823)$} \\
\hline $\begin{array}{l}\text { Access to networks outside the incubator (business, } \\
\text { associations, freelance, etc.) }\end{array}$ & & $0.917^{* * *}$ & \\
\hline $\begin{array}{l}\text { Meetings and events between incubatees in order to } \\
\text { foster contacts and relationships between them }\end{array}$ & & $0.897 * * *$ & \\
\hline
\end{tabular}

Following the Fornell-Larcker criterion, discriminant validity was assessed by the square root of the AVE being greater than the correlation with the other constructs. In the correlation matrix of latent constructs (Table 4.39), it can be observed that this condition is met for the reflective constructs (business experience and networking). In addition, the heterotrait-monotrait (HTMT) ratio of correlations for each pair of constructs (Henseler et al., 2015) was calculated. These values are shown above the main diagonal of the correlation matrix. The highest value is 0.458 , below the critical value of 0.85 . Therefore, the discriminant validity of the reflective scales was accepted.

Table 4.39. Correlation matrix (Study III.1)

\begin{tabular}{lcccccccc}
\hline & $(1)$ & $(2)$ & $(3)$ & $(4)$ & $(5)$ & $(6)$ & (7) & (8) \\
\hline (1) Business experience of the manager & $\mathbf{0 . 9 0 0}$ & 0.303 & 0.458 & n.a. & 0.299 & 0.257 & 0.161 & 0.039 \\
(2) Scientific experience of the manager & 0.284 & n.a. & 0.366 & n.a. & 0.074 & 0.175 & 0.093 & 0.408 \\
(3) Personal assistance & 0.416 & 0.366 & n.a. & n.a. & 0.415 & 0.137 & 0.288 & 0.117 \\
(4) Business assistance & 0.451 & 0.281 & 0.587 & n.a. & n.a. & n.a. & n.a. & n.a. \\
(5) Networking & 0.245 & 0.026 & 0.366 & 0.363 & $\mathbf{0 . 9 0 7}$ & 0.022 & 0.035 & 0.077 \\
(6) Country & 0.251 & 0.175 & 0.137 & -0.054 & 0.020 & n.a. & 0.037 & 0.071 \\
(7) Age of the incubator & -0.145 & -0.093 & -0.288 & -0.280 & 0.032 & 0.037 & n.a. & 0.315 \\
(8) Age of the manager in the incubator & 0.031 & 0.408 & 0.117 & 0.149 & 0.070 & -0.071 & 0.315 & n.a. \\
\hline
\end{tabular}

The main diagonal shows the square root of the AVE. Under the main diagonal are the Pearson correlations and above the main diagonal the heterotrait-monotrait (HTMT) ratio of correlations. n.a. Not applicable.

Although collecting information through questionnaires is felt to be a factor that might lead to common method bias, in this case the risk is heightened due to the fact that in 
certain cases the same manager was the informant for several incubation programmes. Therefore, ruling out common method variance proves particularly necessary in this case. We performed a Harman's one-factor test (Podsakoff et al., 2003). Exploratory factor analysis with all the indicators gave two factors with an eigenvalue of over 1 (total variance explained=64.3\%), with a first factor explaining $25.8 \%$ of variance. Therefore, there is no single factor accounting for the majority of the covariance among the measures, and the impact of common method bias is not critical.

\subsubsection{Model estimation}

The results of the structural model estimation for hypotheses 13 and 14 are shown in Table 4.40. In order to facilitate interpretation, significant relationships of proposed hypotheses are displayed in Figure 4.4.

Table 4.40. Estimation of H13 and H14 (Study III.1)

\begin{tabular}{cll}
\hline Proposed hypotheses & Estimate \\
\hline$H 13 a$ & Business experience $\rightarrow$ Personal assistance & $0.306^{* * *}$ \\
$H 13 b$ & Business experience $\rightarrow$ Business assistance & $0.421^{* * *}$ \\
$H 13 c$ & Business experience $\rightarrow$ Networking & $0.278^{* *}$ \\
\hline$H 13 a$ & Scientific experience $\rightarrow$ Personal assistance & $0.202^{+}$ \\
$H 13 b$ & Scientific experience $\rightarrow$ Business assistance & 0.096 \\
$H 13 c$ & Scientific experience $\rightarrow$ Networking & -0.074 \\
\hline Control variables & \\
\hline Country $\rightarrow$ Scientific experience & 0.175 \\
Country $\rightarrow$ Business experience & $0.251^{*}$ \\
Country $\rightarrow$ Personal assistance & 0.043 \\
Country $\rightarrow$ Business assistance & -0.155 \\
Country $\rightarrow$ Networking & -0.033 \\
\hline Age of the incubator $\rightarrow$ Personal assistance & $-0.262^{*}$ \\
Age of the incubator $\rightarrow$ Business assistance & $-0.256^{*}$ \\
Age of the incubator $\rightarrow$ Networking & 0.042 \\
\hline Years in the incubator $\rightarrow$ Personal assistance & 0.111 \\
Years in the incubator $\rightarrow$ Business assistance & 0.166 \\
Years in the incubator $\rightarrow$ Networking & 0.076 \\
\hline
\end{tabular}

( $\left.{ }^{\mathrm{a}}\right) 0=$ Spain; $1=$ The Netherlands

$\left(^{+}\right) \mathrm{p}<0.10 ;\left({ }^{*}\right) \mathrm{p}<0.05 ;\left({ }^{* *}\right) \mathrm{p}<0.01 ;(* * *) \mathrm{p}<0.001$ 


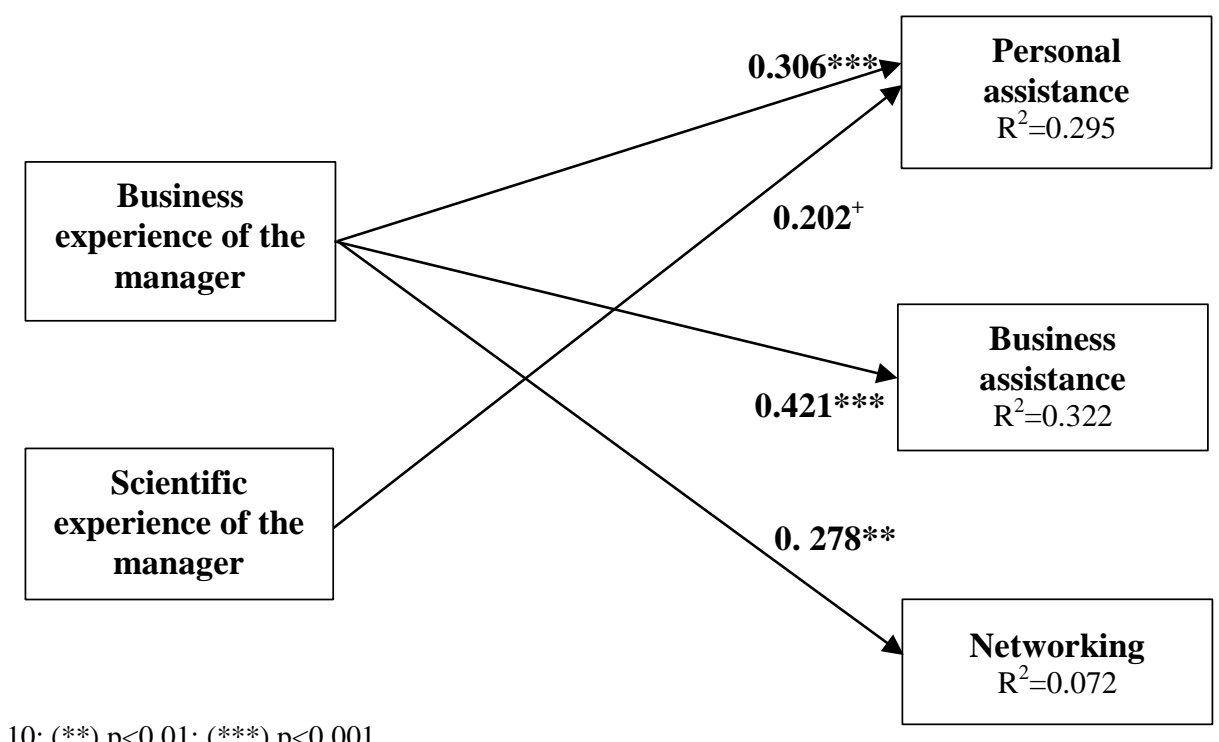

$\left({ }^{+}\right) \mathrm{p}<0.10 ;\left({ }^{* *}\right) \mathrm{p}<0.01 ;(* * *) \mathrm{p}<0.001$

Additionally, path analysis ${ }^{22}$ was conducted using the AMOS v20.0 statistical program, to check the robustness of our results and to offer a global goodness-of-fit measure. Previously, each variable was reduced to a measurement index, specifically the latent variable scores provided by PLS in order to use similar measures. The goodness of fit or the estimated model is adequate: $\chi^{2}(2)=3.467(\mathrm{p}=0.177)$; $\mathrm{RMR}=0.042$; RMSEA=0.089; $\mathrm{GFI}=0.985 ; \mathrm{CFI}=0.984 ; \mathrm{NFI}=0.965$.

Table 4.41. Results of the estimated model using AMOS (Study III.1)

\begin{tabular}{llc}
\hline & $\begin{array}{c}\text { Standardized } \\
\text { Estimate }\end{array}$ & S.E. \\
\hline Business experience $\rightarrow$ Personal assistance & $0.359^{* * *}$ & 0.094 \\
Business experience $\rightarrow$ Business assistance & $0.450^{* * *}$ & 0.093 \\
Business experience $\rightarrow$ Networking & $0.246^{*}$ & 0.101 \\
\hline Scientific experience $\rightarrow$ Personal assistance & $0.216^{* *}$ & 0.081 \\
\hline$\left({ }^{*}\right) \mathrm{p}<0.05 ;\left(^{* *}\right) \mathrm{p}<0.01 ;(* * *) \mathrm{p}<0.001$ & &
\end{tabular}

In order to test hypothesis H15, managers were classified according to their entrepreneurial experience (only experience as entrepreneurs was considered, not general experience) and their academic experience. Table 4.42 shows the contingent table with the distribution of the manager's experience ${ }^{23}$.

${ }^{22}$ The small sample size should be remembered, making this procedure non-appropriate for studies such as the present one. The caution with which results should therefore be interpreted must also be taken into account.

${ }^{23}$ As pointed out previously, managers may be counted more than once if they run several incubation programmes. 
Table 4.42. Incubator managers' entrepreneurial and scientific experience (Study III.1)

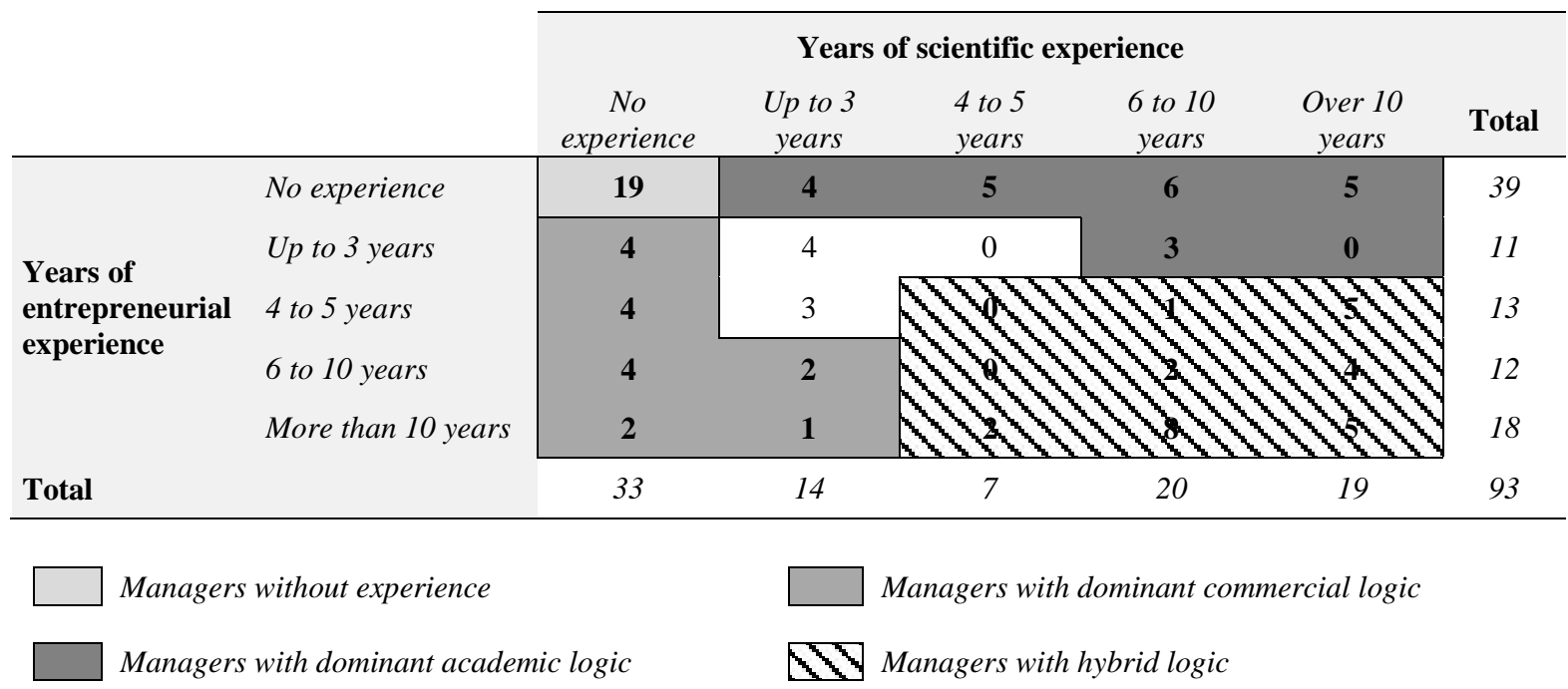

Following this distribution, managers were classified into four categories: (1) Managers without experience (19 cases): those who do not have experience in any field do not belong to any logic; (2) managers with dominant commercial logic (17 cases): those without scientific experience and with entrepreneurial experience, and those with little scientific experience (up to three years) and significant entrepreneurial experience (more than six years); (3) managers with dominant academic logic (23 cases): those without entrepreneurial experience and with some scientific experience, and those with scant entrepreneurial experience (less than three years) and significant scientific experience (more than six years); (4) managers with hybrid logic (27 cases): those with more than four years' experience in both fields, the scientific and the entrepreneurial world. In order to make the differences between the dominant logic clearer, seven cases were excluded from this classification, namely those who have little experience in both fields.

Once managers had been classified, an ANOVA was performed to evaluate the influence of manager profile on the services offered by the incubator: personal assistance, business assistance and networking. ANOVA results are shown in Table 4.43, and Table 4.44 shows the results of Tukey's test to compare the four groups. 
Table 4.43. ANOVA results (Study III.1)

\begin{tabular}{|c|c|c|c|c|c|c|}
\hline $\begin{array}{c}\text { Dependent } \\
\text { variables }\end{array}$ & $\begin{array}{c}\text { Previous experience of } \\
\text { the manager }\end{array}$ & $\mathbf{N}$ & Mean & S.D. & $\mathbf{F}$ & Sig. \\
\hline \multirow{4}{*}{$\begin{array}{l}\text { Personal } \\
\text { assistance }\end{array}$} & No experience & 19 & 3.05 & 1.682 & \multirow{4}{*}{8.437} & \multirow{4}{*}{0.000} \\
\hline & Entrepreneurial experience & 17 & 4.12 & 1.495 & & \\
\hline & Scientific experience & 23 & 4.26 & 1.738 & & \\
\hline & Experience in both fields & 27 & 5.22 & 0.847 & & \\
\hline \multirow{4}{*}{$\begin{array}{l}\text { Business } \\
\text { assistance }\end{array}$} & No experience & 19 & 4.20 & 0.925 & \multirow{4}{*}{9.037} & \multirow{4}{*}{0.000} \\
\hline & Entrepreneurial experience & 17 & 5.04 & 0.801 & & \\
\hline & Scientific experience & 23 & 4.69 & 0.856 & & \\
\hline & Experience in both fields & 27 & 5.39 & 0.616 & & \\
\hline \multirow{4}{*}{ Networking } & No experience & 19 & 4.95 & 1.066 & \multirow{4}{*}{3.712} & \multirow{4}{*}{0.015} \\
\hline & Entrepreneurial experience & 17 & 5.26 & 0.903 & & \\
\hline & Scientific experience & 23 & 4.28 & 1.615 & & \\
\hline & Experience in both fields & 27 & 5.26 & 0.777 & & \\
\hline
\end{tabular}

Table 4.44. Results of Tukey's test (Study III.1)

\begin{tabular}{llc}
\hline $\begin{array}{c}\text { Dependent } \\
\text { variable }\end{array}$ & \multicolumn{1}{c}{ Compared categories } & Sig. \\
\hline & No experience - Entrepreneurial experience & 0.131 \\
Personal & No experience - Scientific experience & $\mathbf{0 . 0 4 2}$ \\
assistance & No experience - Experience in both fields & $\mathbf{0 . 0 0 0}$ \\
& Entrepreneurial experience - Scientific experience & 0.990 \\
& Entrepreneurial experience - Experience in both fields & 0.073 \\
& Scientific experience - Experience in both fields & 0.097 \\
\hline & No experience - Entrepreneurial experience & $\mathbf{0 . 0 1 1}$ \\
& No experience - Scientific experience & 0.206 \\
assinstance & No experience - Experience in both fields & $\mathbf{0 . 0 0 0}$ \\
& Entrepreneurial experience - Scientific experience & 0.507 \\
& Entrepreneurial experience - Experience in both fields & 0.490 \\
& Scientific experience - Experience in both fields & $\mathbf{0 . 0 1 3}$ \\
\hline & No experience - Entrepreneurial experience & 0.838 \\
& No experience - Scientific experience & 0.244 \\
& No experience - Experience in both fields & 0.798 \\
& Entrepreneurial experience - Scientific experience & $\mathbf{0 . 0 4 2}$ \\
& Entrepreneurial experience - Experience in both fields & 1.000 \\
& Scientific experience - Experience in both fields & $\mathbf{0 . 0 1 7}$ \\
\hline
\end{tabular}

\subsubsection{Hypotheses testing}

Firstly, examining the influence which control variables - country, years in the incubator and years as manager in the incubator - might have on the remaining variables proves important at this point. 
The country in which the incubator is located has a direct and significant impact on the professional profile of the manager who is running it. Specifically, and as was seen in the descriptive statistics, managers located in the Netherlands have greater business and scientific experience. This might be due to the high mobility in the labour market, from one field to another, in the Netherlands, coupled with the country's low unemployment rates, which are in stark contrast to those of Spain.

Years in the incubator impacts on the services provided. The longer a UBI has been in operation, the fewer the services provided in terms of advising, both at a business and personal level. This might be due to the actual evolution of the incubator itself. The services, and how useful these prove for incubatees, may change over the various generations as do the actual incubators themselves.

The years the manager has been in charge of the UBI is seen to have no significant effect on any of the variables considered.

As for the proposed hypotheses, the analysis indicates, first, that the manager's business experience has a positive influence on the three services offered, personal assistance, business assistance, and networking. Thus, hypotheses H13a, H13b and H13c are accepted. In contrast, the manager's scientific experience has only a positive and a significant influence on personal assistance in UBIs (H14a is accepted), but hypotheses $\mathrm{H} 14 \mathrm{~b}$ and H14c are rejected. In other words, there is no significant relationship between the manager's scientific experience and the offer of business assistance and networking in the incubator.

Second, there are significant differences vis-à-vis fostering personal assistance depending on manager experience. Personal assistance is greater when managers have scientific, entrepreneurial, or global experience than when they have no experience. Since no differences were found between scientific and entrepreneurial experience, hypothesis H15a cannot be accepted.

Third, there are also significant differences concerning the fostering of business assistance. In this case, the business assistance given to incubatees is greater when managers have experience in both fields than when they have no experience or only scientific experience. In addition, more business assistance is provided when managers have entrepreneurial experience than when they lack experience. Since business 
experience has a greater influence on business assistance than just scientific experience, hypothesis H15b is accepted.

Finally, the manager's entrepreneurial experience exerts a greater influence on networking than scientific experience does. Further, global experience, both scientific and in business, has a greater influence on networking than scientific experience, so, H15c is accepted.

Table 4.45 shows the results.

Table 4.45. Results of hypothesis testing (Study III.1)

\begin{tabular}{|c|c|c|}
\hline Proposed hypotheses & Conclusior & \\
\hline H13a Business experience $\rightarrow$ Personal assistance & Supported & $\sqrt{ }$ \\
\hline$H 13 b$ Business experience $\rightarrow$ Business assistance & Supported & $\checkmark$ \\
\hline H13c Business experience $\rightarrow$ Networking & Supported & $\checkmark$ \\
\hline H14a Scientific experience $\rightarrow$ Personal assistance & Supported & $\sqrt{ }$ \\
\hline$H 14 b$ Scientific experience $\rightarrow$ Business assistance & Not supported & $x$ \\
\hline H14c Scientific experience $\rightarrow$ Networking & Not supported & $x$ \\
\hline H15a (Business experience $>$ Scientific experience) $\rightarrow$ Personal assistance & Supported & $\sqrt{ }$ \\
\hline H15b (Business experience $>$ Scientific experience) $\rightarrow$ Business assistance & Supported & $\checkmark$ \\
\hline$H 15 c$ (Business experience $>$ Scientific experience) $\rightarrow$ Networking & Supported & $\checkmark$ \\
\hline
\end{tabular}

\subsubsection{Study III.2. The role of the incubator manager in building}

\section{incubatees’ social capital}

The last study of this doctoral dissertation, Study III.2, aims to provide insights into the influence of incubators' internal social capital in developing incubatees' individual social capital and the efficiency of their businesses, as well as the role of the incubator manager in building incubator and incubatee social capital (Model 3, and hypotheses H16 to H26).

In order to achieve the above mentioned objective, we develop the same research process followed in studies II and III.1.

\subsubsection{Descriptive statistics of the measurement variables}

Data for this study were collected through questionnaires sent to incubatees.

Incubatees' bonding social capital was measured as the number of incubatees with whom the incubatee maintains frequent and close contacts. The mean of incubatees' bonding social capital is 5.99, very similar to its standard deviation, 5.905.

The remaining items were measured with five-point Likert scales, with the mean values being between 2.78 (there is a tradition of creating spin-offs) and 3.93 (use an 
understandable communication pattern). Regarding the standard deviation of scores ranges between 0.754 (behave in a consistent and honest manner) and 0.254 (there is a tradition of creating spin-offs).

Table 4.46 shows descriptive statistics of the variables.

Table 4.46. Descriptive statistics of the variables (Study III.2)

\begin{tabular}{|c|c|c|c|c|}
\hline & Mean & S.D. & Min. & Max. \\
\hline \multicolumn{5}{|l|}{ Bridging social capital. Since I joined incubation, I have managed... } \\
\hline To develop social skills for the business world & 3.69 & 1.007 & 1 & 5 \\
\hline To increase my network of business contacts & 3.81 & 1.046 & 1 & 5 \\
\hline \multicolumn{5}{|l|}{ Bonding social capital } \\
\hline Number of incubatees with whom you are in frequent contact & 5.99 & 5.905 & 1 & 5 \\
\hline \multicolumn{5}{|l|}{$\begin{array}{l}\text { Relational social capital (trust). The entrepreneurs who are in incubation, in } \\
\text { the same incubator as me ... }\end{array}$} \\
\hline Would not take advantage of others even if the opportunity arose & 3.26 & 0.913 & 1 & 5 \\
\hline Always keep their promises & 3.41 & 0.764 & 2 & 5 \\
\hline Behave in a consistent and honest manner & 3.65 & 0.754 & 2 & 5 \\
\hline Are truthful when dealing with one another & 3.74 & 0.820 & 2 & 5 \\
\hline \multicolumn{5}{|l|}{ Relational social capital (identity) } \\
\hline There is a sense of group belonging within us, the incubatees & 3.36 & 1.016 & 1 & 5 \\
\hline I have the feeling of group togetherness or closeness & 3.27 & 1.038 & 1 & 5 \\
\hline \multicolumn{5}{|l|}{ Relational social capital (reciprocity) } \\
\hline When I ask for help, I feel that other incubatees will provide it & 3.43 & 0.973 & 1 & 5 \\
\hline $\begin{array}{l}\text { Even if an incubatee I have helped cannot help me in the future, others will be } \\
\text { able to }\end{array}$ & 3.34 & 0.930 & 1 & 5 \\
\hline \multicolumn{5}{|l|}{$\begin{array}{l}\text { Cognitive social capital. The entrepreneurs who are in incubation, in the } \\
\text { same incubator as me... }\end{array}$} \\
\hline Use a similar language and jargon to me & 3.72 & 0.896 & 1 & 5 \\
\hline Use an understandable communication pattern & 3.93 & 0.840 & 2 & 5 \\
\hline Share similar interests to mine & 3.71 & 0.876 & 1 & 5 \\
\hline Are people whose interests I can identify with & 3.65 & 0.984 & 1 & 5 \\
\hline \multicolumn{5}{|l|}{ Manager's relational orientation. The incubator manager... } \\
\hline I think he/she encourages contacts between entrepreneurs & 3.81 & 1.093 & 1 & 5 \\
\hline Tries to establish links between entrepreneurs who are able to collaborate & 3.63 & 1.155 & 1 & 5 \\
\hline Facilitates networking between all entrepreneurs & 3.77 & 1.085 & 1 & 5 \\
\hline Facilitates contacts outside the incubator & 3.60 & 1.192 & 1 & 5 \\
\hline \multicolumn{5}{|l|}{ Business efficiency. Since I joined incubation, I have managed ... } \\
\hline To be more efficient in the planning and strategy for my business & 3.56 & 0.984 & 1 & 5 \\
\hline To be more efficient in managing my business & 3.53 & 0.965 & 1 & 5 \\
\hline To be more efficient in implementing specific activities for my business & 3.60 & 0.970 & 1 & 5 \\
\hline \multicolumn{5}{|l|}{ Proactivity of the university. } \\
\hline There is a tradition of creating spin-offs & 2.78 & 1.254 & 1 & 5 \\
\hline $\begin{array}{l}\text { There is specific regulation for creating spin-offs at my university/research } \\
\text { centre }\end{array}$ & 2.95 & 1.186 & 1 & 5 \\
\hline $\begin{array}{l}\text { There is a positive attitude within my university/research centre towards } \\
\text { entrepreneurship }\end{array}$ & 3.78 & 1.035 & 1 & 5 \\
\hline
\end{tabular}

Once again, in order to test the homogeneity of the incubatee samples (Spanish and Dutch) included in the present research, a comparison of averages was conducted through a $t$ test for independent samples. After carrying out the analysis, differences were found in 8 of the 30 indicators. Dutch incubatees gave higher scores than their Spanish counterparts to all the items in which differences were apparent. Specifically, 
these were items related to relational social capital in its dimensions of trust and identity, cognitive social capital, coach, and proactivity of the university (Table 4.47).

Table 4.47. Means test (Study III.2)

\begin{tabular}{|c|c|c|c|c|c|}
\hline & Country & $\mathbf{N}$ & Mean & S.D. & $\mathbf{t}$ \\
\hline \multicolumn{6}{|l|}{ Bridging social capital } \\
\hline \multirow{2}{*}{ To develop social skills for the business world } & Spain & 66 & 3.76 & 1.053 & \multirow{2}{*}{0.883} \\
\hline & The Netherlands & 35 & 3.57 & 0.917 & \\
\hline \multirow{2}{*}{ To increase my network of business contacts } & Spain & 66 & 3.71 & 1.106 & \multirow{2}{*}{-1.321} \\
\hline & The Netherlands & 35 & 4.00 & 0.907 & \\
\hline \multicolumn{6}{|l|}{ Bonding social capital } \\
\hline \multirow{2}{*}{$\begin{array}{l}\text { Number of incubatees with whom you are in frequent } \\
\text { contact }\end{array}$} & Spain & 66 & 5.74 & 6.712 & \multirow{2}{*}{-0.577} \\
\hline & The Netherlands & 35 & 6.46 & 4.010 & \\
\hline \multicolumn{6}{|l|}{ Relational social capital (trust) } \\
\hline \multirow{2}{*}{$\begin{array}{l}\text { Would not take advantage of others even if the } \\
\text { opportunity arose }\end{array}$} & Spain & 66 & 3.14 & 0.959 & \multirow{2}{*}{$-1.853^{+}$} \\
\hline & The Netherlands & 35 & 3.49 & 0.781 & \\
\hline \multirow{2}{*}{ Always keep their promises } & Spain & 66 & 3.42 & 0.842 & \multirow{2}{*}{0.365} \\
\hline & The Netherlands & 35 & 3.37 & 0.598 & \\
\hline \multirow{2}{*}{ Behave in a consistent and honest manner } & Spain & 66 & 3.65 & 0.832 & \multirow{2}{*}{-0.039} \\
\hline & The Netherlands & 35 & 3.66 & 0.591 & \\
\hline \multirow{2}{*}{ Are truthful when dealing with one another } & Spain & 66 & 3.73 & 0.904 & \multirow{2}{*}{-0.283} \\
\hline & The Netherlands & 35 & 3.77 & 0.646 & \\
\hline \multicolumn{6}{|l|}{ Relational social capital (identity) } \\
\hline \multirow{2}{*}{$\begin{array}{l}\text { There is a sense of group belonging within us, the } \\
\text { incubatees }\end{array}$} & Spain & 66 & 3.20 & 1.099 & \multirow{2}{*}{$-2.460 *$} \\
\hline & The Netherlands & 35 & 3.66 & 0.765 & \\
\hline I have the feeling of groun togetherness or closeness & Spain & 66 & 3.14 & 1.108 & $1750^{+}$ \\
\hline Indve tile leeming or group togententess or cioseness & The Netherlands & 35 & 3.51 & 0.853 & -1.759 \\
\hline Relational social capital (reciprocity) & & & & & \\
\hline When I ask for help, I feel that other incubatees will & Spain & 66 & 3.41 & 1.007 & -0.235 \\
\hline provide it & The Netherlands & 35 & 3.46 & 0.919 & \\
\hline Even if an incubatee I have helped cannot help me in the & Spain & 66 & 3.38 & 1.034 & 0.740 \\
\hline future, others will be able to & The Netherlands & 32 & 3.25 & 0.672 & 0.140 \\
\hline Cognitive social capital & & & & & \\
\hline Use a similar lanougoo and jaroon to me & Spain & 66 & 3.61 & 0.926 & $-1819^{+}$ \\
\hline Use a similar language and jargon to me & The Netherlands & 35 & 3.94 & 0.802 & -1.819 \\
\hline Use an understandable communication nattern & Spain & 66 & 3.82 & 0.875 & $-1872^{+}$ \\
\hline & The Netherlands & 35 & 4.14 & 0.733 & \\
\hline Share similar interests to mine & Spain & 66 & 3.65 & 0.984 & -1107 \\
\hline 年 & The Netherlands & 35 & 3.83 & 0.618 & -1.107 \\
\hline Are neonle whose interests I can identify with & Spain & 66 & 3.68 & 1.010 & 0396 \\
\hline & The Netherlands & 35 & 3.60 & 0.946 & 0.396 \\
\hline Manager's relational orientation & & & & & \\
\hline I think he/she encourages contacts between & Spain & 66 & 3.77 & 1.107 & 0006 \\
\hline entrepreneurs & The Netherlands & 35 & 3.77 & 1.060 & 0.006 \\
\hline Tries to establish links between entrepreneurs who are & Spain & 66 & 3.55 & 1.243 & -1139 \\
\hline able to collaborate & The Netherlands & 35 & 3.80 & 0.964 & -1.139 \\
\hline Facilitates networkino hetween all entrepreneurs & Spain & 66 & 3.71 & 1.134 & -1313 \\
\hline & The Netherlands & 35 & 4.00 & 1.000 & -1.313 \\
\hline Facilitates contacts outside the incubator & Spain & 66 & 3.50 & 1.280 & -1302 \\
\hline & The Netherlands & 35 & 3.80 & 0.994 & \\
\hline Business efficiency & & & & & \\
\hline To be more efficient in the planning and strategy for my & Spain & 66 & 3.58 & 1.009 & 0159 \\
\hline business & The Netherlands & 35 & 3.54 & 0.950 & 0.159 \\
\hline To he more efficient in mana aino my business & Spain & 66 & 3.53 & 0.964 & -0.062 \\
\hline To be more efticient in managing my business & The Netherlands & 35 & 3.54 & 0.980 & -0.062 \\
\hline To be more efficient in implementing specific & Spain & 66 & 3.61 & 0.959 & 0.030 \\
\hline
\end{tabular}




\begin{tabular}{|c|c|c|c|c|c|}
\hline for my business & The Netherlands & 35 & 3.60 & 1.006 & \\
\hline \multicolumn{6}{|l|}{ Partners } \\
\hline \multirow{2}{*}{ Business partners } & Spain & 66 & 0.76 & 0.432 & \multirow{2}{*}{1.310} \\
\hline & The Netherlands & 35 & 0.63 & 0.490 & \\
\hline \multicolumn{6}{|l|}{ Time in incubation } \\
\hline \multirow{2}{*}{ Months in incubation } & Spain & 66 & 18.30 & 18.794 & \multirow{2}{*}{1.454} \\
\hline & The Netherlands & 35 & 13.14 & 12.786 & \\
\hline \multicolumn{6}{|l|}{ Entrepreneurial experience } \\
\hline \multirow{2}{*}{ Prior entrepreneurial experience } & Spain & 66 & 0.20 & 0.401 & \multirow{2}{*}{-1.007} \\
\hline & The Netherlands & 35 & 0.29 & 0.458 & \\
\hline \multicolumn{6}{|l|}{ Scientific experience } \\
\hline \multirow{2}{*}{ Scientific experience at a university/research centre } & Spain & 66 & 0.24 & 0.432 & \multirow{2}{*}{0.817} \\
\hline & The Netherlands & 35 & 0.17 & 0.490 & \\
\hline \multicolumn{6}{|l|}{ Coach } \\
\hline \multirow{2}{*}{ Coach assigned in incubation } & Spain & 66 & 0.36 & 0.485 & \multirow{2}{*}{$-2.025^{*}$} \\
\hline & The Netherlands & 35 & 0.57 & 0.502 & \\
\hline \multicolumn{6}{|l|}{ Proactivity of the university } \\
\hline \multirow{2}{*}{ There is a tradition of creating spin-offs } & Spain & 66 & 2.58 & 1.278 & \multirow{2}{*}{$-2.321^{*}$} \\
\hline & The Netherlands & 35 & 3.17 & 1.124 & \\
\hline \multirow{2}{*}{$\begin{array}{l}\text { There is specific regulation for creating spin-offs at my } \\
\text { university/research centre }\end{array}$} & Spain & 66 & 2.98 & 1.295 & \multirow{2}{*}{0.435} \\
\hline & The Netherlands & 35 & 2.89 & 0.963 & \\
\hline \multirow{2}{*}{$\begin{array}{l}\text { There is a positive attitude within my university/research } \\
\text { centre towards entrepreneurship }\end{array}$} & Spain & 66 & 3.62 & 1.134 & \multirow{2}{*}{$-2.475^{*}$} \\
\hline & The Netherlands & 35 & 4.09 & 0.742 & \\
\hline
\end{tabular}

$(+) \mathrm{p}<0.10 ;\left(^{*}\right) \mathrm{p}<0.05$

\subsubsection{Validation of scales}

The model was estimated using the SmartPLS 3.0 program (Ringle et al., 2005). To calculate the significance of the parameters, we used bootstrap re-sampling by substitution with replacement (1000 subsamples), as done in the previous two studies.

As for the reliability and convergent validity of the reflective scales, average variance extracted (AVE) and composite reliability values are acceptable (exceed 0.70), and the loadings are significant and above 0.8 , except for the control variable proactivity of the university, where reliability values and loadings are lower. For the only formative scale (bridging social capital), we calculated the variance inflation factor (VIF) so as to discard multicollinearity. The factor weight of one item is not significant, although the absolute contribution is (the outer loading is above 0.5 ). We therefore maintained it as a component of bridging social capital.

All the information is contained in Table 4.48. 
Table 4.48. Reliability, weights and loadings of the measurement scales (Study III.2)

\begin{tabular}{|c|c|c|c|}
\hline & Weights & Loadings & VIF \\
\hline \multicolumn{4}{|l|}{ Bridging social capital } \\
\hline To develop social skills for the business world & $0.722 * *$ & $0.974 * * *$ & 2.223 \\
\hline To increase my network of business contacts & 0.339 & $0.875^{* * *}$ & 2.223 \\
\hline \multicolumn{4}{|l|}{ Bonding social capital } \\
\hline Number of incubatees with whom you are in frequent contact & 1.000 & & 1.000 \\
\hline \multicolumn{4}{|l|}{ Relational social capital (trust) $(\alpha=.907 ; C R=.935 ; A V E=.783)$} \\
\hline $\begin{array}{l}\text { Would not take advantage of others even if the opportunity } \\
\text { arose }\end{array}$ & & $0.835 * * *$ & \\
\hline Always keep their promises & & $0.894 * * *$ & \\
\hline Behave in a consistent and honest manner & & $0.905^{* * *}$ & \\
\hline Are truthful when dealing with one another & & $0.904 * * *$ & \\
\hline \multicolumn{4}{|l|}{$\begin{array}{l}\text { Relational social capital (identity) } \quad(\alpha=.917 ; \quad C R=.960 ; \\
A V E=.924)\end{array}$} \\
\hline There is a sense of group belonging within us, the incubatees & & $0.958 * * *$ & \\
\hline I have the feeling of group togetherness or closeness & & $0.964 * * *$ & \\
\hline \multicolumn{4}{|l|}{$\begin{array}{l}\text { Relational social capital (reciprocity) }(\alpha=.909 ; C R=.961 ; \\
A V E=.925)\end{array}$} \\
\hline When I ask for help, I feel that other incubatees will provide it & & $0.955^{* * *}$ & \\
\hline $\begin{array}{l}\text { Even if an incubatee I have helped cannot help me in the future, } \\
\text { others will be able to }\end{array}$ & & $0.968^{* * *}$ & \\
\hline \multicolumn{4}{|l|}{ Cognitive social capital $(\alpha=.887 ; C R=.922 ; A V E=.747)$} \\
\hline Use a similar language and jargon to me & & $0.876 * * *$ & \\
\hline Use an understandable communication pattern & & $0.860 * * *$ & \\
\hline Share similar interests to mine & & $0.876^{* * *}$ & \\
\hline Are people whose interests I can identify with & & $0.845^{* * *}$ & \\
\hline \multicolumn{4}{|l|}{$\begin{array}{llll}\text { Manager's } & \text { relational } & \text { orientation } & (\alpha=.953 ; \\
A V E=.876) & & & \end{array}$} \\
\hline I think he/she encourages contacts between entrepreneurs & & $0.937 * * *$ & \\
\hline $\begin{array}{l}\text { Tries to establish links between entrepreneurs who are able to } \\
\text { collaborate }\end{array}$ & & $0.943 * * *$ & \\
\hline Facilitates networking between all entrepreneurs & & $0.948 * * *$ & \\
\hline Facilitates contacts outside the incubator & & $0.915^{* * *}$ & \\
\hline \multicolumn{4}{|l|}{ Business efficiency $(\alpha=.934 ; C R=.958 ; A V E=.884)$} \\
\hline $\begin{array}{l}\text { To be more efficient in the planning and strategy for my } \\
\text { business }\end{array}$ & & $0.940 * * *$ & \\
\hline To be more efficient in managing my business & & $0.956 * * *$ & \\
\hline $\begin{array}{l}\text { To be more efficient in implementing specific activities for my } \\
\text { business }\end{array}$ & & $0.924 * * *$ & \\
\hline \multicolumn{4}{|l|}{ Proactivity of the university $(\alpha=.580 ; C R=.782 ; A V E=.550)$} \\
\hline There is a tradition of creating spin-offs & & $0.867 * * *$ & \\
\hline $\begin{array}{l}\text { There is specific regulation for creating spin-offs at my } \\
\text { university/research centre }\end{array}$ & & $0.734^{* * *}$ & \\
\hline $\begin{array}{l}\text { There is a positive attitude within my university/research centre } \\
\text { towards entrepreneurship }\end{array}$ & & $0.599 * *$ & \\
\hline
\end{tabular}
towards entrepreneurship

$\left.{ }^{(* *}\right) \mathrm{p}<0.01 ;(* * *) \mathrm{p}<0.001$

Following the Fornell-Larcker criterion, discriminant validity was assessed by the square root of the AVE being greater than the correlation with the other constructs. In the correlation matrix of latent constructs (Table 4.49) we observe that this condition is met in all cases. In addition, another indicator of discriminant validity, according to Hair et al. (1999), is that the correlation between constructs is not excessively high, and is below the critical value 0.9. Moreover, Table 4.49 shows all the values are below 0.6. Finally, we calculated the heterotrait-monotrait (HTMT) ratio of correlations for each 
pair of constructs (Henseler et al., 2015). These values are shown above the main diagonal of the correlation matrix. The highest value is 0.715 , below the critical value of 0.85 .

In order to examine if common method variance (CMV) is a problem, first, we performed a Harman's one-factor test (Podsakoff et al., 2003). Exploratory factor analysis with all the indicators gave five factors with an eigenvalue of over 1 (total variance explained $=79.7 \%$ ), with a first factor explaining only $18.4 \%$ of variance. Since there is no single factor accounting for the majority of the covariance among the measures, the possible impact of common method bias is not critical in this research. 


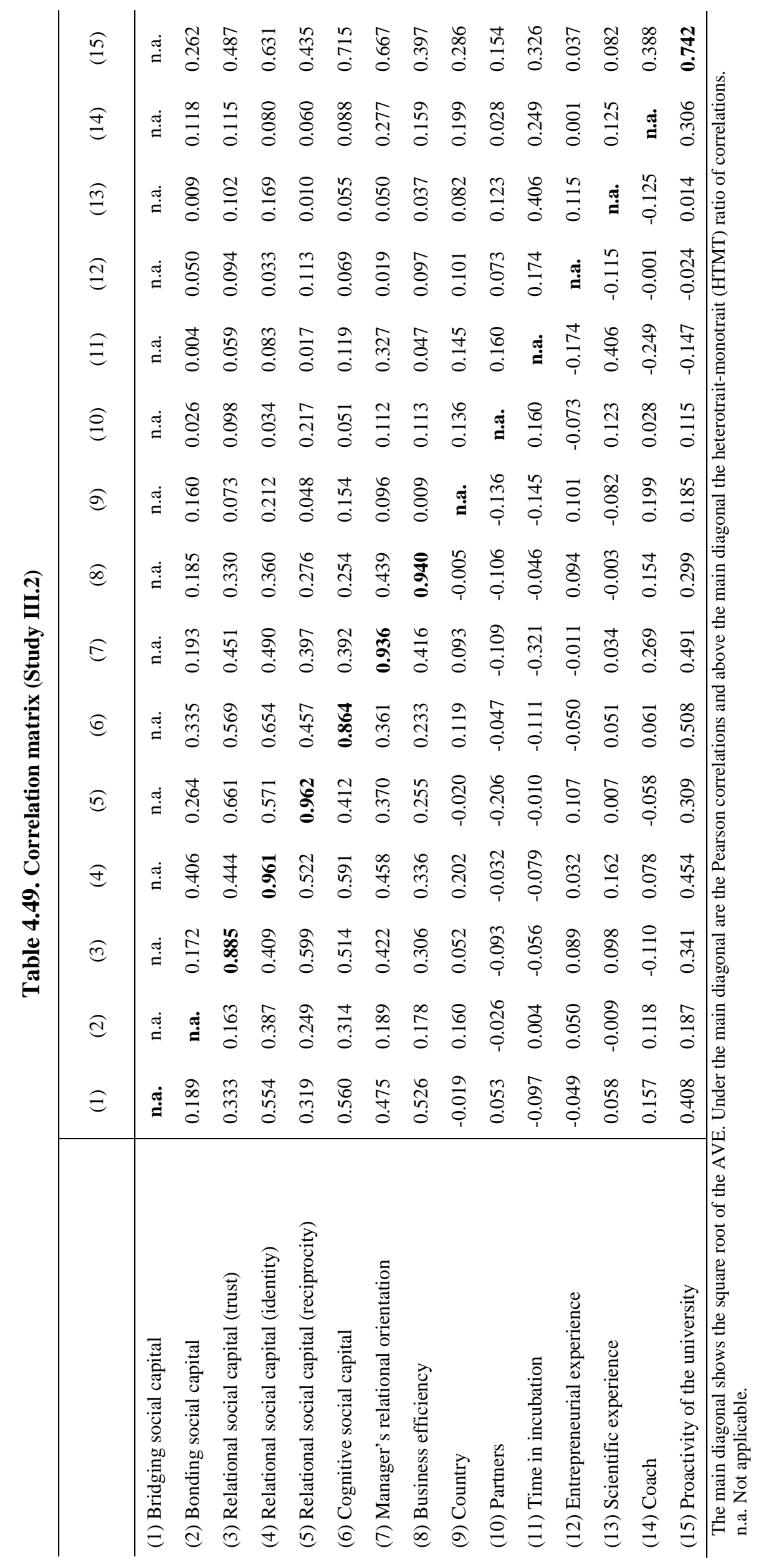




\subsubsection{Model estimation}

The results of the structural Model 3 estimation are shown in Table 4.50. In order to facilitate interpretation, significant relationships of proposed hypotheses are displayed in Figure 4.5.

Table 4.50. Model 3 estimation (Study III.2)

\begin{tabular}{|c|c|c|}
\hline \multicolumn{2}{|c|}{ Proposed hypotheses } & \multirow{2}{*}{$\begin{array}{l}\text { Estimate } \\
-0.016\end{array}$} \\
\hline$H 16$ & Bonding social capital $\rightarrow$ Bridging social capital & \\
\hline$H 17 a$ & Bonding social capital $\rightarrow$ Business efficiency & 0.053 \\
\hline$H 17 b$ & Bridging social capital $\rightarrow$ Business efficiency & $0.453^{* * *}$ \\
\hline$H 18 a$ & Relational social capital (trust) $\rightarrow$ Relational social capital (reciprocity) & $0.462 * * *$ \\
\hline$H 18 b$ & Relational social capital (identity) $\rightarrow$ Relational social capital (reciprocity) & $0.364 * *$ \\
\hline$H 19 a$ & Relational social capital (trust) $\rightarrow$ Bonding social capital & -0.041 \\
\hline$H 19 b$ & Relational social capital (identity) $\rightarrow$ Bonding social capital & $0.326 * *$ \\
\hline$H 19 c$ & Relational social capital (reciprocity) $\rightarrow$ Bonding social capital & 0.102 \\
\hline $\mathrm{H} 20 \mathrm{a}$ & Relational social capital (trust) $\rightarrow$ Bridging social capital & 0.081 \\
\hline$H 20 b$ & Relational social capital (identity) $\rightarrow$ Bridging social capital & $0.471 * * *$ \\
\hline$H 20 c$ & Relational social capital (reciprocity) $\rightarrow$ Bridging social capital & -0.073 \\
\hline$H 21 a$ & Relational social capital (trust) $\rightarrow$ Business efficiency & 0.152 \\
\hline$H 21 b$ & Relational social capital (identity) $\rightarrow$ Business efficiency & 0.012 \\
\hline$H 21 c$ & Relational social capital (reciprocity) $\rightarrow$ Business efficiency & -0.064 \\
\hline$H 22 a$ & Cognitive social capital $\rightarrow$ Relational social capital (trust) & $0.418 * * *$ \\
\hline$H 22 b$ & Cognitive social capital $\rightarrow$ Relational social capital (identity) & $0.478 * * *$ \\
\hline$H 22 c$ & Cognitive social capital $\rightarrow$ Relational social capital (reciprocity) & -0.040 \\
\hline H23 & Manager’s relational orientation $\rightarrow$ Cognitive social capital & $0.354 * * *$ \\
\hline $\mathrm{H} 24 \mathrm{a}$ & Manager's relational orientation $\rightarrow$ Relational social capital (trust) & $0.273^{* *}$ \\
\hline$H 24 b$ & Manager’s relational orientation $\rightarrow$ Relational social capital (identity) & $0.274^{* *}$ \\
\hline$H 24 c$ & Manager's relational orientation $\rightarrow$ Relational social capital (reciprocity) & 0.034 \\
\hline H25 & Manager's relational orientation $\rightarrow$ Bonding social capital & 0.009 \\
\hline H26 & Manager's relational orientation $\rightarrow$ Bridging social capital & $0.268 * *$ \\
\hline \multicolumn{3}{|c|}{ Control effects } \\
\hline & Country $^{\mathrm{a}} \rightarrow$ Bridging social capital & -0.142 \\
\hline & Country $\rightarrow$ Bonding social capital & 0.097 \\
\hline & Country $\rightarrow$ Relational social capital (trust) & -0.024 \\
\hline & Country $\rightarrow$ Relational social capital (identity) & 0.120 \\
\hline & Country $\rightarrow$ Relational social capital (reciprocity) & -0.116 \\
\hline & Country $\rightarrow$ Cognitive social capital & 0.086 \\
\hline & Country $\rightarrow$ Relational orientation & 0.093 \\
\hline & Country $\rightarrow$ Business efficiency & -0.075 \\
\hline & Partners $\rightarrow$ Business efficiency & -0.151 \\
\hline & Time in incubation $\rightarrow$ Business efficiency & 0.098 \\
\hline & Entrepreneurial experience $\rightarrow$ Business efficiency & 0.117 \\
\hline & Scientific experience $\rightarrow$ Business efficiency & -0.048 \\
\hline & Coach $\rightarrow$ Business efficiency & 0.100 \\
\hline & Proactivity of the university $\rightarrow$ Business efficiency & 0.086 \\
\hline
\end{tabular}

(a) $0=$ Spain; $1=$ The Netherlands

$(* *) \mathrm{p}<0.01 ;(* * *) \mathrm{p}<0.001$ 
Figure 4.5. Structural Model 3 estimation. Significant relationships (Study III.2)

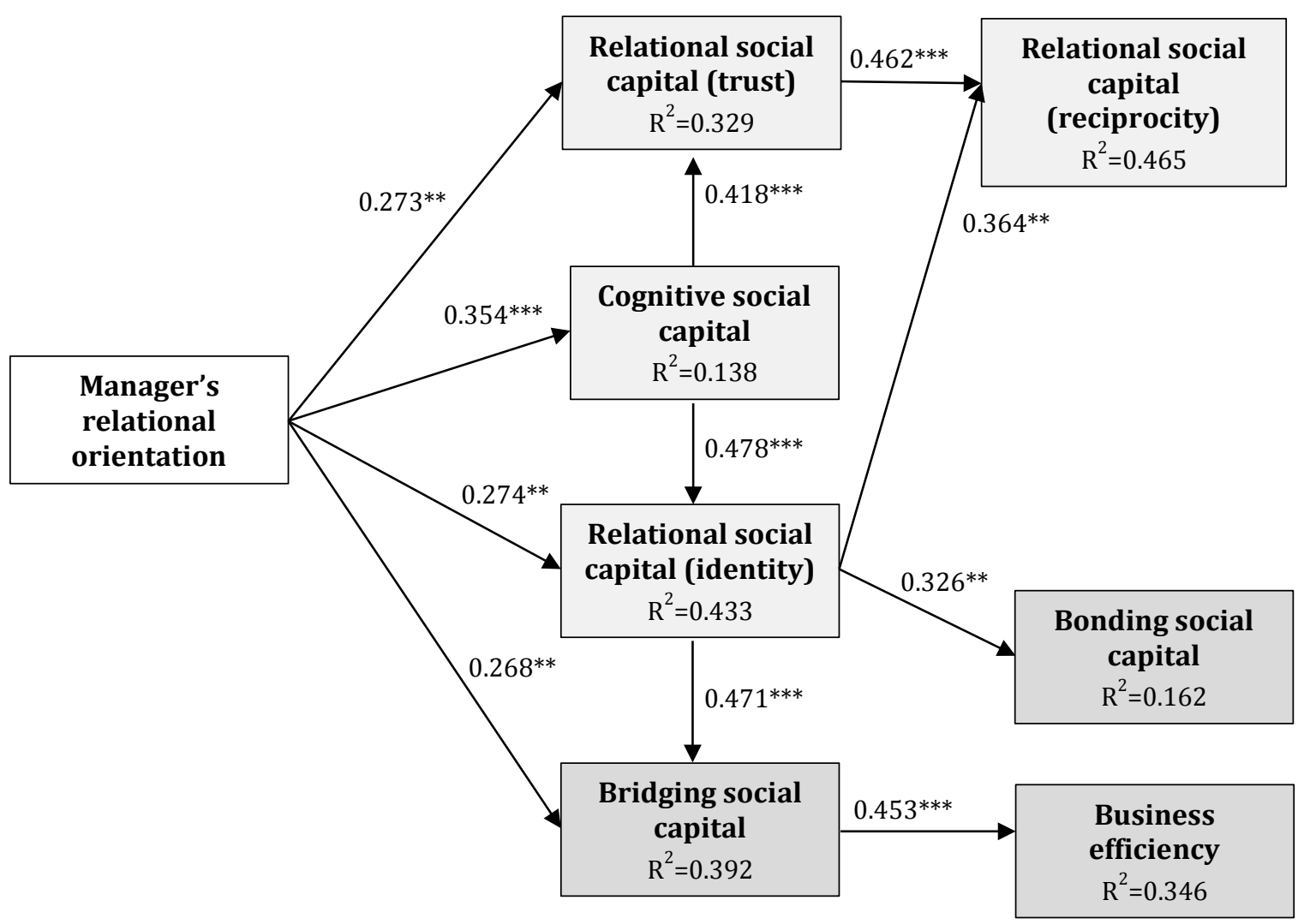

$(* *) \mathrm{p}<0.01 ;(* * *) \mathrm{p}<0.001$

Incubator manager

Incubator's social capital

Incubatee’s social capital

Additionally, we conducted a path analysis using the AMOS v20.0 statistical program to check the robustness of our results and to offer a global goodness-of-fit measure. We previously reduced each variable to a measurement index, specifically the latent variable scores provided by PLS in order to use similar measures. The goodness of fit for the estimated model is adequate: $\chi^{2}(4)=9.087 \quad(\mathrm{p}=0.059) ; \quad \mathrm{RMR}=0.033$; RMSEA=0.113; GFI $=0.978 ; \mathrm{CFI}=0.980 ; \mathrm{NFI}=0.968$. We observe that the AMOS estimation basically concurs with the PLS estimation. 
Table 4.51. Results of estimated model using AMOS (Study III.2)

\begin{tabular}{lll}
\hline & $\begin{array}{c}\text { Standardized } \\
\text { Estimate }\end{array}$ & S.E. \\
\hline Bonding social capital $\rightarrow$ Bridging social capital & -0.068 & 0.081 \\
\hline Bonding social capital $\rightarrow$ Business efficiency & 0.069 & 0.091 \\
Bridging social capital $\rightarrow$ Business efficiency & $0.472^{* * *}$ & 0.102 \\
\hline Relational social capital (trust) $\rightarrow$ Relational social capital (reciprocity) & $0.470^{* * *}$ & 0.090 \\
Relational social capital (identity) $\rightarrow$ Relational social capital (reciprocity) & $0.343^{* * *}$ & 0.097 \\
\hline Relational social capital (trust) $\rightarrow$ Bonding social capital & -0.036 & 0.118 \\
Relational social capital (identity) $\rightarrow$ Bonding social capital & $0.354^{* *}$ & 0.113 \\
Relational social capital (reciprocity) $\rightarrow$ Bonding social capital & 0.081 & 0.124 \\
\hline Relational social capital (trust) $\rightarrow$ Bridging social capital & -0.049 & 0.103 \\
Relational social capital (identity) $\rightarrow$ Bridging social capital & $0.284^{* *}$ & 0.108 \\
Relational social capital (reciprocity) $\rightarrow$ Bridging social capital & -0.025 & 0.101 \\
\hline Relational social capital (trust) $\rightarrow$ Business efficiency & 0.136 & 0.105 \\
Relational social capital (identity) $\rightarrow$ Business efficiency & -0.013 & 0.117 \\
Relational social capital (reciprocity) $\rightarrow$ Business efficiency & 0.013 & 0.113 \\
\hline Cognitive social capital $\rightarrow$ Relational social capital (trust) & $0.416^{* * *}$ & 0.088 \\
Cognitive social capital $\rightarrow$ Relational social capital (identity) & $0.490^{* * *}$ & 0.082 \\
Cognitive social capital $\rightarrow$ Relational social capital (reciprocity) & -0.041 & 0.100 \\
\hline Manager's relational orientation $\rightarrow$ Cognitive social capital & $0.361^{* * *}$ & 0.093 \\
Manager's relational orientation $\rightarrow$ Relational social capital (trust) & $0.271^{* *}$ & 0.088 \\
Manager's relational orientation $\rightarrow$ Relational social capital (identity) & $0.281^{* * *}$ & 0.082 \\
Manager's relational orientation $\rightarrow$ Relational social capital (reciprocity) & 0.032 & 0.087 \\
Manager's relational orientation $\rightarrow$ Bonding social capital & 0.011 & 0.109 \\
Manager's relational orientation $\rightarrow$ Bridging social capital & $0.386^{* * *}$ & 0.101 \\
\hline (**) p< 0.01; $(* * *) p ~$ & &
\end{tabular}

\subsubsection{Hypotheses testing}

\section{Analysis of direct effects}

Results in Table 4.52 show there is no empirical support for hypothesis H16, which proposed the potential influence of the number of an entrepreneur's incubator contacts (bonding social capital) on an increased number of incubatees' business networks and their relational skills in the business world (bridging social capital). Nor is there any evidence to support the idea that contacts inside the incubator help improve business efficiency (H17a is rejected), although bridging social capital does have a positive impact on business efficiency, thereby allowing us to accept hypothesis H17b.

Hypothesis H18 is also accepted. Trust among incubatees positively affects the development of identity (H18a) and reciprocity (H18b) among incubatees. Moreover, as conjectured in hypothesis H19b, the feeling of identity among incubator members fosters the number of close contacts which incubatees can establish (bonding social capital). On the other hand, we find no empirical support for H19a and H19c. That is, there is no direct influence of trust and reciprocity on bonding social capital. 
Similarly, we find support for H20b. A sense of identity among incubator members positively affects incubatee development of contacts outside the incubator (bridging social capital), although we reject the effect of trust (H20a) and reciprocity (H20c) on bridging social capital. Nor do the results support the influence of relational social capital on incubatee business efficiency (H21).

As regards cognitive social capital, results confirm its positive effect on trust and identity among members (H22a and H22b are accepted), although the effect on reciprocity is rejected $(\mathrm{H} 22 \mathrm{c})$.

Finally, the manager's relational orientation has a positive influence on cognitive social capital (H23), as well as on trust (H24a) and identity (H24b), although the influence on reciprocity (H24c) is not significant. Likewise, the manager's relational orientation has a positive influence on the incubatees' creation of bridging social capital (H25), although the effect on bonding social capital (H26) is not supported.

As for the control variables, we discard both the influence of the country on all the proposed variables, and the influence of the other control variables (time in the incubator, previous experience, partners, proactivity of the university) on business efficiency. 
Table 4.52. Results of hypothesis testing (Study III.2)

\begin{tabular}{clcc}
\hline Proposed hypotheses & Conclusion \\
\hline$H 16$ & Bonding social capital $\rightarrow$ Bridging social capital & Not supported & $\mathbf{x}$ \\
\hline$H 17 a$ & Bonding social capital $\rightarrow$ Business efficiency & Not supported & $\mathbf{x}$ \\
$H 17 b$ & Bridging social capital $\rightarrow$ Business efficiency & Supported & $\checkmark$ \\
\hline$H 18 a$ & Relational social capital (trust) $\rightarrow$ Relational social capital (reciprocity) & Supported & $\checkmark$ \\
$H 18 b$ & Relational social capital (identity) $\rightarrow$ Relational social capital (reciprocity) & Supported & $\checkmark$ \\
\hline$H 19 a$ & Relational social capital (trust) $\rightarrow$ Bonding social capital & Not supported & $\mathbf{x}$ \\
$H 19 b$ & Relational social capital (identity) $\rightarrow$ Bonding social capital & Supported & $\checkmark$ \\
$H 19 c$ & Relational social capital (reciprocity) $\rightarrow$ Bonding social capital & Not supported & $\mathbf{x}$ \\
\hline$H 20 a$ & Relational social capital (trust) $\rightarrow$ Bridging social capital & Not supported & $\mathbf{x}$ \\
$H 20 b$ & Relational social capital (identity) $\rightarrow$ Bridging social capital & Supported & $\checkmark$ \\
$H 20 c$ & Relational social capital (reciprocity) $\rightarrow$ Bridging social capital & Not supported & $\mathbf{x}$ \\
\hline$H 21 a$ & Relational social capital (trust) $\rightarrow$ Business efficiency & Not supported & $\mathbf{x}$ \\
$H 21 b$ & Relational social capital (identity) $\rightarrow$ Business efficiency & Not supported & $\mathbf{x}$ \\
$H 21 c$ & Relational social capital (reciprocity) $\rightarrow$ Business efficiency & Not supported & $\mathbf{x}$ \\
\hline$H 22 a$ & Cognitive social capital $\rightarrow$ Relational social capital (trust) & Supported & $\checkmark$ \\
$H 22 b$ & Cognitive social capital $\rightarrow$ Relational social capital (identity) & Supported & $\checkmark$ \\
$H 22 c$ & Cognitive social capital $\rightarrow$ Relational social capital (reciprocity) & Not supported & $\mathbf{x}$ \\
\hline$H 23$ & Manager's relational orientation $\rightarrow$ Cognitive social capital & Supported & $\checkmark$ \\
$H 24 a$ & Manager's relational orientation $\rightarrow$ Relational social capital (trust) & Supported & $\checkmark$ \\
$H 24 b$ & Manager's relational orientation $\rightarrow$ Relational social capital (identity) & Supported & $\checkmark$ \\
$H 24 c$ & Manager's relational orientation $\rightarrow$ Relational social capital (reciprocity) & Not supported & $\mathbf{x}$ \\
$H 25$ & Manager's relational orientation $\rightarrow$ Bonding social capital & Not supported & $\mathbf{x}$ \\
$H 26$ & Manager's relational orientation $\rightarrow$ Bridging social capital & Supported & $\checkmark$ \\
\hline
\end{tabular}

\section{Analysis of indirect and total effects}

In order to offer further information concerning the determinants of social capital in the incubator, we calculated the indirect and total effects (Table 4.53). 
Table 4.53. Indirect and total effects (Study III.2)

\begin{tabular}{|c|c|c|}
\hline & Indirect effect & Total effect \\
\hline \multicolumn{3}{|l|}{ Determinants of relational social capital } \\
\hline Manager’s relational orientation $\rightarrow$ Relational social capital (trust) & $0.148 * * *$ & $0.421 * * *$ \\
\hline Manager's relational orientation $\rightarrow$ Relational social capital (identity) & $0.169 * * *$ & $0.443^{* * *}$ \\
\hline Manager's relational orientation $\rightarrow$ Relational social capital (reciprocity) & $0.342 * * *$ & $0.376^{* * *}$ \\
\hline Cognitive social capital $\rightarrow$ Relational social capital (trust) & - & $0.418^{* * *}$ \\
\hline Cognitive social capital $\rightarrow$ Relational social capital (identity) & - & $0.478 * * *$ \\
\hline Cognitive social capital $\rightarrow$ Relational social capital (reciprocity) & $0.367 * * *$ & $0.328 * *$ \\
\hline \multicolumn{3}{|l|}{ Determinants of bonding social capital } \\
\hline Manager's relational orientation $\rightarrow$ Bonding social capital & $0.166^{*}$ & 0.175 \\
\hline Cognitive social capital $\rightarrow$ Bonding social capital & $0.172 *$ & $0.172 *$ \\
\hline Relational social capital (trust) $\rightarrow$ Bonding social capital & 0.047 & 0.006 \\
\hline Relational social capital (identity) $\rightarrow$ Bonding social capital & 0.037 & $0.363 * * *$ \\
\hline Relational social capital (reciprocity) $\rightarrow$ Bonding social capital & - & 0.102 \\
\hline \multicolumn{3}{|l|}{ Determinants of bridging social capital } \\
\hline Manager's relational orientation $\rightarrow$ Bridging social capital & $0.213^{* *}$ & $0.481 * * *$ \\
\hline Cognitive social capital $\rightarrow$ Bridging social capital & $0.232 * *$ & $0.232 * *$ \\
\hline Relational social capital (trust) $\rightarrow$ Bridging social capital & -0.034 & 0.047 \\
\hline Relational social capital (identity) $\rightarrow$ Bridging social capital & -0.033 & $0.439 * * *$ \\
\hline Relational social capital (reciprocity) $\rightarrow$ Bridging social capital & -0.002 & -0.075 \\
\hline Bonding social capital $\rightarrow$ Bridging social capital & - & -0.016 \\
\hline \multicolumn{3}{|l|}{ Determinants of business efficiency } \\
\hline Manager’s relational orientation $\rightarrow$ Business efficiency & $0.272 * * *$ & $0.272 * * *$ \\
\hline Cognitive social capital $\rightarrow$ Business efficiency & $0.162^{* *}$ & $0.162 * *$ \\
\hline Relational social capital (trust) $\rightarrow$ Business efficiency & -0.008 & 0.144 \\
\hline Relational social capital (identity) $\rightarrow$ Business efficiency & $0.195^{*}$ & 0.207 \\
\hline Relational social capital (reciprocity) $\rightarrow$ Business efficiency & -0.029 & -0.093 \\
\hline Bonding social capital $\rightarrow$ Business efficiency & -0.007 & 0.046 \\
\hline$\underline{\text { Bridging social capital } \rightarrow \text { Business efficiency }}$ & - & $0.453 * * *$ \\
\hline
\end{tabular}

$\left(^{*}\right) \mathrm{p}<0.05 ;\left(^{* *}\right) \mathrm{p}<0.01 ;(* * *) \mathrm{p}<0.001$

In addition to the direct effects, managers' relational orientation indirectly influences relational social capital through cognitive social capital, as a mediating variable. Managers' relational orientation also influences incubatees' bonding and bridging social capital through cognitive and relational social capital. Finally, managers' relational orientation has a positive effect on business efficiency through the incubator's cognitive and relational social capital.

As a final conclusion of the indirect effects, we can state that the incubator's social capital mediates the effect of the manager's relational orientation on the building of incubatees’ bonding and bridging social capital and on business efficiency.

Regarding the total effects, the results indicate that relational social capital in incubators derives from the manager's effort to foster relationships and networking between incubatees and from the existence of cognitive social capital, that is, common interests and communication codes among incubatees. 
Incubatees' bonding social capital, i.e., their number of contacts in the incubator, depends on the existence of a feeling of identity and cohesion between incubatees, and, also, on the existence of cognitive social capital. Incubatees' bridging social capital, i.e., the external relationships they develop while in the incubator, also depends on the manager's relational orientation, the feeling of identity between incubatees, and cognitive social capital. Finally, the entrepreneur's business efficiency improves when bridging social capital increases, and, indirectly, through the manager's relational orientation and the incubator' cognitive social capital. 


\section{Capítulo 5. Conclusions, limitations and further research}





\subsection{Discussion}

The fifth and final chapter of this doctoral dissertation details the main conclusions to emerge from the three studies conducted, outlining the managerial implications for the incubation process and specifying certain limitations and future research lines.

In this section, we explain the conclusions to be drawn from the research. Firstly, the findings from the qualitative study and Model 1, which relate to dyadic relationships between incubatees, are presented. Secondly, the subsequent conclusions of Model 2 and Model 3, which deal with the manager's role in generating relationships and social capital within UBIs, are set out.

\subsubsection{Dyadic relationships between incubatees}

Business incubators are areas created to support firms taking their first steps, and are designed to promote entrepreneurial initiatives. Research into incubators has focused mainly on exploring their success factors (Rubens et al., 2011), their development (McAdam and McAdam, 2008; Bruneel et al., 2012; Schwartz, 2012) or different kinds of incubator (Cooper, 1985; Schwartz and Hornych, 2012). However, few studies have concerned themselves with describing or assessing the relationships established between entrepreneurs working in such incubators (McAdam and Marlow, 2008; Ahmad and Ingle, 2011), despite the enormous interest in relationships among entrepreneurs expressed in relationship marketing literature and in network marketing literature, and the particular features that characterize relationships in business incubators.

In order to address this gap, this thesis contributes to the business-to-business marketing literature examining dyadic relationships in a business incubator, considered to be one particular instance of initiating and managing business relationships. Indeed, these particular relationships evidence clear idiosyncrasies vis-à-vis other business relationship contexts such as the proximity and expectation of frequent entrepreneur interaction, entrepreneurs' inexperience in the business world, and the lack of experience in building business relations. Specifically, the qualitative study and Model 1 seek to identify the key differentiating variables involved in dyadic relationships between entrepreneurs housed in the same incubator, as well as the characteristics and specific outcomes to emerge from this type of relation. To achieve this, we draw on the theoretical foundations of the relationship marketing approach, transaction cost theory, 
resource-based view, and knowledge-based view. We then explain the main conclusions obtained.

\section{From common location to frequency of contact and linking-persons}

One prominent initial aspect to emerge from the qualitative study is frequency of contact as a basis for getting to know others, as well as establishing and maintaining relations. A business incubator provides a setting which encourages and fosters frequent contacts amongst entrepreneurs located in the same place. Proximity should be seen as a connecting yet not relational variable, and is one which allows for contacts between incubator tenants. Although proximity is a key factor in fostering contacts, it might not prove to be sufficient. Third person intervention becomes an important driver in initiating transactions and in potential relationships.

\section{From affinity to trust, friendship and solidarity}

Since we are dealing with small businesses in which the firm is identified with the entrepreneur, the personal side of the relationship is of particular interest. It is in such contexts that contracts of a psychological nature emerge, perceived as the belief that there is a mutual obligation between the two parts (Rousseau and Tijoriwala, 1998). As evidenced in the qualitative study of relationships between incubator tenants, aspects such as friendship, solidarity, personal attention, or a client-based approach prove essential towards initiating and consolidating relations.

Moreover, the findings of the quantitative study support the notion that trust and commitment, the key elements in relationships between entrepreneurs, increase as a result of affinity between firms.

Shared values have been seen as a requirement for creating a relationship. The literature addressing the area of relationships between firms stresses that the latter engage therein when they identify other firms they are compatible with (Morgan and Hunt, 1999). As regards entrepreneurs located in incubators, they share a similar situation, although the question concerns what specific features shape these common values. Some authors highlight educational qualifications as one of the relevant factors considered by entrepreneurs (Lee and Tsang, 2001). Entrepreneurs located in academic incubators share the common values of the academic world. Such values include the same working philosophy, and a desire to promote and disseminate science through mutual 
cooperation. As has emerged through our study, interaction, trust and commitment between firms are greater when companies resemble one another, such as when they share the same field of business or markets or have similar clients (McAdam and McAdam, 2006; Schwartz and Hornych, 2008). These values are innate to entrepreneurs and help to forge a link as well as sympathy between them. The dyadic relationships are thus based on mutual understanding, because both parties are scientists and "speak the same language”.

Another affinity variable to consider is empathy, namely the ability to identify with the needs of others and pinpoint problematic situations (Mayer and Greenberg, 1964). However, empathy can also have negative effects on important aspects of relationships such as trust. Taking the context of our specific research, we might imagine two entrepreneurs who have a relationship, born within the incubator. "Incubatee $x$ " requires the professional services of “incubatee y", for instance, for a staff selection process. “Incubatee y” performs the service professionally, and bills “incubatee x". Nevertheless, “incubatee x", motivated by the empathy between them, confuses a professional service with a personal favour, and does not pay. In this case, empathy is a factor that can lead to misunderstandings between the personal and professional fields. Further, it can have negative effects on the level of confidence between them.

\section{From complementarity, supplementarity and transferability of resources to relationship building}

Contrary to other business-to-business contexts in which specific investments become the main source of dependence and, consequently, the main reason for establishing long-term relationships, in the case of novice entrepreneurs, relationships are not designed as a means of protecting investments with other partners, but as a way to foster them. In fact, one initial variable which stands out as being key to relationships between entrepreneurs in the business incubator is the existence of complementary resources. Trust and exchange of knowledge may emerge between entrepreneurs who seek to obtain complementary benefits by integrating their functional specialization. Since entrepreneurs located in business incubators have hardly any previous experience and are eager to build a network of relationships, finding partners who can offer complementary resources allows them to acquire the skills and capabilities they lack to promote their business. 
In the market, when two entrepreneurs perceive supplementarity (similarity) between their resources they tend to see each other as competitors. However, our research shows that in the specific context of academic incubators, entrepreneurs with similar resources are not perceived as rivals. Hence, the perception of supplementary resources between tenants leads to trust, exchange of knowledge and, ultimately, to relationship building. The reason for this can be found in the academic entrepreneur that focuses more on science more than on economic profit, contrary to what might be expected from a market entrepreneur. Moreover, relationships between firms possessing supplementary resources allow the right size required to generate innovations to be achieved.

Academic incubatees' new ventures are knowledge-intensive and innovative. A priori, these characteristics make transferability of their knowledge difficult. Nevertheless, since they both master and know how to transfer it, academic tenants perceive their own knowledge to be easily transferable and assume that their peers' knowledge is too (maybe because they also belong to the scientific community). Thus, knowledge transferability between incubatees fosters communication and the exchange of knowledge of the dyadic relationship.

An individual's willingness to share knowledge has been considered as a determinant variable in the exchange of knowledge in different contexts. In the current research, we see that it is also true in the field of incubators. As regards incubatee profile, those with a promotion focus are more proactive towards exchanging knowledge as a means to obtain the resource on which to build their businesses. However, although the willingness to share knowledge is influenced by the incubatee's promotion focus, this particular incubatee attribute has no direct or indirect effect on the actual exchange of knowledge.

\section{A dyadic relationship in a protected environment as the initial drive for business success}

The dyadic relationships between academic entrepreneurs in UBIs are based on exchange of knowledge, commitment, and trust. According to the findings, commitment to the relationship between entrepreneurs, that is, the intention to extend the relationship to the long term, is determined by the existence of trust and knowledge exchange. In fact, affinity factors (empathy and shared values) and the type of resources 
(complementary, supplementary and transferable) only have an indirect effect on commitment, through trust and exchange of knowledge.

A regards the dyad outcomes, we propose two expected results of relationships which promote the possibilities of success for the business in question: entrepreneurial commitment and the generation of innovation. Findings indicate that commitment in the relationship and exchange of knowledge reinforce both the entrepreneurs' commitment to their own businesses and the generation of innovation.

However, the relationship has no direct effect on business results. Trust, commitment and exchange of knowledge have an indirect positive effect on business results only through the generation of innovation. In addition, affinity, resources and the willingness that characterized the parties involved in the relationship indirectly drive the entrepreneurs towards positive outcomes (entrepreneurial commitment, generation of innovation, and business results) through the mediation of relationships characterized by trust, commitment and exchange of knowledge. In addition, estimation of the model using a path analysis has provided two additional significant effects, not included a priori in the proposed model: first, a direct effect of the complementary resources on business results, pointing to the tremendous relevance of complementary resources in building profitable relationships, and second, a direct effect of business results on entrepreneurial commitment, suggesting that entrepreneurs become more confident in their business capabilities and willing to continue with their business projects when they obtain positive results from the relationships developed in the incubator.

\section{The dark side of relationships}

Several authors have expressed scepticism vis-à-vis the benefits of long-term relationships and have warned of relationships becoming inefficient over time (Grayson and Ambler, 1999; Selnes and Sallis, 2003). Excessive care in maintaining a pleasant relationship can lead to counterproductive behaviour, such as systematically avoiding negative information so as not to disturb the "friendship" between the two firms, failing to monitor partners' activities, and a loss of creativity. Although we do not explore this issue in depth in the present thesis, in the qualitative study of relationships between incubator tenants we do also observe the dark side of relationships. Entrepreneurs may abuse the partner's willingness to collaborate and behave opportunistically. They may use the relationships as a learning experience in order to, eventually, become a 
competitor. Finally, since they are inexperienced partners, they are forced to trust in each other's potential capabilities. Partners might therefore conceal their inability to fulfil the assigned tasks.

\subsubsection{The manager's role in generating relationships and social capital} within UBIs

The manager's role is a key driver in the incubation process (Fry, 1987; Autio and Klofsten, 1998; Sherman, 1999; Lalkaka, 2002; Rice, 2002; Hackett and Dilts, 2004a; Hannon, 2005). However, managers have been given little consideration in the literature, and only with regard to very specific aspects (Theodorakopoulos et al., 2014). There are many unanswered questions regarding what role managers can play as a driving force in services offered by incubators as well as in building and fostering networks of relationships within incubators. The answers to these dilemmas are found through the conclusions of Models 2 and 3 proposed in this dissertation, and which are explained below.

On the one hand, the reality of incubators shows that, even if they aspire to similar objectives, they do not always operate in the same way. The potential benefits of UBIs are therefore not always achieved.

In the current research, we consider three types of services which basically describe how incubators function, as mentioned in chapter 3 :

(1) Personal assistance, thanks to a coach who can respond to each entrepreneur's specific knowledge requirements.

(2) Business assistance, concerning various management functions such as marketing, human resources, finance, etc.

(3) Networking activities, favouring the development of social skills and the introduction of incubatees into professional networks.

In this regard, Model 2 investigates the role of UBI managers as drivers of the training and advice given to academic incubatees. On the basis of the institutional logics approach, it is proposed that, even if all UBI managers are concerned with training incubatees in business competences and skills, the manager's dominant logic (academic versus commercial) will influence the effectiveness of the services offered. Results 
indicate that commercial logic proves superior to academic logic when training incubatees and instilling this commercial logic in them. Moreover, incubators managed by managers who combine the two logics (a hybrid logic as a consequence of their scientific and entrepreneurial experience) will provide a better offer of services. In particular, the manager's scientific experience does not favour comprehensive business training for incubatees. The scientific experience of academic logic is linked to personal assistance and coaching but does not foster other services required by academic entrepreneurs such as business assistance for developing skills related to information and operations in the business world, or networking competences. By contrast, managers displaying greater business experience know how the business world works, and are more aware of the weaknesses of academic incubatees. As a result, the manager's business experience or commercial logic is related with business assistance, personal assistance and networking, that is, networks of relationships which help entrepreneurs to obtain resources which prove valuable to the incubation process and to developing their businesses.

Finally, from these results, it can be concluded that the ability of managers with business experience and a dominant commercial logic to offer business support services coupled with the effort they make is greater than the effort made or indeed the ability of managers with scientific experience who display a dominant academic logic. In addition, even if they have only basic entrepreneurial experience, managers with a hybrid logic, in other words with experience in both fields, appear to be more skilled at optimizing the work inside the incubator as an environment to guide incubatees in their business activity.

Incubators can also be considered as ideal places for new entrepreneurs to build a network of relationships that proves valuable to help develop their business projects. In the specific case of university incubators, most incubatees have few business contacts (other entrepreneurs, managers, clients, suppliers, etc.) due to their lack of expertise in the business domain. Entrepreneurs who emerge from a university environment are primarily science oriented, yet have embarked on a business venture which will require them to immerse themselves in the world of trade. They therefore need to involve themselves in external networks they are unfamiliar with and which work differently to others they are accustomed to or participate in (for instance, academic networks) 
(Redondo et al., 2014). In order to build business networks, relationships between incubatees must be fostered, that is, the existence of collective internal social capital. However, since incubatees are in the incubator for a limited period of time, they need a driver to develop social capital. This task can be performed by the incubator manager, as a promoter of relationships between incubatees and relationships with external agents.

Literature exploring incubators and social capital has focused on how relationships in the incubator function (Lyons, 2002; Hughes et al., 2007), comparing incubatees' and non-incubatees' social capital (Honig and Karlsson, 2010), or the role of the manager as a coach (Studdard, 2006; Scillitoe and Chakrabarti, 2010; Ahmad, 2014) as well as support in building ties between incubatees and external agents (Bøllingtoft and Ulhøi, 2005; Tötterman and Sten, 2005). Ebbers (2014) also underlines the relevance of the manager vis-à-vis fostering networks between incubatees. However, despite studies which highlight how incubators contribute to developing social capital, there are no studies empirically examining the cause-effect relationships between the work of the manager and the development of social capital, or the influence of collective social capital on individual social capital and the success of incubatees’ businesses.

In this context, Model 3 posits that university incubators can be considered as places where the relational climate among incubatees allows beneficial links to be forged between incubatees and other external networks, all of which proves advantageous for entrepreneurs' business efficiency. Reinforcing this idea, we conjecture that the relational orientation of UBI managers and their endeavour to foster contacts between entrepreneurs and other agents encourages the creation of social capital, both at a collective level (incubator social capital) and at an individual level (incubatee social capital). More specifically, we explain in detail the interrelations between the different dimensions of incubatee and incubator social capital, and their influence on business efficiency, as follows.

First, results confirm the key role played by the manager as a driver of cognitive social capital, that is, the ability to share a common language, objectives and culture. In UBIs, all the individuals share a link with the university and common objectives inherent to their condition as novel entrepreneurs. However, each individual has their own interests and objectives. The manager's relational orientation promotes these common objectives 
and culture and affects the success of the incubator as well as the creation of relational social capital (trust and identity). When incubatees share objectives, concerns and a common language, they understand each other and an environment of trust is built up, as is the incubatees' sense of belonging to a group, as members of the same organization.

Second, the manager's relational orientation has a positive influence on relational social capital (through trust among incubatees, and the feeling of identity). Managers contribute directly to building trust between incubatees and to engendering a feeling of identity with the other tenants, and indirectly, by promoting incubatees' common aims and culture. Managers establish networks and social interactions based on trust among incubator members (Tötterman and Sten, 2005). Moreover, an atmosphere of shared objectives and culture favours the tenants' feeling of being part of a community. Reciprocity between incubatees also appears when there is an atmosphere of trust and identity between tenants.

Third, the incubator's cognitive and relational social capital (identity) helps shape incubatees' social capital. When individuals identify with other incubatees, a feeling of identity emerges which gives academic incubatees the self-confidence to face the challenge of business, prevents incubatees from engaging in opportunistic behaviour and allows social abilities, interactions and relationships to be built. These interactions occur at two levels: at an internal level, with other incubatees, and at an external level, with other external business agents (such as other external entrepreneurs, potential clients or suppliers, financial institutions or consultants). Internal relationships can be considered the incubatee's bonding social capital, and external relationships the bridging social capital.

Finally, university incubatees form part of academic networks, but have had scarcely any contact with the business world. When incubator managers foster the number of business contacts and incubatees' networking abilities, they are influencing the incubatees' bridging social capital. Although some authors consider that the manager's task is not necessary to build relationships because incubatees naturally and instinctively collaborate with one another (Bøllingtoft, 2012), the current study demonstrates that the incubator manager does act as a structural hole (Burt, 1992) linking incubatees with other external agents so as to favour their businesses. Likewise, 
and in line with Granovetter’s social network theory, weak ties or bridging social capital are more relevant for innovation and for developing new businesses than are strong ties or closure in the incubator. Further, it is this bridging social capital that has a significant influence on the efficiency of incubatees' businesses in terms of business planning, implementation and management.

\subsection{Managerial implications}

After detailing the general conclusions of the study, in this section we focus on specific managerial implications.

\section{Proximity: a connecting but not a relational variable}

Proximity is the variable which allows for contacts between incubator occupants, in addition to influencing frequency of contacts and encouraging networking. However, it is not the key factor in engendering and establishing business incubator relationships among firms. Further, proximity is not a determinant factor when it comes to consolidating relations, since once firms have established cooperation with each other, one of them leaving the incubator does not prove a hurdle to the relationship between them. Relationships built during incubation can be long-term and may well indeed survive.

The incubator as a business experience accelerator: an experimental environment for relationships

One managerial implication is that incubators can be seen as an experience accelerator. Sharing facilities in the incubator with other entrepreneurs is expressed in terms of contacts and experiences with dynamic and evolving businesses, and reflects the business world outside the incubator, condensed into a short space of time, since the incubator houses a wide range of firms under one roof. This makes the incubator an area which integrates and accelerates relationships between businesses. However, merely being involved in incubation cannot be expected to achieve such an effect. "The accelerator" must be pressed through proactive contacts and activities between entrepreneurs.

Formal relational action programmes can be designed to foster and promote cooperation, taking advantage of the setting provided by the incubator, cultivating 
trustworthiness, empathy, and solidarity between entrepreneurs so as to encourage mutual support. Therefore, our research proposes that incubators can act as a testing ground for entrepreneurs' first experiences in building and dissolving relationships.

As regards generating social capital, managers should be aware that one of the main skills to be developed by incubatees must be the social ability to build a network of relationships both inside and outside the incubator. The incubator can be perceived as an experimental environment where incubatees acquire social skills, exercise these abilities by building relationships with other incubatees, and establish links with other entrepreneurs who can provide them with access to external networks. Not only that, but these are the first steps towards building networks of relationships.

\section{Selecting incubatees: complementary and supplementary resources}

A further managerial implication to emerge from this research deals with the university incubator decision concerning the right mix of incubatees sharing the incubator. The recommendation is a balance between incubatees with complementary resources and incubatees with supplementary resources. Diversity, in other words the coexistence of incubatees with complementary resources (different academic backgrounds or different abilities in business areas such as engineering, design, production, marketing, etc.) allows them to share skills and to improve their capabilities before venturing out into the market. However, communalities, namely the coexistence of incubatees with supplementary resources (similar academic backgrounds or similar abilities in business areas), are also recommended for leveraging business potential. Entrepreneurs can join forces to obtain results in specific research areas and, therefore, increase the scope of their business projects.

\section{Managers' business experience: key to providing incubatees with what they need}

Business and entrepreneurial experience is key to instilling business logic in incubatees and to providing them with the training and assistance they need. In the case of university and scientific managers, it is essential for them to understand the incubatee need to develop complementary capabilities and skills, capabilities that are not inherent to the world of science, but that prove vital to success in the business world. Prominent among these capabilities and skills are: access to social networks, collaboration with 
other agents in the industry, access to funding and fundraising, and the ability to know how the market operates and to recruit human resources with have market knowledge.

\section{The manager's role: to bridge the social gap between incubatees}

It is also the manager's task to evaluate incubatees' profiles and diversity in order to foster the kind of links that might prove most profitable for them. In university incubators, where incubatees come from an academic background and lack experience, incubatees find more opportunities for their businesses in the relationships outside the incubator. However, in other contexts where diversity among entrepreneurs is greater, the value of relationships inside the incubator should not be underestimated.

Finally, managers should stimulate the feeling and sense of identity among incubator members, since these relational ties are the source of future internal and external relationships. By offering activities for incubator members, designing spaces and rooms for interaction, meetings for sharing experiences, or proposing shared objectives, the feeling of community and collective social capital can be built.

\subsection{Limitations and further research}

To conclude this chapter, some limitations and future lines of research should be mentioned.

Firstly, Study I is exploratory and focuses on one kind of incubator, the BIC. This means that the entrepreneurs are located in incubators which provide basic services (location, administrative services, equipment, etc.). Further qualitative research should explore other types of incubators that offer a wider range of services (advice, learning experiences, networking), in order to identify the effect of incubator support in relationship building and entrepreneur access to social capital. Secondly, the cases analysed belong to the same country, Spain. It would have been interesting to compare entrepreneurs of different nationalities and from different backgrounds. Finally, analysing only the entrepreneurs' point of view, without considering the perspectives of other agents, such as the incubator manager, is a further limitation.

As regards Studies II and III, the first limitation is that the results cannot easily be generalised since they focus on UBIs. Future studies might analyse the case of incubators with other characteristics, such as a greater diversity of incubatee profile, 
greater previous business experience, or incubators devoted to a common industry (culture, high-technology, etc.). Moreover, the sample size (incubatees and managers) is small, although it is justified by the small number of UBIs in Spain and the Netherlands, despite which the study does represent a large percentage of cases.

In relation to each model, we have found certain specific limitations.

Regarding Model 1, we have only considered the point of view of one part of the dyad. Thus, it would be interesting to collect data from both sides in order to obtain an overall view of the relationship, and to compare different perceptions. Moreover, we cannot forget that each relationship must be seen and analysed not as an exogenous phenomenon, but within the context in which it emerges. Future studies might also consider contextual factors and other relationships that influence the dyad.

In addition, it may be worth contrasting the model in other types of incubator so as to analyse whether the exchange of knowledge occurs in any incubation context between knowledge-intensive companies. Should this be the case, the main question would be whether resources (particularly, supplementary resources) prove determinant to the exchange, and whether the results are manifested in the same terms. With further reference to the exchange of knowledge, only factors that encourage it, namely trust and commitment have been studied. However, it would be interesting to explore which factors or occurrences lead to relationship failure. In particular, cases in which attempts have been made to exchange knowledge and which have ultimately failed to succeed also merit inquiry, as do cases in which exchange was achieved, but whose consequences may have proved negative for one of the parties involved. Therefore, the influence of failed experiences on how entrepreneurs build new relationships (the use of contracts or the preference for short-term relationships) should be investigated. Additionally, it may be of interest to study “critical moments” in order to gauge the triggering factors which lead to the breakdown of the relationship.

Model 1 may also be completed by including moderating effects. Firstly, the effect of the proposed antecedents of the relationship (affinity factors, characteristics of the resources, and incubatee characteristics) on its particular features (trust, commitment, and exchange of knowledge) may be conditioned by institutional context factors such as financial aid. Requirements concerning financial support (for instance, requirements about business size), might spark the effect of other antecedents (affinity, resources) in 
the likelihood of building relationships Secondly, the effect of the relationship's characteristic on its ultimate performance (particularly, on business results) may also be conditioned by economic context factors such as the sector's growth rate, the evolution of competition, and so on.

Model 2 considers the incubation project as the unit of analysis. Since some universities may have as many as up to three incubation programmes running in the same incubator (pre-incubation, incubation, and post-incubation programmes), in some cases the incubator manager is the informant for three different projects.

In addition, together with years of experience, measuring the dominant logic may be completed with scales that reflect the manager's entrepreneurial or academic profile.

Finally, a longitudinal study should be undertaken in order to investigate how an academic logic might evolve to business logic in academic incubatees, exploring their evolution in terms of objectives and expectations, from the beginning of the incubation process to some years after they leave the incubator, and taking into account their academic profile and industry characteristics.

Model 3 is focused on the managers' relational orientation as the driver of both incubator and incubatee social capital. Future research should consider the manager's perspective objectively, in other words evaluating the kind of activities and initiatives undertaken by managers to foster the development of social capital inside the incubator. Furthermore, the development of social capital in the model has been set out as a voluntary act, driven by manager initiative. The environmental or institutional requirements and their influence on building relationships between incubatees have not been considered. It would be advisable to consider the view of other agents that influence the incubator's activities and results (sponsors, university, and local government).

Again, we propose conducting longitudinal studies in order to analyse how networks inside the incubator are developed and maintained, and, particularly, how these relationships evolve once incubatees leave the incubator.

As a final challenge for further studies, it would be possible to study incubators as social capital accelerators, comparing entrepreneurs in incubators with other contexts. Creating a control group of non-incubated entrepreneurs would allow the outcomes of 
incubated with non-incubated entrepreneurs to be compared, for example vis-à-vis the time required for entrepreneurs to build social capital, and the characteristics (cognitive, relational, structural) of social capital in each context. 



\section{Referencias bibliográficas}



Aaboen, L. (2009). Explaining incubators using firm analogy. Technovation, 29(10), 657-670.

Abduh, M., D'Souza, C., Quazi, A., \& Burley, H. T. (2007). Investigating and classifying clients' satisfaction with business incubator services. Managing Service Quality, 17(1), 74-91.

Abreu, M., Grinevich, V., Kitson, M., \& Savona, M. (2010). Policies to enhance the 'hidden innovation'in services: Evidence and lessons from the UK. The Service Industries Journal, 30(1), 99-118.

Achrol, R. S. (1991). Evolution of the marketing organization: New forms for turbulent environments. The Journal of Marketing, 55(October), 77-93.

Adkins, D. (2001). A report for the japan association of new business incubation organizations (JANBO): Summary of the US incubator industry. Athens, Ohio: National Business Incubation Association.

Adkins, D. (2002). A brief history of business incubation in the united states. Athens, Ohio: National Business Incubation Association.

Adler, P. S., \& Kwon, S. (2002). Social capital: Prospects for a new concept. Academy of Management Review, 27(1), 17-40.

Aernoudt, R. (2004). Incubators: Tool for entrepreneurship? Small Business Economics, 23, 127-135.

Aerts, K., Matthyssens, P., \& Vandenbempt, K. (2007). Critical role and screening practices of european business incubators. Technovation, 27(5), 254-267.

Agrawal, A. (2006). Engaging the inventor: Exploring licensing strategies for university inventions and the role of latent knowledge. Strategic Management Journal, 27(1), 63-79.

Ahmad, A. J. (2014). A mechanisms-driven theory of business incubation. International Journal of Entrepreneurial Behavior \& Research, 20(4), 375-405.

Ahmad, A. J., \& Ingle, S. (2011). Relationships matter: Case study of a university campus incubator. International Journal of Entrepreneurial Behavior \& Research, 17(6), 626-644.

Ahmed, P. K., \& Rafiq, M. (2003). Internal marketing issues and challenges. European Journal of Marketing, 37(9), 1177-1186.

Ahuja, G., \& Lampert, C. M. (2001). Entrepreneurship in the large corporation: A longitudinal study of how established firms create breakthrough inventions. Strategic Management Journal, 22(6-7), 521-543.

Alajoutsijärvi, K., Möller, K., \& Rosenbröijer, C. (1999). Relevance of focal nets in understanding the dynamics of business relationships. Journal of Business-toBusiness Marketing, 6(3), 3-35.

Aldrich, H. E., \& Zimmer, C. (1986). Entrepreneurship through social networks. In D. L. Sexton, \& R. W. Smilor (Eds.), The art and science of entrepreneurship (pp. 323). Cambridge, MA: Ballinger.

Aldrich, H., Birley, S., Dubini, P., Greve, A., Johannisson, B., Reese, P. R., \& Sakano, T. (1991). The generic entrepreneur? insights from a multinational research project. Babson Conference on Entrepreneurship, 
Aldrich, H. E., \& Fiol, C. M. (1994). Fools rush in? the institutional context of industry creation. The Academy of Management Review, 19(4), 645-670.

Allen, D. (1985). Small business incubators and enterprise development. Washington, D.C.:

Allen, D. N. (1988). Business incubator life cycles. Economic Development Quarterly, 2(1), 19-29.

Allen, D. N., \& McCluskey, R. (1990). Structure, policy, services, and performance in the business incubator industry. Entrepreneurship: Theory \& Practice, 15(2), 61-77.

Almeida, P., Hohberger, J., \& Parada, P. (2011). Individual scientific collaborations and firm-level innovation. Industrial and Corporate Change, 20(6), 1571-1599.

Alvarez, S. A., \& Busenitz, L. W. (2001). The entrepreneurship of resource-based theory. Journal of Management, 27(6), 755-775.

Amit, R., \& Schoemaker, P. J. (1993). Strategic assets and organizational rent. Strategic Management Journal, 14(1), 33-46.

Anderson, B. B., \& Al-Mubaraki, H. (2012). The gateway innovation center: Exploring key elements of developing a business incubator. World Journal of Entrepreneurship, Management and Sustainable Development, 8(4), 208-216.

Anderson, E., \& Weitz, B. (1989). Determinants of continuity in conventional industrial channel dyads. Marketing Science, 8(4), 310-323.

Anderson, J. C., \& Narus, J. A. (1990). A model of distributor firm and manufacturer firm working partnerships. The Journal of Marketing, 54(1), 42-58.

Anderson, J. R. (2013). The architecture of cognition Psychology Press. Taylor \& Francis Group.

Anderson, J. C., \& Narus, J. A. (1999). Business market management: Understanding, creating, and delivering value. Upper Saddle River, New Jersey: Prentice Hall.

Anderson, S. W., \& Dekker, H. C. (2010). Accounting in networks: The transaction cost economics perspective. In Håkansson, H., Kraus, K., Lind, J (Ed.), Accounting in networks (pp. 235-268). New York: Routledge.

Andrew, A. M. (2005). A new magical incubator? Kybernetes, 34(5), 734-737.

Arora, A., Gambardella, A., Magazzini, L., \& Pammolli, F. (2009). A breath of fresh air? firm type, scale, scope, and selection effects in drug development. Management Science, 55(10), 1638-1653.

Arvanitis, S., Sydow, N., \& Woerter, M. (2008). Do specific forms of universityindustry knowledge transfer have different impacts on the performance of private enterprises? an empirical analysis based on swiss firm data. The Journal of Technology Transfer, 33(5), 504-533.

Ascigil, S. F., \& Magner, N. R. (2009). Business incubators: Leveraging skill utilization through social capital. Journal of Small Business Strategy, 20(1), 19-34.

Audretsch, D. B., Aldridge, T. T., \& Oettl, A. (2006). The knowledge filter and economic growth: The role of scientist entrepreneurship. (Working paper). Disponible en: http://econpapers.repec.org/RePEc:esi:egpdis:2006-11: The Group Entrepreneurship, Growth and Public Policy. 
Autio, E., \& Klofsten, M. (1998). A comparative study of two european business incubators. Journal of Small Business Management, 36(1), 30-43.

Ballantyne, D. (1994). Editorial: Marketing at the crossroads. Asia-Australia Marketing Journal (Continued as Australasian Marketing Journal), 2(1), 1-7.

Barclay, D., Higgins, C., \& Thompson, R. (1995). The partial least squares (PLS) approach to causal modeling: Personal computer adoption and use as an illustration. Technology Studies, 2(2), 285-309.

Baregheh, A., Rowley, J., \& Sambrook, S. (2009). Towards a multidisciplinary definition of innovation. Management Decision, 47(8), 1323-1339.

Barnes, T. J. (2001). Retheorizing economic geography: From the quantitative revolution to the "cultural turn". Annals of the Association of American Geographers, 91(3), 546-565.

Barney, J. (1991). Firm resources and sustained competitive advantage. Journal of Management, 17(1), 99-120.

Barney, J. B. (2002). Gaining and sustaining competitive advantage (2nd ed.). Englewood Cliffs, NJ: Prentice Hall.

Barney, J. B., \& Arikan, A. M. (2001). The resource-based view: Origins and implications. In M. Hitt, R. Freeman, \& J. Harrison (Ed.), Handbook of strategic management (pp. 124-185). Oxford, UK: Blackwell.

Barney, J. B., \& Clark, D. N. (2007). Resource-based theory: Creating and sustaining competitive advantage. New York: Oxford University Press.

Barney, J. B., \& Hesterly, W. S. (2012). Strategic management and competitive advantage: Concepts and cases (4th ed. ed.). New Jersey: Pearson.

Barney, J. B., Ketchen, D. J., \& Wright, M. (2011). The future of resource-based theory revitalization or decline? Journal of Management, 37(5), 1299-1315.

Baron, R. A., \& Markman, G. D. (2000). Beyond social capital: How social skills can enhance entrepreneurs' success. The Academy of Management Executive, 14(1), 106-116.

Barrow, C. (2001). Incubator: A realist's guide to the world's new business accelerators. West Sussex, UK: John Wiley \& Sons Ltd.

Bathelt, H., \& Glückler, J. (2003). Toward a relational economic geography. Journal of Economic Geography, 3(2), 117-144.

Batjargal, B. (2003). Social capital and entrepreneurial performance in russia: A longitudinal study. Organization Studies, 24(4), 535-556.

Battilana, J., \& Dorado, S. (2010). Building sustainable hybrid organizations: The case of commercial microfinance organizations. Academy of Management Journal, 53(6), 1419-1440.

Battilana, J., Leca, B., \& Boxenbaum, E. (2009). How actors change institutions: Towards a theory of institutional entrepreneurship. The Academy of Management Annals, 3(1), 65-107.

Bearse, P. (1998). A question of evaluation: NBIA's impact assessment of business incubators. Economic Development Quarterly, 12(4), 322-333. 
Bengtsson, M., Boter, H., \& Vanyushyn, V. (2007). Integrating the Internet and marketing operations A study of antecedents in firms of different size. International Small Business Journal, 25(1), 27-48.

Bercovitz, J. E., \& Feldman, M. P. (2007). Fishing upstream: Firm innovation strategy and university research alliances. Research Policy, 36(7), 930-948.

Bercovitz, J., \& Feldman, M. (2008). Academic entrepreneurs: Organizational change at the individual level. Organization Science, 19(1), 69-89.

Bergek, A., \& Norrman, C. (2008). Incubator best practice: A framework. Technovation, 8(1-2), 20-28.

Berry, L. L. (1983). Relationship marketing American Marketing Association.

Berry, L. L. (1995). Relationship marketing of services-growing interest, emerging perspectives. Journal of the Academy of Marketing Science, 23(4), 236-245.

Berry, L. L. (2002). Relationship marketing of services perspectives from 1983 and 2000. Journal of Relationship Marketing, 1(1), 59-77.

Birley, S. (2002). Universities, academics, and spinout companies: Lessons from imperial. International Journal of Entrepreneurship Education, 1(1), 1-21.

Blackler, F. (1995). Knowledge, knowledge work and organizations: An overview and interpretation. Organization Studies, 16(6), 1021-1046.

Blanco Jiménez, F. J., De Vicente Oliva, María Auxiliadora, Manera Bassa, J., González-Blanch Roca, J. M., Marcos Sanz, R., \& Polo García-Ochoa, C. (2014). Los servicios que prestan los viveros de empresas en españa. Rankings 2013. FUNCAS.

Blazevic, V., \& Lievens, A. (2004). Learning during the new financial service innovation process: Antecedents and performance effects. Journal of Business Research, 57(4), 374-391.

Blumberg, B. F. (2001). Efficient partner search: Embedded firms seeking co-operative partners. Journal of Mathematical Sociology, 25(4), 329-354.

Blumenberg, S., Wagner, H., \& Beimborn, D. (2009). Knowledge transfer processes in IT outsourcing relationships and their impact on shared knowledge and outsourcing performance. International Journal of Information Management, 29(5), 342-352.

Bock, G., Zmud, R. W., Kim, Y., \& Lee, J. (2005). Behavioral intention formation in knowledge sharing: Examining the roles of extrinsic motivators, socialpsychological forces, and organizational climate. MIS Quarterly, 29(1), 87-111.

Bock, G. W., \& Kim, Y. G. (2002). Breaking the myths of rewards: An exploratory study of attitudes about knowledge sharing. Information Resources Management Journal, 15(2), 14-21.

Boggs, J. S., \& Rantisi, N. M. (2003). The'relational turn' in economic geography. Journal of Economic Geography, 3(2), 109-116.

Bojei, J., \& Alwie, A. (2010). The influence of relationship quality on loyalty in service sector. International Journal of Economics and Management, 4(1), 81-100.

Bøllingtoft, A. (2012). The bottom-up business incubator: Leverage to networking and cooperation practices in a self-generated, entrepreneurial-enabled environment. Technovation, 32(5), 304-315. 
Bøllingtoft, A., \& Ulhøi, J. P. (2005). The networked business incubator-leveraging entrepreneurial agency? Journal of Business Venturing, 20(2), 265-290.

Bourdieu, P. (1985). The social space and the genesis of groups. Theory and Society, 14(6), 723-744.

Bourdieu, P., \& Wacquant, L. J. (1992). An invitation to reflexive sociology. Chicago, IL: University of Chicago Press.

Bowen, J. T., \& Shoemaker, S. (1998). Loyalty: A strategic commitment. Cornell Hotel and Restaurant Administration Quarterly, 39(1), 12-25.

Bowman-Upton, N., Seaman, S. L., \& Sexton, D. L. (1989). Innovation evaluation programs: Do they help the inventors? Journal of Small Business Management, 27(3), 23-30.

Boyd, N. G., \& Vozikis, G. S. (1994). The influence of self-efficacy on the development of entrepreneurial intentions and actions. Entrepreneurship Theory and Practice, 18(4), 63-77.

Brettel, M., Engelen, A., Müller, T., \& Schilke, O. (2011). Distribution channel choice of new entrepreneurial ventures. Entrepreneurship Theory and Practice, 35(4), 683708.

Brockner, J., Higgins, E. T., \& Low, M. B. (2004). Regulatory focus theory and the entrepreneurial process. Journal of Business Venturing, 19(2), 203-220.

Brown, S. L., \& Eisenhardt, K. M. (1998). Competing on the edge: Strategy as structured chaos. Boston, MA: Harvard Business School Press.

Bruneel, J., Ratinho, T., Clarysse, B., \& Groen, A. (2012). The evolution of business incubators: Comparing demand and supply of business incubation services across different incubator generations. Technovation, 32(2), 110-121.

Buche, M. W., \& Scillitoe, J. L. (2007). Influence of gender and social networks on organizational learning within technology incubators. American Journal of Business, 22(1), 59-68.

Burt, R. S. (1992). Structural holes: The social structure of competition. Cambridge (MA): Harvard University Press.

Burt, R. S. (2000). The network structure of social capital. Research in Organizational Behavior, 22, 345-423.

Butler, C. J. (2010). Internal and lateral communication in strategic alliance decision making. Management Decision, 48(5), 698-712.

Byosiere, P., Luethge, D. J., Vas, A., \& Paz Salmador, M. (2010). Diffusion of organisational innovation: Knowledge transfer through social networks. International Journal of Technology Management, 49(4), 401-420.

Cai, L., Liu, Q., Deng, S., \& Alon, I. (2012). A general review of entrepreneurship research (1998 to 2010): Theoretical implications, management applications and future research directions. African Journal of Business Management, 6(2), 474-492.

Callan, B. (2001). Generating spin-offs: Evidence from across the OECD. STI Review, 26, $14-54$. 
Camisón-Zornoza, C., Boronat-Navarro, M., \& Villar-López, A. (2010). Technological strategic alliances and performance: The mediating effect of knowledge-based competencies. Journal of Strategic Management Education, 6(1), 5-26.

Campbell, C., Kendrick, R. C., \& Samuelson, D. S. (1985). Stalking the latent entrepreneur: Business incubators and economic development. Economic Development Review, 3(2), 43-49.

Campbell, C., \& Allen, D. N. (1987). The small business incubator industry: Microlevel economic development. Economic Development Quarterly, 1(2), 178-191.

Cannon, J. P., \& Homburg, C. (2001). Buyer-supplier relationships and customer firm costs. Journal of Marketing, 65(1), 29-43.

Capron, L., \& Hulland, J. (1999). Redeployment of brands, sales forces, and general marketing management expertise following horizontal acquisitions: A resourcebased view. The Journal of Marketing, 63(2), 41-54.

Carnabuci, G., \& Operti, E. (2013). Where do firms' recombinant capabilities come from? intraorganizational networks, knowledge, and firms' ability to innovate through technological recombination. Strategic Management Journal, 34(13), 15911613.

Carson, D., \& Gilmore, A. (2000). Marketing at the interface: Not 'what' but 'how'. Journal of Marketing Theory and Practice, 1-7.

Carson, S. J., Devinney, T. M., Dowling, G. R., \& John, G. (1999). Understanding institutional designs within marketing value systems. The Journal of Marketing, 63(Special Issue), 115-130.

Carter, N. M., Gartner, W. B., \& Reynolds, P. D. (1996). Exploring start-up event sequences. Journal of Business Venturing, 11(3), 151-166.

Casson, M. (1982). The entrepreneur: An economic theory Rowman \& Littlefield.

Chan, K., \& Lau, T. (2005). Assessing technology incubator programs in the science park: The good, the bad and the ugly. Technovation, 25(10), 1215-1228.

Chattananon, A., \& Trimetsoontorn, J. (2009). Relationship marketing: A thai case. International Journal of Emerging Markets, 4(3), 252-274.

Chell, E., \& Baines, S. (2000). Networking, entrepreneurship and microbusiness behaviour. Entrepreneurship \& Regional Development, 12(3), 195-215.

Chen, M. (1996). Competitor analysis and interfirm rivalry: Toward a theoretical integration. Academy of Management Review, 21(1), 100-134.

Chetty, S., \& Agndal, H. (2007). Social capital and its influence on changes in internationalization mode among small and medium-sized enterprises. Journal of International Marketing, 15(1), 1-29.

Chiesa, V., \& Piccaluga, A. (2000). Exploitation and diffusion of public research: The case of academic spin-off companies in italy. R and D Management, 30(4), 329338.

Chinsonmboon, O. (2000). Incubators in the new economy. (MBA Dissertation).Massachusetts Institute of Technology. 
Chiu, C., Hsu, M., \& Wang, E. T. (2006). Understanding knowledge sharing in virtual communities: An integration of social capital and social cognitive theories. Decision Support Systems, 42(3), 1872-1888.

Choi, B., \& Lee, H. (2003). An empirical investigation of KM styles and their effect on corporate performance. Information \& Management, 40(5), 403-417.

Choi, S. Y., Kang, Y. S., \& Lee, H. (2008). The effects of socio-technical enablers on knowledge sharing: An exploratory examination. Journal of Information Science, 34(5), 742-754.

Chrisman, J. J., Hynes, T., \& Fraser, S. (1995). Faculty entrepreneurship and economic development: The case of the university of calgary. Journal of Business Venturing, 10(4), 267-281.

Chukumba, C., \& Jensen, R. (2005). University invention, entrepreneurship, and startups. (Working Paper No. 11475). Cambridge: National Bureau of Economic Research.

Chung, S. A., Singh, H., \& Lee, K. (2000). Complementarity, status similarity and social capital as drivers of alliance formation. Strategic Management Journal, 21(1), 1-22.

Clark, L. A., \& Watson, D. (1995). Constructing validity: Basic issues in objective scale development. Psychological Assessment, 7(3), 309-319.

Clarysse, B., \& Bruneel, J. (2007). Nurturing and growing innovative start-ups: The role of policy as integrator. R\&D Management, 37(2), 139-149.

Clarysse, B., Tartari, V., \& Salter, A. (2011a). The impact of entrepreneurial capacity, experience and organizational support on academic entrepreneurship. Research Policy, 40(8), 1084-1093.

Clarysse, B., Wright, M., Lockett, A., Van de Velde, E., \& Vohora, A. (2005). Spinning out new ventures: A typology of incubation strategies from european research institutions. Journal of Business Venturing, 20(2), 183-216.

Clarysse, B., Wright, M., \& Van de Velde, E. (2011b). Entrepreneurial origin, technological knowledge, and the growth of spin-off companies. Journal of Management Studies, 48(6), 1420-1442.

Clifton, N., Keast, R., Pickernell, D., \& Senior, M. (2010). Network structure, knowledge governance, and firm performance: Evidence from innovation networks and SMEs in the UK. Growth and Change, 41(3), 337-373.

Coase, R. H. (1937). The nature of the firm. Economica, 4(16), 386-405.

Cohen, J. (1992). A power primer. Psychological Bulletin, 112(1), 155-159.

Cohen, W. M., \& Levinthal, D. A. (1990). Absorptive capacity: A new perspective on learning and innovation. Administrative Science Quarterly, 35(1), 128-152.

Coleman, J. S. (1988). Social capital in the creation of human capital. American Journal of Sociology, 94(S1), 95-120.

Coleman, J. S. (1990). Foundations of social capital theory. Cambridge (MA): Harvard University Press.

Colette, H., Hill, F., \& Leitch, C. (2003). Entrepreneurship education and training. England: Ashgate Publishing Company. 
Collins, C. J., \& Smith, K. G. (2006). Knowledge exchange and combination: The role of human resource practices in the performance of high-technology firms. Academy of Management Journal, 49(3), 544-560.

Collins, J. D., \& Hitt, M. A. (2006). Leveraging tacit knowledge in alliances: The importance of using relational capabilities to build and leverage relational capital. Journal of Engineering and Technology Management, 23(3), 147-167.

Colyvas, J., Crow, M., Gelijns, A., Mazzoleni, R., Nelson, R. R., Rosenberg, N., \& Sampat, B. N. (2002). How do university inventions get into practice? Management Science, 48(1), 61-72.

Comeche, J. M., \& Loras, J. (2010). The influence of variables of attitude on collective entrepreneurship. International Entrepreneurship and Management Journal, 6(1), 23-38.

DG XVI, doc. XVI/37/84, (1984).

Comisión Europea. (2002). Benchmarking of business incubators, final report. Bruselas.

Comisión Europea. (2010). The smart guide to innovation-based incubators (IBI). Belgium.

Cook, S. D., \& Brown, J. S. (1999). Bridging epistemologies: The generative dance between organizational knowledge and organizational knowing. Organization Science, 10(4), 381-400.

Cooper, A. C., Folta, T. B., \& Woo, C. (1995). Entrepreneurial information search. Journal of Business Venturing, 10(2), 107-120.

Cooper, A. C., \& Gimeno-Gascón, F. J. (1990). Entrepreneurs, processes of founding, and new firm performance Institute for Research in the Behavioral, Economic, and Management Sciences, Krannert Graduate School of Management, Purdue University.

Cooper, C. E., Hamel, S. A., \& Connaughton, S. L. (2012). Motivations and obstacles to networking in a university business incubator. The Journal of Technology Transfer, 37(4), 433-453.

Cooper, A. C. (1985). The role of incubator organizations in the founding of growthoriented firms. Journal of Business Venturing, 1(1), 75-86.

Corolleur, C. D., Carrere, M., \& Mangematin, V. (2004). Turning scientific and technological human capital into economic capital: The experience of biotech startups in france. Research Policy, 33(4), 631-642.

Costa-David, J., Malan, J., \& Lalkaka, R. (2002). Improving business incubator performance through benchmarking and evaluation: Lessons learned from europe. 16Th International Conference on Business Incubation. National Business Incubation, April 28 - may 1, 2002, Toronto, Canadá, Toronto, Canadá. 1-25.

Cowan, R., Soete, L., \& Tchervonnaya, O. (2001). Knowledge transfer and the services sector in the context of the new economy MERIT, Maastricht Economic Research Institute on Innovation and Technology.

Crant, J. M. (2000). Proactive behavior in organizations. Journal of Management, 26(3), 435-462. 
Creswell, J. W. (2003). Research design: Qualitative, quantitative, and mixed methods approaches. London: Sage publications.

Cropanzano, R., \& Mitchell, M. S. (2005). Social exchange theory: An interdisciplinary review. Journal of Management, 31(6), 874-900.

Crowe, E., \& Higgins, E. T. (1997). Regulatory focus and strategic inclinations: Promotion and prevention in decision-making. Organizational Behavior and Human Decision Processes, 69(2), 117-132.

Culp, R. P. (1996). A test of business growth through analysis of a technology incubator program. (Unpublished Georgia Institute of Technology, Atlanta.

Cummings, J. N. (2004). Work groups, structural diversity, and knowledge sharing in a global organization. Management Science, 50(3), 352-364.

Cyert, R. M., \& Goodman, P. S. (1997). Creating effective university-industry alliances: An organizational learning perspective. Organizational Dynamics, 25(4), 45-57.

Dahlin, K. B., Weingart, L. R., \& Hinds, P. J. (2005). Team diversity and information use. Academy of Management Journal, 48(6), 1107-1123.

Danzon, P. M., Epstein, A., \& Nicholson, S. (2007). Mergers and acquisitions in the pharmaceutical and biotech industries. Managerial and Decision Economics, 28(45), 307-328.

Darroch, J. (2005). Knowledge management, innovation and firm performance. Journal of Knowledge Management, 9(3), 101-115.

Das, T., \& Kumar, R. (2010). Interpartner sensemaking in strategic alliances: Managing cultural differences and internal tensions. Management Decision, 48(1), 17-36.

Das, T. K., \& Teng, B. (2000). A resource-based theory of strategic alliances. Journal of Management, 26(1), 31-61.

Davenport, T. H., \& Prusak, L. (1998). Working knowledge: How organizations manage what they know. Boston, MA: Harvard Business Press.

Day, J., Ahmed Dean, A., \& Reynolds, P. L. (1998). Relationship marketing: Its key role in entrepreneurship. Long Range Planning, 31(6), 828-837.

Day, M., Fawcett, S. E., Fawcett, A. M., \& Magnan, G. M. (2013). Trust and relational embeddedness: Exploring a paradox of trust pattern development in key supplier relationships. Industrial Marketing Management, 42(2), 152-165.

De Coster, R., \& Butler, C. (2005). Assessment of proposals for new technology ventures in the UK: Characteristics of university spin-off companies. Technovation, 25(5), 535-543.

De Man, A., \& Duysters, G. (2005). Collaboration and innovation: A review of the effects of mergers, acquisitions and alliances on innovation. Technovation, 25(12), 1377-1387.

Dealtry, R., Elmuti, D., Abebe, M., \& Nicolosi, M. (2005). An overview of strategic alliances between universities and corporations. Journal of Workplace Learning, 17(1/2), 115-129.

Deeds, D. L., \& Hill, C. W. (1996). Strategic alliances and the rate of new product development: An empirical study of entrepreneurial biotechnology firms. Journal of Business Venturing, 11(1), 41-55. 
Dees, J. G. (1998). Enterprising nonprofits. Harvard Business Review, 76(1), 55-67.

Dekker, H. C. (2004). Control of inter-organizational relationships: Evidence on appropriation concerns and coordination requirements. Accounting, Organizations and Society, 29(1), 27-49.

Dekker, H. C. (2008). Partner selection and governance design in interfirm relationships. Accounting, Organizations and Society, 33(7), 915-941.

Dekker, H. C., Sakaguchi, J., \& Kawai, T. (2013). Beyond the contract: Managing risk in supply chain relations. Management Accounting Research, 24(2), 122-139.

Deshpandé, R., Farley, J. U., \& Webster Jr, F. E. (1993). Corporate culture, customer orientation, and innovativeness in japanese firms: A quadrad analysis. The Journal of Marketing, 57(1), 23-37.

Dess, G. G., Ireland, R. D., Zahra, S. A., Floyd, S. W., Janney, J. J., \& Lane, P. J. (2003). Emerging issues in corporate entrepreneurship. Journal of Management, 29(3), 351-378.

Dess, G., \& Lumpkin, G. (2005). Entrepreneurial orientation as a source of innovative strategy. In S. W. Floyd, J. Roos, C. D. Jacobs \& F. W. Kellermanns (Eds.), Innovating strategy processes (pp. 3-9). Cornwall, UK: Blackwell Publishing.

Dettwiler, P., Lindelöf, P., \& Löfsten, H. (2006). Utility of location: A comparative survey between small new technology-based firms located on and off science Parks-Implications for facilities management. Technovation, 26(4), 506-517.

Devaraj, S., Fan, M., \& Kohli, R. (2002). Antecedents of B2C channel satisfaction and preference: Validating e-commerce metrics. Information Systems Research, 13(3), 316-333.

Dhanaraj, C., Lyles, M. A., Steensma, H. K., \& Tihanyi, L. (2004). Managing tacit and explicit knowledge transfer in IJVs: The role of relational embeddedness and the impact on performance. Journal of International Business Studies, 35(5), 428-442.

Di Gregorio, D., \& Shane, S. (2003). Why do some universities generate more start-ups than others? Research Policy, 32(2), 209-227.

Diamantopoulos, A., \& Winklhofer, H. M. (2001). Index construction with formative indicators: An alternative to scale development. Journal of Marketing Research, 38(2), 269-277.

Dickson, A. (2005). Pre-incubation and the new zealand business incubation industry. New Zealand Centre for SME Research.

Dierickx, I., \& Cool, K. (1989). Asset stock accumulation and sustainability of competitive advantage. Management Science, 35(12), 1504-1513.

Dilk, C., Gleich, R., Wald, A., \& Motwani, J. (2008). State and development of innovation networks: Evidence from the european vehicle sector. Management Decision, 46(5), 691-701.

DiMaggio, P. J. (1988). Interest and agency in institutional theory. Institutional Patterns and Organizations: Culture and Environment, 1, 3-22.

Dodourova, M. (2009). Alliances as strategic tools: A cross-industry study of partnership planning, formation and success. Management Decision, 47(5), 831844. 
Donaldson, B., \& O'Toole, T. (2007). Strategic market relationships: From strategy to implementation. Chichester: John Wiley \& Sons Ltd.

Doney, P. M., \& Cannon, J. P. (1997). An examination of the nature of trust in buyerseller relationships. The Journal of Marketing, 61(2), 35-51.

Dose, J. J. (1997). Work values: An integrative framework and illustrative application to organizational socialization. Journal of Occupational and Organizational Psychology, 70(3), 219-241.

Dougherty, D. (1992). Interpretive barriers to successful product innovation in large firms. Organization Science, 3(2), 179-202.

Doutriaux, J., \& Dew, G. (1992). Motivation of academic entrepreneurs and spin-off development: Analysis of regional and university effect through case studies. Frontiers of Entrepreneurship Research, , 231-232.

Doutriaux, J., \& Peterman, B. F. (1982). Technology transfer and academic entrepreneurship. Frontiers of Entrepreneurship Research, 430-448.

Doz, Y. L., \& Hamel, G. (1998). Alliance advantage: The art of creating value through partnering Harvard Business Press.

Duncan, T., \& Moriarty, S. E. (1998). A communication-based marketing model for managing relationships. The Journal of Marketing, 62(April), 1-13.

Dussauge, P., Garrette, B., \& Mitchell, W. (2000). Learning from competing partners: Outcomes and durations of scale and link alliances in europe, north america and asia. Strategic Management Journal, 21(2), 99-126.

Dwyer, F. R., Schurr, P. H., \& Oh, S. (1987). Developing buyer-seller relationships. The Journal of Marketing, 51(April), 11-27.

Dyer, J. H., \& Chu, W. (2003). The role of trustworthiness in reducing transaction costs and improving performance: Empirical evidence from the united states, japan, and korea. Organization Science, 14(1), 57-68.

Dyer, J. H., \& Hatch, N. W. (2006). Relation-specific capabilities and barriers to knowledge transfers: Creating advantage through network relationships. Strategic Management Journal, 27(8), 701-719.

Dyer, J. H., \& Singh, H. (1998). The relational view: Cooperative strategy and sources of interorganizational competitive advantage. Academy of Management Review, 23(4), 660-679.

Dyer, W. G. (1994). Toward a theory of entrepreneurial careers. Entrepreneurship Theory and Practice, 19(2), 7-21.

Ebbers, J. J. (2014). Networking behavior and contracting relationships among entrepreneurs in business incubators. Entrepreneurship Theory and Practice, 38(5), 1159-1181.

Egan, J. (2011). Relationship marketing: Exploring relational strategies in marketing (Vol. Fourth Edition ed.) Prentice Hall.

Eisenberg, N., \& Miller, P. A. (1987). The relation of empathy to prosocial and related behaviors. Psychological Bulletin, 101(1), 91-119.

Eisenhardt, K. M. (1989). Building theories from case study research. Academy of Management Review, 14(4), 532-550. 
Eisenhardt, K. M., \& Santos, F. M. (2002). Knowledge-based view: A new theory of strategy. In A. Pettigrew, H. Thomas, and R. Whittington (Ed.), Handbook of strategy and management (pp. 139-164). London: Sage Publications.

Eisenhardt, K. M., \& Schoonhoven, C. B. (1996). Resource-based view of strategic alliance formation: Strategic and social effects in entrepreneurial firms. Organization Science, 7(2), 136-150.

Eklinder-Frick, J., Eriksson, L. T., \& Hallén, L. (2012). Effects of social capital on processes in a regional strategic network. Industrial Marketing Management, 41(5), 800-806.

Elg, U. (2002). Inter-firm market orientation: Its significance and antecedents in distribution networks. Journal of Marketing Management, 18(7-8), 633-655.

Ellis, N., \& Mayer, R. (2001). Inter-organisational relationships and strategy development in an evolving industrial network: Mapping structure and process. Journal of Marketing Management, 17(1-2), 183-223.

Emerson, R. M. (1976). Social exchange theory. Annual Review of Sociology, 2, 335362.

Erikson, T. (2002). Entrepreneurial capital: The emerging venture's most important asset and competitive advantage. Journal of Business Venturing, 17(3), 275-290.

Eriksson, K., Johanson, J., Majkgard, A., \& Sharma, D. D. (1997). Experiential knowledge and cost in the internationalization process. Journal of International Business Studies, 28(2), 337-360.

Eriksson, P., Vilhunen, J., \& Voutilainen, K. (2014). Incubation as co-creation: Case study of proactive technology business development. International Journal of Entrepreneurship and Innovation Management, 18(5-6), 382-396.

Etzkowitz, H. (1998). The norms of entrepreneurial science: Cognitive effects of the new university-industry linkages. Research Policy, 27(8), 823-833.

Etzkowitz, H. (2002). Networks of innovation: Science, technology and development in the triple helix era. International Journal of Technology Management \& Sustainable Development, 1(1), 7-20.

Etzkowitz, H. (2004). The evolution of the entrepreneurial university. International Journal of Technology and Globalisation, 1(1), 64-77.

European Commission. (2003). The role of universities in the europe of knowledge. (No. 58). Brussels.

European Commission. (2004). The europe of knowledge 2020: A vision for universitybased research and innovation. Leige: DG for Science \& Society.

Fabrizio, K. (2005). Opening the dam or building channels: University patenting and the use of public science in industrial innovation. (Working paper).

Fabrizio, K. R. (2009). Absorptive capacity and the search for innovation. Research Policy, 38(2), 255-267.

Fang, S., Tsai, F., \& Lin, J. L. (2010). Leveraging tenant-incubator social capital for organizational learning and performance in incubation programme. International Small Business Journal, 28(1), 90-113. 
Fayolle, A., Basso, O., \& Tornikoski, E. T. (2011). Entrepreneurial commitment and new venture creation: A conceptual exploration. In K. Hindle, \& K. Klyver (Eds.), Handbook of research on new venture creation (pp. 160-182). Cheltenham, U.K.: Edward Elgar Publishing.

Feldman, M. P., Feller, I., Bercovitz, J. L., \& Burton, R. (2001). Understanding evolving university-industry relationships. Innovation policy in the knowledgebased economy (pp. 171-188) Springer.

Feldman, M., Feller, I., Bercovitz, J., \& Burton, R. (2002). Equity and the technology transfer strategies of american research universities. Management Science, 48(1), 105-121.

Felsenstein, D. (1994). University-related science parks—_seedbeds' or 'enclaves' of innovation? Technovation, 14(2), 93-110.

Fernald, K., Pennings, E., \& Claassen, E. (2015). Biotechnology commercialization strategies: Risk and return in interfirm cooperation. Journal of Product Innovation Management, 32(6), 971-996. doi:10.1111/jpim.12218

Fillis, I. (2004). The internationalizing smaller craft firm insights from the Marketing/Entrepreneurship interface. International Small Business Journal, 22(1), 57-82.

Fink, A. (1995). The survey handbook. Thousand Oaks, CA: Sage.

Fisher, R. J., Maltz, E., \& Jaworski, B. J. (1997). Enhancing communication between marketing and engineering: The moderating role of relative functional identification. The Journal of Marketing, 61(July), 54-70.

Fleming, L. (2001). Recombinant uncertainty in technological search. Management Science, 47(1), 117-132.

Fleming, L., \& Sorenson, O. (2004). Science as a map in technological search. Strategic Management Journal, 25(8), 909-928.

Florin, J., Karri, R., \& Rossiter, N. (2007). Fostering entrepreneurial drive in business education: An attitudinal approach. Journal of Management Education, 31(1), 1742.

Folinas, D., Pastos, P., Manthou, V., \& Vlachopoulou, M. (2006). Virtual pre-incubator: A new entrepreneurship approach. International Journal of Enterprise Network Management, 1(1), 29-40.

Fontenot, R. J., \& Wilson, E. J. (1997). Relational exchange: A review of selected models for a prediction matrix of relationship activities. Journal of Business Research, 39(1), 5-12.

Ford, D. (2011). IMP and service-dominant logic: Divergence, convergence and development. Industrial Marketing Management, 40(2), 231-239.

Fornell, C., \& Larcker, D. F. (1981). Evaluating structural equation models with unobservable variables and measurement error. Journal of Marketing Research, 18(february), 39-50.

Fornoni, M., Arribas, I., \& Vila, J. E. (2011). Measurement of an individual entrepreneur's social capital: A multidimensional model. International Entrepreneurship and Management Journal, 7(4), 495-507. 
Förster, J., Higgins, E. T., \& Bianco, A. T. (2003). Speed/accuracy decisions in task performance: Built-in trade-off or separate strategic concerns? Organizational Behavior and Human Decision Processes, 90(1), 148-164.

Förster, J., Grant, H., Idson, C. L., \& Higgins, E. T. (2001). Effects of success and failure on motivational strenght: Regulatory focus as moderator. Journal of Experimental Social Psychology, 37, 253-260.

Foss, N. J., Minbaeva, D. B., Pedersen, T., \& Reinholt, M. (2009). Encouraging knowledge sharing among employees: How job design matters. Human Resource Management, 48(6), 871-893.

Franklin, S. J., Wright, M., \& Lockett, A. (2001). Academic and surrogate entrepreneurs in university spin-out companies. The Journal of Technology Transfer, 26(1-2), 127-141.

Franzoni, C., \& Lissoni, F. (2006). Academic entrepreneurship, patents, and spin-offs: Critical issues and lessons for europe. (Working paper No. 80).Centro di Ricerca sui Processi di Innovazione e Internazionalizzazione CESPRI, Università Commerciale Luigi Bocconi.

Freeman, J., Carroll, G. R., \& Hannan, M. T. (1983). The liability of newness: Age dependence in organizational death rates. American Sociological Review, 48, 692710.

Friedman, R. S., \& Förster, J. (2001). The effects of promotion and prevention cues on creativity. Journal of Personality and Social Psychology, 81(6), 1001-1013.

Fry, F. L. (1987). The role of incubators in small business planning. American Journal of Small Business, 12(1), 51-61.

Galunic, D. C., \& Rodan, S. (1998). Resources recombinations in the firm: Knowledge structures and the potential for schumpeterian innovation. Strategic Management Journal, 19(12), 1193-1201.

Ganesan, S. (1994). Determinants of long-term orientation in buyer-seller relationships. The Journal of Marketing, 58(2), 1-19.

Ganesan, S. (1994). Determinants of long-term orientation in buyer-seller relationships. The Journal of Marketing, 58(1), 1-19.

Ganesan, S., \& Hess, R. (1997). Dimensions and levels of trust: Implications for commitment to a relationship. Marketing Letters, 8(4), 439-448.

García-Morales, V. J., Llorens-Montes, F. J., \& Verdú-Jover, A. J. (2006). Antecedents and consequences of organizational innovation and organizational learning in entrepreneurship. Industrial Management \& Data Systems, 106(1), 21-42.

Garrette, B., Castañer, X., \& Dussauge, P. (2009). Horizontal alliances as an alternative to autonomous production: Product expansion mode choice in the worldwide aircraft industry 1945-2000. Strategic Management Journal, 30(8), 885-894.

Gartner, W. B. (1988). Who is an entrepreneur? is the wrong question. American Journal of Small Business, 12(4), 11-32.

Gassenheimer, J. B., \& Ramsey, R. (1994). The impact of dependence on dealer satisfaction: A comparison of reseller-supplier relationships. Journal of Retailing, 70(3), 253-266. 
George, G., Zahra, S. A., Wheatley, K. K., \& Khan, R. (2001). The effects of alliance portfolio characteristics and absorptive capacity on performance: A study of biotechnology firms. The Journal of High Technology Management Research, 12(2), 205-226.

Geyskens, I., Steenkamp, J. E., Scheer, L. K., \& Kumar, N. (1996). The effects of trust and interdependence on relationship commitment: A trans-atlantic study. International Journal of Research in Marketing, 13(4), 303-317.

Ghosh, M., \& John, G. (1999). Governance value analysis and marketing strategy. The Journal of Marketing, 63(Special Issue), 131-145.

Ghoshal, S., \& Bartlett, C. A. (1988). Creation, adoption, and diffusion of innovations by subsidiaries of multinational corporations. Journal of International Business Studies, 19(3), 365-388.

Gibb, A. A. (1997). Small firms' training and competitiveness. building upon the small business as a learning organisation. International Small Business Journal, 15(3), 13-29.

Gibson, L. (1988). Economic development: The university and commercialization of research. Economic Development Review, 6(2), 7-11.

Gilmore, A. (2011). Entrepreneurial and SME marketing. Journal of Research in Marketing and Entrepreneurship, 13(2), 137-145.

Gilmore, A., Carson, D., \& Rocks, S. (2006). Networking in SMEs: Evaluating its contribution to marketing activity. International Business Review, 15(3), 278-293.

Goerzen, A., \& Beamish, P. W. (2005). The effect of alliance network diversity on multinational enterprise performance. Strategic Management Journal, 26(4), 333354.

Gold, A. H., Malhotra, A., \& Segars, A. H. (2001). Knowledge management: An organizational capabilities perspective. Journal of Management Information Systems, 18(1), 185-214.

Gorovaia, N., \& Windsperger, J. (2010). The use of knowledge transfer mechanisms in franchising. Knowledge and Process Management, 17(1), 12-21.

Grande, J., Madsen, E. L., \& Borch, O. J. (2011). The relationship between resources, entrepreneurial orientation and performance in farm-based ventures. Entrepreneurship and Regional Development, 23(3-4), 89-111.

Granovetter, M. S. (1973). The strength of weak ties. American Journal of Sociology, 78(6), 1360-1380.

Granovetter, M. S. (1974). Getting a job: A study of contacts and careers. Chicago: The University of Chicago Press.

Granovetter, M. S. (1983). The strength of weak ties: A network theory revisited. Sociological Theory, 1, 201-233.

Grant, R. M. (1996). Toward a knowledge-based theory of the firm. Strategic Management Journal, 17(Winter Special Issue), 109-122.

Grant, R. M., \& Baden-Fuller, C. (2004). A knowledge accessing theory of strategic alliances. Journal of Management Studies, 41(1), 61-84. 
Granzin, K., \& Olsen, J. (1991). Characterizing participants in activities protecting the environment: A focus on donating, recycling and conservation behaviors. Journal of Public Policy \& Marketing, 10(2), 1-27.

Grayson, K., \& Ambler, T. (1999). The dark side of long-term relationships in marketing services. Journal of Marketing Research, 36(February), 132-141.

Greve, A., \& Salaff, J. W. (2003). Social networks and entrepreneurship. Entrepreneurship Theory and Practice, 28(1), 1-22.

Grimaldi, R., \& Grandi, A. (2005). Business incubators and new venture creation: An assessment of incubating models. Technovation, 25(2), 111-121.

Grimaldi, R., \& Grandi, A. (2001). The contribution of university business incubators to new knowledge-based ventures: Some evidence from italy. Industry and Higher Education, 15(4), 239-250.

Grönroos, C. (1994). From marketing mix to relationship marketing: Towards a paradigm shift in marketing. Management Decision, 32(2), 4-20.

Grönroos, C. (1997). Value-driven relational marketing: From products to resources and competencies. Journal of Marketing Management, 13(5), 407-419.

Grönroos, C. (2000). Service management and marketing. Chichester: John Wiley \& Sons Ltd.

Grönroos, C. (2004). The relationship marketing process: Communication, interaction, dialogue, value. Journal of Business \& Industrial Marketing, 19(2), 99-113.

Grosse, R. (1996). International technology transfer in services. Journal of International Business Studies, 27(4), 781-800.

Gulati, R. (1995). Does familiarity breed trust? the implications of repeated ties for contractual choice in alliances. Academy of Management Journal, 38(1), 85-112.

Gulati, R. (1999). Network location and learning: The influence of network resources and firm capabilities on alliance formation. Strategic Management Journal, 20(5), 397-420.

Gulati, R., \& Singh, H. (1998). The architecture of cooperation: Managing coordination costs and appropriation concerns in strategic alliances. Administrative Science Quarterly, 43(4), 781-814.

Gummesson, E. (2000). Qualitative methods in management research. Thousand Oaks: Sage Publications.

Gundlach, G. T., Achrol, R. S., \& Mentzer, J. T. (1995). The structure of commitment in exchange. The Journal of Marketing, 59(1), 78-92.

Gupta, A. K., \& Govindarajan, V. (2000). Knowledge flows within multinational corporations. Strategic Management Journal, 21(4), 473-496.

Gustafsson, V. (2006). Entrepreneurial decision-making: Individuals, tasks and cognitions Edward Elgar Publishing.

Hackett, S. M., \& Dilts, D. M. (2004a). A systematic review of business incubation research. The Journal of Technology Transfer, 29(1), 55-82.

Hackett, S. M., \& Dilts, D. M. (2004b). A real options-driven theory of business incubation. Journal of Technology Transfer, 29(1), 41-54. 
Hagedoorn, J., \& Duysters, G. (2002). External sources of innovative capabilities: The preferences for strategic alliances or mergers and acquisitions. Journal of Management Studies, 39(2), 167-188.

Hair, J. F. J., Anderson, R., Tatham, R., \& Black, W. (1999). Análisis multivariante. Madrid: Prentice Hall.

Hair, J. F. J., Hult, G. T. M., Ringle, C. M., \& Sarstedt, M. (2014). A primer on partial least squares structural equation modeling (PLS-SEM) Sage Publications.

Håkansson, H., \& Ford, D. (2002). How should companies interact in business networks? Journal of Business Research, 55(2), 133-139.

Håkansson, H., \& Snehota, I. (1989). No business is an island: The network concept of business strategy. Scandinavian Journal of Management, 5(3), 187-200.

Hall, H. (2001). Input-friendliness: Motivating knowledge sharing across intranets. Journal of Information Science, 27(3), 139-146.

Hamel, G., Doz, Y. L., \& Prahalad, C. K. (1989). Collaborate with your competitors and win. Harvard Business Review, 67(1), 133-139.

Hannan, M. T., \& Freeman, J. (1984). Structural inertia and organizational change. American Sociological Review, 49(2), 149-164.

Hannon, P. D. (2004). A qualitative sense-making classification of business incubation environments. Qualitative Market Research: An International Journal, 7(4), 274283.

Hannon, P. D. (2005). Incubation policy and practice: Building practitioner and professional capability. Journal of Small Business and Enterprise Development, 12(1), 57-75.

Hannon, P. D., \& Chaplin, P. (2003). Are incubators good for business? understanding incubation practice - the challenges for policy. Environment and Planning C: Government and Policy, 21(6), 861-881.

Hansen, D. J., \& Eggers, F. (2010). The marketing/entrepreneurship interface: A report on the "Charleston summit". Journal of Research in Marketing and Entrepreneurship, 12(1), 42-53.

Hansen, E. L. (1995). Entrepreneurial networks and new organization growth. Entrepreneurship Theory and Practice, 19(4), 7-19.

Hansen, M. T. (1999). The search-transfer problem: The role of weak ties in sharing knowledge across organization subunits. Administrative Science Quarterly, 44(1), 82-111.

Hansen, M. T. (2002). Knowledge networks: Explaining effective knowledge sharing in multiunit companies. Organization Science, 13(3), 232-248.

Hansen, M. T., Mors, M. L., \& Løvås, B. (2005). Knowledge sharing in organizations: Multiple networks, multiple phases. Academy of Management Journal, 48(5), 776793.

Hansen, M. T., Chesbrough, H. W., Nohria, N., \& Sull, D. N. (2000). Networked incubators. hothouses of the new economy. Harvard Business Review, 78(5), 7484. 
Harrigan, P., Ramsey, E., \& Ibbotson, P. (2012). Exploring and explaining SME marketing: Investigating e-CRM using a mixed methods approach. Journal of Strategic Marketing, 20(2), 127-163.

Hartley, J. F. (1994). Case studies in organizational research. In G. Symon, \& C. Cassell (Eds.), Qualitative methods in organizational research: A practical guide (pp. 209229). London: Sage.

Harvey, L., \& Anderson, J. (1996). Transfer of declarative knowledge in complex information-processing domains. Human-Computer Interaction, 11(1), 69-96.

Hatzakis, T., Lycett, M., Macredie, R. D., \& Martin, V. A. (2005). Towards the development of a social capital approach to evaluating change management interventions. European Journal of Information Systems, 14(1), 60-74.

Hauser, C., Tappeiner, G., \& Walde, J. (2007). The learning region: The impact of social capital and weak ties on innovation. Regional Studies, 41(1), 75-88.

Hayek, F. A. (1945). The use of knowledge in society. The American Economic Review, 35(4), 519-530.

He, J., \& Fallah, M. H. (2009). Is inventor network structure a predictor of cluster evolution? Technological Forecasting and Social Change, 76(1), 91-106.

Hedlund, G., \& Zander, U. (1993). Architectonic and list-like knowledge structuring: A critique of modern concepts of knowledge management. (Working paper).Stockholm School of Economics.

Heide, J. B. (1994). Interorganizational governance in marketing channels. Journal of Marketing, , 71-85.

Heide, J. B., \& John, G. (1990). Alliances in industrial purchasing: The determinants of joint action in buyer-supplier relationships. Journal of Marketing Research, 27(1), 24-36.

Helfert, G., Ritter, T., \& Walter, A. (2002). Redefining market orientation from a relationship perspective: Theoretical considerations and empirical results. European Journal of Marketing, 36(9/10), 1119-1139.

Henderson, R. (1995). Of life cycles real and imaginary: The unexpectedly long old age of optical lithography. Research Policy, 24(4), 631-643.

Henderson, R. M., \& Clark, K. B. (1990). Architectural innovation: The reconfiguration of existing product technologies and the failure of established firms. Administrative Science Quarterly, 35(1), 9-30.

Hendriks, P. (1999). Why share knowledge? the influence of ICT on the motivation for knowledge sharing. Knowledge and Process Management, 6(2), 91-100.

Hennart, J. (1993). Explaining the swollen middle: Why most transactions are a mix of "market" and "hierarchy". Organization Science, 4(4), 529-547.

Henseler, J., Ringle, C. M., \& Sarstedt, M. (2015). A new criterion for assessing discriminant validity in variance-based structural equation modeling. Journal of the Academy of Marketing Science, 43(1), 115-135.

Henseler, J., Ringle, C. M., \& Sinkovics, R. R. (2009). The use of partial least squares path modeling in international marketing. Advances in International Marketing, 20, 277-319. 
Herrero, F. V., \& Ángel, P. O. (2008). OTRI: Agenda de investigación. Investigaciones Europeas De Dirección y Economía De La Empresa, 14(3), 67-78.

Heydebreck, M., Klofsten, M., \& Maier, J. C. (2000). Innovation support for new technology-based ventures. R\&D Management, 30(1), 89-100.

Higgins, E. T. (1998). Promotion and prevention: Regulatory focus as a motivational principle. Advances in Experimental Social Psychology, 30, 1-46.

Higgins, E. T., Friedman, R. S., Harlow, R. E., Idson, L. C., Ayduk, O. N., \& Taylor, A. (2001). Achievement orientations from subjective histories of success: Promotion pride versus prevention pride. European Journal of Social Psychology, 31(1), 3-23.

Hindle, K., \& Yencken, J. (2004). Public research commercialisation, entrepreneurship and new technology based firms: An integrated model. Technovation, 24(10), 793803.

Hite, J. M., \& Hesterly, W. S. (2001). The evolution of firm networks: From emergence to early growth of the firm. Strategic Management Journal, 22(3), 275-286.

Hitt, M. A., Dacin, M. T., Levitas, E., Arregle, J., \& Borza, A. (2000). Partner selection in emerging and developed market contexts: Resource-based and organizational learning perspectives. Academy of Management Journal, 43(3), 449-467.

Hitt, M. A., \& Reed, T. S. (2000). Entrepreneurship in the new competitive landscape. In G. D. Meyer \& K. A. Heppard (Eds.) (Ed.), Entrepreneurship as strategy (pp. 23-48). Thousand Oaks, CA: Sage Publications.

Hoang, H., \& Antoncic, B. (2003). Network-based research in entrepreneurship: A critical review. Journal of Business Venturing, 18(2), 165-187.

Hogan, R. (1969). Development of an empathy scale. Journal of Consulting and Clinical Psychology, 33(3), 307-316.

Hohberger, J. (2014). Searching for emerging knowledge: The influence of collaborative and geographically proximate search. European Management Review, 11(2), 139-157.

Hohberger, J., Almeida, P., \& Parada, P. (2015). The direction of firm innovation: The contrasting roles of strategic alliances and individual scientific collaborations. Research Policy, 44(8), 1473-1487.

Honig, B., \& Karlsson, T. (2010). Social capital and the modern incubator: A comparison of in-group and out-group social networks. Journal of Small Business \& Entrepreneurship, 23(sup 1), 719-731.

Hsieh, Y., Chiu, H., \& Hsu, Y. (2008). Supplier market orientation and accommodation of the customer in different relationship phases. Industrial Marketing Management, 37(4), 380-393.

Hsu, D., \& Bernstein, T. (1997). Managing the university technology licensing process: Findings from case studies. Journal of the Association of University Technology Managers, 9(9), 1-33.

Hsu, I. (2008). Knowledge sharing practices as a facilitating factor for improving organizational performance through human capital: A preliminary test. Expert Systems with Applications, 35(3), 1316-1326. 
Huang, Y., Lin, C., Liu, Y. C., \& Tung, M. (2013). The effects of IT resource alignment and organizational dynamism on alliance performance in hemodialysis centers. The International Technology Management Review, 3(2), 105-115.

Huber, G. P. (1991). Organizational learning: The contributing processes and the literatures. Organization Science, 2(1), 88-115.

Hughes, M., Morgan, R. E., Ireland, R. D., \& Hughes, P. (2011). Network behaviours, social capital, and organisational learning in high-growth entrepreneurial firms. International Journal of Entrepreneurship and Small Business, 12(3), 257-272.

Hughes, M., Ireland, R. D., \& Morgan, R. E. (2007). Stimulating dynamic value: Social capital and business incubation as a pathway to competitive success. Long Range Planning, 40(2), 154-177.

Hultman, C. M., \& Hills, G. E. (2011). Influence from entrepreneurship in marketing theory. Journal of Research in Marketing and Entrepreneurship, 13(2), 120-125.

Hunt, S. D., Arnett, D. B., \& Madhavaram, S. (2006). The explanatory foundations of relationship marketing theory. Journal of Business \& Industrial Marketing, 21(2), 72-87.

Hunt, S. D., \& Morgan, R. M. (1994). Relationship marketing in the era of network competition. Marketing Management, 3(1), 19-28.

Ibarra, H. (1992). Structural alignments, individual strategies, and managerial action: Elements toward a theory of getting things done. In N. Noria \& R.G. Eccles (Ed.), Networks and organizations:Structure, form and action (pp. 165-188). Boston: Division of Research, Harvard Business School.

Ihrig, M., MacMillan, I., Boisot, M., \& Zu Knyphausen-Aufsess, D. (2010). Knowledge-based opportunity recognition strategies: A simulation approach. Proceedings of the Strategic Management Conference 2010, Rome, Italy,

Inkpen, A. C. (2000). Learning through joint ventures: A framework of knowledge acquisition. Journal of Management Studies, 37(7), 1019-1043.

Inkpen, A. C. (2002). Learning, knowledge management, and strategic alliances: So many studies, so many unanswered questions. In F. J. Contracto, \& P. Lorange (Eds.), Cooperative strategies and alliances (pp. 267-289) Pergamon: Oxford.

Ipe, M. (2003). Knowledge sharing in organizations: A conceptual framework. Human Resource Development Review, 2(4), 337-359.

Ireland, R. D., Hitt, M. A., \& Sirmon, D. G. (2003). A model of strategic entrepreneurship: The construct and its dimensions. Journal of Management, 29(6), 963-989.

Ireland, R. D., Hitt, M. A., \& Vaidyanath, D. (2002). Alliance management as a source of competitive advantage. Journal of Management, 28(3), 413-446.

Istvan, D. F. (1991). Coming full circle in practice management. Journal of Accountancy, 171(5), 42-48.

Jackson, B. B. (1985). Build customer relationships that last. Harvard Business Review, 63(November - December), 120-128.

Jacobs, J. (1961). The death and life of great american cities Vintage. 
Jap, S. D. (1999). Pie-expansion efforts: Collaboration processes in buyer-supplier relationships. Journal of Marketing Research, 36(4), 461-475.

Jap, S. D., \& Ganesan, S. (2000). Control mechanisms and the relationship life cycle: Implications for safeguarding specific investments and developing commitment. Journal of Marketing Research, 37(2), 227-245.

Jarillo, J. C. (1993). Strategic networks: Creating the borderless organization. Oxford, UK: Butterworth-Heinemann.

Jayachandran, S., Sharma, S., Kaufman, P., \& Raman, P. (2005). The role of relational information processes and technology use in customer relationship management. Journal of Marketing, 69(4), 177-192.

Jensen, M. C., \& Meckling, W. H. (1992). Specific and general knowledge and organizational structure. In L . Werin and H . Wijkander (Ed.), Contract economics (pp. 251-274). Oxford: Blackwell.

Jensen, R. A., Thursby, J. G., \& Thursby, M. C. (2003). Disclosure and licensing of university inventions: 'The best we can do with the $\mathrm{s}^{* *} \mathrm{t}$ we get to work with' International Journal of Industrial Organization, 21(9), 1271-1300.

Jensen, R., \& Thursby, M. (2001). Proofs and prototypes for sale: The licensing of university inventions. American Economic Review, 91, 240-259.

Jiang, L., Tan, J., \& Thursby, M. (2011). Incumbent firm invention in emerging fields: Evidence from the semiconductor industry. Strategic Management Journal, 32(1), 55-75.

Johanson, J., \& Mattsson, L. (1987). Inter-organizational relations in industrial systems: A network approach compared with the transaction-cost approach. International Studies of Management \& Organization, XVII(1), 34-48.

Johlke, M. C., \& Duhan, D. F. (2001). Testing competing models of sales force communication. Journal of Personal Selling \& Sales Management, 21(4), 265-277.

John, G., \& Reve, T. (2010). Transaction cost analysis in marketing: Looking back, moving forward. Journal of Retailing, 86(3), 248-256.

Johnson, A. M., \& Lederer, A. L. (2005). The effect of communication frequency and channel richness on the convergence between chief executive and chief information officers. Journal of Management Information Systems, 22(2), 227-252.

Jones, R., \& Rowley, J. (2011). Entrepreneurial marketing in small businesses: A conceptual exploration. International Small Business Journal, 29(1), 25-36.

Jones-Evans, D. (1998). Universities, technology transfer and spin-off activities: Academic entrepreneurship in different european regions. (TSER Report No. 1042). Cardiff: University of Glamorgan.

Jones-Evans, D., \& Klofsten, M. (1998). Academic entrepreneurship in europe: A survey. 44Th ICSB World Conference, Innovation and Economic Development. June 20-23, Nápoles, Italia.

Jung, T. H., Ineson, E. M., \& Green, E. (2013). Online social networking: Relationship marketing in UK hotels. Journal of Marketing Management, 29(3-4), 393-420.

Kale, P., Singh, H., \& Perlmutter, H. (2000). Learning and protection of proprietary assets in strategic alliances: Building relational capital. Strategic Management Journal, 21(3), 217-237. 
Katila, R., \& Shane, S. (2005). When does lack of resources make new firms innovative? Academy of Management Journal, 48(5), 814-829.

Kenney, M., \& Patton, D. (2011). Does inventor ownership encourage university research-derived entrepreneurship? A six university comparison. Research Policy, 40(8), 1100-1112.

Khojastehpour, M., \& Johns, R. (2014). Internationalization and relationship marketing: An introduction. European Business Review, 26(3), 238-253.

Kirzner, I. (1979). Perception, opportunity, and profit. Chicago: University of Chicago Press.

Kirzner, I. (1997). Entrepreneurial discovery and the competitive market process: An austrian approach. Journal of Economic Literature, 35, 60-85.

Kleijnen, M., Lievens, A., de Ruyter, K., \& Wetzels, M. (2009). Knowledge creation through mobile social networks and its impact on intentions to use innovative mobile services. Journal of Service Research, 12(1), 15-35.

Kline, R. B. (2011). Principles and practice of structural equation modeling. New York: Guilford Press.

Knopp, L. (2007). State of the business incubation industry. Athens, Ohio: National Business Incubation Association.

Kodish, S., \& Pettegrew, L. S. (2008). Enlightened communication is the key to building relationships. Journal of Relationship Marketing, 7(2), 151-176.

Koestner, R., \& Losier, G. F. (2002). Distinguishing three ways of being highly motivated: A closer look at introjection, identification, and intrinsic motivation. In E. L. Deci \& R. M. Ryan (Ed.), Handbook of self-determination research (pp. 101121). Rochester, NY: University of Rochester Press.

Kogut, B. (2000). The network as knowledge: Generative rules and the emergence of structure. Strategic Management Journal, 21(3), 405-425.

Kogut, B., \& Zander, U. (1992). Knowledge of the firm, combinative capabilities, and the replication of technology. Organization Science, 3(3), 383-397.

Kogut, B., \& Zander, U. (1996). What firms do? coordination, identity, and learning. Organization Science, 7(5), 502-518.

Kortelainen, S., Huizingh, E., Kärkkäinen, H., \& Piirainen, K. (2010). Acquiring and applying innovation resources: A resource-based model to predict market shares. Proceedings of the XXI ISPIM Conference Dynamics of Innovation Bilbao, Spain, 6-9 June 2010,

Kozlenkova, I. V., Samaha, S. A., \& Palmatier, R. W. (2014). Resource-based theory in marketing. Journal of the Academy of Marketing Science, 42(1), 1-21.

Kraatz, M. S., \& Moore, J. H. (2002). Executive migration and institutional change. Academy of Management Journal, 45(1), 120-143.

Krishna, A. (2000). Creating and harnessing social capital. In P. Dasgupta, \& I. Serageldin (Eds.), Social capital: A multifaceted perspective (pp. 71-93). Washington, DC: The World Bank. 
Krueger, N. F. (1993). The impact of prior entrepreneurial exposure on perceptions of new venture feasibility and desirability. Entrepreneurship Theory and Practice, 18(1), 5-21.

Kucukkancabas, S., Akyol, A., \& Ataman, B. M. (2009). Examination of the effects of the relationship marketing orientation on the company performance. Quality and Quantity, 43(3), 441-450.

Kuratko, D. F., \& LaFollete, W. R. (1987). Small business incubators for local economic development. Economic Development Review, 5(2), 49-55.

Küster, I., \& Vila, N. (2007). Relational strategies in the textile sector: Internet use. Journal of Relationship Marketing, 5(4), 3-22.

Lahiri, N. (2010). Geographic distribution of R\&D activity: How does it affect innovation quality? Academy of Management Journal, 53(5), 1194-1209.

Lahti, R. K., \& Beyerlein, M. M. (2000). Knowledge transfer and management consulting: A look at the firm. Business Horizons, 43(1), 65-74.

Lalkaka, R. (2002). Technology business incubator to assist a innovation-based economy. Journal of Change Management, 3(2), 167-176.

Lalkaka, R. (2003). Technology business incubation: Role, performance, linkages, trends. National Workshop on Technology Parks and Business Incubators, Isfahan, Iran, Isfahan, Irán.

Lalkaka, R., \& Bishop, J. (1996). Business incubators in economic development-an initial assessment in industrialising countries. Nueva York: United Nation Development Programme.

Lam, W., \& Harker, M. J. (2014). Marketing and entrepreneurship: An integrated view from the entrepreneur's perspective. International Small Business Journal, 0(0), 129. doi:10.1177/0266242613496443.

Lambe, C. J., Spekman, R. E., \& Hunt, S. D. (2002). Alliance competence, resources, and alliance success: Conceptualization, measurement, and initial test. Journal of the Academy of Marketing Science, 30(2), 141-158.

Landry, R., Amara, N., \& Rherrad, I. (2006). Why are some university researchers more likely to create spin-offs than others? evidence from canadian universities. Research Policy, 35(10), 1599-1615.

Lane, P. J., \& Lubatkin, M. (1998). Relative absorptive capacity and interorganizational learning. Strategic Management Journal, 19(5), 461-477.

Langley, A., \& Royer, I. (2006). Perspectives on doing case study research in organizations. M@n@gement, 9(3),73-86.

Laroia, G., \& Krishnan, S. (2005). Managing drug discovery alliances for success. Research Technology Management, 48(5), 42-50.

Larson, A. (1992). Network dyads in entrepreneurial settings: A study of the governance of exchange relationships. Administrative Science Quarterly, 37(1), 76104.

Lawson, B., Tyler, B. B., \& Cousins, P. D. (2008). Antecedents and consequences of social capital on buyer performance improvement. Journal of Operations Management, 26(3), 446-460. 
Leana, C. R., \& van Buren, H. J. (1999). Organizational social capital and employment practices. Academy of Management Review, 24(3), 538-555.

Lee, D. Y., \& Tsang, E. W. (2001). The effects of entrepreneurial personality, background and network activities on venture growth. Journal of Management Studies, 38(4), 583-602.

Lee, K. C., Lee, S., \& Kang, I. W. (2005). KMPI: Measuring knowledge management performance. Information \& Management, 42(3), 469-482.

Lee, R. (2009). Social capital and business and management: Setting a research agenda. International Journal of Management Reviews, 11(3), 247-273.

Lee, S. S., \& Osteryoung, J. S. (2004). A comparison of critical success factors for effective operations of university business incubators in the united states and korea. Journal of Small Business Management, 42(4), 418-426.

Lender, C. (2003). Management, professionals and funding of university business incubators worldwide. 48th ICSB Conference Proceedings, Belfast, 16-18 June, Belfast.

Lendner, C. (2007). University technology transfer through university business incubators and how they help start-ups. In F. Thérin (Ed.), Handbook of research on techno-entrepreneurship (pp. 163-169). Cheltenham, UK: Edward Elgar.

Leonidou, L. C., Palihawadana, D., Chari, S., \& Leonidou, C. N. (2011). Drivers and outcomes of importer adaptation in international buyer-seller relationships. Journal of World Business, 46(4), 527-543.

Leonidou, L. C., Palihawadana, D., \& Theodosiou, M. (2006). An integrated model of the behavioural dimensions of industrial buyer-seller relationships. European Journal of Marketing, 40(1/2), 145-173.

Leung, A., Zhang, J., Wong, P. K., \& Foo, M. D. (2006). The use of networks in human resource acquisition for entrepreneurial firms: Multiple "fit" considerations. Journal of Business Venturing, 21(5), 664-686.

Levin, D. Z., \& Cross, R. (2004). The strength of weak ties you can trust: The mediating role of trust in effective knowledge transfer. Management Science, 50(11), 1477-1490.

Lewis, D., Harper-Anderson, E., \& Molnar, L. (2011). Incubating success. incubation best practices that lead to successful new ventures. (Institute for Research on Labor Employment, and the Economy, University of Michigan, Ann Arbor). Michigan: University of Michigan.

Lewis, D. A. (2001). Does technology incubation work? A critical review. ( No. 11).Economic Development Administration, U.S. Department of Commerce.

Liao, C., Wang, H., Chuang, S., Shih, M., \& Liu, C. (2010). Enhancing knowledge management for $\mathrm{R} \& \mathrm{D}$ innovation and firm performance: An integrative view. African Journal of Business Management, 4(14), 3026-3038.

Liao, J., \& Welsch, H. (2005). Roles of social capital in venture creation: Key dimensions and research implications. Journal of Small Business Management, 43(4), 345-362. 
Liberman, N., Idson, L. C., Camacho, C. J., \& Higgins, E. T. (1999). Promotion and prevention choices between stability and change. Journal of Personality and Social Psychology, 77(6), 1135-1145.

Liebowitz, J., \& Chen, Y. (2001). Developing knowledge-sharing proficiencies. Knowledge Management Review, 3(6), 12-15.

Lin, C. (2007). To share or not to share: Modeling tacit knowledge sharing, its mediators and antecedents. Journal of Business Ethics, 70(4), 411-428.

Lin, J., \& Si, S. X. (2010). Can guanxi be a problem? contexts, ties, and some unfavorable consequences of social capital in china. Asia Pacific Journal of Management, 27(3), 561-581.

Lindholm, D. A. (1997). Growth and incentiveness in technology based spin-off firms. Research Policy, 26, 331-344.

Link, A. N., \& Scott, J. T. (2003). US science parks: The diffusion of an innovation and its effects on the academic missions of universities. International Journal of Industrial Organization, 21(9), 1323-1356.

Liu, S. (2009). Determinants of service innovative dimensions in knowledge intensive business services: Evidence from PR china. International Journal of Technology Management, 48(1), 95-114.

Lockett, A., Siegel, D., Wright, M., \& Ensley, M. D. (2005). The creation of spin-off firms at public research institutions: Managerial and policy implications. Research Policy, 34(7), 981-993.

Lockett, A., \& Wright, M. (2005). Resources, capabilities, risk capital and the creation of university spin-out companies. Research Policy, 34(7), 1043-1057.

Lockett, A., Wright, M., \& Franklin, S. (2003). Technology transfer and universities' spin-out strategies. Small Business Economics, 20(2), 185-200.

Löfsten, H., \& Lindelöf, P. (2001). Science parks in Sweden-industrial renewal and development? R\&D Management, 31(3), 309-322.

Löfsten, H., \& Lindelöf, P. (2003). Determinants for an entrepreneurial milieu: Science parks and business policy in growing firms. Technovation, 23(1), 51-64.

Low, M. B., \& MacMillan, I. C. (1988). Entrepreneurship: Past research and future challenges. Journal of Management, 14(2), 139-161.

Lowe, R. A., \& Ziedonis, A. A. (2006). Overoptimism and the performance of entrepreneurial firms. Management Science, 52(2), 173-186.

Lumineau, F., \& Malhotra, D. (2011). Shadow of the contract: How contract structure shapes inter-firm dispute resolution. Strategic Management Journal, 32(5), 532555.

Lumpkin, G. T., \& Dess, G. G. (1996). Clarifying the entrepreneurial orientation construct and linking it to performance. Academy of Management Review, 21(1), 135-172.

Lumpkin, J. R., \& Ireland, R. D. (1988). Screening practices of new business incubators: The evaluation of critical success factors. American Journal of Small Business, 12(4), 59-81. 
Luo, Y. (2002). Contract, cooperation, and performance in international joint ventures. Strategic Management Journal, 23(10), 903-919.

Lyles, M. A., \& Salk, J. E. (1996). Knowledge acquisition from foreign parents in international joint ventures: An empirical examination in the hungarian context. Journal of International Business Studies, 27(5), 877-903.

Lyons, T. S. (2000). Building social capital for sustainable enterprise development in country towns and regions: Successful practices from the united states. First National Conference on the Future of Australia's Country Towns, LaTrobe University, Center for Sustainable Regional Communities, Australia. June,

Lyons, T. S. (2002). Building social capital for rural enterprise development: Three case studies in the united states. Journal of Developmental Entrepreneurship, 7(2), 193216.

Macneil, I. R. (1980). The new social contract: An inquiry into modern contractual relations.

Malhotra, N. K. (1997). Investigación de mercados: Un enfoque práctico. México: Prentice Hall Hispanoamericana.

Malthouse, E. C., \& Blattberg, R. C. (2005). Can we predict customer lifetime value? Journal of Interactive Marketing, 19(1), 2-16.

Mansfield, E. (1990). Academic research and industrial innovation. Research Policy, 20, $1-12$.

Markman, G., Phillip, P., Balkan, D., \& Ganoids, P. (2005). Entrepreneurship and university-based technology transfer. Journal of Business Venturing, 20(2), 241263.

Martin, F. (1997). Business incubators and enterprise development: Neither tried or tested? Journal of Small Business and Enterprise Development, 4(1), 3-11.

Massey, G. R., \& Dawes, P. L. (2007). The antecedents and consequence of functional and dysfunctional conflict between marketing managers and sales managers. Industrial Marketing Management, 36(8), 1118-1129.

Mayer, D., \& Greenberg, H. M. (1964). What makes a good salesman? Harvard Business Review, 42(4), 119-125.

McAdam, M., \& Marlow, S. (2007). Building futures or stealing secrets? entrepreneurial cooperation and conflict within business incubators. International Small Business Journal, 25(4), 361-382.

McAdam, M., \& Marlow, S. (2008). A preliminary investigation into networking activities within the university incubator. International Journal of Entrepreneurial Behaviour \& Research, 14(4), 219-241.

McAdam, M., \& McAdam, R. (2006). The networked incubator: The role and operation of entrepreneurial networking with the university science park incubator (USI). The International Journal of Entrepreneurship and Innovation, 7(2), 87-97.

McAdam, M., \& McAdam, R. (2008). High tech start-ups in university science park incubators: The relationship between the start-up's lifecycle progression and use of the incubator's resources. Technovation, 28(5), 277-290.

McEvily, B., \& Marcus, A. (2005). Embedded ties and the acquisition of competitive capabilities. Strategic Management Journal, 26(11), 1033-1055. 
McKee, B. (1992). A boost for start-ups. Nation's Business, 80(8), 40-42.

McKnight, D. H., Choudhury, V., \& Kacmar, C. (2002). Developing and validating trust measures for e-commerce: An integrative typology. Information Systems Research, 13(3), 334-359.

Medina, C., \& Espinoza, M. (1994). La innovación en las organizaciones modernas. Gestión y Estrategia, 20(5), 54-63.

Mentzer, J. T., Flint, D. J., \& Hult, G. T. M. (2001). Logistics service quality as a segment-customized process. Journal of Marketing, 65(4), 82-104.

Merriam, S. B. (1988). Case study research in education: A qualitative approach. San Francisco: Jossey-Bass.

Merrifield, D. B. (1987). New business incubators. Journal of Business Venturing, 2(4), 277-284.

Merton, R. K. (1973). The sociology of science: Theoretical and empirical investigations University of Chicago Press.

Mesmer-Magnus, J. R., \& DeChurch, L. A. (2009). Information sharing and team performance: A meta-analysis. Journal of Applied Psychology, 94(2), 535-546.

Mian, S. A. (1994). US university-sponsored technology incubators: An overview of management, policies and performance. Technovation, 14(8), 515-528.

Mian, S. A. (1996). Assessing value-added contributions of university technology business incubators to tenant firms. Research Policy, 25(3), 325-335.

Michael, S. C. (2007). Transaction cost entrepreneurship. Journal of Business Venturing, 22(3), 412-426.

Miles, M., Crispin, S., \& Kasouf, C. (2011). Entrepreneurship's relevance to marketing. Journal of Research in Marketing and Entrepreneurship, 13(2), 126-136.

Minbaeva, D. B. (2007). Knowledge transfer in multinational corporations. Management International Review, 47(4), 567-593.

Mitussis, D., O'Malley, L., \& Patterson, M. (2006). Mapping the re-engagement of CRM with relationship marketing. European Journal of Marketing, 40(5/6), 572589.

Moberg, C. R., \& Speh, T. W. (2003). Evaluating the relationship between questionable business practices and the strength of supply chain relationships. Journal of Business Logistics, 24(2), 1-19.

Mohr, J., \& Spekman, R. (1994). Characteristics of partnership success: Partnership attributes, communication behavior, and conflict resolution techniques. Strategic Management Journal, 15(2), 135-152.

Möller, K. (2006). Marketing mix discussion-Is the mix misleading us or are we misreading the mix? comment on: The marketing mix revisited: Towards the 21st century marketing by E. constantinides. Journal of Marketing Management, 22, 439-450.

Möller, K. (2010). Sense-making and agenda construction in emerging business networks-How to direct radical innovation. Industrial Marketing Management, 39(3), 361-371. 
Möller, K. (2013). Theory map of business marketing: Relationships and networks perspectives. Industrial Marketing Management, 42(3), 324-335.

Möller, K. E., \& Törrönen, P. (2003). Business suppliers' value creation potential: A capability-based analysis. Industrial Marketing Management, 32(2), 109-118.

Möller, K., \& Rajala, A. (2007). Rise of strategic nets-New modes of value creation. Industrial Marketing Management, 36(7), 895-908.

Möller, K., Rajala, A., \& Svahn, S. (2005). Strategic business nets-their type and management. Journal of Business Research, 58(9), 1274-1284.

Möller, K., \& Svahn, S. (2006). Role of knowledge in value creation in business nets. Journal of Management Studies, 43(5), 985-1007.

Morales Gualdrón, S. T. (2008). El emprendedor académico y la decisión de crear spin off: Un análisis del caso español.

Mora-Valentin, E. M., Montoro-Sanchez, A., \& Guerras-Martin, L. A. (2004). Determining factors in the success of $\mathrm{R} \& \mathrm{D}$ cooperative agreements between firms and research organizations. Research Policy, 33(1), 17-40.

Morgan, R. M., \& Hunt, S. (1999). Relationships-based competitive advantage: The role of relationship marketing in marketing strategy. Journal of Business Research, 46(3), 281-290.

Morgan, R. M., \& Hunt, S. D. (1994). The commitment-trust theory of relationship marketing. Journal of Marketing, 58(July), 20-38.

Morrish, S. C., Miles, M. P., \& Deacon, J. H. (2010). Entrepreneurial marketing: Acknowledging the entrepreneur and customer-centric interrelationship. Journal of Strategic Marketing, 18(4), 303-316.

Mosakowski, E. (1991). Organizational boundaries and economic performance: An empirical study of entrepreneurial computer firms. Strategic Management Journal, 12(2), 115-133.

Mosey, S., \& Wright, M. (2007). From human capital to social capital: A longitudinal study of technology-based academic entrepreneurs. Entrepreneurship Theory and Practice, 31(6), 909-935.

Mowery, D. C., Oxley, J. E., \& Silverman, B. S. (1996). Strategic alliances and interfirm knowledge transfer. Strategic Management Journal, 17(Winter Special Issue), 77-91.

Mowery, D. C., Nelson, R. R., Sampat, B. N., \& Ziedonis, A. A. (2001). The growth of patenting and licensing by U.S. universities: An assessment of the effects of the bayh-dole act of 1980. Research Policy, 30(1), 99-119.

Murphy, P. E., Laczniak, G. R., \& Wood, G. (2007). An ethical basis for relationship marketing: A virtue ethics perspective. European Journal of Marketing, 41(1/2), 37-57.

Murray, F. (2004). The role of academic inventors in entrepreneurial firms: Sharing the laboratory life. Research Policy, 33(4), 643-659.

Nadler, J., Thompson, L., \& Boven, L. V. (2003). Learning negotiation skills: Four models of knowledge creation and transfer. Management Science, 49(4), 529-540. 
Nahapiet, J., \& Ghoshal, S. (1998). Social capital, intellectual capital, and the organizational advantage. Academy of Management Review, 23(2), 242-266.

Narayan, D., \& Cassidy, M. F. (2001). A dimensional approach to measuring social capital: Development and validation of a social capital inventory. Current Sociology, 49(2), 59-102.

Narayandas, D., \& Rangan, V. K. (2004). Building and sustaining buyer-seller relationships in mature industrial markets. Journal of Marketing, 68(3), 63-77.

Narin, F., Hamilton, K. S., \& Olivastro, D. (1997). The increasing linkage between US technology and public science. Research Policy, 26(3), 317-330.

Naudé, P., \& Buttle, F. (2000). Assessing relationship quality. Industrial Marketing Management, 29(4), 351-361.

NBIA (National Business Incubator Association). (2009). Business incubation FAQ. Disponible en: http://www.nbia.org/resource_library/faq/index.php.

Ndonzuau, F. N., Pirnay, F., \& Surlemont, B. (2002). A stage model of academic spinoff creation. Technovation, 22(5), 281-289.

Ndubisi, N. O., \& Wah, C. K. (2005). Factorial and discriminant analyses of the underpinnings of relationship marketing and customer satisfaction. International Journal of Bank Marketing, 23(7), 542-557.

Nelson, R. R. (2001). Observations on the post-bayh-dole rise of patenting at american universities. Journal of Technology Transfer, 26(1-2), 13-19.

Newbert, S. L. (2007). Empirical research on the resource-based view of the firm: An assessment and suggestions for future research. Strategic Management Journal, 28(2), 121-146.

Nicholson, C. Y., Compeau, L. D., \& Sethi, R. (2001). The role of interpersonal liking in building trust in long-term channel relationships. Journal of the Academy of Marketing Science, 29(1), 3-15.

Nicolaou, N., Shane, S., Cherkas, L., Hunkin, J., \& Spector, T. D. (2008). Is the tendency to engage in entrepreneurship genetic? Management Science, 54(1), 167179.

Nicolaou, N., Shane, S., Cherkas, L., \& Spector, T. D. (2009). Opportunity recognition and the tendency to be an entrepreneur: A bivariate genetics perspective. Organizational Behavior and Human Decision Processes, 110(2), 108-117.

Nonaka, I. (1991). The knowledge-creating company. Harvard Business Review, 69(6), 96-104.

Nonaka, I. (1994). A dynamic theory of organizational knowledge creation. Organization Science, 5(1), 14-37.

Nonaka, I., \& Takeuchi, H. (1995). The knowledge creating company. New York: Oxford University Press.

Nonaka, I., Von Krogh, G., \& Voelpel, S. (2006). Organizational knowledge creation theory: Evolutionary paths and future advances. Organization Studies, 27(8), 11791208.

North, D. C. (1990). Institutions, institutional change and economic performance. Cambridge, UK: Cambridge University Press. 
Nouira, S., Klofsten, M., \& Lindholm-Dahlstrand, A. (2005). The logic of the entrepreneur: Implications of the entrepreneur's perception of early-stage financing. The International Journal of Entrepreneurship and Innovation, 6(2), 85-96.

O'Cass, A., \& Sok, P. (2013). The role of intellectual resources, product innovation capability, reputational resources and marketing capability combinations in SME growth. International Small Business Journal, 0(0), 1-23.

Olotu, A. O., Maclayton, D. W., \& Opara, B. C. (2010). An empirical study of relationship marketing orientation and bank performance. Research Journal of International Studies, 16(September), 47-57.

O'Neill, B. S., \& Adya, M. (2007). Knowledge sharing and the psychological contract: Managing knowledge workers across different stages of employment. Journal of Managerial Psychology, 22(4), 411-436.

Pache, A., \& Santos, F. (2013). Embedded in hybrid contexts: How individuals in organizations respond to competing institutional logics. In M. Lounsbury, \& E. Boxenbaum (Eds.), Institutional logics in action, part B (research in the sociology of organizations, volume 39 part B) (pp. 3-35). Bingley, UK: Emerald Group Publishing Limited.

Paden, N. L., \& McAlister, R. (1996). Retail credit usage and relationship marketing. Journal of Consumer Marketing, 13(2), 26-35.

Palmatier, R. W., Houston, M. B., Dant, R. P., \& Grewal, D. (2013). Relationship velocity: Toward a theory of relationship dynamics. Journal of Marketing, 77(1), 13-30.

Park, B. R., Srivastava, M. K., \& Gnyawali, D. R. (2014). Walking the tight rope of coopetition: Impact of competition and cooperation intensities and balance on firm innovation performance. Industrial Marketing Management, 43(2), 210-221.

Parmigiani, A., \& Rivera-Santos, M. (2011). Clearing a path through the forest: A metareview of interorganizational relationships. Journal of Management, 37(4), 11081136.

Parolini, C. (1999). The value net: A tool for competitive strategy. Chichester, UK: Wiley \& Sons Ltd.

Partanen, J., Möller, K., Westerlund, M., Rajala, R., \& Rajala, A. (2008). Social capital in the growth of science-and-technology-based SMEs. Industrial Marketing Management, 37(5), 513-522.

Paruchuri, S. (2010). Intraorganizational networks, interorganizational networks, and the impact of central inventors: A longitudinal study of pharmaceutical firms. Organization Science, 21(1), 63-80.

Pateli, A. G. (2009). Decision making on governance of strategic technology alliances. Management Decision, 47(2), 246-270.

Payne, A., \& Holt, S. (1999). A review of the 'value'literature and implications for relationship marketing. Australasian Marketing Journal (AMJ), 7(1), 41-51.

Payne, G. T., Moore, C. B., Griffis, S. E., \& Autry, C. W. (2011). Multilevel challenges and opportunities in social capital research. Journal of Management, 37(2), 491520. 
Penrose, E. (2009). The theory of the growth of the firm (Fourth edition ed.). New York: Oxford University Press.

Pérez, M. P., \& Sánchez, A. M. (2003). The development of university spin-offs: Early dynamics of technology transfer and networking. Technovation, 23(10), 823-831.

Perkmann, M., \& Salter, A. (2012). How to create productive partnerships with universities. MIT Sloan Management Review, 53(4), 79-105.

Peteraf, M. A., \& Barney, J. B. (2003). Unraveling the resource-based tangle. Managerial and Decision Economics, 24(4), 309-323.

Peters, L., Rice, M., \& Sundararajan, M. (2004). The role of incubators in the entrepreneurial process. The Journal of Technology Transfer, 29(1), 83-91.

Pfeffer, J., \& Salancik, G. (1978). The external control of organizations: A resource dependence perspective. New York: Harper \& Row.

Phan, P. H., Siegel, D. S., \& Wright, M. (2005). Science parks and incubators: Observations, synthesis and future research. Journal of Business Venturing, 20(2), 165-182.

Phene, A., Fladmoe-Lindquist, K., \& Marsh, L. (2006). Breakthrough innovations in the US biotechnology industry: The effects of technological space and geographic origin. Strategic Management Journal, 27(4), 369-388.

Pirnay, F., Surlemont, B., \& Nlemvo, F. (2003). Toward a typology of university spinoffs. Small Business Economics, 21(4), 355-369.

Pisano, G. P. (1988). Innovation through markets, hierarchies, and joint ventures: Technology strategy and collaborative arrangements in the biotechnology industry. (Unpublished University of California, Berkeley.

Ploetner, O., \& Ehret, M. (2006). From relationships to partnerships-new forms of cooperation between buyer and seller. Industrial Marketing Management, 35(1), 49.

Plummer, L. A., Haynie, J. M., \& Godesiabois, J. (2007). An essay on the origins of entrepreneurial opportunity. Small Business Economics, 28(4), 363-379.

Podsakoff, P. M., MacKenzie, S. B., Lee, J., \& Podsakoff, N. P. (2003). Common method biases in behavioral research: A critical review of the literature and recommended remedies. Journal of Applied Psychology, 88(5), 879-903.

Polanyi, M. (1966). The tacit dimension. New York: Anchor Day.

Portes, A. (1998). Social capital: Its origins and applications in modern sociology. Annual Review of Sociology, 24, 1-24.

Powell, W. W., Koput, K. W., \& Smith-Doerr, L. (1996). Interorganizational collaboration and the locus of innovation: Networks of learning in biotechnology. Administrative Science Quarterly, 41(1), 116-145.

Powell, W. W., White, D. R., Koput, K. W., \& Owen-Smith, J. (2005). Network dynamics and field evolution: The growth of interorganizational collaboration in the life sciences1. American Journal of Sociology, 110(4), 1132-1205.

Purvis, R. L., Sambamurthy, V., \& Zmud, R. W. (2001). The assimilation of knowledge platforms in organizations: An empirical investigation. Organization Science, 12(2), 117-135. 
Putnam, R. (2000). Bowling alone, the collapse and revival of civic america

Putnam, R. D. (1993). The prosperous community. The American Prospect, 4(13), 3542.

Putnam, R. D. (1995). Bowling alone: America's declining social capital. Journal of Democracy, 6(1), 65-78.

Quintas, P., Wield, D., \& Massey, D. (1992). Academic-industry links and innovation: Questioning the science park model. Technovation, 12(3), 161-175.

Raab, J., \& Kenis, P. (2009). Heading toward a society of networks: Empirical developments and theoretical challenges. Journal of Management Inquiry, 18(3), 198-210.

Radosevich, R. (1995). A model for entrepreneurial spin-offs from public technology sources. International Journal of Technology Management, 10(7/8), 879-893.

Rahman, N., \& Korn, H. J. (2010). Alliance structuring behavior: Relative influence of alliance type and specific alliance experience. Management Decision, 48(5), 809825.

Rashid, T. (2003). Relationship marketing: Case studies of personal experiences of eating out. British Food Journal, 105(10), 742-750.

Ravald, A., \& Grönroos, C. (1996). The value concept and relationship marketing. European Journal of Marketing, 30(2), 19-30.

Reagans, R., \& McEvily, B. (2003). Network structure and knowledge transfer: The effects of cohesion and range. Administrative Science Quarterly, 48(2), 240-267.

Redondo, M., David, F., \& van der Sijde, P. (2014). Development of "business logics" in novice entrepreneurs in an academic incubator. Academic Proceedings of the 2014 University-Industry Interaction Conference: Challenges and Solutions for Fostering Entrepreneurial Universities and Collaborative Innovation, Barcelona. 117-128.

Reich, R. (1991). The work of nations. Londres: Simon \& Schuster.

Renault, C. S. (2006). Academic capitalism and university incentives for faculty entrepreneurship. The Journal of Technology Transfer, 31(2), 227-239.

Reuber, A. R., \& Fischer, E. (1999). Understanding the consequences of founders' experience. Journal of Small Business Management, 37(2), 30-45.

Reynolds, P. D. (1997). Who starts new firms?-Preliminary explorations of firms-ingestation. Small Business Economics, 9(5), 449-462.

Rice, M. P. (2002). Co-production of business assistance in business incubators: An exploratory study. Journal of Business Venturing, 17(2), 163-187.

Riege, A. M. (2003). Validity and reliability tests in case study research: A literature review with "hands-on" applications for each research phase. Qualitative Market Research: An International Journal, 6(2), 75-86.

Rindfleisch, A., \& Heide, J. B. (1997). Transaction cost analysis: Past, present, and future applications. Journal of Marketing, 61(4), 30-54.

Ring, P. S., \& Van de Ven, Andrew H. (1994). Developmental processes of cooperative interorganizational relationships. Academy of Management Review, 19(1), 90-118. 
Ringle, C. M., Wende, S., \& Becker, J. M. (2015). Smart PLS 3 (computer software). Disponible en: www.smartpls.com.

Ritala, P., Golnam, A., \& Wegmann, A. (2014). Coopetition-based business models: The case of amazon.com. Industrial Marketing Management, 43(2), 236-249.

Ritter, T., Wilkinson, I. F., \& Johnston, W. J. (2002). Measuring network competence: Some international evidence. Journal of Business \& Industrial Marketing, 17(2/3), 119-138.

Rivkin, J. W., \& Siggelkow, N. (2003). Balancing search and stability: Interdependencies among elements of organizational design. Management Science, 49(3), 290-311.

Roberts, E. B. (1991). Entrepreneurs in high technology: Lessons from MIT and beyond. Nueva York: Oxford University Press.

Robinson, P. B., Stimpson, D. V., Huefner, J. C., \& Hunt, H. K. (1991). An attitude approach to the prediction of entrepreneurship. Entrepreneurship Theory and Practice, 15(4), 13-31.

Robson, M. J., Katsikeas, C. S., \& Bello, D. C. (2008). Drivers and performance outcomes of trust in international strategic alliances: The role of organizational complexity. Organization Science, 19(4), 647-665.

Rodríguez, C. M., \& Wilson, D. T. (2002). Relationship bonding and trust as a foundation for commitment in US-mexican strategic alliances: A structural equation modeling approach. Journal of International Marketing, 10(4), 53-76.

Rogers, E. M. (1986). The role of the research university in the spin-off of hightechnology companies. Technovation, 4(3), 169-181.

Rosenkopf, L., \& Almeida, P. (2003). Overcoming local search through alliances and mobility. Management Science, 49(6), 751-766.

Rosenkopf, L., \& Padula, G. (2008). Investigating the microstructure of network evolution: Alliance formation in the mobile communications industry. Organization Science, 19(5), 669-687.

Rosenkopf, L., \& Schilling, M. A. (2007). Comparing alliance network structure across industries: Observations and explanations. Strategic Entrepreneurship Journal, 1(34), 191-209.

Rothaermel, F. T., \& Deeds, D. L. (2004). Exploration and exploitation alliances in biotechnology: A system of new product development. Strategic Management Journal, 25(3), 201-221.

Rousseau, D. M., \& Tijoriwala, S. A. (1998). Assessing psychological contracts: Issues, alternatives and measures. Journal of Organizational Behavior, 19(S1), 679-695.

Rubalcaba, L., Gallego, J., \& Hertog, P. D. (2010). The case of market and system failures in services innovation. The Service Industries Journal, 30(4), 549-566.

Rust, R. T., Lemon, K. N., \& Zeithaml, V. A. (2004). Return on marketing: Using customer equity to focus marketing strategy. Journal of Marketing, 68(1), 109-127.

Ryan, R. M., \& Deci, E. L. (2000). Self-determination theory and the facilitation of intrinsic motivation, social development, and well-being. American Psychologist, 55(1), 68-78. 
Sako, M. (1992). Price, quality and trust: Inter-firm relations in britain and japan. Cambridge, UK: Cambridge University Press.

Samaha, S. A., Palmatier, R. W., \& Dant, R. P. (2011). Poisoning relationships: Perceived unfairness in channels of distribution. Journal of Marketing, 75(3), 99117.

Samsom, K. J., \& Gurdon, M. A. (1993). University scientists as entrepreneurs: A special case of technology transfer and high-tech venturing. Technovation, 13(2), 63-71.

Sarkar, M. B., Echambadi, R., Cavusgil, S. T., \& Aulakh, P. S. (2001). The influence of complementarity, compatibility, and relationship capital on alliance performance. Journal of the Academy of Marketing Science, 29(4), 358-373.

Scheirer, M. A. (1985). Innovation and enterprise: A study of NSF's innovation centers program. Rockville, MD: Westat, Inc. and National Science Foundation.

Schoonhoven, C. B., Eisenhardt, K. M., \& Lyman, K. (1990). Speeding products to market: Waiting time to first product introduction in new firms. Administrative Science Quarterly, 35(1), 177-207.

Schumpeter, J. A. (1934). The theory of economic development: An inquiry into profits, capital, credit, interest, and the business cycle Transaction Publishers.

Schutte, F. (1999). The university-industry relations of an entrepreneurial university: The case of the university of twente. Higher Education in Europe, 24(1), 47-65.

Schwartz, M., \& Hornych, C. (2008). Specialization as strategy for business incubators: An assessment of the central german multimedia center. Technovation, 28(7), 436449.

Schwartz, M., \& Hornych, C. (2010). Cooperation patterns of incubator firms and the impact of incubator specialization: Empirical evidence from germany. Technovation, 30(9-10), 485-495.

Scillitoe, J. L., \& Chakrabarti, A. K. (2005). The sources of social capital within technology incubators: The roles of historical ties and organisational facilitation. International Journal of Learning and Intellectual Capital, 2(4), 327-345.

Scillitoe, J. L., \& Chakrabarti, A. K. (2009). A conceptual model of the incubation of new technology-based ventures: A social capital perspective. Review of International Comparative Management, 10(3), 468-482.

Scillitoe, J. L., \& Chakrabarti, A. K. (2010). The role of incubator interactions in assisting new ventures. Technovation, 30(3), 155-167.

Selnes, F., \& Sallis, J. (2003). Promoting relationship learning. Journal of Marketing, 67(3), 80-95.

Senge, P. M. (2006). The fifth discipline: The art and practice of the learning organization (Second edition ed.) Doubleday, a division of Random House Inc.

Shah, J., \& Higgins, E. T. (1997). Expectancy x value effects: Regulatory focus as determinant of magnitude and direction. Journal of Personality and Social Psychology, 73(3), 447-458.

Shane, S. (2001). Technology regimes and new firm formation. Management Science, 47(9), 1173-1190. 
Shane, S. (2010). Born entrepreneurs, born leaders: How your genes affect your work life. Nueva York: Oxford University Press.

Shane, S. A. (2004). Academic entrepreneurship: University spinoffs and wealth creation. Cheltenham, United Kingdom: Edward Elgar Publishing.

Shane, S., \& Khurana, R. (2003). Bringing individuals back in: The effects of career experience on new firm founding. Industrial and Corporate Change, 12(3), 519543.

Shane, S., \& Stuart, T. (2002). Organizational endowments and the performance of university start-ups. Management Science, 48(1), 154-170.

Shane, S., \& Venkataraman, S. (2000). The promise of entrepreneurship as a field of research. Academy of Management Review, 25(1), 217-226.

Sharma, P., \& Chrisman, J. J. (1999). Reconciling the definitional issues in the field of corporate entrepreneurship. Entrepreneurship Theory and Practice, 23(3), 11-27.

Shaw, E. (1998). Social networks: Their impact on the innovative behaviour of small service firms. International Journal of Innovation Management, 2(2), 201-222.

Sherer, S. A. (2003). Critical success factors for manufacturing networks as perceived by network coordinators. Journal of Small Business Management, 41(4), 325-345.

Sherman, H. D. (1999). Assessing the intervention effectiveness of business incubation programs on new business start-ups. Journal of Development Entrepreneurship, 4(2), 117-133.

Siegel, D. S., Waldman, D., \& Link, A. (2003). Assessing the impact of organizational practices on the relative productivity of university technology transfer offices: An exploratory study. Research Policy, 32(1), 27-48.

Siguaw, J. A., Simpson, P. M., \& Baker, T. L. (1998). Effects of supplier market orientation on distributor market orientation and the channel relationship: The distributor perspective. The Journal of Marketing, 62(3), 99-111.

Simonin, B. L. (1997). The importance of collaborative know-how: An empirical test of the learning organization. Academy of Management Journal, 40(5), 1150-1174.

Simonin, B. L. (1999). Ambiguity and the process of knowledge transfer in strategic alliances. Strategic Management Journal, 20(7), 595-623.

Simonin, B. L. (2004). An empirical investigation of the process of knowledge transfer in international strategic alliances. Journal of International Business Studies, 35(September), 407-427.

Simonin, B. L., \& Özsomer, A. (2009). Knowledge processes and learning outcomes in MNCs: An empirical investigation of the role of HRM practices in foreign subsidiaries. Human Resource Management, 48(4), 505-530.

Sin, L. Y., Tse, A. C., Yau, O. H., Chow, R. P., Lee, J. S., \& Lau, L. B. (2005). Relationship marketing orientation: Scale development and cross-cultural validation. Journal of Business Research, 58(2), 185-194.

Sin, Y. M. L., Tse, C. B. A., Yau, H. M. O., Lee, S. Y. J., \& Chow, R. (2002). The effect of relationship marketing orientation on business performance in a service oriented economy. Journal of Services Marketing, 16(7), 656-676. 
Singh, J., \& Sirdeshmukh, D. (2000). Agency and trust mechanisms in consumer satisfaction and loyalty judgments. Journal of the Academy of Marketing Science, 28(1), 150-167.

Singh, J. (2005). Collaborative networks as determinants of knowledge diffusion patterns. Management Science, 51(5), 756-770.

Sirmon, D. G., Gove, S., \& Hitt, M. A. (2008). Resource management in dyadic competitive rivalry: The effects of resource bundling and deployment. Academy of Management Journal, 51(5), 919-935.

Sirmon, D. G., Hitt, M. A., \& Ireland, R. D. (2007). Managing firm resources in dynamic environments to create value: Looking inside the black box. Academy of Management Review, 32(1), 273-292.

Slotegraaf, R. J., Moorman, C., \& Inman, J. J. (2003). The role of firm resources in returns to market deployment. Journal of Marketing Research, 40(3), 295-309.

Slotte-Kock, S., \& Coviello, N. (2010). Entrepreneurship research on network processes: A review and ways forward. Entrepreneurship Theory and Practice, 34(1), 31-57.

Smeltzer, L. R., Van Hook, B. L., \& Hutt, R. W. (1991). Analysis of the use of advisers as information sources in venture startups. Journal of Small Business Management, 29(3), 10-20.

Smilor, R. W., \& Gill, M. D. J. (1986). The new business incubator: Linking talent, technology, capital, and know-how. Toronto: Lexington Books.

Somsuk, N., \& Laosirihongthong, T. (2014). A fuzzy AHP to prioritize enabling factors for strategic management of university business incubators: Resource-based view. Technological Forecasting and Social Change, 85, 198-210.

Song, J., Almeida, P., \& Wu, G. (2003). Learning-by-Hiring: When is mobility more likely to facilitate interfirm knowledge transfer? Management Science, 49(4), 351365.

Spender, J. (1996). Making knowledge the basis of a dynamic theory of the firm. Strategic Management Journal, 17(Special Issue: Knowledge and the Firm (Winter)), 45-62.

Spender, J., \& Grant, R. M. (1996). Knowledge and the firm: Overview. Strategic Management Journal, 17(Suppl. Winter), 5-9.

Srivastava, M. K., \& Gnyawali, D. R. (2011). When do relational resources matter? leveraging portfolio technological resources for breakthrough innovation. Academy of Management Journal, 54(4), 797-810.

Stankiewicz, R. (1994). Spin-off companies from universities. Science and Public Policy, 21(2), 99-107.

Steensma, H. K., \& Corley, K. G. (2000). On the performance of technology-sourcing partnerships: The interaction between partner interdependence and technology attributes. Academy of Management Journal, 43(6), 1045-1067.

Stephan, P. E. (1996). The economics of science. Journal of Economic Literature, 34(3), 1199-1235. 
Sternberg, R. (2004). Technology centres in germany: Economic justification, effectiveness and impact on high-tech regions. International Journal of Technology Management, 28(3), 444-469.

Stiglitz, J. E. (2000). Formal and informal institutions. In P. Dasgupta, \& I. Serageldin (Eds.), Social capital: A multifaceted perspective (pp. 59-68). Washington, DC: The World Bank.

Stone, W., \& Hughes, J. (2002). Empirical meaning and measurement validity. (Research Paper No. 27). Melbourne, Australia: Australian Institute of Family Studies.

Stuart, T. E., \& Ding, W. W. (2006). When do scientists become entrepreneurs? the social structural antecedents of commercial activity in the academic life sciences. American Journal of Sociology, 112(1), 97-144.

Studdard, N. L. (2006). The effectiveness of entrepreneurial firm's knowledge acquisition from a business incubator. International Entrepreneurship and Management Journal, 2(2), 211-225.

Sundbo, J. (2009). Innovation in the experience economy: A taxonomy of innovation organisations. The Service Industries Journal, 29(4), 431-455.

Szulanski, G. (1996). Exploring internal stickiness: Impediments to the transfer of best practice within the firm. Strategic Management Journal, 17(Winter Special Issue), 27-43.

Szulanski, G. (2000). The process of knowledge transfer: A diachronic analysis of stickiness. Organizational Behavior and Human Decision Processes, 82(1), 9-27.

Szulanski, G., Cappetta, R., \& Jensen, R. J. (2004). When and how trustworthiness matters: Knowledge transfer and the moderating effect of causal ambiguity. Organization Science, 15(5), 600-613.

Tamásy, C. (2002). Are there too many innovation centres in germany? Technological change and regional development in europe (pp. 112-131) Springer.

Teece, D. J. (1986). Profiting from technological innovation: Implications for integration, collaboration, licensing and public policy. Research Policy, 15(6), 285305.

Temali, M., \& Campbell, C. (1984). Business incubator profiles: A national survey Hubert H. Humphrey Institute.

Teng, B., \& Das, T. (2008). Governance structure choice in strategic alliances: The roles of alliance objectives, alliance management experience, and international partners. Management Decision, 46(5), 725-742.

Teo, T. S. H., Srivastava, S. C., \& Jiang, L. (2008). Trust and electronic government success: An empirical study. Journal of Management Information Systems, 25(3), 99-132.

Theodorakopoulos, N., K. Kakabadse, N., \& McGowan, C. (2014). What matters in business incubation? A literature review and a suggestion for situated theorising. Journal of Small Business and Enterprise Development, 21(4), 602-622.

Thornton, P. H. (2002). The rise of the corporation in a craft industry: Conflict and conformity in institutional logics. Academy of Management Journal, 45(1), 81-101. 
Thornton, P. H., \& Ocasio, W. (1999). Institutional logics and the historical contingency of power in organizations: Executive succession in the higher education publishing industry, 1958-1990. American Journal of Sociology, 105(3), 801-843.

Toivonen, M., \& Tuominen, T. (2009). Emergence of innovations in services. The Service Industries Journal, 29(7), 887-902.

Tomkins, C. (2001). Interdependencies, trust and information in relationships, alliances and networks. Accounting, Organizations and Society, 26(2), 161-191.

Tötterman, H., \& Sten, J. (2005). Start-ups business incubation and social capital. International Small Business Journal, 23(5), 487-511.

Trigilia, C. (2003). Capital social y desarrollo local. In Bagnasco et al. (Ed.), El capital social. instrucciones de uso. Buenos Aires, Argentina: Fondo de Cultura Económica.

Tripp, C. (2013). No empathy-No service. Design Management Review, 24(3), 58-64.

Tsai, W., \& Ghoshal, S. (1998). Social capital and value creation: The role of intrafirm networks. Academy of Management Journal, 41(4), 464-476.

Tsai, W. (2001). Knowledge transfer in intra-organizational networks: Effects of network position and absorptive capacity on business unit innovation and performance. Academy of Management Journal, 44(5), 996-1004.

Ucbasaran, D., Lockett, A., Wright, M., \& Westhead, P. (2003). Entrepreneurial founder teams: Factors associated with member entry and exit. Entrepreneurship Theory and Practice, 28(2), 107-128.

Udell, G. G. (1990). Are business incubators really creating new jobs by creating new business and new products. Journal of Product Innovation Management, 7(2), 108122.

UKBI (UK Business Incubation). (2012). Best practice in business incubation. (Business Incubation). Birmingham:

Un, C. A., Cuervo-Cazurra, A., \& Asakawa, K. (2010). R\&D collaborations and product innovation. Journal of Product Innovation Management, 27(5), 673-689.

USINE, University Start-up of International Entrepreneurs. (2002). The pre-incubation approach. Disponible en: http://www.usine.uni-bonn.de.

Uzzi, B. (1996). The sources and consequences of embeddedness for the economic performance of organizations: The network effect. American Sociological Review, 61(4), 674-698.

Uzzi, B. (1997). Social structure and competition in interfirm networks: The paradox of embeddedness. Administrative Science Quarterly, 42(1), 35-67.

Vaccaro, A., Parente, R., \& Veloso, F. M. (2010). Knowledge management tools, interorganizational relationships, innovation and firm performance. Technological Forecasting and Social Change, 77(7), 1076-1089.

Van de Ven, Andrew H, \& Ferry, D. L. (1980). Measuring and assessing organizations. New York: John Wiley \& Sons. 
van de Vrande, V., Vanhaverbeke, W., \& Duysters, G. (2011). Technology in-sourcing and the creation of pioneering technologies. Journal of Product Innovation Management, 28(6), 974-987.

van den Hooff, B., \& de Leeuw van Weenen, F. (2004). Committed to share: Commitment and CMC use as antecedents of knowledge sharing. Knowledge and Process Management, 11(1), 13-24.

van der Sijde, P., David, F., Frederik, H., \& Carretero, M. R. (2014). Universitybusiness cooperation: A tale of two logics. In T. Kliewe, \& T. Kesting (Eds.), Moderne konzepte des organisationalen marketing (pp. 145-160). Alphen aan den Rijn: Springer.

van Wijk, R., Jansen, J. J., \& Lyles, M. A. (2008). Inter-and Intra-Organizational knowledge transfer: A Meta-Analytic review and assessment of its antecedents and consequences. Journal of Management Studies, 45(4), 830-853.

Vanderstraeten, J., \& Matthyssens, P. (2012). Service-based differentiation strategies for business incubators: Exploring external and internal alignment. Technovation, 32(12), 656-670.

Vanhaverbeke, W., Beerkens, B., Gilsing, V., \& Duysters, G. (2006). Exploration and exploitation in technology-based alliance networks. (UNU-MERIT Working Papers). Maastricht, the Netherlands: United Nations University - Maastricht Economic and social Research and training centre on Innovation and Technology.

Vargas Forero, G. (2002). Hacia una teoría del capital social. Revista De Economía Institucional, 4(6), 71-108.

Veciana, J. M. (2007). Entrepreneurship as a scientific research programme. In A. Cuervo, D. Ribeiro, \& S. Roig (Eds.) (Ed.), Entrepreneurship: Concepts, theory and perspective (pp. 23-71). Heidelberg: Springer.

Veciana, J. M. (1999). Creación de empresas como programa de investigación científica. Revista Europea De Dirección y Economía De La Empresa, 8(3), 11-36.

Vedel, B., \& Gabarret, I. (2014). The role of trust as mediator between contract, information and knowledge within business incubators. International Journal of Entrepreneurship and Small Business, 23(4), 509-527.

Venkataraman, S. (1997). The distinctive domain of entrepreneurship research. Advances in Entrepreneurship, Firm Emergence and Growth, 3(1), 119-138.

Vesper, K. H., \& Crosswhite, J. (1983). Faculty start-ups from schools without entrepreneurship courses. Proceedings of the 1983 Conference on Entrepreneurship at Babson College, 72-95.

Vohora, A., Wright, M., \& Lockett, A. (2004). Critical junctures in the development of university high-tech spinout companies. Research Policy, 33(1), 147-175.

Voisey, P., Jones, P., \& Thomas, B. (2013). The pre-incubator: A longitudinal study of 10 years of university pre-incubation in wales. Industry and Higher Education, 27(5), 349-363.

Von Krogh, G., Roos, J., \& Slocum, K. (1994). An essay on corporate epistemology. Strategic Management Journal, 15(Summer Special Issue), 53-71.

von Raesfeld, A., Geurts, P., Jansen, M., Boshuizen, J., \& Luttge, R. (2012). Influence of partner diversity on collaborative public R\&D project outcomes: A study of 
application and commercialization of nanotechnologies in the netherlands. Technovation, 32(3), 227-233.

von Zedtwitz, M. (2003). Classification and management of incubators: Aligning strategic objectives and competitive scope for new business facilitation. International Journal of Entrepreneurship and Innovation Management, 3(1), 176196.

Vorhies, D. W., \& Morgan, N. A. (2005). Benchmarking marketing capabilities for sustainable competitive advantage. Journal of Marketing, 69(1), 80-94.

Voss, C., Tsikriktsis, N., \& Frohlich, M. (2002). Case research in operations management. International Journal of Operations \& Production Management, 22(2), 195-219.

Wallace, S. L. (1999). Social entrepreneurship: The role of social purpose enterprises in facilitating community economic development. Journal of Developmental Entrepreneurship, 4(2), 153-174.

Wang, C. L. (2007). Guanxi vs. relationship marketing: Exploring underlying differences. Industrial Marketing Management, 36(1), 81-86.

Wang, Z., \& Wang, N. (2012). Knowledge sharing, innovation and firm performance. Expert Systems with Applications, 39(10), 8899-8908.

Wasko, M. M., \& Faraj, S. (2005). Why should I share? examining social capital and knowledge contribution in electronic networks of practice. MIS Quarterly, 29(1), 35-57.

Wathne, K. H., \& Heide, J. B. (2004). Relationship governance in a supply chain network. Journal of Marketing, 68(1), 73-89.

Webb, J. W., Ireland, R. D., Hitt, M. A., Kistruck, G. M., \& Tihanyi, L. (2011). Where is the opportunity without the customer? an integration of marketing activities, the entrepreneurship process, and institutional theory. Journal of the Academy of Marketing Science, 39(4), 537-554.

Weick, K. E. (1993). The collapse of sensemaking in organizations: The mann gulch disaster. Administrative Science Quarterly, 38(4), 628-652.

Weick, K. E., \& Roberts, K. H. (1993). Collective mind in organizations: Heedful interrelating on flight decks. Administrative Science Quarterly, 38, 357-381.

Weitz, B. A., \& Jap, S. D. (1995). Relationship marketing and distribution channels. Journal of the Academy of Marketing Science, 23(4), 305-320.

Westhead, P., \& Wright, M. (1998). Novice, portfolio, and serial founders: Are they different? Journal of Business Venturing, 13(3), 173-204.

Wiersema, M. F., \& Bantel, K. A. (1992). Top management team demography and corporate strategic change. Academy of Management Journal, 35(1), 91-121.

Wilken, P. H. (1979). Entrepreneurship: A comparative and historical study. Norwood, NJ: Ablex Publishing Corporation.

Wilkinson, I. F., \& Young, L. C. (1994). Business dancing-the nature and role of interfirm relations in business strategy. Asia-Australia Marketing Journal (Continued as Australasian Marketing Journal), 2(1), 67-79. 
Williamson, O. E. (1979). Transaction cost economics: The governance of contractual relations. Journal of Law and Economics, 22, 233-261.

Williamson, O. E. (1985). The economic institutions of capitalism. New York: Free Press.

Williamson, O. E. (2000). The new institutional economics: Taking stock, looking ahead. Journal of Economic Literature, 38(3), 595-613.

Williamson, O., \& Ghani, T. (2012). Transaction cost economics and its uses in marketing. Journal of the Academy of Marketing Science, 40(1), 74-85.

Williamson, O. E. (1975). Markets and hierarchies: Analysis and antitrust implications. New York: Free Press.

Wilson, D. T., \& Jantrania, S. (1994). Understanding the value of a relationship. AsiaAustralia Marketing Journal (Continued as Australasian Marketing Journal), 2(1), 55-66.

Wilson, E. J., \& Vlosky, R. P. (1997). Partnering relationship activities: Building theory from case study research. Journal of Business Research, 39(1), 59-70.

Wissema, J. G. (2009). Towards the third generation university: Managing the university in transition. Higher Education Quarterly, 64(2), 216-225.

Wittmann, C. M., Hunt, S. D., \& Arnett, D. B. (2009). Explaining alliance success: Competences, resources, relational factors, and resource-advantage theory. Industrial Marketing Management, 38(7), 743-756.

Woolcock, M. (1998). Social capital and economic development: Toward a theoretical synthesis and policy framework. Theory and Society, 27(2), 151-208.

Woolthuis, R. K., Hillebrand, B., \& Nooteboom, B. (2005). Trust, contract and relationship development. Organization Studies, 26(6), 813-840.

Wright, M., Clarysse, B., Mustar, P., \& Lockett, A. (2007). Academic entrepreneurship in europe Edward Elgar Publishing.

Wulung, R. S., Takahashi, K., \& Morikawa, K. (2014). An interactive multi-objective incubatee selection model incorporating incubator manager orientation. Operational Research, 14(3), 409-438.

Yin, R. K. (2009). Case study research: Design and methods (4nd Ed. ed.). Los Angeles: Sage.

Yli-Renko, H., Autio, E., \& Sapienza, H. J. (2001). Social capital, knowledge acquisition, and knowledge exploitation in young technology-based firms. Strategic Management Journal, 22(6-7), 587-613.

Yli-Renko, H., Autio, E., \& Tontti, V. (2002). Social capital, knowledge, and the international growth of technology-based new firms. International Business Review, 11(3), 279-304.

Young-Ybarra, C., \& Wiersema, M. (1999). Strategic flexibility in information technology alliances: The influence of transaction cost economics and social exchange theory. Organization Science, 10(4), 439-459.

Zaheer, A., \& George, V. P. (2004). Reach out or reach within? performance implications of alliances and location in biotechnology. Managerial and Decision Economics, 25(6-7), 437-452. 
Zaheer, A., McEvily, B., \& Perrone, V. (1998). Does trust matter? exploring the effects of interorganizational and interpersonal trust on performance. Organization Science, 9(2), 141-159.

Zahra, S. A., Ireland, R. D., \& Hitt, M. A. (2000). International expansion by new venture firms: International diversity, mode of market entry, technological learning, and performance. Academy of Management Journal, 43(5), 925-950.

Zander, U., \& Kogut, B. (1995). Knowledge and the speed of the transfer and imitation of organizational capabilities: An empirical test. Organization Science, 6(1), 76-92.

Zhang, X., Chen, Z., Vogel, D., Yuan, M., \& Guo, C. (2010). Knowledge-sharing reward dynamics in knowledge management systems: Game theory-based empirical validation. Human Factors and Ergonomics in Manufacturing \& Service Industries, 20(2), 103-122.

Zhao, L., \& Aram, J. D. (1995). Networking and growth of young technology-intensive ventures in china. Journal of Business Venturing, 10(5), 349-370.

Zott, C. (2003). Dynamic capabilities and the emergence of intraindustry differential firm performance: Insights from a simulation study. Strategic Management Journal, 24(2), 97-125.

Zucker, L. G., Darby, M. R., \& Armstrong, J. S. (2002). Commercializing knowledge: University science, knowledge capture, and firm performance in biotechnology. Management Science, 48(1), 138-153. 


\section{Anexo I: Cuestionario para incubados (versión en español)}



CUESTIONARIO INCUBACIÓN

Incubadora:

País:

$\mathrm{N}^{\circ}$ de meses que lleva en incubación:

Estatus: $\square$ Profesor Tipo: $\square$ Asociado $\square$ Ayudante $\square$ Ayudante doctor $\square$ Contratado doctor $\square$ Titular $\square$ Catedrático
$\square$ Investigador
$\square$ Becario
$\square$ Estudiante
$\square$ Otro:

Área de conocimiento: $\square$ Ciencias $\square$ Ciencias de la salud $\square$ Ciencias sociales y jurídicas $\square$ Ingeniería y arquitectura $\square$ Arte y humanidades ¿Ha estado en pre-incubación? $\square$ No

$\square$ Sí ¿En qué grado mantiene contacto con emprendedores que conoció en pre-incubación?

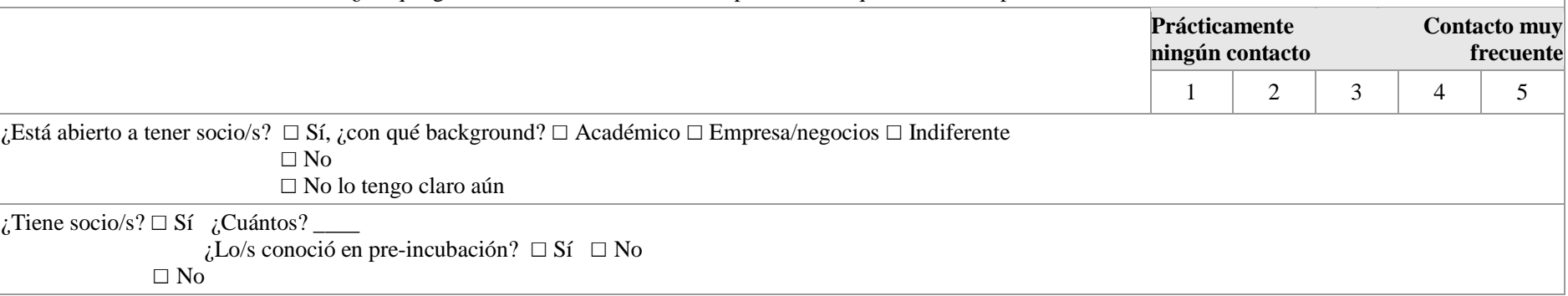

\section{Elija UNA relación, interacción o contacto profesional que haya mantenido o mantenga con OTRO EMPRENDEDOR EN EL PROCESO DE} INCUBACIÓN y responda a las siguientes preguntas.

\begin{tabular}{|c|c|c|c|c|c|}
\hline \multirow{2}{*}{$\begin{array}{l}\text { Este emprendedor: } \\
\text { Tiene recursos diferentes a los míos que son muy valiosos para mi }\end{array}$} & \multicolumn{3}{|c|}{$\begin{array}{l}\text { Totalmente en } \\
\text { desacuerdo }\end{array}$} & \multicolumn{2}{|c|}{$\begin{array}{r}\text { Totalmente } \\
\text { de acuerdo }\end{array}$} \\
\hline & 1 & 2 & 3 & 4 & 5 \\
\hline Tiene recursos que son diferentes y complementarios a los míos & 1 & 2 & 3 & 4 & 5 \\
\hline Sus recursos son necesarios para conseguir mis objetivos & 1 & 2 & 3 & 4 & 5 \\
\hline Sus recursos, al combinarse con los míos, me permiten alcanzar resultados más satisfactorios & 1 & 2 & 3 & 4 & 5 \\
\hline Tiene recursos similares a los míos pero que son muy valiosos para mi & 1 & 2 & 3 & 4 & 5 \\
\hline Tiene recursos que son similares, pero suplementarios a los míos & 1 & 2 & 3 & 4 & 5 \\
\hline Sus recursos son similares a los míos y la combinación de ambos me permite alcanzar resultados más satisfactorios & 1 & 2 & 3 & 4 & 5 \\
\hline Sus valores y normas de conducta son congruentes con los míos & 1 & 2 & 3 & 4 & 5 \\
\hline Su filosofía/enfoque para los negocios es compatible con la mía & 1 & 2 & 3 & 4 & 5 \\
\hline Sus metas y objetivos son compatibles con los míos & 1 & 2 & 3 & 4 & 5 \\
\hline Es honesto y sincero & 1 & 2 & 3 & 4 & 5 \\
\hline La información que intercambia conmigo es fiable & 1 & 2 & 3 & 4 & 5 \\
\hline Me comunica con sinceridad cualquier problema que pueda afectarme & 1 & 2 & 3 & 4 & 5 \\
\hline Está dispuesto a ofrecer asistencia y ayuda cuando las circunstancias lo requieren & 1 & 2 & 3 & 4 & 5 \\
\hline Creo que actúa en mi mejor interés & 1 & 2 & 3 & 4 & 5 \\
\hline En general, es una persona que mantiene sus compromisos & 1 & 2 & 3 & 4 & 5 \\
\hline Es competente y eficaz & 1 & 2 & 3 & 4 & 5 \\
\hline Está comprometido en compartir ideas y conocimiento conmigo & 1 & 2 & 3 & 4 & 5 \\
\hline Tiene la voluntad de que nuestra relación se fortalezca con el tiempo & 1 & 2 & 3 & 4 & 5 \\
\hline Tiene la voluntad de que nuestra relación continúe durante mucho tiempo & 1 & 2 & 3 & 4 & 5 \\
\hline Evalúe las siguientes afirmaciones: & $\begin{array}{l}\text { Total } \\
\text { desac }\end{array}$ & & & & $\begin{array}{l}\text { mente } \\
\text { uerdo }\end{array}$ \\
\hline Tengo intención de que nuestra relación se fortalezca con el tiempo & 1 & 2 & 3 & 4 & 5 \\
\hline Tengo intención de que nuestra relación continúe durante mucho tiempo & 1 & 2 & 3 & 4 & 5 \\
\hline Estoy comprometido en compartir ideas y conocimiento con él & 1 & 2 & 3 & 4 & 5 \\
\hline
\end{tabular}


La colaboración con este emprendedor es un medio efectivo de aprendizaje

Colaborar con este emprendedor es una sabia decisión

\begin{tabular}{l|l|l|l|l}
1 & 2 & 3 & 4 & 5 \\
\hline 1 & 2 & 3 & 4 & 5
\end{tabular}

\section{En relación a mis conocimientos o formación aplicados al negocio que he puesto en marcha ...}

El conocimiento (técnico-científico) que tengo es fácil de transferir

La asociación entre causas y efectos, entradas y salidas, y las acciones y los resultados relacionados con el conocimiento que tengo es claro

Mi conocimiento es más explícito que tácito

Tengo procedimientos y rutinas para restringir el intercambio de información pertinente sobre mi conocimiento

Soy muy protector con mi conocimiento

Evalúe las siguientes afirmaciones sobre este emprendedor:

El conocimiento (técnico-científico) que tiene es fácil de transferir

La asociación entre causas y efectos, entradas y salidas, y las acciones y los resultados relacionados con el conocimiento que tiene es claro

Su conocimiento es más explícito que tácito

Tiene procedimientos y rutinas para restringir el intercambio de información pertinente sobre su conocimiento

Es muy protector con su conocimiento

\begin{tabular}{|l|l|l|l|l|}
\hline 1 & 2 & 3 & 4 & 5 \\
\hline 1 & 2 & 3 & 4 & 5 \\
\hline 1 & 2 & 3 & 4 & 5 \\
\hline 1 & 2 & 3 & 4 & 5 \\
\hline 1 & 2 & 3 & 4 & 5 \\
\hline
\end{tabular}

es ming prector con su conocimiento

\section{En nuestra relación...}

d

Nos solicitamos consejos y recomendaciones

Compartimos todo tipo de información

Nos proporcionamos cualquier información que pueda ser útil a la otra parte

Cada parte informa a la otra de los acontecimientos que le puedan afectar

Trabajamos juntos con frecuencia

Con frecuencia estamos en contacto

La relación con este emprendedor me ha permitido...

Totalmente en

desacuerdo

Estar más comprometido con mis metas empresariales

Ser más exigente con mis objetivos empresariales

Ser más ambicioso con mis objetivos empresariales

\section{La relación con este emprendedor me ha permitido que mi negocio}

Sea más innovador en cuanto a productos o servicios

Pueda llegar a un mercado más amplio

Sea más factible en su desarrollo

\section{En el futuro, creo que la relación con este emprendedor favorecerá...}

La generación de innovación

Nuevos productos/servicios

Por medio de este emprendedor...

Tengo acceso a conocimientos sobre el mercado
Totalmente en

desacuerdo desacuerdo

\begin{tabular}{|c|c|c|c|c|}
$\begin{array}{l}\text { Totalmente en } \\
\text { desacuerdo }\end{array}$ & \multicolumn{2}{|r|}{$\begin{array}{r}\text { Totalmente } \\
\text { de acuerdo }\end{array}$} \\
\hline 1 & 2 & 3 & 4 & 5 \\
\hline 1 & 2 & 3 & 4 & 5 \\
\hline 1 & 2 & 3 & 4 & 5 \\
\hline 1 & 2 & 3 & 4 & 5 \\
\hline 1 & 2 & 3 & 4 & 5 \\
\hline 1 & 2 & 3 & 4 & 5 \\
\hline
\end{tabular}

Totalmente de acuerdo

\begin{tabular}{|l|l|l|l|l|}
\hline 1 & 2 & 3 & 4 & 5 \\
\hline 1 & 2 & 3 & 4 & 5 \\
\hline 1 & 2 & 3 & 4 & 5 \\
\hline
\end{tabular}

Totalmente

de acuerdo

desacuerdo

\begin{tabular}{|l|l|l|l|l|}
\hline 1 & 2 & 3 & 4 & 5 \\
\hline 1 & 2 & 3 & 4 & 5 \\
\hline 1 & 2 & 3 & 4 & 5 \\
\hline
\end{tabular}

Totalmente

de acuerdo

\begin{tabular}{|c|c|c|c|c|}
\multicolumn{2}{|c|}{ desacuerdo } & \multicolumn{3}{|r}{ de acuerdo } \\
\hline 1 & 2 & 3 & 4 & 5 \\
\hline 1 & 2 & 3 & 4 & 5 \\
\hline
\end{tabular}

Totalmente de acuerdo 
Obtengo conocimientos técnicos y un importante volumen de saber hacer

Aprendo de su conocimiento

Aprendo de su experiencia

Asimilo el conocimiento que me facilita, el cual contribuye al desarrollo de mi start-up

\begin{tabular}{|l|l|l|l|l|}
\hline 1 & 2 & 3 & 4 & 5 \\
\hline 1 & 2 & 3 & 4 & 5 \\
\hline 1 & 2 & 3 & 4 & 5 \\
\hline 1 & 2 & 3 & 4 & 5 \\
\hline
\end{tabular}

\begin{tabular}{|c|c|c|c|c|c|}
\hline \multirow{2}{*}{$\begin{array}{l}\text { A través de mi, el otro emprendedor... } \\
\text { Tiene acceso a conocimientos sobre el mercado }\end{array}$} & \multicolumn{3}{|c|}{$\begin{array}{l}\text { Totalmente en } \\
\text { desacuerdo }\end{array}$} & \multicolumn{2}{|c|}{$\begin{array}{l}\text { Totalmente } \\
\text { de acuerdo }\end{array}$} \\
\hline & 1 & 2 & 3 & 4 & 5 \\
\hline Obtiene conocimientos técnicos y un importante volumen de saber hacer & 1 & 2 & 3 & 4 & 5 \\
\hline Aprende de mi conocimiento & 1 & 2 & 3 & 4 & 5 \\
\hline Aprende de mi experiencia & 1 & 2 & 3 & 4 & 5 \\
\hline Asimila el conocimiento que le facilito, el cual contribuye al desarrollo de su start-up & 1 & 2 & 3 & 4 & 5 \\
\hline Valore el grado en el cual la relación ha influido en los siguientes aspectos: & \multicolumn{3}{|c|}{$\begin{array}{l}\text { Totalmente en } \\
\text { desacuerdo }\end{array}$} & \multicolumn{2}{|c|}{$\begin{array}{l}\text { Totalmente } \\
\text { de acuerdo }\end{array}$} \\
\hline Incremento en las ventas & 1 & 2 & 3 & 4 & 5 \\
\hline Generación de nuevas oportunidades de mercado & 1 & 2 & 3 & 4 & 5 \\
\hline Generación de beneficios & 1 & 2 & 3 & 4 & 5 \\
\hline
\end{tabular}

En la incubadora, ¿tiene un COACH asignado? $\square$ Sí, ¿de qué tipo? $\square$ Único para mi $\square$ Común para un grupo, ¿de cuántos?

\begin{tabular}{|c|c|c|c|c|c|}
\hline \multirow{2}{*}{$\begin{array}{l}\text { En caso afirmativo, considere la relación o interacción profesional que mantenga con el COACH y responda a las } \\
\text { siguientes preguntas: } \\
\text { Nos tratamos de manera frecuente }\end{array}$} & \multicolumn{3}{|c|}{$\begin{array}{l}\text { Totalmente en } \\
\text { desacuerdo }\end{array}$} & \multicolumn{2}{|c|}{$\begin{array}{r}\text { Totalmente } \\
\text { de acuerdo }\end{array}$} \\
\hline & 1 & 2 & 3 & 4 & 5 \\
\hline Es honesto y sincero & 1 & 2 & 3 & 4 & 5 \\
\hline La información que intercambia conmigo es fiable & 1 & 2 & 3 & 4 & 5 \\
\hline Me ayuda compartiendo su conocimiento y experiencia & 1 & 2 & 3 & 4 & 5 \\
\hline Me incentiva a hacer contactos con otros emprendedores & 1 & 2 & 3 & 4 & 5 \\
\hline Creo que actúa en mi mejor interés & 1 & 2 & 3 & 4 & 5 \\
\hline Si necesito ayuda, hará lo posible por ayudarme & 1 & 2 & 3 & 4 & 5 \\
\hline En general, es una persona que mantiene sus compromisos & 1 & 2 & 3 & 4 & 5 \\
\hline Es competente y eficaz en la prestación de asesoramiento & 1 & 2 & 3 & 4 & 5 \\
\hline Ejerce su función de coach muy bien & 1 & 2 & 3 & 4 & 5 \\
\hline Me anima a transferir conocimiento & 1 & 2 & 3 & 4 & 5 \\
\hline Tiene experiencia en el mundo de los negocios & 1 & 2 & 3 & 4 & 5 \\
\hline Tiene experiencia en el mundo de la ciencia & 1 & 2 & 3 & 4 & 5 \\
\hline
\end{tabular}

Piense en el MANAGER de la incubadora y valore su grado de acuerdo o desacuerdo con cada de una de las siguientes afirmaciones:

\begin{tabular}{|c|c|c|c|c|c|}
\hline \multirow[b]{2}{*}{ Considero que favorece los contactos entre los emprendedores } & \multicolumn{3}{|c|}{$\begin{array}{l}\text { Totalmente en } \\
\text { desacuerdo }\end{array}$} & \multicolumn{2}{|c|}{$\begin{array}{r}\text { Totalmente } \\
\text { de acuerdo }\end{array}$} \\
\hline & 1 & 2 & 3 & 4 & 5 \\
\hline Trata de establecer lazos entre emprendedores que pueden llegar a colaborar & 1 & 2 & 3 & 4 & 5 \\
\hline Facilita el networking entre todos los emprendedores & 1 & 2 & 3 & 4 & 5 \\
\hline Facilita contactos fuera de la incubadora & 1 & 2 & 3 & 4 & 5 \\
\hline
\end{tabular}


En el tiempo que llevo en incubación he conseguido:

Totalmente en

desacuerdo

Ser más eficiente en la planificación y en la estrategia de mi negocio

Ser más eficiente en la gestión de mi negocio

Ser más eficiente en la implementación de las actividades propias de mi negocio

Desarrollar habilidades sociales para el mundo de los negocios

Incrementar mi red de contactos de negocios

\begin{tabular}{|c|c|c|c|c|}
\multicolumn{2}{|c|}{ desacuerdo } & \multicolumn{2}{|r}{ de acuerdo } \\
\hline 1 & 2 & 3 & 4 & 5 \\
\hline 1 & 2 & 3 & 4 & 5 \\
\hline 1 & 2 & 3 & 4 & 5 \\
\hline 1 & 2 & 3 & 4 & 5 \\
\hline
\end{tabular}

\section{Los emprendedores que están aquí en incubación:}

Usan un lenguaje y una jerga similar a la mía

Usan un patrón de comunicación comprensible

Comparten intereses similares a los míos

Son personas con cuyos intereses me puedo identificar

No podrían aprovecharse de los demás, incluso cuando se presenta la oportunidad

Siempre cumplen sus promesas

Se comportan de una manera consistente y honesta

Son leales en el trato con los demás

\begin{tabular}{|c|c|c|c|c|}
\hline \multicolumn{3}{|c|}{$\begin{array}{l}\text { Totalmente en } \\
\text { desacuerdo }\end{array}$} & \multicolumn{2}{|c|}{$\begin{array}{r}\text { Totalmente } \\
\text { de acuerdo }\end{array}$} \\
\hline 1 & 2 & 3 & 4 & 5 \\
\hline 1 & 2 & 3 & 4 & 5 \\
\hline 1 & 2 & 3 & 4 & 5 \\
\hline 1 & 2 & 3 & 4 & 5 \\
\hline 1 & 2 & 3 & 4 & 5 \\
\hline 1 & 2 & 3 & 4 & 5 \\
\hline 1 & 2 & 3 & 4 & 5 \\
\hline 1 & 2 & 3 & 4 & 5 \\
\hline
\end{tabular}

\section{Enfoque sobre su perfil}

\section{La siguiente serie de preguntas se refieren a eventos específicos de su vida.}

Comparado con las demás personas, ¿no le es posible obtener lo que quiere en su vida?

Al crecer, ¿alguna vez “cruzó la línea” haciendo cosas que sus padres no toleraban?

¿Frecuentemente sacó de sus casillas a sus padres cuando crecía?

¿Con qué frecuencia obedecía las reglas establecidas por sus padres?

$\mathrm{Al}$ crecer, ¿̇alguna vez actuó de una manera que sus padres consideraban cuestionable?

¿A menudo hace bien las diferentes cosas que intenta?

No ser suficientemente cuidadoso me ha metido en problemas

Cuando se trata de lograr cosas que son importantes para mí, encuentro que no desempeño tan bien como idealmente quisiera hacerlo

Siento que progreso hacia el éxito en mi vida

He encontrado muy pocos hobbies o actividades que capturen mi interés o me motiven a poner empeño en ellos

\section{Evalúe las siguientes afirmaciones:}

Tengo pocas dificultades en "ponerme en la piel de otros"

Normalmente tengo bastante mal humor con la gente que me molesta con preguntas tontas

Con frecuencia me comprometo más de lo que puedo conseguir

Tiendo a ser cínico y escéptico de las intenciones de los demás

Creo que la mayoría de la gente se aprovecha de ti si se les deja

Cuando aprendo algo nuevo, se lo cuento a mis compañeros

Comparto la información que tengo con mis compañeros cuando ellos me lo piden

Comparto mis habilidades\destrezas con mis compañeros cuando ellos me lo piden

Disfruto tomando mis propias decisiones

Prefiero que alguien se haga cargo del papel de líder cuando estoy involucrado en un proyecto

Cuando veo un problema, prefiero hacer algo al respecto en lugar de sentarme y dejar que continúe

\begin{tabular}{|c|c|c|c|c|}
\hline \multicolumn{3}{|c|}{$\begin{array}{l}\text { Nunca o pocas } \\
\text { veces }\end{array}$} & \multicolumn{2}{|c|}{$\begin{array}{r}\text { Muy } \\
\text { frecuentement }\end{array}$} \\
\hline 1 & 2 & 3 & 4 & 5 \\
\hline 1 & 2 & 3 & 4 & 5 \\
\hline 1 & 2 & 3 & 4 & 5 \\
\hline 1 & 2 & 3 & 4 & 5 \\
\hline 1 & 2 & 3 & 4 & 5 \\
\hline 1 & 2 & 3 & 4 & 5 \\
\hline 1 & 2 & 3 & 4 & 5 \\
\hline 1 & 2 & 3 & 4 & 5 \\
\hline 1 & 2 & 3 & 4 & 5 \\
\hline 1 & 2 & 3 & 4 & 5 \\
\hline
\end{tabular}




\begin{tabular}{|c|c|c|c|c|c|}
\hline Cuando se trata de órdenes, prefiero darlas que recibirlas & 1 & 2 & 3 & 4 & 5 \\
\hline Siempre estoy en busca de mejores formas de hacer las cosas & 1 & 2 & 3 & 4 & 5 \\
\hline No importan las probabilidades, si creo en algo haré que suceda & 1 & 2 & 3 & 4 & 5 \\
\hline No hay nada más emocionante que ver que mis ideas se convierten en realidad & 1 & 2 & 3 & 4 & 5 \\
\hline Evalúe las siguientes afirmaciones: & \multicolumn{3}{|c|}{$\begin{array}{l}\text { Totalmente en } \\
\text { desacuerdo }\end{array}$} & \multicolumn{2}{|c|}{$\begin{array}{r}\text { Totalmente } \\
\text { de acuerdo }\end{array}$} \\
\hline Entre nosotros, los incubados, existe un sentido de pertenencia hacia el grupo & 1 & 2 & 3 & 4 & 5 \\
\hline Tengo un sentimiento de unión o cercanía con el grupo & 1 & 2 & 3 & 4 & 5 \\
\hline Cuando pido ayuda, siento que los demás incubados me la proporcionarán & 1 & 2 & 3 & 4 & 5 \\
\hline \multirow[t]{2}{*}{ Incluso si un incubado al que he ayudado no me puede ayudar en el futuro, otros lo harán } & 1 & 2 & 3 & 4 & 5 \\
\hline & \multicolumn{3}{|c|}{ Muy bajo } & \multicolumn{2}{|c|}{ Muy alto } \\
\hline Grado de diversidad (formación, procedencia, especialidad) entre los incubados & 1 & 2 & 3 & 4 & 5 \\
\hline
\end{tabular}

\section{Perfil de la universidad/centro de investigación de origen}

\begin{tabular}{|c|c|c|c|c|c|}
\hline \multirow{2}{*}{$\begin{array}{l}\text { Valore los siguientes aspectos sobre su universidad/centro de investigación de origen. } \\
\text { Existe una tradición de generación de spin-offs }\end{array}$} & \multicolumn{3}{|c|}{$\begin{array}{l}\text { Totalmente en } \\
\text { desacuerdo }\end{array}$} & \multicolumn{2}{|c|}{$\begin{array}{l}\text { Totalment } \\
\text { de acuerd }\end{array}$} \\
\hline & 1 & 2 & 3 & 4 & 5 \\
\hline Existe un alto nivel de burocracia en mi universidad/centro de investigación & 1 & 2 & 3 & 4 & 5 \\
\hline Existe una baja orientación al riesgo en el entorno de investigación & 1 & 2 & 3 & 4 & 5 \\
\hline Existe una normativa específica para la creación de spin-offs en mi universidad/centro de investigación & 1 & 2 & 3 & 4 & 5 \\
\hline Es difícil el desarrollo de otras actividades emprendedoras (congresos, cursos, edición de revistas, etc.) & 1 & 2 & 3 & 4 & 5 \\
\hline Existe una actitud positiva dentro de mi universidad/centro de investigación hacia la creación de empresas & 1 & 2 & 3 & 4 & 5 \\
\hline
\end{tabular}

\section{Identificación del emprendedor}

¿Tiene experiencia emprendedora previa?: $\square$ Sí, ¿¿uántos años? __ ¿en qué sector?

$$
\square \text { No }
$$

¿Ha sido trabajador por cuenta ajena, fuera del ámbito académico? $\square$ Sí, ¿cuántos años? ¿en qué sector?

$$
\square \text { No }
$$

¿Está trabajando en una Universidad/centro de investigación? $\square$ Sí ¿desde hace cuántos años?

$$
\square \text { No }
$$

¿Ha creado anteriormente algún grupo de investigación? $\square$ Sí $\square$ No

¿Forma parte de un grupo de investigación? $\square$ Sí ¿Cuántas personas forman parte de ese grupo (excluyéndole a usted)?

$$
\square \text { No }
$$

Nivel de estudios completado: $\square$ Doctor $\square$ Master $\square$ Licenciado $\square$ Diplomado $\square$ Grado

En la actualidad, ¿está realizando estudios?: $\square$ Sí ¿Cuáles? $\square$ Doctorado $\square$ Master $\square$ Grado

$$
\square \text { No }
$$

Edad: $\square$ Menos de $25 \quad \square$ Entre 25 y $35 \quad \square$ Entre 36 y $45 \square$ Entre 46 y $55 \square$ Entre 56 y 65

Sexo: $\square$ Hombre $\square$ Mujer 



\section{Anexo II: Cuestionario para incubados (versión en inglés)}



Number of months in incubation:

Status: $\square$ Professor Type: $\square$ Assistant $\square$ Associate $\square$ Full $\square$ Other

$\square$ Researcher

$\square$ Student

$\square$ Other:

Area of knowledge: $\square$ Sciences $\square$ Health sciences $\square$ Social sciences $\square$ Engineering \& architecture $\square$ Arts \& humanities Have you been in pre-incubation? $\square$ No

$\square$ Yes, How often are you in contact with the entrepreneurs you met in pre-incubation?

Are you open to having partner/s? $\square$ Yes

$$
\begin{aligned}
& \square \text { No } \\
& \square \text { I am not sure yet }
\end{aligned}
$$

If yes, in which background? $\square$ Academic $\quad \square$ Business $\square$ Not important

Have you got any partner? $\square$ Yes, how many?

Did you meet them/him/her in pre-incubation? $\square$ Yes $\square$ No

$\square$ No

\begin{tabular}{l|l|l|l|c|}
$\begin{array}{l}\text { Barely any } \\
\text { contact }\end{array}$ & \multicolumn{2}{r}{$\begin{array}{r}\text { Regular } \\
\text { contact }\end{array}$} \\
\hline 1 & 2 & 3 & 4 & 5 \\
\hline
\end{tabular}

Consider ONE professional relationship, interaction or contact that you have or have had with ANOTHER ENTREPRENEUR IN THE INCUBATION

\begin{tabular}{|c|c|c|c|c|c|}
\hline \multirow{2}{*}{$\begin{array}{l}\text { This entrepreneur: } \\
\text { Has different resources to mine that are very precious to me }\end{array}$} & \multicolumn{4}{|c|}{$\begin{array}{l}\text { Strongly } \\
\text { disagree }\end{array}$} & $\begin{array}{r}\text { Strongly } \\
\text { agree }\end{array}$ \\
\hline & 1 & 2 & 3 & 4 & 5 \\
\hline Has different and complementary resources to mine & 1 & 2 & 3 & 4 & 5 \\
\hline His/her resources are necessary to achieve my goals & 1 & 2 & 3 & 4 & 5 \\
\hline His/her resources, combined with mine, enable me to achieve more satisfactory results & 1 & 2 & 3 & 4 & 5 \\
\hline Has similar resources to mine, but nevertheless they are very precious to me & 1 & 2 & 3 & 4 & 5 \\
\hline Has similar resources to mine, but supplementary to mine & 1 & 2 & 3 & 4 & 5 \\
\hline His/her resources are similar to mine, but when combined, its allowed me to achieve more satisfactory results & 1 & 2 & 3 & 4 & 5 \\
\hline His/her values and conduct norms are congruent with mine & 1 & 2 & 3 & 4 & 5 \\
\hline His/her philosophy/approach to business is compatible with mine & 1 & 2 & 3 & 4 & 5 \\
\hline His/her goals and objectives are compatible with mine & 1 & 2 & 3 & 4 & 5 \\
\hline He/she honest and truthful & 1 & 2 & 3 & 4 & 5 \\
\hline The information he/she exchanges with me is reliable & 1 & 2 & 3 & 4 & 5 \\
\hline He/she honestly communicate any problem that may affect me & 1 & 2 & 3 & 4 & 5 \\
\hline He/she is willing to provide assistance and support when circumstances required & 1 & 2 & 3 & 4 & 5 \\
\hline I believe that he/she acts in my best interest & 1 & 2 & 3 & 4 & 5 \\
\hline In general, he/she is a person who keeps his/her commitments & 1 & 2 & 3 & 4 & 5 \\
\hline He/she is competent and effective & 1 & 2 & 3 & 4 & 5 \\
\hline He/she is committed to sharing ideas and knowledge with me & 1 & 2 & 3 & 4 & 5 \\
\hline He/she is willing to strengthen our relationship over time & 1 & 2 & 3 & 4 & 5 \\
\hline He/she is willing to continue our relationship for a long time & 1 & 2 & 3 & 4 & 5 \\
\hline Evaluate the following statements: & $\begin{array}{l}\text { Stron } \\
\text { disag }\end{array}$ & & & & $\begin{array}{r}\text { rongly } \\
\text { agree }\end{array}$ \\
\hline I intend to strengthen our relationship over time & 1 & 2 & 3 & 4 & 5 \\
\hline I intend to continue our relationship for a long time & 1 & 2 & 3 & 4 & 5 \\
\hline I am committed to sharing ideas and knowledge with him/her & 1 & 2 & 3 & 4 & 5 \\
\hline The collaboration with this entrepreneur is an effective medium of learning & 1 & 2 & 3 & 4 & 5 \\
\hline Collaborating with this entrepreneur is a wise decision & 1 & 2 & 3 & 4 & 5 \\
\hline
\end{tabular}
PROCESS and answer the following questions. 
Regarding my knowledge or training applied to business that I have started:

The knowledge (technical-scientific) held by me is easily transferable

The association between causes and effects, inputs and outputs, and actions and outcomes related to the knowledge held by me is clear

My knowledge is more explicit than tacit

I have procedures and routines to restrict the sharing of relevant information concerning my knowledge

I am very protective of my knowledge

\section{Evaluate the following statements about this entrepreneur:}

The knowledge (technical-scientific) held by him/her is easily transferable

The association between causes and effects, inputs and outputs, and actions and outcomes related to the knowledge hold by him/her is clear

His/her knowledge is more explicit than tacit

$\mathrm{He} /$ she has procedures and routines to restrict the sharing of relevant information concerning my knowledge

He/she is very protective of his/her knowledge

\begin{tabular}{|c|c|c|c|c|}
\hline \multicolumn{1}{|c|}{ disagree } \\
\hline 1 & 2 & 3 & 4 & 5 \\
\hline 1 & 2 & 3 & 4 & 5 \\
\hline 1 & 2 & 3 & 4 & 5 \\
\hline 1 & 2 & 3 & 4 & 5 \\
\hline 1 & 2 & 3 & 4 & 5 \\
\hline
\end{tabular}

In our relationship:

Strongly

disagree

\begin{tabular}{|l|l|l|l|l}
\hline 1 & 2 & 3 & 4 & 5 \\
\hline 1 & 2 & 3 & 4 & 5 \\
\hline 1 & 2 & 3 & 4 & 5 \\
\hline 1 & 2 & 3 & 4 & 5 \\
\hline 1 & 2 & 3 & 4 & 5 \\
\hline
\end{tabular}

We ask for mutual advice and recommendations

We share all types of information

We provide any information that may be useful to the other party

Each party informs the other about events that may affect them

We work together frequently

We frequently have contact

Strongly

disagree

\begin{tabular}{c|c|c|c|c|}
\hline 1 & 2 & 3 & 4 & 5 \\
\hline 1 & 2 & 3 & 4 & 5 \\
1 & 2 & 3 & 4 & 5 \\
\hline 1 & 2 & 3 & 4 & 5 \\
\hline 1 & 2 & 3 & 4 & 5 \\
\hline 1 & 2 & 3 & 4 & 5 \\
\hline
\end{tabular}

\section{The relationship with this entrepreneur has allowed me:}

Strongly

disagree

To be more committed to my entrepreneurial goals

To be more demanding about my entrepreneurial goals

To be more ambitious about my entrepreneurial goals

\begin{tabular}{|l|l|l|l|l}
1 & 2 & 3 & 4 & 5 \\
\hline 1 & 2 & 3 & 4 & 5 \\
\hline 1 & 2 & 3 & 4 & 5 \\
\hline
\end{tabular}

\section{The relationship with this entrepreneur has allowed me that my business:}

\begin{tabular}{|c|c|c|c|r|}
$\begin{array}{c}\text { Strongly } \\
\text { disagree }\end{array}$ & \multicolumn{2}{r}{$\begin{array}{r}\text { Strongly } \\
\text { agree }\end{array}$} \\
\hline 1 & 2 & 3 & 4 & 5 \\
\hline 1 & 2 & 3 & 4 & 5 \\
\hline 1 & 2 & 3 & 4 & 5 \\
\hline
\end{tabular}

Is more innovative in terms of product or service

Can reach a wider market

Is more feasible in its development

Strongly

disagree
Strongly agree

Generation of innovation

New products/services

\begin{tabular}{|l|l|l|l|l|}
\hline 1 & 2 & 3 & 4 & 5 \\
\hline 1 & 2 & 3 & 4 & 5 \\
\hline
\end{tabular}

\section{Through this entrepreneur:}

I have access to market knowledge

I get technical knowledge and a tremendous amount of know-how

I learn from his/her knowledge

I learn from his/her experience

I assimilate the knowledge that he/she gives me and contributes to the development of my start-up

\begin{tabular}{|c|c|c|c|r|}
\begin{tabular}{|} 
Strongly \\
disagree
\end{tabular} & \multicolumn{2}{r}{$\begin{array}{r}\text { Strongly } \\
\text { agree }\end{array}$} \\
\hline 1 & 2 & 3 & 4 & 5 \\
\hline 1 & 2 & 3 & 4 & 5 \\
\hline 1 & 2 & 3 & 4 & 5 \\
\hline 1 & 2 & 3 & 4 & 5 \\
\hline 1 & 2 & 3 & 4 & 5 \\
\hline
\end{tabular}


Through me, the other entrepreneur:

Has access to market knowledge

Gets technical knowledge and a tremendous amount of know-how

Learns from my knowledge

Learns from my experience

Assimilates the knowledge that I give him/her and contributes to the development of his/her start-up

\begin{tabular}{|l|l|l|l|l|}
\hline 1 & 2 & 3 & 4 & 5 \\
\hline 1 & 2 & 3 & 4 & 5 \\
\hline 1 & 2 & 3 & 4 & 5 \\
\hline 1 & 2 & 3 & 4 & 5 \\
\hline 1 & 2 & 3 & 4 & 5 \\
\hline
\end{tabular}

The relationship with this entrepreneur has allowed me:

\begin{tabular}{|c|c|c|c|c|}
$\begin{array}{l}\text { Strongly } \\
\text { disagree }\end{array}$ & \multicolumn{2}{r}{$\begin{array}{r}\text { Strongly } \\
\text { agree }\end{array}$} \\
\hline 1 & 2 & 3 & 4 & 5 \\
\hline 1 & 2 & 3 & 4 & 5 \\
\hline 1 & 2 & 3 & 4 & 5 \\
\hline
\end{tabular}

To increase sales

To create new market opportunities

To generate profits

In the incubator, is there a COACH assigned to you? $\square$ Yes, unique to me

$\square$ Yes, he/she is a group coach; how many people are in the group? $\square$ No

\begin{tabular}{|c|c|c|c|c|c|}
\hline \multirow{2}{*}{$\begin{array}{l}\text { If yes, consider the relationship or professional interaction you have with THE COACH and answer the following } \\
\text { questions: } \\
\text { We deal with each other frequently }\end{array}$} & \multicolumn{4}{|c|}{$\begin{array}{l}\text { Strongly } \\
\text { disagree }\end{array}$} & $\begin{array}{r}\text { Strongly } \\
\text { agree }\end{array}$ \\
\hline & 1 & 2 & 3 & 4 & 5 \\
\hline He/she is honest and truthful & 1 & 2 & 3 & 4 & 5 \\
\hline The information he/she exchanges me is reliable & 1 & 2 & 3 & 4 & 5 \\
\hline He/she helps me by sharing his/her knowledge and experience & 1 & 2 & 3 & 4 & 5 \\
\hline He/she encourages me to make contacts with other entrepreneurs & 1 & 2 & 3 & 4 & 5 \\
\hline I believe that he/she acts in my best interest & 1 & 2 & 3 & 4 & 5 \\
\hline If I required help, he/she would do his/her best to help me & 1 & 2 & 3 & 4 & 5 \\
\hline In general, he/she is a person who keeps his/her commitments & 1 & 2 & 3 & 4 & 5 \\
\hline He/she is competent and effective in providing advice & 1 & 2 & 3 & 4 & 5 \\
\hline He/she performs his/her role of coaching very well & 1 & 2 & 3 & 4 & 5 \\
\hline He/she encourages me to transfer knowledge & 1 & 2 & 3 & 4 & 5 \\
\hline He/she has experience in the business world & 1 & 2 & 3 & 4 & 5 \\
\hline He/she has experience in the science world & 1 & 2 & 3 & 4 & 5 \\
\hline
\end{tabular}

Think of the INCUBATOR MANAGER and assess your level of agreement or disagreement with each of the following statements:

\begin{tabular}{|c|c|c|c|c|c|}
\hline & \multicolumn{3}{|c|}{$\begin{array}{l}\text { Strongly } \\
\text { disagree }\end{array}$} & & $\begin{array}{r}\text { Strongly } \\
\text { agree }\end{array}$ \\
\hline I think he/she encourages contacts between entrepreneurs & 1 & 2 & 3 & 4 & 5 \\
\hline Tries to establish links between entrepreneurs who can get to collaborate & 1 & 2 & 3 & 4 & 5 \\
\hline Facilitates networking between all entrepreneurs & 1 & 2 & 3 & 4 & 5 \\
\hline Facilitates contacts outside the incubator & 1 & 2 & 3 & 4 & 5 \\
\hline Since I joined incubation, I have achieved: & \multicolumn{3}{|c|}{$\begin{array}{l}\text { Strongly } \\
\text { disagree }\end{array}$} & \multicolumn{2}{|c|}{$\begin{array}{r}\text { Strongly } \\
\text { agree }\end{array}$} \\
\hline To be more efficient in the planning and strategy for my business & 1 & 2 & 3 & 4 & 5 \\
\hline To be more efficient in managing my business & 1 & 2 & 3 & 4 & 5 \\
\hline To be more efficient in implementing the specific activities for my business & 1 & 2 & 3 & 4 & 5 \\
\hline To develop social skills for the business world & 1 & 2 & 3 & 4 & 5 \\
\hline To increase my network of business contacts & 1 & 2 & 3 & 4 & 5 \\
\hline The entrepreneurs who are in incubation, in the same incubator as me: & \multicolumn{3}{|c|}{$\begin{array}{l}\text { Strongly } \\
\text { disagree }\end{array}$} & \multicolumn{2}{|c|}{$\begin{array}{r}\text { Strongly } \\
\text { agree }\end{array}$} \\
\hline Use a similar language and jargon to me & 1 & 2 & 3 & 4 & 5 \\
\hline Use an understandable communication pattern & 1 & 2 & 3 & 4 & 5 \\
\hline Share similar interests to mine & 1 & 2 & 3 & 4 & 5 \\
\hline Are people whose interests I can identify with & 1 & 2 & 3 & 4 & 5 \\
\hline
\end{tabular}


Would not take advantage of others even when the opportunity arises

Always keep their promises

Behave in a consistent and honest manner

Are truthful in dealing with one another

Profile approach

\section{The following questions regard specific events in your life.}

Compared to most people, are you unable to get what you want out of life?

Growing up, would you ever "cross the line” by doing things that your parents would not tolerate?

Did you often get on your parents' nerves when you were growing up?

How often did you obey rules that were established by your parents?

Growing up, did you ever act in ways that your parents thought were objectionable?

Do you often do well at different things that you try?

Not being careful enough has gotten me into troubles at times

When it comes to achieving things that are important to me, I find that I don't perform as well as I ideally would like to

do

I feel like I have made progress toward being successful in my life

I have found very few hobbies or activities in my life that capture my interest or motivate me to put effort into them

\begin{tabular}{|c|c|c|c|c|}
\begin{tabular}{|} 
Never or seldom \\
Very \\
often
\end{tabular} \\
\hline 1 & 2 & 3 & 4 & 5 \\
\hline 1 & 2 & 3 & 4 & 5 \\
\hline 1 & 2 & 3 & 4 & 5 \\
\hline 1 & 2 & 3 & 4 & 5 \\
\hline 1 & 2 & 3 & 4 & 5 \\
\hline 1 & 2 & 3 & 4 & 5 \\
\hline 1 & 2 & 3 & 4 & 5 \\
\hline 1 & 2 & 3 & 4 & 5 \\
\hline 1 & 2 & 3 & 4 & 5 \\
\hline
\end{tabular}

\section{Evaluate the following statements:}

Strongly

I have little difficulty in "putting myself into other people's shoes"

I am usually rather short-tempered with people who bother me with foolish questions

I frequently undertake more than I can accomplish

I tend to be cynical and sceptical of others' intentions

I believe that most people take advantage of you if you let them

When I learn something new, I tell my colleagues

I share the information I have with my colleagues when they ask me to

I share my skills with my colleagues when they ask me to

I enjoy making my own decisions

I would rather someone else took over the leadership role when I am involved in a project

When I see a problem I prefer to do something about it rather than sit by and let it continue

When it comes to orders, I would rather give them than receive them

I am always looking for better ways to do things

No matter what the odds are, if I believe in something I will make it happen

Nothing is more exciting than seeing my ideas turn into reality

\begin{tabular}{|c|c|c|c|c|}
\hline 1 & 2 & 3 & 4 & 5 \\
\hline 1 & 2 & 3 & 4 & 5 \\
\hline 1 & 2 & 3 & 4 & 5 \\
\hline 1 & 2 & 3 & 4 & 5 \\
\hline 1 & 2 & 3 & 4 & 5 \\
\hline 1 & 2 & 3 & 4 & 5 \\
\hline 1 & 2 & 3 & 4 & 5 \\
\hline 1 & 2 & 3 & 4 & 5 \\
\hline 1 & 2 & 3 & 4 & 5 \\
\hline 1 & 2 & 3 & 4 & 5 \\
\hline 1 & 2 & 3 & 4 & 5 \\
\hline 1 & 2 & 3 & 4 & 5 \\
\hline 1 & 2 & 3 & 4 & 5 \\
\hline 1 & 2 & 3 & 4 & 5 \\
\hline 1 & 2 & 3 & 4 & 5 \\
\hline
\end{tabular}

\section{Evaluate the following statements:}

There is a sense of group belonging within us, the incubatees

I have the feeling of group togetherness or closeness

When I ask for help, I feel that other incubatees will provide it

Even if an incubatee I have helped cannot help me in the future, others will be able to

Level of diversity (education, background, speciality) between the incubatees

\begin{tabular}{|c|c|c|c|c|}
\begin{tabular}{|} 
Strongly \\
disagree
\end{tabular} & \multicolumn{2}{r|}{$\begin{array}{r}\text { Strongly } \\
\text { agree }\end{array}$} \\
\hline 1 & 2 & 3 & 4 & 5 \\
\hline 1 & 2 & 3 & 4 & 5 \\
\hline 1 & 2 & 3 & 4 & 5 \\
\hline 1 & 2 & 3 & 4 & 5 \\
\hline Very low & & \multicolumn{3}{|c|}{ Very high } \\
\hline 1 & 2 & 3 & 4 & 5 \\
\hline
\end{tabular}

Indicate the number of incubatees with whom your are in frequent contact:

\begin{tabular}{|l|l|l|l|l|}
\hline 1 & 2 & 3 & 4 & 5 \\
\hline 1 & 2 & 3 & 4 & 5 \\
\hline 1 & 2 & 3 & 4 & 5 \\
\hline 1 & 2 & 3 & 4 & 5 \\
\hline
\end{tabular}


University/research centre of origin profile

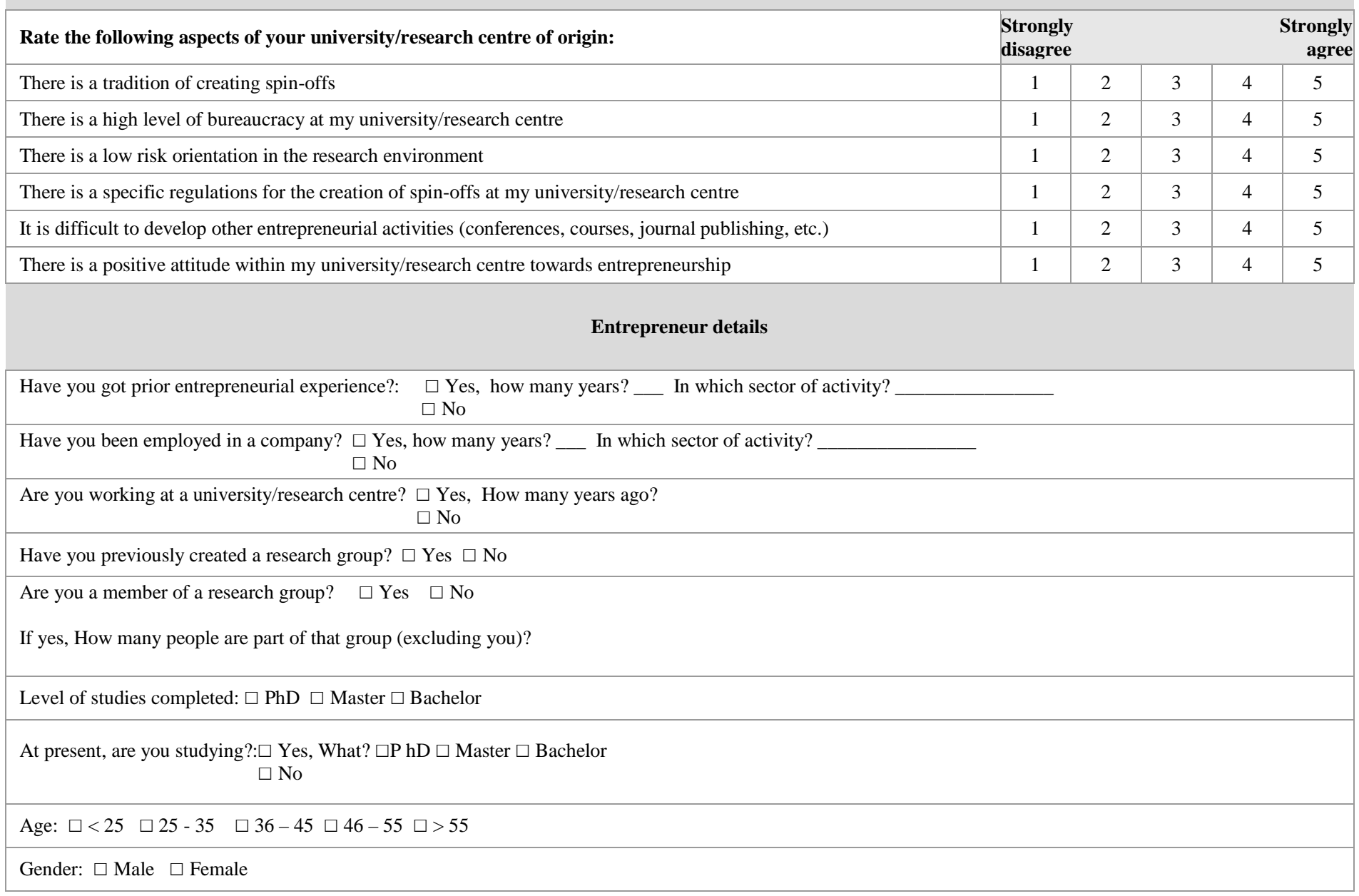





\section{Anexo III: Cuestionario para mánagers (versión en español)}



CUESTIONARIO DIRECTOR/A DE LA INCUBADORA

Incubadora:

País:

¿Prestan servicios de pre-incubación? $\square$ Sí $\square$ No

En caso afirmativo, por favor, responda a las siguientes preguntas.

\section{Pre-incubación}

¿Ponen a disposición de los pre-incubados algún tipo de espacio físico para que trabajen en su idea/plan de negocio? $\square$ Sí $\square$ No

Periodo máximo de pre-incubación (meses):

Periodo medio que suelen estar en pre-incubación (meses):

Precio por mes: $\quad$ Ese precio incluye: $\square$ uso del espacio $\square$ servicios $\square$ otros:

Capacidad máxima (número de proyectos):

Nivel de ocupación (número actual de proyectos): Nivel de ocupación (número actual de personas que están en pre-incubación):

¿Qué porcentaje de proyectos suele pasar, por término medio, de pre-incubación a incubación?

De los siguientes servicios, para aquellos que presten en pre-incubación, indique el grado de intensidad en el que los impulsan.

Análisis y asesoramiento en el desarrollo de la idea de negocio

Asesoramiento en el desarrollo del plan de negocio

Guía práctica en aspectos como contacto con organismos, trámites para la puesta en marcha de un negocio, etc.

Formación general en emprendimiento y negocios

Formación en otros temas concretos (gestión, ventas, recursos humanos, transferencia de tecnología, etc.)

Coaching o mentoring

Asesoramiento financiero (información o apoyo en la cumplimentación para obtener apoyo financiero)

Acceso a redes que tiene la incubadora (con empresas, asociaciones, profesionales como consultores, abogados, etc.)

Reuniones y eventos entre los pre-incubados para fomentar contactos y relaciones entre ellos

Servicios relacionados con la universidad (acceso a mentores académicos, programas de transferencia de tecnología y formación, acceso a instalaciones, etc.)

\begin{tabular}{|c|c|c|c|c|c|}
\hline \multirow[t]{2}{*}{$\begin{array}{l}\text { No prestamos } \\
\text { este servicio }\end{array}$} & \multicolumn{3}{|c|}{$\begin{array}{l}\text { Intensidad Muy } \\
\text { baja }\end{array}$} & \multicolumn{2}{|c|}{$\begin{array}{r}\text { Intensidad } \\
\text { Muy alta }\end{array}$} \\
\hline & 1 & 2 & 3 & 4 & 5 \\
\hline & 1 & 2 & 3 & 4 & 5 \\
\hline & 1 & 2 & 3 & 4 & 5 \\
\hline & 1 & 2 & 3 & 4 & 5 \\
\hline & 1 & 2 & 3 & 4 & 5 \\
\hline & 1 & 2 & 3 & 4 & 5 \\
\hline & 1 & 2 & 3 & 4 & 5 \\
\hline & 1 & 2 & 3 & 4 & 5 \\
\hline & 1 & 2 & 3 & 4 & 5 \\
\hline & 1 & 2 & 3 & 4 & 5 \\
\hline
\end{tabular}

De manera general, ¿cómo diría que es el nivel de participación de los pre-incubados en las distintas actividades que organizan?

Muy bajo 12345 Muy alto

¿Prestan servicios de incubación? $\square$ Sí $\square$ No

En caso afirmativo, por favor, responda a las siguientes preguntas.

\section{Incubación}

¿Ponen a disposición de los incubados espacios físicos (oficinas, laboratorios, etc.) para poder desarrollar su actividad? $\square$ Sí $\square$ No

Periodo máximo de incubación (meses):

Periodo medio que suelen estar en incubación (meses):

Precio por mes: $\quad$ Ese precio incluye: $\square$ Uso del espacio $\square$ servicios $\square$ otros:

Capacidad máxima (número de empresas):

Nivel de ocupación (número actual de empresas):

Nivel de ocupación (número actual de socios de esas empresas):

¿Qué porcentaje de empresas, por término medio, suele graduarse (empresas que salen de incubación, pudiendo mantener su estructura y seguir con su actividad fuera)?

Por favor, de los siguientes servicios, para aquellos que presten en incubación, indique el grado de intensidad en el que los impulsan.

Asesoramiento en el desarrollo del plan de negocios

Asistencia en la implementación de productos y/o servicios

Formación (talleres, jornadas, etc.)

Coaching o mentoring

Asesoramiento financiero (información o apoyo en la cumplimentación para obtener apoyo

financiero, tramitación de ayudas, etc.)

\begin{tabular}{|l|r|r|r|r|c|}
\hline $\begin{array}{l}\text { No prestamos } \\
\text { este servicio }\end{array}$ & $\begin{array}{l}\text { Intensidad Muy } \\
\text { baja }\end{array}$ & \multicolumn{3}{|c|}{$\begin{array}{r}\text { Intensidad } \\
\text { Muy alta }\end{array}$} \\
\hline & 1 & 2 & 3 & 4 & 5 \\
\hline & 1 & 2 & 3 & 4 & 5 \\
\hline & 1 & 2 & 3 & 4 & 5 \\
\hline & 1 & 2 & 3 & 4 & 5 \\
\hline & 1 & 2 & 3 & 4 & 5 \\
\hline
\end{tabular}


Asesoramiento y apoyo en la captación de financiación, presentación de proyectos de I+D+i a convocatorias nacionales, europeas, etc.

Acceso a redes que tiene la incubadora (con empresas, asociaciones, agentes profesionales como consultores, abogados, etc.)

Reuniones y eventos entre los incubados para fomentar contactos y relaciones entre ellos

Servicios relacionados con la universidad (acceso a mentores académicos, a estudiantes, egresados, programas de transferencia de tecnología y formación, acceso a instalaciones, etc.)

De manera general, ¿cómo diría que es el nivel de participación de los incubados en las distintas actividades que organizan? Muy bajo 12345 Muy alto

¿Prestan servicios de post-incubación? $\square$ Sí $\square$ No

En caso afirmativo, por favor, responda a las siguientes preguntas.

\section{Post - incubación}

Periodo máximo de post-incubación (meses):

Periodo medio que suelen estar en post-incubación (meses):

Precio por mes: Ese precio incluye: $\square$ servicios $\square$ otros:

Número de empresas que el programa de post-incubación puede admitir:

Nivel de participación (número actual de empresas): $\quad$ Nivel de participación (número actual de socios de esas empresas):

De los siguientes servicios, para aquellos que presten en post-incubación, indique el grado de intensidad en el que los impulsan.

Disposición de infraestructuras tales como salas de conferencias, de reuniones, laboratorios, etc.

Apoyo a la internacionalización

Asesoramiento en la comercialización

Apoyo en el desarrollo del negocio

Formación (talleres, jornadas, etc.)

Coaching o mentoring

Asesoramiento financiero (información o apoyo en la cumplimentación para obtener apoyo financiero)

Asesoramiento y apoyo en la captación de financiación, presentación de proyectos de $\mathrm{I}+\mathrm{D}+\mathrm{i}$ a convocatorias nacionales, europeas, etc.

Acceso a redes que tiene la incubadora (con empresas, asociaciones, agentes profesionales como consultores, abogados, etc.)

Reuniones y eventos entre los incubados para fomentar contactos y relaciones entre ellos

Servicios relacionados con la universidad (acceso a mentores académicos, a estudiantes, egresados, programas de transferencia de tecnología y formación, acceso a instalaciones, etc.)

\begin{tabular}{|c|c|c|c|c|}
\hline 1 & 2 & 3 & 4 & 5 \\
\hline 1 & 2 & 3 & 4 & 5 \\
\hline 1 & 2 & 3 & 4 & 5 \\
\hline 1 & 2 & 3 & 4 & 5 \\
\hline
\end{tabular}

De manera general, ¿cómo diría que es el nivel de participación de los post-incubados en las distintas actividades que organizan?

Muy bajo 12345 Muy alto

\section{Identificación del manager de la incubadora}

¿En qué año empezó a funcionar la incubadora?

Indique el número y el tipo de organismos que forman parte de la incubadora:

¿La incubadora se autofinancia? $\square$ Sí, ¿en qué porcentaje?

$\square$ No

¿Cuánto tiempo lleva como responsable de la incubadora?:

¿Tiene dedicación exclusiva a ello? $\square$ Sí $\square$ No

¿Tiene experiencia emprendedora?: $\square$ Sí, ¿cuántos años? __ ¿en qué sector?

$$
\square \text { No }
$$

¿Tiene experiencia en el mundo de los negocios? $\square$ Sí, ¿cuántos años? __ ¿en qué sector?

$$
\square \text { No }
$$

¿Tiene experiencia en el mundo de la ciencia? $\square$ Sí, ¿cuántos años? __ ¿en qué área de conocimiento? $\square$ Ciencias $\square$ Ciencias de la salud $\square$ Ciencias sociales y jurídicas $\square$ Ingeniería y arquitectura $\square$ Arte y humanidades

$$
\square \text { No }
$$

Nivel de estudios completado: $\square$ Doctor $\square$ Master $\square$ Licenciado $\square$ Diplomado $\square$ Grado

Área de conocimiento: $\square$ Ciencias $\square$ Ciencias de la salud $\square$ Ciencias sociales y jurídicas $\square$ Ingeniería y arquitectura $\square$ Arte y humanidades

Edad: $\square$ Menos de $25 \quad \square$ Entre 25 y $35 \quad \square$ Entre 36 y $45 \quad \square$ Entre 46 y $55 \quad \square$ Entre 56 y 65

Sexo: $\square$ Hombre $\square$ Mujer 


\section{Anexo IV: Cuestionario para mánagers (versión en inglés)}



Incubator:

Have you got pre-incubation program/services? $\square$ Yes $\square$ No

If yes, please, answer the following questions.

Country:

\section{Pre-incubation}

Is there space available for pre-incubatees in order to work on their business idea/plan? $\square$ Yes $\square$ No

Maximum pre-incubation period (months): $\quad$ Average pre-incubation period (months):

Cost per month: $\quad$ This cost includes: $\square$ use of the space $\square$ main services $\square$ another:

Maximum occupancy (number of projects) per pre-incubation:

Occupancy (number of present projects): $\quad$ Occupancy (number of present pre-incubatees):

Average percentage of projects that move from pre-incubation to incubation phase:

Which of the following services (and to which extent) do you offer/support in the pre-incubation phase?

Sparring and assistance in developing a business idea

Sparring and assistance in preparing a business plan

Practical tips and tricks about how to start up a business

Business and entrepreneurship training

Specialized training program (management, sales, human resources, technology transfer, etc.)

Coaching or mentoring

Assistance in planning financing

Access to incubator networks (business, associations, freelance, etc.)

Meetings and events between pre-incubatees in order to foster contacts and relationships between them

University support (academic mentors, training program, transfer technology program, use of spaces, etc.)

In general, what is the level of participation of pre-incubatees in different activities you organize?

Very low 12345 Very high

Have you got incubation program/services? $\square$ Yes $\square$ No

If yes, please, answer the following questions.

\section{Incubation}

Is there space available (offices, labs, etc.) for incubatees in order to develop their business activities? $\square$ Yes $\square$ No

Maximum incubation period (months): $\quad$ Average incubation period (months):

Cost per month: $\quad$ This cost includes: $\square$ use of the space $\square$ main services $\square$ another:

Maximum occupancy (number of start-ups):

Occupancy (number of present start-ups): $\quad$ Occupancy (number of present incubatees):

Rate of graduated companies (\%):

Which of the following services (and to which extent) do you offer/support in the incubation phase?

Sparring and assistance in developing company's business plan

Sparring and assistance in implementation of product/service development

Training (workshops, seminars, etc.)

Coaching or mentoring

Assistance in planning and organization of necessary financing

\begin{tabular}{|l|l|l|l|l|l|}
\hline $\begin{array}{l}\text { We do not } \\
\text { offer/support } \\
\text { this service }\end{array}$ & \multicolumn{4}{|l|}{ Not much } \\
\hline & 1 & 2 & 3 & 4 & 5 \\
\hline & 1 & 2 & 3 & 4 & 5 \\
\hline & 1 & 2 & 3 & 4 & 5 \\
\hline & 1 & 2 & 3 & 4 & 5 \\
\hline & 1 & 2 & 3 & 4 & 5 \\
\hline & 1 & 2 & 3 & 4 & 5 \\
\hline & 1 & 2 & 3 & 4 & 5 \\
\hline & 1 & 2 & 3 & 4 & 5 \\
\hline & 1 & 2 & 3 & 4 & 5 \\
\hline & 1 & 2 & 3 & 4 & 5 \\
\hline
\end{tabular}


Assistance in obtaining financing and in applying R\&D\&I projects for national and European calls, etc.

Access to incubator networks (business, associations, freelance, etc.)

\begin{tabular}{|l|l|l|l|l|}
\hline 1 & 2 & 3 & 4 & 5 \\
\hline 1 & 2 & 3 & 4 & 5 \\
\hline
\end{tabular}

Meetings and events between incubatees in order to foster contacts and relationships between them

University support (academic mentors, student interns, technology transfer program, training program, use of spaces, etc.)

In general, what is the level of participation of incubatees in different activities you organize?

Very low 12345 Very high

Have you got post-incubation program/services? $\square$ Yes $\square$ No

If yes, please, answer the following questions.

\section{Post - incubation}

Maximum post-incubation period (months):

Average post-incubation period (months):

Cost per month:

This cost includes: $\square$ main services $\square$ others:

Maximum number of firms that can participate in post-incubation:

Number of present firms in post-incubation:

Number of partners of those firms:

Which of the following services (and to which extent) do you offer/support in the post- incubation phase?

Access to facilities (conference rooms, meeting rooms, labs, etc.)

Contacts and first steps in internationalization

Assistance in commercialization

Assistance in developing company’s business strategy

Training (workshops, seminars, etc.)

Coaching or mentoring

Assistance in planning financing

Assistance in obtaining financing and in applying R\&D\&I projects for national and European calls, etc.

Access to incubator networks (business, associations, freelance, etc.)

Meetings and events between post-incubatees in order to foster contacts and relationships between them

University support (academic mentors, student interns, technology transfer program, training program, access to facilities, etc.)

In general, what is the level of participation of post-incubatees in different activities you organize?

Very low 12345 Very high

\section{Incubator manager details}

In which year was the incubator founded?

Indicate the number and the type of organizations that support and are involved in the incubator:

Is the incubator self-financed? $\square$ Yes, What is the percentage of this self-financing?

$$
\square \text { No }
$$

For how long have you been the manager of the incubator?:

Is it your only job? $\square$ Yes $\square$ No

Have you got entrepreneurial experience?: $\square$ Yes, how many years? __ In which sector of activity?

$$
\square \text { No }
$$

Have you got experience in the business world? $\square$ Yes, how many years? __ In which sector of activity?

$\square$ No

Have you got experience in the science world? $\square$ Yes, how many years? _ In which area of knowledge? $\square$ Sciences $\square$ Health sciences $\square$ Social sciences

$\square$ Engineering \& architecture $\square$ Arts \& humanities

Level of studies completed: $\square$ PhD $\square$ Master $\square$ Bachelor $\square$ Other

Area of knowledge: $\square$ Sciences $\square$ Health sciences $\square$ Social sciences $\square$ Engineering \& architecture $\square$ Arts \& humanities

Age: $\square<25 \square 25-35 \quad \square 36-45 \square 46-55 \square>55$

Gender: $\square$ Male $\square$ Female 
